\title{
ESTUDO DE PARÂMETROS TURBULENTOS E SUA RELAÇÃO COM O COEFICIENTE DE REAERAÇÃO COM O USO DA TÉCNICA FOTOGRÁFICA
}

\author{
CARLOS EUGENIO PEREIRA
}

Dissertação apresentada à Escola de Engenharia de São Carlos da Universidade de São Paulo, como parte dos requisitos para obtenção do título de Mestre em Hidráulica e Saneamento

ORIENTADOR: Prof. Titular WOODROW N. L. ROMA

SÃO CARLOS

2002 


\section{DIANTE DO TRONO}

\section{ÁGUAS PURIFICADORAS}

Ana Paula Valadão

Existe um rio, senhor

Que flui do teu grande amor

Águas que correm do trono

Águas que curam, que limpam

Por onde o rio passar

Tudo vai transformar

Pois leva a vida do próprio DEUS

E este rio está neste lugar

Quero beber do teu rio, senhor

Sacia minha sede, lava o meu interior

Eu quero fluir em tuas águas

Eu quero beber da tua fonte

Fonte de águas vivas

Tu és a fonte, senhor

\section{O CHEIRO DAS ÁGUAS}

Ana Paula Valadão

Há esperança para o ferido

Como árvore cortado, marcado pela dor

Ainda que na terra envelheça a raiz

E no chão, abandonado o seu tronco morrer

Há esperança pra você

Ao cheiro das águas brotará

Como planta nova florescerá

Seus ramos se renovação

Não cessarão os seus frutos

E viverá 
À minha grande família,

Ao meu pai Seu Normando e minha amada mãe Maria. Esse trabalho é o fruto da dedicação que os dois reservaram a mim, e não se preocuparam com o sacrifício que seria feito,

Meus queridos irmãos Normando, Alexsandro, Fernanda e Magic Chel, meu muito obrigado à DEUS por eles existirem ao meu lado,

Dedico este trabalho. 


\section{AGRADECIMENTO}

Ao Prof. Woodrow N. L. Roma,

Pelos incentivos e orientação, em meu coração sempre guardarei a pessoa dedicada que és. 


\section{AGRADECIMENTOS}

À DEUS o autor da minha vida, que me deu nova vida, e me deu alegria, tu és o dono do meu coração, a Ele toda honra, toda glória seja dada

Ao técnico do laboratório de Fenômenos de Transportes, o amigo Roberto Cezar Bergamo pelo companheirismo, amizade e principalmente pelas idéias e pelo apoio na manutenção da bancada de ensaios.

Ao pessoal da $4^{\mathrm{a}}$ Igreja do Evangelho Quadrangular de São Carlos pelo companheirismo e amizade que me foram dados logo na minha chegada a essa cidade, que foram tempos difíceis.

Ao amigo José Eduardo Alamy Filho, meu companheiro de república, meu muito obrigado pelo apoio dado nos momentos difíceis dessa caminhada

E ao amigo que fala mais que a língua Marcelo Mello Barroso (sem moral), companheiro de república, dos jogos de Basket e das “brocas”, saiba que sempre terá moral comigo, valeu por tudo.

Aos meus professores de Iniciação Cientifica, Prof. Péricles Alves Medeiros, Prof $^{\mathrm{a}}$ Doralice Ap. Favaro Soares e ao Prof. Osni Pereira, pelos ensinamentos e amizade, quando comecei a dar meus primeiros passos na área da pesquisa, meu muito obrigado.

A minha irmã Rachel Lúcia pelo auxílio na obtenção e analise dos dados.

A todos os colegas, professores e funcionários do Departamento de Hidraúlica e Saneamento da EESC/USP pela colaboração. 


\section{SUMÁRIO}

LISTA DE FIGURAS

pág.

LISTA DE TABELAS

xiv

LISTA DE ABREVIATURAS E SIGLAS................................. xV

LISTA DE SÍMBOLOS

XVi

RESUMO

$\mathrm{XX}$

ABSTRACT

xxi

1 - INTRODUÇÃO

1

2 - OBJETIVOS 3

3 - ANÁLISE TEÓRICA E REVISÃO BIBLIOGRÁFICA $\ldots \ldots \ldots \ldots . .4$

3.1 Fundamentos de Transferência de Massa $\quad \ldots \ldots \ldots \ldots \ldots \ldots \ldots \ldots . \ldots 4$

3.1.1 Lei de Fick da Difusão Molecular $\quad \ldots \ldots \ldots \ldots \ldots \ldots \ldots \ldots \ldots \ldots \ldots \ldots . \ldots \ldots$

3.1.2 Coeficiente de Difusão Molecular $\quad$................................. 8

3.1.2.1 A Equação de Chapman-Enskog ................................ 11

3.1.3 Equação de Advecção-Difusão ................................ 12

3.2 Análise Linear para a Transferência de Massa na Superfície $\quad$....... 16

3.2.1 Simplificação da Equação de Balanço de Massa $\quad$.................... 17

3.2.2 Análise para Grandes Freqüências ................................ 20

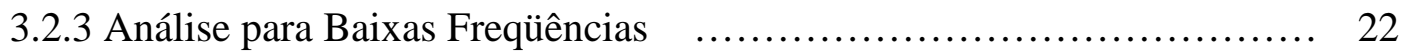

3.3 Definição Matemática dos Processos de Absorção $\quad$................... 26

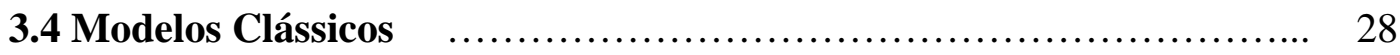

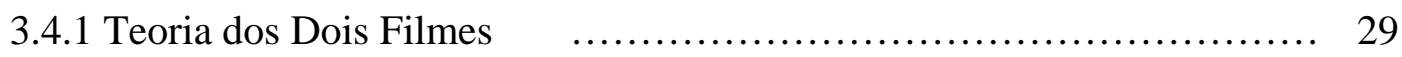

3.4.2 Teoria da Penetração $\quad$.......................................... 31

3.4.3 Teoria da Renovação Superficial ............................... 32

3.4.4 Modelo da Penetração do Filme $\quad$................................. 32

3.4.5 Outros Modelos .............................................. 34 
3.5. Fundamentos de Turbulência $\quad$................................. 35

3.5.1 Turbulência $\quad$....................................................... 35

3.5.2 Caracterização da Turbulência $\quad$................................ 36

3.5.3 Modelos de Turbulência nas proximidades da Superfície Livre $\quad \ldots . \ldots . .38$

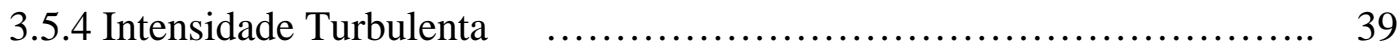

3.5.5 Funções de Correlação $\quad$............................................ 40

3.5.6 Ergodicidade $\quad$................................................. 42

3.6. Tanques com Grades Oscilantes $\quad$............................... 43

3.7 Visualização do Escoamento $\quad$.................................. 45

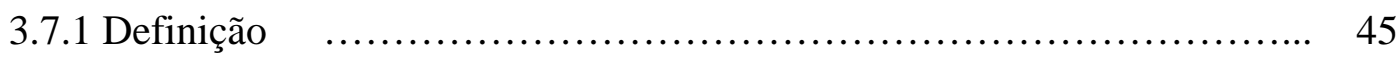

3.7.2 Resumo da História da Visualização do Escoamento ............... 46

3.7.3 Técnica de Trilhagem de Partículas $\quad$............................ 47

4-MATERIAIS E MÉTODOS $\quad$...................................... 50

4.1 Materiais $\quad$.................................................... 50

4.1.1 Equipamento de geração da Turbulência $\quad$............................ 51

4.1.2 Equipamento utilizado para a Desoxigenação da Água $\quad$.............. 52

4.1.3 Instrumentação de Medida $\quad$................................... 52

4.1.3.1 Sensor ótico para medida da deformação da superfície líquida $\quad$....... 52

4.1.3.2 Aparelho Medidor de Oxigênio Dissolvido ....................... 53

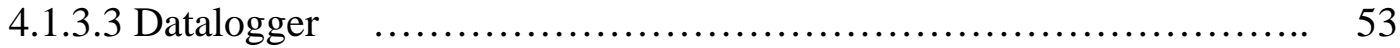

4.1.3.4 Psicrômetro $\quad$.................................................. 54

4.1.3.5 Instrumentos utilizados na obtenção de fotografias $\quad$................ 54

4.2 Metodologia $\quad$........................................................... 55

4.2.1 A Deaeração e a Reoxigenação da Água ........................... 56

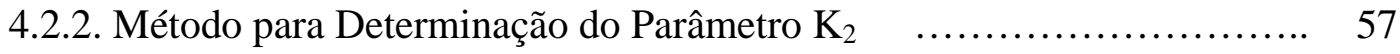

4.2.3. Método para obtenção dos Dados e Medida dos Parâmetros Turbulentos (Sonda Ótica)............................................. 59

4.2.4. Técnica Fotográfica e a Metodologia na Obtenção das Fotografias (Método Fotográfico) .............................................. 60

4.2.5. Digitalização e Interpolação $\quad$..................................... 63

4.2.6. Campo de Velocidade $\quad$....................................... 63

4.2.7. A equação da Continuidade $\quad$........................................ 66 
4.2.8. Obtenção dos Parâmetros através da Técnica Fotográfica........................ 67

4.2.9. Umidade Relativa $\quad$............................................. 68

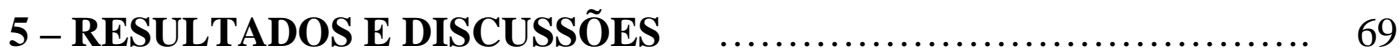

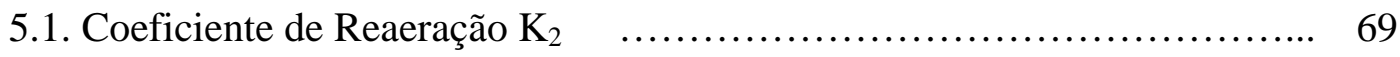

5.2. Resultados da Sonda Ótica $\quad$......................................... 76

5.3. Resultados obtidos através do Método Fotográfico .................... 79

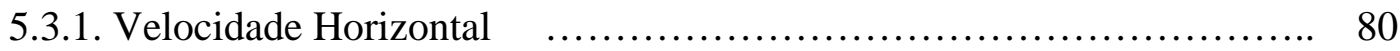

5.3.2. Gradiente de Velocidade na direção z ........................... 109

5.3.2.1 Ajuste do valor RMS do gradiente da velocidade vertical em função da

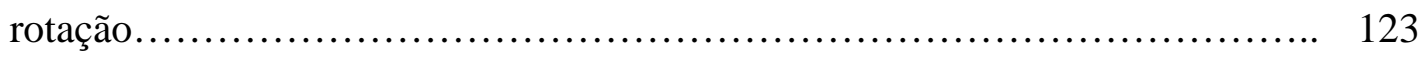

5.4 Comparação entre a Função de autocorrelação da sonda ótica e do método

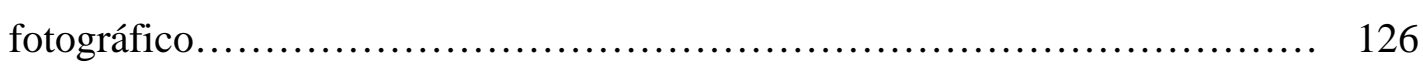

5.5 Comparação entre o espectro de freqüência da sonda ótica e o espectro do método fotográfico .................................................... 140

5.6. Relação entre o coeficiente de reaeração $K_{2}$ e o valor RMS do método ótico

5.7. Relação entre o coeficiente de reaeração $K_{2}$ e o valor RMS do método fotográfico........................................................ 157

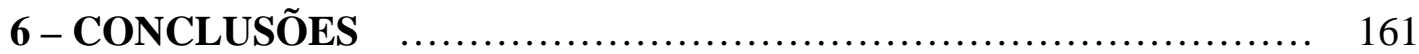

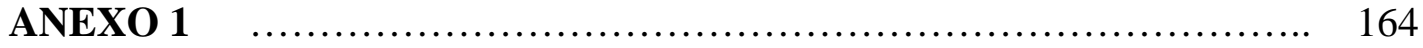

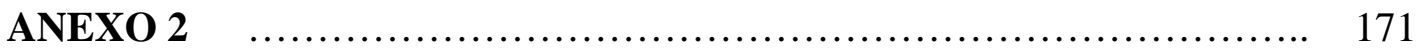

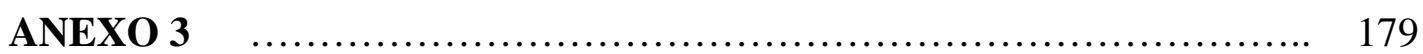

$\begin{array}{ll}\text { BIBLIOGRAFIA } & 194\end{array}$ 


\section{LISTA DE FIGURAS}

FIGURA 1: Sistema isolado com dois reservatórios separados pela

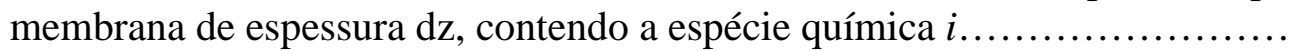

FIGURA 2: Sistema isolado contendo a espécie química $i$, após retirada da membrana de espessura $\mathrm{dz}$.

FIGURA 3: Gráfico de concentração de O. D. em função do tempo.......... 58

FIGURA 4: Dados de tensão amplificados

FIGURA 5: Esquema mostrando o aparato utilizado para obtenção das fotografias.

FIGURA 6: Ilustração da trajetória obtida com o método fotográfico.

FIGURA 7: fotografia da superfície livre.

FIGURA 8: O movimento de uma partícula no campo de escoamento.

FIGURA 9: Gráfico de $K_{2}$ em função da freqüência de oscilação da grade de 26,5 mm de abertura e barras com 10mm de espessura. ...

FIGURA 10: Melhor ajuste dos três trabalhos conjuntos (Grade de 26,5 mm de abertura e barras com $10 \mathrm{~mm}$ de espessura)....

FIGURA 11: Gráfico de $K_{2}$ em função da freqüência de oscilação da grade de 39,0 mm de abertura e barras com 10mm de espessura

FIGURA 12: Melhor ajuste dos três trabalhos conjuntos (Grade 39,0 mm de abertura e barras com $10 \mathrm{~mm}$ de espessura).

FIGURA 13: Gráfico de $K_{2}$ em função da freqüência de oscilação da grade de $64,5 \mathrm{~mm}$ de abertura e barras com $10 \mathrm{~mm}$ de espessura.

FIGURA 14: Melhor ajuste dos três trabalhos conjuntos (Grade 64,5 mm de abertura e barras com $10 \mathrm{~mm}$ de espessura).

FIGURA 15: Melhor ajuste para RMS sonda versus freqüência de oscilação da grade de $26,5 \mathrm{~mm}$ de abertura e barras com $10 \mathrm{~mm}$ de espessura

FIGURA 16: Melhor ajuste para RMS sonda versus freqüência de oscilação da grade de $39,0 \mathrm{~mm}$ de abertura e barras com $10 \mathrm{~mm}$ de espessura.

FIGURA 17: Melhor ajuste para RMS sonda versus freqüência de oscilação da grade de $64,5 \mathrm{~mm}$ de abertura e barras com 10mm de espessura. 
FIGURA 18: Visualização da Componente da Velocidade Horizontal na direção X com a grade de malha quadrada $2,65 \mathrm{~cm}$ e rotação de 120 rpm.

FIGURA 19: Visualização das Isolinhas da Componente da Velocidade Horizontal na direção $X$ com a grade de malha quadrada $2,65 \mathrm{~cm}$ e rotação de $120 \mathrm{rpm}$.

FIGURA 20: Visualização da Componente da Velocidade Horizontal na direção X com a grade de malha quadrada $2,65 \mathrm{~cm}$ e rotação de $140 \mathrm{rpm}$.....

FIGURA 21: Visualização das Isolinhas da Componente da Velocidade Horizontal na direção X com a grade de malha quadrada $2,65 \mathrm{~cm}$ e rotação de $140 \mathrm{rpm}$.

FIGURA 22: Visualização da Componente da Velocidade Horizontal na direção X com a grade de malha quadrada 2,65cm e rotação de 160 rpm.

FIGURA 23: Visualização das Isolinhas da Componente da Velocidade Horizontal na direção $X$ com a grade de malha quadrada $2,65 \mathrm{~cm}$ e rotação de $160 \mathrm{rpm}$.

FIGURA 24: Visualização da Componente da Velocidade Horizontal na direção X com a grade de malha quadrada $2,65 \mathrm{~cm}$ e rotação de $180 \mathrm{rpm}$.

FIGURA 25: Visualização das Isolinhas da Componente da Velocidade Horizontal na direção $X$ com a grade de malha quadrada $2,65 \mathrm{~cm}$ e rotação de $180 \mathrm{rpm}$.

FIGURA 26: Visualização da Componente da Velocidade Horizontal na direção X com a grade de malha quadrada $2,65 \mathrm{~cm}$ e rotação de 200 rpm.

FIGURA 27: Visualização das Isolinhas da Componente da Velocidade Horizontal na direção X com a grade de malha quadrada $2,65 \mathrm{~cm}$ e rotação de 200 rpm.

FIGURA 28: Visualização da Componente da Velocidade Horizontal na direção X com a grade de malha quadrada $3,90 \mathrm{~cm}$ e rotação de $140 \mathrm{rpm}$.

FIGURA 29: Visualização das Isolinhas da Componente da Velocidade Horizontal na direção X com a grade de malha quadrada $3,90 \mathrm{~cm}$ e rotação de $140 \mathrm{rpm}$.

FIGURA 30: Visualização da Componente da Velocidade Horizontal na direção X com a grade de malha quadrada 3,90cm e rotação de $160 \mathrm{rpm}$.

FIGURA 31: Visualização das Isolinhas da Componente da Velocidade Horizontal na direção X com a grade de malha quadrada $3,90 \mathrm{~cm}$ e rotação de $160 \mathrm{rpm}$. 
FIGURA 32: Visualização da Componente da Velocidade Horizontal na direção X com a grade de malha quadrada $3,90 \mathrm{~cm}$ e rotação de $180 \mathrm{rpm}$

FIGURA 33: Visualização das Isolinhas da Componente da Velocidade Horizontal na direção X com a grade de malha quadrada $3,90 \mathrm{~cm}$ e rotação de $180 \mathrm{rpm}$.

FIGURA 34: Visualização da Componente da Velocidade Horizontal na direção X com a grade de malha quadrada $3,90 \mathrm{~cm}$ e rotação de $210 \mathrm{rpm}$.

FIGURA 35: Visualização das Isolinhas da Componente da Velocidade Horizontal na direção $X$ com a grade de malha quadrada $3,90 \mathrm{~cm}$ e rotação de $210 \mathrm{rpm}$.

FIGURA 36: Visualização da Componente da Velocidade Horizontal na direção X com a grade de malha quadrada 3,90cm e rotação de 240 rpm.

FIGURA 37: Visualização das Isolinhas da Componente da Velocidade Horizontal na direção X com a grade de malha quadrada $3,90 \mathrm{~cm}$ e rotação de $240 \mathrm{rpm}$.

FIGURA 38: Visualização da Componente da Velocidade Horizontal na direção X com a grade de malha quadrada $6,45 \mathrm{~cm}$ e rotação de $180 \mathrm{rpm}$.

FIGURA 39: Visualização das Isolinhas da Componente da Velocidade Horizontal na direção $X$ com a grade de malha quadrada $6,45 \mathrm{~cm}$ e rotação de $180 \mathrm{rpm}$.

FIGURA 40: Visualização da Componente da Velocidade Horizontal na direção X com a grade de malha quadrada $6,45 \mathrm{~cm}$ e rotação de $200 \mathrm{rpm}$

FIGURA 41: Visualização das Isolinhas da Componente da Velocidade Horizontal na direção X com a grade de malha quadrada $6,45 \mathrm{~cm}$ e rotação de 200 rpm.

FIGURA 42: Visualização da Componente da Velocidade Horizontal na direção X com a grade de malha quadrada $6,45 \mathrm{~cm}$ e rotação de $220 \mathrm{rpm}$.

FIGURA 43: Visualização das Isolinhas da Componente da Velocidade Horizontal na direção X com a grade de malha quadrada $6,45 \mathrm{~cm}$ e rotação de $220 \mathrm{rpm}$.

FIGURA 44: Visualização da Componente da Velocidade Horizontal na direção X com a grade de malha quadrada $6,45 \mathrm{~cm}$ e rotação de $250 \mathrm{rpm}$.

FIGURA 45: Visualização das Isolinhas da Componente da Velocidade Horizontal na direção X com a grade de malha quadrada $6,45 \mathrm{~cm}$ e rotação de $250 \mathrm{rpm}$. 
FIGURA 46: Visualização da Componente da Velocidade Horizontal na direção X com a grade de malha quadrada $2,65 \mathrm{~cm}$ e rotação de 120 rpm.

FIGURA 47: Visualização das Isolinhas da Componente da Velocidade Horizontal na direção $X$ com a grade de malha quadrada $2,65 \mathrm{~cm}$ e rotação de $120 \mathrm{rpm}$.

FIGURA 48: Visualização da Componente da Velocidade Horizontal na direção X com a grade de malha quadrada $2,65 \mathrm{~cm}$ e rotação de $140 \mathrm{rpm}$.

FIGURA 49: Visualização das Isolinhas da Componente da Velocidade Horizontal na direção X com a grade de malha quadrada $2,65 \mathrm{~cm}$ e rotação de $140 \mathrm{rpm}$.

FIGURA 50: Visualização da Componente da Velocidade Horizontal na direção X com a grade de malha quadrada 2,65cm e rotação de 160 rpm.

FIGURA 51: Visualização das Isolinhas da Componente da Velocidade Horizontal na direção X com a grade de malha quadrada $2,65 \mathrm{~cm}$ e rotação de $160 \mathrm{rpm}$.

FIGURA 52: Visualização da Componente da Velocidade Horizontal na direção X com a grade de malha quadrada $2,65 \mathrm{~cm}$ e rotação de $180 \mathrm{rpm}$.

FIGURA 53: Visualização das Isolinhas da Componente da Velocidade Horizontal na direção $X$ com a grade de malha quadrada $2,65 \mathrm{~cm}$ e rotação de $180 \mathrm{rpm}$.

FIGURA 54: Visualização da Componente da Velocidade Horizontal na direção X com a grade de malha quadrada $2,65 \mathrm{~cm}$ e rotação de 200 rpm.

FIGURA 55: Visualização das Isolinhas da Componente da Velocidade Horizontal na direção X com a grade de malha quadrada $2,65 \mathrm{~cm}$ e rotação de 200 rpm.

FIGURA 56: Visualização da Componente da Velocidade Horizontal na direção X com a grade de malha quadrada $3,90 \mathrm{~cm}$ e rotação de $140 \mathrm{rpm}$.

FIGURA 57: Visualização das Isolinhas da Componente da Velocidade Horizontal na direção X com a grade de malha quadrada $3,90 \mathrm{~cm}$ e rotação de $140 \mathrm{rpm}$.

FIGURA 58: Visualização da Componente da Velocidade Horizontal na direção X com a grade de malha quadrada $3,90 \mathrm{~cm}$ e rotação de 160 rpm.

FIGURA 59: Visualização das Isolinhas da Componente da Velocidade Horizontal na direção X com a grade de malha quadrada $3,90 \mathrm{~cm}$ e rotação de $160 \mathrm{rpm}$. 
FIGURA 60: Visualização da Componente da Velocidade Horizontal na direção X com a grade de malha quadrada $3,90 \mathrm{~cm}$ e rotação de $180 \mathrm{rpm}$

FIGURA 61: Visualização das Isolinhas da Componente da Velocidade Horizontal na direção X com a grade de malha quadrada $3,90 \mathrm{~cm}$ e rotação de $180 \mathrm{rpm}$.

FIGURA 62: Visualização da Componente da Velocidade Horizontal na direção X com a grade de malha quadrada $3,90 \mathrm{~cm}$ e rotação de $210 \mathrm{rpm}$.

FIGURA 63: Visualização das Isolinhas da Componente da Velocidade Horizontal na direção $X$ com a grade de malha quadrada $3,90 \mathrm{~cm}$ e rotação de $210 \mathrm{rpm}$.

FIGURA 64: Visualização da Componente da Velocidade Horizontal na direção X com a grade de malha quadrada $3,90 \mathrm{~cm}$ e rotação de 240 rpm.

FIGURA 65: Visualização das Isolinhas da Componente da Velocidade Horizontal na direção $X$ com a grade de malha quadrada $3,90 \mathrm{~cm}$ e rotação de $240 \mathrm{rpm}$.

FIGURA 66: Visualização da Componente da Velocidade Horizontal na direção X com a grade de malha quadrada $6,45 \mathrm{~cm}$ e rotação de 180 rpm.

FIGURA 67: Visualização das Isolinhas da Componente da Velocidade Horizontal na direção $X$ com a grade de malha quadrada $6,45 \mathrm{~cm}$ e rotação de $180 \mathrm{rpm}$.

FIGURA 68: Visualização da Componente da Velocidade Horizontal na direção X com a grade de malha quadrada $6,45 \mathrm{~cm}$ e rotação de $200 \mathrm{rpm}$.

FIGURA 69: Visualização das Isolinhas da Componente da Velocidade Horizontal na direção X com a grade de malha quadrada $6,45 \mathrm{~cm}$ e rotação de 200 rpm.

FIGURA 70: Visualização da Componente da Velocidade Horizontal na direção X com a grade de malha quadrada $6,45 \mathrm{~cm}$ e rotação de $220 \mathrm{rpm}$.

FIGURA 71: Visualização das Isolinhas da Componente da Velocidade Horizontal na direção X com a grade de malha quadrada $6,45 \mathrm{~cm}$ e rotação de $220 \mathrm{rpm}$.

FIGURA 72: Visualização da Componente da Velocidade Horizontal na direção X com a grade de malha quadrada $6,45 \mathrm{~cm}$ e rotação de $250 \mathrm{rpm}$.

FIGURA 73: Visualização das Isolinhas da Componente da Velocidade Horizontal na direção X com a grade de malha quadrada $6,45 \mathrm{~cm}$ e rotação de $250 \mathrm{rpm}$. 
FIGURA 74: Visualzação do Gradiente da Velocidade Vertical (direção Z) com a grade de malha quadrada de espaçamento entre barras de 2,65 cm e rotação de $120 \mathrm{rpm}$.

FIGURA 75: Visualzação das Isolinhas do Gradiente da Velocidade Vertical (direção $Z$ ) com a grade de malha quadrada de espaçamento entre barras de 2,65cm e rotação de 120 rpm.

FIGURA 76: Visualzação do Gradiente da Velocidade Vertical (direção Z) com a grade de malha quadrada de espaçamento entre barras de 2,65 cm e rotação de 140 rpm....

FIGURA 77: Visualzação das Isolinhas do Gradiente da Velocidade Vertical (direção $Z$ ) com a grade de malha quadrada de espaçamento entre barras de $2,65 \mathrm{~cm}$ e rotação de $140 \mathrm{rpm}$.

FIGURA 78: Visualzação do Gradiente da Velocidade Vertical (direção Z) com a grade de malha quadrada de espaçamento entre barras de 2,65 cm e rotação de $160 \mathrm{rpm}$.

FIGURA 79: Visualzação das Isolinhas do Gradiente da Velocidade Vertical (direção $Z$ ) com a grade de malha quadrada de espaçamento entre barras de 2,65cm e rotação de 160 rpm.

FIGURA 80: Visualzação do Gradiente da Velocidade Vertical (direção Z) com a grade de malha quadrada de espaçamento entre barras de 2,65 cm e rotação de 180 rpm.

FIGURA 81: Visualzação das Isolinhas do Gradiente da Velocidade Vertical (direção $Z$ ) com a grade de malha quadrada de espaçamento entre barras de $2,65 \mathrm{~cm}$ e rotação de $180 \mathrm{rpm}$.

FIGURA 82: Visualzação do Gradiente da Velocidade Vertical (direção Z) com a grade de malha quadrada de espaçamento entre barras de 2,65 cm e rotação de $200 \mathrm{rpm}$.

FIGURA 83: Visualzação das Isolinhas do Gradiente da Velocidade Vertical (direção $Z$ ) com a grade de malha quadrada de espaçamento entre barras de $2,65 \mathrm{~cm}$ e rotação de $200 \mathrm{rpm}$.

FIGURA 84: Visualzação do Gradiente da Velocidade Vertical (direção Z) com a grade de malha quadrada de espaçamento entre barras de 3,90 cm e rotação de $120 \mathrm{rpm}$.

FIGURA 85: Visualzação das Isolinhas do Gradiente da Velocidade Vertical (direção $Z$ ) com a grade de malha quadrada de espaçamento entre barras de $3,90 \mathrm{~cm}$ e rotação de $120 \mathrm{rpm}$. 
FIGURA 86: Visualzação do Gradiente da Velocidade Vertical (direção Z) com a grade de malha quadrada de espaçamento entre barras de 3,90 cm e rotação de 160 rpm.

FIGURA 87: Visualzação das Isolinhas do Gradiente da Velocidade Vertical (direção $Z$ ) com a grade de malha quadrada de espaçamento entre barras de $3,90 \mathrm{~cm}$ e rotação de $160 \mathrm{rpm}$.

FIGURA 88: Visualzação do Gradiente da Velocidade Vertical (direção Z) com a grade de malha quadrada de espaçamento entre barras de $3,90 \mathrm{~cm}$ e rotação de 180 rpm.

FIGURA 89: Visualzação das Isolinhas do Gradiente da Velocidade Vertical (direção $Z$ ) com a grade de malha quadrada de espaçamento entre barras de $3,90 \mathrm{~cm}$ e rotação de $180 \mathrm{rpm}$.

FIGURA 90: Visualzação do Gradiente da Velocidade Vertical (direção Z) com a grade de malha quadrada de espaçamento entre barras de 3,90 cm e rotação de $210 \mathrm{rpm}$.

FIGURA 91: Visualzação das Isolinhas do Gradiente da Velocidade Vertical (direção $Z$ ) com a grade de malha quadrada de espaçamento entre barras de $3,90 \mathrm{~cm}$ e rotação de $210 \mathrm{rpm}$.

FIGURA 92: Visualzação do Gradiente da Velocidade Vertical (direção Z) com a grade de malha quadrada de espaçamento entre barras de 3,90 cm e rotação de $240 \mathrm{rpm}$.

FIGURA 93: Visualzação das Isolinhas do Gradiente da Velocidade Vertical (direção $Z$ ) com a grade de malha quadrada de espaçamento entre barras de $3,90 \mathrm{~cm}$ e rotação de $240 \mathrm{rpm}$.

FIGURA 94: Visualzação do Gradiente da Velocidade Vertical (direção Z) com a grade de malha quadrada de espaçamento entre barras de 6,45 cm e rotação de 180 rpm.

FIGURA 95: Visualzação das Isolinhas do Gradiente da Velocidade Vertical (direção $Z$ ) com a grade de malha quadrada de espaçamento entre barras de $6,45 \mathrm{~cm}$ e rotação de $180 \mathrm{rpm}$.

FIGURA 96: Visualzação do Gradiente da Velocidade Vertical (direção Z) com a grade de malha quadrada de espaçamento entre barras de $6,45 \mathrm{~cm}$ e rotação de $200 \mathrm{rpm}$.

FIGURA 97: Visualzação das Isolinhas do Gradiente da Velocidade Vertical (direção $Z$ ) com a grade de malha quadrada de espaçamento entre barras de $6,45 \mathrm{~cm}$ e rotação de $200 \mathrm{rpm}$. 
FIGURA 98: Visualzação do Gradiente da Velocidade Vertical (direção Z) com a grade de malha quadrada de espaçamento entre barras de 6,45 cm e rotação de 220 rpm.

FIGURA 99: Visualzação das Isolinhas do Gradiente da Velocidade Vertical (direção $Z$ ) com a grade de malha quadrada de espaçamento entre barras de $6,45 \mathrm{~cm}$ e rotação de $220 \mathrm{rpm}$.

FIGURA 100: Visualzação do Gradiente da Velocidade Vertical (direção Z) com a grade de malha quadrada de espaçamento entre barras de $6,45 \mathrm{~cm}$ e rotação de 250 rpm.

FIGURA 101: Visualzação das Isolinhas do Gradiente da Velocidade Vertical (direção $Z$ ) com a grade de malha quadrada de espaçamento entre barras de $6,45 \mathrm{~cm}$ e rotação de $250 \mathrm{rpm}$....

FIGURA 102: Melhor ajuste para RMS foto versus freqüência de oscilação da grade de 26,5 $\mathrm{mm}$ de abertura e 10,0 $\mathrm{mm}$ de espessura.

FIGURA 103: Melhor ajuste para RMS foto versus freqüência de oscilação da grade de 39,0 mm de abertura e 10,0 mm de espessura.

FIGURA 104: Melhor ajuste para RMS foto versus freqüência de oscilação da grade de $64,5 \mathrm{~mm}$ de abertura e $10,0 \mathrm{~mm}$ de espessura.

FIGURA 105: Autocorrelação da Sonda: Ensaio da Grade de 26,5mm de abertura e barras com 10,0mm de espessura (Freqüência de oscilação da grade de $120 \mathrm{rpm})$.

FIGURA 106: Autocorrelação da Foto: Ensaio da Grade de 26,5mm de abertura e barras com 10,0mm de espessura (Freqüência de oscilação da grade de $120 \mathrm{rpm})$.

FIGURA 107: Autocorrelação da Sonda: Ensaio da Grade de 26,5mm de abertura e barras com 10,0mm de espessura (Freqüência de oscilação da grade de $140 \mathrm{rpm})$.

FIGURA 108: Autocorrelação da Foto: Ensaio da Grade de 26,5mm de abertura e barras com 10,0mm de espessura (Freqüência de oscilação da grade de $140 \mathrm{rpm})$.

FIGURA 109: Autocorrelação da Sonda: Ensaio da Grade de 26,5mm de abertura e barras com 10,0mm de espessura (Freqüência de oscilação da grade de $160 \mathrm{rpm})$.

FIGURA 110: Autocorrelação da Foto: Ensaio da Grade de 26,5mm de abertura e barras com 10,0mm de espessura (Freqüência de oscilação da grade de $160 \mathrm{rpm})$. 
FIGURA 111: Autocorrelação da Sonda: Ensaio da Grade de 26,5mm de abertura e barras com 10,0mm de espessura (Freqüência de oscilação da grade de $180 \mathrm{rpm})$.

FIGURA 112: Autocorrelação da Foto: Ensaio da Grade de 26,5mm de abertura e barras com 10,0mm de espessura (Freqüência de oscilação da grade de $180 \mathrm{rpm})$.

FIGURA 113: Autocorrelação da Sonda: Ensaio da Grade de 26,5mm de abertura e barras com 10,0mm de espessura (Freqüência de oscilação da grade de $200 \mathrm{rpm}$ ).

FIGURA 114: Autocorrelação da Foto: Ensaio da Grade de 26,5mm de abertura e barras com 10,0mm de espessura (Freqüência de oscilação da grade de $200 \mathrm{rpm})$.

FIGURA 115: Autocorrelação da Sonda: Ensaio da Grade de 39,0mm de abertura e barras com 10,0mm de espessura (Freqüência de oscilação da grade de $140 \mathrm{rpm})$.

FIGURA 116: Autocorrelação da Foto: Ensaio da Grade de 39,0mm de abertura e barras com 10,0mm de espessura (Freqüência de oscilação da grade de $140 \mathrm{rpm})$....

FIGURA 117: Autocorrelação da Sonda: Ensaio da Grade de 39,0mm de abertura e barras com 10,0mm de espessura (Freqüência de oscilação da grade de $160 \mathrm{rpm})$.

FIGURA 118: Autocorrelação da Foto: Ensaio da Grade de 39,0mm de abertura e barras com 10,0mm de espessura (Freqüência de oscilação da grade de $160 \mathrm{rpm})$.

FIGURA 119: Autocorrelação da Sonda: Ensaio da Grade de 39,0mm de abertura e barras com 10,0mm de espessura (Freqüência de oscilação da grade de $180 \mathrm{rpm})$.

FIGURA 120: Autocorrelação da Foto: Ensaio da Grade de 39,0mm de abertura e barras com 10,0mm de espessura (Freqüência de oscilação da grade de $180 \mathrm{rpm})$....

FIGURA 121: Autocorrelação da Sonda: Ensaio da Grade de 39,0mm de abertura e barras com 10,0mm de espessura (Freqüência de oscilação da grade de $210 \mathrm{rpm})$.

FIGURA 122: Autocorrelação da Foto: Ensaio da Grade de 39,0mm de abertura e barras com 10,0mm de espessura (Freqüência de oscilação da grade de $210 \mathrm{rpm})$. 
FIGURA 123: Autocorrelação da Sonda: Ensaio da Grade de 39,0mm de abertura e barras com 10,0mm de espessura (Freqüência de oscilação da grade de $240 \mathrm{rpm})$.

FIGURA 124: Autocorrelação da Foto: Ensaio da Grade de 39,0mm de abertura e barras com 10,0mm de espessura (Freqüência de oscilação da grade de $240 \mathrm{rpm})$.

FIGURA 125: Autocorrelação da Sonda: Ensaio da Grade de 64,5mm de abertura e barras com 10,0mm de espessura (Freqüência de oscilação da grade de $180 \mathrm{rpm})$.

FIGURA 126: Autocorrelação da Foto: Ensaio da Grade de 64,5mm de abertura e barras com 10,0mm de espessura (Freqüência de oscilação da grade de $180 \mathrm{rpm})$.

FIGURA 127: Autocorrelação da Sonda: Ensaio da Grade de 64,5mm de abertura e barras com 10,0mm de espessura (Freqüência de oscilação da grade de $200 \mathrm{rpm})$.

FIGURA 128: Autocorrelação da Foto: Ensaio da Grade de 64,5mm de abertura e barras com 10,0mm de espessura (Freqüência de oscilação da grade de $200 \mathrm{rpm})$....

FIGURA 129: Autocorrelação da Sonda: Ensaio da Grade de 64,5mm de abertura e barras com 10,0mm de espessura (Freqüência de oscilação da grade de $220 \mathrm{rpm})$.

FIGURA 130: Autocorrelação da Foto: Ensaio da Grade de 64,5mm de abertura e barras com 10,0mm de espessura (Freqüência de oscilação da grade de $220 \mathrm{rpm}$ ).

FIGURA 131: Autocorrelação da Sonda: Ensaio da Grade de 64,5mm de abertura e barras com 10,0mm de espessura (Freqüência de oscilação da grade de $250 \mathrm{rpm})$.

FIGURA 132: Autocorrelação da Foto: Ensaio da Grade de $64,5 \mathrm{~mm}$ de abertura e barras com 10,0mm de espessura (Freqüência de oscilação da grade de $250 \mathrm{rpm})$....

FIGURA 133: Espectro Sonda: Ensaio da Grade de 26,5mm de abertura e barras com 10,0mm de espessura (Freqüência de oscilação da grade de 120 rpm).

FIGURA 134: Espectro Foto: Ensaio da Grade de 26,5mm de abertura e barras com 10,0mm de espessura (Freqüência de oscilação da grade de 120 rpm). 
FIGURA 135: Espectro Sonda: Ensaio da Grade de 26,5mm de abertura e barras com 10,0mm de espessura (Freqüência de oscilação da grade de 140 rpm).

FIGURA 136: Espectro Foto: Ensaio da Grade de 26,5mm de abertura e barras com 10,0mm de espessura (Freqüência de oscilação da grade de 140 rpm).

FIGURA 137: Espectro Sonda: Ensaio da Grade de 26,5mm de abertura e barras com 10,0mm de espessura (Freqüência de oscilação da grade de 160 rpm)....

FIGURA 138: Espectro Foto: Ensaio da Grade de 26,5mm de abertura e barras com 10,0mm de espessura (Freqüência de oscilação da grade de 160 rpm).

FIGURA 139: Espectro Sonda: Ensaio da Grade de 26,5mm de abertura e barras com 10,0mm de espessura (Freqüência de oscilação da grade de 180 rpm).

FIGURA 140: Espectro Foto: Ensaio da Grade de 26,5mm de abertura e barras com 10,0mm de espessura (Freqüência de oscilação da grade de 180 rpm).

FIGURA 141: Espectro Sonda: Ensaio da Grade de 26,5mm de abertura e barras com 10,0mm de espessura (Freqüência de oscilação da grade de 200 rpm).

FIGURA 142: Espectro Foto: Ensaio da Grade de 26,5mm de abertura e barras com 10,0mm de espessura (Freqüência de oscilação da grade de 200 rpm).

FIGURA 143: Espectro Sonda: Ensaio da Grade de 39,0mm de abertura e barras com 10,0mm de espessura (Freqüência de oscilação da grade de 140 rpm).

FIGURA 144: Espectro Foto: Ensaio da Grade de 39,0mm de abertura e barras com 10,0mm de espessura (Freqüência de oscilação da grade de 140 rpm).

FIGURA 145: Espectro Sonda: Ensaio da Grade de 39,0mm de abertura e barras com 10,0mm de espessura (Freqüência de oscilação da grade de 160 rpm).

FIGURA 146: Espectro Foto: Ensaio da Grade de 39,0mm de abertura e barras com 10,0mm de espessura (Freqüência de oscilação da grade de 160 rpm).... 
FIGURA 147: Espectro Sonda: Ensaio da Grade de 39,0mm de abertura e barras com 10,0mm de espessura (Freqüência de oscilação da grade de 180 rpm).

FIGURA 148: Espectro Foto: Ensaio da Grade de 39,0mm de abertura e barras com 10,0mm de espessura (Freqüência de oscilação da grade de 180 rpm).

FIGURA 149: Espectro Sonda: Ensaio da Grade de 39,0mm de abertura e barras com 10,0mm de espessura (Freqüência de oscilação da grade de 210 rpm)....

FIGURA 150: Espectro Foto: Ensaio da Grade de 39,0mm de abertura e barras com 10,0mm de espessura (Freqüência de oscilação da grade de 210 rpm).

FIGURA 151: Espectro Sonda: Ensaio da Grade de 39,0mm de abertura e barras com 10,0mm de espessura (Freqüência de oscilação da grade de 240 rpm).

FIGURA 152: Espectro Foto: Ensaio da Grade de 39,0mm de abertura e barras com 10,0mm de espessura (Freqüência de oscilação da grade de 240 rpm).

FIGURA 153: Espectro Sonda: Ensaio da Grade de 64,5mm de abertura e barras com 10,0mm de espessura (Freqüência de oscilação da grade de 180 rpm).

FIGURA 154: Espectro Foto: Ensaio da Grade de 64,5mm de abertura e barras com 10,0mm de espessura (Freqüência de oscilação da grade de 180 rpm).

FIGURA 155: Espectro Sonda: Ensaio da Grade de 64,5mm de abertura e barras com 10,0mm de espessura (Freqüência de oscilação da grade de 200 rpm).

FIGURA 156: Espectro Foto: Ensaio da Grade de $64,5 \mathrm{~mm}$ de abertura e barras com 10,0mm de espessura (Freqüência de oscilação da grade de 200 rpm).

FIGURA 157: Espectro Sonda: Ensaio da Grade de 64,5mm de abertura e barras com 10,0mm de espessura (Freqüência de oscilação da grade de 220 rpm).

FIGURA 158: Espectro Foto: Ensaio da Grade de $64,5 \mathrm{~mm}$ de abertura e barras com 10,0mm de espessura (Freqüência de oscilação da grade de 220 rpm).... 
FIGURA 159: Espectro Sonda: Ensaio da Grade de 64,5mm de abertura e barras com 10,0mm de espessura (Freqüência de oscilação da grade de 250 rpm).

FIGURA 160: Espectro Foto: Ensaio da Grade de 64,5mm de abertura e barras com 10,0mm de espessura (Freqüência de oscilação da grade de 250

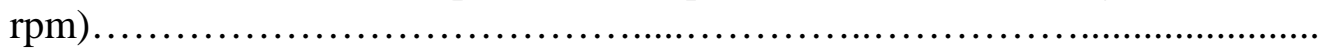

FIGURA 161: $\mathrm{K}_{2}$ em função de RMS (Grade de 26,5mm de abertura e barras com 10,0mm de espessura)

FIGURA 162: $\mathrm{K}_{2}$ em função de RMS (Grade de 39,0mm de abertura e barras com 10,0mm de espessura).

FIGURA 163: $\mathrm{K}_{2}$ em função de RMS (Grade de 64,5mm de abertura e barras com 10,0mm de espessura)....

FIGURA 164: RMS Foto em função de $\mathrm{K}_{2}$ (Grade de 26,5mm de abertura e barras com 10,0mm de espessura)...

FIGURA 165: RMS Foto em função de $K_{2}$ (Grade de 39,0mm de abertura e barras com 10,0mm de espessura)...

FIGURA 166: RMS Foto em função de $K_{2}$ (Grade de $64,5 \mathrm{~mm}$ de abertura e barras com 10,0mm de espessura)... 


\section{LISTA DE TABELAS}

pág.

TABELA 1: Resultados do coeficiente de reaeração $K_{2}$, medido na temperatura do experimento e a $25^{\circ} \mathrm{C}$. Coeficiente de transferência de massa $\mathrm{K}_{\mathrm{L}}$ e as condições experimentais de cada ensaio (temperaturas e umidade relativa do ar.

TABELA 2: Comparativo entre os valores $K_{2}$ para o ensaio da grade fina.

TABELA 3: Comparativo entre os valores K2 para o ensaio da grade média... 73

TABELA 4: Comparativo entre os valores K2 para o ensaio da grade larga.... 74

TABELA 5: Parâmetros turbulentos obtidos nos ensaios com o método ótico. Comparação dos valores RMS e Macro escala desta pesquisa com os de ROMA (1988).

TABELA 6: Valores de RMS obtidos pelo método fotográfico para o gradiente de velocidade vertical.

TABELA 7: Valores de $\mathrm{K}_{2}$ e RMS da sonda medidos em laboratório e estimados para a grade de $26,5 \mathrm{~mm}$ de abertura e barras com $10 \mathrm{~mm}$ de espessura......

TABELA 8: Valores de $K_{2}$ e RMS da sonda medidos em laboratório e estimados para a grade de $39,0 \mathrm{~mm}$ de abertura e barras com $10 \mathrm{~mm}$ de espessura......

TABELA 9: Valores de $K_{2}$ e RMS da sonda medidos em laboratório e estimados para a grade de $64,5 \mathrm{~mm}$ de abertura e barras com $10 \mathrm{~mm}$ de espessura...

TABELA 10: Valores de $\mathrm{K}_{2}$ e RMS foto medidos em laboratório e estimados para a grade de $26,5 \mathrm{~mm}$ de abertura e barras com $10 \mathrm{~mm}$ de espessura..

TABELA 11 Valores de $\mathrm{K}_{2}$ e RMS foto medidos em laboratório e estimados para a grade de $39,0 \mathrm{~mm}$ de abertura e barras com $10 \mathrm{~mm}$ de espessura......

TABELA 12: Valores de $\mathrm{K}_{2}$ e RMS foto medidos em laboratório e estimados para a grade de $64,5 \mathrm{~mm}$ de abertura e barras com $10 \mathrm{~mm}$ de espessura...... 


\title{
LISTA DE ABREVIATURAS E SIGLAS
}

\author{
CPU - Unidade Central de Processamento \\ DPIV - velocimetria por Processamento de Imagens Digitais \\ FFT - Fast Fourier Transform \\ PIV - Velocimetria por Processamento de Imagens \\ RMS - Raiz Média Quadrática \\ SHS - Setor de Hidráulica e Saneamento
}




\section{LISTA DE SÍMBOLOS}

\begin{tabular}{|c|c|c|}
\hline$A$ & - área de interface gás- líquido & $\mathrm{L}^{2}$ \\
\hline$A_{e}$ & - valor máximo da velocidade no interior da célula & $\mathrm{L}^{2}$ \\
\hline$C$ & - flutuação da concentração em relação ao valor médio & $\mathrm{M} \mathrm{L}^{-3}$ \\
\hline$C$ & - concentração do gás dissolvido no líquido & $\mathrm{M} \mathrm{L}^{-3}$ \\
\hline $\bar{C}$ & - concentração média temporal & $\mathrm{M} \mathrm{L}^{-3}$ \\
\hline$C_{o}$ & - concentração inicial do gás dissolvido & $\mathrm{M} \mathrm{L}^{-3}$ \\
\hline$C_{I}$ & - concentração molar da espécie i & $\mathrm{M} \mathrm{L}^{-3}$ \\
\hline$C_{I}$ & - concentração na interface & $\mathrm{M} \mathrm{L}^{-3}$ \\
\hline$C_{L}$ & - concentração do gás dissolvido no volume líquido & $\mathrm{M} \mathrm{L}^{-3}$ \\
\hline$C_{s}$ & - concentração de saturação do gás no líquido & $\mathrm{M} \mathrm{L}^{-3}$ \\
\hline$D$ & - diâmetro de colisão & $\mathrm{L}$ \\
\hline$D_{A B}$ & - diâmetro de colisão mútuo de A em B e de B em A & $\mathrm{L}$ \\
\hline$D_{i i}$ & - coeficiente de difusão ou autodifusão & $\mathrm{L}^{2} \mathrm{~T}^{-1}$ \\
\hline$D_{A B}$ & - coeficiente de difusão do soluto A no meio B & $\mathrm{L}^{2} \mathrm{~T}^{-1}$ \\
\hline$D_{m}$ & - coeficiente de difusão molecular do soluto & $\mathrm{L}^{2} \mathrm{~T}^{-1}$ \\
\hline$D_{T i}$ & - coeficiente de difusão turbulenta & $\mathrm{L}^{2} \mathrm{~T}^{-1}$ \\
\hline$e$ & - exponencial & \\
\hline$f$ & - freqüência de oscilação da grade & $\mathrm{t}^{-1}$ \\
\hline$F C$ & - somatório de todas as fontes e sumidouros & \\
\hline$H$ & - coeficiente de solubilidade da lei de Henry & $\mathrm{L}^{2} \mathrm{M} \mathrm{t}^{-2}$ \\
\hline$H$ & - profundidade & $\mathrm{L}$ \\
\hline$J$ & - fluxo de massa por unidade de área & $\mathrm{M} \mathrm{L}^{-2} \mathrm{~T}^{-1}$ \\
\hline \multirow[t]{2}{*}{$J_{i, z}$} & - fluxo difusivo da espécie i por unidade de área na direção & \\
\hline & $z$ & $\mathrm{M} \mathrm{L}^{-2} \mathrm{~T}^{-1}$ \\
\hline $\mathrm{K}$ & - coeficiente de transferência de massa & \\
\hline$L_{f}$ & - espessura do filme & $\mathrm{L}$ \\
\hline$k$ & - energia cinética turbulenta & $\mathrm{M} \mathrm{L} \mathrm{T}^{-1}$ \\
\hline$K_{2}$ & - coeficiente de reaeração & $\mathrm{t}^{-1}$ \\
\hline$K_{G}$ & - coeficiente do filme gasoso & $\mathrm{L} \mathrm{T}^{-1}$ \\
\hline
\end{tabular}


$K_{G} \quad$ - coeficiente global de transferência de massa no filme $\mathrm{L} \mathrm{T}^{-1}$ gasoso

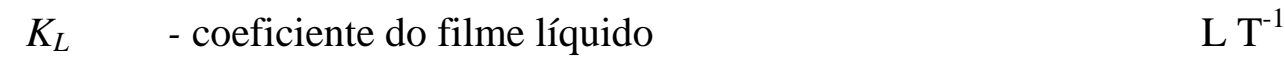

$K_{L} \quad$ - coeficiente global de transferência de massa no filme $\mathrm{L} \mathrm{T}^{-1}$ líquido

$K_{T}$ - coeficiente de dessorção $\quad \mathrm{t}^{-1}$

$L$ - comprimento de escala integral L

$\begin{array}{lll}L_{m} & \text { - macro escala de turbulência } & \mathrm{T}\end{array}$

M - lado da malha da grade $\quad$ L

$M \quad$ - massa molecular $\quad \mathrm{M} \mathrm{mol}^{-1}$

$m \quad$ - massa de gás dissolvido $\quad \mathrm{M}$

$N_{0} \quad$ - número de Avogrado

$N_{n} \quad$ - fator de associação que define o peso molecular efetivo do solvente

$\mathrm{O}_{2} \quad$ - oxigênio

$P \quad$ - pressão

$P_{G} \quad$ - pressão parcial no gás $\quad \mathrm{L}^{-1} \mathrm{M} \mathrm{t}^{-2}$

$P_{I} \quad$ - pressão parcial na interface $\quad \mathrm{L}^{-1} \mathrm{M} \mathrm{t}^{-2}$

$P_{S} \quad$ - pressão parcial correspondente a concentração de $\mathrm{L}^{-1} \mathrm{M} \mathrm{t}^{-2}$ saturação

$R \quad$ - constante universal dos gases

S - número de Schmidt

$S \quad$ - amplitude de oscilação da grade L

$s \quad$ - razão média de renovação superficial por unidade total de $\mathrm{t}^{-1}$ área da superfície da teoria da penetração

$\mathrm{S}_{\beta} \quad$ - espectro da flutuação do gradiente de velocidade vertical $\quad \mathrm{L}^{2} \mathrm{~T}^{2}$ 


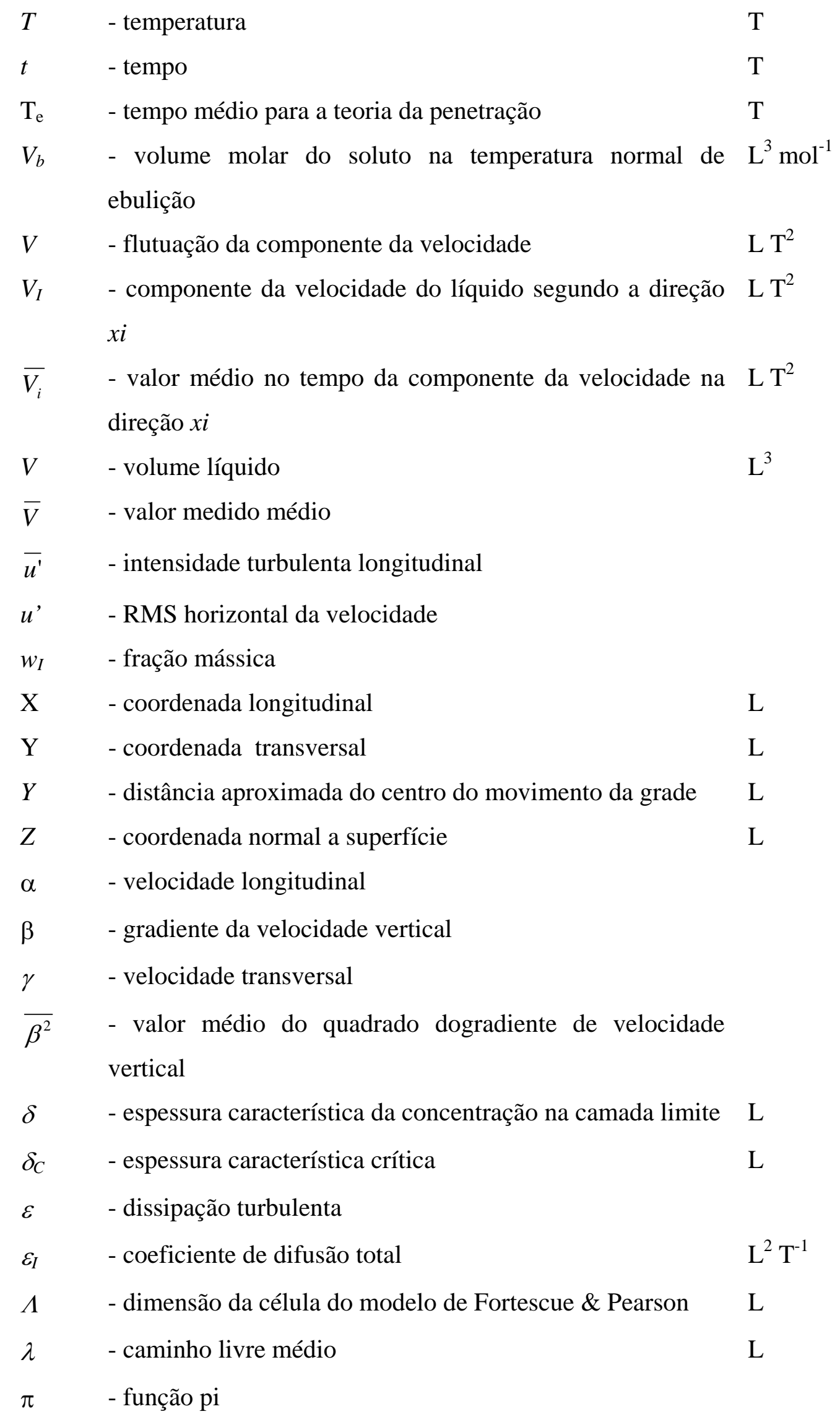




$\begin{array}{lll}\mu & \text { - viscosidade dinâmica da água } & \mathrm{L}^{-1} \mathrm{M} \mathrm{T}^{-1} \\ v_{t} & \text { - viscosidade turbulenta } & \mathrm{L}^{2} \mathrm{~T}^{-1} \\ \rho & \text { - densidade do fluido } & \mathrm{M} \mathrm{L}^{-3} \\ \rho(d x) & \text { - coeficiente da função de autocorrelação espacial } & \\ \rho(d t) & \text { - coeficiente da função de autocorrelação temporal } & \\ \sigma_{\mathrm{AB}} & \text { - diâmetro médio de colisão para a mistura (A+B) } & \mathrm{L} \\ \phi & \text { - função de distribuição das idades dos elementos líquidos } & \\ \Omega & \text { superficiais } & \\ \Omega_{\mathrm{D}} & \text { - velocidade média molecular } & \mathrm{L} \mathrm{T}^{-1} \\ \sigma & \text { - fatograr de forma } & \\ \omega_{C} & \text { - freqüência crítica } & \mathrm{T}^{-1} \\ \omega_{m} & \text { - freqüência média } & \mathrm{T}^{-1} \\ \partial & \text { - símbolo de derivada parcial } & \end{array}$




\section{RESUMO}

PEREIRA, C. E. (2002). Estudo de parâmetros turbulentos e sua relação com o coeficiente de reaeração com o uso da técnica fotográfica. São Carlos, 2002. 162 p. Dissertação (Mestrado) - Escola de Engenharia de São Carlos, Universidade de São Paulo.

A importância dada aos parâmetros de qualidade da água, principalmente nas últimas décadas justifica a realização desde trabalho, que investiga a relação de alguns parâmetros turbulentos com o coeficiente de reaeração, $\mathrm{K}_{2}$, através de duas técnicas distintas de medida: o método ótico e a técnica fotográfica.

O método ótico relaciona a intensidade de luz recebida por um diodo imerso na água com a velocidade vertical no ponto onde é realizada a medida; os dados coletados pelo método ótico constituem um sinal elétrico que contém a informação da deformação da superfície. A partir desse sinal determinam-se os seguintes parâmetros: Valor RMS da tensão, função de autocorrelação, macroescala e espectro. Os resultados obtidos por esse método são funções temporais.

O método fotográfico consiste em obter fotografias de partículas iluminadas sobre a superfície livre da água, com tempo de exposição conhecido. O método foi melhorado pela adição de dois disparos de flash, para permitir a determinação da variação da velocidade. As fotos são digitalizadas em um software gráfico e os valores obtidos são interpolados através do método Kriging de interpolação. O método fotográfico é uma função espacial.

A partir do método fotográfico são determinados os seguintes parâmetros: Valor RMS, função de autocorrelação e espectro. Os resultados obtidos permitem a comparação quantitativa entre as funções de autocorrelação e espectros, e a relação entre o coeficiente de reaeração, $K_{2}$ e o valor RMS obtidos pela sonda e pela foto.

Palavras-chave: reoxigenação; coeficiente de reaeração; método fotográfico; parâmetros turbulentos; visualização do escoamento. 


\begin{abstract}
PEREIRA, C. E. Study of turbulent parameters and your relation with the coefficient reaeration with the use of the photographic technique. São Carlos, 2002. 162 p. Dissertação (Mestrado) - Escola de Engenharia de São Carlos, Universidade de São Paulo.
\end{abstract}

The importance given to the parameters of quality of the water, mainly in the last decades, it justifies the accomplishment of this work, that it investigates the relation of some turbulent parameters with the re-aeration coefficient, $\mathrm{K}_{2}$, through two different techniques of measure: the optic method and the photographic technique.

The optic method relates the intensity of the light received by a immersed diode in the water with the vertical speed at the point where the measure is accomplished; the data collected by the optic method are electric signs that contains the information of the deformation of the surface. Thereafter this signs, the following parameters are determined: RMS value of tension, self-correlation function, macroscale and spectrum. The results obtained for this method they are temporal functions.

The photographic method consists of obtaining pictures of illuminated particles on the free surface of the water, with time of exhibition known. The method was improved by addition of two shots of flashes, to allow the determination of the variation of the speed. The pictures, then, are digitized in a graphic software and the values obtained are interpolated through the Kriging interpolation method. The photographic method is a spatial function.

With the photographic method may be determined the following parameters: RMS value, self-correlation function and spectrum. The results obtained may provide the quantitative comparison between the self-correlation function and spectrum; and also the relation between the re-aeration coefficient, $\mathrm{K}_{2}$, and the RMS value, that are obtained through the probe and the picture.

Keywords: re-oxygenation; re-aeration coefficient; photographic method; turbulent parameters; visualization of the drainage. 


\section{INTRODUÇÃO}

O desenvolvimento industrial dos últimos dois séculos foi acompanhado pelo crescimento populacional urbano, verificado mais fortemente no último século, no qual, principalmente a atmosfera terrestre e os rios acabaram recebendo grandes cargas de poluentes, decorrentes de despejos domésticos e industriais. A cada dia o problema torna-se mais crescente nos grandes centros urbanos. Como conseqüência, os processos naturais sofrem grande alteração, acarretando em rios poluídos, no efeito estufa e outras conseqüências geradas pelos processos de degradação.

Todos os processos naturais, como a reaeração em rios e oceanos e os ciclos térmicos e de massa do meio ambiente, são afetados pelas ações antrópicas.

No estudo de tratamento de corpos d’água um dos processos envolvidos é o transporte de massa na interface líquido/gás. Um dos gases relevantes nesses processos é o oxigênio, geralmente incorporado no líquido a partir da atmosfera. Este processo é conhecido como reaeração e vem ganhando importância devido à preocupação com o tratamento das águas de abastecimento e residuárias.

Um dos parâmetros de grande importância na qualidade da água é o oxigênio dissolvido, e dentre os despejos lançados nos rios está a matéria orgânica. Esse composto serve de alimento para as bactérias, que consomem no seu metabolismo o oxigênio dissolvido, acarretando um déficit de oxigênio na água.

O processo conhecido como autodepuração dos rios é a resposta que a natureza dá à ação da contaminação deles. Dentro desse processo existe a recuperação da carga de oxigênio dissolvido, através da absorção de oxigênio pela água.

A absorção de gás por um líquido é influenciada fortemente pelo campo de velocidade. Em um corpo de água parada o processo de transferência de massa se dá através de um processo lento, a difusão molecular. E em águas agitadas o fenômeno 
é acelerado e passa a ser estudado com ferramentas mais complexas vinculadas aos escoamentos turbulentos.

O parâmetro que é utilizado para representar a absorção de oxigênio pela água é o coeficiente de reaeração $\left(\mathrm{K}_{2}\right)$. Diversos pesquisadores desenvolveram fórmulas de natureza teóricas, empíricas ou semi-empíricas, bem como equipamentos e métodos para realizar essas medidas, tanto em laboratório quanto diretamente nos próprios rios.

Vê-se que o movimento turbulento na superfície livre na interface entre dois meios é de grande importância nos processos de transferência de massa e calor. Grande atenção tem sido dada à absorção de gases em escoamentos turbulentos. O tema é de entendimento complexo, com poucos estudos direcionados aos detalhes da interface.

Os lançamentos de despejos domésticos e industriais em rios poluem a água utilizada para consumo humano. Este motivo simples aponta para a necessidade de maiores estudos nesta área, uma vez que a oxigenação é uma das formas de recuperar águas poluídas.

Através de observações da própria natureza, e pela utilização do fenômeno da refração, ROMA (1988) desenvolveu uma sonda ótica, instrumento capaz de detectar a deformação da superfície através de um sinal luminoso e produzir um sinal elétrico que contém informações da deformação. A sonda ótica foi desenvolvida para ser utilizada em medidas de turbulência superficial em água, e assim caracterizar escoamentos turbulentos. Com o sinal gerado pela sonda é possível determinar parâmetros turbulentos, como o valor RMS, a função de auto correlação, a macro escala e o espectro, caracterizando o escoamento.

Outro método presente na literatura é o método de trilhagem de partículas, um método fotográfico que consiste basicamente na trilhagem de partículas iluminadas sobre a superfície livre. Pelos traços que as partículas deixam impressas na imagem e pelo tempo de exposição da tomada fotográfica, o campo de velocidade instantâneo pode ser calculado. 


\section{OBJETIVOS}

O objetivo deste trabalho é comparar os resultados obtidos pelo método ótico desenvolvido por ROMA (1988), com os resultados do método fotográfico por trilhagem de partículas, na obtenção de uma relação com o coeficiente de reaeração, $\mathrm{K}_{2}$.

Os resultados dos parâmetros obtidos pelo método ótico serão comparados com os parâmetros do método fotográfico, buscando-se uma relação entre os dois resultados, que permita avaliar a qualidade dos dados obtidos pelo sensor ótico.

Avaliação dos parâmetros obtidos pelos dois métodos, identificando os que apresentam melhor correlação com o coeficiente de reaeração superficial. 


\section{ANÁLISE TEÓRICA E REVISÃO BIBLIOGRÁFICA}

\subsection{Fundamentos de Transferência de Massa}

O fenômeno da transferência de massa nasce da “diferença” de concentração entre espécies químicas ou constituintes em dois meios ou duas regiões distintas em um único meio. Se em uma região qualquer do espaço uma determinada espécie química se encontra em grande número de moléculas por unidade de volume (concentração) e, em contrapartida, em uma outra região próxima, o número de moléculas por unidade de massa dessa mesma espécie é mais reduzido, a tendência das moléculas seria a de migrarem da região de maior para a de menor concentração e, se não houver nenhum efeito neutralizador, buscarem o equilíbrio.

No estudo de tratamento de corpos d’água, um dos processos importantes é o transporte de massa na interface líquido/gás. Este processo é conhecido como reaeração e vem ganhando importância devido à preocupação com o tratamento das águas de abastecimento e residuárias. Na absorção de gás por um líquido é nítida a relação entre a taxa de absorção e o campo de velocidades existente no líquido. Em um corpo com água praticamente parada, o processo de transferência de massa se dá, unicamente, pela difusão, que é caracterizada por ser um processo lento e se deve às interações moleculares sendo descrita pela Lei de Fick. Já em águas agitadas o fenômeno é acelerado e passa a ser estudado pela equação do balanço de massa.

Os principais mecanismos para o transporte de massa são a difusão, já mencionada, e a advecção. Na advecção, o transporte de massa ocorre principalmente devido ao movimento do fluido. 
Inicialmente, a fim de que se descreva a difusão, será estudada a lei de Fick e, e em seguida a equação de balanço de massa, que apresenta a variação da concentração no tempo em função do campo de velocidades.

\subsubsection{Lei de Fick da Difusão Molecular}

A princípio, tomam-se dois reservatórios A e B com a mesma temperatura e separados por uma membrana impermeável e fixa de espessura dz. No início, o reservatório A contém uma quantidade maior da espécie química $i$ do que em $\mathrm{B}$,

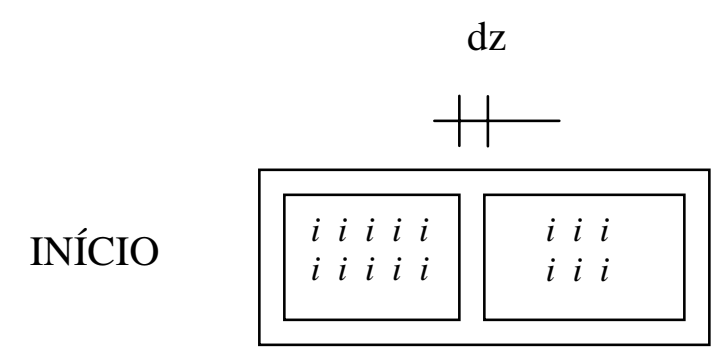

FIGURA 1: Sistema isolado com dois reservatórios separados pela membrana de espessura $\mathrm{dz}$, contendo a espécie química $i$

Retirando-se a membrana, a tendência é de homogeneização da espécie química $i$ por todo o volume.

FIM

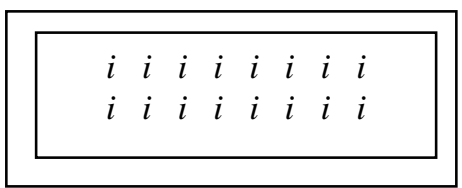

FIGURA 2: Sistema isolado contendo a espécie química $i$, após retirada da membrana de espessura dz.

Observa-se, dessa forma, que o fenômeno surgiu de uma "diferença” e a tendência foi a de homogeneização.

Vale ressaltar, ainda, que este processo ocorre se houver alguma modificação no sistema e aparece como decorrência da diferença de potencial químico da espécie i. 
Segundo CREMASCO (1998) e de acordo com a segunda lei da termodinâmica, haverá fluxo de matéria de uma região de maior a outra de menor concentração de uma dada espécie química. A espécie transferida chama-se soluto e designa-se de solvente a população de uma ou mais espécies químicas distintas do soluto, as quais podem estar abrigadas nas regiões que contêm o soluto. O conjunto soluto/solvente constitui o meio onde estará ocorrendo o fenômeno da transferência de massa.

A diferença de concentração de soluto é a causa da transferência de massa e, por conseguinte, do efeito movimento. Essa diferença seria a “força motriz” necessária ao movimento da espécie $i$.

CREMASCO (1998, p.24) define da seguinte maneira o movimento da matéria, que seria a base para o entendimento da $1^{\circ}$ lei de Fick:

(movimento da matéria) $=1$ / Resistência . (Força motriz)

A resistência seria a reação a esse movimento e estaria relacionada à interação soluto/meio (difusão) e soluto/meio mais ação externa (convecção).

Na contribuição difusiva, o transporte da espécie $i$ se dá devido às interações moleculares e pode ser entendido da seguinte maneira:

Um barco a remo em uma lagoa calma.

Soluto : barco (é a que se movimenta)

Difusão Meio : lagoa (onde o barco se movimenta)

Elemento gerador do movimento: remo

Um tanque com água sem agitação.

Soluto : $\mathrm{O}_{2}$

Difusão Meio : água

Elemento gerador do movimento: a interação a nível molecular entre soluto/meio. 
A nível molecular haverá colisões entre as moléculas, que, tomarão rumos aleatórios, migrando para qualquer sentido e direção e tendendo, porém, a ocupar lugares onde a sua população seja menor. Assim, como já foi visto, a "diferença” possibilita o fluxo da matéria.

Pelo que foi analisado na equação (1), temos:

$$
J_{i, z}=-\frac{1}{3} \cdot \Omega \cdot \lambda \cdot \frac{d C i}{d z}
$$

em que,

$J_{i, z}$ : indica o fluxo difusivo da matéria na direção z $\left(\mathrm{M} / \mathrm{L}^{2} . \mathrm{T}\right)$,

$\Omega$ : é a velocidade média molecular $(\mathrm{L} / \mathrm{T})$,

$\lambda$ : é o caminho livre médio, definido como a distância média entre duas moléculas na iminência de colisão (L).

Com base na equação (1), pode-se definir o coeficiente de difusão por:

$$
D_{i i}=\frac{1}{3} \Omega \cdot \lambda
$$

Substituindo a eq. (3) na eq. (2), tem-se:

$$
\begin{aligned}
& J_{i, z}=-D_{i i} \cdot \frac{d C i}{d z} \\
& \text { efeito } \longleftarrow \text { causa }
\end{aligned}
$$

O efeito citado na eq. (4) é o movimento da espécie $i$, causado pela diferença de concentração e o sinal negativo indica decréscimo da concentração da espécie $i$ com o sentido do fluxo. Essa é a lei de Fick, que também é definida por ser a taxa 
com que uma substância se difunde através de uma seção de área unitária e é proporcional ao gradiente de concentração normal a esta seção, e pode também ser expressa em termos de fração mássica, como:

$$
J_{i, z}=-\rho \cdot D_{i i} \cdot \frac{d w i}{d z}
$$

em que,

$J_{i, z}$ : fluxo de massa por unidade de área $\left(\mathrm{M} / \mathrm{L}^{2} . \mathrm{T}\right)$,

$\rho$ : densidade do fluido $\left(\mathrm{M} / \mathrm{L}^{3}\right)$,

$w_{i}$ : fração mássica (adim.),

$D_{i i}$ : coeficiente de difusão ou autodifusão ( $\mathrm{L}^{2} / \mathrm{T}$ ),

$d w_{i} / d z$ : gradiente de concentração na direção z em termos de fração mássica $(1 / \mathrm{L})$

$d C / d z$ : gradiente de concentração na direção z em termos de massa $\left(M / L^{4}\right)$.

\subsubsection{Coeficiente de Difusão Molecular}

O coeficiente de difusão está relacionado com a resistência à difusão:

$$
D_{i i}=\frac{1}{\text { Resistência à difusão }}
$$

“A importância do entendimento da difusividade ou do coeficiente de difusão reside no fato de que ao se procurar compreendê-lo, a difusão, em si, estará apreendida” (CREMASCO, 1998,p.43). Ela representa a interação soluto/meio na difusão em gases e está caracterizada na velocidade média molecular e no caminho livre médio, melhor entendido na teoria cinética dos gases. 
Pela teoria cinética dos gases, o coeficiente de difusão fica definido da seguinte maneira:

$$
D_{i i}=\frac{2}{3 \cdot N_{0} \cdot P \cdot d^{2}}\left(\frac{R T}{\pi}\right)^{3 / 2}\left(\frac{1}{M}\right)^{1 / 2}
$$

em que,

$N_{0}$ : é o número de Avogrado,

$P$ : é a pressão $\left(\mathrm{M} / \mathrm{L} \cdot \mathrm{T}^{2}\right)$,

$d$ : é o diâmetro de colisão (L),

$R$ : é a constante universal dos gases,

$T$ : é a temperatura $(t)$

$M$ : é a massa molar (M.mol $\left.{ }^{-1}\right)$.

A equação (7) relaciona a difusividade às propriedades do gás e ao efeito da energia cinética (R.T), ou seja, quanto mais agitado melhor a mobilidade.

O coeficiente de difusão em gases pode ser definido para o par apolar $A / B$, onde $D_{A B}$ é o coeficiente de difusão mútua, pois $A$ se difunde no meio $B$, assim como $B$ se difunde no meio $A$.

$$
D_{A B}=\frac{2}{3 \sqrt{2} N_{0} \cdot P \cdot d_{A B}^{2}}\left(\frac{R \cdot T}{\pi}\right)^{3 / 2} \cdot\left[\frac{1}{M_{A}}+\frac{1}{M_{B}}\right]^{1 / 2}
$$

Substituindo-se $\quad N_{0}=6.023 \times 10^{23}$ moléculas/(g.mol) e $R=8.3144 \times 10^{7}$ (g.cm²/(g.mol.s $\left.{ }^{2} . K\right)$ ) na equação (8), obtém-se o seguinte resultado:

$$
D_{A B}=1.066 \times 10^{-13} \frac{T^{3 / 2}}{P . d_{A B}^{2}} \cdot\left[\frac{1}{M_{A}}+\frac{1}{M_{B}}\right]^{1 / 2}
$$


em que,

$D_{A B}$ : é o coeficiente de difusão $\left(\mathrm{cm}^{2} / \mathrm{s}\right)$,

$T$ é a temperatura dada em $\mathrm{K}$,

$P$ é a pressão (g.cm $\left./ \mathrm{s}^{2}\right)$,

$d_{A B}$ é o diâmetro de colisão $(\mathrm{cm})$.

Segundo CREMASCO (1998) essa equação pode ser rearranjada em termos de atm e $\AA$ conservando, contudo, as outras unidades. Assim tem-se:

$$
D_{A B}=1.053 \times 10^{-3} \frac{T^{3 / 2}}{P . d^{2}{ }_{A B}}\left[\frac{1}{M_{A}}+\frac{1}{M_{B}}\right]^{1 / 2}
$$

O coeficiente de difusão $\left(D_{A B}\right)$ para um sistema binário recebe a influência do meio, caracterizando-se como função da temperatura e da pressão e apresentando características moleculares próprias das espécies químicas A e B.

Vale ressaltar que o coeficiente de difusão binária em gases para o sistema ar/água a temperatura de $298 \mathrm{~K}\left(25^{\circ} \mathrm{C}\right)$ é dado da seguinte maneira: $D_{A B}$.P é igual a $0.260 \mathrm{~cm}^{2}$.atm/s ou, aproximadamente, $D_{A B}$ igual a $0.20 \mathrm{~cm}^{2} / \mathrm{s}$ à pressão de $1 \mathrm{~atm}$, podendo também ser obtido experimentalmente através da Lei de Fick.

As moléculas detêm cargas elétricas; estas geram forças atrativas e repulsivas entre o par soluto/solvente, e as forças passam a governar o fenômeno das colisões moleculares por meio da energia potencial de atração/repulsão, conhecida como o potencial de Lennard-Jones.

A energia potencial de atração/repulsão é conhecida como o potencial de Lennard-Jones e, de posse desse potencial, é possível reescrever a equação (10).

$$
D_{A B}=1.053 \times 10^{-3} \frac{T^{3 / 2}}{P \cdot \sigma^{2}{ }_{A B}}\left[\frac{1}{M_{A}}+\frac{1}{M_{B}}\right]^{1 / 2}
$$

em que $\sigma^{2}{ }_{\mathrm{AB}}$ é o diâmetro médio de colisão para a mistura $(\mathrm{A}+\mathrm{B})$. 


\subsubsection{A Equação de Chapman-Enskog}

$$
D_{A B}=b x 10^{-3} \frac{T^{3 / 2}}{P \cdot \sigma_{A B}^{2} \cdot \Omega_{D}}\left[\frac{1}{M_{A}}+\frac{1}{M_{B}}\right]^{1 / 2}
$$

Essa equação é baseada na teoria cinética dos gases e o coeficiente de transporte, na energia potencial. O valor de $b$ é igual a 1,858.

Wilke e Lee (1955), citados por CREMASCO (1998), propuseram uma expressão para a constante $b$ :

$$
b=2,17-\frac{1}{2}\left(\frac{1}{M_{A}}+\frac{1}{M_{B}}\right)^{1 / 2}
$$

Segundo MOMESSO (1996), existe grande escassez de dados experimentais para o coeficiente de difusão. Assim, várias expressões semi-empíricas foram desenvolvidas, considerando cada estado da matéria, contendo estes diferentes forças intermoleculares.

A Correlação empírica de Fuller, Schetter e Giddings (1966), mencionados por CREMASCO (1998, p.57) remete à formulação original, equação (10), sendo corrigida no termo da temperatura de acordo com a equação a seguir.

$$
D_{A B}=1.0 \times 10^{-3} \frac{T^{1.75}}{P . d^{2}{ }_{A B}}\left[\frac{1}{M_{A}}+\frac{1}{M_{B}}\right]^{1 / 2}
$$

A temperatura é dada em Kelvin e a pressão em atm. O coeficiente $D_{A B}$ é definido em função de uma grandeza $(\Sigma v)$, que é um volume associado à difusão da molécula $A$.

Wilke citado, por BIRD (1976), desenvolveu uma correlação para o coeficiente de difusão com base na equação de Stokes-Einstein. Seus resultados podem ser resumidos em uma relação analítica aproximada. Um dos modelos para 
previsão da difusividade em transferência de massa gás/líquido foi apresentado por Wilke e Chang, citados por BIRD (1976), sendo:

$$
D_{m}=7,4 \times 10^{-8} \frac{\left(N_{n} \cdot M_{n}\right)^{1 / 2} \cdot T}{\mu \cdot V_{b}^{0,6}}
$$

em que,

$D_{m}$ : difusividade molecular do soluto $\mathrm{em} \mathrm{cm}^{2} / \mathrm{s}$,

$M_{n}$ : peso molecular do solvente (g/mole),

$N_{n}$ : fator de associação que define o peso molecular efetivo do solvente, para a água vale 2,6,

$\mu$ : viscosidade dinâmica da água, em centipoise,

$T$ : temperatura absoluta, em Kelvin,

$V_{b}$ : volume molar do soluto em seu ponto normal de ebulição em $\mathrm{cm}^{3} / \mathrm{g}$ mol.

Alguns modelos para o coeficiente de difusão para sólidos, líquidos e gases são encontrados em CREMASCO (1998), HINES e MADOX (1985), BIRD (1976), entre outros estudiosos.

\subsubsection{Equação de Advecção-Difusão}

Aplicando-se a equação do balanço de massa a um volume infinitesimal de um líquido incompressível em escoamento permanente, obtém-se a equação (16) em termos da concentração do gás dissolvido, conforme apresentado por Bird et al. citado por BARBOSA (1989).

$$
\frac{\partial C}{\partial t}+V_{i} \frac{\partial C}{\partial x_{i}}=\frac{\partial}{\partial x_{i}}\left[D_{m} \frac{\partial C}{\partial x_{i}}\right]+F C
$$

em que, 
$C$ : concentração do gás dissolvido (soluto) no líquido (solvente) $\left(\mathrm{M} / \mathrm{L}^{3}\right)$,

$V_{i}$ : componente da velocidade do líquido segundo a direção $x i\left(\mathrm{~L} / \mathrm{T}^{2}\right)$,

$D_{m}$ : coeficiente de difusão molecular do gás no líquido $\left(\mathrm{L}^{2} / \mathrm{T}\right)$,

FC : somatório de todas as fontes e sumidouros.

Considerando as variações médias no tempo, proporcionadas pelo efeito da turbulência do escoamento, as expressões para a concentração e as velocidades são consideradas como valores médios.

$$
\begin{aligned}
& v_{i}=V_{i}-\overline{V_{i}} \\
& c=C-\bar{C}
\end{aligned}
$$

$V_{i}$ : componente da velocidade do líquido segundo a direção xi $\left(\mathrm{L} / \mathrm{T}^{2}\right)$,

$v_{i}$ : flutuação da velocidade segundo a direção $x i\left(\mathrm{~L} / \mathrm{T}^{2}\right)$,

$\overline{V_{i}}$ : velocidade média segundo a direção $x i\left(\mathrm{~L} / \mathrm{T}^{2}\right)$,

$C$ : concentração do soluto dissolvido no líquido $\left(\mathrm{M} / \mathrm{L}^{3}\right)$,

$c$ : flutuação da concentração relativa ao seu valor médio $\bar{C}\left(\mathrm{M} / \mathrm{L}^{3}\right)$,

$\bar{C}$ : concentração média $\left(\mathrm{M} / \mathrm{L}^{3}\right)$.

Substituindo as equações (17) na equação (16), tem-se a equação resultante

$$
\frac{\partial \bar{C}}{\partial t}+\bar{V}_{i} \frac{\partial \bar{C}}{\partial x_{i}}=\frac{\partial}{\partial x_{i}}\left[D_{m} \frac{\partial \bar{C}}{\partial x_{i}}-\overline{v_{i} C}\right]+\bar{F} C
$$

O termo $\overline{v_{i} c}$ indica média relativa ao tempo.

A massa pode ser transportada pelo movimento de parcelas finitas de fluido. É possível expressar a velocidade desse transporte em vários termos, entre eles a difusividade turbilhonar, que também pode ser relacionada a um comprimento de mistura. 
A taxa de difusão turbulenta é representada por

$$
-\overline{v_{i} c}=D_{T i} \frac{\partial \bar{C}}{\partial x_{j}}
$$

em que,

$D_{T i}$ : coeficiente de difusão turbulenta $\left(\mathrm{L}^{2} / \mathrm{T}\right)$,

$\overline{u_{i} c}$ : taxa de difusão turbulenta, na direção xi (M/T.L $\left.{ }^{2}\right)$

Assim, pode-se reescrever a equação de advecção-difusão como:

$$
\frac{\partial \bar{C}}{\partial t}+\overline{V_{i}} \frac{\partial \bar{C}}{\partial x_{i}}=\frac{\partial}{\partial x_{i}}\left[\varepsilon_{i} \frac{\partial \bar{C}}{\partial x_{i}}\right]+\overline{F_{C}}
$$

sendo

$$
\varepsilon_{i}=D_{m}+D_{T i}
$$

$\varepsilon_{i}$ é o coeficiente de difusão total, correspondendo à soma entre a difusão molecular e a turbulenta.

Considerando uma profundidade $h$, de um canal ou tanque d'água, define-se concentração média da seguinte maneira:

$$
\bar{C}=\frac{1}{h} \int_{0}^{h} C \cdot d z
$$

Nota-se que a transferência de massa através do fundo, abaixo da camada de escoamento, é nulo. Logo, 


$$
\left.\varepsilon_{z} \frac{\partial C}{\partial z}\right|_{z=o}=0
$$

Pode-se aplicar a média sobre a profundidade h, considerando a concentração da substância dissolvida constante na direção vertical, e obter a seguinte equação:

$$
\frac{\partial \bar{C}}{\partial t}+\overline{V_{i}} \frac{\partial \bar{C}}{\partial x}=\overline{\varepsilon_{x}} \frac{\partial^{2} \bar{C}}{\partial x^{2}}+\frac{1}{h}\left(\varepsilon_{z} \frac{\partial C}{\partial z}\right)_{z=h}+\overline{F_{C}}
$$

BENNETT \& RATHBUN (1972) argumentam que, por conveniência e tradição, o segundo termo do lado direito da equação é geralmente expresso usando um dos dois coeficientes de transferência de massa, $K_{L}$ ou $K_{2}$. O coeficiente geralmente utilizado, para o filme líquido, é o coeficiente de transferência de massa, e é possível defini-lo por

$$
K_{L}=\frac{1}{\left(C_{s}-\bar{C}\right)}\left(\varepsilon_{z} \frac{\partial \bar{C}}{\partial z}\right)_{z=h}
$$

Em que $C_{L}$ é a concentração de oxigênio dissolvido no volume da fase líquida.

O coeficiente de reaeração pode ser expresso em função do coeficiente de transferência de massa, segundo descrito em BENNETT e RATHBUN (1972, p.8)

$$
K_{2}=\frac{K_{L}}{H}
$$

BARBOSA (1989, p.11) reescreve a equação (25) da seguinte maneira:

$$
K_{2}=\frac{1}{\left(C_{s}-\bar{C}\right)} \frac{1}{h}\left(-\varepsilon_{z} \frac{\partial \bar{C}}{\partial z}\right)_{z=0}
$$


A equação (24) pode ser reescrita em termos do coeficiente de reaeração, alcançando-se o seguinte resultado:

$$
\frac{\partial \bar{C}}{\partial t}+\overline{V_{i}} \frac{\partial \bar{C}}{\partial x}=\overline{\varepsilon_{x}} \frac{\partial^{2} \bar{C}}{\partial x^{2}}+K_{2} \cdot\left(C_{S}-\bar{C}\right)+\overline{F C}
$$

Segundo BARBOSA (1989), o termo de difusão longitudinal, por ser pequeno quando comparado ao termo advectivo, é, freqüentemente, desprezado e esse fato simplifica a equação (28), como se pode notar a seguir:

$$
\frac{\partial \bar{C}}{\partial t}+\overline{V_{i}} \frac{\partial \bar{C}}{\partial x}=K_{2} \cdot\left(C_{S}-\bar{C}\right)+\overline{F C}
$$

BARBOSA (1989) afirma que o uso da equação (20) para obter uma relação mais completa a fim de descrever o balanço de massa, requer a quantificação do campo de velocidades. Este pode ser conseguido através da solução simultânea das equações, ou por meio da conservação da quantidade de movimento, da continuidade e do estado, nas três dimensões. Há, com certeza, grande dificuldade para obtenção de tais resultados e isso se explica pelo uso de modelos hidrodinâmicos ainda muito sofisticados. O autor diz, ainda, que, devido a diversos fatores, a aplicação de tais modelos fica restrita, e recorre-se, desse modo, a simplificações do campo de velocidades.

\subsection{Análise Linear para a Transferência de Massa na Superfície}

A transferência de massa pode ser estudada em superfícies móveis (interface ar/água) ou em superfícies imóveis (um sólido). MC. CREADY ET AL. (1986) afirmam que os dois processos são fundamentalmente diferentes, e que a flutuação das velocidades em todas as freqüências é apresentada como tendo um papel importante; isso se reflete nas equações para o coeficiente de transferência de massa. 
Nas superfícies móveis, a velocidade normal é dada por $v=\beta(x, y, t) . z$ e, para as superfícies imóveis, $v=\beta(x, y, t) z^{2}$, em que todos os termos são adimensionalizados usando a velocidade de atrito e a viscosidade cinemática.

A expansão de Taylor descreve a velocidade em termos da distância em uma interface, como se percebe abaixo.

$$
\begin{aligned}
& V=\bar{V}(z)+\alpha(x, y, t) \\
& v=\beta(x, y, t) \cdot z \\
& w=\gamma(x, y, t)
\end{aligned}
$$

Essas equações satisfazem a equação da continuidade.

\subsubsection{Simplificação da Equação de Balanço de Massa}

É possível escrever uma equação similar a apresentada acima, considerando $S$ $=v / D_{m}$, onde $S$ é o número de Schmidt.

Como já foi descrito, o campo de concentração é praticamente homogêneo na direção do escoamento, e a variação de concentração na direção z (normal a superfície) é maior do que em relação as direções x e y. Sirkar e Hanratty, aos quais CAMPBELL \& HANRATTY (1983) fazem menção, argumentam que pode ser usada a equação de balanço de massa da forma simplificada, para escoamentos plenamente desenvolvidos em altos números de Schmidt, conforme se mostra a seguir:

$$
\frac{\partial C}{\partial t}+v \frac{\partial C}{\partial z}+w \frac{\partial C}{\partial y}=\frac{1}{S} \frac{\partial^{2} C}{\partial z^{2}}
$$

Todas as outras quantidades estão adimensionalizadas usando a velocidade de atrito, a viscosidade cinemática e a diferença de concentração $C_{L}-C_{I}$.

A equação deve ser resolvida usando as condições limites $C=0$ em $z=0$ e $C$ $=1$ em grandes $z$. 
Para a interface móvel ar/água, pode-se descrever a equação (31) por duas maneiras: considerando as flutuações da concentração, conhecidas como decomposição de Reynolds $c=C-\bar{C}$ ou desprezando-se a variação de concentração na direção do escoamento e os termos não lineares dentro das quantidades flutuantes (MC. CREADY ET AL (1986)), tem-se

$$
\frac{\partial c}{\partial t}+\beta \cdot z \frac{\partial \bar{C}}{\partial z}=\frac{1}{S} \frac{\partial^{2} c}{\partial z^{2}}
$$

Assim é obtida, portanto, a equação de balanço de massa, que relata o campo de concentração variando com o tempo $C(x, y, z, t)$ e relaciona-se ao campo de velocidades.

TAMBURRINO (1994) apresenta a adimensionalização das expressões para o coeficiente de transferência de massa. Igualmente ao campo de velocidade e concentração, o coeficiente pode ser expresso como uma composição de uma média temporal e sua parte flutuante, se o fluxo de massa através de uma interface for dada por

$$
J=K_{L} \cdot\left(C_{S}-C_{L}\right)=\left.D_{A, Z} \cdot \frac{d \bar{C}}{d z}\right|_{Z=0}
$$

Pode-se escrever

$$
K_{L}=\left.\frac{D_{A, Z}}{\left(C_{S}-C_{L}\right)} \cdot \frac{d \bar{C}}{d z}\right|_{Z=0}
$$

Até aqui, considerou-se o coeficiente de transferência de massa tendo dimensão ( $\left.\mathrm{L} / \mathrm{T}^{-1}\right)$. Agora, ele será adimensionalizado, como segue:

$$
K=\frac{K_{L}}{u^{*}}=\left.\frac{D}{v} \frac{1}{\left(C_{S}-C_{L}\right)} \frac{d \bar{C}}{d z}\right|_{Z=0}
$$


como

$\frac{d}{d z}\left(\frac{\bar{C}}{\left(C_{S}-C_{L}\right)}\right)=\frac{d \bar{C}}{d z}$

então,

$$
k=\left.\frac{1}{S} \frac{d \bar{C}}{d z}\right|_{z=0}
$$

TAMBURRINO (1994) afirma que se $\delta$ for definido como espessura característica da concentração na camada limite, tem-se $C$ médio próximo ao valor 1 , e z próximo a esta espessura, reduzindo a equação (37) a

$$
K \approx(S . \delta)^{-1}
$$

A flutuação do coeficiente de transferência de massa recebe a mesma análise, obtendo-se:

$$
K=\left.\frac{1}{S} \frac{\partial c}{\partial z}\right|_{Z=0}
$$

De acordo com MC. CREADY ET AL (1986), as freqüências predominantes são as menores e o coeficiente de transferência de massa depende basicamente do espectro de $\beta$ na freqüência zero. 


\subsubsection{Análise para Grandes Freqüências}

Para a região próxima a superfície $y>\delta_{C}$, exceto para a região $y<\delta_{C}$, é valido que

$$
\frac{\partial c}{\partial t}>>\frac{1}{S} \frac{\partial^{2} c}{\partial z^{2}}
$$

O que implica em

$$
\frac{\partial c}{\partial t}+\beta \cdot z \cdot \frac{d \bar{C}}{d z} \approx 0
$$

Define-se a espessura característica da concentração da camada limite como:

$$
\frac{1}{\delta}=\frac{d \bar{C}}{d y}
$$

Espera-se que a flutuação da concentração, $c$ possa ser máxima em $y \approx \delta$ e ser igual a zero em $y=0$ e em grandes $y$. No que diz respeito as equações acima, pode-se escrever:

$$
c \approx \beta / \omega
$$

Aproximadamente em $y=\delta$, é esperado que o termo que caracteriza o transporte turbulento seja máximo. A magnitude de $v c$ ’é dada como:

$$
v \cdot c^{\prime}=\frac{\beta^{2} \delta}{w}
$$


A difusão molecular passa a ser importante em $y=\delta_{C}$, afetando o campo de flutuação da concentração.

$$
\frac{\partial c}{\partial t} \approx \frac{1}{S} \frac{\partial^{2} c}{\partial z^{2}}
$$

Essa equação implicará em:

$$
\begin{aligned}
& \delta_{C}^{2}=\frac{1}{w \cdot S} \\
& \text { em } y=\delta_{C} \\
& c^{\prime}=\frac{\beta \delta_{C}}{w} \frac{d \bar{C}}{d y}
\end{aligned}
$$

Infere-se que:

$$
\frac{k}{\bar{K}} \approx \frac{\beta}{\omega}
$$

TAMBURRINO (1994) afirma que, se a equação acima for multiplicada pelo seu complexo conjugado, a relação entre o espectro de $k$ e $\beta$ para grandes freqüências é obtida. Assim, tem-se:

$$
\frac{S_{K}(\omega)}{K^{2}} \approx \frac{S_{\beta}(\omega)}{\omega^{2}}
$$

Essa equação está de acordo concorda com o proposto por MC. CREADY \& HANRATTY (1984 a). 


\subsubsection{Análise para Baixas Freqüências}

Para baixas freqüências deve-se observar que:

$$
\frac{\partial c}{\partial t}<<\frac{1}{S} \frac{\partial^{2} c}{\partial z^{2}}
$$

Então, a flutuação da concentração é estimada como segue

$$
\frac{1}{S} \frac{\partial^{2} c}{\partial z^{2}} \approx v \frac{d \bar{C}}{d z}
$$

Das equações (51) e (42) obtém-se uma relação entre as flutuações da velocidade e da concentração, e é dada por

$$
c^{\prime}=\beta . \delta^{2} . S
$$

Das equações (43) e (48) e (52 ), tem-se

$$
\begin{aligned}
& \frac{k}{\bar{K}} \approx \beta \cdot \delta^{2} . S \\
& \mathrm{e} \\
& v \cdot c^{\prime}=\beta^{2} \cdot \delta^{3} \cdot S
\end{aligned}
$$

para a flutuação da velocidade em baixas freqüências. 
Considerando para as diferentes freqüências (altas e baixas), pode-se assumir que a equação (44) é válida para $w<w_{C}$ e que a equação (54) é válida para $w>w_{C}$, onde $w_{C}$ é estimado pela relação em que $z=w_{C}$.

$$
\frac{\partial c}{\partial t} \approx \frac{1}{S} \frac{\partial^{2} c}{\partial z^{2}}
$$

ou que

$$
\omega_{C}=\frac{1}{\delta^{2} \cdot S}
$$

Assim, as escalas dos termos para o transporte de Reynolds podem ser representadas como se segue:

$$
V . c^{\prime}=\int_{0}^{W_{C}} \delta^{3} . S . S_{\beta}(\omega) d \omega+\int_{\omega_{R}}^{\infty} \delta \frac{S_{\beta}(\omega)}{\omega} d \omega
$$

Podendo ser reescrito como

$$
v . c^{\prime}=\int_{0}^{1} \delta . S_{\beta}(\omega) \cdot d \frac{\omega}{\omega_{C}}+\int_{1}^{\infty} \delta \frac{S_{\beta}(\omega)}{\left(\omega / \omega_{C}\right)} d\left(\frac{\omega}{\omega_{C}}\right)
$$

Desde que $Z=\delta$, o transporte turbulento é aproximadamente igual ao transporte molecular

$$
v . c^{\prime} \approx \frac{1}{S} \frac{d \bar{C}}{d z}
$$

Pelas equações (58) e (59), a relação seguinte para $\delta$ é obtida: 


$$
\delta^{2}=S^{-1} \cdot\left[\int_{0}^{1} S_{\beta}(\omega) \cdot d \frac{\omega}{\omega_{C}}+\int_{1}^{\infty} \frac{S_{\beta}(\omega)}{\left(\omega / \omega_{C}\right)} d\left(\frac{\omega}{\omega_{C}}\right)\right]^{-1}
$$

Vassiliadou (1985), citado por MC. CREADY ET AL (1986), apresenta a função de espectro, assumida para ser da seguinte forma:

$$
S_{\beta}(\omega)=\frac{S_{\beta}(0)}{1+\left(\frac{\omega . \sigma}{\omega_{m}}\right)^{2}}
$$

em que $\omega_{m}$ é a freqüência média

$$
\omega_{m}=\frac{\int_{0}^{\infty} \omega \cdot S_{\beta}(\omega) \cdot d \omega}{\int_{0}^{\infty} S_{\beta}(\omega) d \omega}
$$

e $\sigma$ é um fator de forma

$$
\sigma=\omega_{m} \pi \frac{S_{\beta}(0)}{\overline{\beta^{2}}}
$$

Substituindo a equação (61) em (60) tem-se:

$$
\delta \approx S^{-1 / 2} \cdot S_{\beta}^{-1 / 2}(0)\left\{\frac{\tan ^{-1}\left(\frac{\sigma \cdot \omega_{C}}{\omega_{m}}\right)}{\left(\frac{\sigma \omega_{c}}{\omega_{m}}\right)}+\frac{1}{2} \ln \left(1+\frac{\omega_{m}}{\sigma \cdot \omega_{C}}\right)^{2}\right\}^{-1 / 2}
$$


É visto que essa escala depende da razão de $\omega_{C}$ e $\omega_{m}$,

$$
\frac{\sigma \cdot \omega_{C}}{\omega_{m}}=\frac{\pi \cdot S_{\beta}(0) \cdot \omega_{C}}{\overline{\beta^{2}}}
$$

Assumindo que

$$
\bar{K}=\frac{1}{\delta . S}
$$

Substituindo (66) em (56), tem-se:

$$
\omega_{C}=\overline{K^{2}} S
$$

e substituindo (67) em (65), segue:

$$
\frac{\sigma \cdot \omega_{C}}{\omega_{m}}=\frac{\pi \cdot S_{\beta}(0) \cdot \overline{K^{2}} \cdot S}{\overline{\beta^{2}}}
$$

Para grandes $\sigma . \omega_{C} / \omega_{m}$, a equação (64) fica simplificada para

$$
\delta \approx S^{-1 / 2} \cdot\left(\overline{\beta^{2}}\right)^{-1 / 4}
$$

e das equações (68) e (66), segue:

$$
\bar{K} \approx S^{-1 / 2}\left(\overline{\beta^{2}}\right)^{1 / 4}
$$


para grandes $\sigma . \omega_{C} / \omega_{m}$.

Pode-se apresentar para pequenos $\sigma . \omega_{C} / \omega_{m}$, que $K$ médio depende unicamente de $S_{\beta}(0)$,

$$
\bar{K} \approx S^{-1 / 2} \cdot S_{\beta}^{1 / 2}(0)
$$

Para valores intermediários $\sigma \omega_{C} / \omega_{m}$, o coeficiente de transferência de massa dependerá de ambos $\overline{\beta^{2}}$ e $S_{\beta}(0)$.

\subsection{Definição Matemática dos Processos de Absorção}

Adeney e Becker, entre outros citados por CUNHA (1993), propuseram, através de dados experimentais, um modelo matemático geral para descrever o processo de absorção gasosa. Tal modelo sugere que o fluxo de massa por unidade de área nominal é diretamente proporcional ao déficit relativo à saturação do gás no líquido, como se pode notar na equação a seguir:

$$
J=\frac{1}{A} \frac{d m}{d t}=K_{L} \cdot\left(C_{s}-C_{L}\right)
$$

em que:

$J$ : fluxo de massa por unidade de área $\left(\mathrm{M} / \mathrm{L}^{2} . \mathrm{T}\right)$,

$A$ : área de interface gás- líquido $\left(\mathrm{L}^{2}\right)$,

$m$ : massa de gás dissolvido (M),

$t$ : representa o tempo de processo $(\mathrm{t})$,

$K_{L}$ : coeficiente de transferência de massa (coeficiente global de transferência gasosa) (L/T),

$C_{s}$ : concentração de saturação do gás no líquido $\left(\mathrm{M} / \mathrm{L}^{3}\right)$

$C_{L}$ : concentração do gás dissolvido no volume líquido $\left(\mathrm{M} / \mathrm{L}^{3}\right)$ 
Sabendo-se que $m$ representa a massa gasosa absorvida através da interface gás/líquido, $V$ o volume líquido onde a massa se dissolve e contando, ainda, com a fórmula da concentração dada por $m=C_{L} . V$, pode-se reescrever a equação (72), substituindo $m$ por $C_{L} . V$.

$$
\begin{aligned}
& J=\frac{d C_{L} \cdot V}{d t}=K_{L} \cdot A \cdot\left(C_{s}-C_{L}\right) \\
& J=\frac{d C_{L}}{d t}=K_{L} \frac{A}{V} \cdot\left(C_{s}-C_{L}\right)
\end{aligned}
$$

Geralmente, ao se tratar de processos com interface ar-água, a relação $(A / V)^{-1}$ é igualada à profundidade média do escoamento $H$, como se nota abaixo.

$$
\left(\frac{A}{V}\right)^{-1}=\text { profundidade } h
$$

Assim, a equação é escrita da seguinte forma:

$$
J=\frac{d C_{L}}{d t}=\frac{K_{L}}{H}\left(C_{s}-C_{L}\right)
$$

$K_{2}$ é o coeficiente de reaeração, definido em unidade de inverso do tempo nos processos de absorção de oxigênio e depende de três fatores: do volume líquido onde a massa é dissolvida, da área interfacial e do coeficiente $K_{L}$.

$$
K_{2}=\frac{K_{L} \cdot A}{V}
$$


Assim, pode-se escrever:

$$
J=\frac{d C_{L}}{d t}=K_{2}\left(C_{s}-C_{L}\right)
$$

A integração definida de $C_{o}$ a $C_{L}$ da equação (78) resulta na seguinte função exponencial para a absorção:

$$
\left.\left(C_{s}-C_{L}\right)=\left(C_{s}-C_{0}\right) \cdot e^{(-K} \cdot T\right)
$$

O processo inverso ao da absorção de qualquer gás é o chamado processo de dessorção. Na dessorção gasosa, a concentração na superfície do líquido (Cs) é, geralmente, zero. Isto simplifica a equação (79) e o coeficiente $K_{2}$ é substituído por $K_{T}$.

Assim, a equação (79) é representada por:

$$
C=C_{0} \cdot e^{\left(-K_{T} \cdot t\right)}
$$

Os coeficientes de absorção $K_{2}$ e dessorção $K_{T}$ dependem das características hidráulicas do corpo d’água, da temperatura do ar e da água, e da velocidade do vento ou de qualquer outro distúrbio existente na superfície.

\subsection{Modelos Clássicos}

O fenômeno de transferência de massa interfacial em um escoamento turbulento foi quantificado pela primeira vez por Nernst, mencionado por GULLIVER (1991) em 1904. Esta teoria propõe que a transferência de massa ocorra através de filmes estagnados, constantes no tempo, não transportáveis e existindo em cada lado da interface. Lewis \& Whitman (1924) descreveram o modelo dos dois filmes, que detalha as características acima mencionadas. 


\subsubsection{Teoria dos Dois Filmes}

Lewis e Whitman (1924) citados em BENNETT e RATHBUN (1972) e COULSON e RICHARDSON (1985), postularam que, na interface entre dois fluidos, a transferência de massa é regida por duas camadas laminares: uma gasosa (na fase gasosa) e outra líquida (na fase líquida). Essas camadas laminares foram chamadas de filmes e a transferência entre esses filmes se dá unicamente, por difusão molecular, processo muito lento se comparado à difusão turbulenta. Conforme este modelo, as zonas de resistência à transferência de massa se concentram nestes dois filmes.

Nos locais não pertencentes aos filmes, as massas líquidas e gasosas são bem misturadas, devido à turbulência. A interface parece não apresentar nenhuma resistência ao transporte de massa. No caso de uma interface $\mathrm{O}_{2}$ / água, o fluxo de oxigênio é dado por

$$
J=k_{L} \cdot\left(C_{I}-C_{L}\right)=k_{G} \cdot\left(p_{G}-p_{I}\right)
$$

em que $C_{L}$ é a concentração na fase líquida, $C_{I}$ é a concentração na interface, $p_{G}$ é pressão parcial no gás, $p_{I}$ é a pressão parcial na interface $k_{L}$ e $k_{G}$ são os coeficientes dos filmes líquido e gasoso.

Condições de equilíbrio são assumidas na interface, assim a pressão $p_{I}$ e a concentração $C_{I}$ estão relacionados pela lei de Henry, dada como $p_{I}=H$. $C_{I}$, onde $H$ é a constante de Henry. Os coeficientes dos filmes não dependem da concentração do gás dissolvido no líquido.

BENNETT e RATHBUN (1972) descrevem a dificuldade em medir a concentração e a pressão parcial, o que prejudica, assim, a obtenção dos coeficientes dos filmes individuais. E a equação (81) usualmente é escrita em termos dos coeficientes globais dos filmes gasoso e líquido.

$$
J=K_{L} \cdot\left(C_{S}-C_{L}\right)=K_{G} \cdot\left(p_{G}-p_{S}\right)
$$


em que $p_{S}$ é a pressão parcial correspondente a concentração de saturação, $C_{S}, e K_{L} e$ $K_{G}$ são respectivamente os coeficientes globais do filme liquido e gasoso.

O coeficiente global de transferência de massa pode ser escrito pela seguinte expressão:

$$
\frac{1}{K}=\frac{1}{K_{L}}+\frac{1}{H \cdot K_{g}}
$$

O gradiente de concentração foi admitido linear em cada camada e o transporte de massa dentro do filme ocorre somente por difusão molecular; pode-se escrever, portanto:

$$
J=D_{m} \frac{\left(C_{S}-C_{L}\right)}{L_{f}}
$$

em que $L_{f}$ é a espessura do filme.

Considerando,

$$
J=K_{L} \cdot\left(C_{S}-C_{L}\right)
$$

Então,

$$
\begin{aligned}
& K_{L}=J /\left(C_{S}-C_{L}\right)=D_{m} / L_{f} \\
& \text { O que implica em: } \\
& K_{L}=D_{m} / L_{f}
\end{aligned}
$$

em que, 
$D_{m}$ : coeficiente de difusão molecular;

$L_{f}$ : espessura do filme;

$K$ : Coeficiente global de transferência de massa .

Finalmente, observa-se que as propriedades do soluto e do solvente estão descritas pelo coeficiente de difusão molecular e as condições hidrodinâmicas do escoamento, pela espessura do filme.

\subsubsection{Teoria da Penetração}

Higbe (1935) citado por COULSON e RICHARDSON (1985), durante a investigação da existência ou não de resistência ao deslocamento de massa na interface no momento da absorção de um gás por um líquido, considera a existência de um filme laminar na superfície desse líquido. Esse pesquisador defende, ainda, que cada elemento fluido da superfície estava exposto ao gás por um determinado tempo médio te. Esse é o tempo de vida do filme, que é também o tempo entre a formação do filme sob a superfície e sua reposição pelo novo líquido, vindo do volume do escoamento, onde se processa a transferência de massa.

Todos os elementos da superfície são considerados como possuidores de uma mesma idade e todos sendo substituídos no mesmo tempo $t_{e}$.

O gradiente de velocidade no fluido é ignorado e o fluido se movimenta igualmente, inclusive na interface. Durante o tempo de contato, a transferência de massa se dá puramente por difusão molecular e não estacionária.

Dessa forma, a nova avaliação sugerida para o coeficiente de absorção pode ser representada por:

$$
K_{L}=2 \cdot \sqrt{\frac{D_{m}}{\pi . t_{e}}}
$$




\subsubsection{Teoria da Renovação Superficial}

Essa teoria pode ser considerada uma expansão conceitual da teoria da penetração de Higbie (1935).

Danckwerts (1951), citado por COULSON e RICHARDSON (1985), sugeriu que cada elemento da superfície não fosse exposto para o mesmo tempo, considerando uma distribuição aleatória de idades, dada por:

$$
\phi(t)=s . e^{-s . t}
$$

em que $s$ é a razão média de renovação superficial por unidade total de área da superfície. Ele assume que a probabilidade de qualquer elemento da superfície de se incorporar no meio líquido é independente do tempo de permanência nesta superfície. Assim, Danckwerts calculou a distribuição de idades dos elementos superficiais.

O autor admite que a concentração constante na superfície é igual à de saturação, e a taxa de produção da superfície por unidade total de área (s) independe da idade do elemento em questão.

O coeficiente de transferência de massa para a teoria da Renovação Superficial é dado por:

$$
K_{L}=\sqrt{D_{m} \cdot S}
$$

\subsubsection{Modelo da Penetração do Filme}

TOOR \& MARCHELLO (1958) fizeram uma composição entre a teoria dos Dois Filmes e a teoria da Penetração dos Filmes. A base da teoria consiste em considerar uma zona laminar limitada pela região turbulenta, de espessura $L_{f}$, como na teoria dos dois filmes, e localizada ao nível da superfície de um líquido turbulento que se encontra uniforme, e na concentração do soluto $C_{L}$. A transferência de massa 
ocorre somente por difusão molecular e a idade dos elementos superficiais é assumida para se ter a distribuição, conforme proposto por Danckwerts.

A equação que governa o processo de difusão é a seguinte:

$$
\frac{\partial C}{\partial \theta}=D \frac{\partial^{2} C}{\partial y^{2}}
$$

e as condições limites para essa teoria são:

$\begin{array}{lll}C=C_{L} & t=0 & 0<y<L_{f} \\ C=C_{S} & t>0 & y=0 \\ C=C_{L} & t>0 & y=L_{f}\end{array}$

A solução obtida para essa teoria foi dividida para tempos de exposição curtos (teoria da penetração) e longos (teoria do filme), conforme descrito abaixo.

Para tempos curtos:

$$
J=\Delta C \sqrt{\frac{D_{m}}{\pi \cdot t}} \cdot\left[1+2 \sum \exp \left\{\frac{-n^{2} \cdot \delta^{2}}{D_{m} \cdot t}\right\}\right]
$$

Válida para $t<<\left(\delta^{2} / D_{m}\right)$.

Para tempos longos:

$$
J=\Delta C \frac{D_{m}}{\delta} \cdot\left[1+2 \sum \exp \left\{-n^{2} \pi^{2} \frac{D_{m} \cdot t}{\delta^{2}}\right\}\right]
$$

Válida para $t>>\left(\delta^{2} / D_{m}\right)$ 


\subsubsection{Outros Modelos}

Kishinevsky (1955), mencionado por BENNETT e RATHBUN (1972), apresentou um modelo baseado na difusão turbulenta. Para líquidos altamente agitados, a difusividade turbulenta $\varepsilon_{Y}$, é muito maior do que a difusividade molecular, mesmo na superfície. Assim, para um processo de absorção totalmente controlado pela difusão turbulenta, tem-se a relação

$$
K_{L}=\frac{2}{\sqrt{\pi}} \cdot \sqrt{\varepsilon_{y} \cdot S}
$$

Em seguida, KISHINEVSKY \& SEREBRIANSKY (1956) determinaram, por meio de estudos experimentais em um tanque com água altamente agitada, a taxa de absorção pela água de diferentes gases (hidrogênio, nitrogênio e oxigênio), constatando que eram todos aproximadamente iguais e verificando, ainda, a hipótese da independência de $K_{L}$ com a difusividade molecular. Contudo, em baixas velocidades, a difusividade molecular passa a influenciar na medida do coeficiente.

FORTESCUE \& PEARSON (1967), apresentaram um modelo denominado modelo dos grandes vórtices, fizeram a suposição de que as propriedades médias da transferência de massa podem ser modeladas pela média de uma série de células quadradas ao nível da superfície. As células tocam a superfície do escoamento e são lançadas para baixo do fluxo, com velocidade igual à velocidade média do escoamento na superfície. Cada célula apresenta uma vorticidade dentro dos turbilhões e o campo de velocidade de cada célula é dada por:

$$
\begin{aligned}
& u_{e}=A_{e} \operatorname{sen} \frac{\pi \cdot x}{\Lambda} \cdot \cos \frac{\pi \cdot y}{\Lambda} \\
& v_{e}=-A_{e} \cos \frac{\pi \cdot x}{\Lambda} \cdot \operatorname{sen} \frac{\pi \cdot y}{\Lambda}
\end{aligned}
$$




$$
\omega=0
$$

onde $\Lambda$ é a dimensão da célula, tomada como seção quadrada e $A_{e}$ é o valor máximo da velocidade no interior da célula, ou escala de velocidade $\Lambda$, usando os parâmetros obtidos das medidas das grandezas cinemáticas características do escoamento turbulento. O modelo dos grandes vórtices fornece, para o coeficiente médio de transferência de massa, a seguinte equação:

$$
K_{L}=1.46 \cdot \sqrt{\frac{D_{m} \cdot \overline{u^{\prime}}}{\Lambda}}
$$

onde $u$ ' médio é a intensidade turbulenta longitudinal e $D_{m}$ é o coeficiente de difusão molecular.

\subsection{Fundamentos de Turbulência}

\subsubsection{Turbulência}

“O predomínio das forças de inércia sobre as de viscosidade rompe a estabilidade do escoamento, dando lugar a um regime complexo de movimento, no qual as grandezas físicas em todos os pontos da massa fluida variam a cada instante. Este fenômeno, denominado turbulência, acarreta um intercâmbio contínuo de matéria em zonas contíguas do escoamento, como foi demostrado pela difusão do corante na experiência de Reynolds” (FEGHALI, 1974, p.229).

Muitos escoamentos que ocorrem na natureza e têm aplicação na engenharia são turbulentos. Como exemplo pode-se citar: A camada limite na atmosfera terrestre (exceto possíveis condições muito estacionárias); jatos de fluxo acima da troposfera, nuvens de cumulus; as correntes de água sobre a superfície dos oceanos; a fotosfera do sol e as fotosferas de estrelas similares e as nuvens de gases interestrelares. $\mathrm{O}$ rastro na terra dos ventos solares é, possivelmente, um rastro de turbulência. Muitos 
processos de combustão envolvem turbulência e muitas vezes de igual dependência sob isso; o fluxo natural do gás e óleo dentro de linhas de tubos é turbulento. Engenheiros químicos usam turbulência para misturar e homogeneizar misturas de fluidos e para acelerar reações químicas dentro de líquidos ou gases. O fluxo de água dentro de rios e canais é turbulento; o rastro deixado por navios, carros, submarinos, estão dentro dos movimentos turbulentos. O estudo para esclarecer a turbulência é uma atividade interdisciplinar, e a aplicação desse estudo é muito ampla. A exceção está na dinâmica dos fluidos no fluxo laminar onde pequenas dimensões e grande viscosidade são as principais características. O fluxo de óleo lubrificante dentro de um conduto é um típico exemplo.

\subsubsection{Caracterização da Turbulência}

Taylor e Von Karmàn (1937), citados em HINZE (1959), afirmam que a turbulência é um movimento irregular que geralmente ocorre nos fluidos, líquidos ou gases, quando eles escoam passando por uma superfície sólida ou por outro fluido. RODI (1980) descreve a turbulência como sendo um movimento do fluido altamente randômico, não permanente e tridimensional. Markatos (1986), citado em SOUZA FILHO (1995), somou a esta série de atributos a não-linearidade e ainda qualificou o movimento de rotacional, intermitente, com grande desordem, difuso e dissipativo.

TANNEKES e LUMLEY (1972) listam as seguintes características da turbulência:

Irregularidade: essa característica aparece em todos os escoamentos turbulentos, sendo estimada somente através de métodos estatísticos para a turbulência.

Difusividade: causa rápida mistura e acréscimo na razão de momento, calor e transferência de massa.

Altos números de Reynolds: a turbulência freqüentemente se origina de uma instabilidade do escoamento laminar, quando o número de Reynolds torna-se muito alto. 
Flutuações tridimensionais da vorticidade: a turbulência é rotacional e tridimensional.

Dissipação: os escoamentos turbulentos são sempre dissipativos.

Continuum: é um fenômeno contínuo, governado pelas equações da mecânica dos fluidos.

Os trabalhos de Reynolds e Bussinesq descrevem a irregularidade da turbulência a partir de modelos estatísticos. Reynolds foi quem fundou a teoria da turbulência, e usou unicamente a forma mais simples de média em um intervalo de tempo e, ao mesmo tempo, ele indicou a natureza das condições gerais a qual qualquer aplicação da média na fluidodinâmica deve obedecer. De acordo com o refinamento de seu postulado, cinco relações devem ser satisfeita:

$$
\begin{array}{ll}
\overline{f+g}=\bar{f}+\bar{g} & \\
\bar{a} \cdot f=\overline{a \cdot f} & \text { se } \mathrm{a}=\text { constante } \\
\bar{a}=a & \text { se a }=\text { constante } \\
\overline{\frac{\partial f}{\partial s}}=\frac{\partial \bar{f}}{\partial s} & \text {,quando s é } \mathrm{x}, \mathrm{y}, \mathrm{z} \text { ou } \mathrm{t} \\
\overline{\bar{f} g}=\bar{f} \cdot \bar{g} &
\end{array}
$$

Vale ressaltar, que essas relações são conhecidas como as condições de Reynolds. SOUZA FILHO (1995) cita o recente desenvolvimento da abordagem dos sistemas dinâmicos não-lineares, partindo da noção do caos determinístico.

ROMA (1988) descreve o escoamento turbulento como a sobreposição de um escoamento principal, que dá a noção de direção, a um escoamento secundário, que fornece a idéia de não uniformidade e é caracterizado por uma velocidade de perturbação bem menor do que a velocidade média do escoamento principal. 


\subsubsection{Modelos de Turbulência nas proximidades da Superfície Livre}

Hunt (1984), citado por TAMBURRINO (1994), afirma que as características gerais da estrutura turbulenta e a transferência de massa na interface gás/líquido quando os efeitos devido à tensão superficial e da gravidade são relativamente grandes para evitar deformação significativa na superfície livre. Embora os efeitos da superfície livre sob a turbulência sejam similares aos efeitos próximos de uma parede no sentido em que ambos, tanto no caso da superfície livre quanto no caso da parede, o comprimento de escala e intensidade turbulenta se reduzem. Em contrapartida existem algumas diferenças importantes entre os dois casos. Por exemplo, numa superfície sem agitação, a tensão de cisalhamento é zero e a componente da flutuação da velocidade vertical decresce quando se aproxima da superfície livre. Simultaneamente, a flutuação das componentes horizontais da velocidade $\left(V_{x}\right.$ e $\left.V_{y}\right)$ aumentam, conduzindo a uma distribuição não uniforme da energia turbulenta. Com o atrito muito próximo à superfície, a turbulência produzida é pequena e o transporte turbulento torna-se mais importante. Próxima a uma parede sólida, a produção, devido ao cisalhamento, é importante e a restrição imposta pelas condições da camada laminar limitam a difusão turbulenta.

$\mathrm{k}-\varepsilon$ é um modelo de viscosidade turbulenta $\left(v_{t}\right)$ aplicada para o escoamento de energia, que é relatado pela viscosidade turbulenta por meio da relação de Kolmogorov-Prandtl, $v_{\mathrm{t}} \cong \mathrm{k}^{1 / 2}$. L , onde $\mathrm{L}$ é o comprimento de escala integral. O modelo k- $\varepsilon$ utiliza como escala das flutuações turbulentas de velocidade a raiz quadrada da energia cinética turbulenta e, na equação de transporte da escala de comprimento, faz uso da dissipação turbulenta. Tem-se, para a razão de dissipação da energia turbulenta, a seguinte equação:

$$
\varepsilon=\frac{k^{3 / 2}}{L}
$$

rearranjando, 


$$
L=\frac{k^{3 / 2}}{\varepsilon}
$$

e substituindo em

$$
v_{t} \cong k^{1 / 2} \cdot L
$$

tem-se:

$$
v_{t}=\frac{k^{2}}{\varepsilon}
$$

Segundo SOUZA FILHO (1995), o modelo k- $\varepsilon$ é construído a partir de três preceitos: da equação para a viscosidade turbulenta, pelas equações de transporte de energia cinética turbulenta $(\mathrm{k})$ e pela equação de transporte da dissipação turbulenta (ع).

\subsubsection{Intensidade Turbulenta}

A flutuação turbulenta tem valor médio nulo, e a quantificação de seu valor deve ser feita pelo valor RMS (raiz da média quadrática), que tem as mesmas unidades da grandeza original.

O valor RMS, é uma intensidade de turbulência e representa o grau de oscilação ou flutuação da variável em questão.

A intensidade da flutuação turbulenta é calculada como segue:

$$
V_{R M S}=\left(\int_{0}^{T}(V-\bar{V})^{2} d t\right)^{1 / 2}
$$

em que, 
$V_{R M S}$ : é a intensidade turbulenta;

V : valor instantâneo;

$V$ médio: valor médio;

$T$ : é o tempo de integração da medida.

\subsubsection{Funções de Correlação}

O escoamento turbulento pode ser representado por dois movimentos (escoamentos) distintos:

a) um escoamento bem comportado, responsável pelas características médias (velocidade média do escoamento).

b) e outro composto por turbilhões de diversos tamanhos, formas e velocidade de rotação (movimento aleatório).

O tamanho dos turbilhões pode ser representado pela escala de turbulência, e o coeficiente de correlação é o que permite avaliar o grau de dependência entre duas variáveis; analisar se existe uma certa associação entre a velocidade em dois pontos distintos é um exercício que exemplifica bem esta questão.

ROMA (1988) afirma que a caracterização de um escoamento turbulento apenas pelo valor médio e pelo valor RMS das flutuações leva à perda de informações importantes, como, por exemplo, o fato de não considerar as diversas freqüências existentes e que estão diretamente relacionadas ao tamanho dos turbilhões.

Para descrever a flutuação de uma certa variável (como por exemplo a velocidade) $u(t)$, é necessário conhecer como se comportam os valores da velocidade (u) em diferentes tempos. A partir da formação de um conjunto de dados para $u(t)$ e $u$ $(t+d t)$, pode-se definir a correlação $\overline{u(t) \cdot u(t+d t)}$ entre os valores de $u$ em dois diferentes tempos. Essa correlação é chamada de autocorrelação e define-se o 
coeficiente de correlação entre a velocidade medida na posição x e a velocidade medida na posição $\mathrm{x}+\mathrm{dx}$, da seguinte maneira:

$$
\rho(d x)=\frac{1}{X} \int_{0}^{x} \frac{\left(V_{x}-\bar{V}\right) \cdot\left(V_{x+d x}-\bar{V}\right)}{V_{R M S}^{2}} \cdot d x
$$

A equação acima mostra que, quando a distância dx entre os pontos de medida tende a zero, o coeficiente de correlação tende ao valor 1. Quando dx aumenta em um campo aleatório, deixa de haver correlação entre as medidas, indicando que os pontos não mais estão no mesmo turbilhão (ROMA 1988, p.24).

Com os dados coletados em um mesmo ponto fixo $\mathrm{x}$, as flutuações da velocidade são coletadas em um tempo t e, posteriormente, em um tempo $t+d t$; define-se, assim, o coeficiente de correlação da seguinte forma:

$$
\rho(d t)=\frac{1}{T} \int_{0}^{t} \frac{\left(V_{t}-\bar{V}\right) \cdot\left(V_{t+d t}-\bar{V}\right)}{V_{R M S}^{2}} \cdot d t
$$

O segmento negativo de $\rho(d x)$ ou $\rho(d t)$ está associado a uma correlação negativa que deve existir entre as velocidades em lados opostos de um turbilhão.

Taylor (1935), citado em ROMA (1988), introduziu as escalas de turbulência (macro escala e micro escala), que são calculadas a partir do coeficiente de correlação. A macroescala de turbulência é obtida pela integração da função de correlação:

$$
L_{m}=\int_{0}^{\infty} \rho(x, t) d x
$$

Essa escala relaciona-se ao tamanho médio dos turbilhões. 


\subsubsection{Ergodicidade}

Na mecânica estatística assume-se que quando o intervalo de tempo torna-se muito grande, a média temporal converge para a média do sistema. Em alguns casos, a hipótese torna-se valida pelo teorema da ergodicidade, assumindo o resultado como exato, já em outros casos o teorema é adaptado como uma hipótese adicional.

ROMA (1988) afirma que como a função de correlação das flutuações turbulentas pode ser assumida como tendendo a zero, quando t tende ao infinito, a teoria de turbulência parte do principio que, para escoamentos turbulentos, as grandezas médias de qualquer campo fluidodinâmico podem ser determinadas de um registro sobre um intervalo de tempo suficientemente grande.

SCHULZ (1985) afirma que para a maioria dos dados estacionários, os valores médios obtidos tanto pela forma espacial quanto pela forma temporal são iguais. Sendo justificado pelo teorema da ergodicidade de G.D. Birkhoff, que pode ser enunciado assim: Para dados estacionários, as propriedades obtidas através de médias temporais sobre registros individuais são as mesmas para quaisquer registros e são ainda iguais às propriedades obtidas através de médias sobre o conjunto num tempo especifico.

Teorema geral: Para que um processo aleatório estacionário seja ergódico é necessário e suficiente que a função de correlação satisfaça a condição:

$$
\operatorname{Lim} \frac{1}{T} \int_{0}^{T} \rho(t) d t=0
$$

Slutskyi (1938) citado em MONIN \& YAGLOM (1979) foi quem provou primeiramente este teorema, que normalmente é chamado de Lei dos Grandes Números ou teorema da Ergodicidade, para dados estacionários aleatórios.

Em conceitos gerais a ergodicidade considera a existência de uma relação entre a descrição espacial e a descrição temporal de um fenômeno físico. Que está relacionada com a estabilidade probabilística, em que os cálculos estatísticos são equivalentes para os dois sistemas, ou seja, nos sistemas temporal e espacial. 


\subsection{Tanques com Grades Oscilantes}

A influência da turbulência nas proximidades da superfície líquida e a relação com a transferência de massa vêm sendo pesquisadas desde 1955, utilizando-se a técnica de grades oscilantes para produção de turbulência.

Rouse e Dodu, citados por THOMPSON e TURNER (1975), foram os primeiros a utilizar um tanque com grades oscilantes a fim de examinar o movimento entre dois meios de diferentes densidades. As grades geravam a turbulência em uma interface líquido-líquido.

Cromwell (1960), Turner e Kraus (1967) e Turner (1968), entre outros citados por THOMPSON e TURNER (1975), utilizaram grades oscilantes e, em todos esses trabalhos, as taxas de mistura foram interpretadas usando-se medidas das escalas de comprimento e velocidade, baseadas na geometria e freqüência da grade oscilante.

THOMPSON e TURNER (1975) sugerem o uso de grades, utilizadas no estudo da estrutura turbulenta, pelo fato de ser um sistema no qual se obtém um maior controle da turbulência e maior confiança na generalização dos resultados. Com base em experimentos de outros pesquisadores, esses autores, usando três formas de grades oscilantes dentro de um tanque, relatam o valor RMS da velocidade turbulenta e a macro escala para alguns parâmetros externos, como a freqüência e amplitude.

HOPFINGER e TOLY (1976) afirmam que uma grade oscilante gera uma turbulência horizontal homogênea e que o valor RMS horizontal da velocidade $u$, dentro do tanque, pode ser descrito por parâmetros medidos externamente. Desta forma, se as grades movimentam-se em uma amplitude $S$ e oscilam com freqüência $f$, sendo o lado da malha $M$, tem-se:

$$
u^{\prime}=0,25 \cdot f \cdot S^{1,5} \cdot M^{0,5} \cdot y^{-1}
$$

em que y é a distância aproximada do centro do movimento da grade. 
BRUMLEY (1984) utilizou um tanque de 0,50 m de lado, cuja profundidade era de 0,40 m com grades cujas barras eram de $13 \mathrm{~mm}$ espaçadas de $64 \mathrm{~mm}$, operadas pela parte inferior do tanque. Nas medidas de turbulência, usou um anemômetro de filme quente, com o qual foi possível medir as flutuações de velocidade em duas direções, horizontal e vertical na profundidade de $0,4 \mathrm{~mm}$ da superfície. A proposta principal era dar uma idéia melhor da superfície hidrodinâmica para, em seguida, conduzir ao desenvolvimento de algum modelo de transferência de gás.

DICKEY ET AL.(1984) realizaram, por meio de digitalização das linhas deixadas em fotografias, medidas simultâneas das flutuações de velocidade nas direções vertical e horizontal, com origem na direção média do comprimento de escala integral. Esses estudiosos desenharam o campo de velocidades na superfície, assumindo a turbulência isotrópica dentro do plano horizontal. Com os resultados de parâmetros turbulentos, caracterizados pela velocidade turbulenta e pelo comprimento de escala integral, concluíram o trabalho, desenvolvendo um coeficiente através de análise dimensional e comparando-o ao coeficiente de transferência de gás.

BRUMLEY e JIRKA (1987) realizaram medidas turbulentas em um tanque de grades oscilantes, com o objetivo de esclarecer a estrutura turbulenta, elucidando os detalhes da transferência mecânica na interface gás/líquido e a existência de variáveis hidrodinâmicas e da difusão na camada limite. As velocidades vertical e horizontal foram medidas usando o anemômetro de filme quente. Os resultados experimentais foram comparados com outras pesquisas.

ROMA (1988) desenvolveu o sensor ótico para estudar a interface ar/água. Trata-se de uma sonda baseada no fenômeno da refração ótica. Em seu trabalho utilizou um tanque com grades oscilantes para obter uma correlação entre os parâmetros turbulentos gerados pela sonda ótica (RMS e macro escala) e o coeficiente de transferência de massa $K_{L}$ em cada ensaio realizado.

CHU e JIRKA (1991) realizaram experimentos para estudar o mecanismo de transferência de massa na interface ar-água. A turbulência nas proximidades da superfície líquida e a concentração de oxigênio foram medidas em um tanque com 
grades oscilantes. Eles afirmam que a grande escala do movimento turbilhonar é dominante dentro do processo de transferência de massa interfacial.

Dentro da região interfacial, o movimento turbulento é fortemente afetado pelo efeito cinético da superfície livre. Desta forma, o transporte turbulento fica limitado, e a difusão molecular acaba tendo igual importância.

DE SILVA e FERNANDO (1994) utilizaram grades oscilantes a fim de estudar certas propriedades da turbulência isotrópica. Os dados obtidos foram usados para avaliar o espectro de freqüência Euleriano. As observações experimentais foram comparadas com a formulação teórica, bem como, com experimentos realizados anteriormente.

ORLINS e GULLIVER (2000) utilizaram um tanque com grelhas oscilantes para investigar a relação entre turbulência na superfície livre e o transporte de massa. A técnica utilizada para observar as variações temporais foi a Velocimetria por Processamento de Imagens (PIV). Os autores obtiveram dados de oito sub regiões da superfície da água, e a velocidade, a vorticidade e o divergente bi-dimensional eram calculados como função do espaço e do tempo em cada região.

CHENG e LAW (2001) investigaram a turbulência gerada por uma grelha vertical, usando a técnica da velocimetria por Processamento de Imagens Digitais (DPIV). Em sua análise comparativa, seus resultados concordaram bem com os resultados presentes na literatura.

\subsection{Visualização do Escoamento}

\subsubsection{Definição}

Segundo FREYMUTH (1993), a visualização do escoamento é a arte e a ciência de se obter imagens claras de um campo de escoamento físico e a habilidade para capturar um esboço, uma fotografia ou um vídeo, utilizando diversos processos. 
A velocidade e a vorticidade são os parâmetros de maior interesse no campo de escoamento e, devido à dificuldade em visualizá-los, torna-se necessário a utilização de traçadores para marcar o escoamento.

A visualização do escoamento explora o campo de escoamento físico global, contrastando com as sondas locais, como o tubo de Pitot e a anemometria.

\subsubsection{Resumo da História da Visualização do Escoamento}

Esta seção foi extraída do artigo de FREYMUTH (1993) e tem ênfase no método de rastreamento de partículas obtidas por fotografias.

Na pré-história, já apareciam espirais e ondas na arte visual do homem, sendo que as espirais representavam os vórtices. Leonardo da Vinci é geralmente considerado o pai da visualização do escoamento; fez esboços de escoamentos com vórtices ao redor de vários objetos, com considerável realismo e sempre no regime turbulento.

A comunicação por rascunhos descreve, em 1883, a transição para o regime turbulento em tubos por meio de sinais deixados por traços e esboçando vórtices que arrebentam dentro de cano d'água nos séculos 18 e 19 e também dentro do laboratório, todos produzidos por Lugt.

A primeira fotografia da mecânica dos fluidos, com certa relevância para visualização do escoamento, foi a fotografia de um jato d’água que era lançado, tirada por Raleigh em 1879. O tempo de exposição foi obtido por uma faísca elétrica.

A introdução da fotografia na visualização do escoamento se deve especialmente a Mach e Salcher que visualizaram ondas de descarga, fotografando com um tempo de exposição de $0.8 \times 10^{-6}$ segundos através de faísca elétrica.

A visualização de linhas de fluxo foi obtida fotografando um traço curto, utilizando-se de um grupo de partículas visíveis individualmente e geradas pelo seu movimento durante um curto tempo de exposição foi, primeiramente, adaptado por Marey. As partículas neutras flutuantes têm sido colocadas sob um onda de água, espaçadas para obter melhor visualização das linhas de corrente. Esse método foi aperfeiçoado por Ahlborn em 1902, utilizando Lycopodium lançado sobre a 
superfície de um tanque d’água. A iluminação foi obtida por meio de uma cortina de luz na direção do escoamento, proveniente de um flash de magnésio de duração finita. Suas fotos detalham bem o escoamentos dos vórtices.

O método do uso de flocos suspensos em líquidos foi visto por Prandtl; este utilizou flocos de mica em um túnel de água em 1904 para visualização dos vótices. É interessante dizer que a visualização do escoamento na superfície iniciou-se com a observação do fenômeno em uma xícara, e muitos outros investigaram (ex. Riabouchinsky, Hinderks). O método dos flocos vem sendo utilizado ao longo do tempo, especialmente em líquidos ( Prandtl e Tietjens 1934, Clayton e Massey 1967, Werle 1973, Merzkchz 1974, Sommerscales 1980 e Emrich 1981). A tradição de visualizar novos fenômenos de escoamento continua com a adição de novas descobertas para a mecânica dos fluidos.

Nos últimos cinqüenta anos, muitas técnicas foram desenvolvidas como, por exemplo, a técnica da folha de luz utilizada conjuntamente com a técnica de “streamline”, o recente método ótico e a utilização de flocos.

Reznicek, mencionado em FREYMUTH (1993), cita uma expressiva lista de resultados específicos, que podem ser obtidos pela visualização do escoamento, como segue: campo de velocidade, imagem do escoamento nas proximidades de um corpo, perfis de velocidade, mecanismos de formação de vórtices, suas variedades e propriedades, áreas de escoamento laminar, entre outros.

\subsubsection{Técnica de Trilhagem de Partículas}

O método dos traçadores está subdivido em: “Streamline” e "Streakline”. Será apresentado aqui somente o primeiro método.

Partículas pequenas, porém visíveis individualmente são lançadas no escoamento. Essas partículas são rastreadas durante um curto e controlado tempo de exposição, com o comprimento do traço proporcional a velocidade.

O método consiste, basicamente, na obtenção de fotografias tiradas com uma câmara fotográfica, na qual é possível conhecer o tempo de exposição do objeto 
observado, e a iluminação é obtida através de lâmpada apropriada arranjada ao lado do elemento a ser visualizado. Desta maneira, fica um traço impresso na foto que define o movimento da partícula, com um ponto forte seguido de rabicho.

Segundo AGÜI \& JIMÉNEZ (1987), a técnica de trilhagem de partículas é um método simples e muito poderoso de quantificar a visualização de um fluxo, e um dos poucos métodos capazes de prover instantaneamente mapas de magnitudes, tanto de velocidade quanto de vorticidade, sobre extensas áreas. Os autores afirmam que o estudo dos problemas associados à extração de informações quantitativas obtidas experimentalmente com o uso de uma imagem fotográfica é recente. E, provavelmente, esse estudo é uma obrigação pela falta de avaliação da computação digital, de métodos práticos para lidar com grandes quantias de informações geradas por esse método.

Nas formas modernas desse método, os traços são obtidos semeando o fluxo a ser estudado com partículas, que são aderidas pelo movimento do fluido. Medindo o comprimento dos traços e conhecendo-se o período de tempo, torna-se possível o estudo de um ou outro traço deixado pelas partículas nas diferentes fotografias. $\mathrm{O}$ resultando obtido são velocidades associadas a algumas posições da área estudada.

“A interpolação, tanto para uma grade regular como para uma série de contornos de linhas, requer o processamento dos dados por digitalização das figuras, que pode ser manual, como fizeram Imaichi e Ohmi (1983); Utami e Ueno (1984), (1987) ou, automaticamente, como fizeram Dimotakis, Debussy e Koochesfahani (1981); Jian e Schmitt (1982), processando em um computador” (AGÜI e JIMÉNEZ (1987)).

AGÜÍ e JIMÉNEZ (1987) afirmam que os passos citados no parágrafo anterior introduzem erros no final da estimação das velocidades. E que alguns dos autores citados acima têm considerável atenção para com os erros introduzidos por essa técnica de visualização, porém, são poucos que têm considerado o erro cometido durante o processo de interpolação. Considerando tal fato, os autores testaram vários métodos de interpolacão e concluíram que os melhores resultados são obtidos usando o método de Kriging. 
A influência da concentração de partículas sob um maior poder de resolução; é preciso dizer, ainda, que uma validação do método pela correlação com outras medidas simultâneas e por outros meios estabelecidos é, geralmente, ausente.

A descrição do experimento dentro daquele trabalho foi conduzido objetivando estimar os erros introduzidos pelo método de trilhagem de partículas, dentro de medidas da velocidade bidimensional e da estimação de quantificação de alguns vórtices. 


\section{MATERIAIS E MÉTODOS}

Para cumprir o objetivo do presente trabalho, que é encontrar uma relação entre o coeficiente de reaeração e os parâmetros turbulentos obtidos por dois métodos de medida: a sonda ótica (sinal elétrico proporcional à deformação da superfície, em um ponto, em função do tempo) e o método fotográfico (campo de velocidade), foi utilizado um tanque com grades oscilantes, construído no SHSEESC, para a produção de turbulência.

\subsection{MATERIAIS}

A bancada de ensaios experimentais foi composta pelos seguintes instrumentos e equipamentos:

A) equipamento para produção de turbulência constituído por um tanque com grades oscilantes, já existente no Laboratório de Fenômenos dos Transportes, composto de um tanque confeccionado em chapa de aço, três grades de alumínio de diferentes malhas e sistema mecânico de oscilação da grade;

B) equipamento para deaeração da água composto de uma bomba e tubulação para recirculação da água do tanque através de um orifício;

C) equipamento de controle da temperatura ambiente, constituído por um aparelho de ar condicionado de $12000 \mathrm{Btu}$;

D) equipamento de aquisição e armazenamento de dado composto de microcomputador e datalogger de oito canais diferenciais; 
E) equipamento fotográfico composto de máquina fotográfica, dois flash e um tripé para o suporte da máquina;

F) instrumento de medida de concentração de Oxigênio Dissolvido da água do tipo eletroquímico;

G) instrumento ótico de medida da deformação da superfície da água com base no fenômeno da refração.

\subsubsection{Equipamento de geração da Turbulência}

O equipamento foi montado com base nas diversas experiências encontradas na literatura, e consiste em um tanque contendo água e apresentando superfície livre. A água é agitada através de grades oscilantes, acionadas por um motor elétrico através de um sistema biela-manivela, que movimenta um eixo instalado na parte inferior do tanque. O movimento oscilatório da grade gera movimento turbulento nessa região, que é transmitida até a superfície.

A utilização das grades oscilantes se justifica pelo fato desta forma de produção de turbulência ser muito citada na literatura por apresentar turbulência com características bastante reproduzíveis. Em planos paralelos horizontais a turbulência é homogênea, havendo decaimento apenas na direção vertical.

O tanque, construído em chapas de aço, tem formato prismático com base quadrada de $0,5 \times 0,5 \mathrm{~m}^{2}$ e altura de $0,70 \mathrm{~m}$. No fundo foram instalados: o sistema biela-manivela de raio variável, responsável por promover a oscilação vertical das grades e o dispositivo de esgotamento da água ao fim de cada ensaio.

Como já foi mencionado, para estabelecer o nível de turbulência em cada ensaio serão empregadas grades oscilantes. As grades são quadradas, constituídas por barras de seção medindo $10 \times 10 \mathrm{~mm}^{2}$, montadas segundo malhas quadradas com espaçamento entre barras de 6,45 cm , 3,9 cm e 2,65 cm. As medidas externas das grades são de $46,0 \times 46,0 \mathrm{~cm}^{2}$.

As grades estão conectadas a um eixo de aço inóx polido, que desliza axialmente em um mancal de bronze, movimentado pelo mecanismo biela-manivela. Esse sistema para movimentação das grades é acionado por um motor de corrente contínua, que transfere sua potência através de um sistema de transmissão com 
correias e polias. O motor, de potência nominal igual a 1,0 HP, bem como todo o sistema foi montado na base do tanque de reaeração.

Para obter a variação da freqüência de oscilação, o motor é alimentado por fonte com regulagem eletrônica da tensão da corrente contínua. A velocidade de rotação da grade é medida por um dispositivo contador eletrônico, que mede o número de revoluções da polia no intervalo de 1(um) minuto, fornecendo portanto a rotação em Rotações por Minuto, rpm.

\subsubsection{Equipamento utilizado para a Desoxigenação da Água}

A desoxigenação da água foi feita através da evaporação à temperatura ambiente, provocada por abaixamento da pressão em uma placa de orifício. Para conseguir o efeito uma placa de orifício foi conectada a um circuito fechado de tubos de PVC, alimentado por uma bomba hidráulica Mark, modelo XD2 com potência de 1 HP. A circulação da água do tanque através desse circuito hidráulica provoca a cavitação imediatamente a jusante da placa de orifício causando o aparecimento de bolhas de vapor d’água, que devido a diferença de concentração de oxigênio capturam o oxigênio dissolvido na água liberando-o para a atmosfera.

\subsubsection{Instrumentação de Medida}

\subsubsection{Sensor ótico para medida da deformação da superfície líquida}

O sensor ótico para estudar a turbulência na superfície de um líquido foi proposto por ROMA (1988), e seu funcionamento é baseado na refração ótica da luz. Com o movimento da interface ar/água, a sonda capta a variação da luz causada pela refração e produz um sinal elétrico proporcional à deformação.

O sensor ótico é constituído por duas partes rigidamente conectadas: uma delas é o emissor de luz, composto por uma lâmpada incandescente e refletor parabólico, localizado no ar, alimentado por voltagem variável (0 a 6 Volts) de corrente contínua, e a outra parte é o receptor de luz constituído por um foto-diodo, ou um foto-transistor, submerso na água e que funciona com um foto detetor. As 
deformações da superfície da água e o fenômeno da refração da luz ao atravessar a superfície líquida provocam um sinal elétrico que passa a conter informações relativas a deformação da superfície d’água imposta pela ascensão do sistema de turbilhões.

O sinal elétrico produzido pelo foto-receptor é digitalizado e coletado por um Datalogger.

\subsubsection{Aparelho Medidor de Oxigênio Dissolvido}

As medidas de concentração de Oxigênio Dissolvido (OD) no meio líquido para cada experimento foram realizadas por processo eletroquímico, utilizando-se um oxímetro MWM, modelo OXI 127, de procedência alemã. A calibração do aparelho foi conferida por comparação com a concentração de Oxigênio Dissolvido obtida por análise química pelo método de Winkler.

O oxímetro fornece leitura digital em porcentagem (\%) e/ou concentração de O.D. em miligramas por litro (mg/l). Colocando o sensor diretamente dentro d’água, ele realiza medidas instantâneas de concentração de oxigênio dissolvido, permitindo um monitoramento contínuo desse dado.

\subsubsection{Datalogger}

O Datalogger é um aparelho para aquisição de dados e foi utilizado na coleta e armazenamento dos dados da sonda ótica. O Datalogger modelo CR10, fabricado pela Campbell Scientific, Inc (1993), é basicamente constituído de uma CPU (Unidade Central de Processamento), de uma memória de armazenamento de dados, e de canais de entrada e saída analógicos e digitais.

A principal vantagem de se utilizar um Datalogger, reside na possibilidade de sua programação que permite seu funcionamento sem a necessidade de estar conectado a um computador. A programação permite estipular diversas funções durante a coleta de dados, podendo ser citadas: tipo de medida, o número de medidas a serem registradas, o intervalo de tempo entre cada uma delas, cálculo de médias, desvio padrão e outras. 
Os dados coletados ficam armazenados no Datalogger e sua recuperação é feita ligando-o a um micro computador por meio de um cabo serial. Os dados recuperados do Datalogger podem ser lidos por uma planilha eletrônica para seu tratamento e análise.

\subsubsection{Psicrômetro}

Na medida da umidade atmosférica da sala onde foram conduzidos os ensaios, utilizou-se um psicrômetro de aspiração. Sua composição é basicamente um tubo de PVC de 4”, por onde o ar, devido a um ventilador elétrico instalado em uma das extremidades do tubo, é forçado a passar.

No tubo de PVC foram montados dois termômetros graduados para medir as temperaturas do bulbo úmido e do bulbo seco. Os termômetros foram colocados no tubo da seguinte maneira: um bulbo permaneceu seco (em contato com o ar) e o outro esteve envolvido por uma mecha de algodão umedecida constantemente com água.

A umidade relativa do ar foi obtida realizando-se medidas simultâneas de temperatura, tanto no termômetro de bulbo úmido, quanto no termômetro de bulbo seco. Desta forma, obtidos os valores dessas temperaturas e, de posse de uma carta psicrométrica, foi possível obter a umidade relativa do ar.

\subsubsection{Instrumentos utilizados na obtenção de fotografias}

Uma câmera marca PENTAX, modelo K1000, foi utilizada na obtenção das fotografias tiradas da superfície livre da água. Essa câmera permite o ajuste manual da abertura da velocidade do obturador para as condições de luz ambiente. Após alguns ensaios preliminares, optou-se por um filme de $35 \mathrm{~mm}$, ISO 400/27 . A velocidade do obturador foi medida através de um calibrador especialmente construído para esse fim.

A superfície livre continha partículas utilizadas como traçadores e estas foram iluminadas por uma lâmpada halógena de $600 \mathrm{~W}$, em um “spot” fixado ao lado do tanque. 
Nas laterais do tanque, foram ajustados dois flashes; cujas posições foram definidas de forma a impedir que seus reflexos na superfície da água, atingissem a objetiva da câmera.

\subsection{METODOLOGIA}

Os ensaios foram conduzidos no Laboratório de Fenômeno dos Transportes do Departamento de Hidráulica e Saneamento (SHS), mais especificamente, em uma sala com dimensões de aproximadamente $12 \mathrm{~m}^{2}$ e altura de $2,70 \mathrm{~m}$, climatizada por meio de um aparelho de ar condicionado, que foi utilizado para que a temperatura não sofresse variações maiores que $1^{0} \mathrm{C}$, obtendo-se, assim, um bom controle da temperatura do ambiente.

Os procedimentos seguidos em cada ensaio foram:

A) inicialmente procedia-se à desoxigenação da água, realizada a partir do sistema de recirculação d’água através de uma bomba e por meio da introdução de gás nitrogênio na tubulação de entrada do tanque.

B) em seguida, iniciava-se a reaeração do meio líquido através da produção de turbulência pelas grades oscilantes.

C) durante o procedimento de reaeração, realizaram-se as medidas de: concentração de O.D., coleta de dados provenientes da sonda ótica e, ao final de cada ensaio de reaeração, procedeu-se à obtenção dos dados para o método fotográfico de trilhagem de partículas.

\subsubsection{A Deaeração e a Reoxigenação da Água}

O processo de deaeração ou desoxigenação do meio líquido, como se sabe, consiste em diminuir a concentração de oxigênio dissolvido presente na água, para possibilitar a realização dos experimentos de reoxigenação.

A deaeração da água seguiu o método proposto por Maxwell e Holley citados em MELLO (1996). Este modelo consiste em gerar um escoamento forçado, através 
de uma placa de orifício, criando uma região de alta velocidade e produzindo, portanto, uma região de baixa pressão, que acaba causando a cavitação.

Este processo físico é obtido em um sistema de canalização em circuito fechado, com uma bomba de recirculação e uma placa de orifício calculada para produzir baixa pressão no interior do tubo, próximo à sucção da bomba. As bolhas de vapor são formadas ao se atingir a pressão de vapor e como não apresentam oxigênio em seu interior provocam a migração do oxigênio dissolvido no meio líquido para as bolhas devido à diferença de pressão parcial ou de concentração (Lei de Henry). Esse efeito foi reforçado pela introdução de gás nitrogênio na tubulação de recirculação A diferença de pressão parcial de oxigênio entre as bolhas de nitrogênio e a água, gera a migração do oxigênio para as bolhas. Assim, o oxigênio presente nas bolhas escapa para a atmosfera através da superfície livre.

A água utilizada nos ensaios (137,5 litros por ensaio) foi coletada da rede pública do Campus, proveniente de um poço profundo que apresentava a taxa de Oxigênio Dissolvido em um nível próximo ou igual ao de saturação.

O nível de água no tanque foi estabelecido conforme duas condições observadas em ensaios preliminares: o valor mínimo de duas vezes a largura da malha da grade utilizada, e o melhor nível para a obtenção das fotografias, observando uma melhor dimensão das fotos e do ajuste do foco. Esse valor foi mantido em aproximadamente 0,55 m (metros), desde a base do tanque até a superfície livre. A distância entre a posição média de oscilação da grade até a superfície foi de 0,455 m (metro).

O término da desoxigenação é estabelecido de acordo com Boyle et al., citado em COSTA (1992); que recomenda como concentração mínima de O.D., um valor próximo a $20 \%$ da concentração de saturação, e permite, assim, que o período de desoxigenação não se estenda por muito tempo. Considera-se também que os dados do início do teste menores que 10 ou 30 \% da concentração de saturação teriam pouco efeito sobre a estimativa de $\mathrm{C}_{\mathrm{S}}$ e $\mathrm{K}_{2}$.

O teor de Oxigênio Dissolvido para o início do processo de reaeração ficou na faixa de 2 a 2,5 mg/l.

Após completar a deaeração da água, dá-se início aos procedimentos de reoxigenação: 

a) a bomba para recirculação é desligada;
b) o motor que aciona o sistema biela-manivela e as grades são acionados;
c) através de regulagem eletrônica obtém-se a freqüência de oscilação da grade;

d) a contagem da freqüência de oscilação da grade é realizada com um dispositivo contador digital.

Estabelecida a freqüência, inicia-se o processo de reoxigenação da água, sendo o O.D. medido durante as três primeiras horas a cada 3 (três) minutos e, em seguida, até o final do ensaio de reoxigenação, a cada 5 (cinco) minutos.

Os dados coletados são analisados plotando os valores em um gráfico de concentração de Oxigênio Dissolvido em função do tempo, para a determinação do coeficiente de reaeração.

\subsubsection{Método para Determinação do Parâmetro $K_{2}$}

O parâmetro $\mathrm{K}_{2}$ é determinado através da aplicação de um modelo matemático aos dados de reaeração obtidos experimentalmente em função do tempo. Como o modelo aproxima perfeitamente a curva experimental através do ajuste do parâmetro $\mathrm{K}_{2}$ este método oferece excelente aproximaçãp do valor de $\mathrm{K}_{2}$.

Os valores de concentração de Oxigênio Dissolvido foram plotados em função do tempo fornecendo uma curva do tipo exponencial; como o comportamento dos diversos gráficos é similar para todos os ensaios, a apresentação de um deles, como exemplo, é suficiente para ilustrar o método utilizado. Assim, a FIGURA 3 representa a curva de reoxigenação do ensaio egl220. No ANEXO 1 encontram-se as curvas de todos os ensaios. 
O.D. vs Tempo

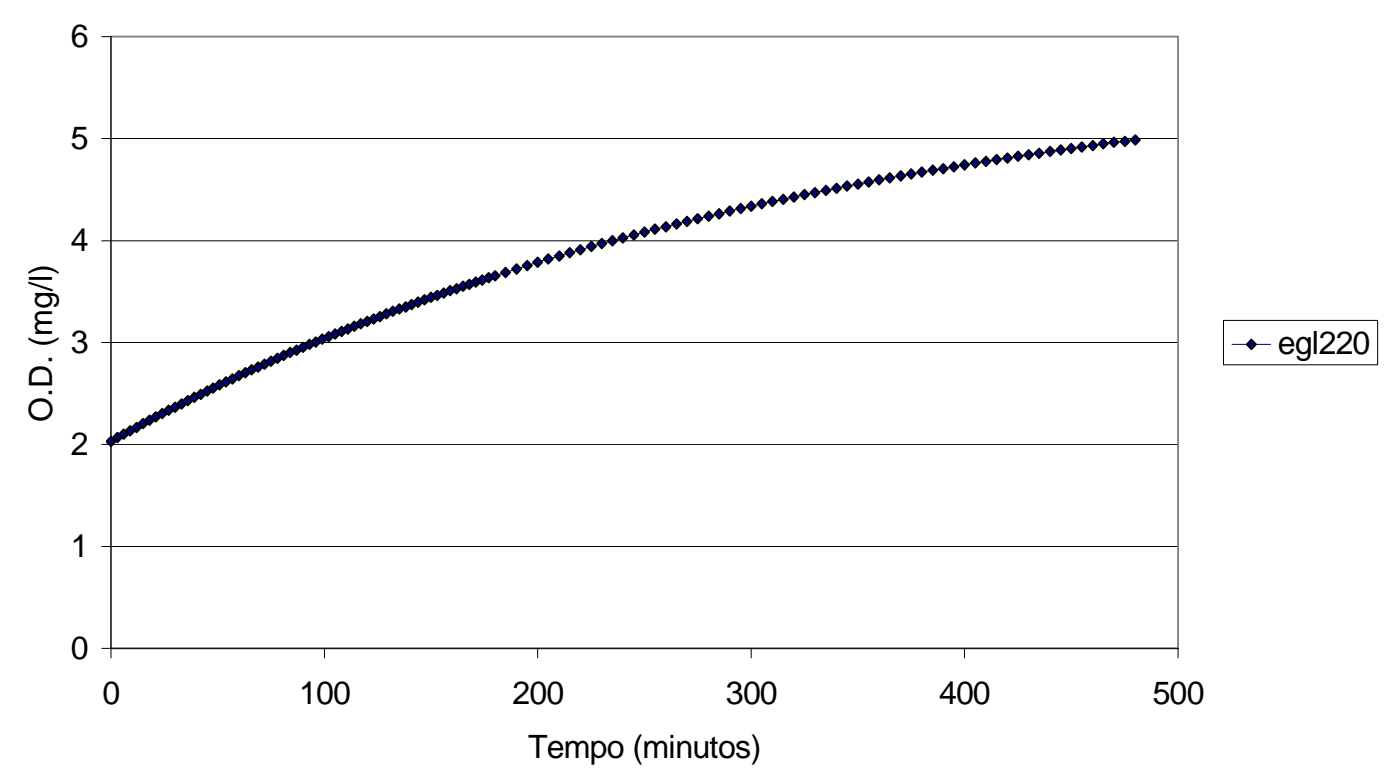

FIGURA 3: Gráfico de concentração de O. D. em função do tempo

O modelo utilizado para avaliação do coeficiente de reaeração é representado pela equação (115).

$$
C=C_{S}-\left(C_{S}-C_{0}\right) \cdot \exp \left(-K_{2} \cdot t\right)
$$

em que:

$\mathrm{C}_{\mathrm{S}}$ : é a concentração de saturação de Oxigênio Dissolvido do meio líquido;

$\mathrm{C}_{0}$ : concentração inicial de Oxigênio Dissolvido na água;

C : concentração de Oxigênio Dissolvido na água em um certo tempo;

$\mathrm{K}_{2}$ : coeficiente de reaeração para o oxigênio;

$\mathrm{t}$ : tempo em que o dado é coletado.

Para a análise dos dados dos ensaios de reoxigenação do meio líquido adotouse o método exponencial. Neste método, os valores de O.D. são usados de forma 
direta, e a equação (115) é utilizada no ajuste dos dados experimentais através do método dos mínimos quadrados não linear.

Observou-se como vantagem principal deste método, o fato de permitir com o auxílio de recursos computacionais, estimar os parâmetros $\mathrm{K}_{2}, \mathrm{C}_{\mathrm{S}}$ e $\mathrm{C}_{0}$ deixando-os livres para a verificação da adequabilidade do modelo utilizado.

A opção pelo método exponencial é justificada, pois é recomendada por BOYLE (1974) e segundo BROWN \& BAILLOD (1982), os erros observados nos valores de concentração próximos da saturação tendem a ser menores do que aqueles observados na fase inicial do experimento, onde a taxa de transferência de oxigênio é alta.

\subsubsection{Método para obtenção dos Dados e Medida dos Parâmetros Turbulentos (Sonda Ótica)}

A tomada de dados pelo método da sonda ótica foi realizada simultaneamente ao processo de reoxigenação da água. A série numérica coletada e armazenada no Datalogger é uma representação digital do sinal elétrico produzido pela sonda. Como trata-se de um sinal representando a turbulência em um ponto na superfície da água em função do tempo, obtém-se um gráfico característico de um sinal aleatório, com muita semelhança entre os diversos ensaios. Assim nesta seção será apresentado apenas o gráfico de um ensaio a título de exemplo.

Para ilustrar a forma do sinal coletado, foi escolhido o ensaio egm210. O gráfico mostrado na FIGURA 4 representa o sinal de tensão elétrica em função do tempo.

O sensor ótico foi mantido durante todos os ensaios em um dos cantos internos do tanque, objetivando manter um mesmo padrão de medida em todos os ensaios.

Um osciloscópio conectado na entrada do Datalogger, foi utilizado para visualizar qualitativamente o sinal proveniente do sensor. Ele mostra, em tempo real, as intensidades do sinal em função do tempo. 


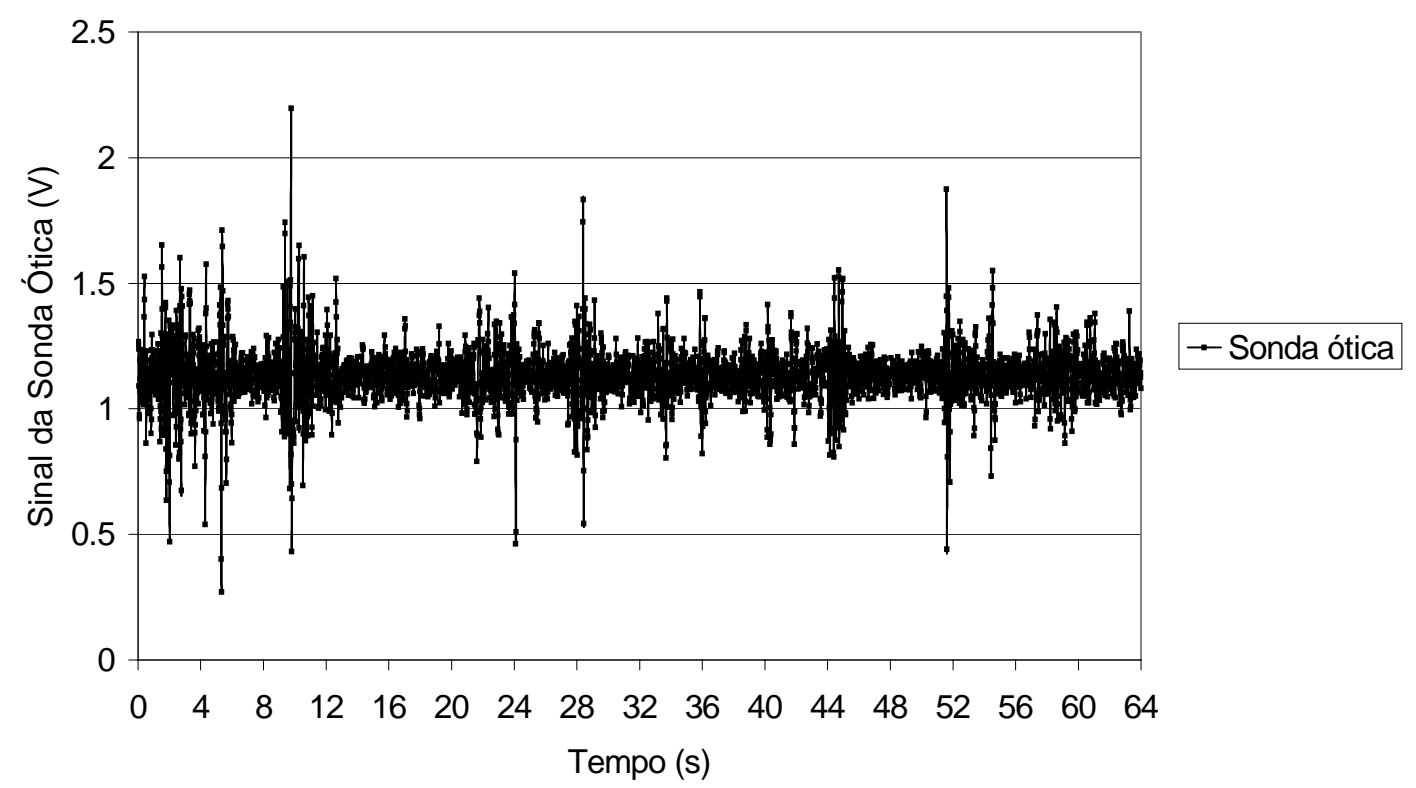

FIGURA 4: Dados de tensão amplificados

Os dados adquiridos pela sonda ótica foram tratados em planilha eletrônica, para calcular as características turbulentas do sinal. Permitindo, assim, o cálculo do valor RMS da tensão, da função de autocorrelação e do valor da macro escala de turbulência, obtida por integração da função de autocorrelação.

Programou-se os cálculos do valor RMS, da função de autocorrelação, da função de autocovariância e da FFT em uma planilha eletrônica, utilizando os 4096 pontos que foram obtidos em cada ensaio. Todos os valores calculados estão apresentados no capítulo 5, Resultados e Discussões.

\subsubsection{Técnica Fotográfica e a Metodologia na Obtenção das Fotografias} (Método Fotográfico)

A técnica fotográfica aqui utilizada inclui uma modificação importante no método de trilhagem de partículas, com melhora significativa na qualidade da obtenção da derivada das componentes da velocidade. A principal modificação consiste na introdução de um segundo disparo de flash na metade do intervalo de tempo de exposição, obtendo-se uma imagem da partícula que mostra sua trajetória 
durante a exposição e dois pontos mais brilhantes, um indicando o início do movimento e o outro um ponto no meio da trajetória.

Na obtenção das trajetórias são usadas partículas de granulometria fina, com densidade inferior a da água. É importante lembrar que a iluminação, aliada aos disparos de flash, permite definir perfeitamente a trajetória e a direção do movimento das partículas.

O aparato para obtenção das fotografias era montado imediatamente após o término do processo de reaeração da água. Esse procedimento foi adotado para evitar que o pó utilizado como traçador atrapalhasse o fenômeno da reaeração. Foram evitados, assim, erros nas medidas da concentração de O.D.

Nos experimentos, a montagem do aparato para obtenção das fotos foi baseada em um tripé que mantinha a câmera. a uma distância aproximada de $20 \mathrm{~cm}$ da superfície da água, tomando o cuidado de manter o filme da máquina paralelo à superfície livre, evitando erros nas medidas dos traços.

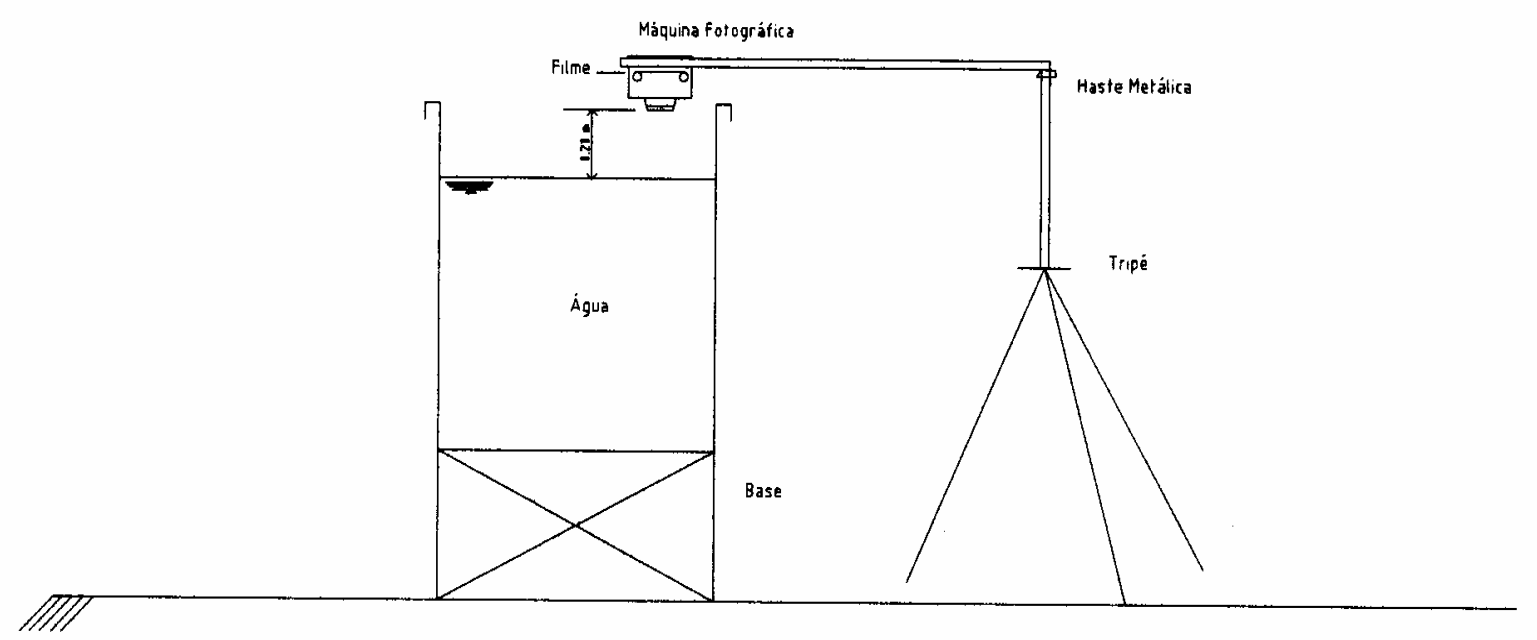

FIGURA 5: Esquema mostrando o aparato utilizado para obtenção das fotografias. 
As fotos foram tomadas com velocidade de exposição de 1/4 de segundo (250 $\mathrm{ms}$ ), com o primeiro disparo de flash na abertura do diafragma e o segundo disparo após um tempo de $130 \mathrm{~ms}$.

Para obter o tempo exato de exposição em cada experimento foi construído um dispositivo para calibração da máquina fotográfica a partir de um fotodiodo que acionava um contador de milisegundos enquanto o obturador estava aberto. Diversas medidas do tempo de exposição de $1 / 4$ de segundo permitiram definir o tempo de abertura do obturador em 270ms (milisegundos).

Para emitir o segundo disparo de flash foi também construído um dispositivo de disparo com retardo de tempo controlado. O dispositivo foi montado juntamente com o calibrador de velocidade do obturador, e o tempo de retardo pode ser ajustado com auxílio do contador de milisegundos. O retardo foi acertado para acionar o segundo flash 130ms (milisegundo) após receber o sinal elétrico proveniente do disparo do primeiro flash. Assim o intervalo de tempo entre o segundo flash e o final da trajetória ficou definido em 140ms. Esses tempos foram utilizados no cálculo das componentes da velocidade nas direções x e y.

A iluminação permanente, responsável pela definição da trajetória do traçador sobre o filme, foi obtida por meio de uma lâmpada de iluminação fotográfica convenientemente ajustada ao lado do tanque.

Convém relembrar que a trajetória de um ponto traçador, observada nas fotografias, é mostrada como uma linha com dois pontos mais brilhantes, devido à incidência dos flashes, como ilustrado no desenho da figura FIGURA 6.

A direção do movimento das partículas é definida pelos pontos fortes deixados pela emissão da luz dos flashes, que indica o ponto de início do movimento.

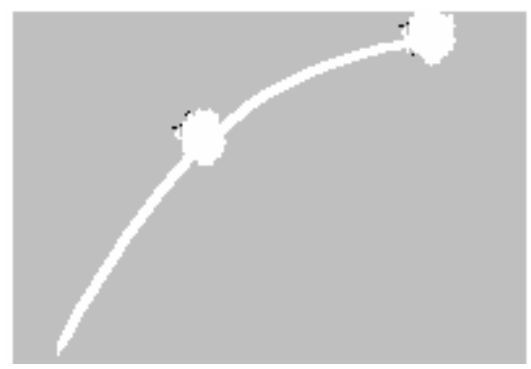

FIGURA 6: Ilustração da trajetória obtida com o método fotográfico 


\subsubsection{Digitalização e Interpolação}

As figuras foram ampliadas e digitalizadas para calcular o campo de vetores na superfície livre.

As fotos, após devidamente processadas por um "scanner", foram transportadas para um software gráfico onde foram digitalizadas para a obtenção do comprimento dos traços. As fotografias tiradas nos ensaios estão no ANEXO 2 e um exemplo pode ser observado na FIGURA 7.

A digitalização foi conduzida manualmente, usando diretamente a tela do computador. Os dados obtidos ficam distribuídos aleatoriamente na foto.

Para favorecer o processamento, é necessário que os dados fiquem espaçados igualmente tanto ao longo do eixo transversal quanto no eixo longitudinal. A interpolação foi conduzida através de um Software que ajustava valores da velocidade para os nós de uma grade previamente estabelecida.

Para a interpolação dos dados, existem tipos de métodos de interpolação, classificados em métodos estatísticos e não estatísticos.

Os métodos não estatísticos utilizam-se de interpolação comum por meio de polinômios. Entre os métodos estatísticos destaca-se a técnica de interpolação conhecida como método de Kriging que é a única que mantém os parâmetros estatísticos dos dados originais e responde bem nas regiões com baixa densidade de informação.

\subsubsection{Campo de Velocidade}

Podemos analisar o movimento de uma partícula pelo conhecimento do vetor posição (R) da partícula em função do tempo; para isso, devemos imaginar um sistema de coordenadas cartesianas xyz e um ponto P no sistema. 


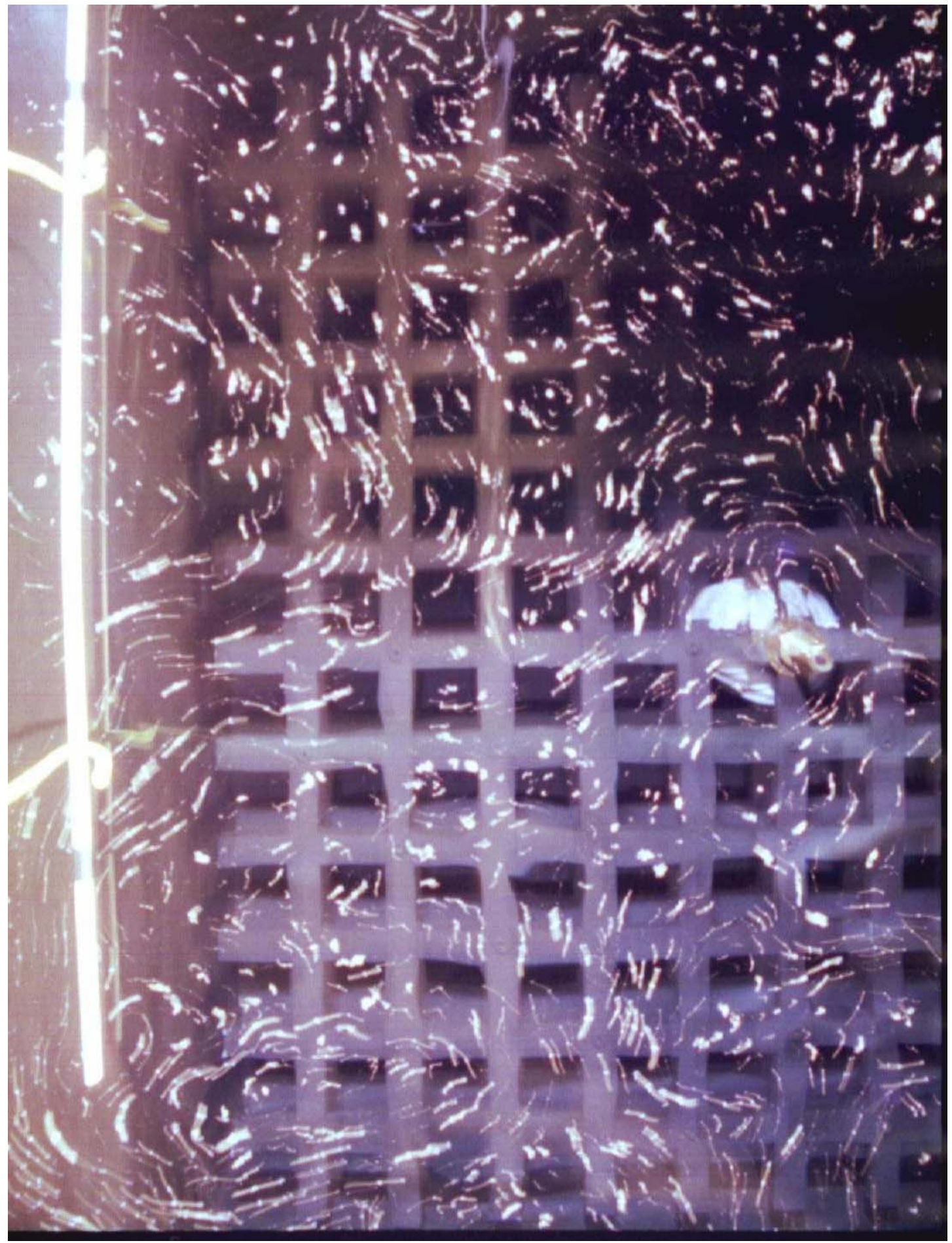

FIGURA 7: Fotografia da superfície livre. 


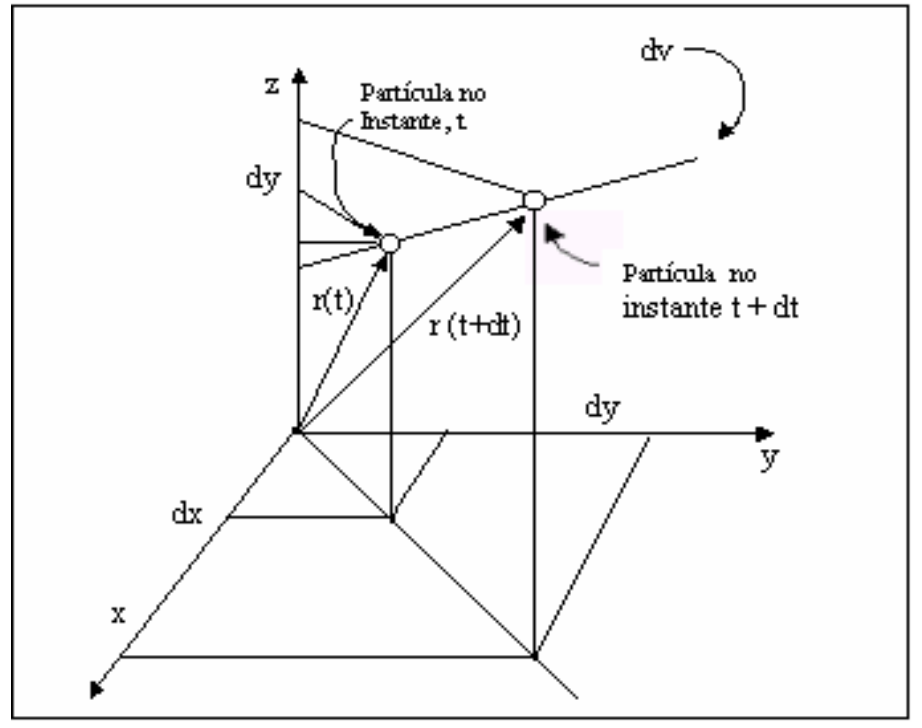

FIGURA 8: O movimento de uma partícula no campo de escoamento

$$
\mathrm{R}=\mathrm{r}(\mathrm{t})=\mathrm{xi}+\mathrm{yj}+\mathrm{zk}
$$

que pode ser representada pelas suas componentes:

$$
\mathrm{X}=\mathrm{x}(\mathrm{t}) ; \quad \mathrm{Y}=\mathrm{y}(\mathrm{t}) ; \quad \mathrm{Z}=\mathrm{z}(\mathrm{t})
$$

Consideremos uma partícula movendo-se num campo de velocidades. No instante t, a partícula está na posição $\mathrm{x}, \mathrm{y}, \mathrm{z}$ e tem uma velocidade correspondente à velocidade naquele ponto no espaço, em t.

$$
\mathrm{Vp}] \mathrm{t}=\mathrm{V}(\mathrm{x}, \mathrm{y}, \mathrm{z}, \mathrm{t})
$$

Em $\mathrm{t}+\mathrm{dt}$, a partícula moveu-se para uma nova posição, com as coordenadas $\mathrm{x}$ $+\mathrm{dx}, \mathrm{y}+\mathrm{dy}, \mathrm{z}+\mathrm{dz}$, e a velocidade pode ser dada por:

$$
\vec{V}_{t}=\frac{\vec{R}(t+d t)-\vec{R}(t)}{d t}
$$

ou, calculando-se as componentes: 


$$
\mathrm{Vx}_{\mathrm{t}}=\mathrm{dx} / \mathrm{dt}, \quad \mathrm{Vy}_{\mathrm{t}}=\mathrm{dy} / \mathrm{dt} \quad \text { e } \quad \mathrm{Vz}_{\mathrm{t}}=\mathrm{dz} / \mathrm{dt}
$$

As velocidades podem ser calculadas da mesma forma para o instante $t+d t$.

A diferença entre as velocidades nos instantes $t+d t$ e $t$ correspondem à variação da velocidade entre dois instantes distintos. Se forem conhecidas as coordenadas espaciais do vetor posição no sistema cartesiano para os dois instantes, torna-se possível conhecer as diferenciais da velocidade em relação ao espaço para as três dimensões, sendo elas, portanto: $\partial \mathrm{V} / \partial \mathrm{x}, \partial \mathrm{V} / \partial \mathrm{y}, \partial \mathrm{V} / \partial \mathrm{z}$.

\subsubsection{A equação da Continuidade}

Para o caso particular de um fluido incompressível, ou seja, $\rho$ constante, a massa específica não é função das coordenadas espaciais nem do tempo sendo, assim, a equação da continuidade simplificada para:

$$
\frac{\partial \mathrm{u}}{\partial \mathrm{x}}+\frac{\partial \mathrm{v}}{\partial \mathrm{y}}+\frac{\partial \mathrm{w}}{\partial \mathrm{z}}=0
$$

Então, o campo de velocidade deve satisfazer a $\nabla \cdot V=0$.

Das fotos obtém-se o comprimento dos traços, deixados pelas partículas, através de digitalização e, conhecendo-se o tempo de exposição de cada experimento, pode-se calcular a velocidade nos pontos de inicio da trajetória marcadas na fotografia. Realizando-se as digitalizações de forma a obter as componentes x e y da distância percorrida pelo ponto, é possível determinar as velocidades horizontais $\mathrm{V}_{\mathrm{x}} \mathrm{e}$ $\mathrm{V}_{\mathrm{y}}$. Pela digitalização da segunda parte da trajetória obtém-se novos valores da velocidade, através de suas coordenadas, para um ponto deslocado do ponto inicial de uma distância definida pelo tempo de exposição dt (entre o primeiro e o segundo disparo de flash). Tendo obtido dois valores da velocidade defasados de uma distância conhecida pode-se avaliar com razoável precisão a derivada de cada componente obtida. Pelo uso da equação da continuidade obtém-se a derivada da componente vertical, $\partial \mathrm{w} / \partial \mathrm{z}$, utilizando-se a equação 122 , obtendo-se desta forma 0 gradiente da componente vertical da velocidade. 
$\partial \mathrm{w} / \partial \mathrm{z}=-(\partial \mathrm{u} / \partial \mathrm{x}+\partial \mathrm{v} / \partial \mathrm{y})$

A planilha montada para a determinação das velocidades horizontais e do gradiente da componente vertical da velocidade pode ser encontrada no anexo xx.

A importância dessa componente consiste no fato de que a literatura cita que entre as variáveis cinemáticas que afetam o fenômeno da transferência de massa através da superfície livre o gradiente da componente vertical da velocidade é a mais importante.

\subsubsection{Obtenção dos Parâmetros através da Técnica Fotográfica}

O campo de velocidade obtido com a interpolação pelo método de Kriging, no software utilizado é apresentado na forma de malhas, onde cada nó apresenta o valor da velocidade (horizontal ou o gradiente de velocidade vertical) em um ponto, e que pode ser extraído através de uma janela do software. Os dados nas malhas ficam espaçados igualmente em ambas as direções, nos eixos transversais e longitudinais.

Adotou-se quatro linhas por fotografia e os valores foram obtidos na direção $\mathrm{x}$, e os dados conseguidos foram copiados manualmente para uma planilha eletrônica.

Os dados das linhas retirados das fotos são utilizados na obtenção do valor RMS e dos coeficientes de autocorrelação e autocovariância espaciais.

Aplicando-se o algoritmo FFT na função de autocovariância obtém-se o espectro, que para as fotografias é uma função espacial. Assim, obtiveram-se os espectros em cada ensaio, plotados em um gráfico log-log.

Nos catorze ensaios foram obtidos os espectros da velocidade vertical na superfície livre. Os valores plotados em gráfico log-log, são comparados de forma qualitativa com os obtidos nos ensaios da sonda ótica.

Nos ensaios da sonda ótica seguiu-se a mesma metodologia aqui apresentada para se obter os espectros de freqüência. 


\subsubsection{Umidade Relativa}

A umidade relativa do ar foi monitorada com um psicrômetro localizado nas proximidades do tanque d'água.

As medidas no bulbo úmido e no bulbo seco eram realizadas a cada 30 minutos. Optou-se por calcular a média aritmética das temperaturas e através de carta psicrométrica obtinha-se a umidade relativa em porcentagem. 


\section{RESULTADOS E DISCUSSÕES}

Devido à quantidade de dados obtidos, a apresentação dos resultados será dividida da seguinte maneira:

A) coeficiente de Reaeração, $K_{2}$;

B) resultados obtidos por meio do Método Fotográfico, sendo este item dividido em: Velocidade Horizontal, Gradiente de Velocidade na direção z (determinação dos parâmetros RMS, Função de Autocorrelação e Espectro);

C) resultados da Sonda Ótica (Sinal, RMS, Função de autocorrelação, Macro escala e Espectro de Freqüência);

D) comparação entre a Função de autocorrelação da sonda ótica e do método fotográfico;

E) comparação entre o Espectro de freqüência da sonda ótica com o Espectro do método fotográfico;

F) relação entre $\mathrm{K}_{2}$ e RMS do método ótico;

$\mathrm{G})$ relação entre $\mathrm{K}_{2}$ e RMS do método fotográfico.

\subsection{Coeficiente de Reaeração $K_{2}$}

A determinação de $K_{2}$ para cada ensaio segue o item 4.2.2, apresentado no capítulo 4.

Na TABELA 1, encontram-se os resultados do coeficiente de reaeração $K_{2}$, medido na temperatura do experimento, bem como, o valor corrigido para a temperatura de $25^{0} \mathrm{C}$. As condições experimentais de cada ensaio também são apresentadas nesta tabela (temperatura, umidade relativa do ar e outros). 
TABELA 1: Coeficiente de reaeração $K_{2}$, medido na temperatura do experimento e a $25^{0} \mathrm{C}$. Coeficiente de transferência de massa $\mathrm{K}_{\mathrm{L}}$ e as condições experimentais de cada ensaio (temperaturas e umidade relativa do ar).

\section{ENSAIO DA GRADE FINA (EGF)}

Ensaio da Grade de abertura 26,5 mm e espessura $10 \mathrm{~mm}$

\begin{tabular}{c|c|c|c|c|c|c|c}
\hline EXP. & $\mathrm{N}$ & $\begin{array}{c}\text { Coeficiente } \\
\text { Reaeração }\end{array}$ & $\begin{array}{c}\text { Coeficiente } \\
\text { Reaeração }\end{array}$ & $\begin{array}{c}\text { coef. Transf. de } \\
\text { Massa }\end{array}$ & $\begin{array}{c}\text { Temperatura } \\
\text { Ambiente }\end{array}$ & $\begin{array}{c}\text { Temperat. } \\
\text { Água }\end{array}$ & UR \\
\hline $\mathrm{n}^{0}$ & Rpm & K2,T (h-1) & K2,25(h-1) & KL,25 (m/s) & $\begin{array}{c}\text { Graus } \\
\text { Celsius }\end{array}$ & $\begin{array}{c}\text { Graus } \\
\text { Celsius }\end{array}$ & $\%$ \\
\hline & & & & & & & \\
\hline egf120 & 120 & 0.1069 & 0.1113 & $1.69733 \mathrm{E}-05$ & 23.3 & 25.4 & 44.5 \\
\hline egf140 & 138 & 0.1022 & 0.1074 & $1.63785 \mathrm{E}-05$ & 22.9 & 25.6 & 44 \\
\hline egf160 & 158 & 0.1227 & 0.1308 & $1.99470 \mathrm{E}-05$ & 22.3 & 24.6 & 44.4 \\
\hline egf180 & 180 & 0.2598 & 0.2712 & $4.13580 \mathrm{E}-05$ & 23.2 & 21.9 & 73.1 \\
\hline & 180 & 0.2784 & 0.2919 & $4.45148 \mathrm{E}-05$ & 23 & 24.9 & 57.6 \\
\hline egf200 & 200 & 0.2863 & 0.2939 & $4.48198 \mathrm{E}-05$ & 23.9 & 26.6 & 51.8 \\
\hline
\end{tabular}

\section{ENSAIO DA GRADE MÉDIA (EGM)}

Ensaio da Grade de abertura 39,0 mm e espessura $10 \mathrm{~mm}$

\begin{tabular}{l|c|c|c|c|c|c|c}
\hline egm140 & 138 & 0.0808 & 0.0859 & $1.30998 \mathrm{E}-05$ & 22.4 & 24.5 & 50 \\
\hline egm160 & 158 & 0.0921 & 0.0982 & $1.49755 \mathrm{E}-05$ & 22.3 & 24.3 & 44.9 \\
\hline & 178 & 0.0874 & 0.0914 & $1.39385 \mathrm{E}-05$ & 23.1 & 25.2 & sem \\
\hline egm180 & 180 & 0.0889 & 0.0948 & $1.44570 \mathrm{E}-05$ & 22.3 & 24.5 & 45.8 \\
\hline & 198 & 0.0996 & 0.1049 & $1.59973 \mathrm{E}-05$ & 22.8 & 25.4 & sem \\
\hline egm210 & 208 & 0.1429 & 0.1495 & $2.27988 \mathrm{E}-05$ & 23.1 & 25 & 58.5 \\
\hline egm240 & 238 & 0.1049 & 0.1095 & $1.66988 \mathrm{E}-05$ & 23.2 & 25.7 & 45.5 \\
\hline
\end{tabular}

ENSAIO DA GRADE LARGA (EGL)

Ensaio da Grade de abertura 64,5 mm e espessura $10 \mathrm{~mm}$

\begin{tabular}{c|c|c|c|c|c|c|c}
\hline egl180 & 180 & 0.0745 & 0.0802 & $1.22305 \mathrm{E}-05$ & 21.9 & 23.6 & 39.8 \\
\hline egl200 & 200 & 0.0738 & 0.0781 & $1.19103 \mathrm{E}-05$ & 22.6 & 24.8 & 44.9 \\
\hline egl220 & 220 & 0.0814 & 0.0868 & $1.32370 \mathrm{E}-05$ & 22.3 & 23.7 & 55.4 \\
\hline egl250 & 250 & 0.0951 & 0.1007 & $1.53568 \mathrm{E}-05$ & 22.6 & 24.4 & 43.4 \\
\hline
\end{tabular}


O coeficiente de reaeração $K_{2}$, dos trabalhos de ROMA (1988) e de MIRANDA (2000) é comparado aos valores de $K_{2}$ do presente trabalho. Vale lembrar, que as grades utilizadas para geração de turbulência são aqui chamadas de grade fina, grade média e grade larga. As TABELAS 2, 3, 4 apresentam os resultados comparativos para as três grades.

Os dados dessas tabelas foram plotados em gráficos ( $\mathrm{K}_{2}$ versus Rotação), onde se buscou o melhor ajuste através de regressão. Esses resultados são apresentados nas FIGURAS 9, 11, 13.

Com o objetivo de obter-se uma relação entre $\mathrm{K}_{2}$ e o valor RMS, tanto para o método da sonda ótica, como para o método fotográfico, foram plotados todos os valores de $K_{2}$ obtidos nos três trabalhos, comparados em função da rotação e, por meio de regressão, buscou-se a equação com o melhor ajuste. Esta equação foi programada em planilha eletrônica para se obter valores de $K_{2}$ estimado. Os resultados podem ser observados nas FIGURAS 10, 12, 14.

TABELA 2: Comparativo entre os valores $K_{2}$ para o ensaio da grade fina

\begin{tabular}{c|c|c|c}
\hline Rotação (rpm) & $\begin{array}{c}\text { Valores de } \mathrm{K}_{2} \text { de } \\
\text { ROMA (1988) }\end{array}$ & $\begin{array}{c}\text { Valores de } \mathrm{K}_{2} \text { de } \\
\text { MIRANDA (2000) }\end{array}$ & $\begin{array}{c}\text { Valores de } \mathrm{K}_{2} \\
\text { deste Trabalho }\end{array}$ \\
\hline 69 & 0.0468 & & \\
\hline 84 & 0.0510 & & \\
\hline 108 & 0.0778 & & 0.1069 \\
\hline 115 & 0.0822 & & 0.1022 \\
\hline 120 & & & 0.1227 \\
\hline 138 & & & \\
\hline 150 & 0.1425 & 0.1182 & 0.2598 \\
\hline 158 & & 0.1162 & \\
\hline 165 & & 0.1845 & \\
\hline 175 & & 0.2056 & \\
\hline 180 & & & \\
\hline 198 & & 0.2793 & \\
\hline 200 & & & \\
\hline 208 & & & \\
\hline 218 & & & \\
\hline
\end{tabular}


Comparação de Valores de K2 para a Grade Fina

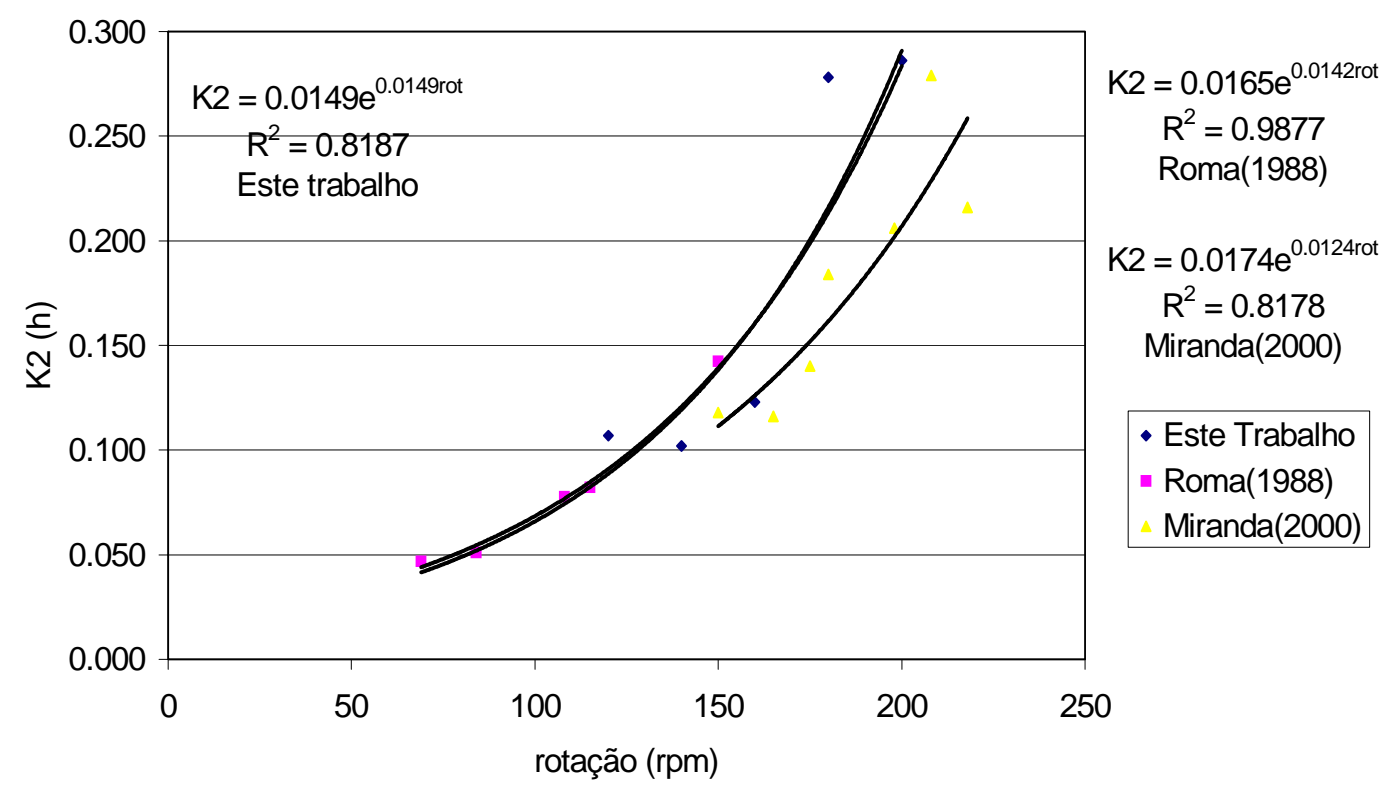

FIGURA 9: Gráfico de $K_{2}$ em função da freqüência de oscilação da grade de 26,5 mm de abertura e barras com 10mm de espessura

Melhor ajuste dos três trabalhos

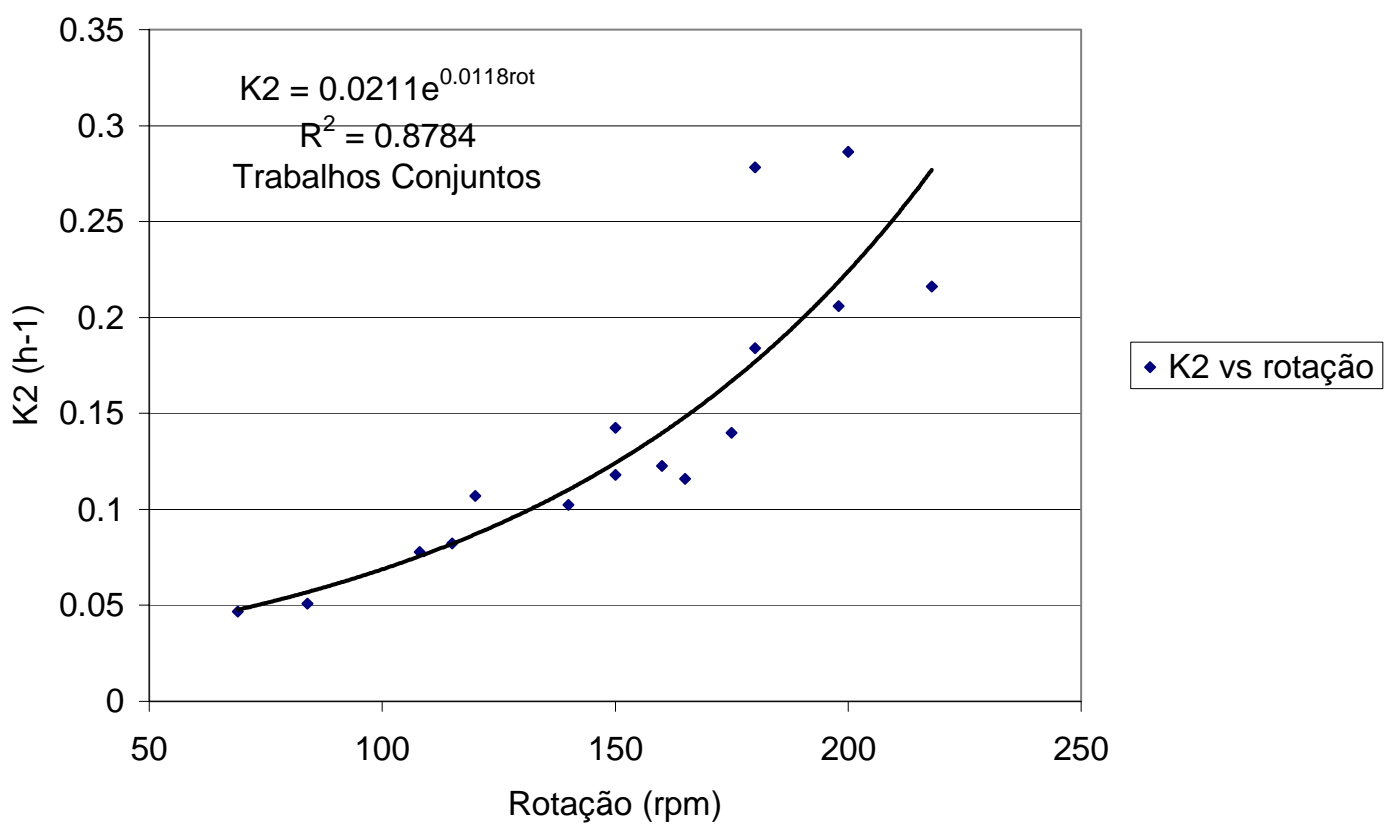

FIGURA 10: Melhor ajuste dos três trabalhos conjuntos (Grade de 26,5 mm de abertura e barras com 10mm de espessura) 
TABELA 3: Comparativo entre os valores K2 para o ensaio da grade média

\begin{tabular}{c|c|c|c}
\hline Rotação (rpm) & $\begin{array}{c}\text { Valores de } \mathbf{K}_{2} \text { de } \\
\text { ROMA (1988) }\end{array}$ & $\begin{array}{c}\text { Valores de } \mathrm{K}_{2} \text { de } \\
\text { MIRANDA (2000) }\end{array}$ & $\begin{array}{c}\text { Valores de } \mathrm{K}_{2} \\
\text { deste Trabalho }\end{array}$ \\
\hline 90 & 0.0509 & & \\
\hline 116 & 0.0645 & & 0.0808 \\
\hline 138 & & & 0.0921 \\
\hline 155 & & 0.0859 & \\
\hline 158 & & 0.0757 & 0.0889 \\
\hline 168 & & 0.0999 & \\
\hline 178 & & & 0.1046 \\
\hline 180 & & & 0.1429 \\
\hline 185 & & & 0.10987 \\
\hline 188 & & & \\
\hline 195 & & & \\
\hline 198 & & & \\
\hline 208 & & 0.1336 & \\
\hline 218 & & &
\end{tabular}

Comparação de Valores de K2 para o Ensaio da Grade Média

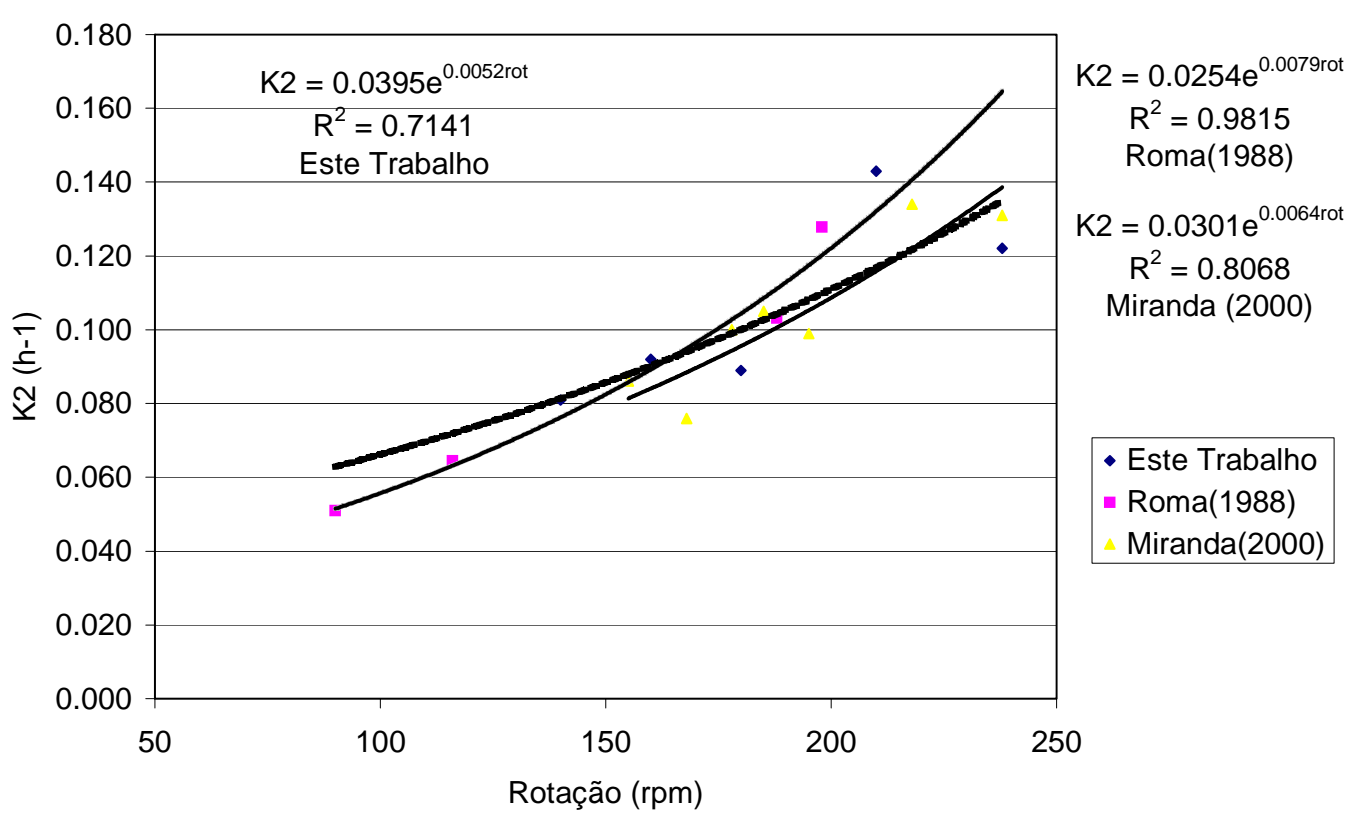

FIGURA 11: Gráfico de $K_{2}$ em função da freqüência de oscilação da grade de 39,0 mm de abertura e barras com 10mm de espessura 
K2 vs Rotação (Melhor ajuste dos três trabalhos)

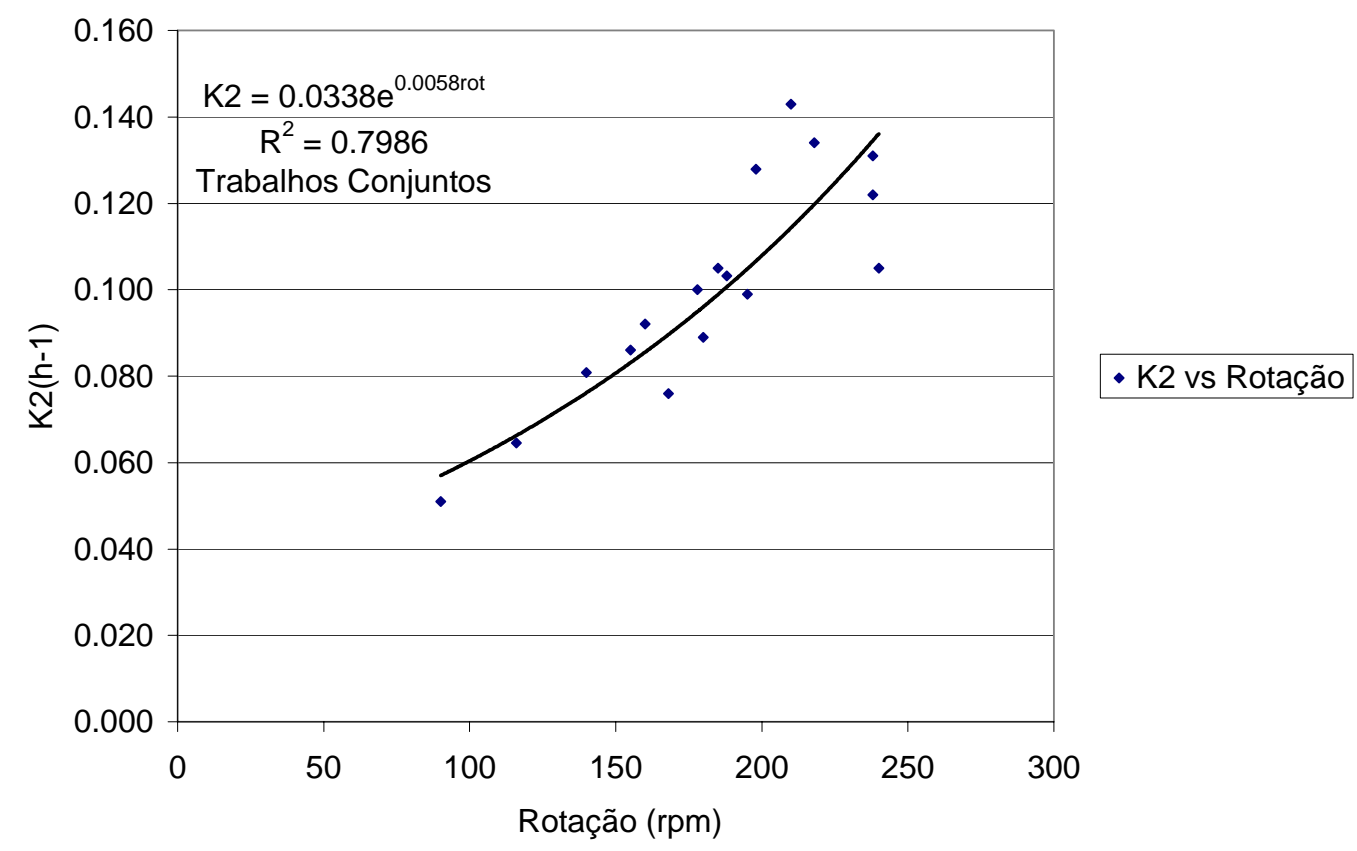

FIGURA 12: Melhor ajuste dos três trabalhos Conjuntos (Grade de 39,0 mm de abertura e barras com 10mm de espessura)

TABELA 4: Comparativo entre os valores $\mathrm{K}_{2}$ para o ensaio da grade larga

\begin{tabular}{c|c|c|c}
\hline Rotação (rpm) & $\begin{array}{c}\text { Valores de } \mathrm{K}_{2} \text { de } \\
\text { ROMA (1988) }\end{array}$ & $\begin{array}{c}\text { Valores de } \mathrm{K}_{2} \text { de } \\
\text { MIRANDA (2000) }\end{array}$ & $\begin{array}{c}\text { Valores de } \mathrm{K}_{2} \\
\text { deste Trabalho }\end{array}$ \\
\hline 115 & 0.0526 & & \\
\hline 165 & & 0.0730 & \\
\hline 172 & 0.0782 & & 0.0745 \\
\hline 180 & & 0.0405 & \\
\hline 196 & & 0.0632 & 0.0738 \\
\hline 198 & 0.0845 & & \\
\hline 200 & 0.0831 & & 0.0814 \\
\hline 206 & & 0.08968 & \\
\hline 218 & & & 0.0938 \\
\hline 220 & & & 0.1568 \\
\hline 235 & & & \\
\hline 238 & 0.1065 & & \\
\hline 250 & & & \\
\hline
\end{tabular}


Comparação de Valores de K2 para o Ensaio da Grade Larga

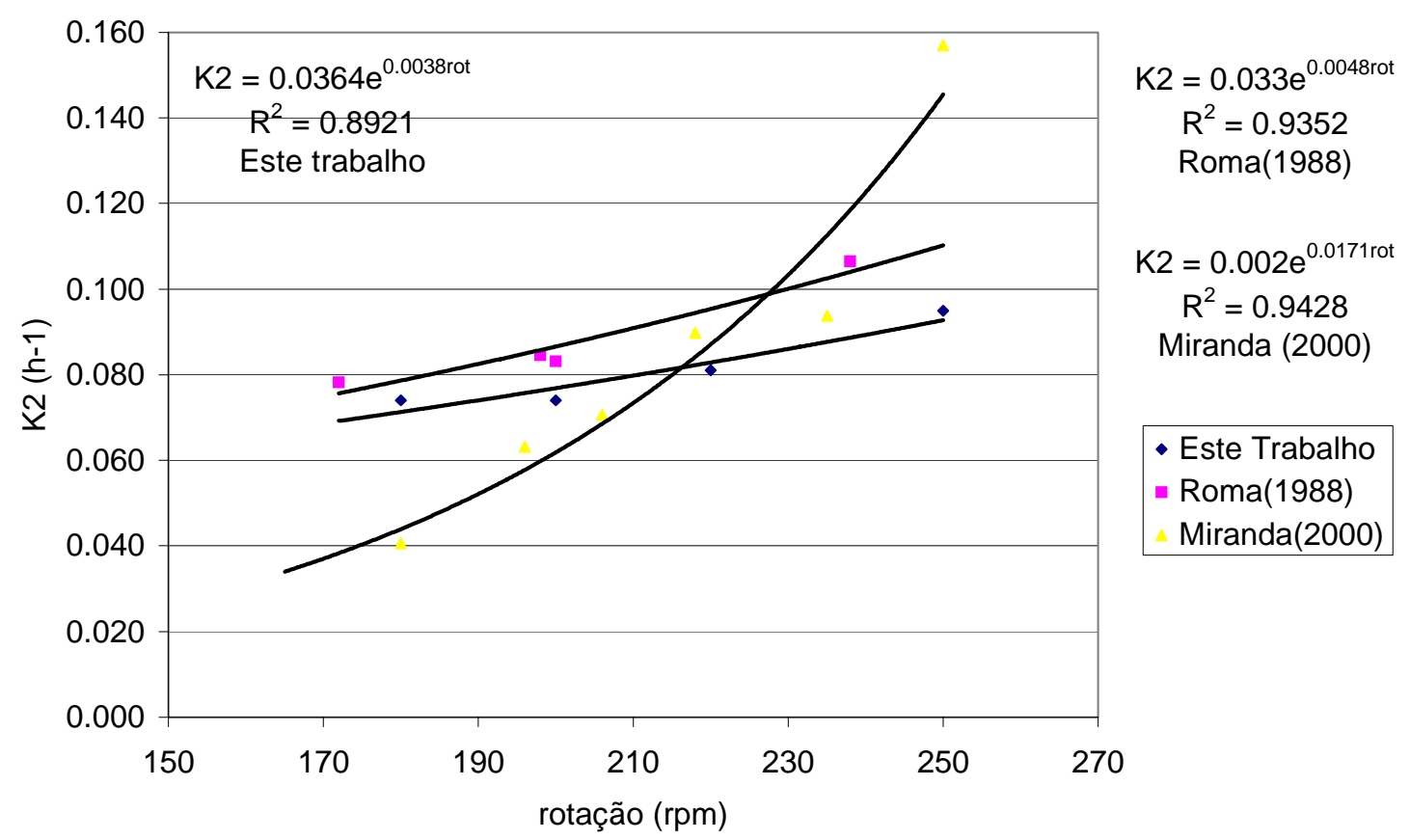

FIGURA 13: Gráfico de $K_{2}$ em função da freqüência de oscilação da grade de 64,5 mm de abertura e barras com 10mm de espessura

A FIGURA 13 apresenta o gráfico de $K_{2}$ em função da freqüência de oscilação da grade (rotação), os dados dos trabalhos utilizados foram organizados de forma separada, para se obter uma equação distinta para cada um dos trabalhos. Desta maneira com os dados de cada trabalho obteve-se uma equação de $K_{2}$ em função da rotação. Esse gráfico representa um comparativo, que pode servir como uma calibração do equipamento utilizado, já que os três trabalhos, aqui apresentados utilizaram o mesmo tanque com grades que oscilam através do motor rotativo.

Na FIGURA 14 juntou-se todos os valores de $K_{2}$ dos três trabalhos e, montou-se o gráfico em função da rotação, alcançando-se o melhor ajuste para os três trabalhos conjuntos. Por meio de regressão, a equação obtida será utilizada para obter os valores de $\mathrm{K}_{2}$ estimado.

Em altas rotações observa-se um maior espalhamento dos pontos, que pode ser justificado pela quebra da superfície livre. 
K2 vs Rotação (Melhor ajuste para os três trabalhos)

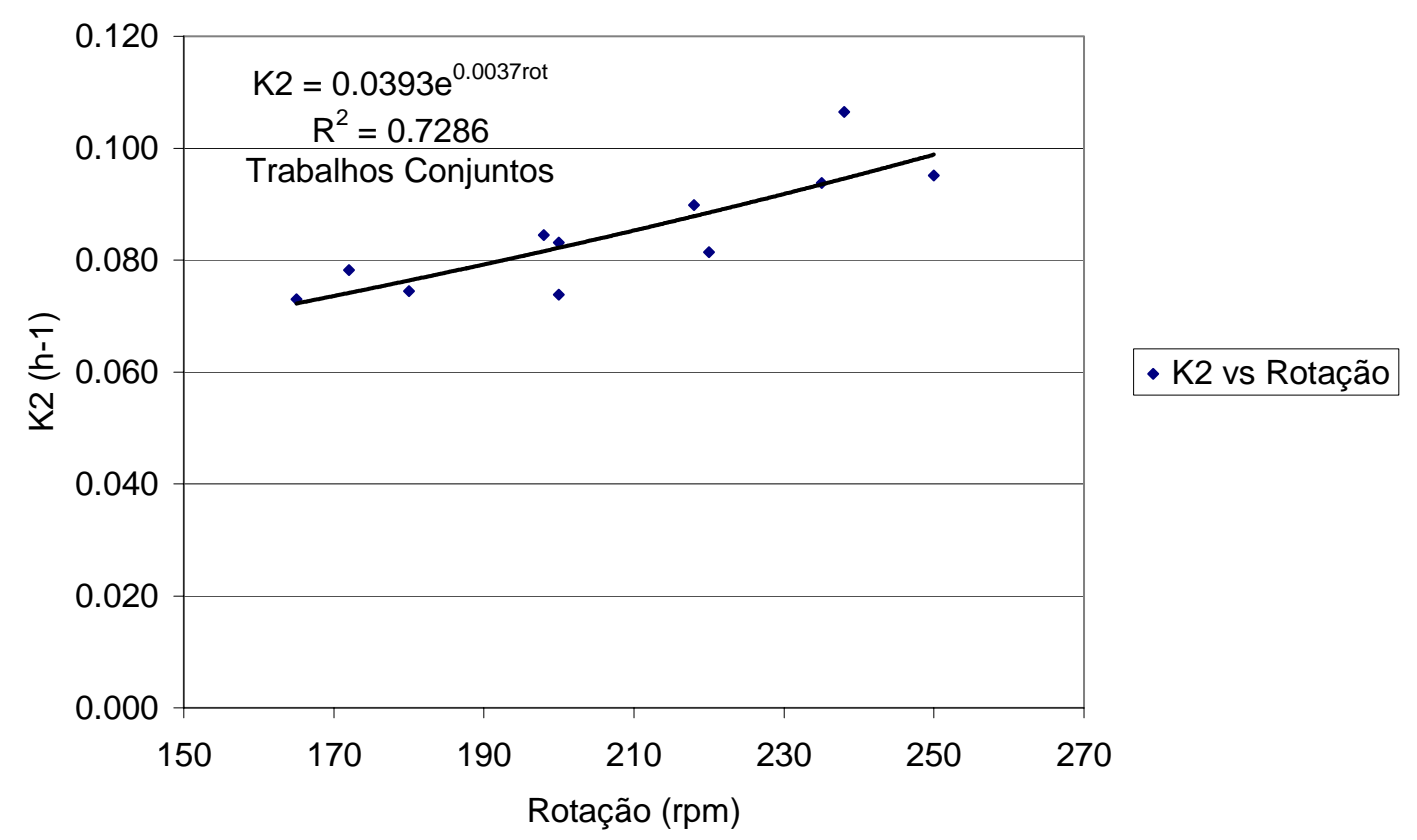

FIGURA 14: Melhor ajuste dos três trabalhos Conjuntos (Grade de 64,5 mm de abertura e barras com 10mm de espessura )

\subsection{Resultados da Sonda Ótica}

Os valores RMS são comparados aos de ROMA (1988) através da TABELA 5.

As FIGURAS 15, 16 e 17 apresentam os melhores ajustes dos valores de RMS do sinal da sonda obtidos em laboratório. A equação resultante foi utilizada a fim de estimar os valores de RMS para a mesma faixa de rotação em que $K_{2}$ foi estimado.

Na análise qualitativa observa-se que a função de autocorrelação para os dois diferentes métodos, apesar de a forma das duas funções serem bem distintas, apresenta um comportamento similar no que diz respeito a "rapidez" com que perdem a correlação.

O valor da macro escala de turbulência foi obtido em um software gráfico e foi também comparado aos valores do trabalho de ROMA (1988), na TABELA 5. 
O espectro de freqüência foi conseguido a partir da transformada de Fourier (FFT) da função de autocovariância, e será utilizado de forma qualitativa na comparação com o espectro espacial ao longo do eixo $\mathrm{x}$, do método fotográfico, no item 5.5.

TABELA 5: Parâmetros turbulentos obtidos nos ensaios com o método ótico. Comparação dos valores RMS e Macro escala desta pesquisa com os de ROMA (1988).

\begin{tabular}{|c|c|c|c|c|}
\hline Ensaio & $\begin{array}{l}\text { Valor RMS de } \\
\text { ROMA (1988) }\end{array}$ & $\begin{array}{c}\text { Valor RMS } \\
\text { deste Trabalho }\end{array}$ & $\begin{array}{l}\text { Macro escala de } \\
\text { ROMA (1988) }\end{array}$ & $\begin{array}{r}\text { Macro escala } \\
\text { deste trabalho }\end{array}$ \\
\hline Egf 69 & 0.118 & & 0.002 & \\
\hline Egf 84 & 0.176 & & 0.004 & \\
\hline Egf 108 & 0.348 & & 0.006 & \\
\hline Egf 115 & 0.359 & & 0.007 & \\
\hline Egf 120 & & 0.067 & & 0.023 \\
\hline Egf 140 & & 0.132 & & 0.018 \\
\hline Egf 150 & 0.610 & & 0.010 & \\
\hline Egf 160 & & 0.197 & & 0.016 \\
\hline Egf 180 & & 0.238 & & 0.015 \\
\hline Egf 200 & & 0.264 & & 0.015 \\
\hline Egm 90 & 0.106 & & 0.001 & \\
\hline Egm 116 & 0.171 & & 0.003 & \\
\hline Egm 140 & & 0.055 & & 0.026 \\
\hline Egm 160 & & 0.060 & & 0.020 \\
\hline Egm 180 & & 0.088 & & 0.021 \\
\hline Egm 188 & 0.520 & & 0.010 & \\
\hline Egm 198 & 0.366 & & 0.005 & \\
\hline Egm 210 & & 0.101 & & 0.017 \\
\hline Egm 240 & & 0.169 & & 0.015 \\
\hline Egl 115 & 0.071 & & 0.0009 & \\
\hline Egl 172 & 0.108 & & 0.003 & \\
\hline Egl 180 & & 0.041 & & 0.048 \\
\hline Egl 198 & 0.287 & & 0.006 & \\
\hline Egl 200 & 0.344 & & 0.007 & \\
\hline Egl 200 & & 0.078 & & 0.017 \\
\hline Egl 220 & & 0.096 & & 0.016 \\
\hline Egl 238 & 0.189 & & 0.006 & \\
\hline Egl 250 & & 0.139 & & 0.015 \\
\hline
\end{tabular}


Rotação vs RMS sonda

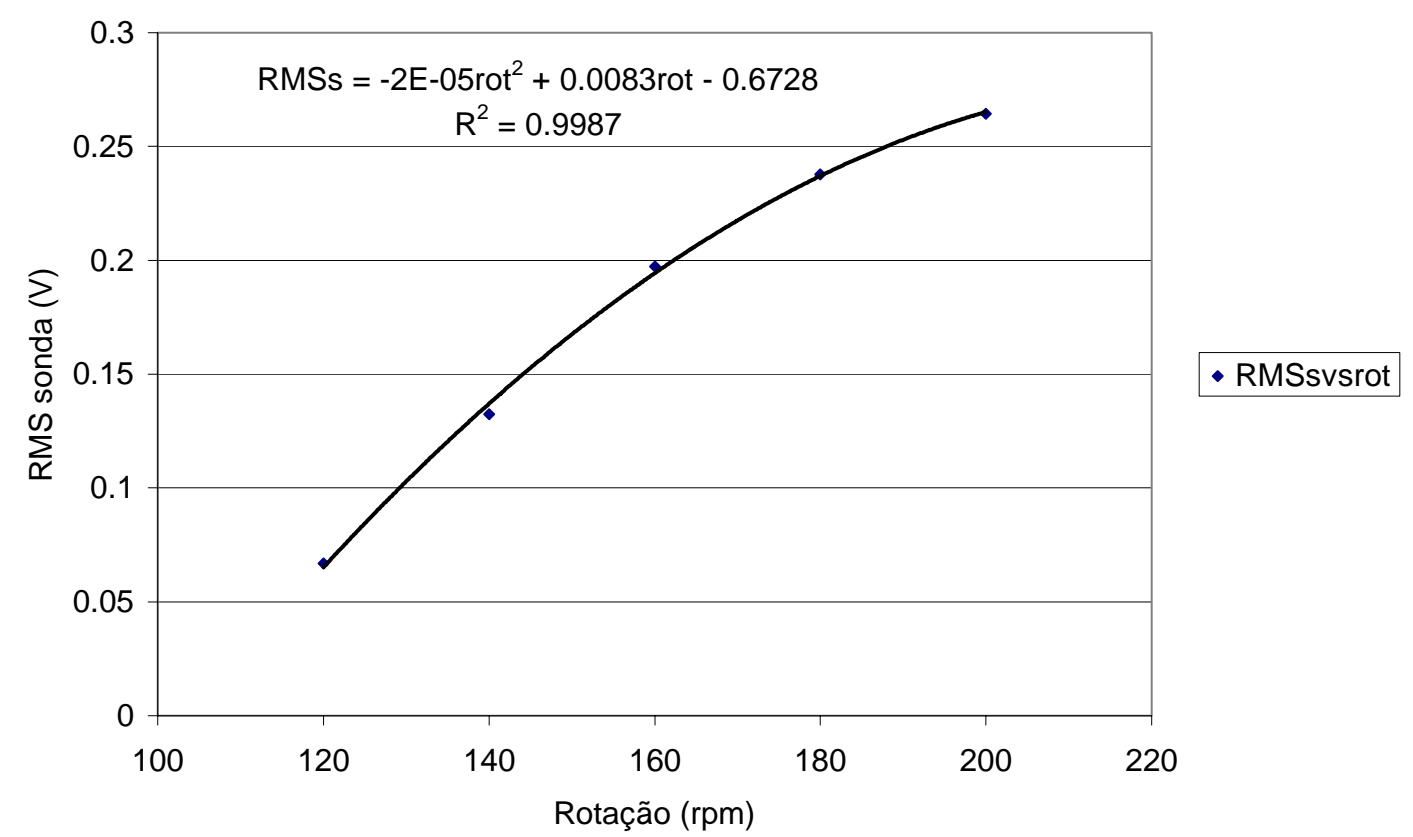

FIGURA 15: Melhor ajuste do valor de RMS sonda versus freqüência de oscilação da grade de $26,5 \mathrm{~mm}$ de abertura e barras com $10 \mathrm{~mm}$ de espessura

RMSs vs Rotação

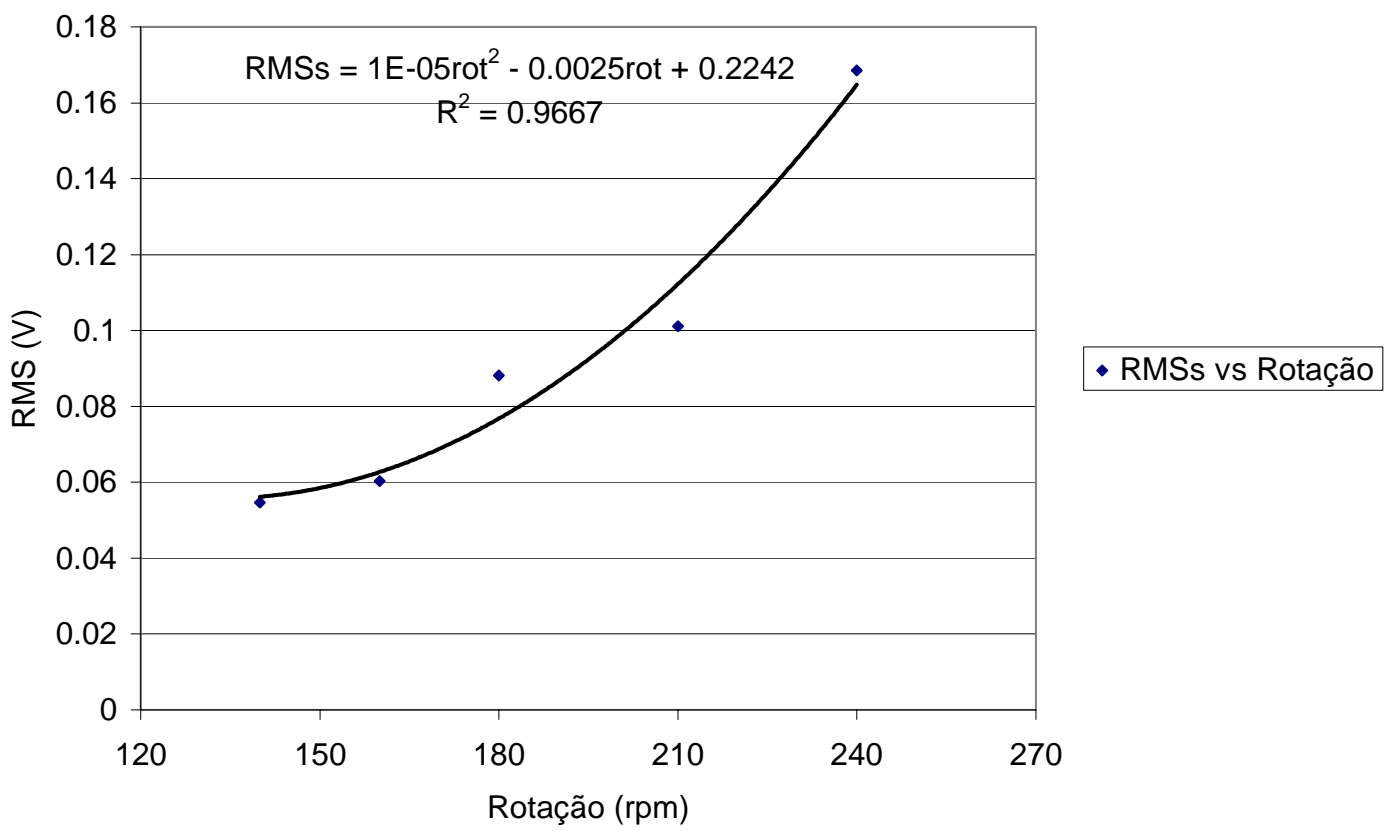

FIGURA 16: Melhor ajuste do valor de RMS sonda versus freqüência de oscilação da grade de 39,0 mm de abertura e barras com 10mm de espessura 
RMSs vs Rotação

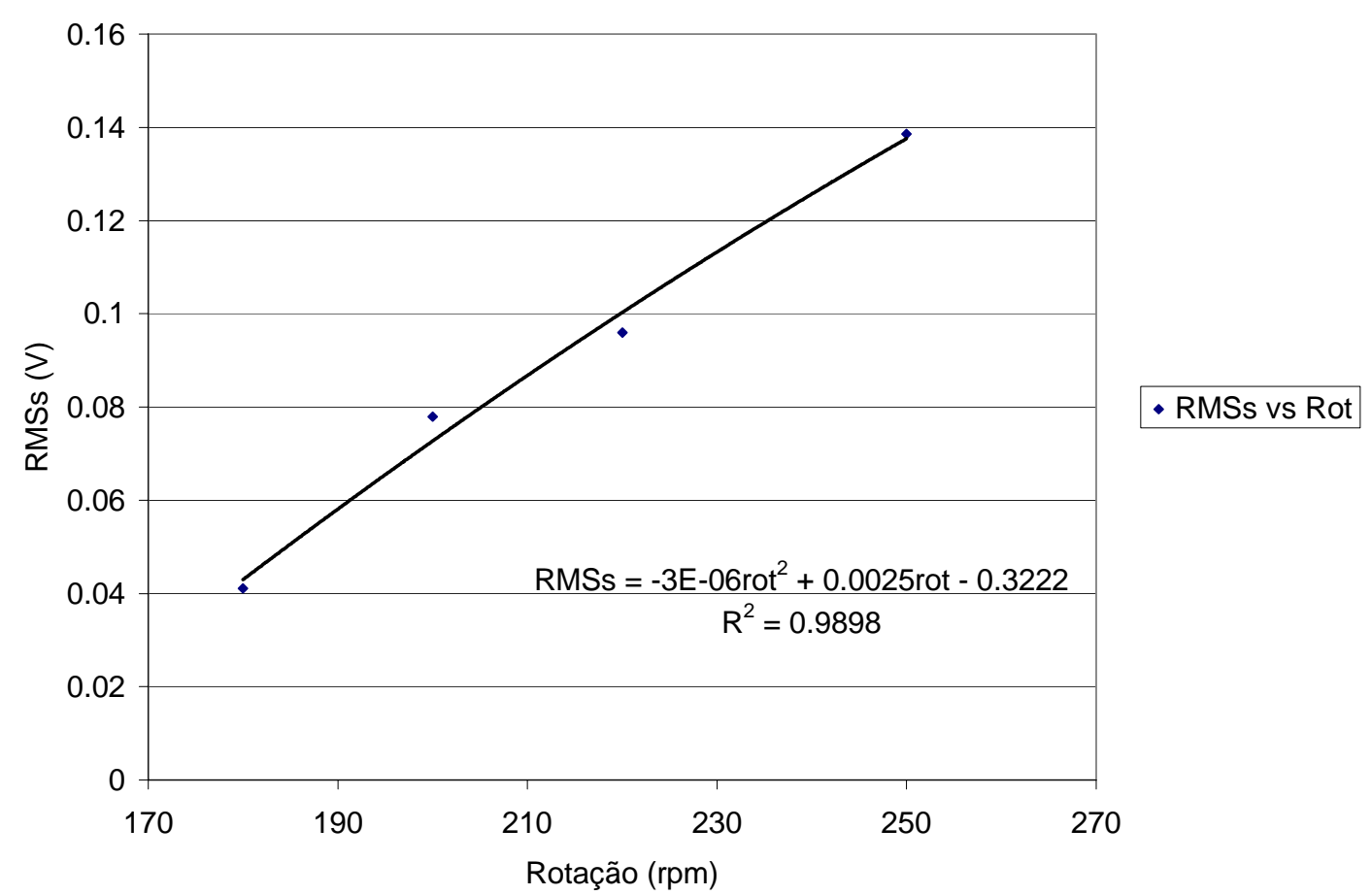

FIGURA 17: Melhor ajuste do valor de RMS sonda versus da freqüência de oscilação da grade de 64,5 mm de abertura e barras com $10 \mathrm{~mm}$ de espessura

\subsection{Resultados obtidos através do Método Fotográfico}

Em cada experimento, foi obtida uma fotografia de onde foram tirados o campo de velocidade e, após posterior análise, determinaram-se os parâmetros turbulentos. A região da superfície livre na qual foram conseguidas as imagens é a mesma região em que se localizou a sonda ótica na coleta dos dados por meio do método ótico.

A apresentação dos campos de velocidade encontrados nos ensaios será realizada de duas formas, sendo a primeira em gráficos espaciais, onde a velocidade é indicada no eixo vertical (z), e a segunda maneira é na forma de isolinhas, cujo intuito foi o de indicar os locais com mesma velocidade. 


\subsubsection{Velocidade Horizontal}

O campo de velocidade nas direções x (longitudinal) e y (transversal) é apresentado neste item. As FIGURAS 18 a 73 mostram os resultados para os 14 ensaios realizados, sendo as figuras de números pares as isolinhas dos gráficos espaciais.

Em muitos ensaios, observa-se um contraste entre regiões que apresentam velocidades mais suaves e locais onde há forte variação de velocidade, como é o caso dos ensaios egf120; egf160; egf180; egm140; egm180; egm240 e egl220. Também são identificadas regiões de máxima e mínima velocidades, como se pode observar no egf200; egl250.

Alguns ensaios apresentaram regiões com alta velocidade, como ocorreu em egl180 e egl200 e, em egf140, houve uma grande região com baixa velocidade. Verificou-se, por exemplo, que no ensaio da grade média, rotação de 160 rpm (egm160), $x=200 \mathrm{~mm}$, existem duas ou três regiões com alta velocidade (picos), contrastando com locais de baixa velocidade; note-se que isso ocorre em todas as figuras.

Nas fotografias existem regiões com poucas informações, e o resultado após a interpolação desses locais apresenta-se muito suave, como pode ser observado, por exemplo, na FIGURA 20.

Faz-se interessante observar as FIGURAS 34 e $\mathbf{6 2}$ onde existe o contraste entre uma região com alta velocidade, uma região de baixa velocidade e outra região com velocidade aproximadamente constante. 


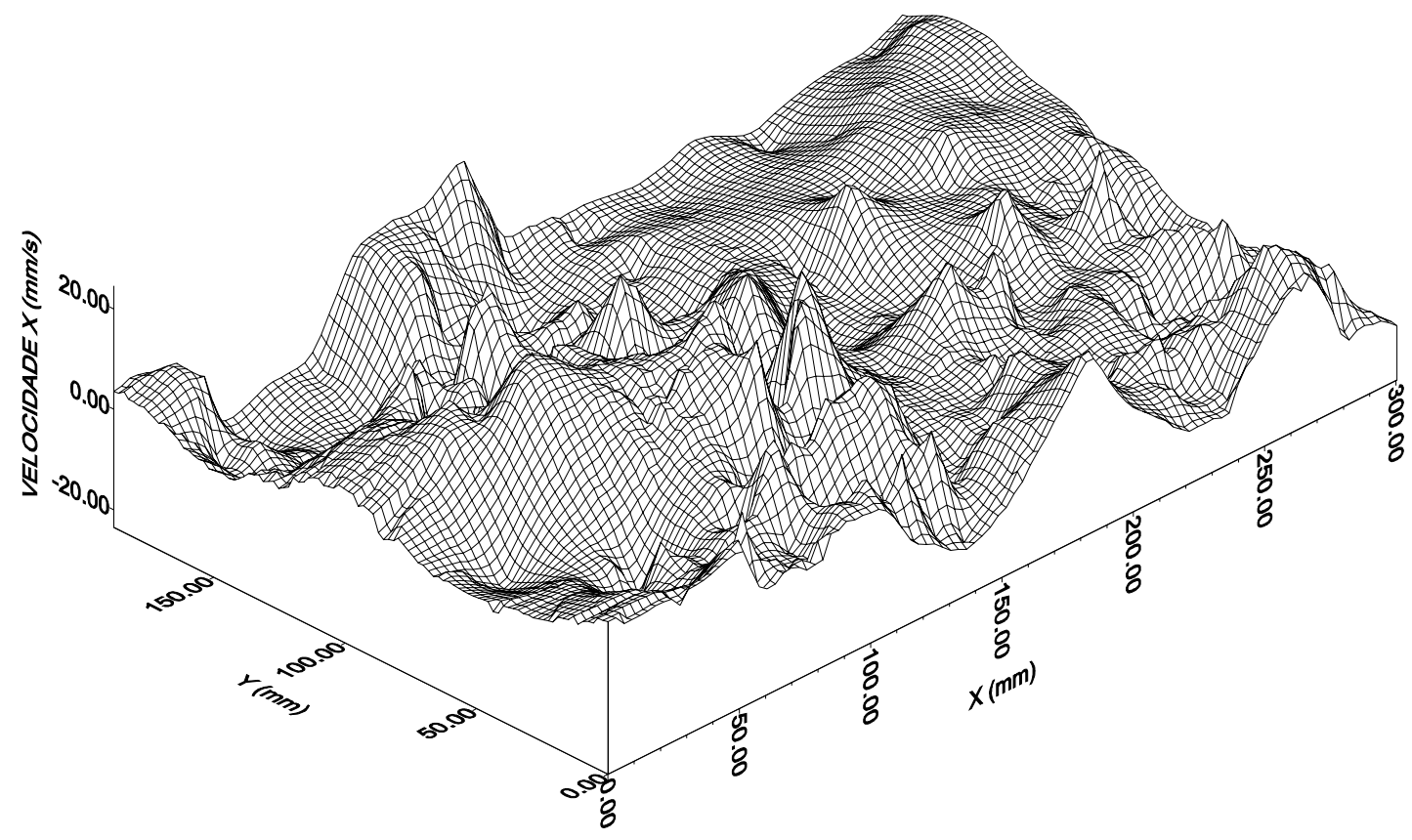

FIGURA 18. Visualização da Componente da Velocidade Horizontal na direção X com a grade de malha quadrada de espaçamento entre barras de $2,65 \mathrm{~cm}$ e rotação de $120 \mathrm{rpm}$

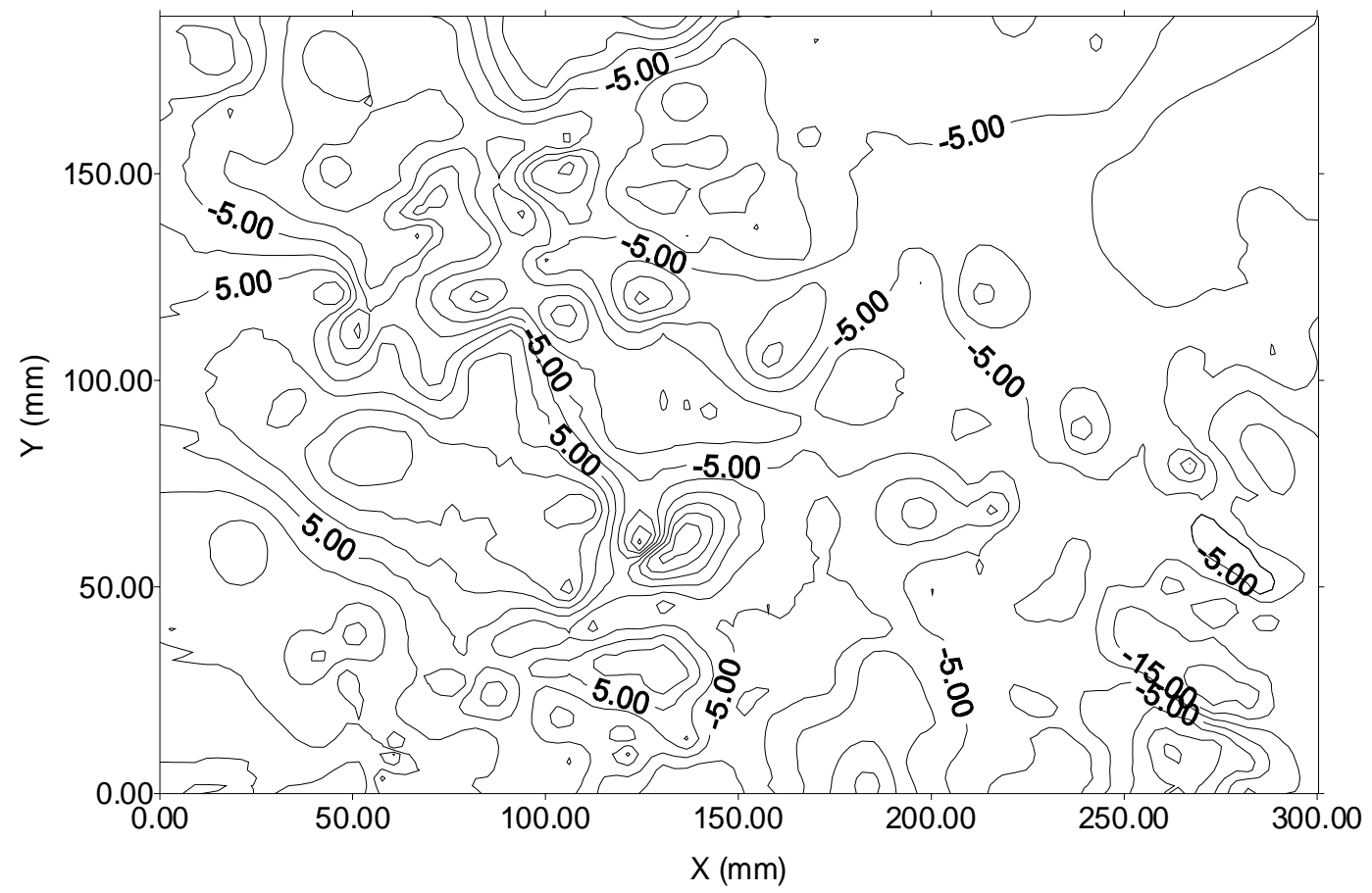

FIGURA 19. Visualização das Isolinhas da Componente da Velocidade Horizontal na direção X com a grade de malha quadrada de espaçamento entre barras de 2,65 cm e rotação de 120 rpm 


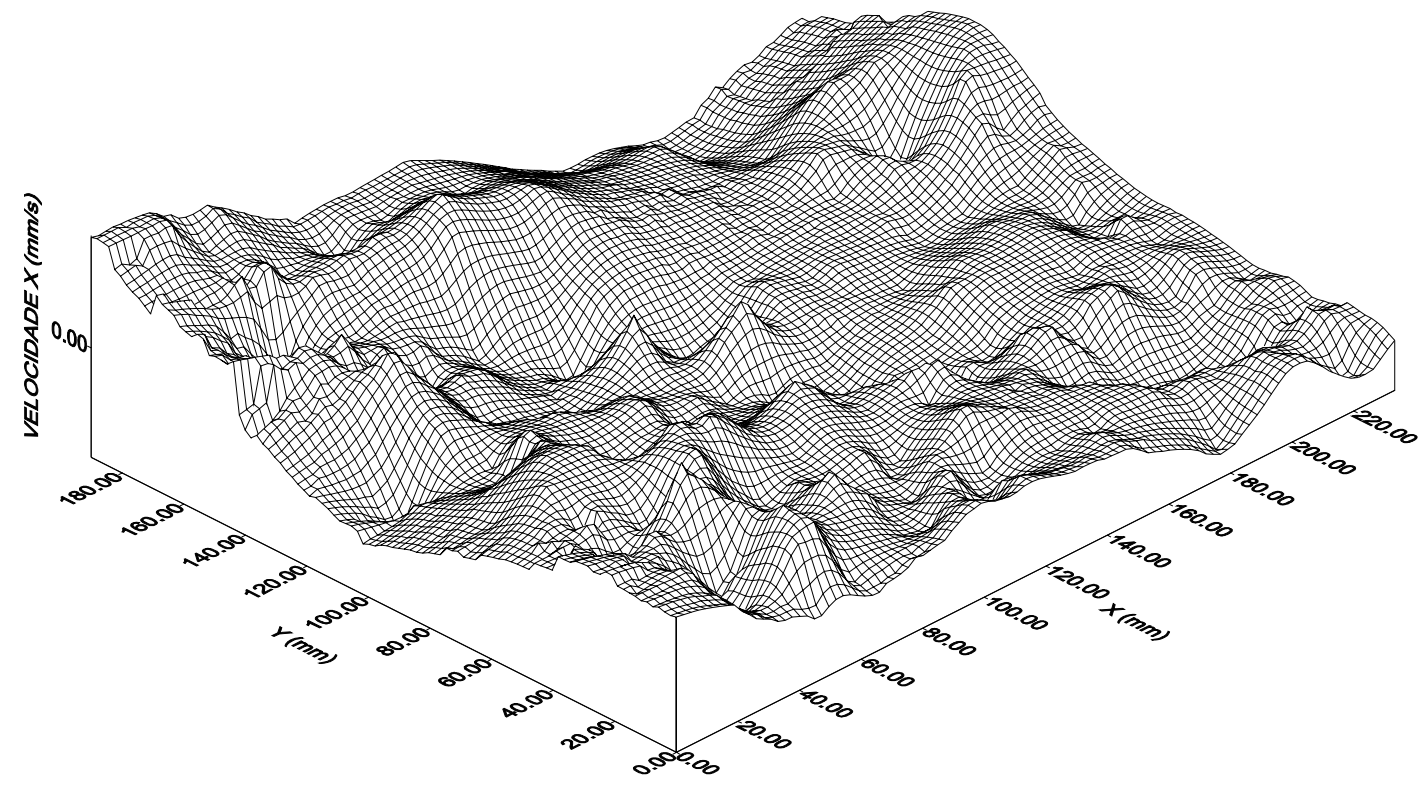

FIGURA 20. Visualização da Componente da Velocidade Horizontal na direção X com a grade de malha quadrada de espaçamento entre barras de $2,65 \mathrm{~cm}$ e rotação de $140 \mathrm{rpm}$

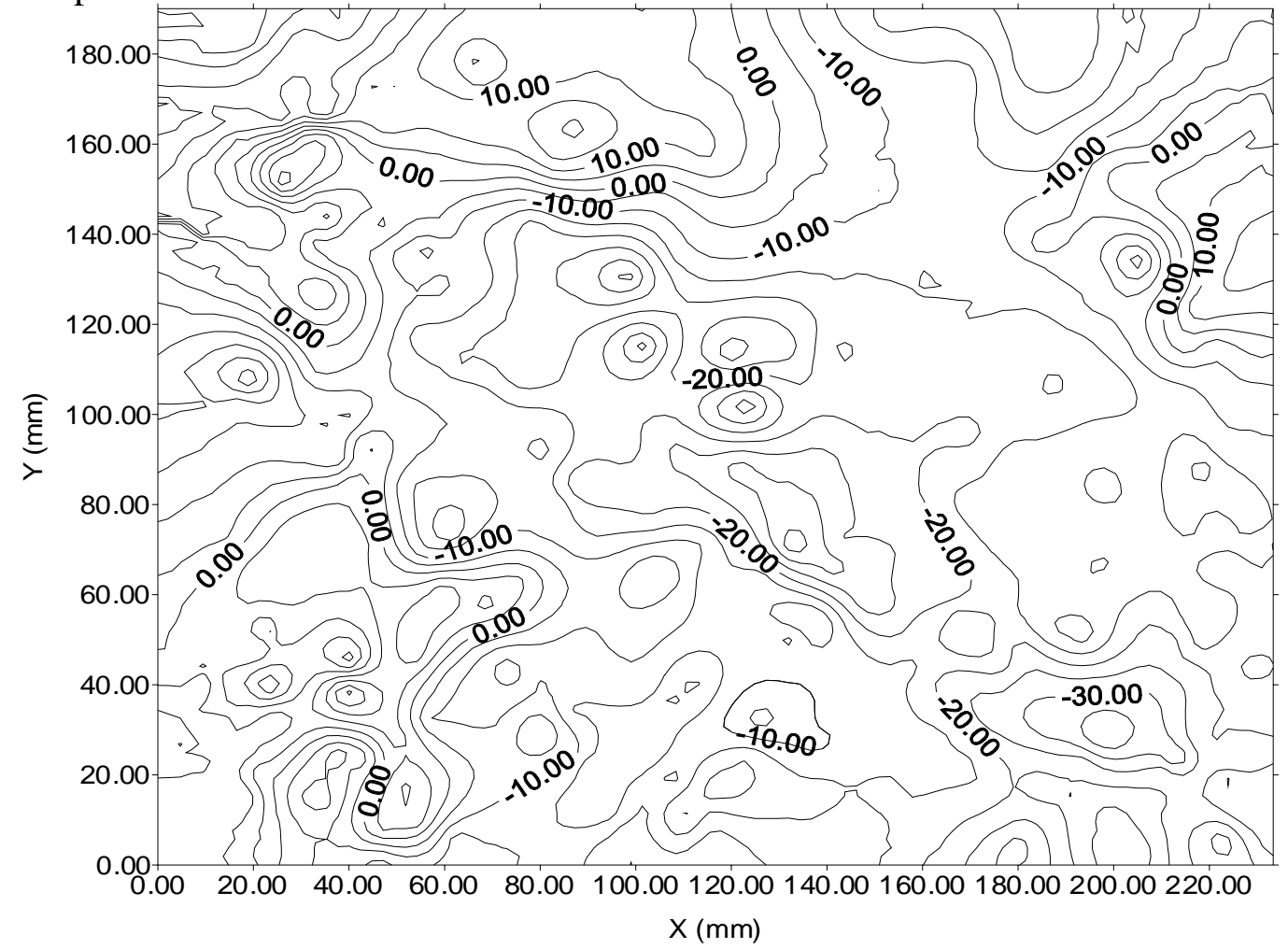

FIGURA 21. Visualização das Isolinhas da Componente da Velocidade Horizontal na direção X com a grade de malha quadrada de espaçamento entre barras de 2,65 cm e rotação de 140 rpm 


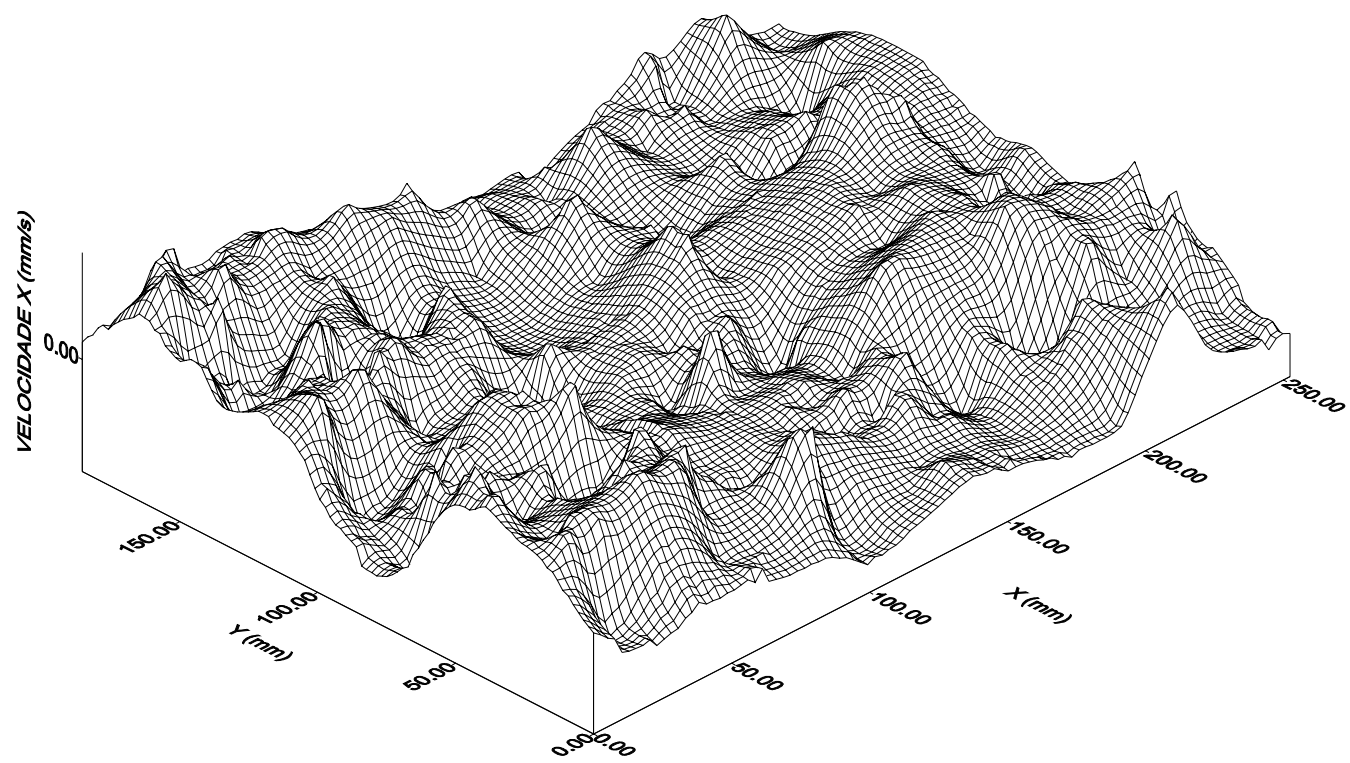

FIGURA 22. Visualização da Componente da Velocidade Horizontal na direção X com a grade de malha quadrada de espaçamento entre barras de $2,65 \mathrm{~cm}$ e rotação de $160 \mathrm{rpm}$

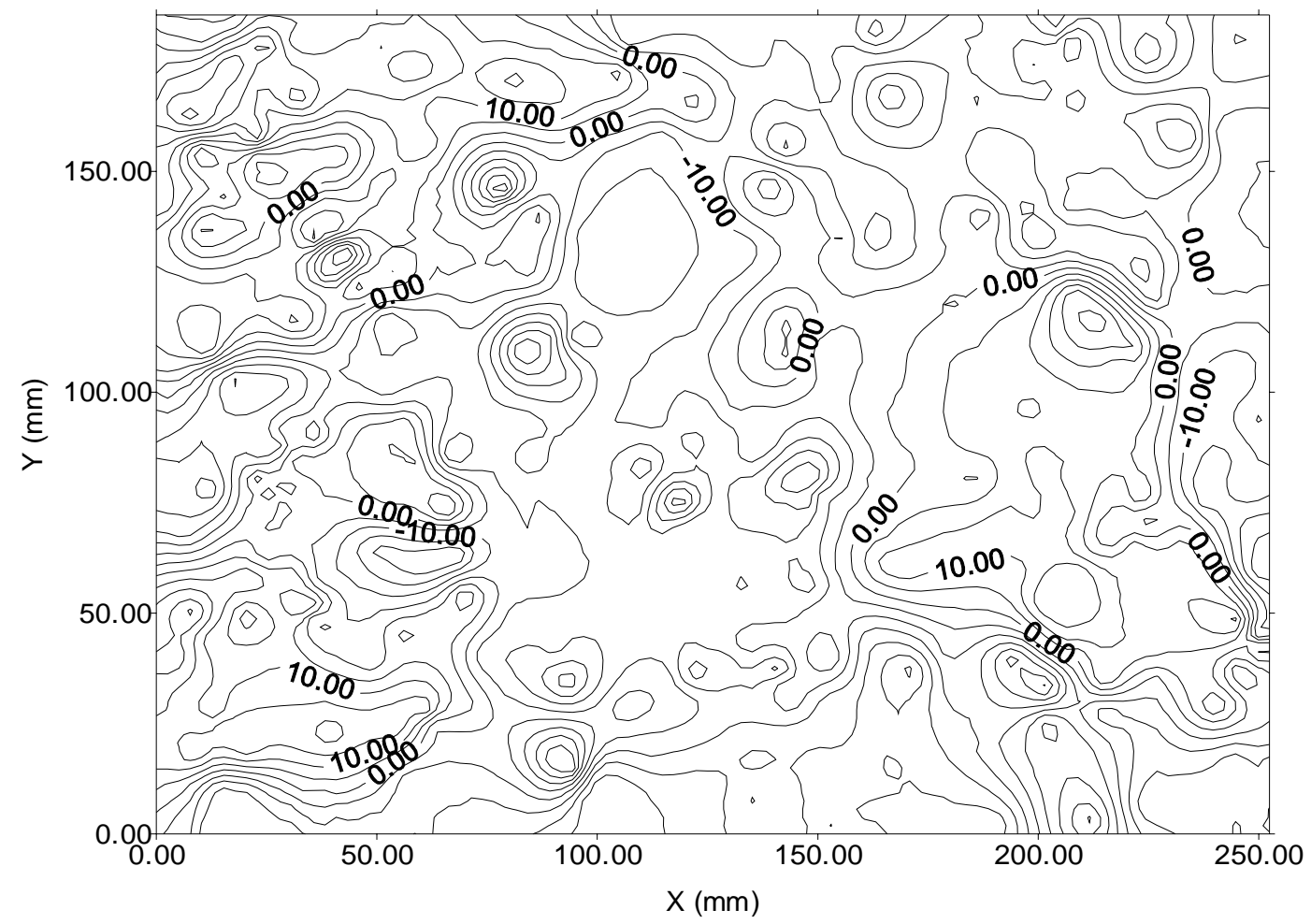

FIGURA 23. Visualização das Isolinhas da Componente da Velocidade Horizontal na direção X com a grade de malha quadrada de espaçamento entre barras de 2,65 cm e rotação de 160 rpm 


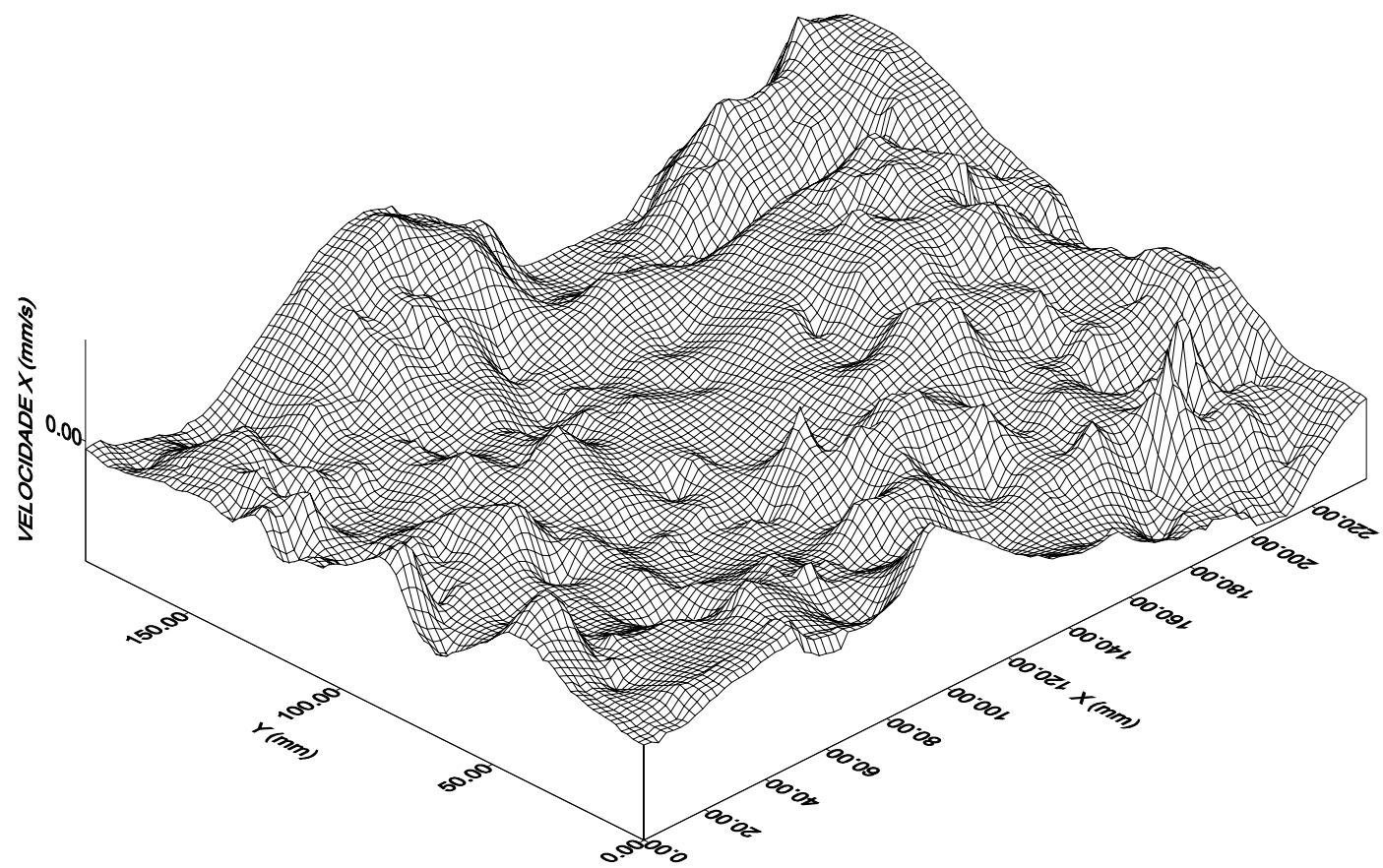

FIGURA 24. Visualização da Componente da Velocidade Horizontal na direção X com a grade de malha quadrada de espaçamento entre barras de 2,65 cm e rotação de $180 \mathrm{rpm}$

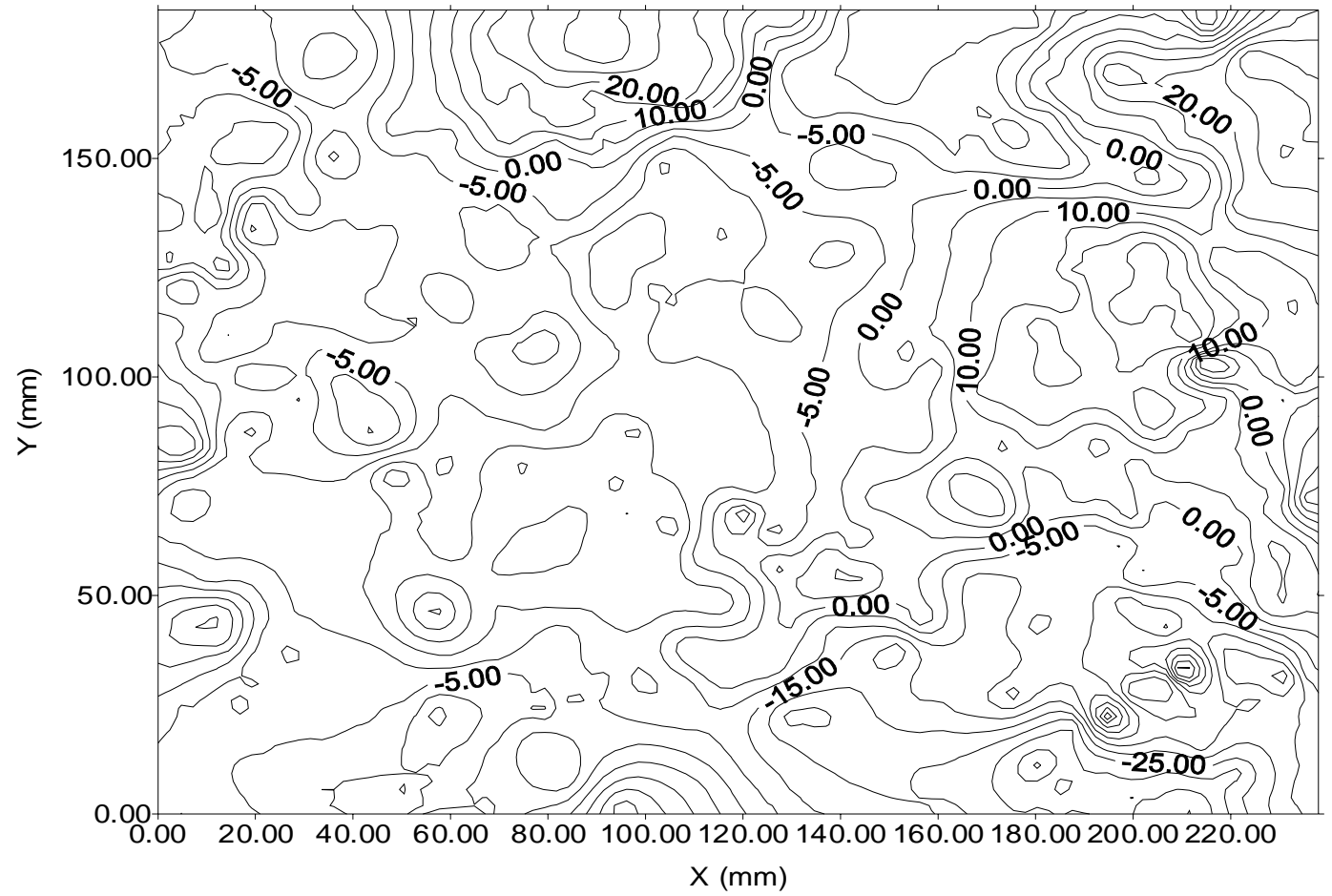

FIGURA 25. Visualização das Isolinhas da Componente da Velocidade Horizontal na direção $X$ com a grade de malha quadrada de espaçamento entre barras de 2,65 cm e rotação de 180 rpm. 


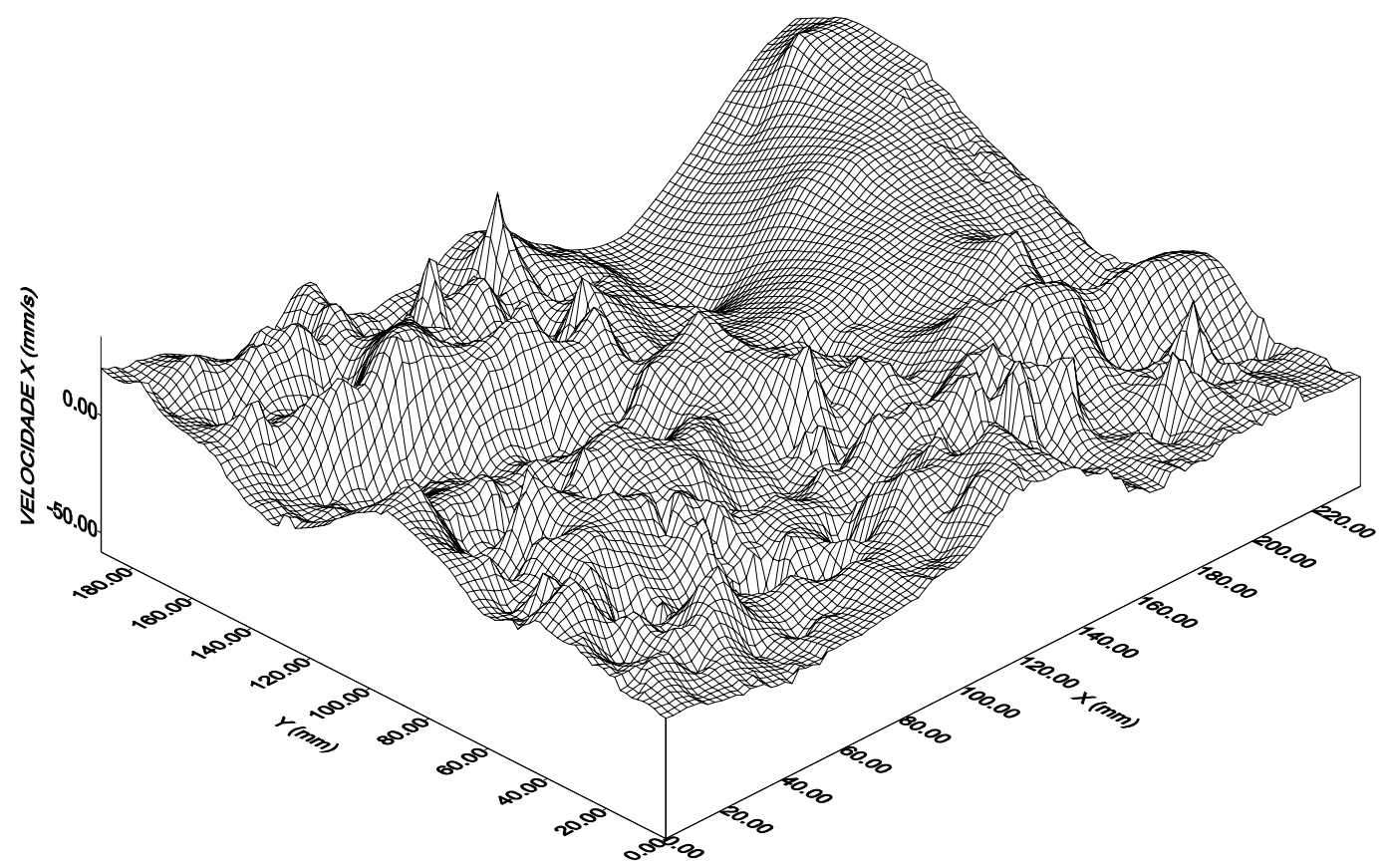

FIGURA 26. Visualização da Componente da Velocidade Horizontal na direção X com a grade de malha quadrada de espaçamento entre barras de $2,65 \mathrm{~cm}$ e rotação de $200 \mathrm{rpm}$

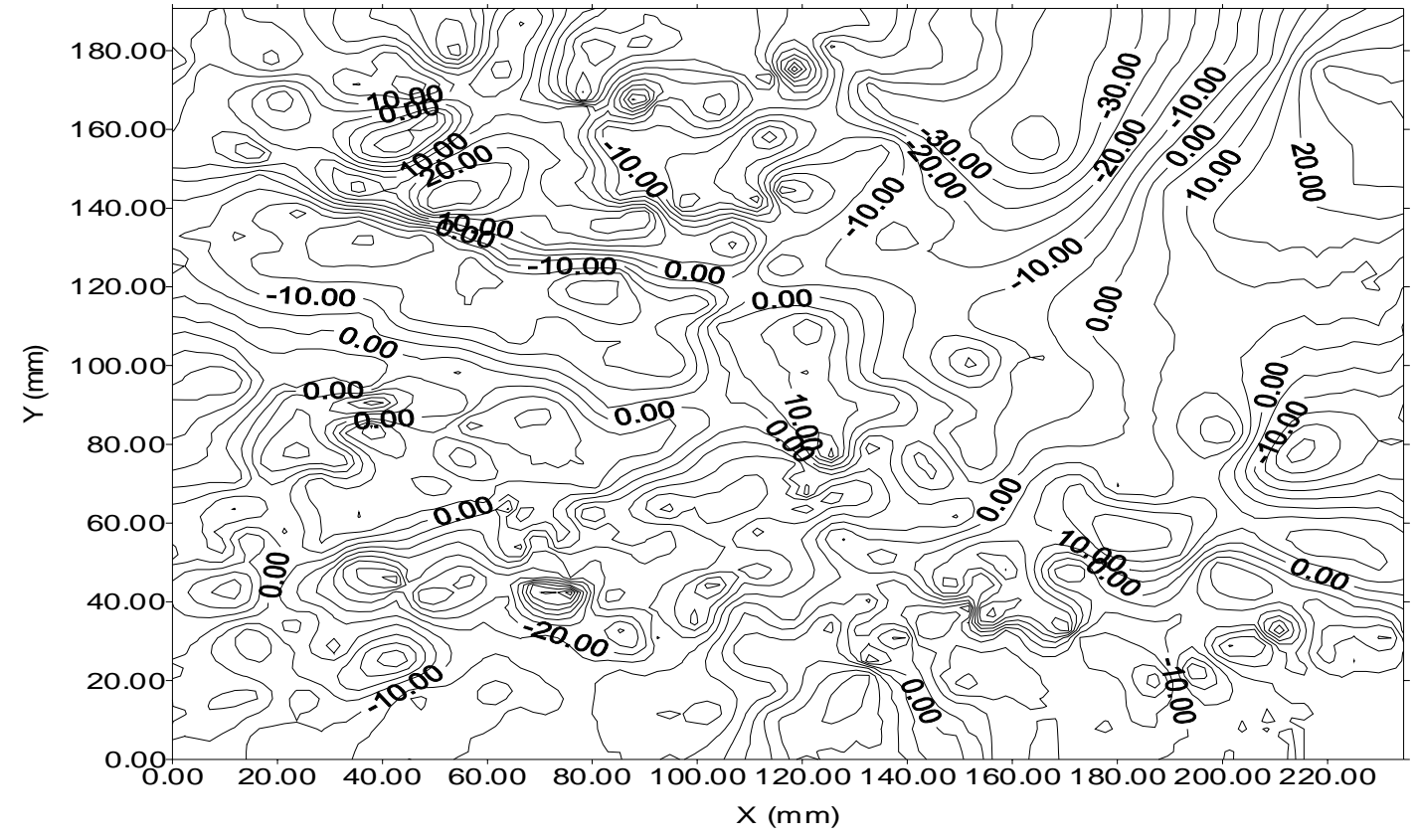

FIGURA 27. Visualização das Isolinhas da Componente da Velocidade Horizontal na direção $\mathrm{X}$ com a grade de malha quadrada de espaçamento entre barras de 2,65 cm e rotação de 200 rpm 


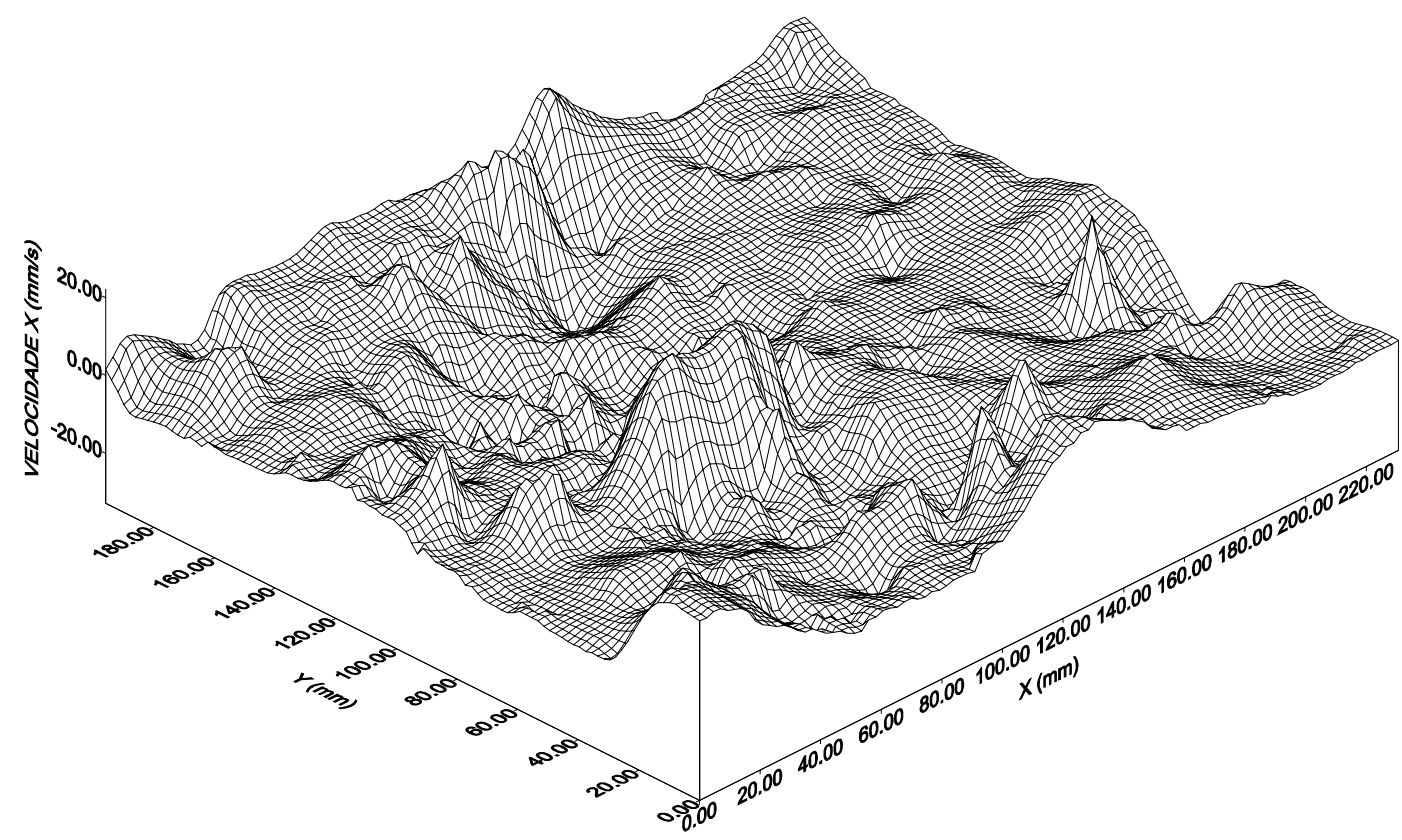

FIGURA 28. Visualização da Componente da Velocidade Horizontal na direção X com a grade de malha quadrada de espaçamento entre barras de $3,90 \mathrm{~cm}$ e rotação de $140 \mathrm{rpm}$.

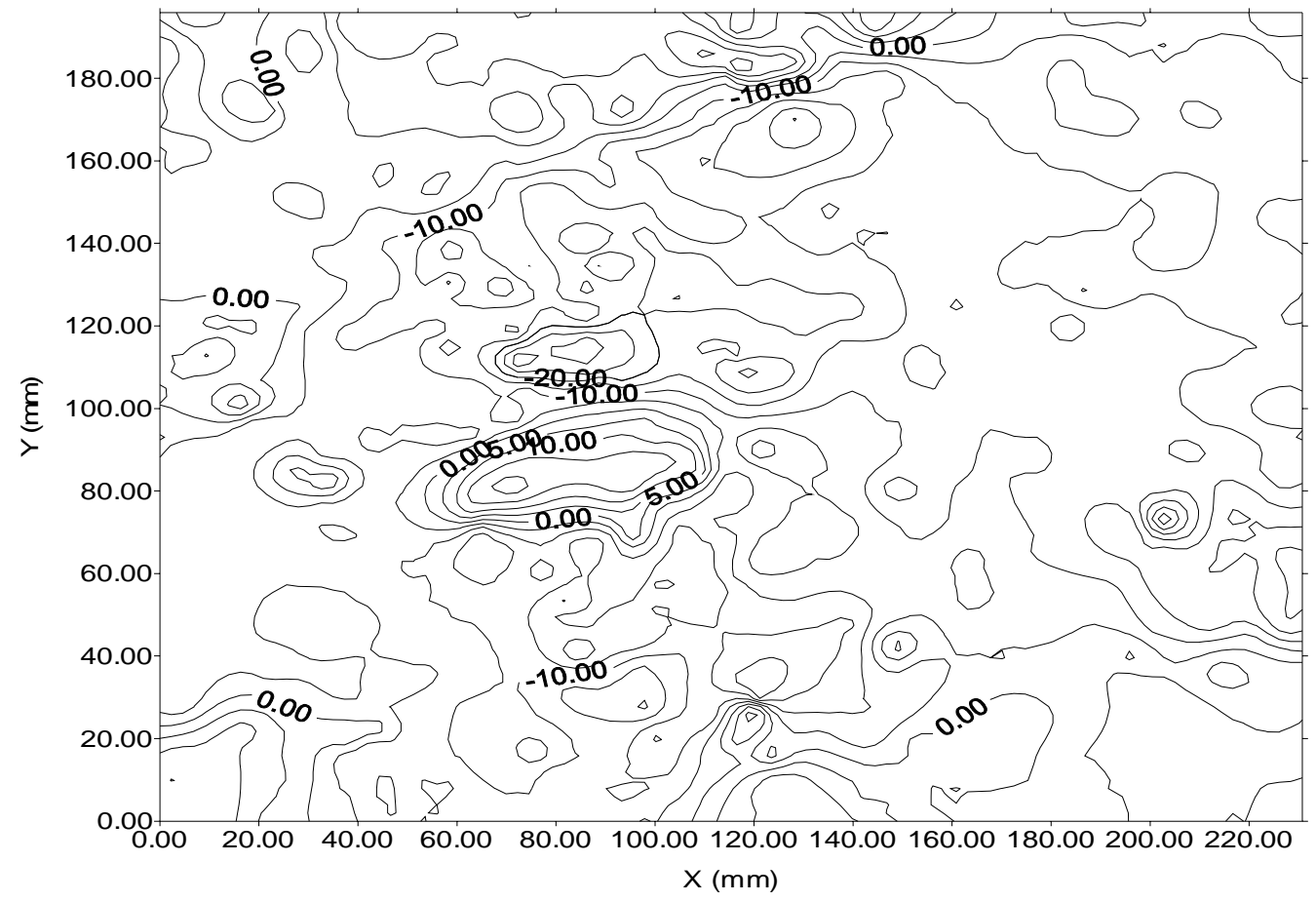

FIGURA 29. Visualização das Isolinhas da Componente da Velocidade Horizontal na direção X com a grade de malha quadrada de espaçamento entre barras de 3,90 cm e rotação de 140 rpm 


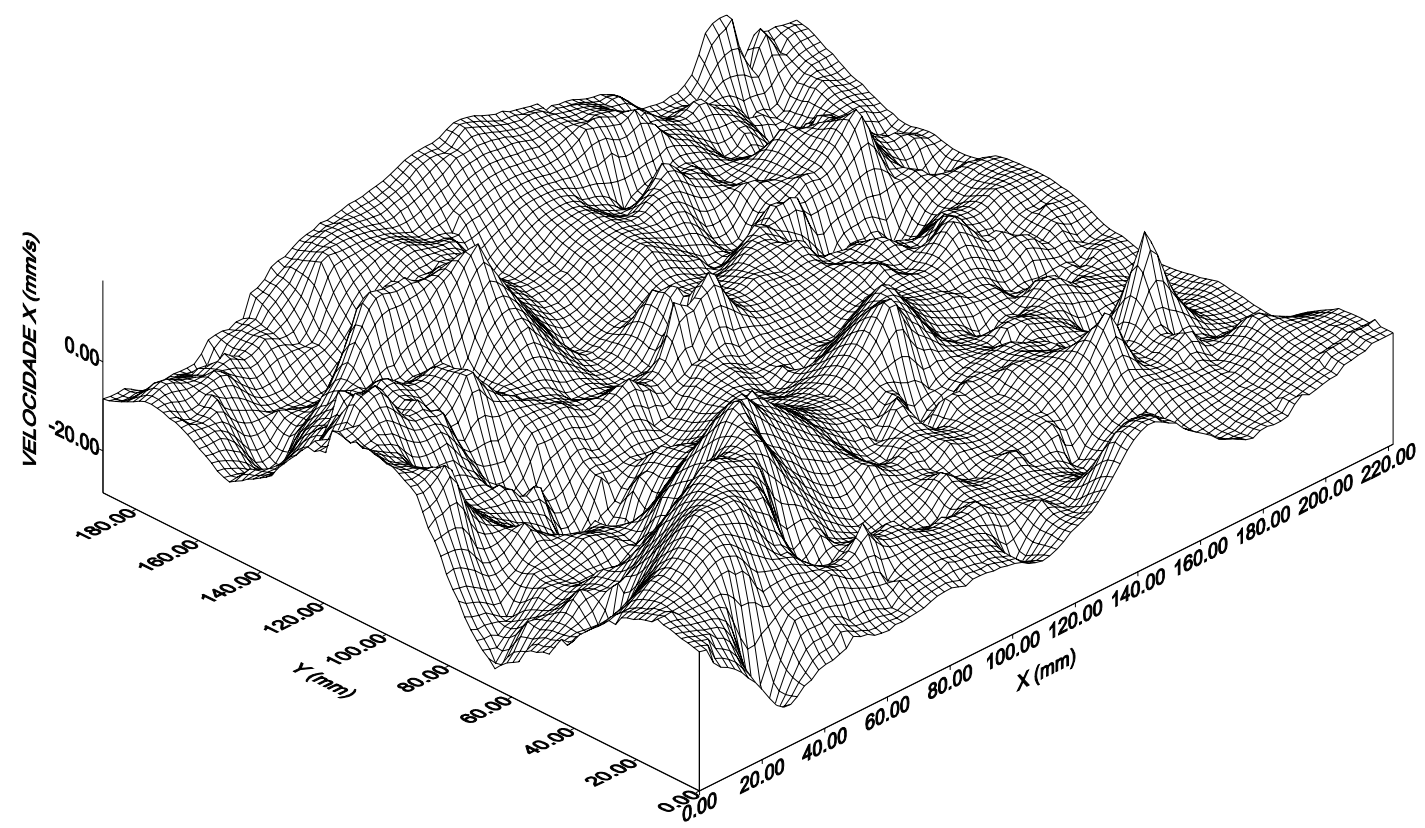

FIGURA 30. Visualização da Componente da Velocidade Horizontal na direção X com a grade de malha quadrada de espaçamento entre barras de $3,90 \mathrm{~cm}$ e rotação de $160 \mathrm{rpm}$

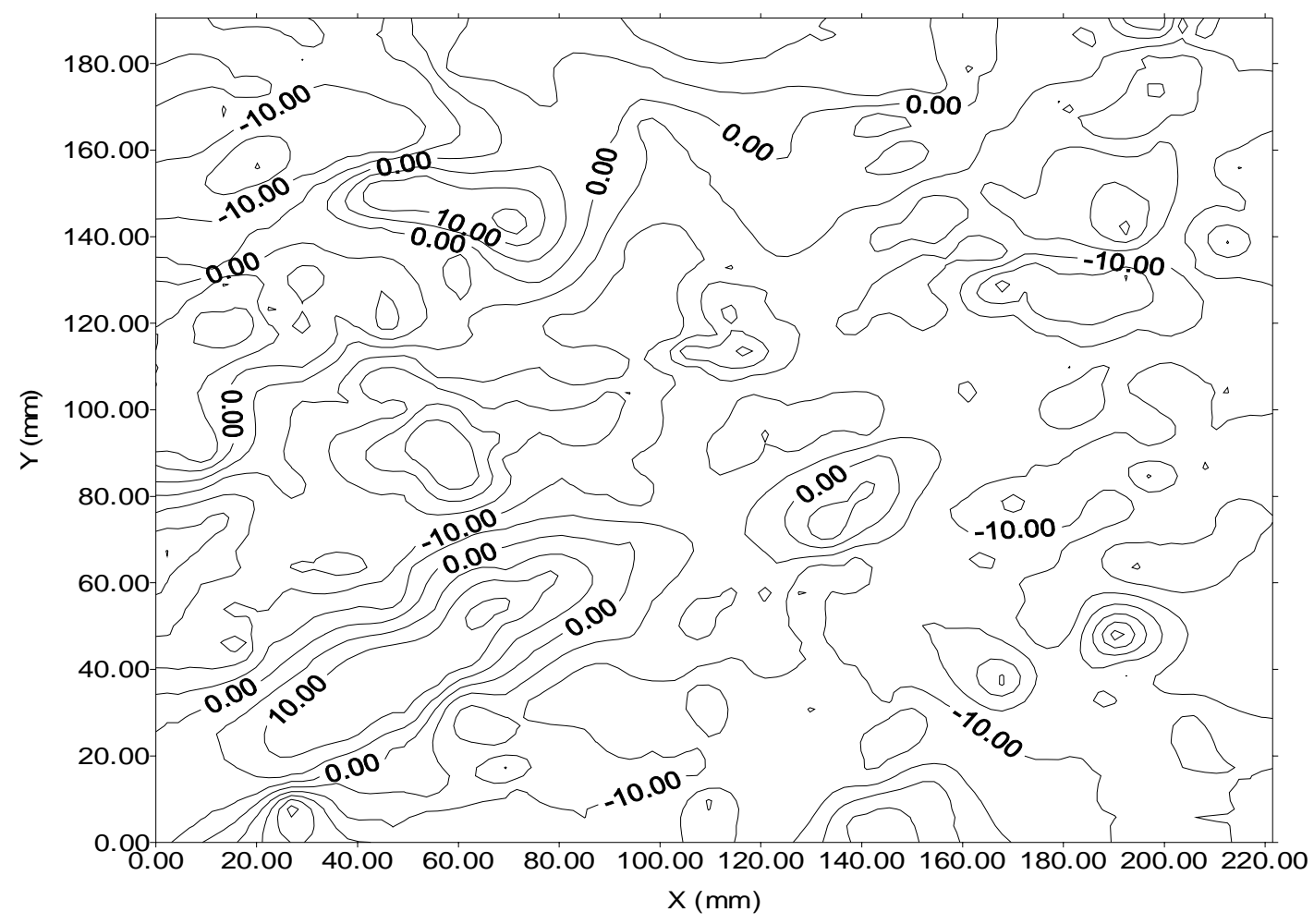

FIGURA 31. Visualização das Isolinhas da Componente da Velocidade Horizontal na direção X com a grade de malha quadrada de espaçamento entre barras de 3,90 cm e rotação de 160 rpm 


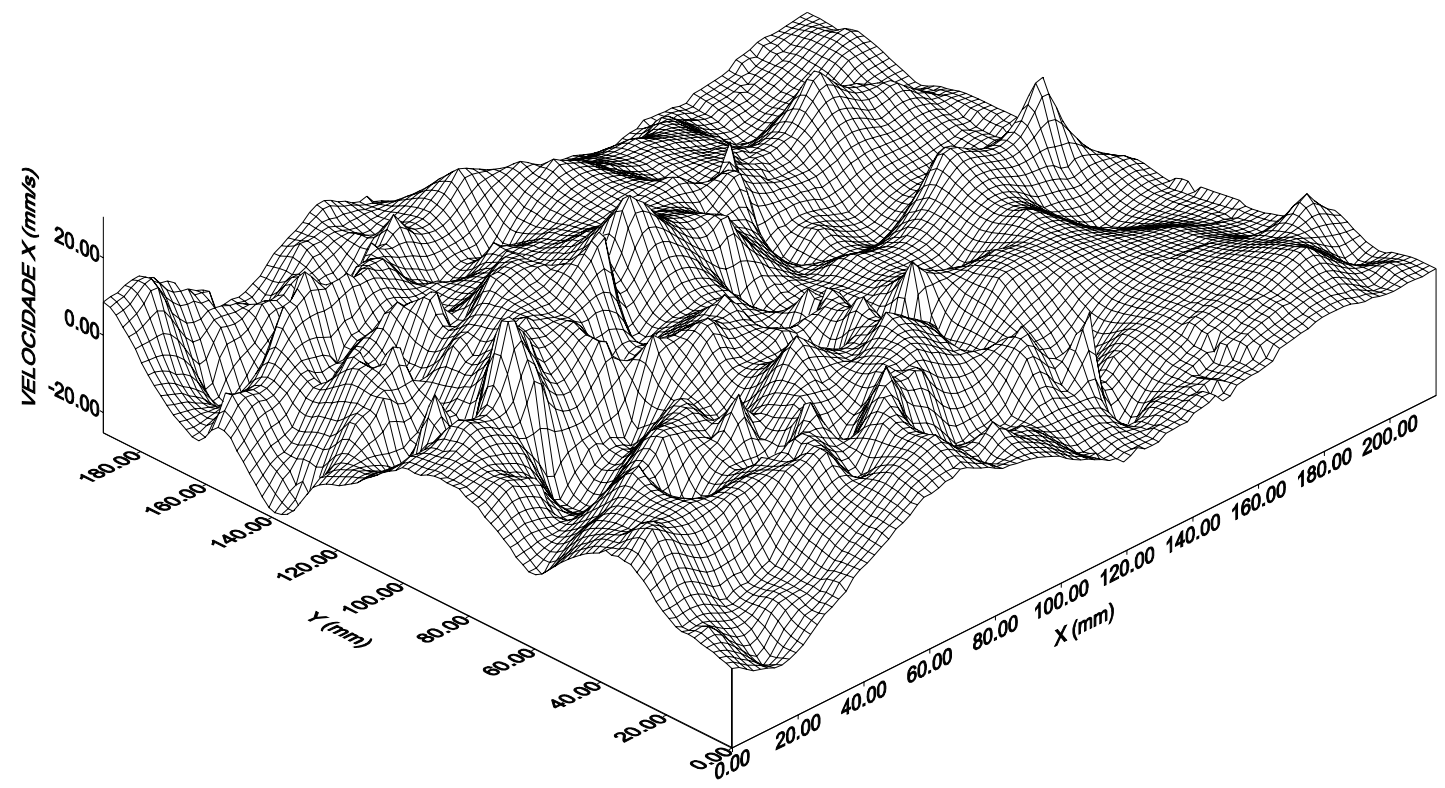

FIGURA 32. Visualização da Componente da Velocidade Horizontal na direção X com a grade de malha quadrada de espaçamento entre barras de $3,90 \mathrm{~cm}$ e rotação de $180 \mathrm{rpm}$

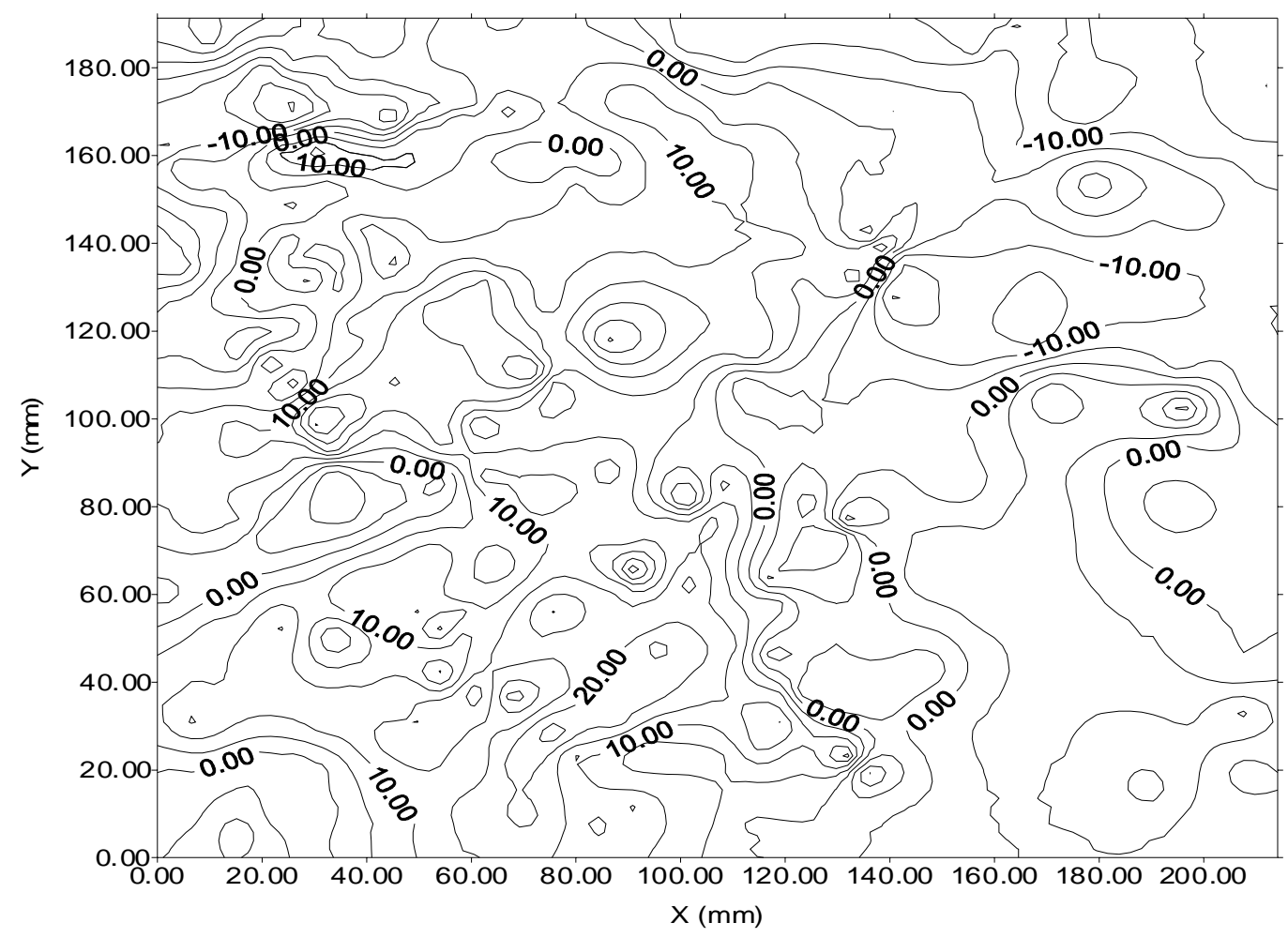

FIGURA 33. Visualização das Isolinhas da Componente da Velocidade Horizontal na direção X com a grade de malha quadrada de espaçamento entre barras de 3,90 cm e rotação de 180 rpm 


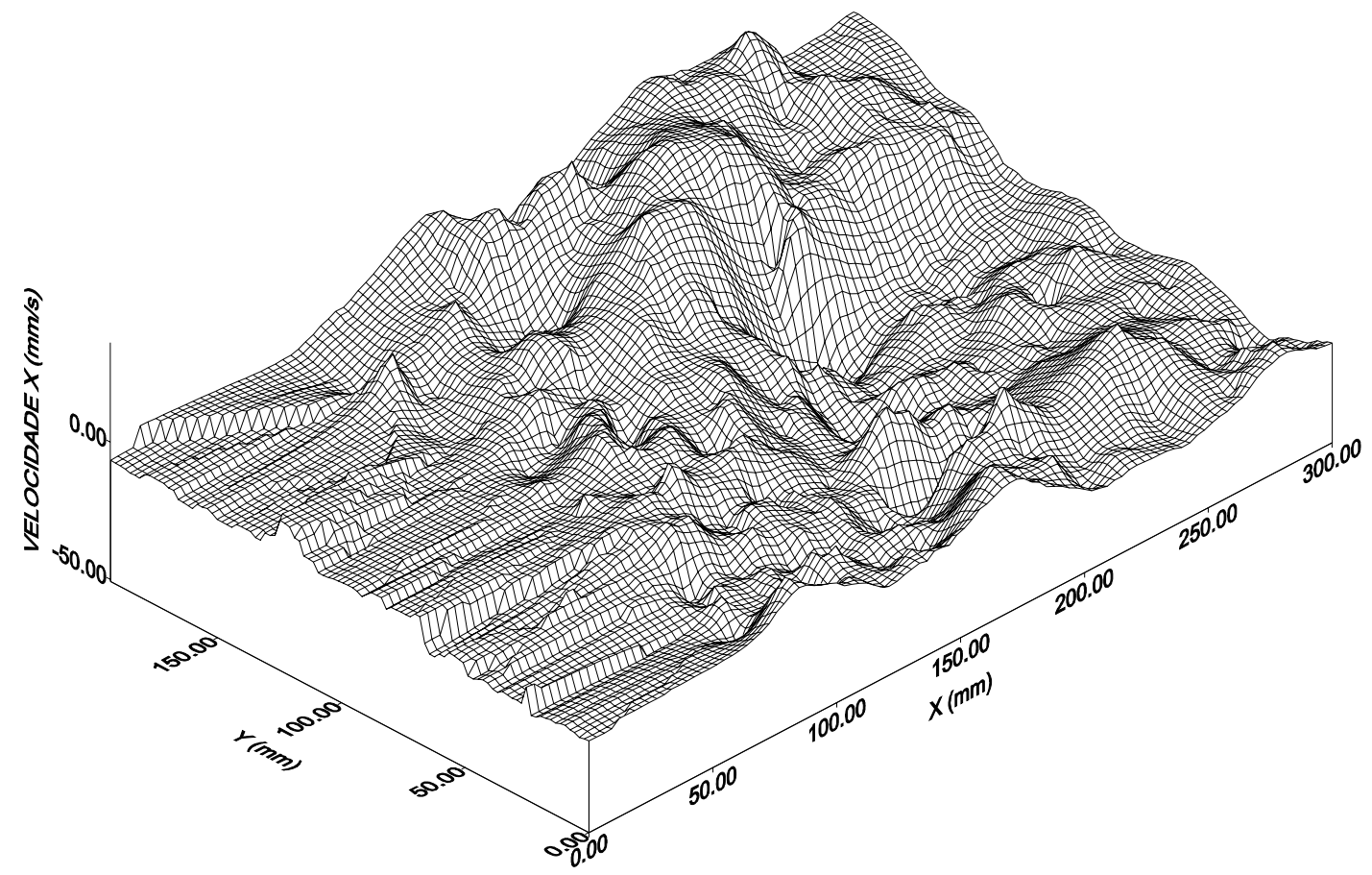

FIGURA 34. Visualização da Componente da Velocidade Horizontal na direção X com a grade de malha quadrada de espaçamento entre barras de $3,90 \mathrm{~cm}$ e rotação de $210 \mathrm{rpm}$

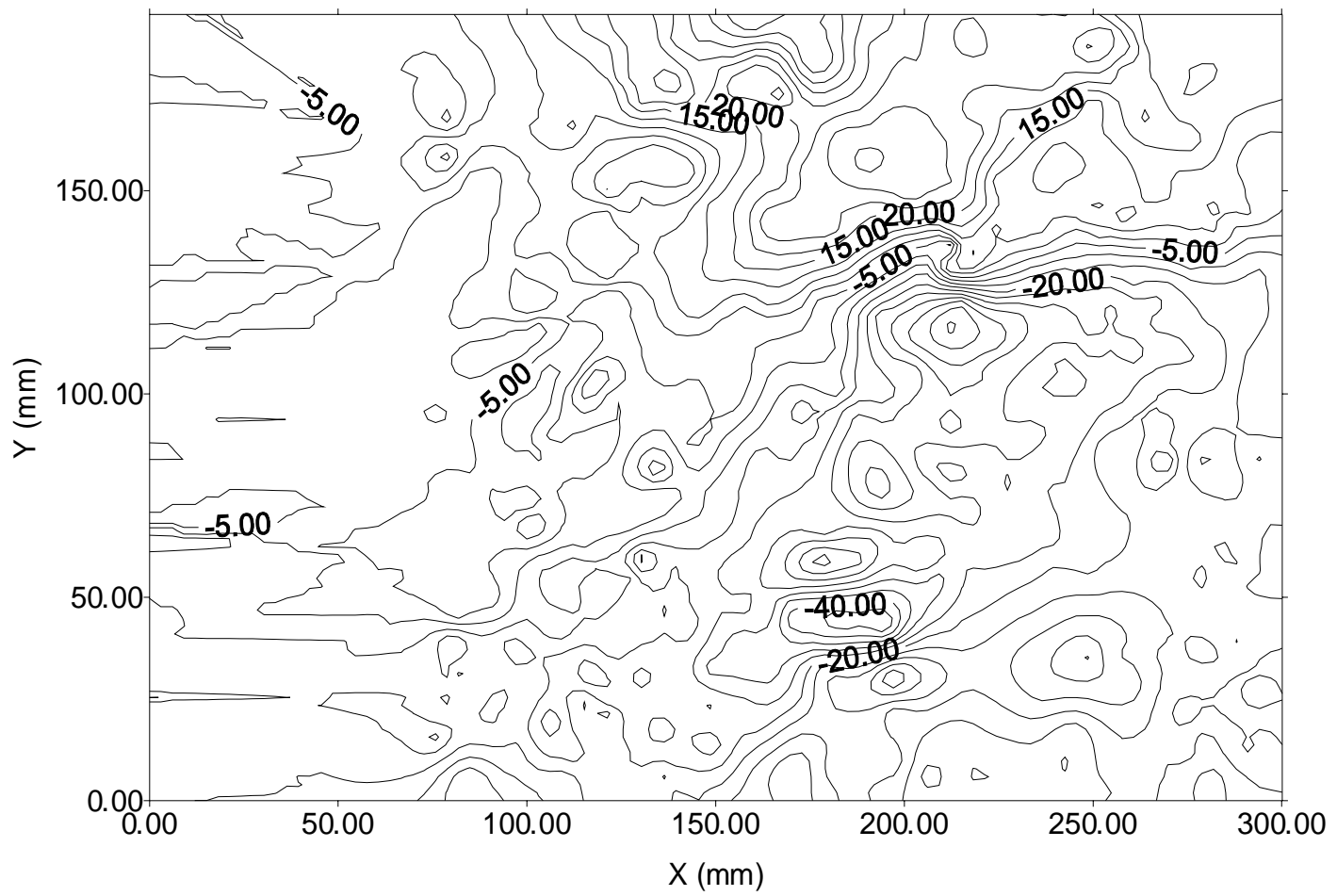

FIGURA 35. Visualização das Isolinhas da Componente da Velocidade Horizontal na direção X com a grade de malha quadrada de espaçamento entre barras de 3,90 cm e rotação de 210 rpm 


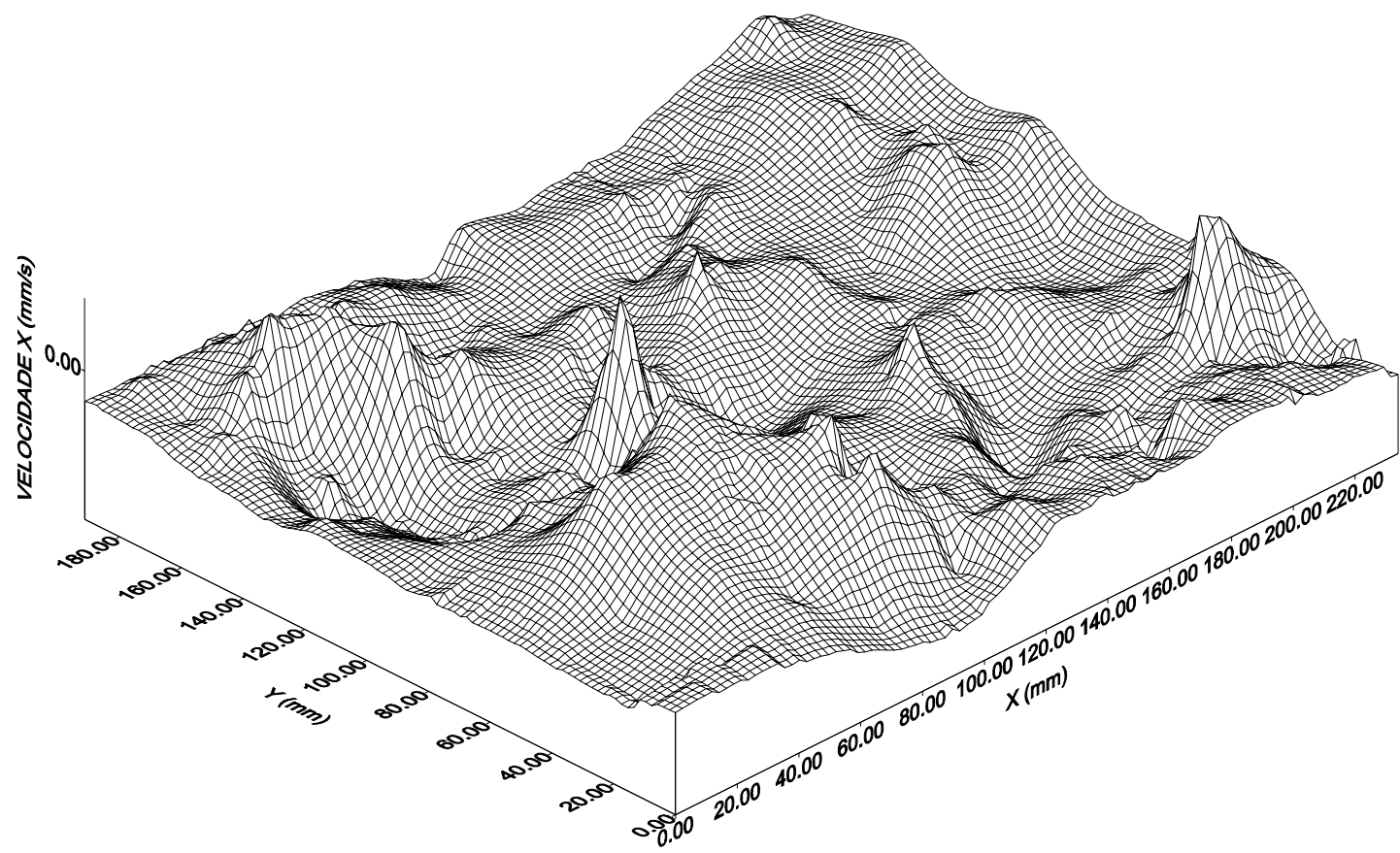

FIGURA 36. Visualização da Componente da Velocidade Horizontal na direção X com a grade de malha quadrada de espaçamento entre barras de $3,90 \mathrm{~cm}$ e rotação de $240 \mathrm{rpm}$

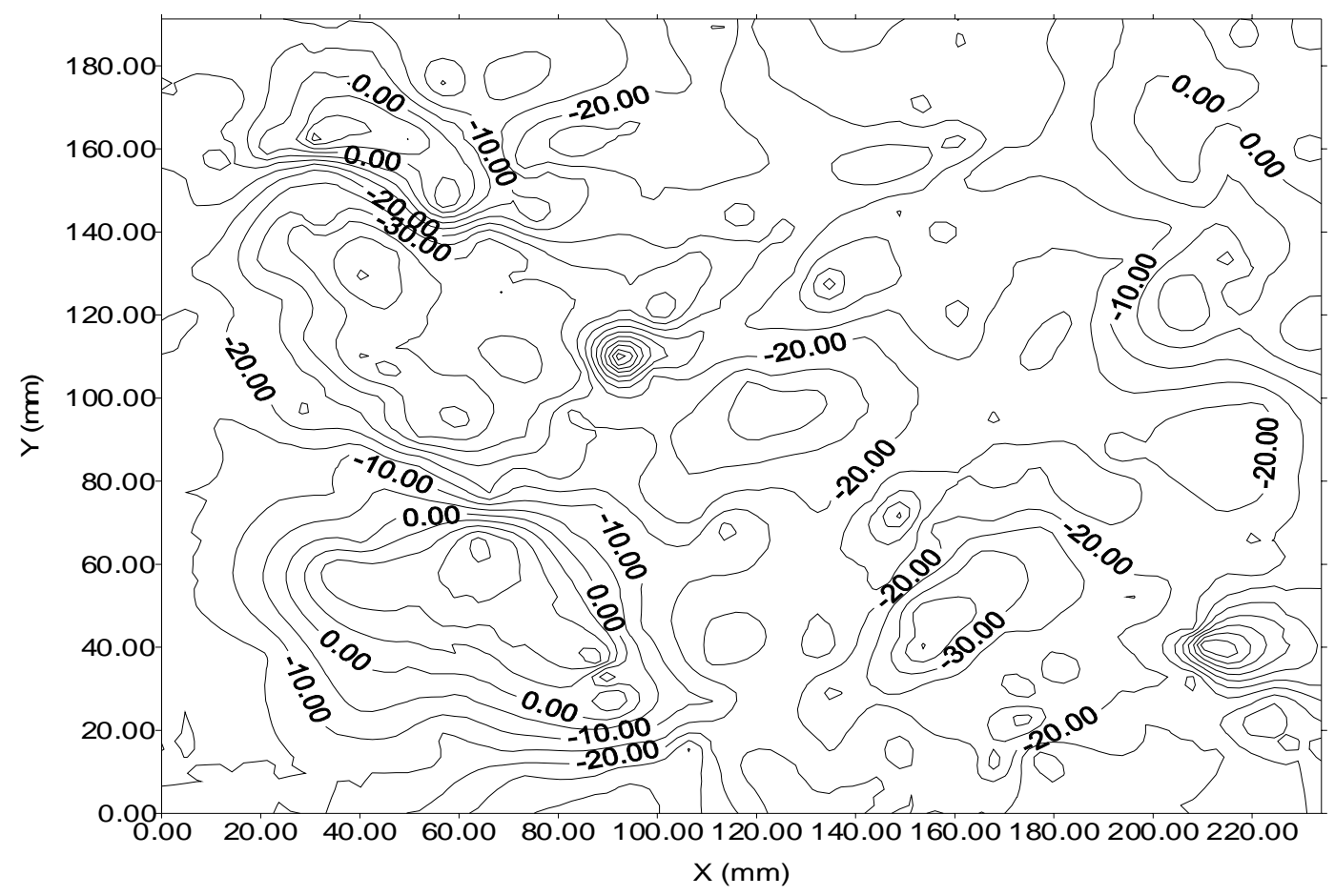

FIGURA 37. Visualização das Isolinhas da Componente da Velocidade Horizontal na direção X com a grade de malha quadrada de espaçamento entre barras de 3,90 cm e rotação de 240 rpm 


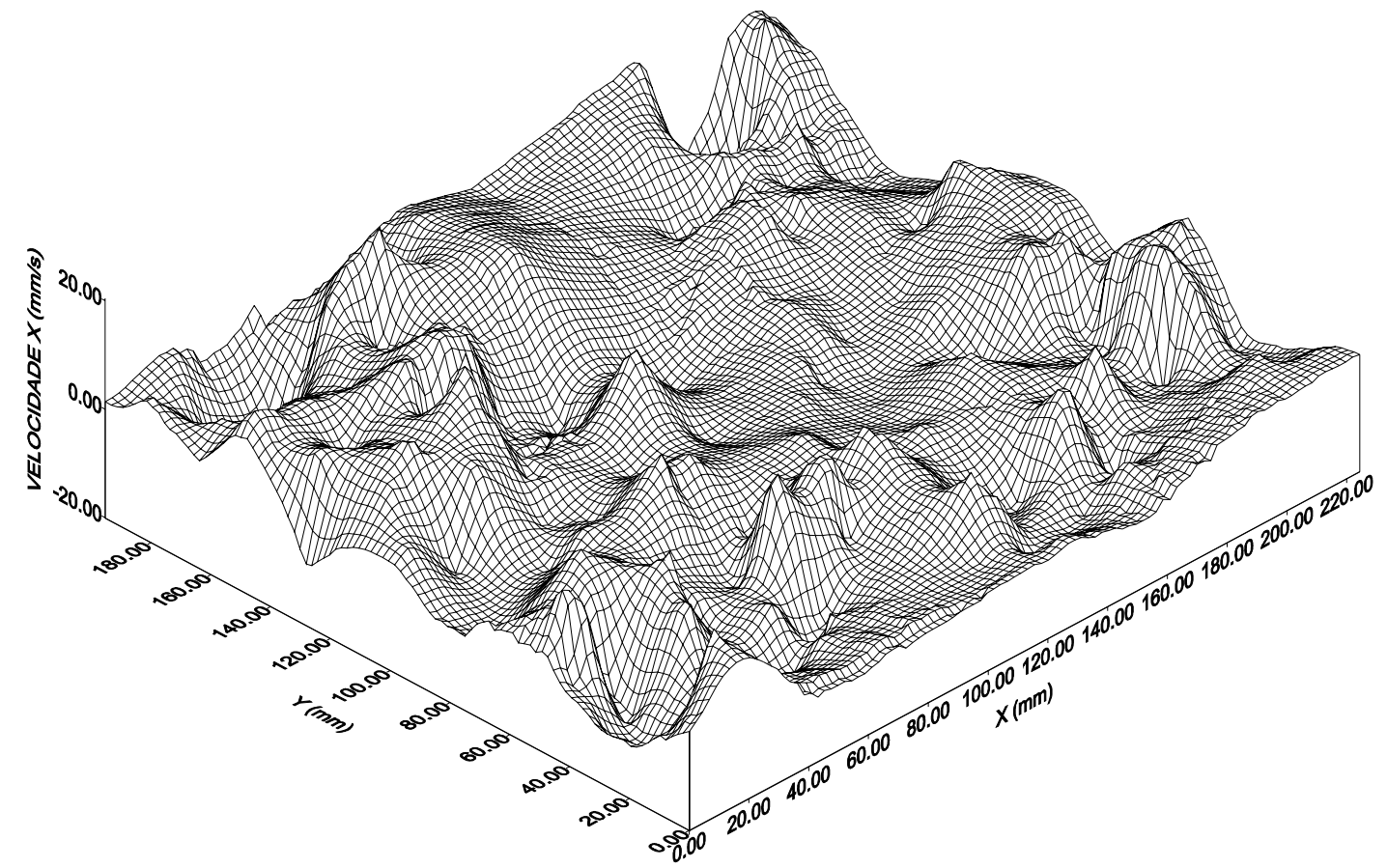

FIGURA 38. Visualização da Componente da Velocidade Horizontal na direção X com a grade de malha quadrada de espaçamento entre barras de $6,45 \mathrm{~cm}$ e rotação de $180 \mathrm{rpm}$

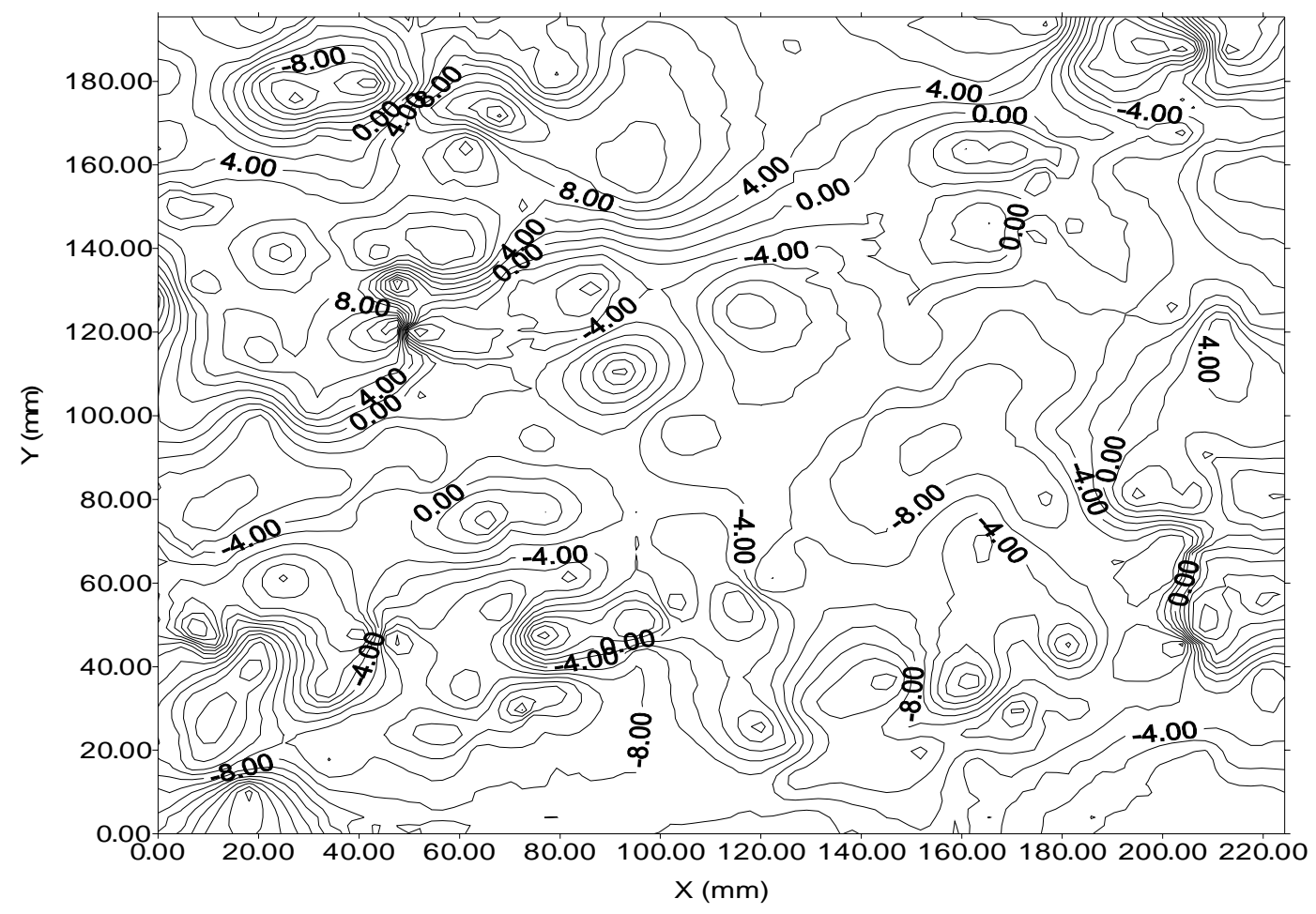

FIGURA 39. Visualização das Isolinhas da Componente da Velocidade Horizontal na direção X com a grade de malha quadrada de espaçamento entre barras de 6,45 cm e rotação de 180 rpm 


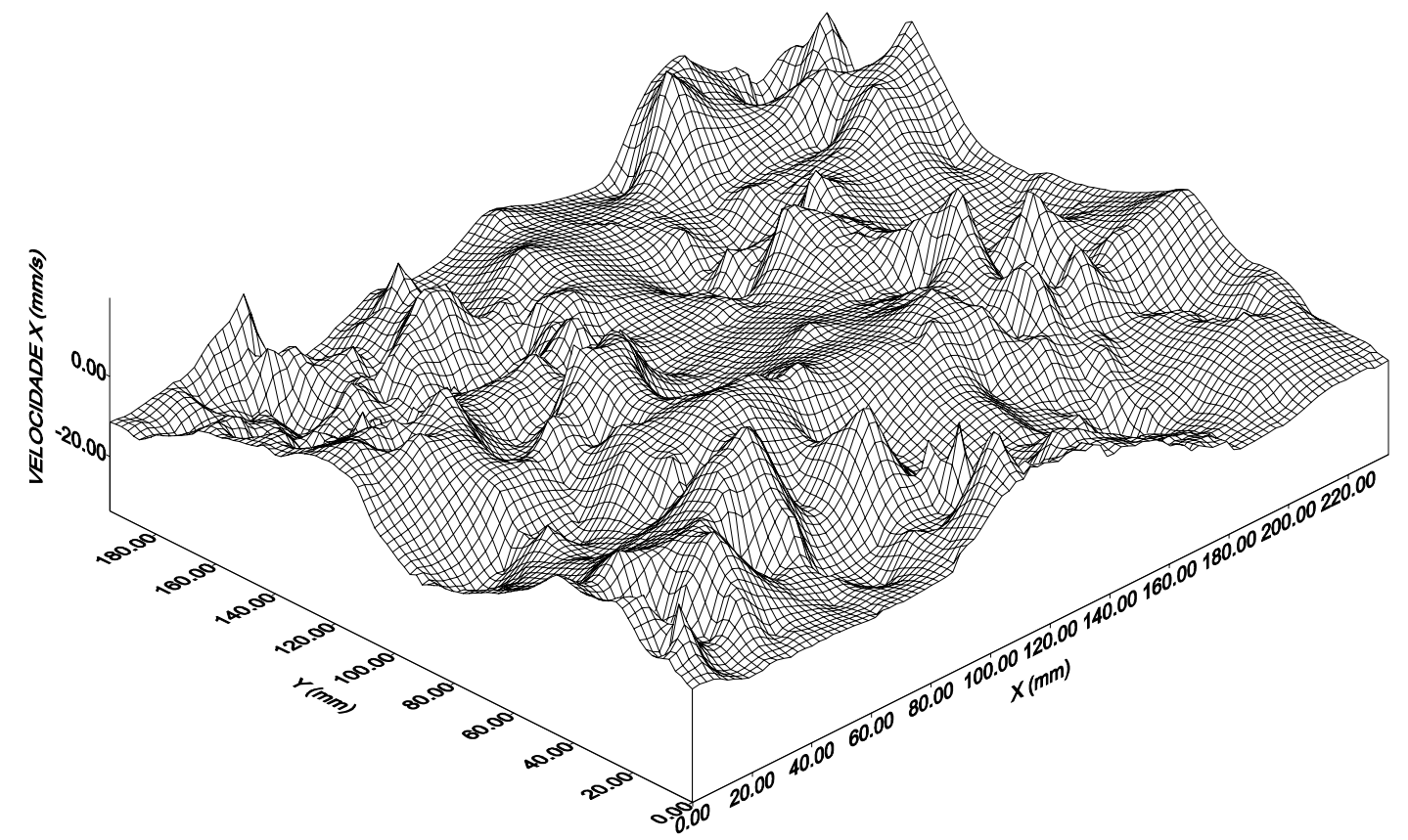

FIGURA 40. Visualização da Componente da Velocidade Horizontal na direção X com a grade de malha quadrada de espaçamento entre barras de $6,45 \mathrm{~cm}$ e rotação de $200 \mathrm{rpm}$

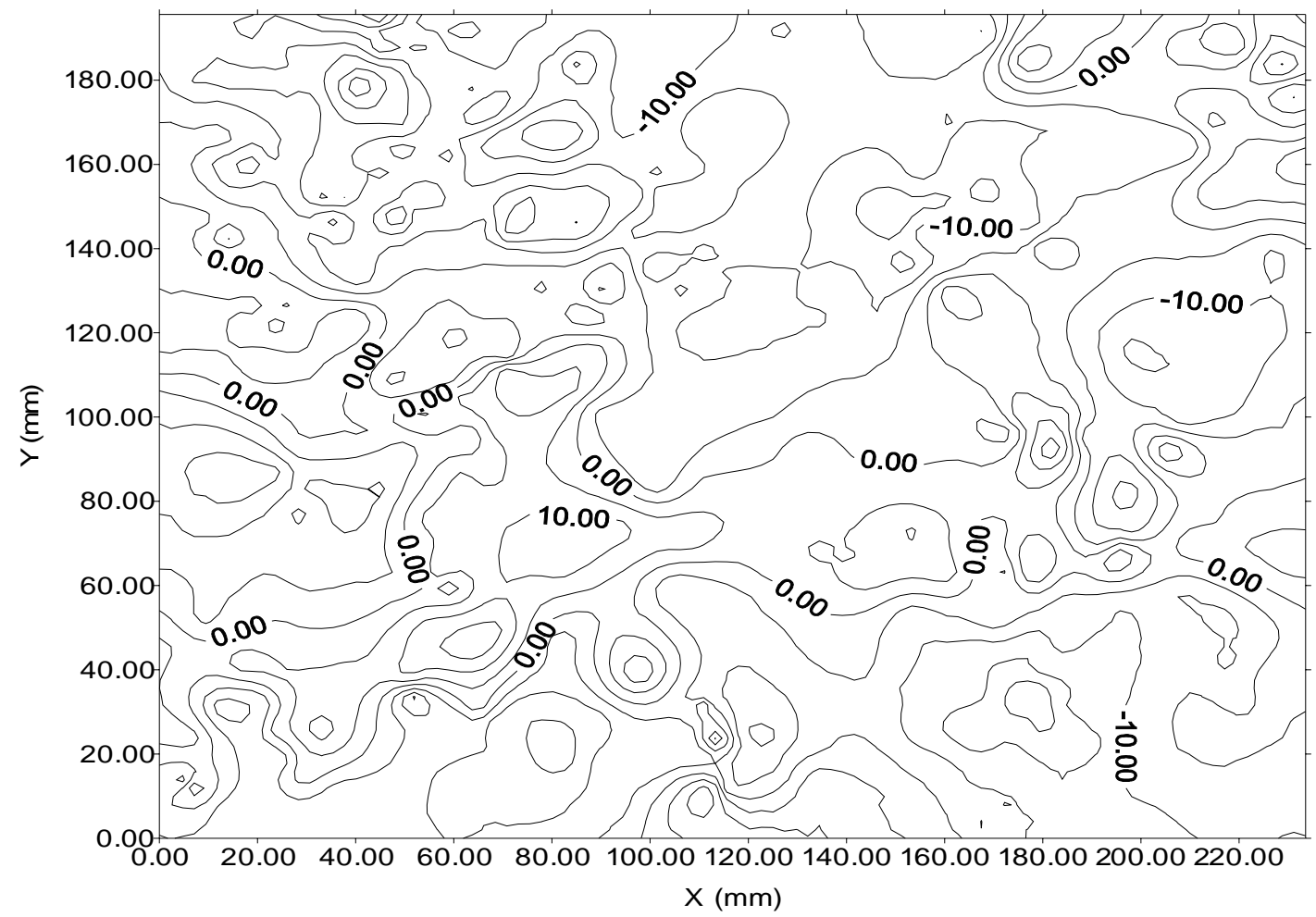

FIGURA 41. Visualização das Isolinhas da Componente da Velocidade Horizontal na direção X com a grade de malha quadrada de espaçamento entre barras de 6,45 cm e rotação de 200 rpm 


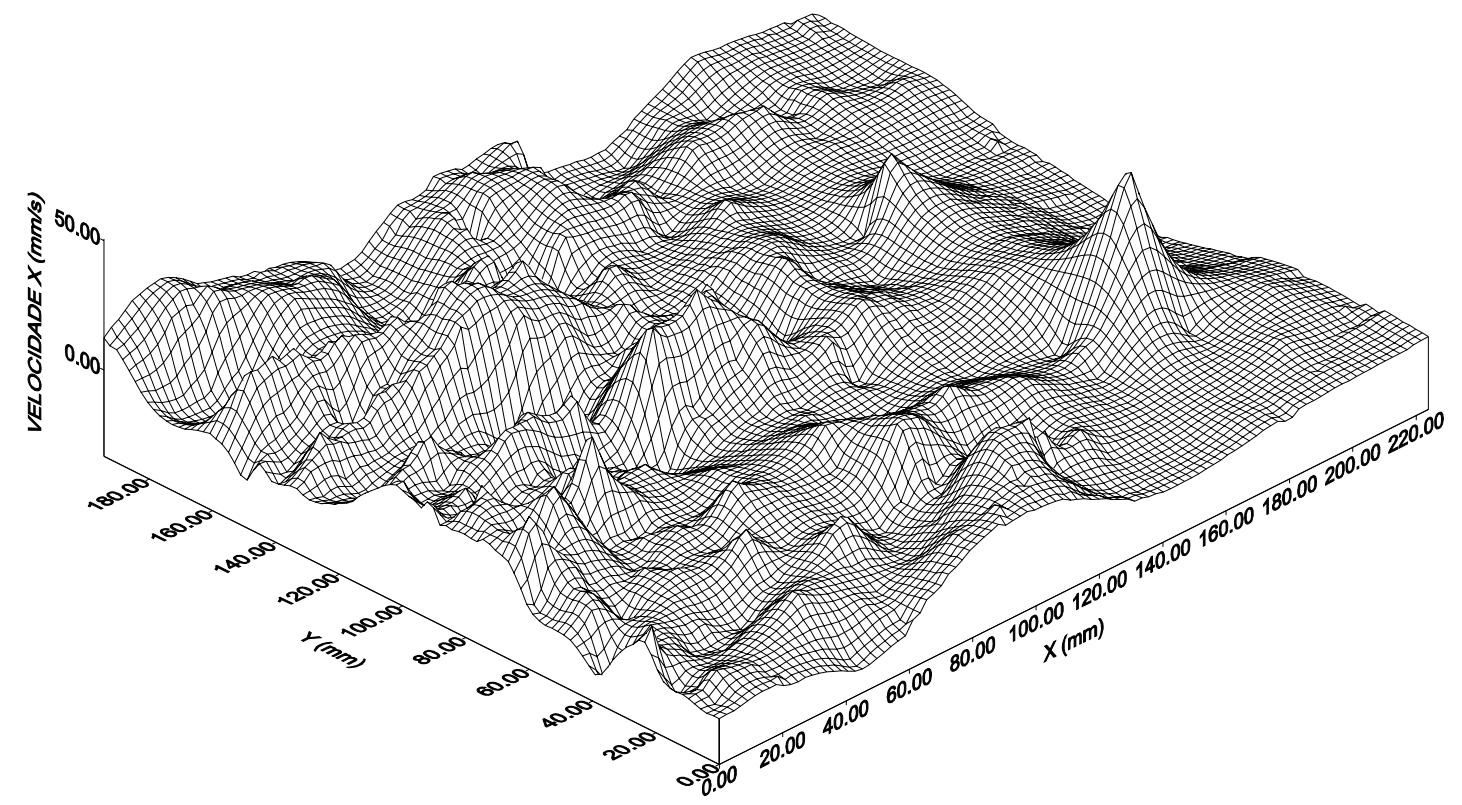

FIGURA 42. Visualização da Componente da Velocidade Horizontal na direção X com a grade de malha quadrada de espaçamento entre barras de $6,45 \mathrm{~cm}$ e rotação de $220 \mathrm{rpm}$

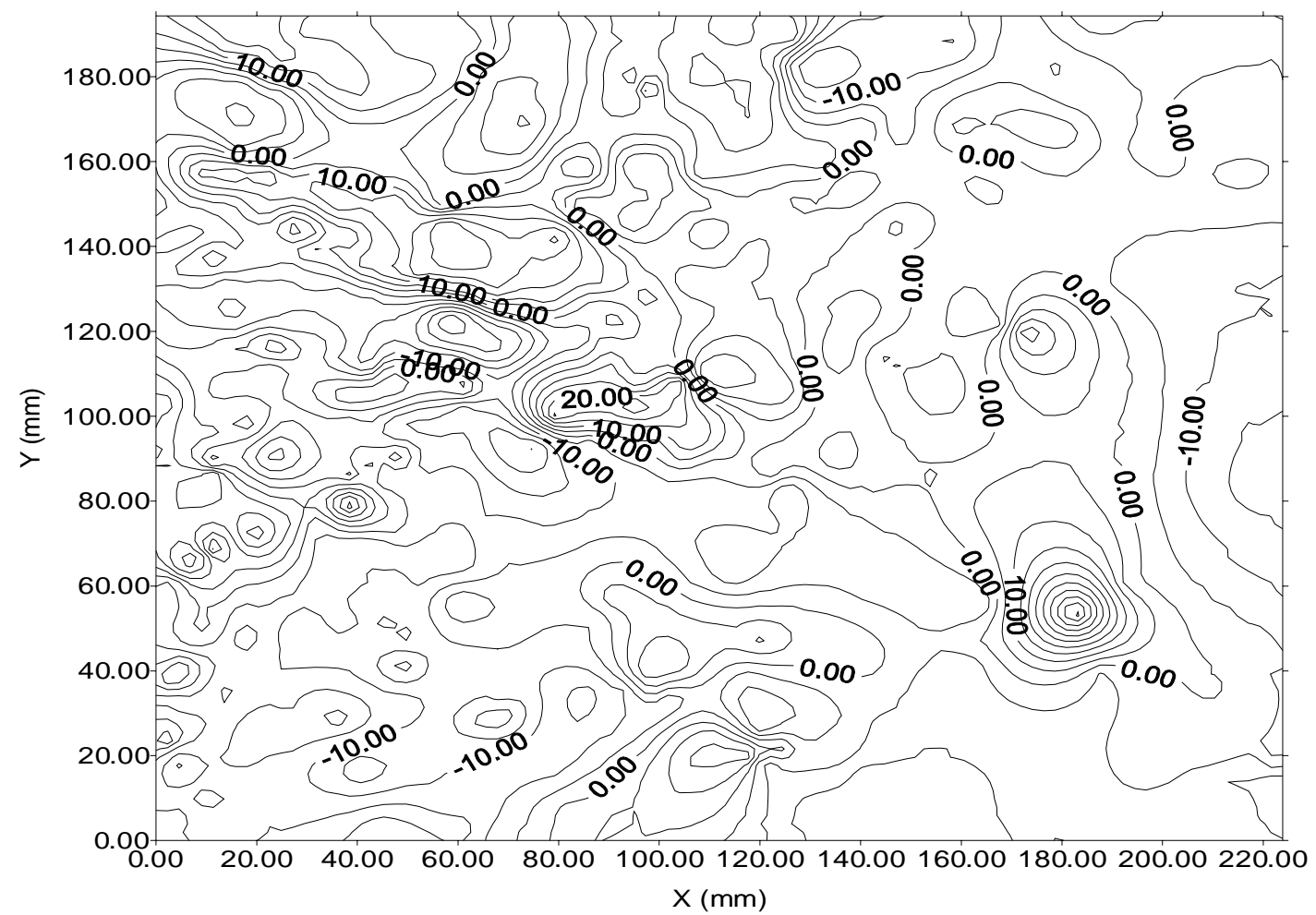

FIGURA 43. Visualização das Isolinhas da Componente da Velocidade Horizontal na direção $\mathrm{X}$ com a grade de malha quadrada de espaçamento entre barras de 6,45 cm e rotação de $220 \mathrm{rpm}$. 


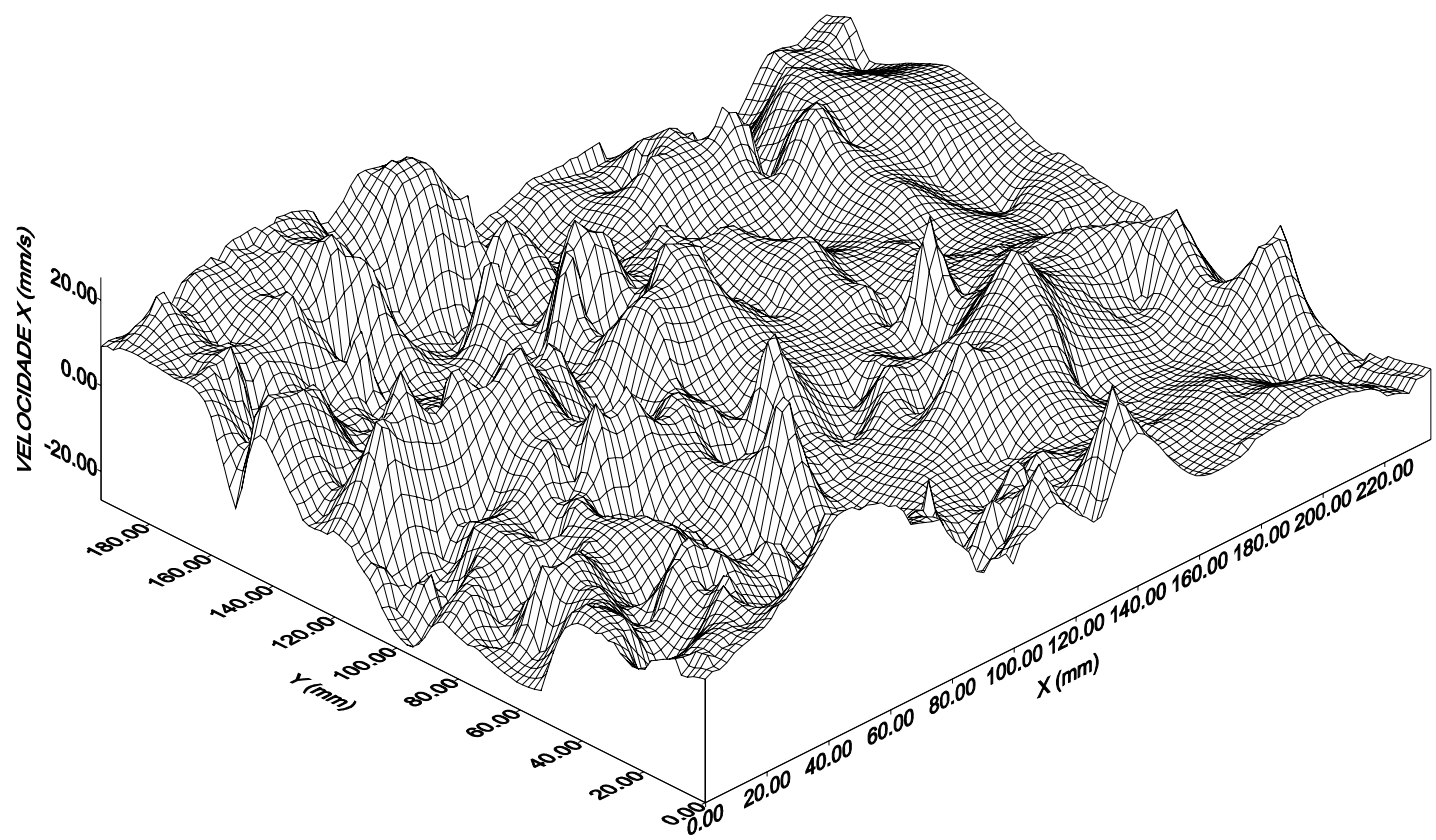

FIGURA 44. Visualização da Componente da Velocidade Horizontal na direção X com a grade de malha quadrada de espaçamento entre barras de $6,45 \mathrm{~cm}$ e rotação de $250 \mathrm{rpm}$

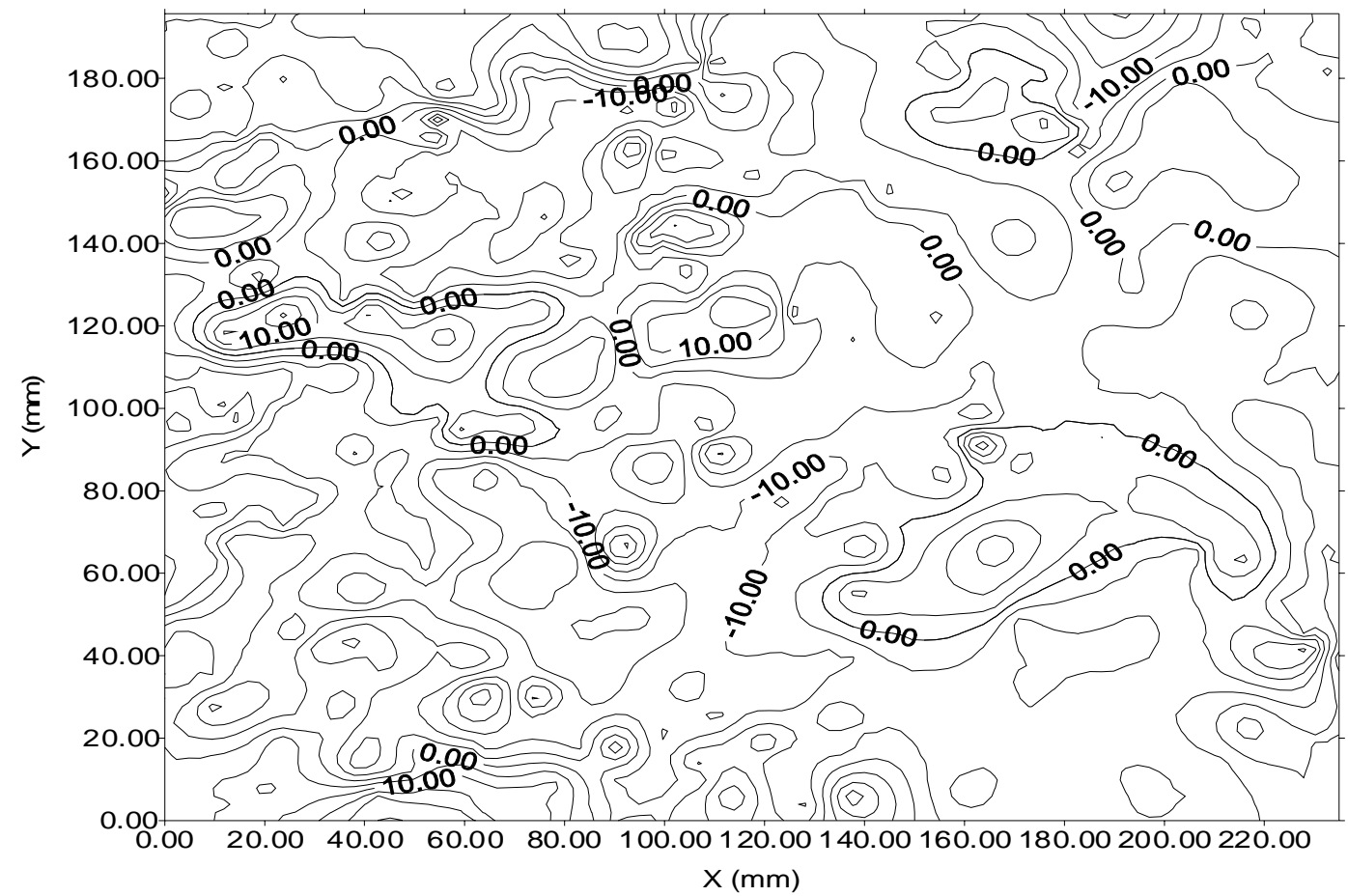

FIGURA 45. Visualização das Isolinhas da Componente da Velocidade Horizontal na direção X com a grade de malha quadrada de espaçamento entre barras de 6,45 cm e rotação de 250 rpm 


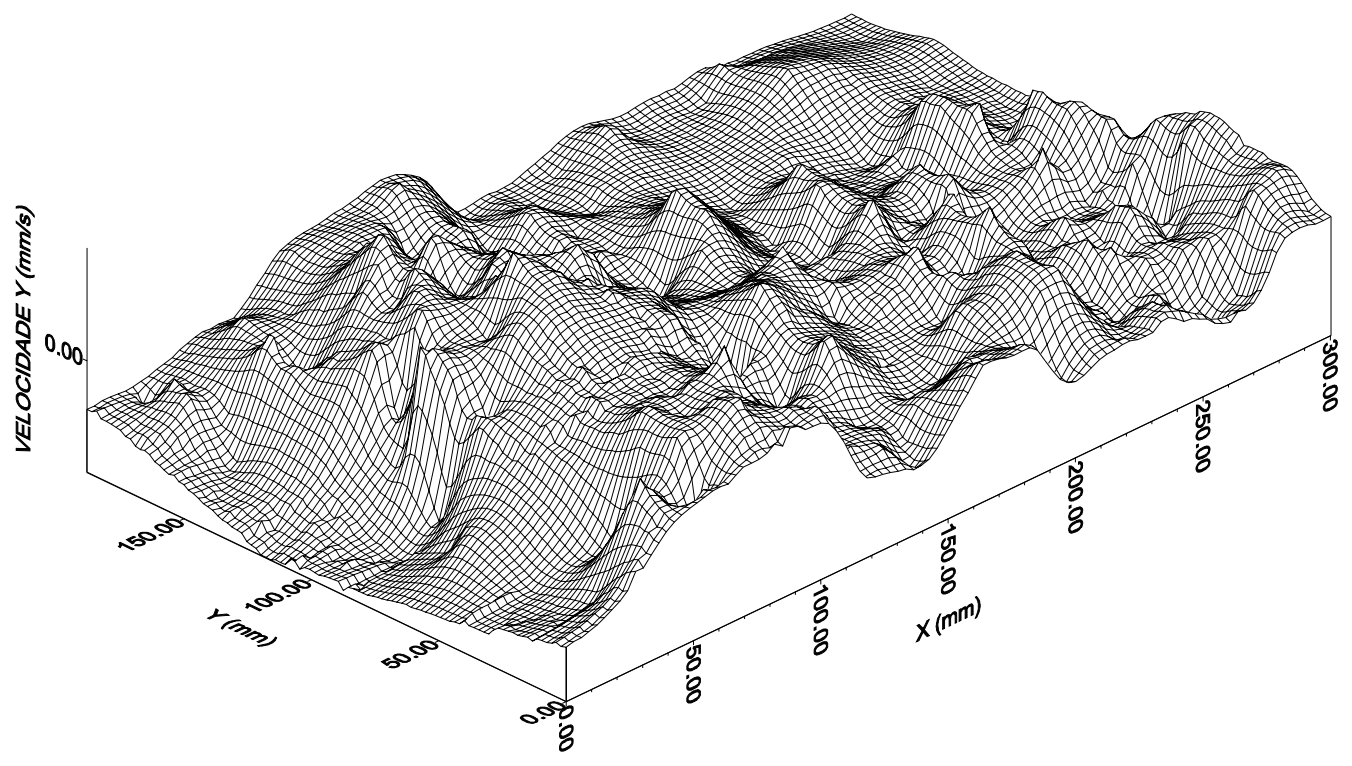

FIGURA 46. Visualização da Componente da Velocidade Horizontal na direção Y com a grade de malha quadrada de espaçamento entre barras de 2,65 cm e rotação de $120 \mathrm{rpm}$

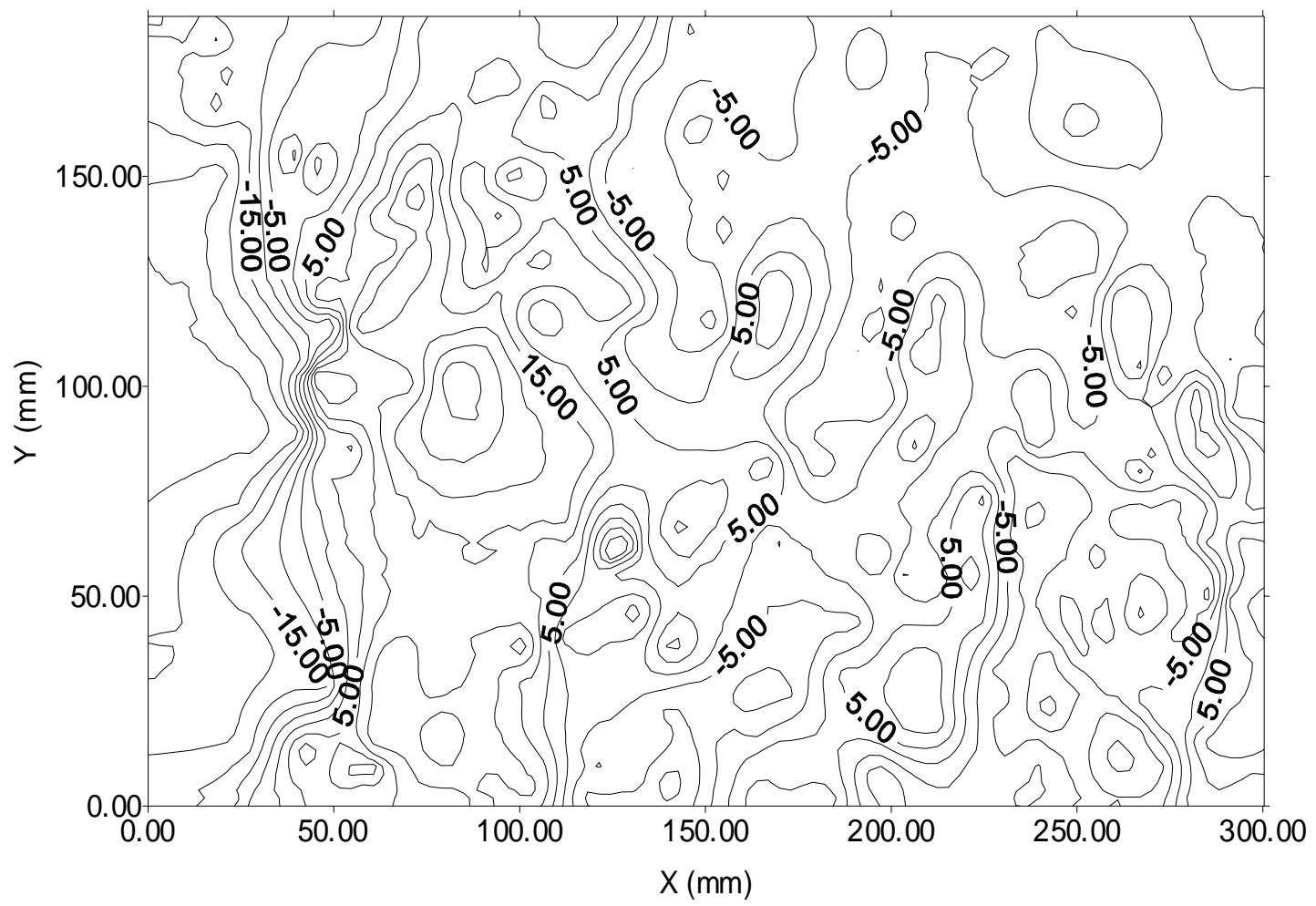

FIGURA 47. Visualização das Isolinhas da Componente da Velocidade Horizontal na direção Y com a grade de malha quadrada de espaçamento entre barras de 2,65 cm e rotação de 120 rpm. 


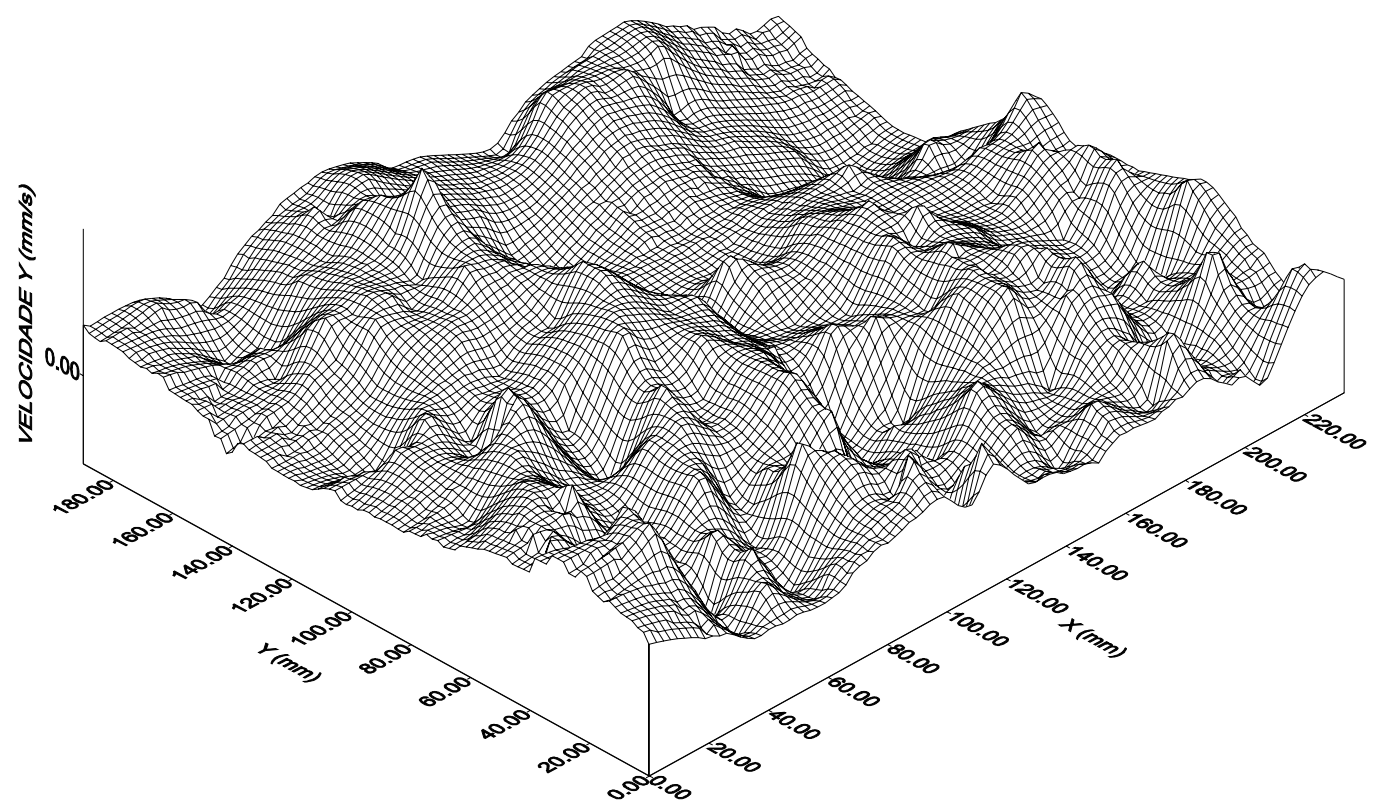

FIGURA 48. Visualização da Componente da Velocidade Horizontal na direção Y com a grade de malha quadrada de espaçamento entre barras de 2,65 cm e rotação de $140 \mathrm{rpm}$

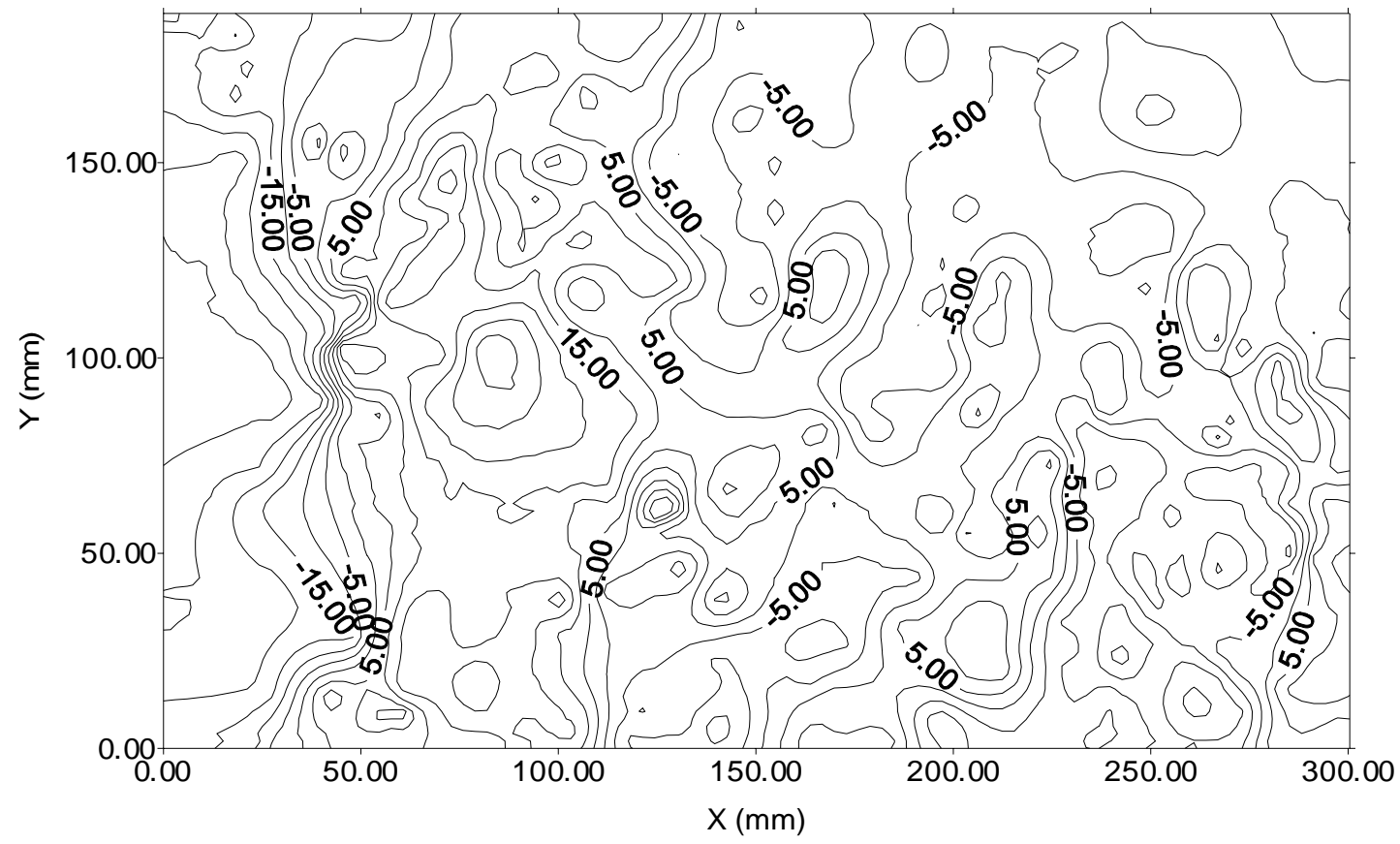

FIGURA 49. Visualização das Isolinhas da Componente da Velocidade Horizontal na direção Y com a grade de malha quadrada de espaçamento entre barras de 2,65 cm e rotação de 140 rpm 


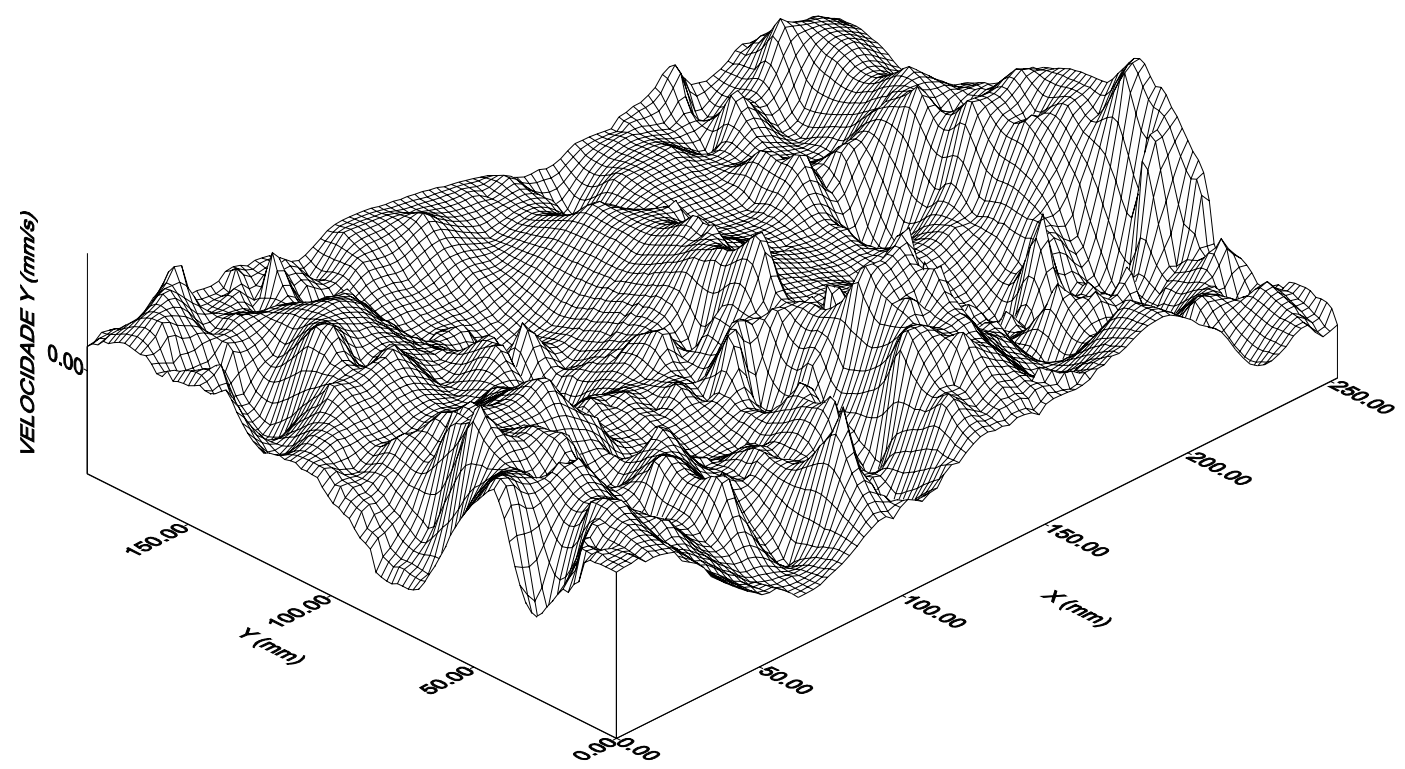

FIGURA 50. Visualização da Componente da Velocidade Horizontal na direção $Y$ com a grade de malha quadrada de espaçamento entre barras de 2,65 cm e rotação de $160 \mathrm{rpm}$

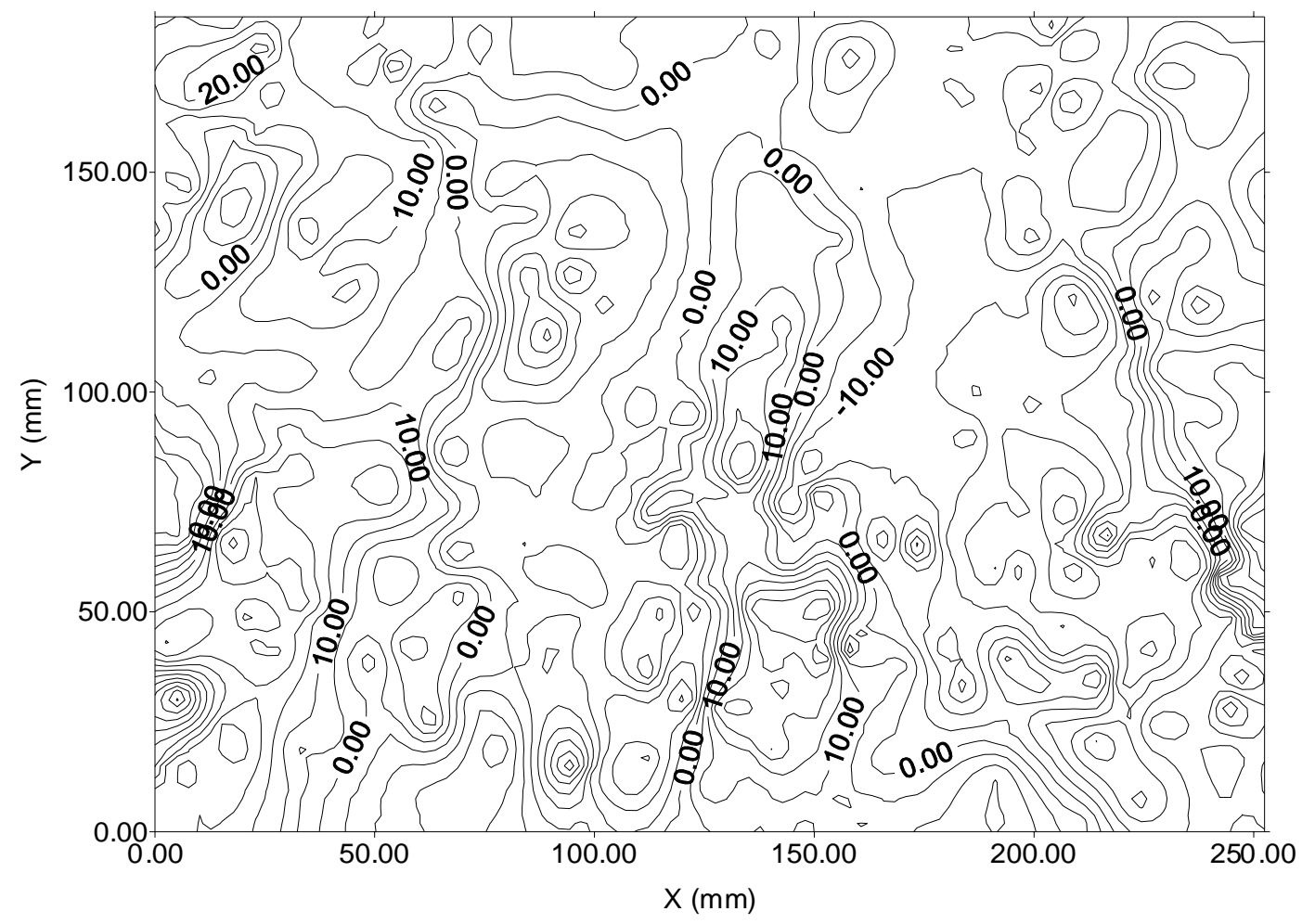

FIGURA 51. Visualização das Isolinhas da Componente da Velocidade Horizontal na direção Y com a grade de malha quadrada de espaçamento entre barras de 2,65 cm e rotação de 160 rpm 


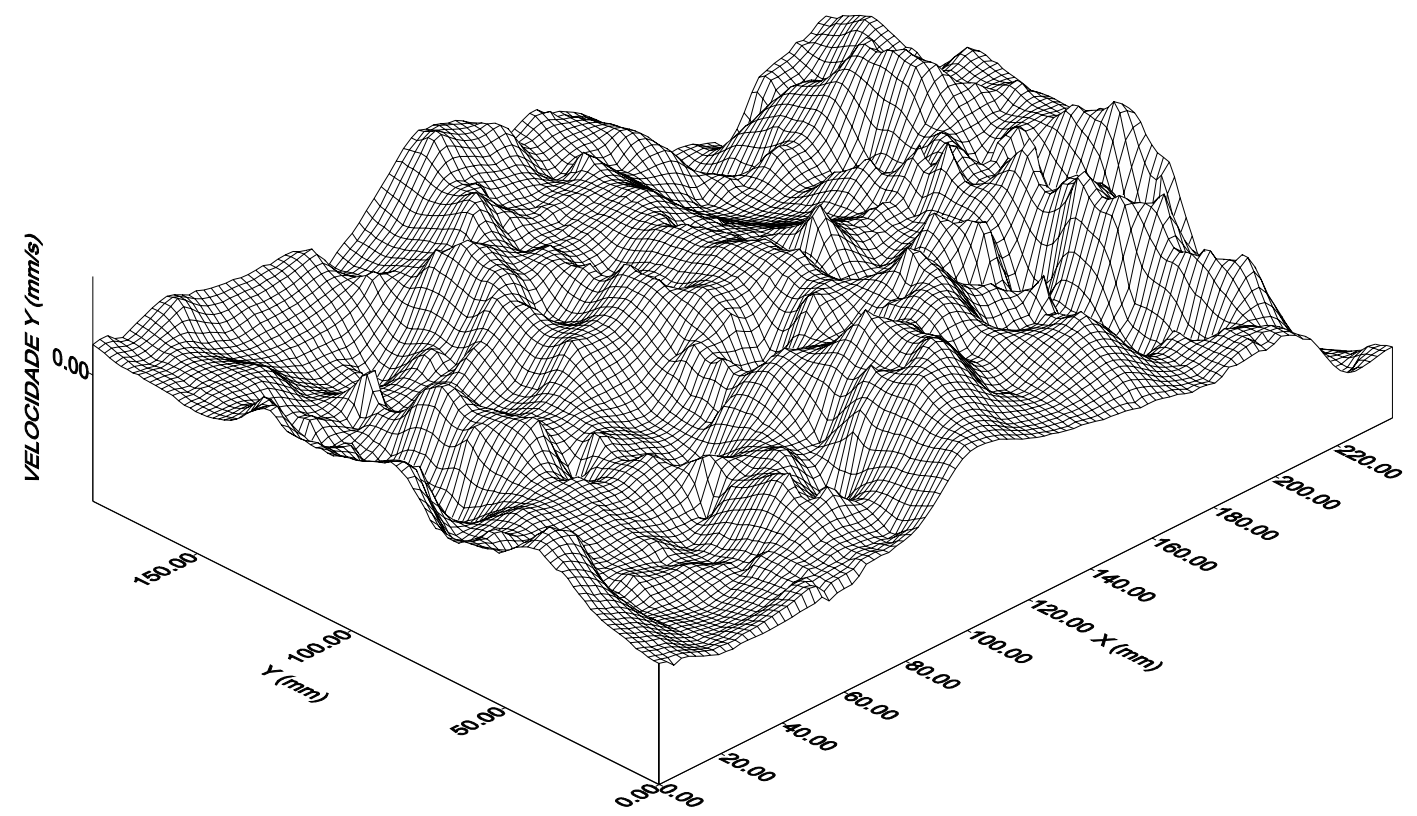

FIGURA 52. Visualização da Componente da Velocidade Horizontal na direção Y com a grade de malha quadrada de espaçamento entre barras de 2,65 cm e rotação de $180 \mathrm{rpm}$

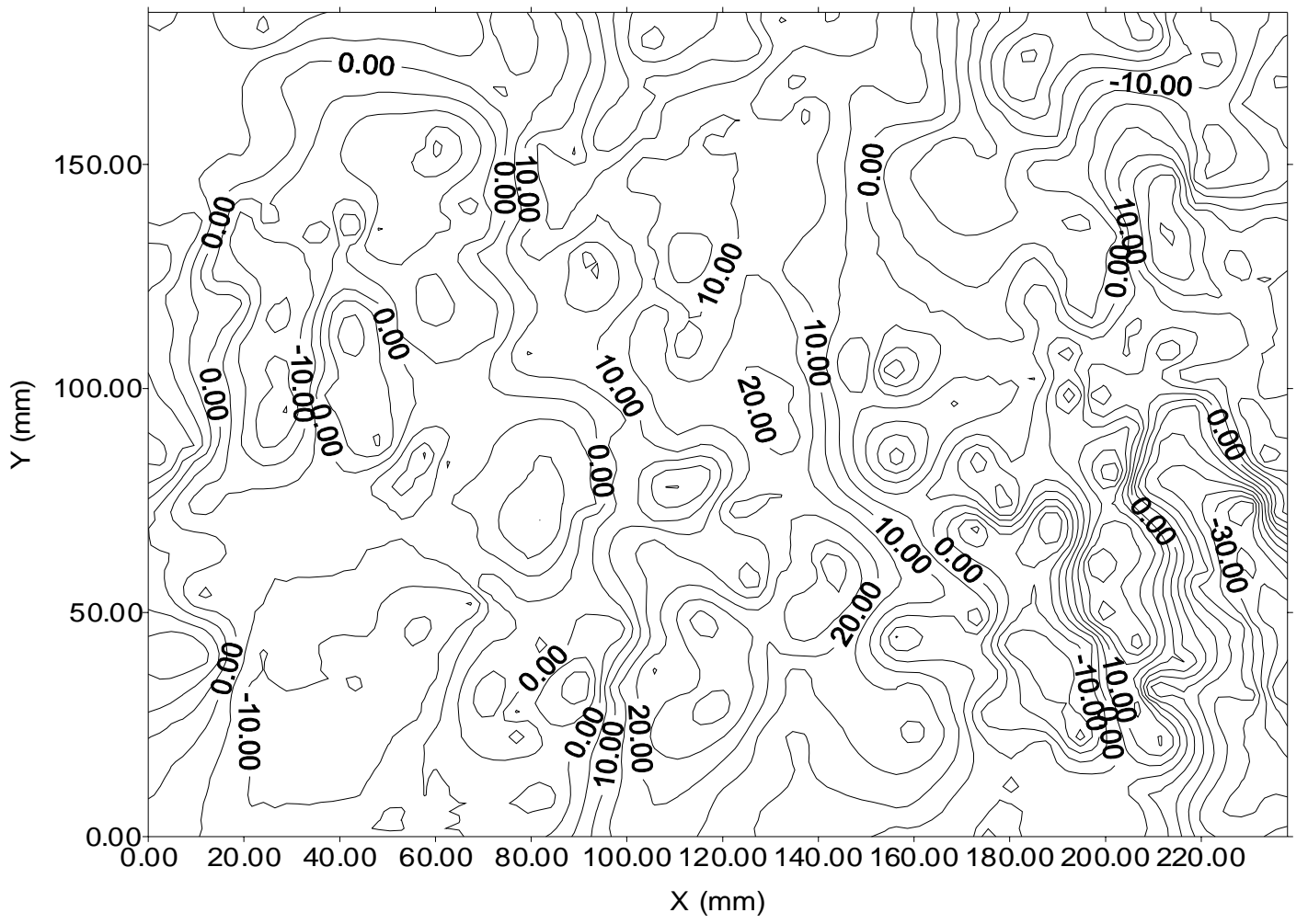

FIGURA 53. Visualização das Isolinhas da Componente da Velocidade Horizontal na direção Y com a grade de malha quadrada de espaçamento entre barras de 2,65 cm e rotação de 180 rpm 


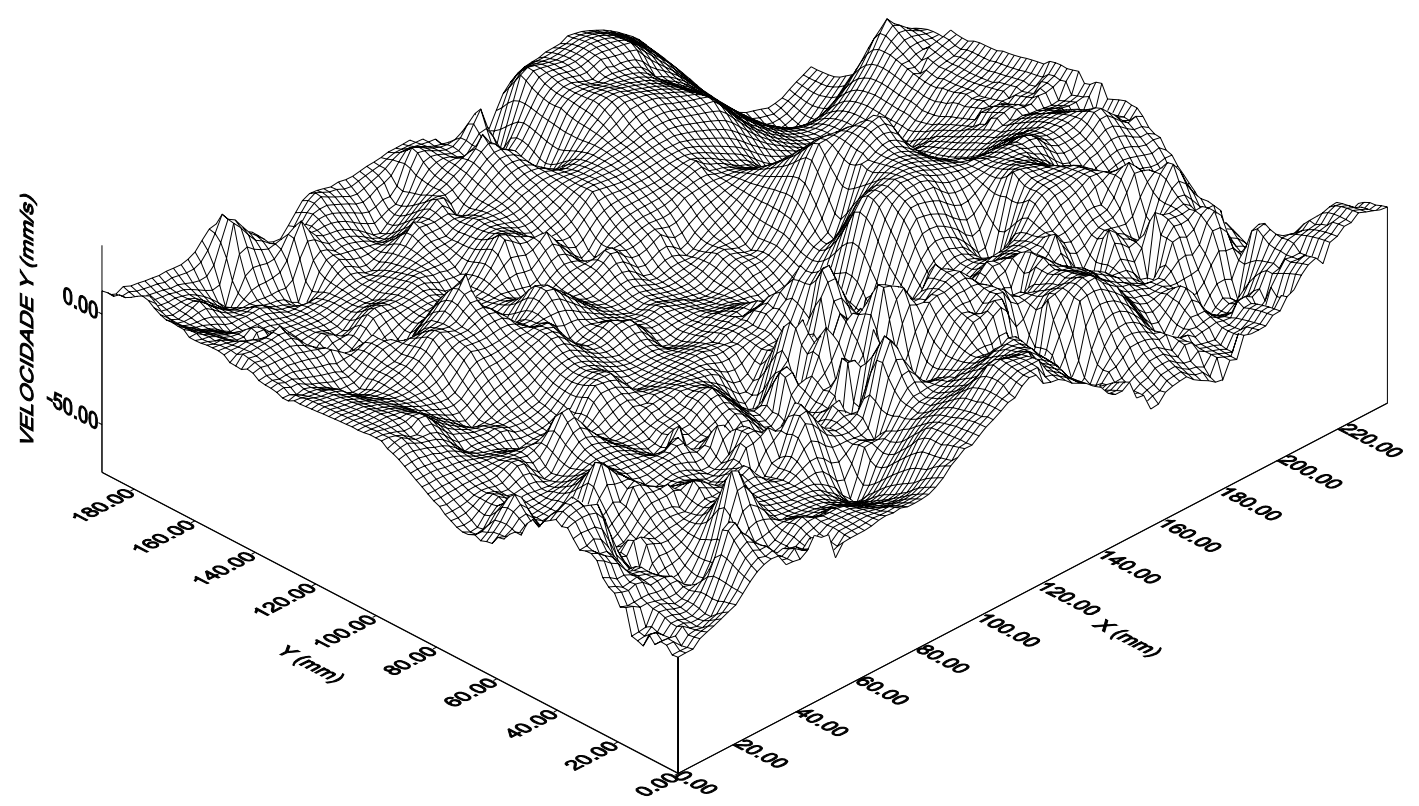

FIGURA 54. Visualização da Componente da Velocidade Horizontal na direção Y com a grade de malha quadrada de espaçamento entre barras de 2,65 cm e rotação de $200 \mathrm{rpm}$

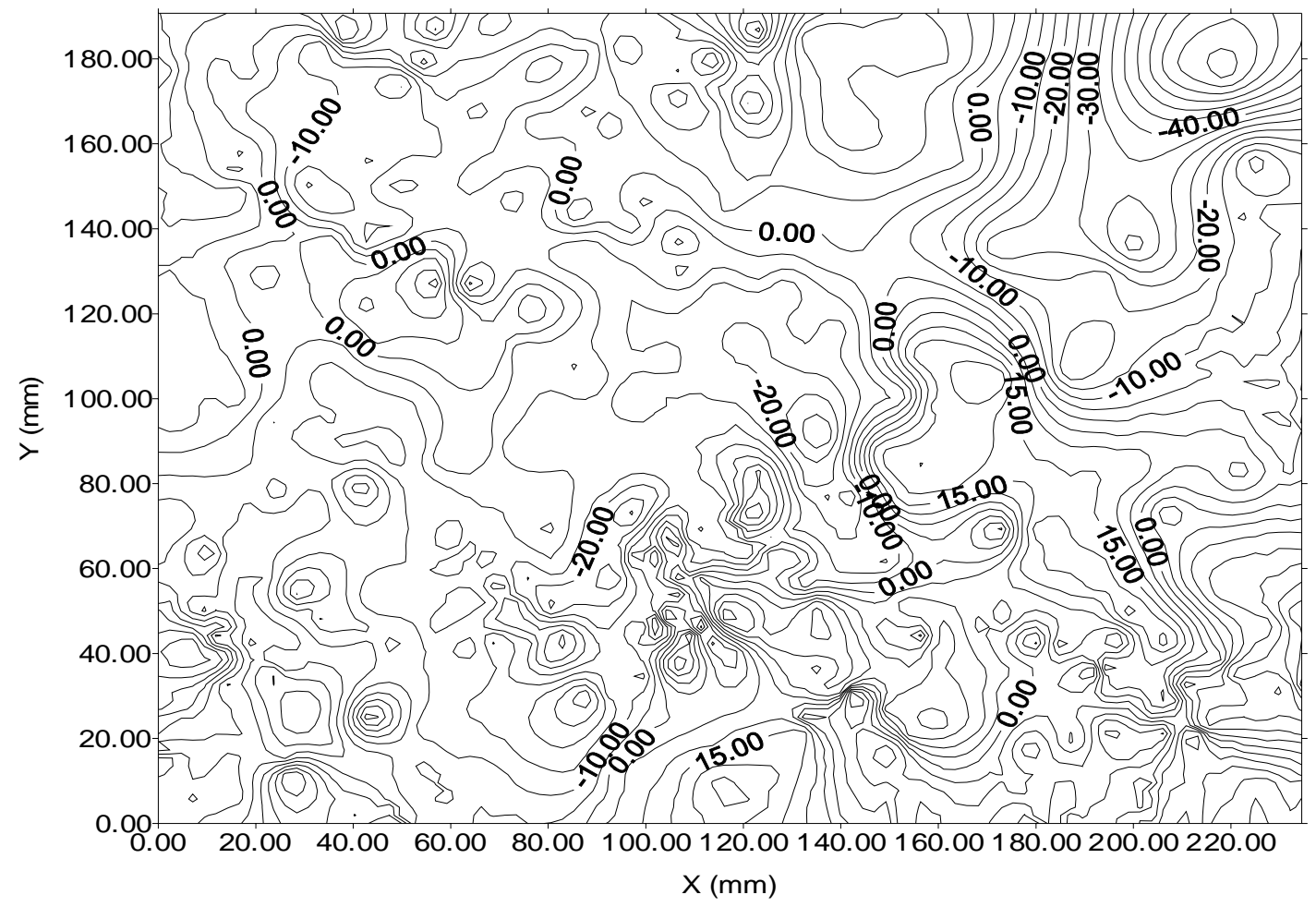

FIGURA 55. Visualização das Isolinhas da Componente da Velocidade Horizontal na direção Y com a grade de malha quadrada de espaçamento entre barras de 2,65 cm e rotação de $200 \mathrm{rpm}$. 


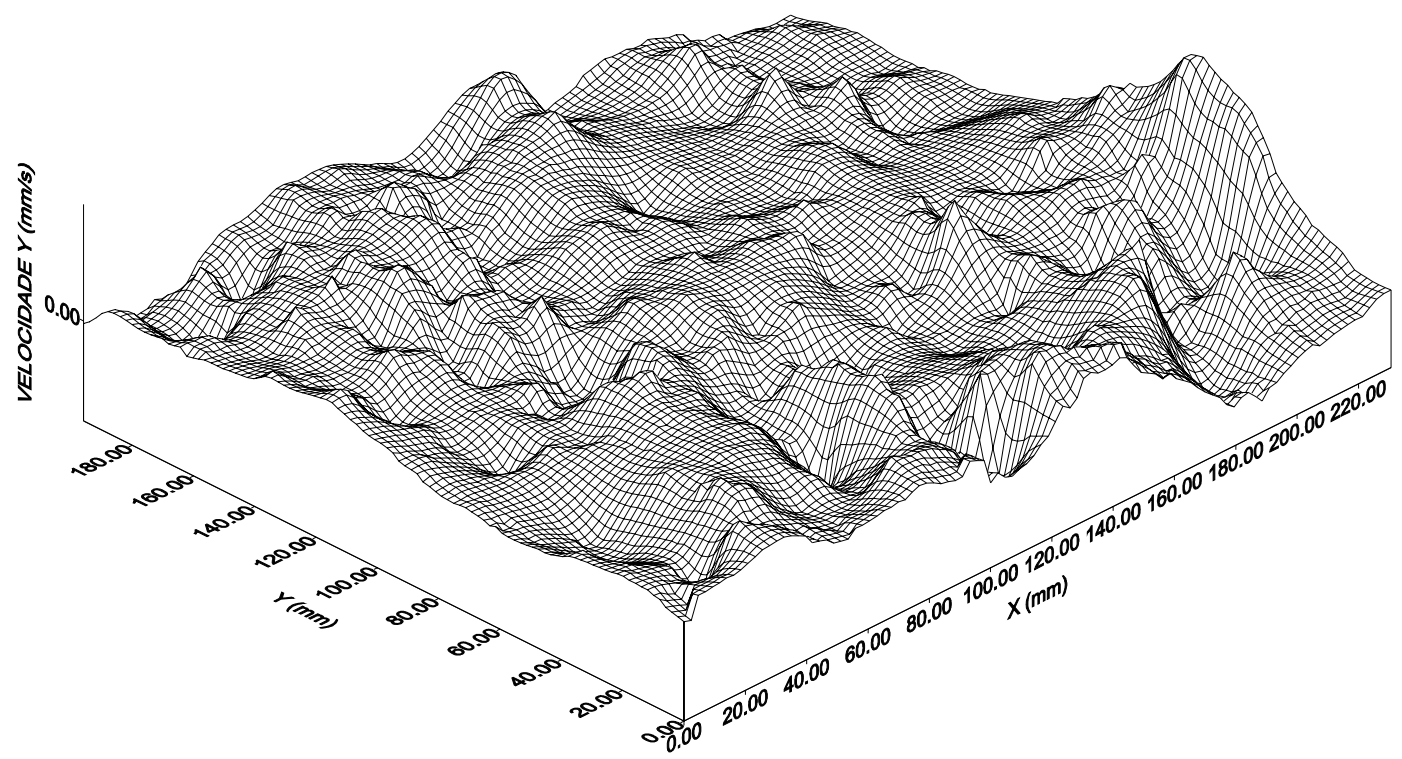

FIGURA 56. Visualização da Componente da Velocidade Horizontal na direção Y com a grade de malha quadrada de espaçamento entre barras de $3,90 \mathrm{~cm}$ e rotação de $140 \mathrm{rpm}$

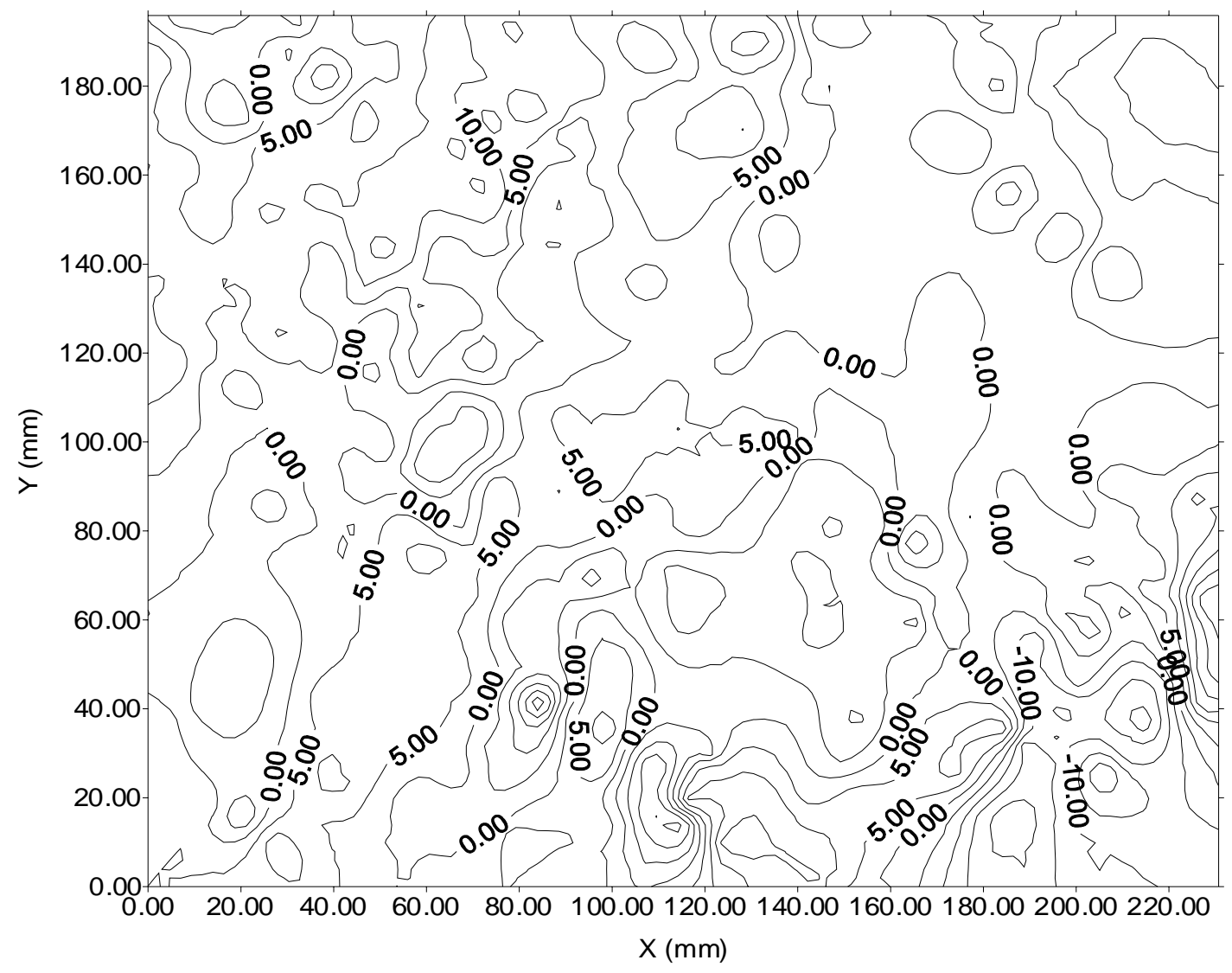

FIGURA 57. Visualização das Isolinhas da Componente da Velocidade Horizontal na direção Y com a grade de malha quadrada de espaçamento entre barras de 3,90 cm e rotação de 140 rpm 


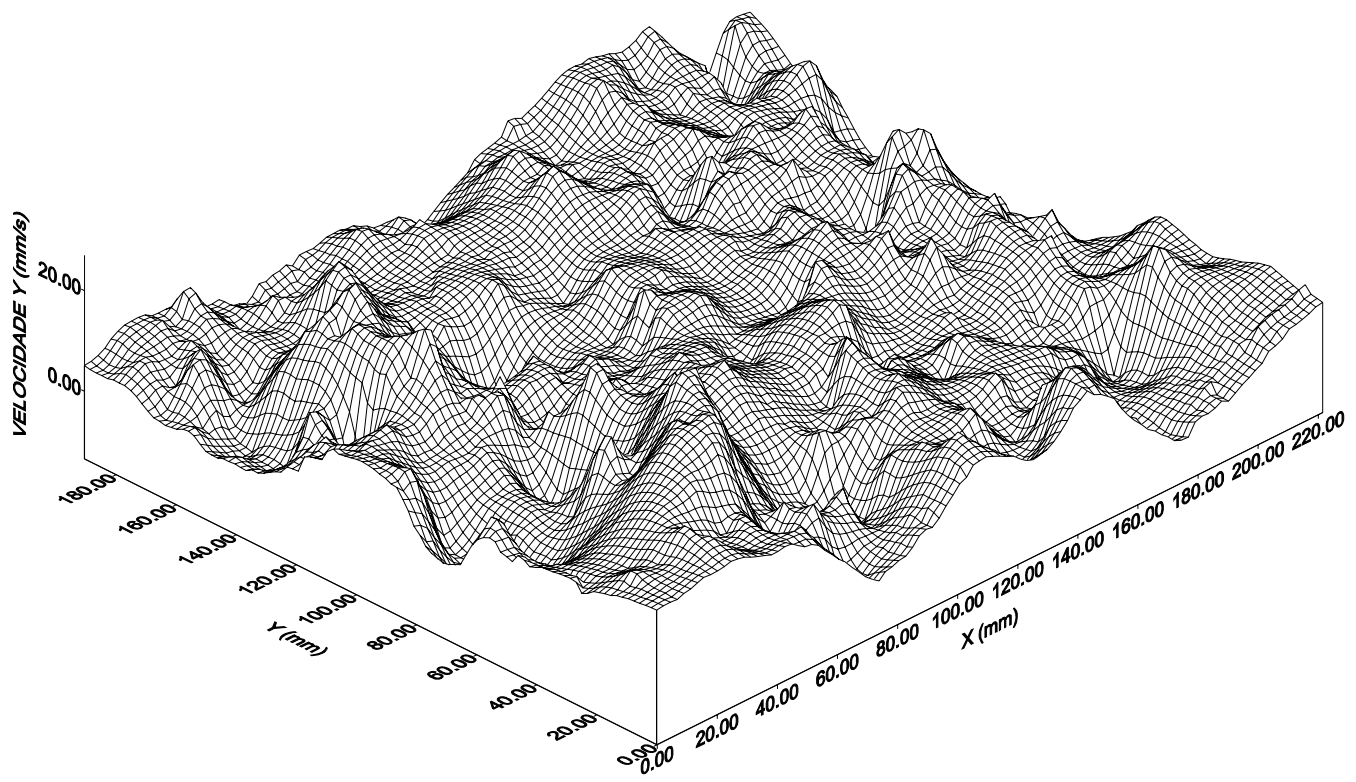

FIGURA 58. Visualização da Componente da Velocidade Horizontal na direção Y com a grade de malha quadrada de espaçamento entre barras de $3,90 \mathrm{~cm}$ e rotação de $160 \mathrm{rpm}$

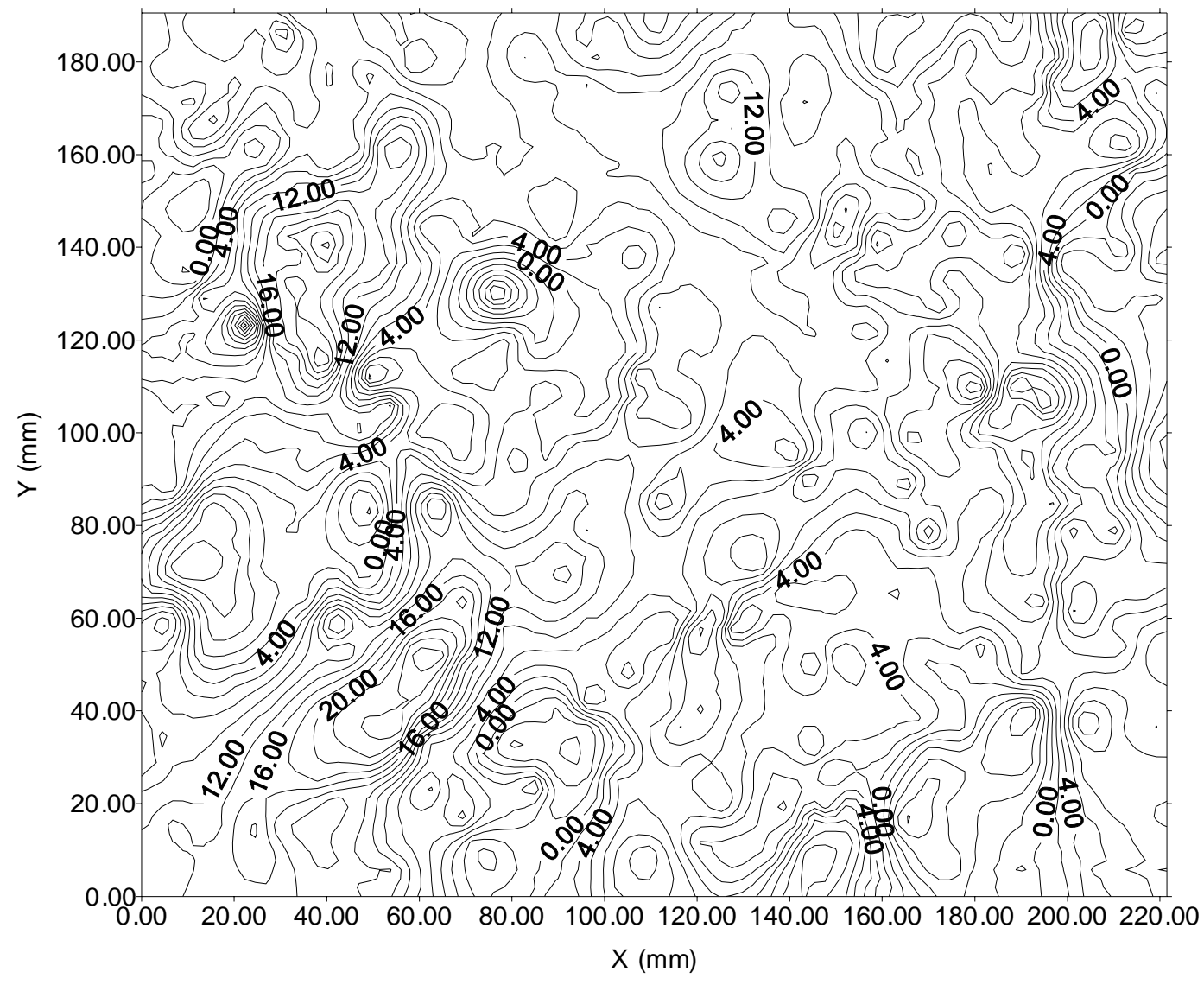

FIGURA 59. Visualização das Isolinhas da Componente da Velocidade Horizontal na direção Y com a grade de malha quadrada de espaçamento entre barras de 3,90 cm e rotação de $160 \mathrm{rpm}$. 


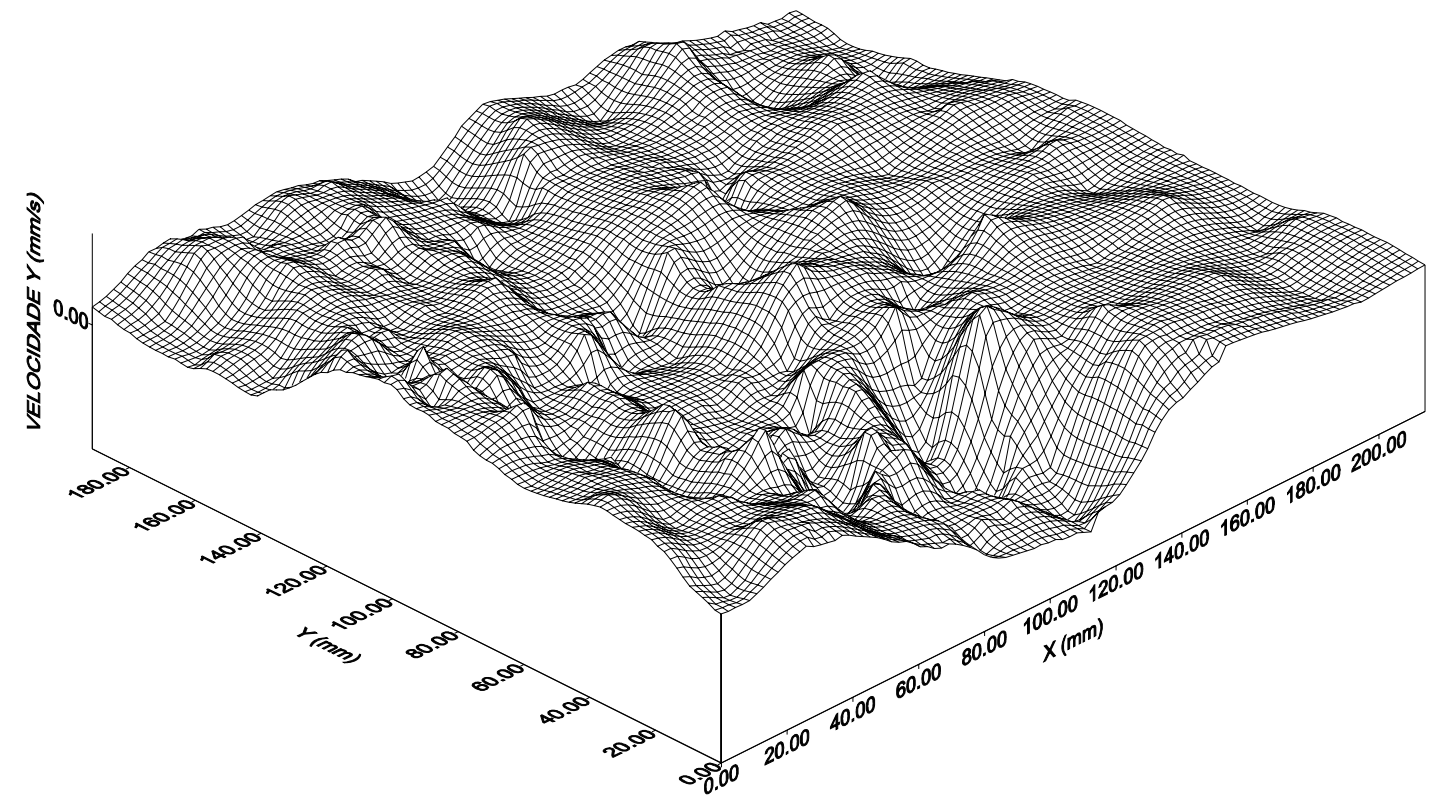

FIGURA 60. Visualização da Componente da Velocidade Horizontal na direção Y com a grade de malha quadrada de espaçamento entre barras de $3,90 \mathrm{~cm}$ e rotação de $180 \mathrm{rpm}$

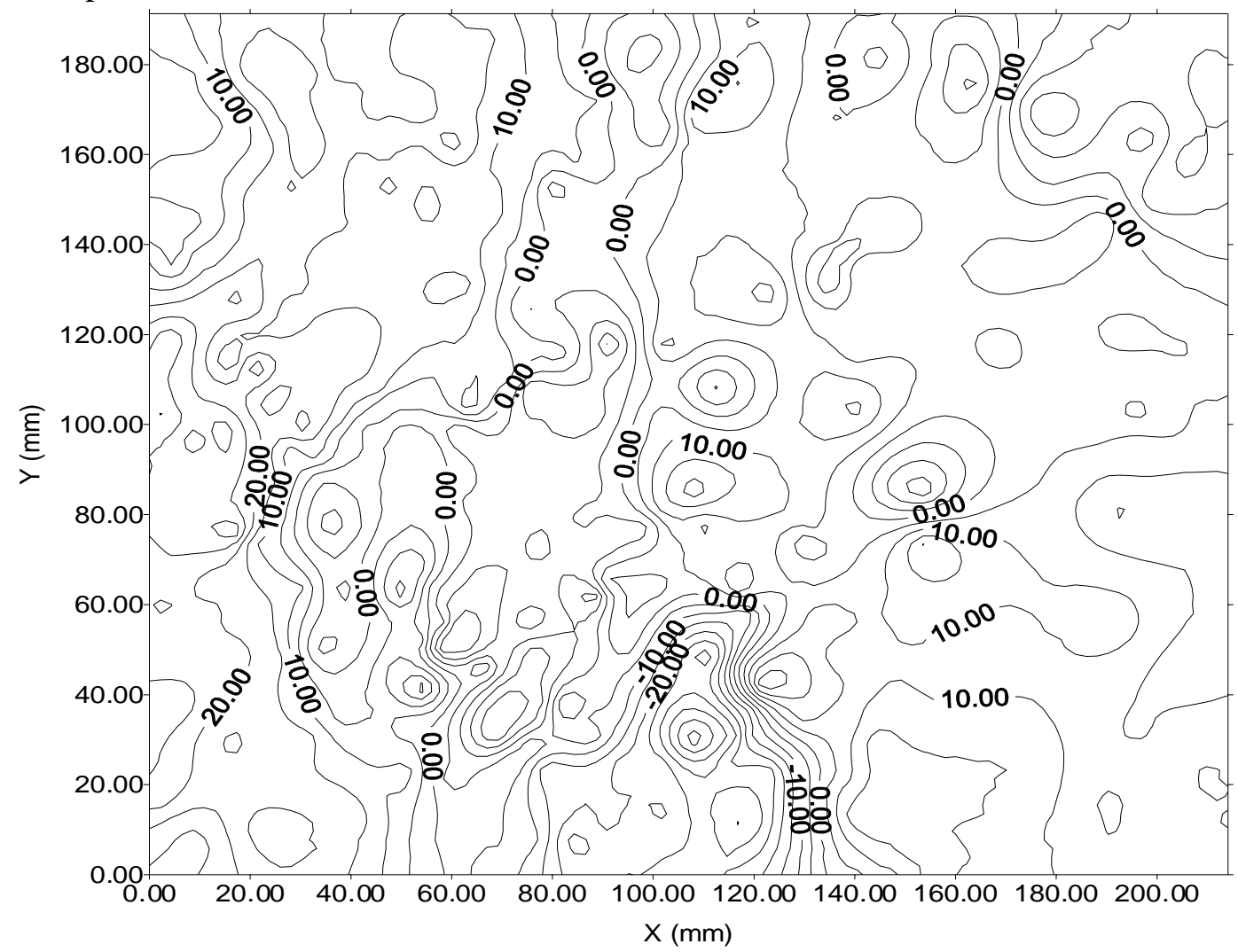

FIGURA 61. Visualização das Isolinhas da Componente da Velocidade Horizontal na direção Y com a grade de malha quadrada de espaçamento entre barras de 3,90 cm e rotação de 180 rpm 


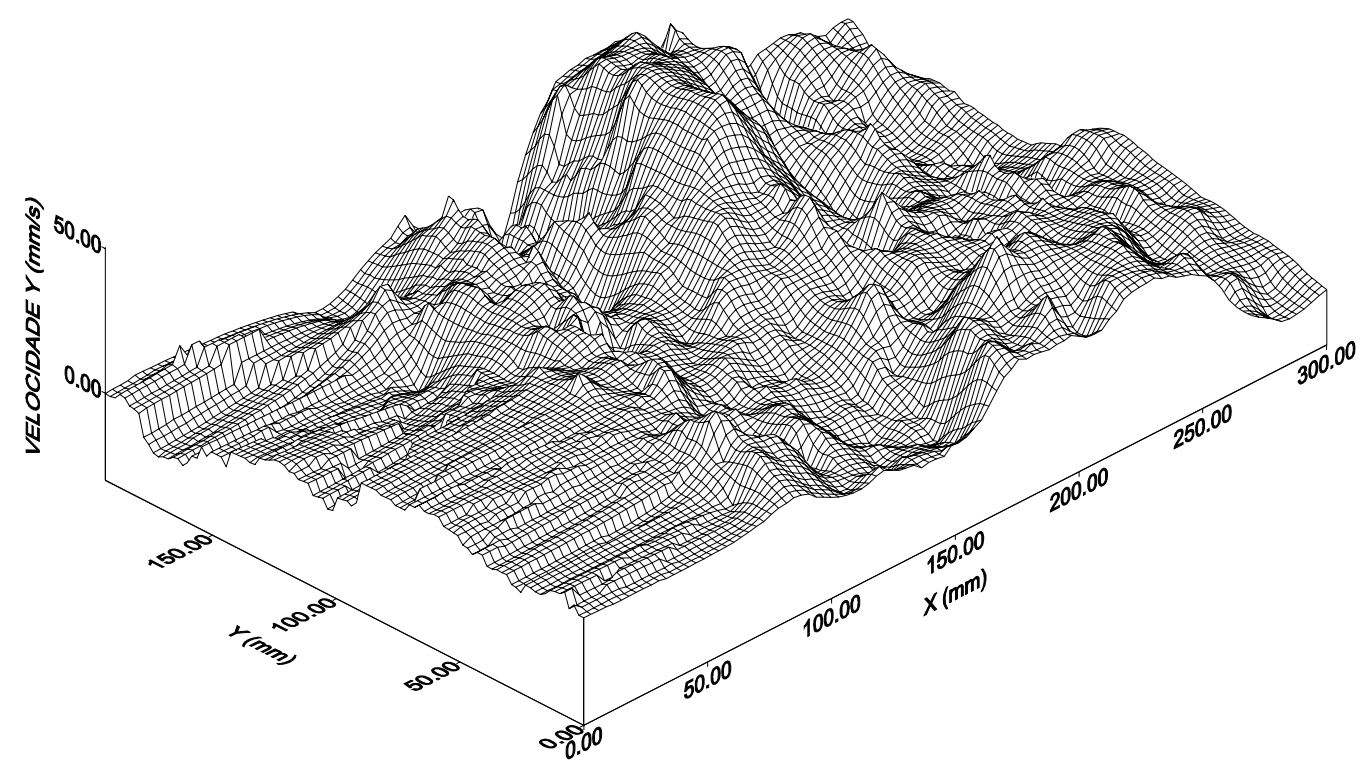

FIGURA 62. Visualização da Componente da Velocidade Horizontal na direção Y com a grade de malha quadrada de espalhamento entre barras de 3,90 cm e rotação de $210 \mathrm{rpm}$

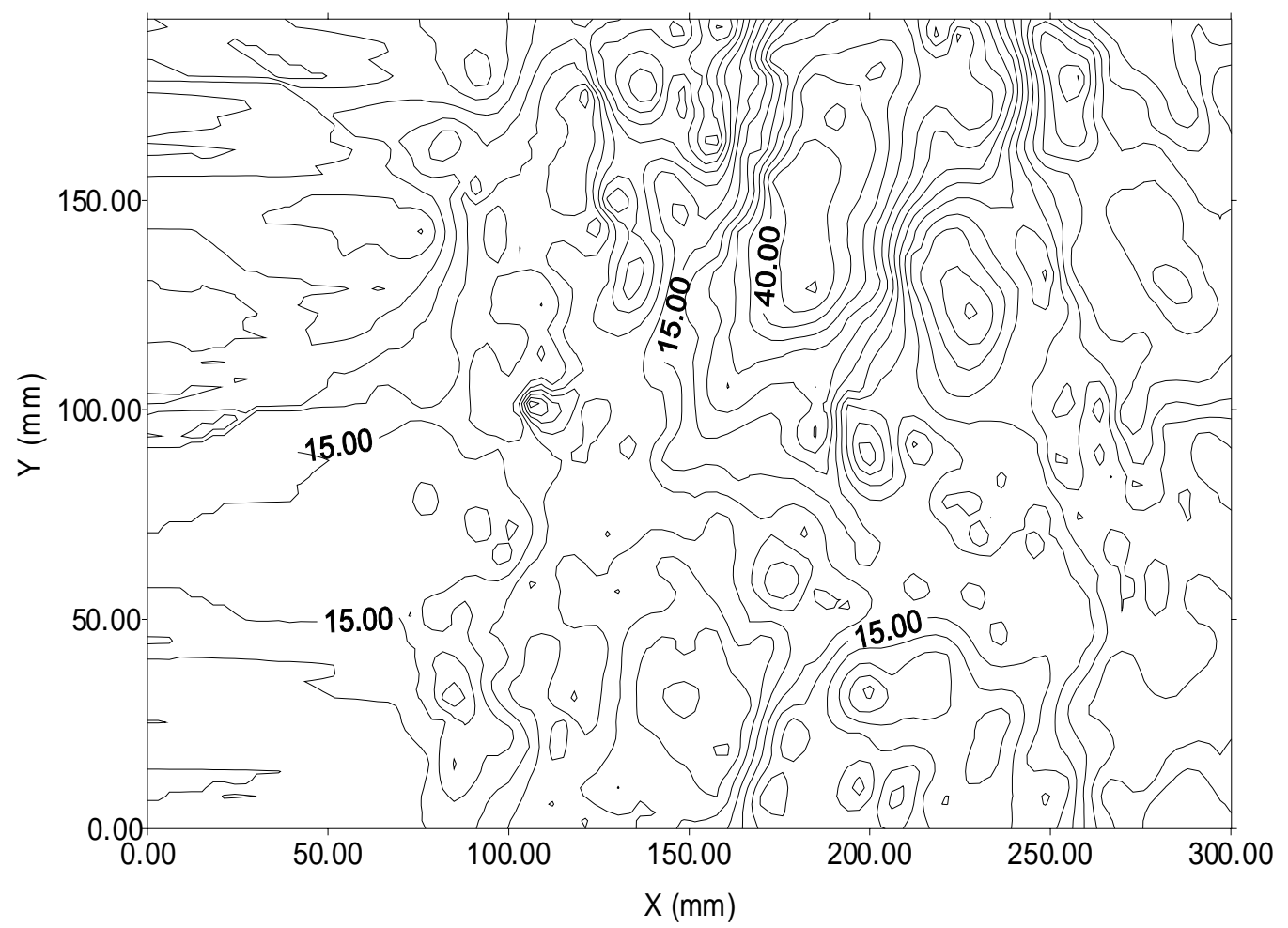

FIGURA 63. Visualização das Isolinhas da Componente da Velocidade Horizontal na direção Y com a grade de malha quadrada de espaçamento entre barras de 3,90 cm e rotação de 210 rpm 


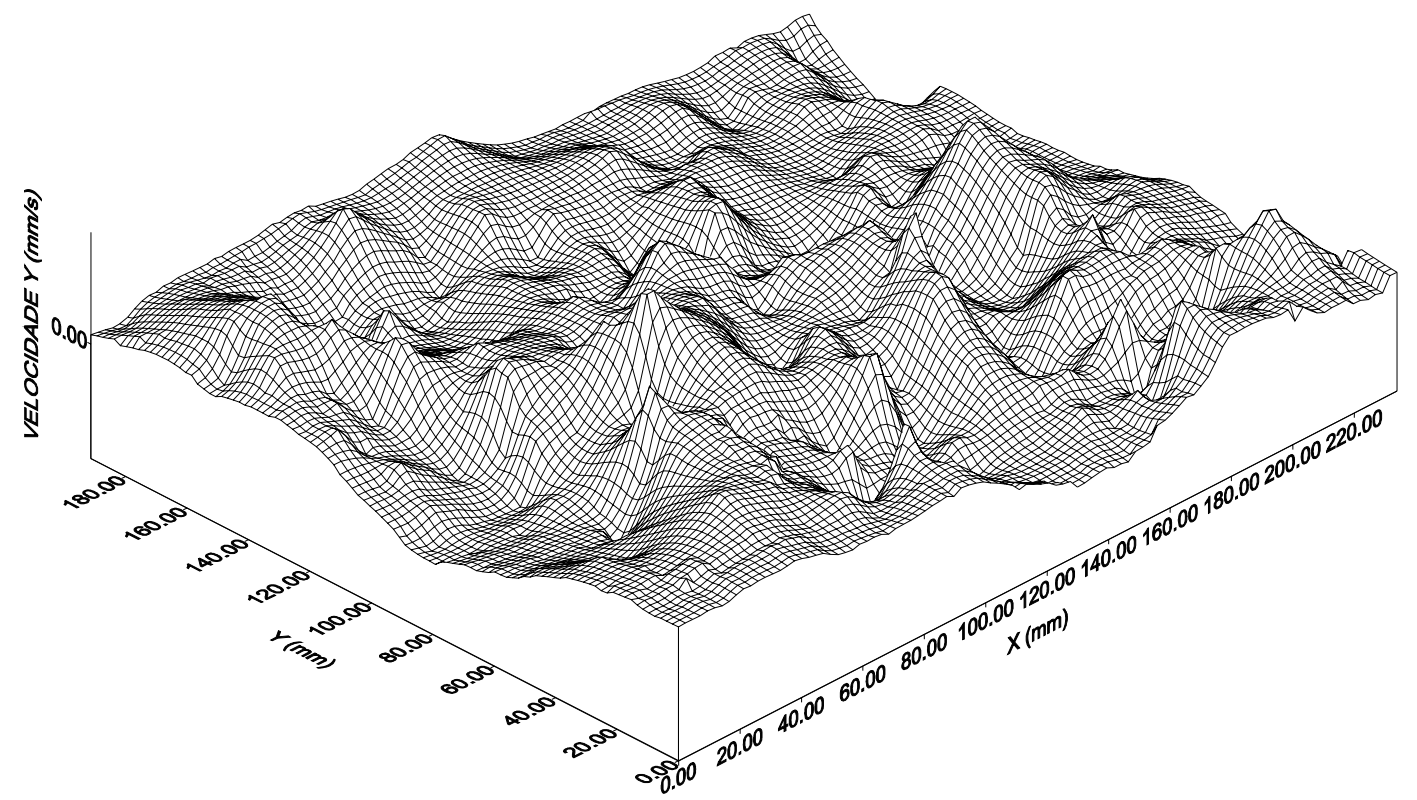

FIGURA 64. Visualização da Componente da Velocidade Horizontal na direção Y com a grade de malha quadrada de espaçamento entre barras de $3,90 \mathrm{~cm}$ e rotação de $240 \mathrm{rpm}$

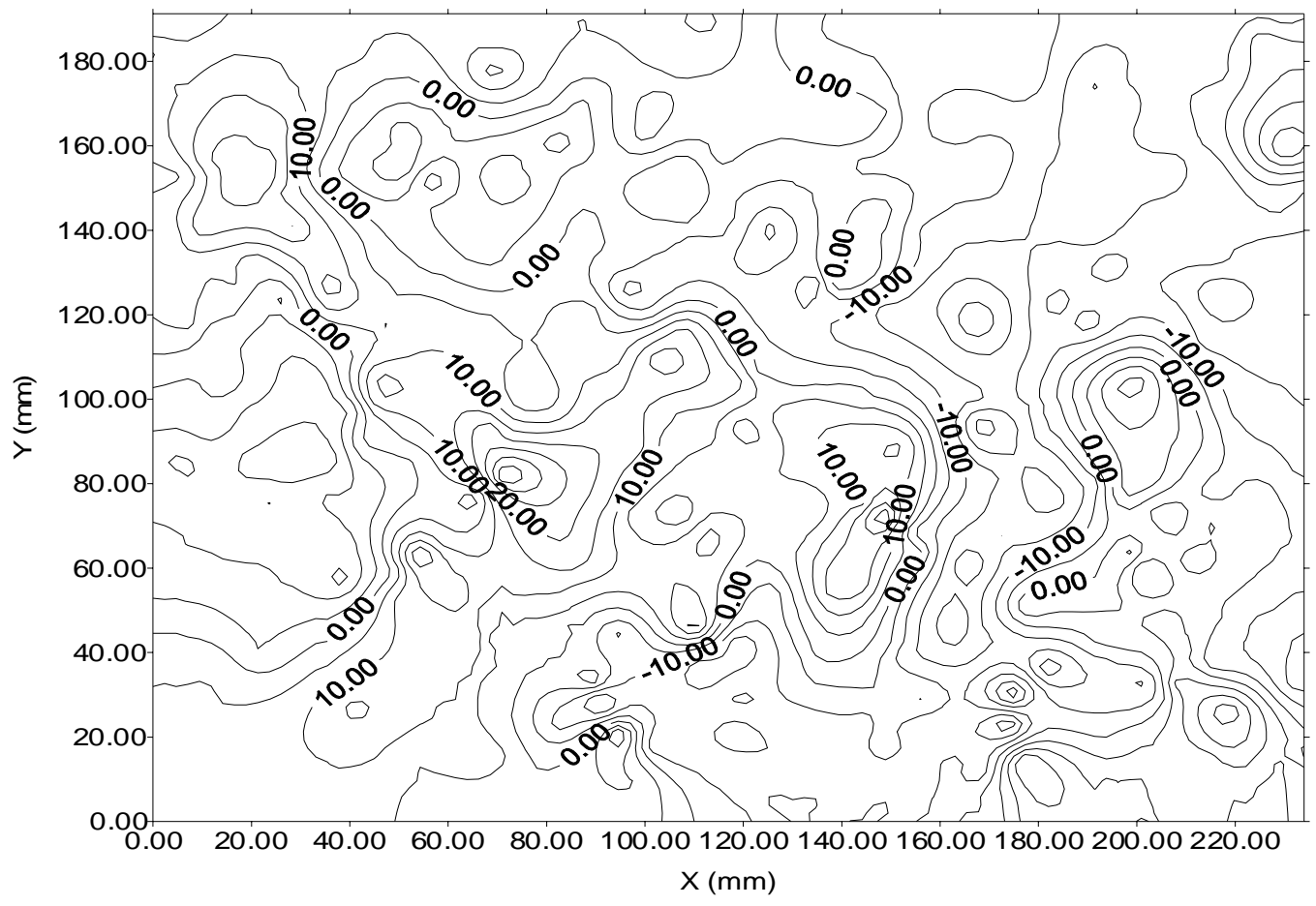

FIGURA 65. Visualização das Isolinhas da Componente da Velocidade Horizontal na direção Y com a grade de malha quadrada de espaçamento entre barras de 3,90 cm e rotação de 240 rpm 


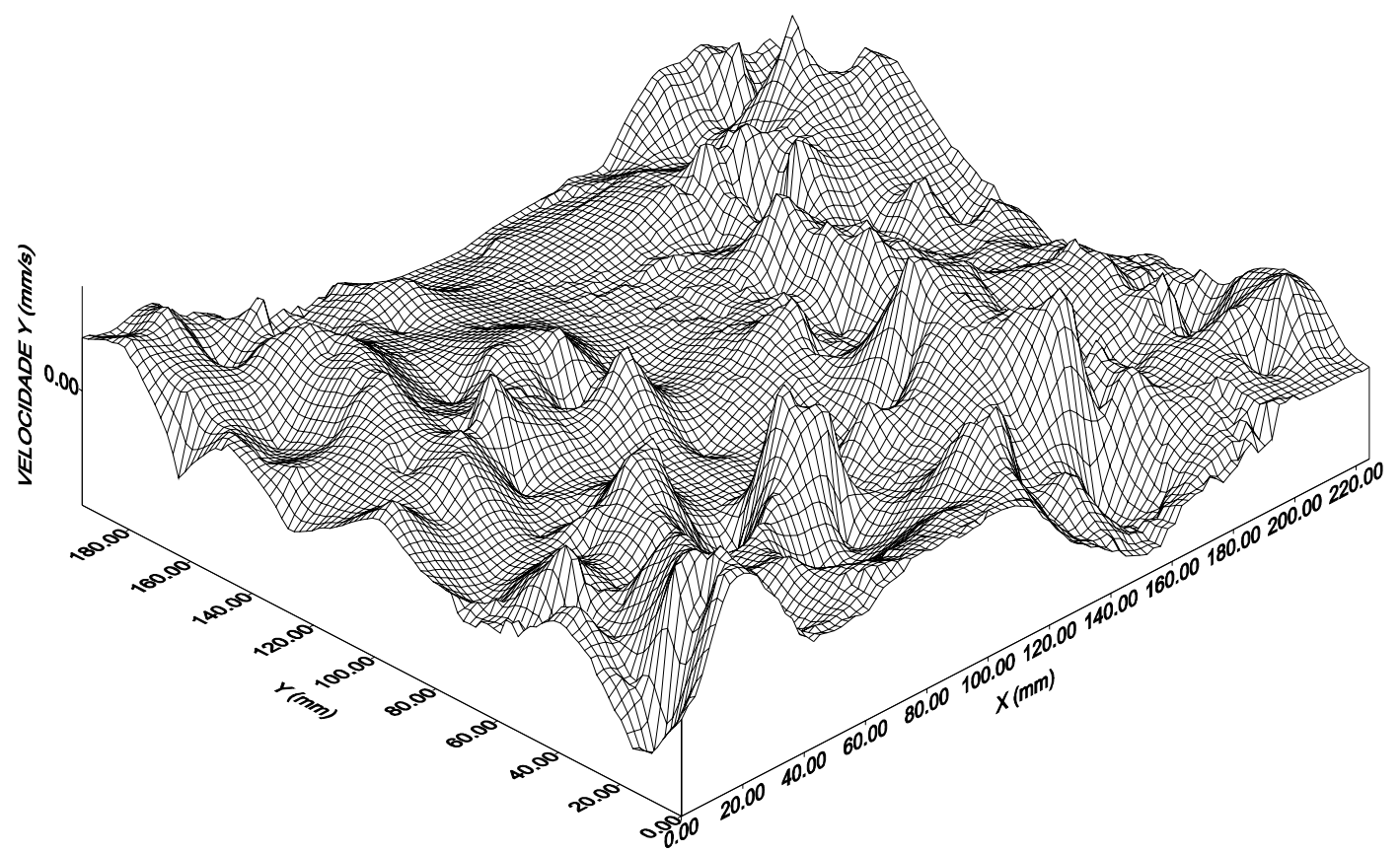

FIGURA 66. Visualização da Componente da Velocidade Horizontal na direção Y com a grade de malha quadrada de espaçamento entre barras de $6,45 \mathrm{~cm}$ e rotação de $180 \mathrm{rpm}$.

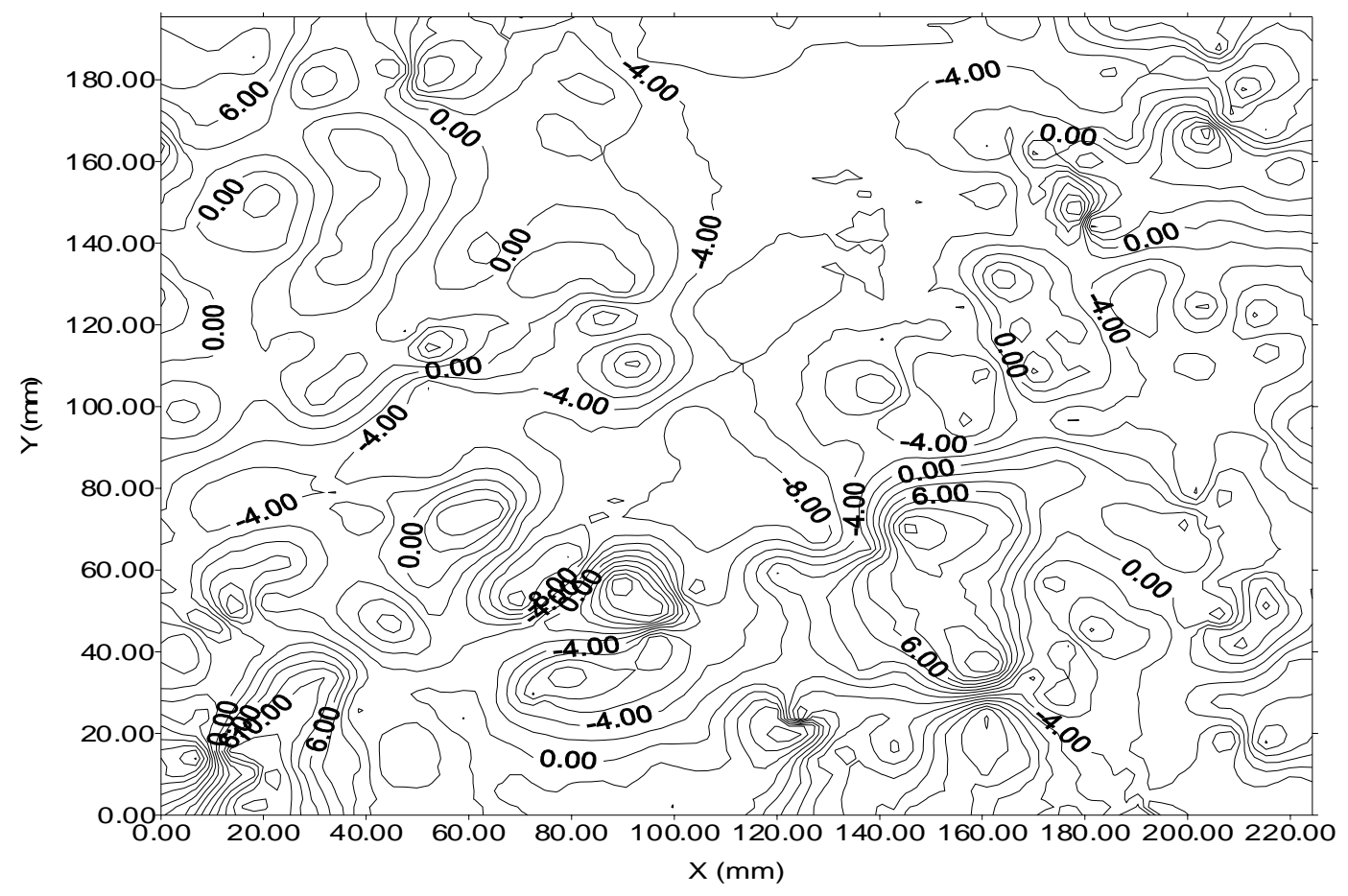

FIGURA 67. Visualização das Isolinhas da Componente da Velocidade Horizontal na direção Y com a grade de malha quadrada de espaçamento entre barras de 6,45 cm e rotação de 180 rpm 


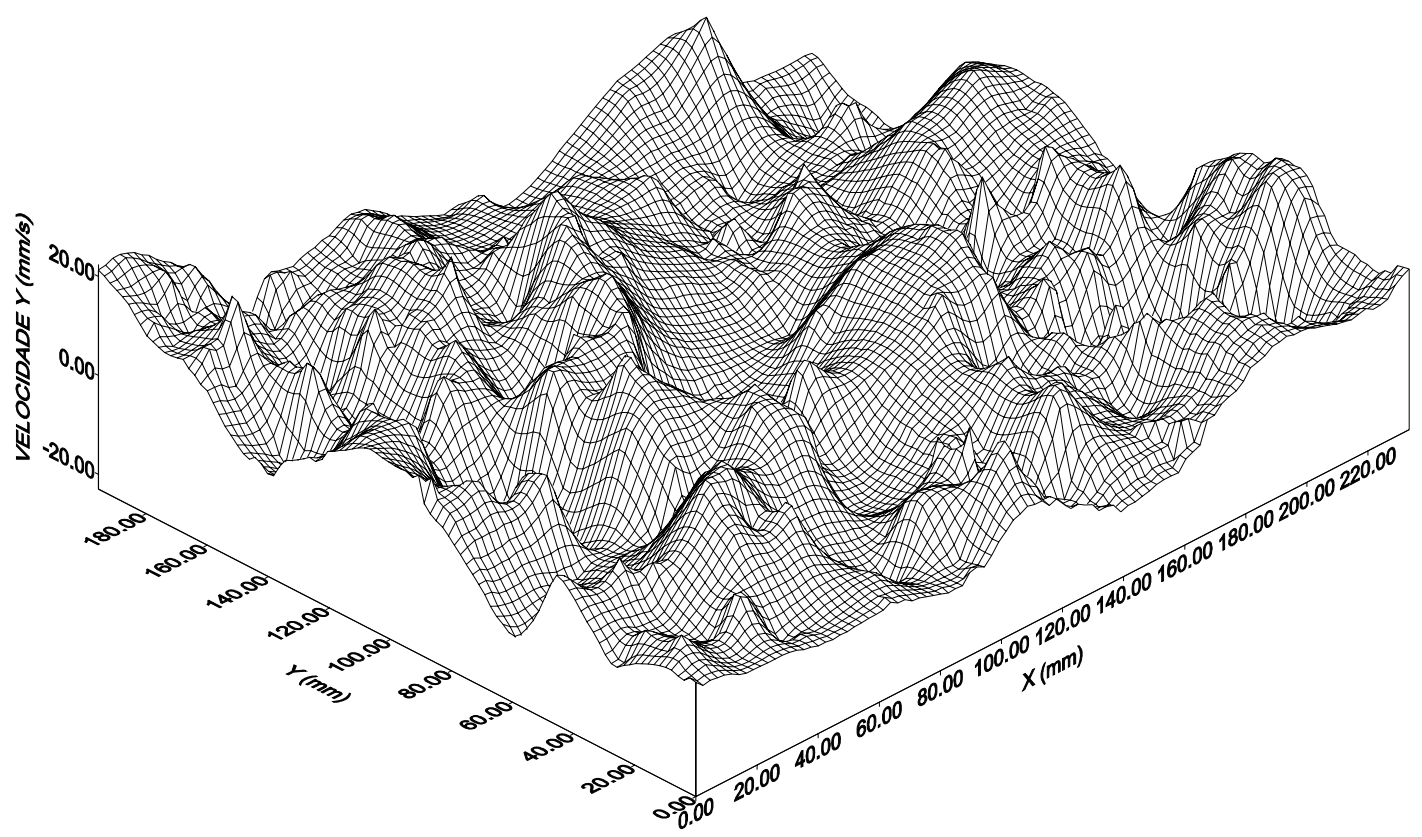

FIGURA 68. Visualização da Componente da Velocidade Horizontal na direção Y com a grade de malha quadrada de espaçamento entre barras de $6,45 \mathrm{~cm}$ e rotação de $200 \mathrm{rpm}$

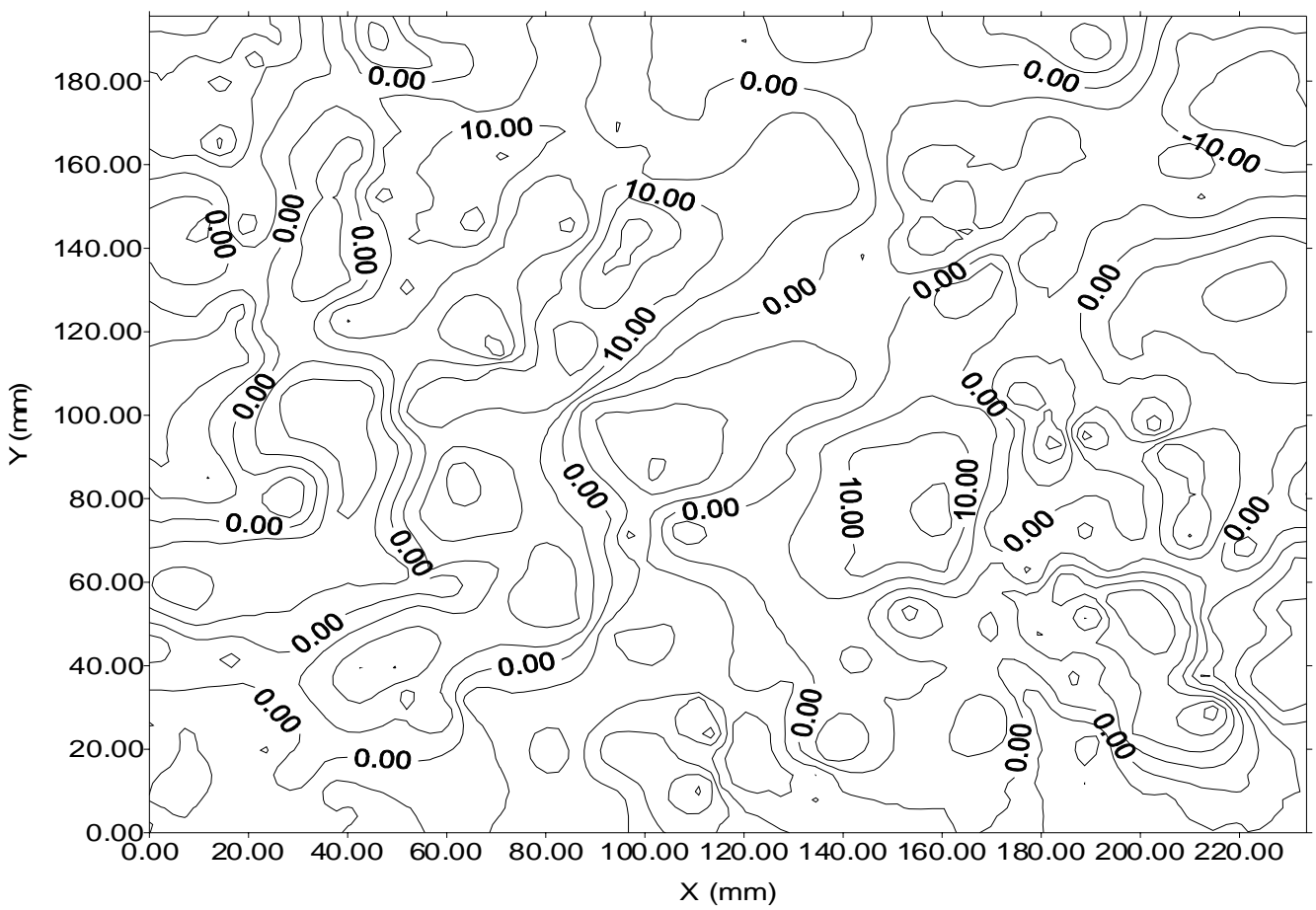

FIGURA 69. Visualização das Isolinhas da Componente da Velocidade Horizontal na direção Y com a grade de malha quadrada de espaçamento entre barras de 6,45 cm e rotação de 200 rpm 


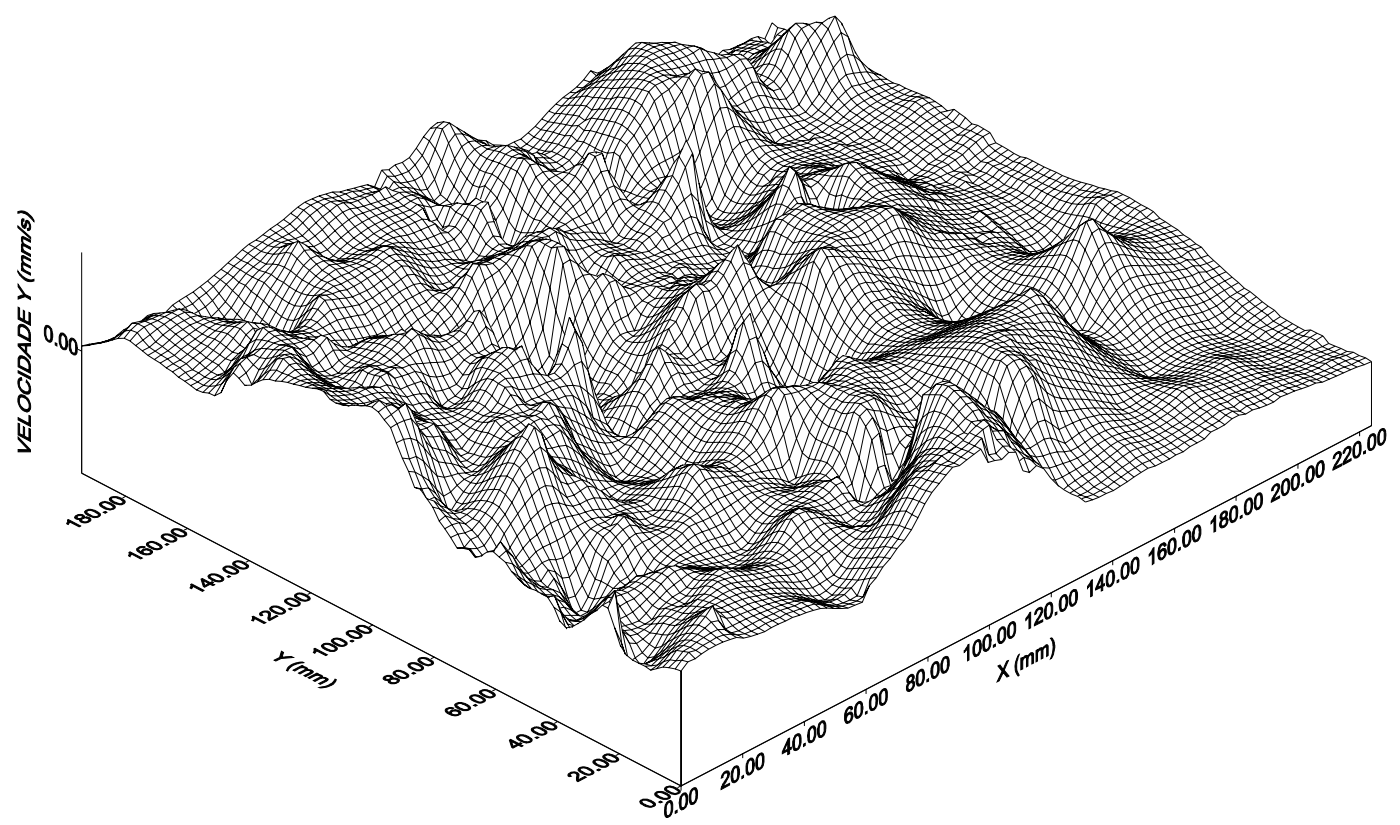

FIGURA 70. Visualização da Componente da Velocidade Horizontal na direção Y com a grade de malha quadrada de espaçamento entre barras de $6,45 \mathrm{~cm}$ e rotação de $220 \mathrm{rpm}$

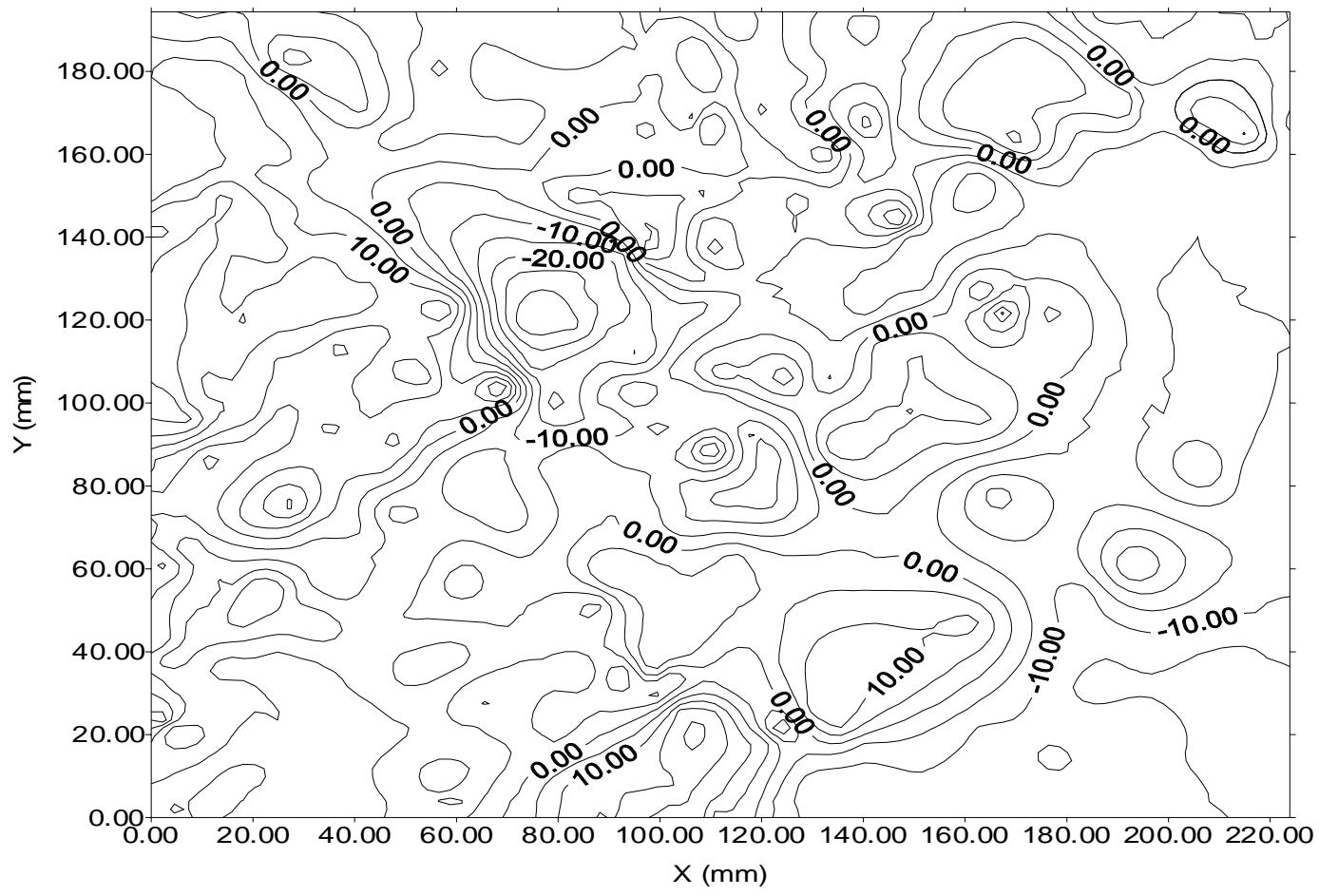

FIGURA 71. Visualização das Isolinhas da Componente da Velocidade Horizontal na direção Y com a grade de malha quadrada de espaçamento entre barras de 6,45 cm e rotação de 220 rpm 


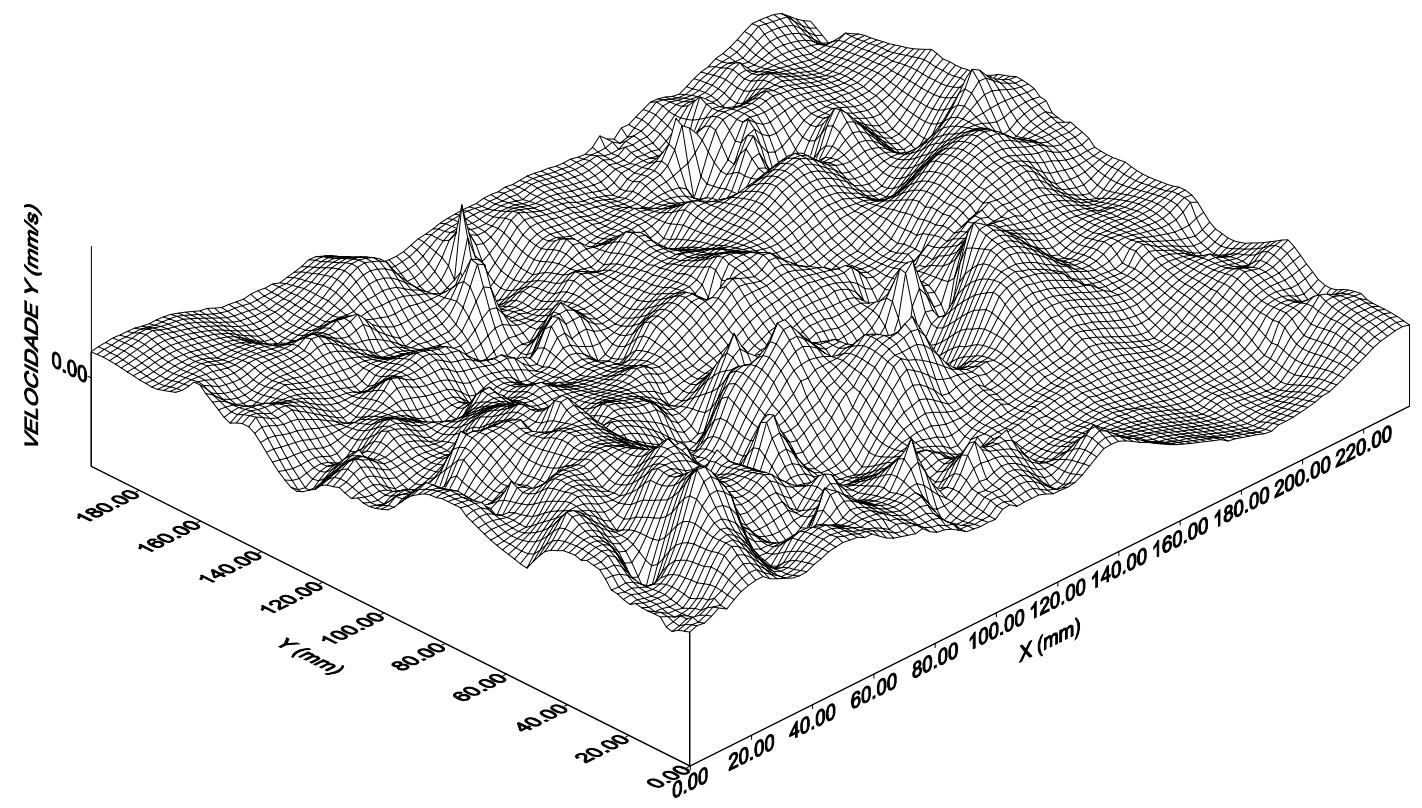

FIGURA 72. Visualização da Componente da Velocidade Horizontal na direção Y com a grade de malha quadrada de espaçamento entre barras de $6,45 \mathrm{~cm}$ e rotação de $250 \mathrm{rpm}$

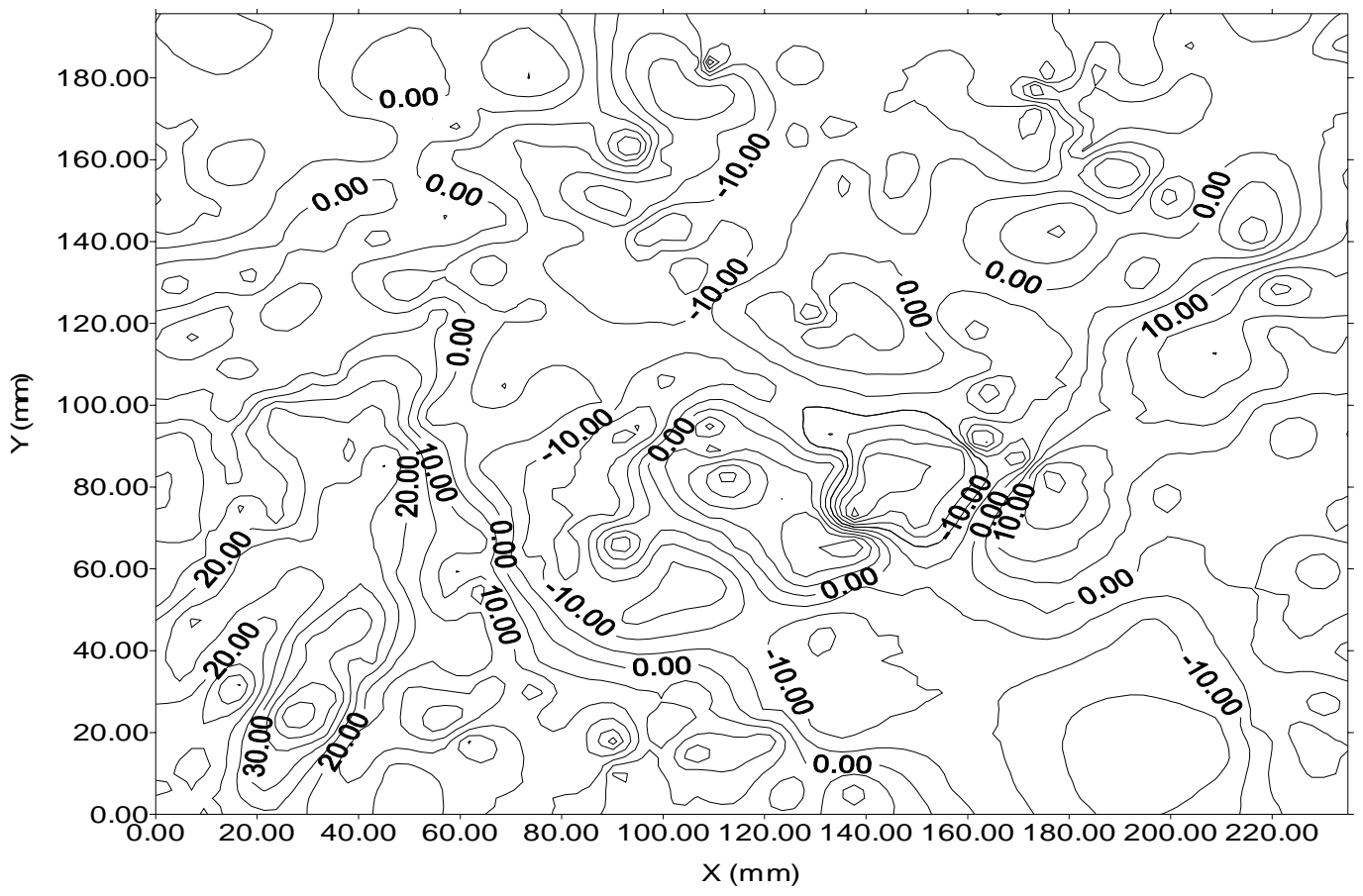

FIGURA 73. Visualização das Isolinhas da Componente da Velocidade Horizontal na direção Y com a grade de malha quadrada de espaçamento entre barras de 6,45 cm e rotação de 250 rpm 


\subsubsection{Gradiente de Velocidade na direção $\mathrm{z}$}

No capítulo 4 foi apresentada a metodologia para a obtenção do gradiente de velocidade vertical por meio da computação da equação (121), e os resultados interpolados serão apresentados nesta seção.

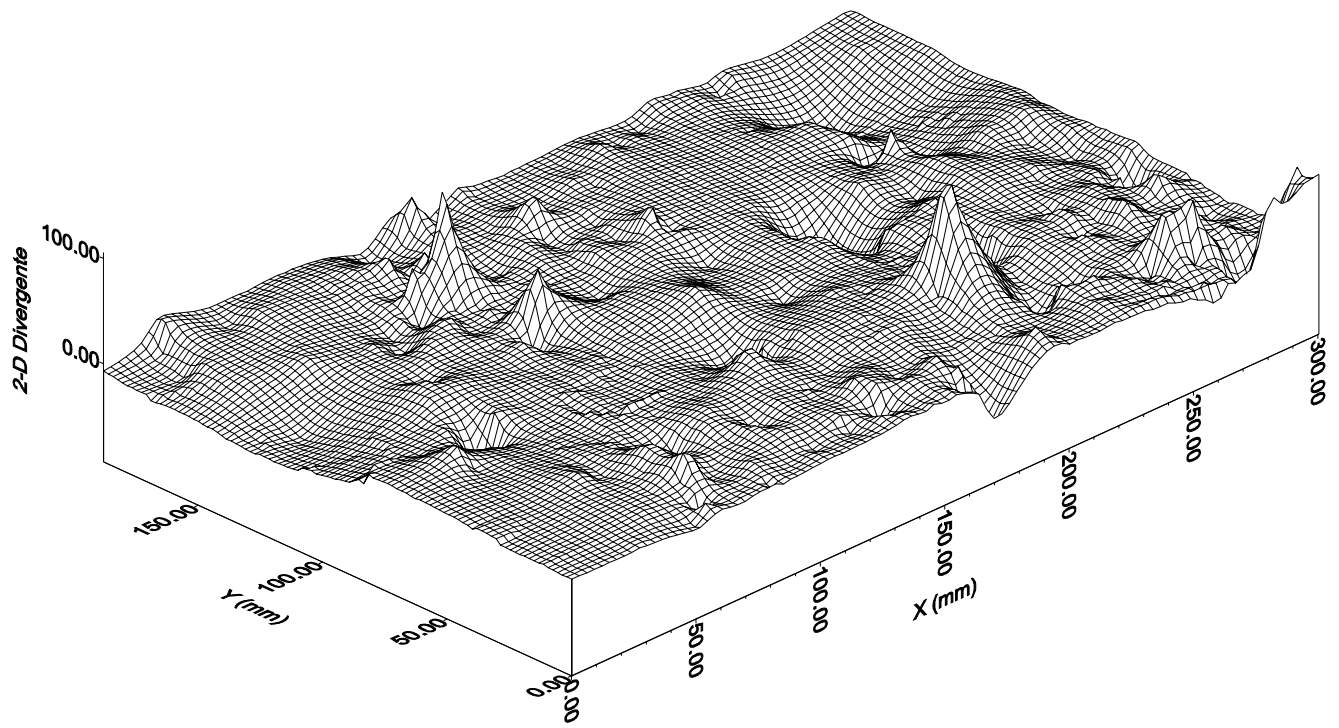

FIGURA 74. Visualização do Gradiente da Velocidade Vertical (direção Z) com a grade de malha quadrada de espaçamento entre barras de 2,65 cm e rotação de 120 rpm.

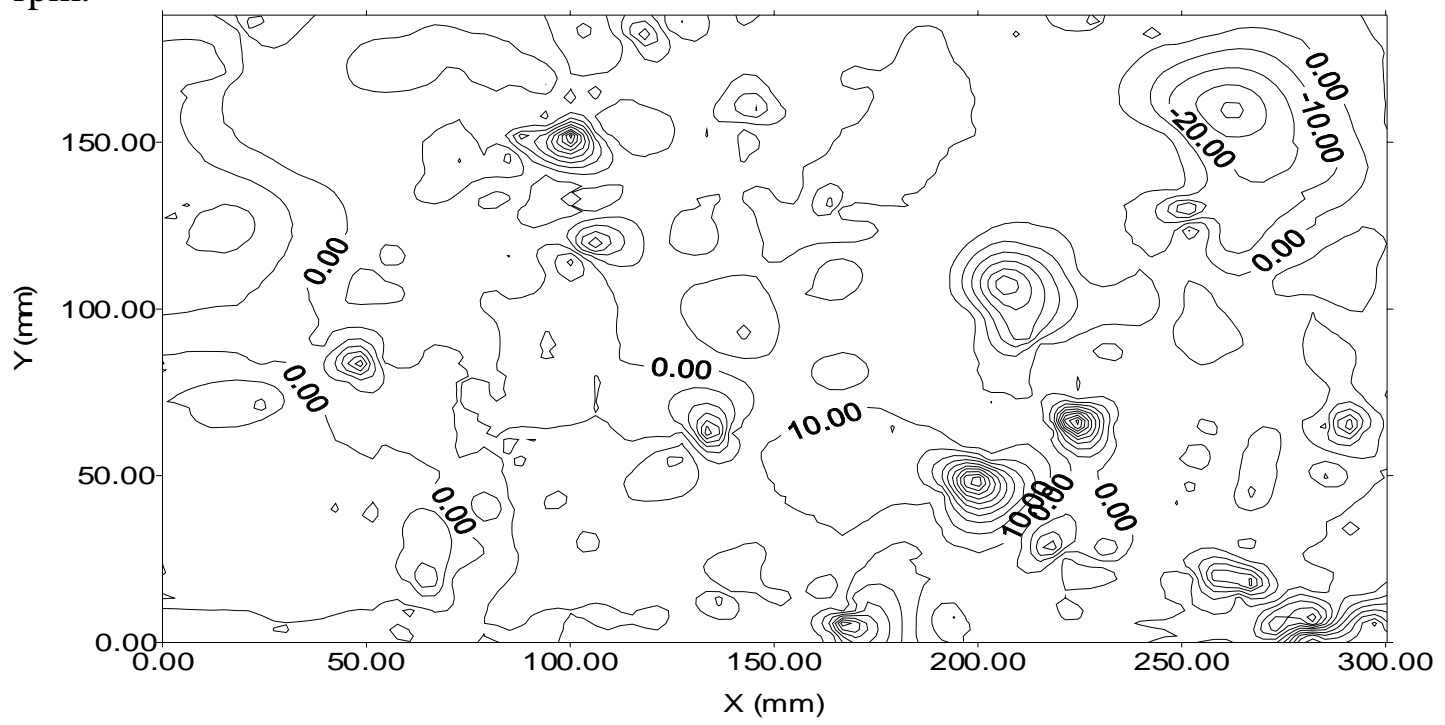

FIGURA 75. Visualização das Isolinhas do Gradiente da Velocidade Vertical (direção $Z$ ) com a grade de malha quadrada de espaçamento entre barras de 2,65 cm e rotação de 120 rpm. 


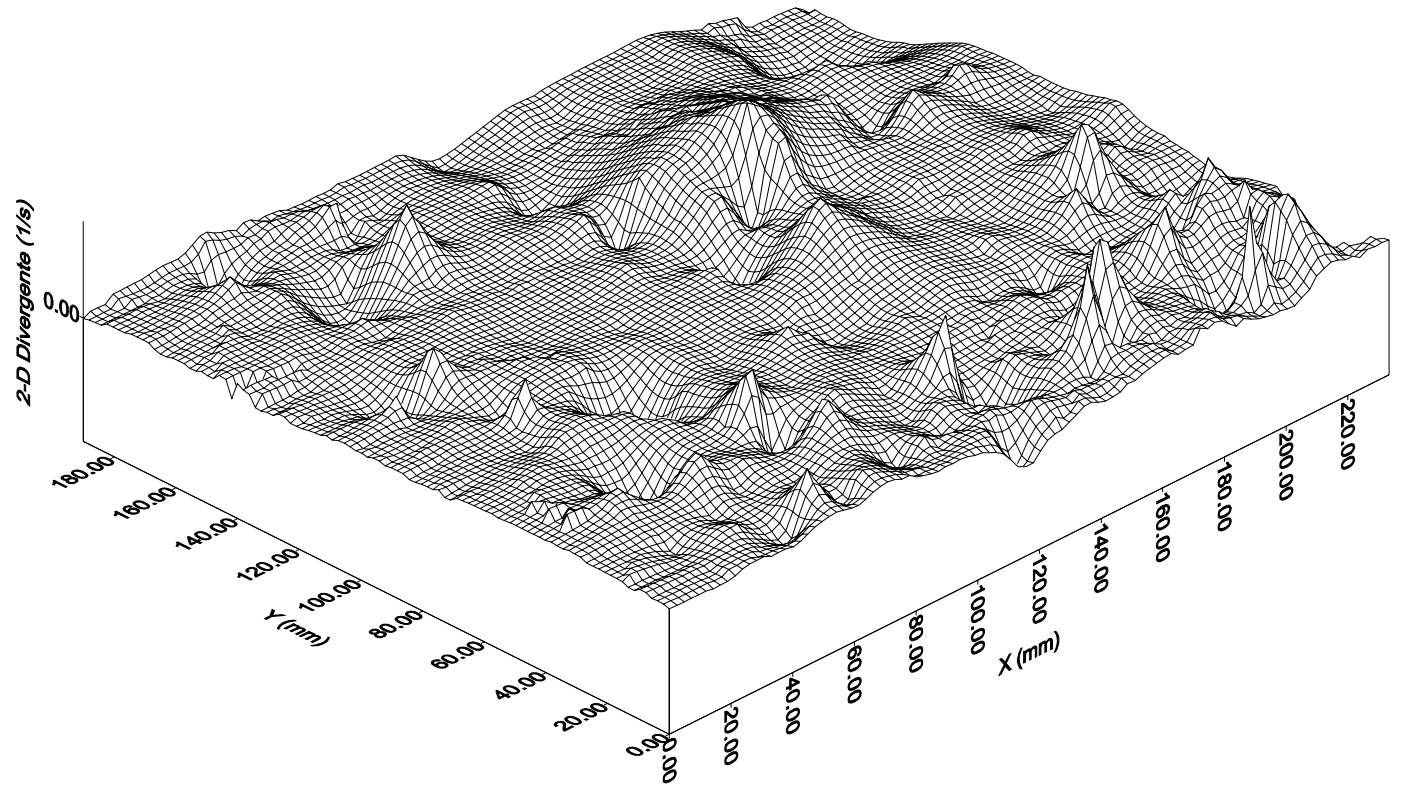

FIGURA 76. Visualização do Gradiente da Velocidade Vertical (direção Z) com a grade de malha quadrada de espaçamento entre barras de 2,65 cm e rotação de 140 rpm.

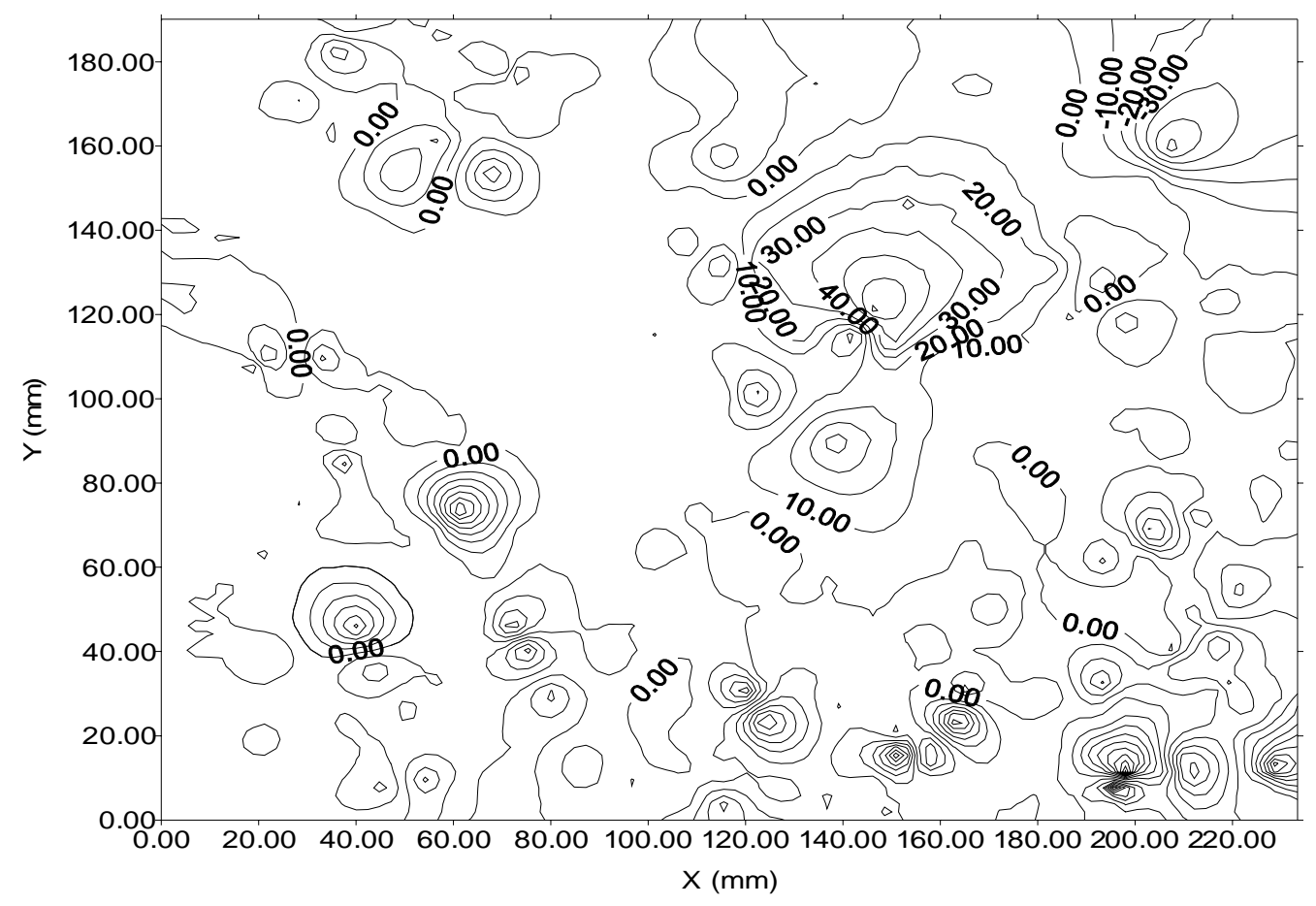

FIGURA 77. Visualização das Isolinhas do Gradiente da Velocidade Vertical (direção $Z$ ) com a grade de malha quadrada de espaçamento entre barras de 2,65 cm e rotação de $140 \mathrm{rpm}$. 


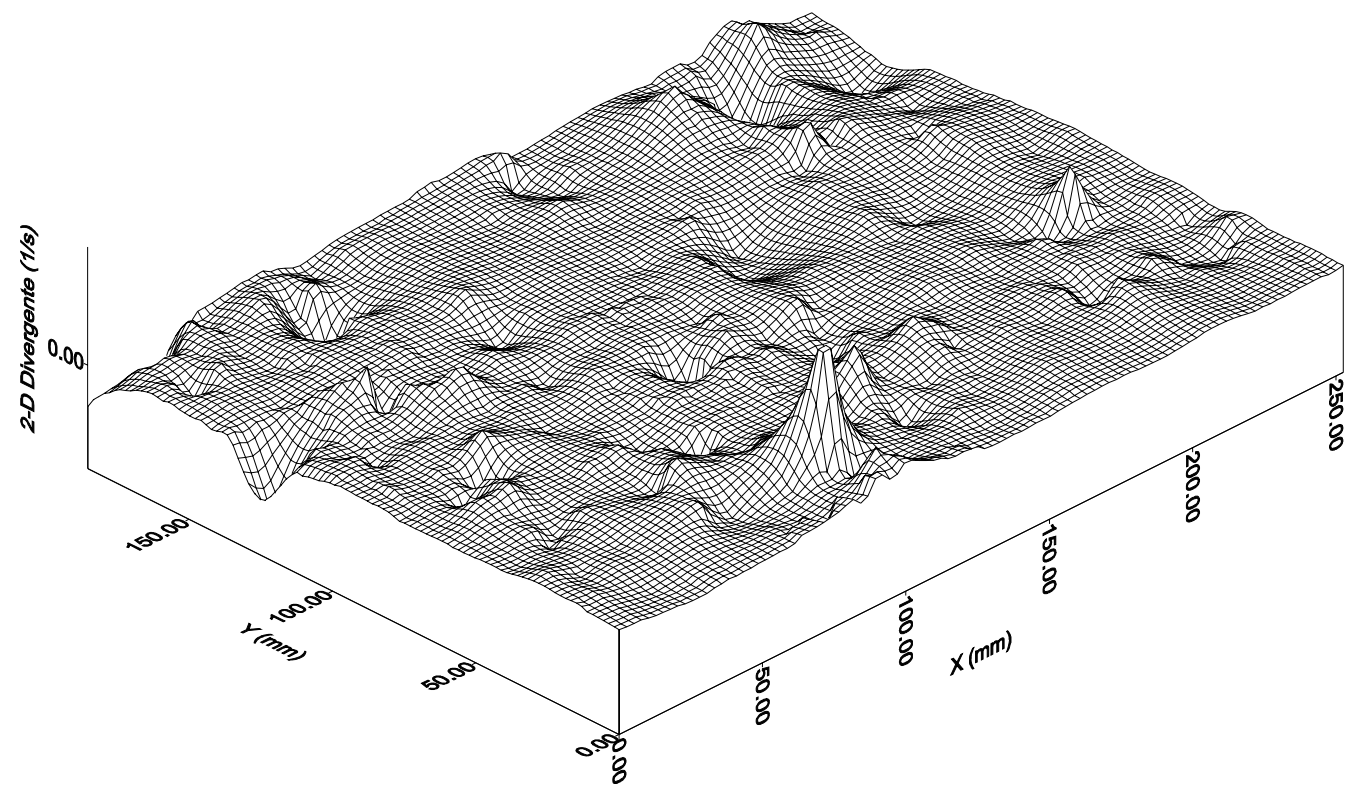

FIGURA 78. Visualização do Gradiente da Velocidade Vertical (direção Z) com a grade de malha quadrada de espaçamento entre barras de 2,65 cm e rotação de 160 rpm.

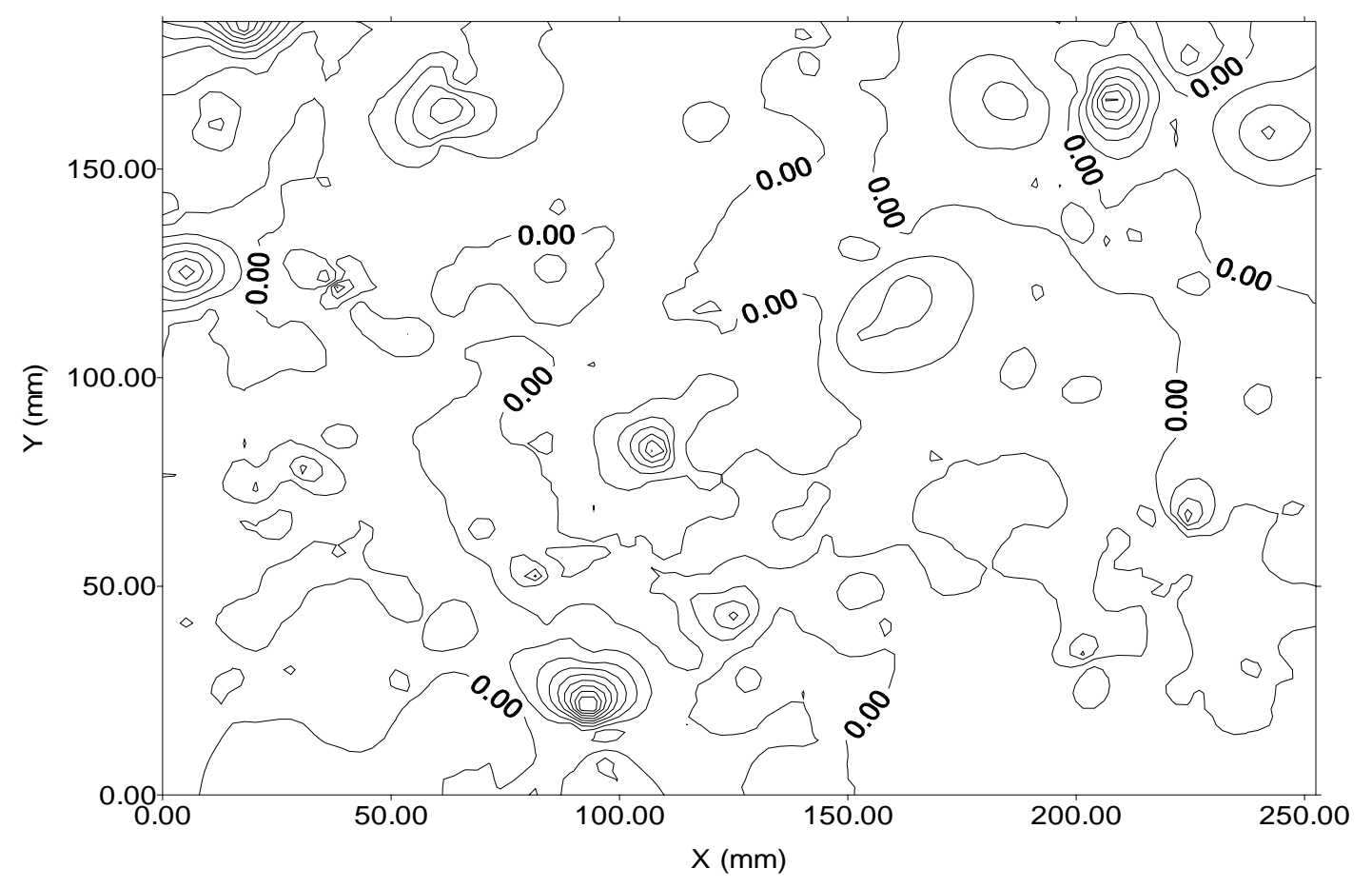

FIGURA 79. Visualização das Isolinhas do Gradiente da Velocidade Vertical (direção $Z$ ) com a grade de malha quadrada de espaçamento entre barras de 2,65 cm e rotação de $160 \mathrm{rpm}$. 


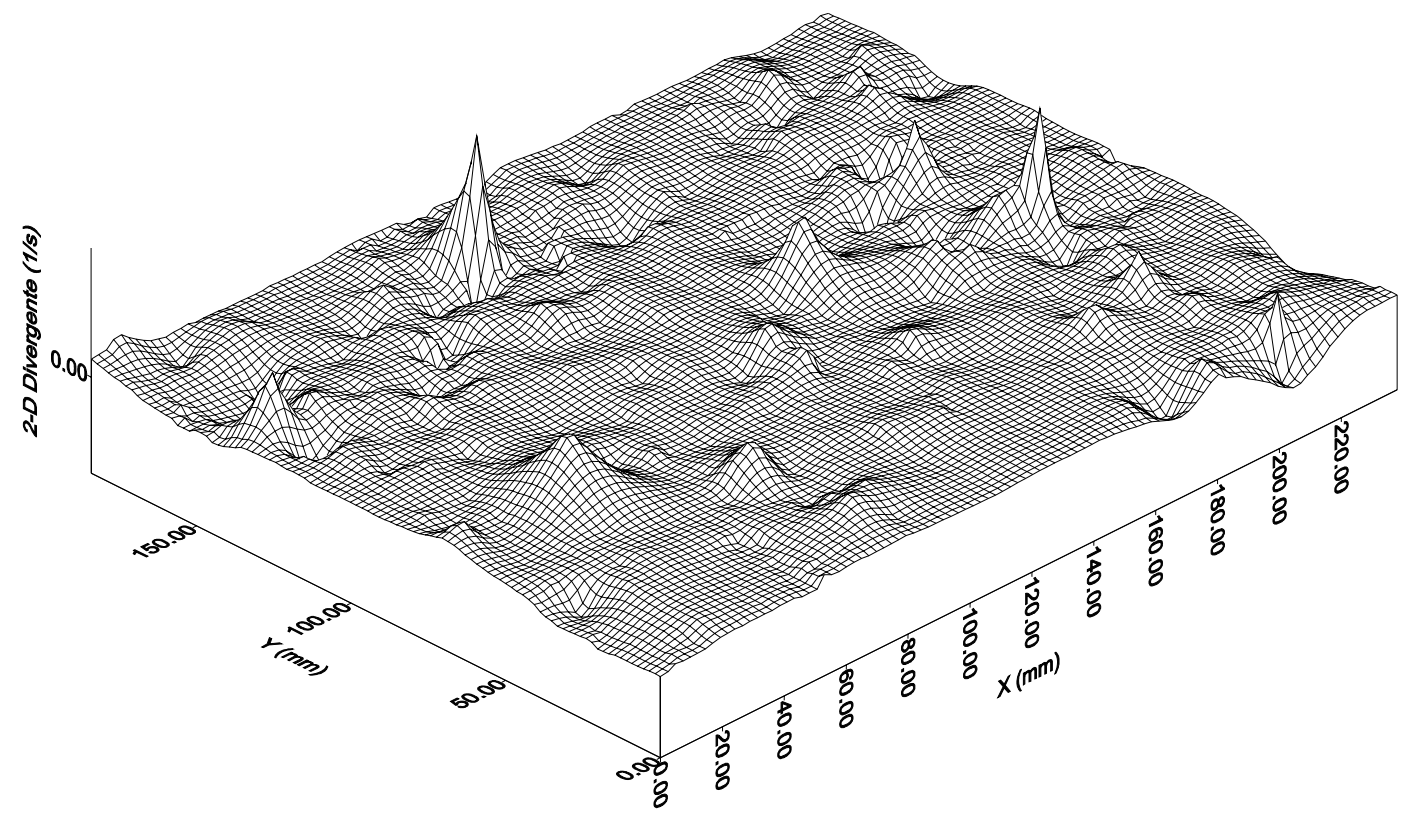

FIGURA 80. Visualização do Gradiente da Velocidade Vertical (direção Z) com a grade de malha quadrada de espaçamento entre barras de 2,65 cm e rotação de 180 rpm.

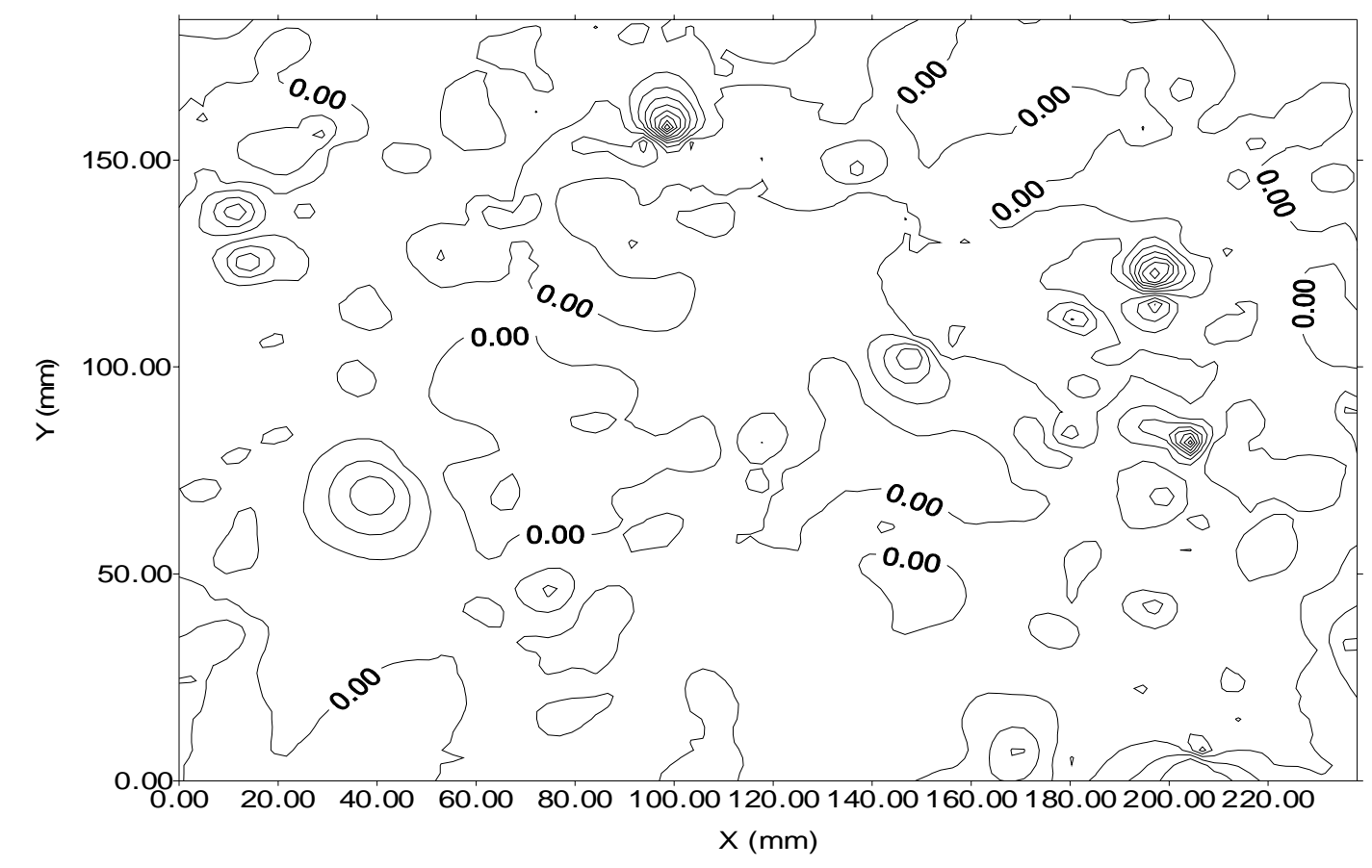

FIGURA 81. Visualização das Isolinhas do Gradiente da Velocidade Vertical (direção $Z$ ) com a grade de malha quadrada de espaçamento entre barras de 2,65 cm e rotação de $180 \mathrm{rpm}$. 


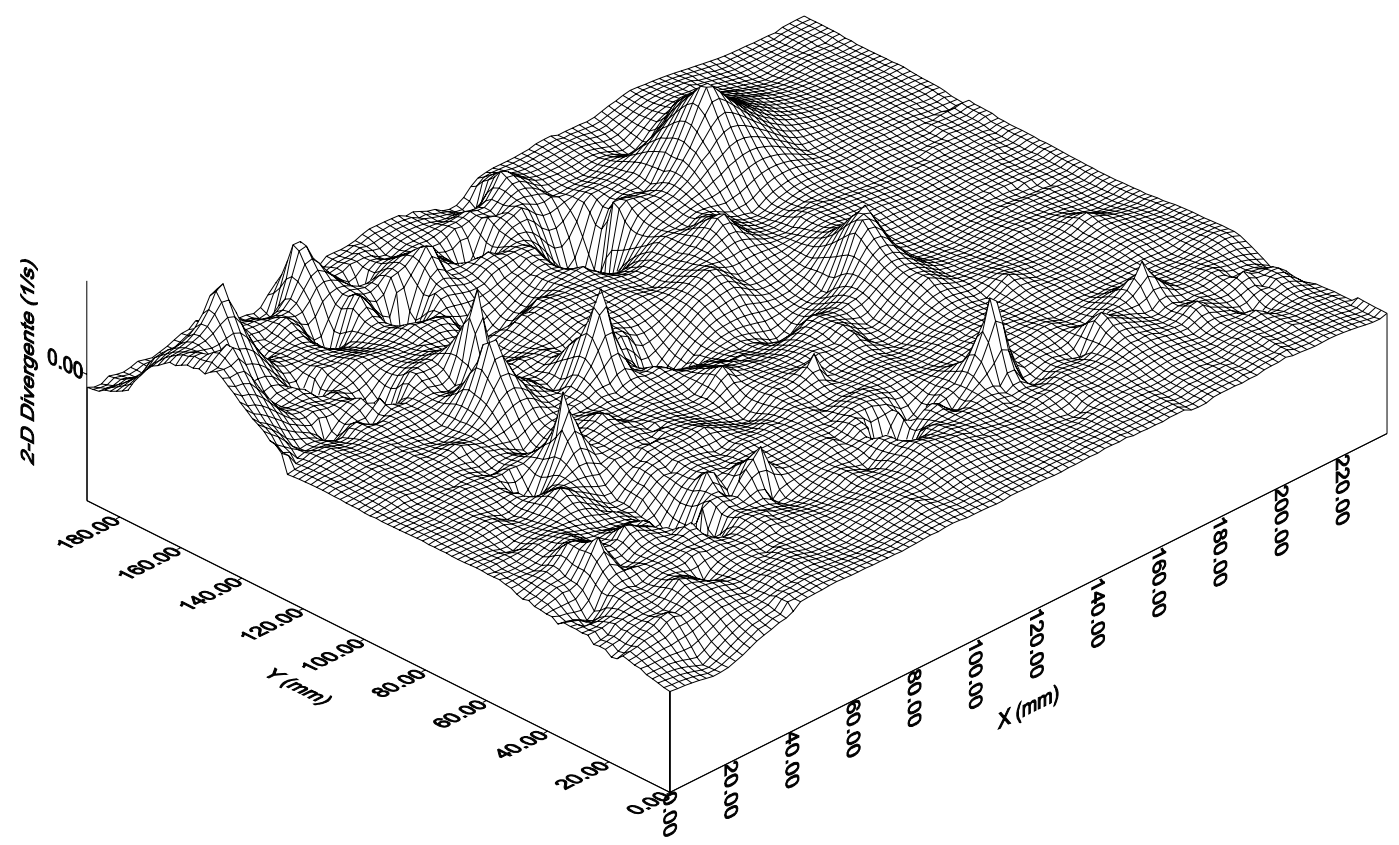

FIGURA 82. Visualização do Gradiente da Velocidade Vertical (direção Z) com a grade de malha quadrada de espaçamento entre barras de 2,65 cm e rotação de 200 rpm.

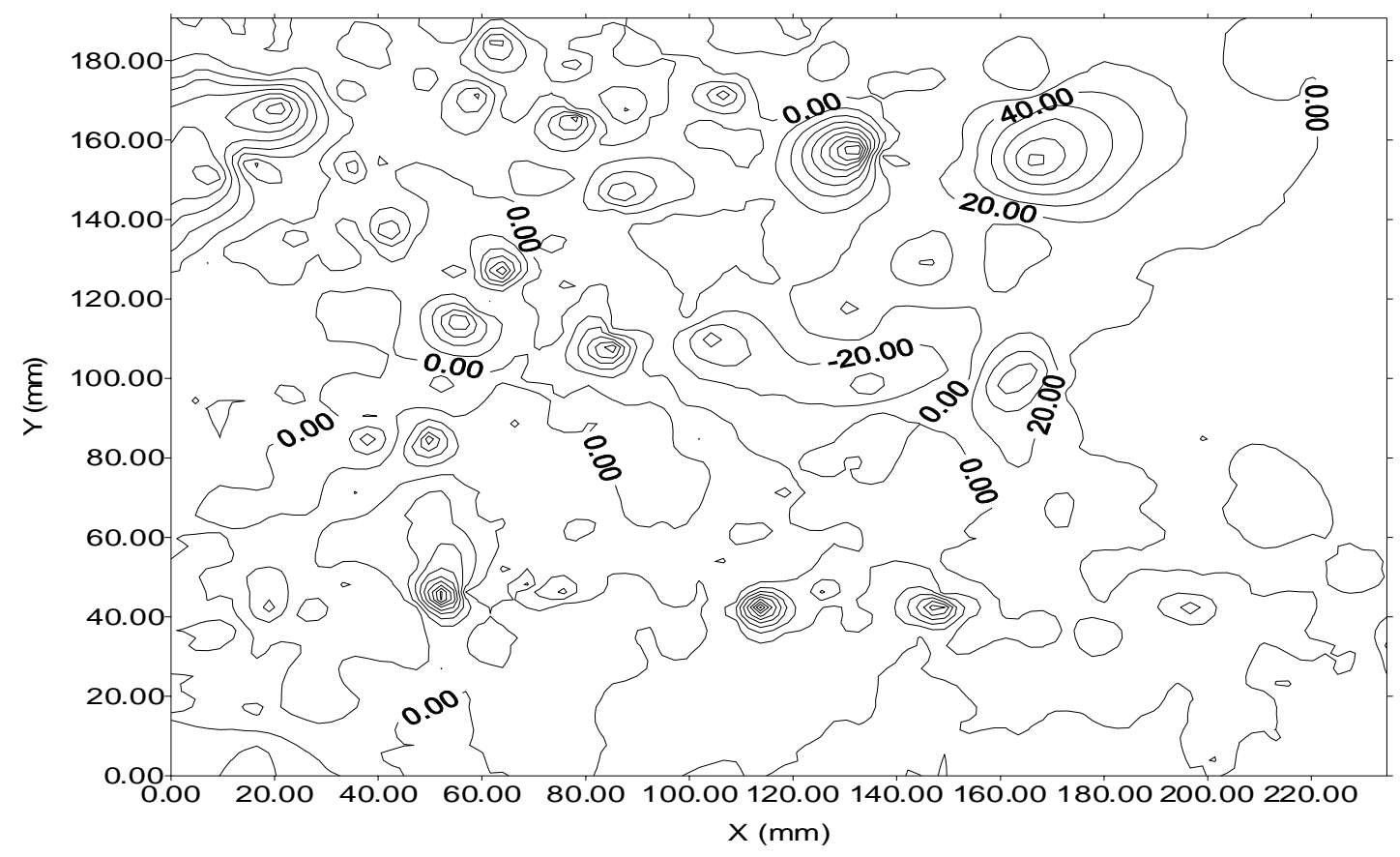

FIGURA 83. Visualização das Isolinhas do Gradiente da Velocidade Vertical (direção $Z$ ) com a grade de malha quadrada de espaçamento entre barras de 2,65 cm e rotação de 200 rpm. 


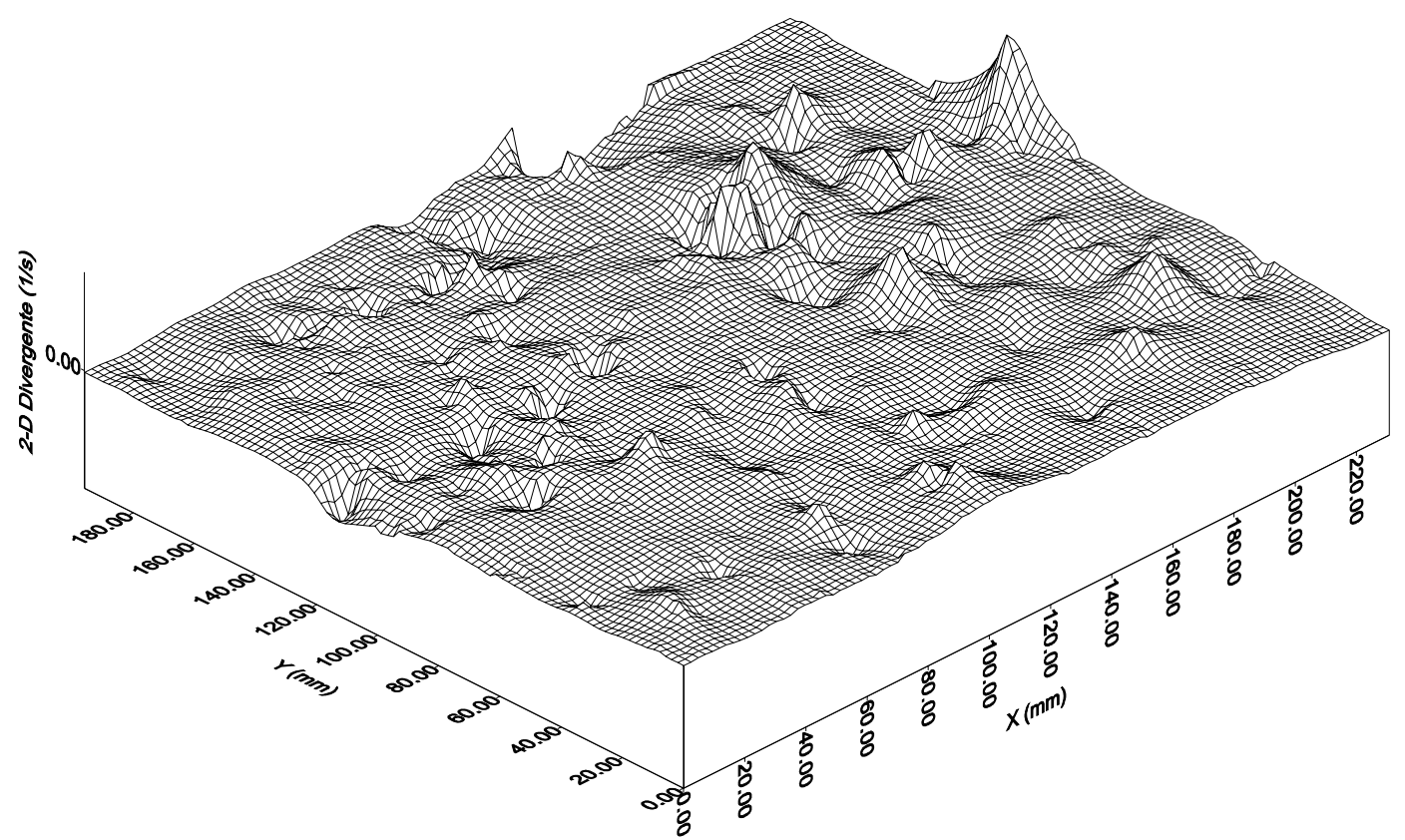

FIGURA 84. Visualização do Gradiente da Velocidade Vertical (direção Z) com a grade de malha quadrada de espaçamento entre barras de 3,90 cm e rotação de 140 rpm.

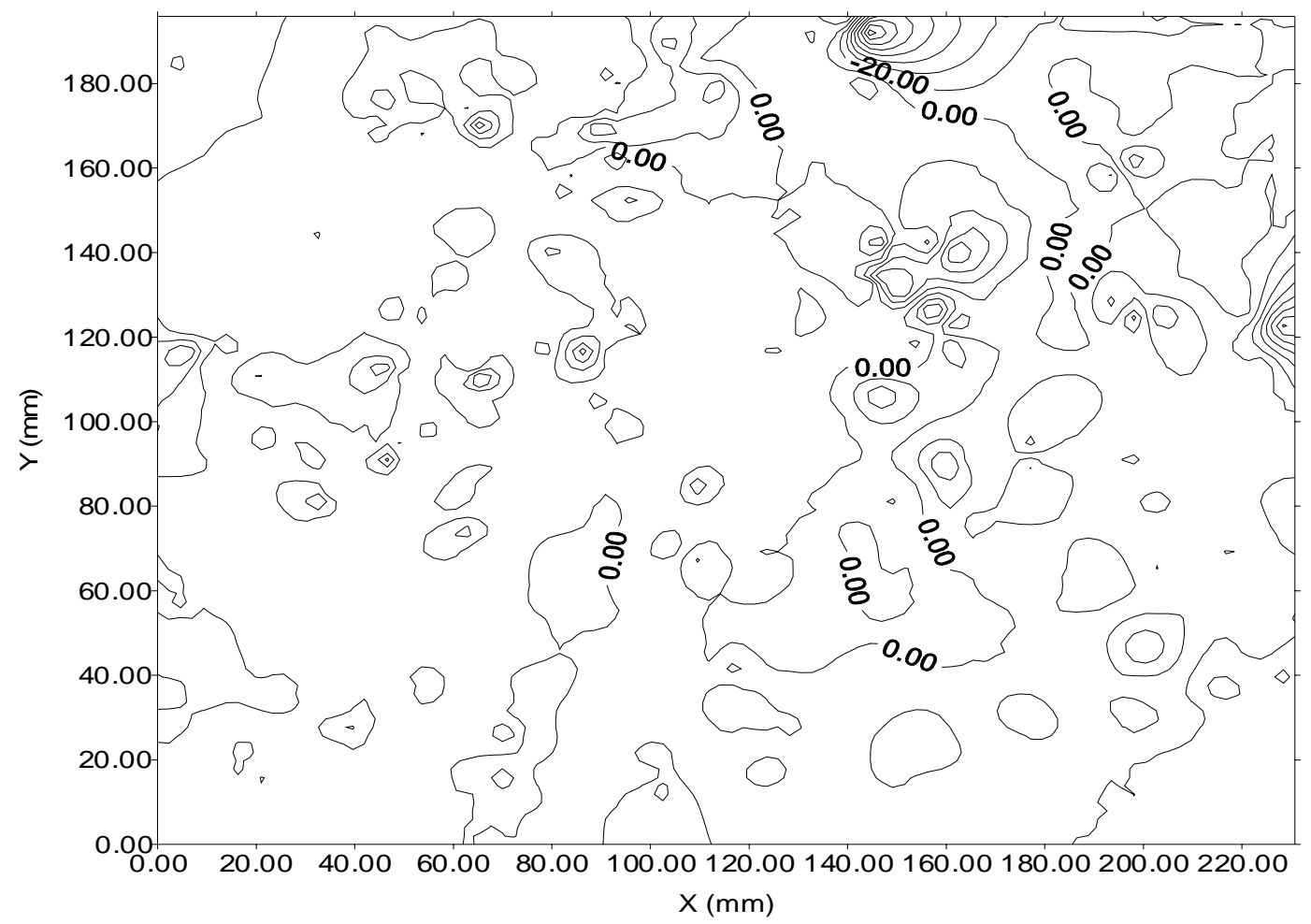

FIGURA 85. Visualização das Isolinhas do Gradiente da Velocidade Vertical (direção $Z$ ) com a grade de malha quadrada de espaçamento entre barras de 3,90 cm e rotação de $1400 \mathrm{rpm}$. 


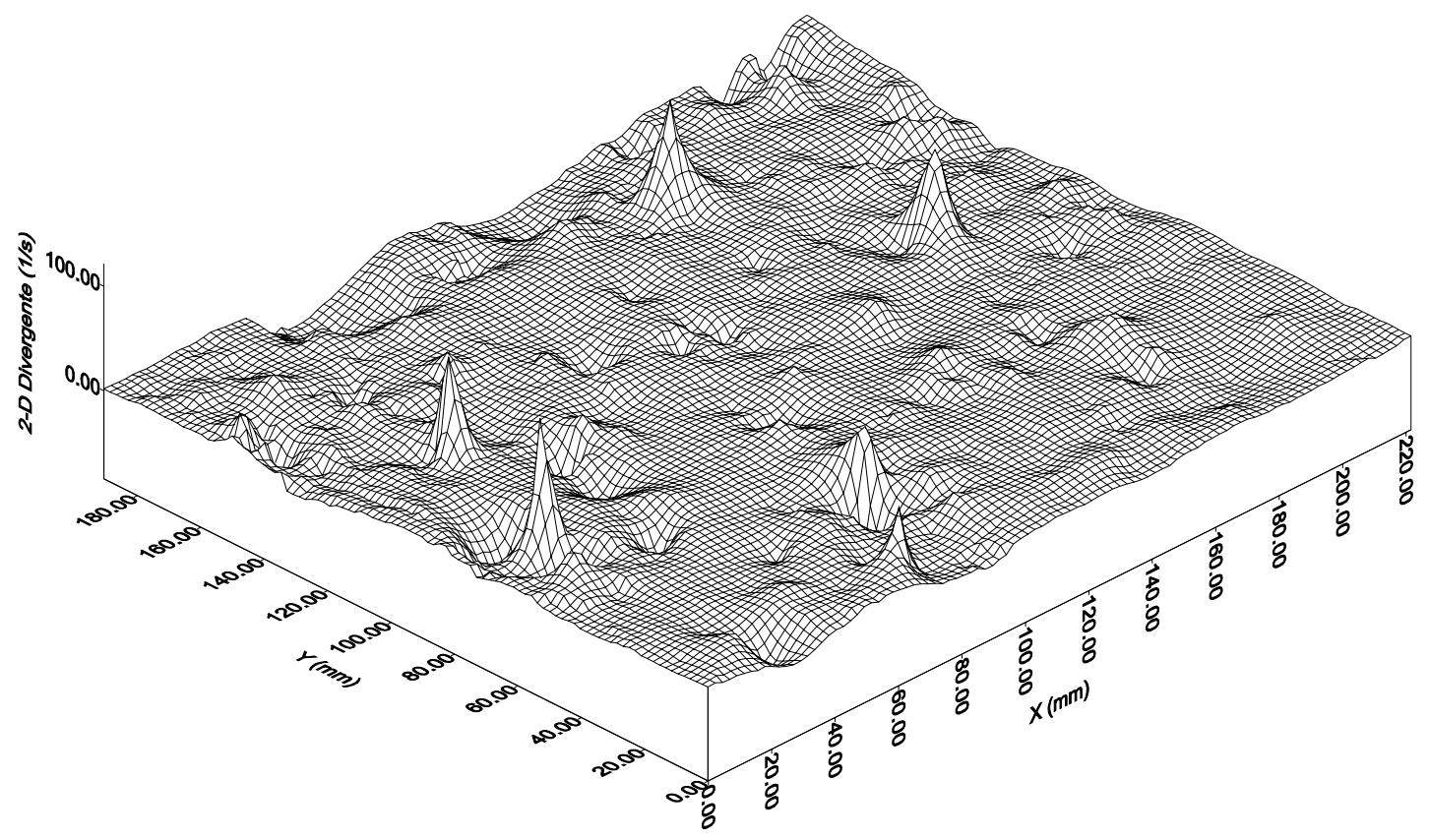

FIGURA 86. Visualização do Gradiente da Velocidade Vertical (direção Z) com a grade de malha quadrada de espaçamento entre barras de 3,90 cm e rotação de 160 rpm.

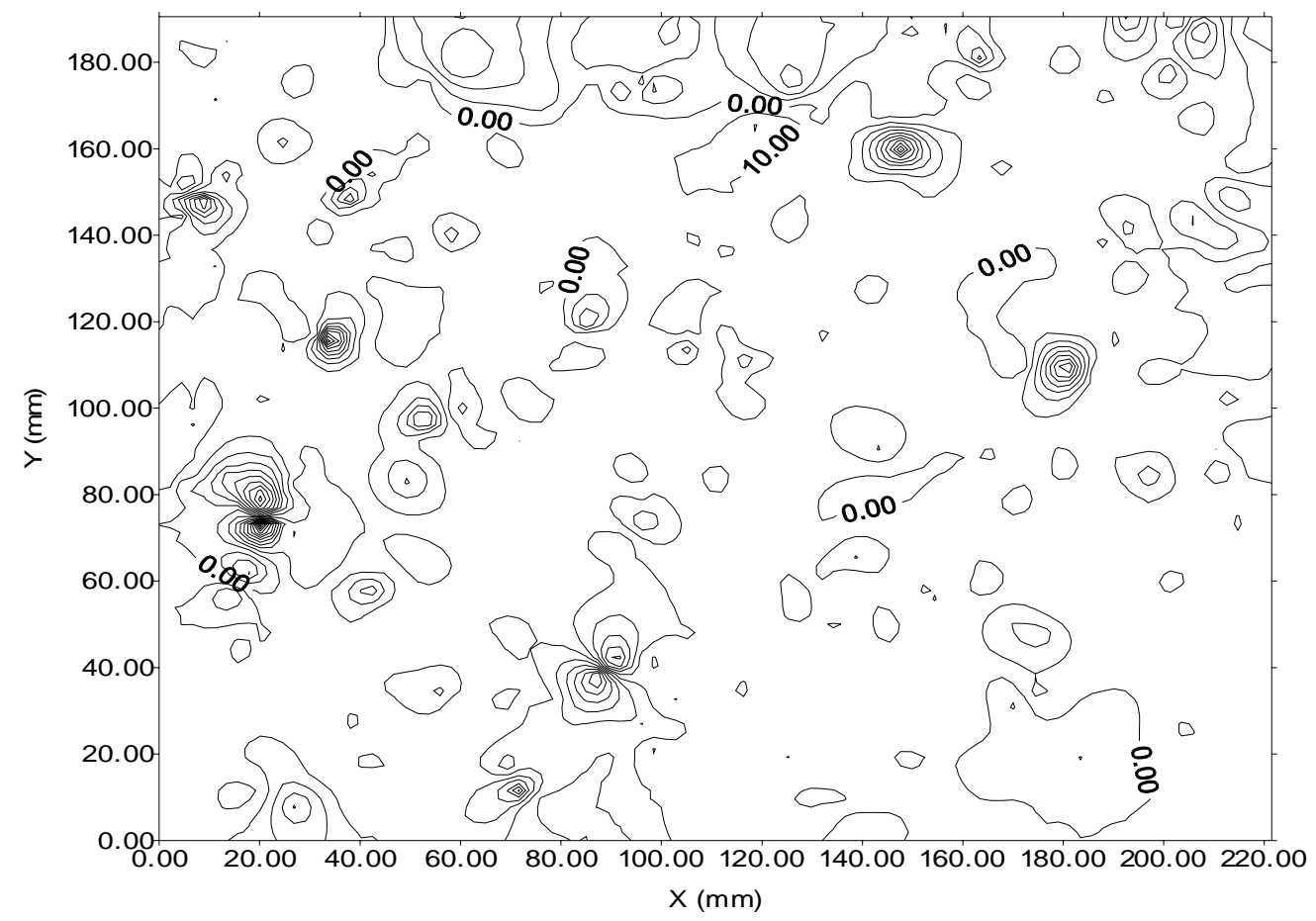

FIGURA 87. Visualização das Isolinhas do Gradiente da Velocidade Vertical (direção $Z$ ) com a grade de malha quadrada de espaçamento entre barras de 3,90 cm e rotação de $160 \mathrm{rpm}$. 


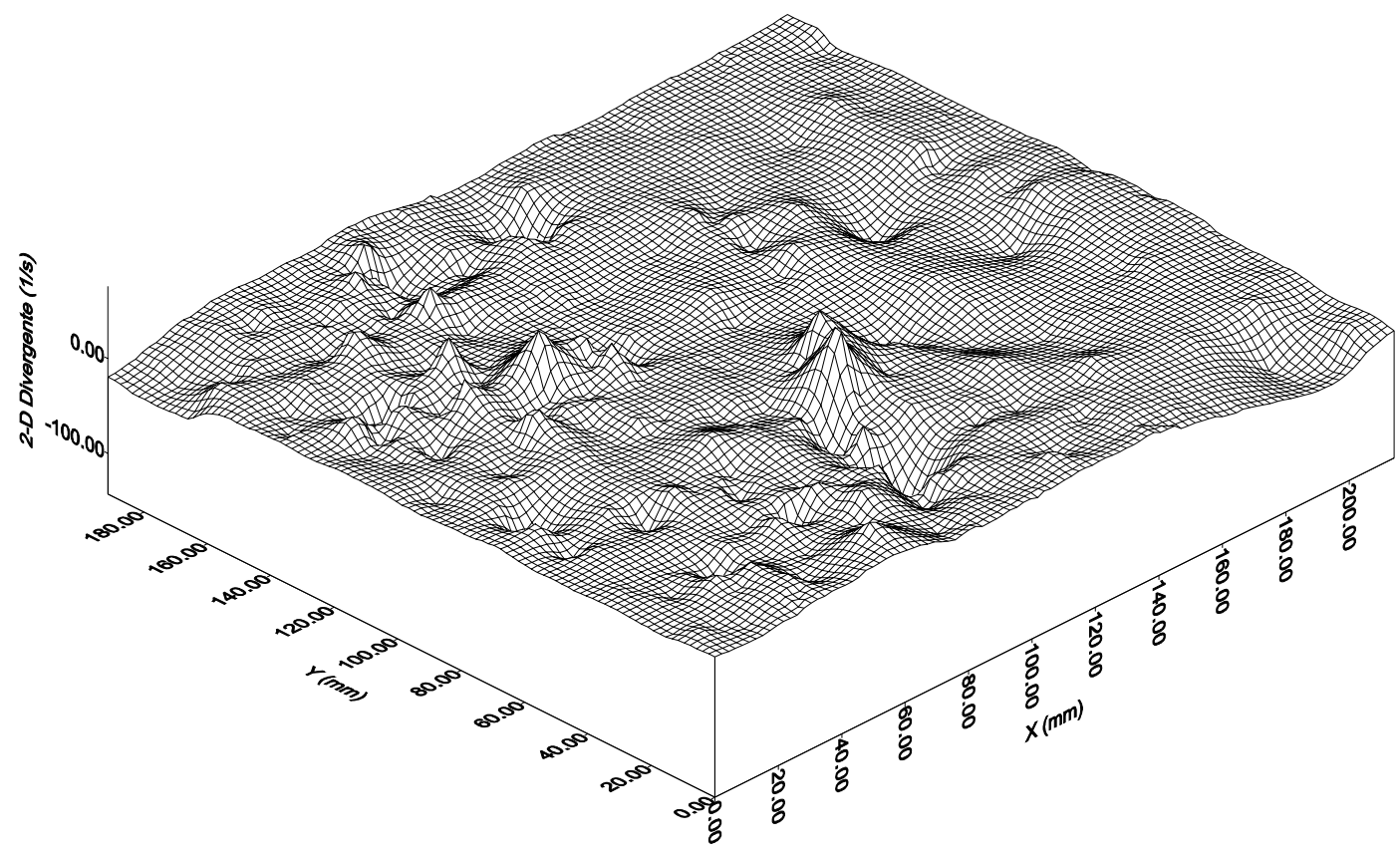

FIGURA 88. Visualização do Gradiente da Velocidade Vertical (direção Z) com a grade de malha quadrada de espaçamento entre barras de 3,90 cm e rotação de 180 rpm.

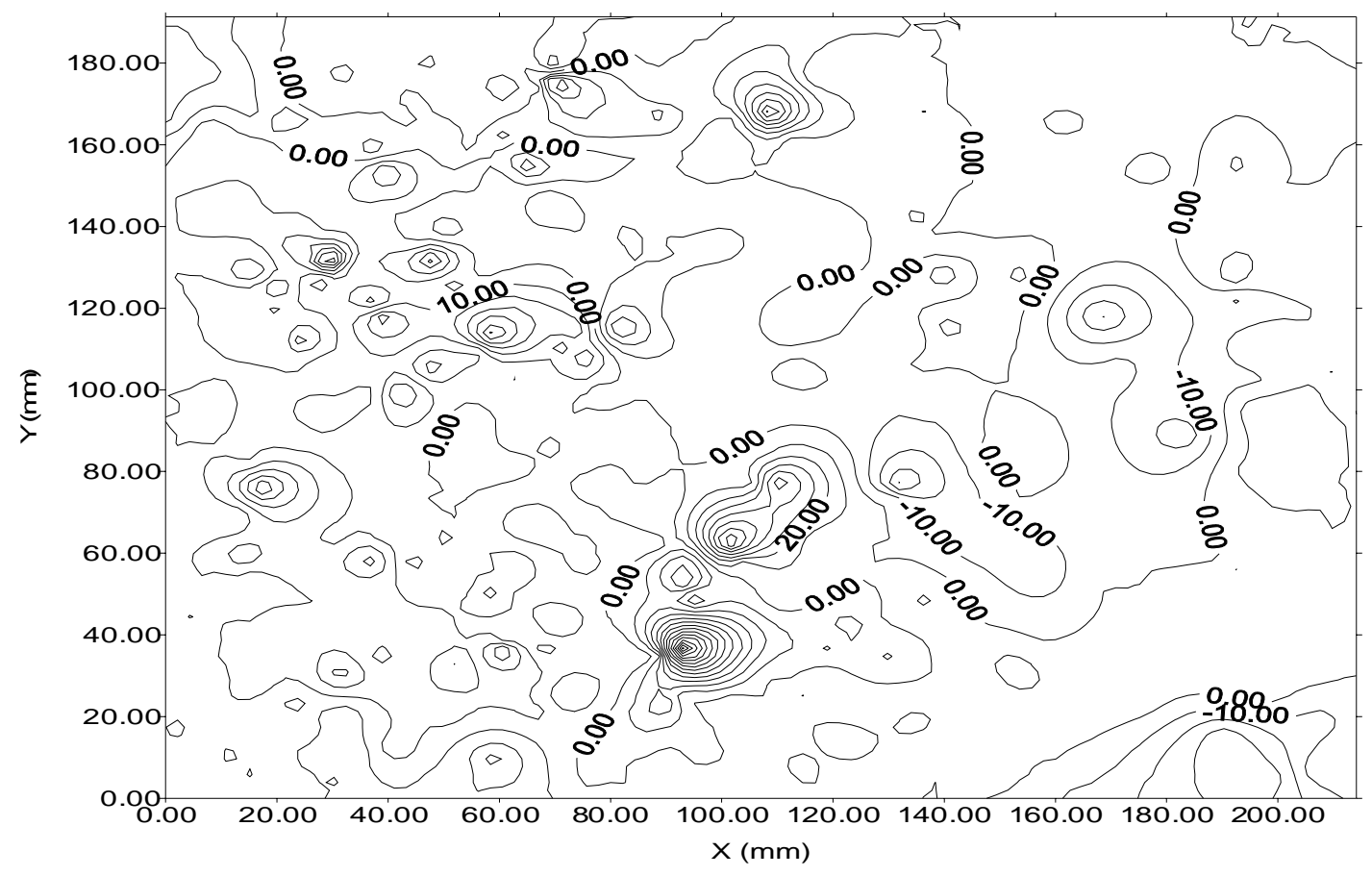

FIGURA 89. Visualização das Isolinhas do Gradiente da Velocidade Vertical (direção $Z$ ) com a grade de malha quadrada de espaçamento entre barras de 3,90 cm e rotação de $180 \mathrm{rpm}$. 


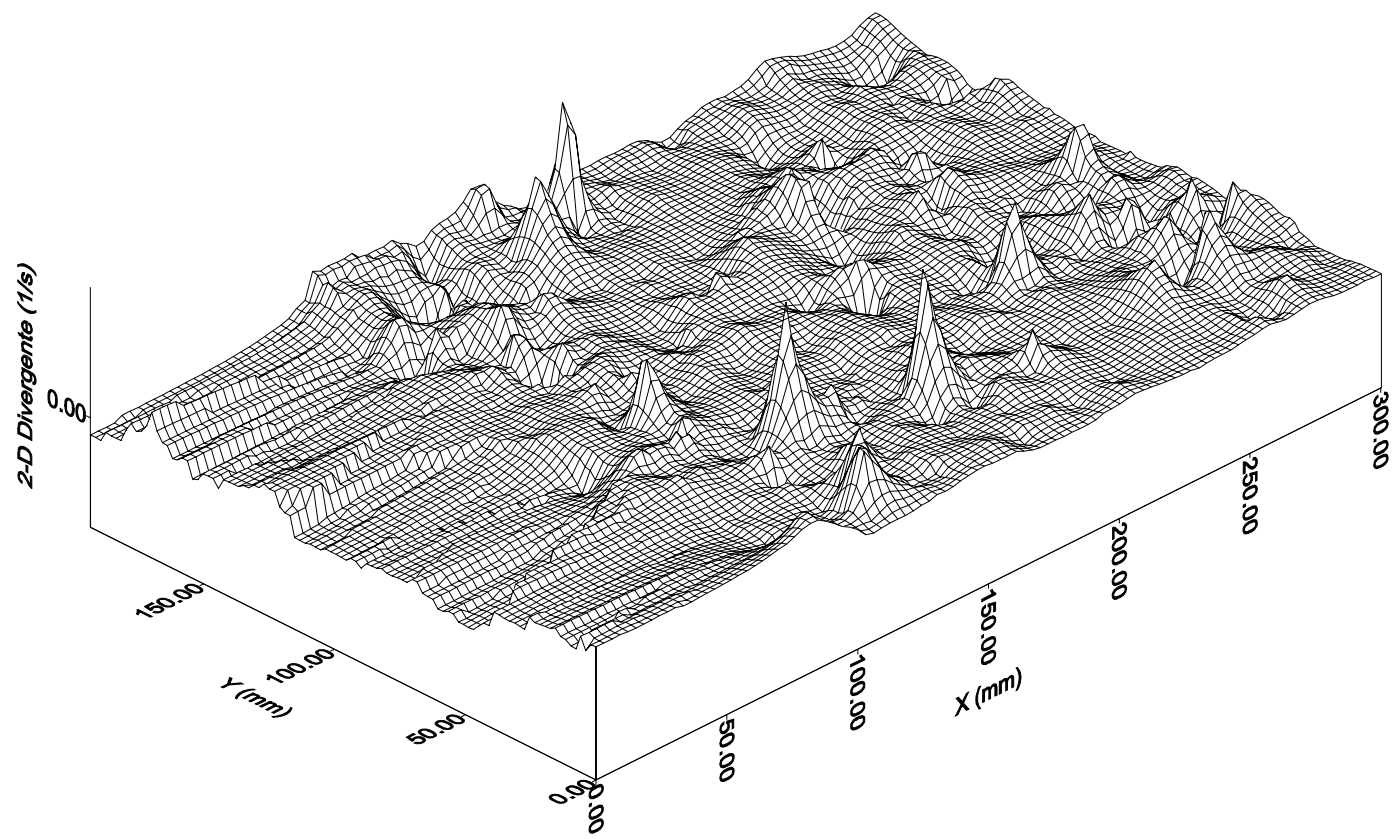

FIGURA 90. Visualização do Gradiente da Velocidade Vertical (direção Z) com a grade de malha quadrada de espaçamento entre barras de 3,90 cm e rotação de 210 rpm.

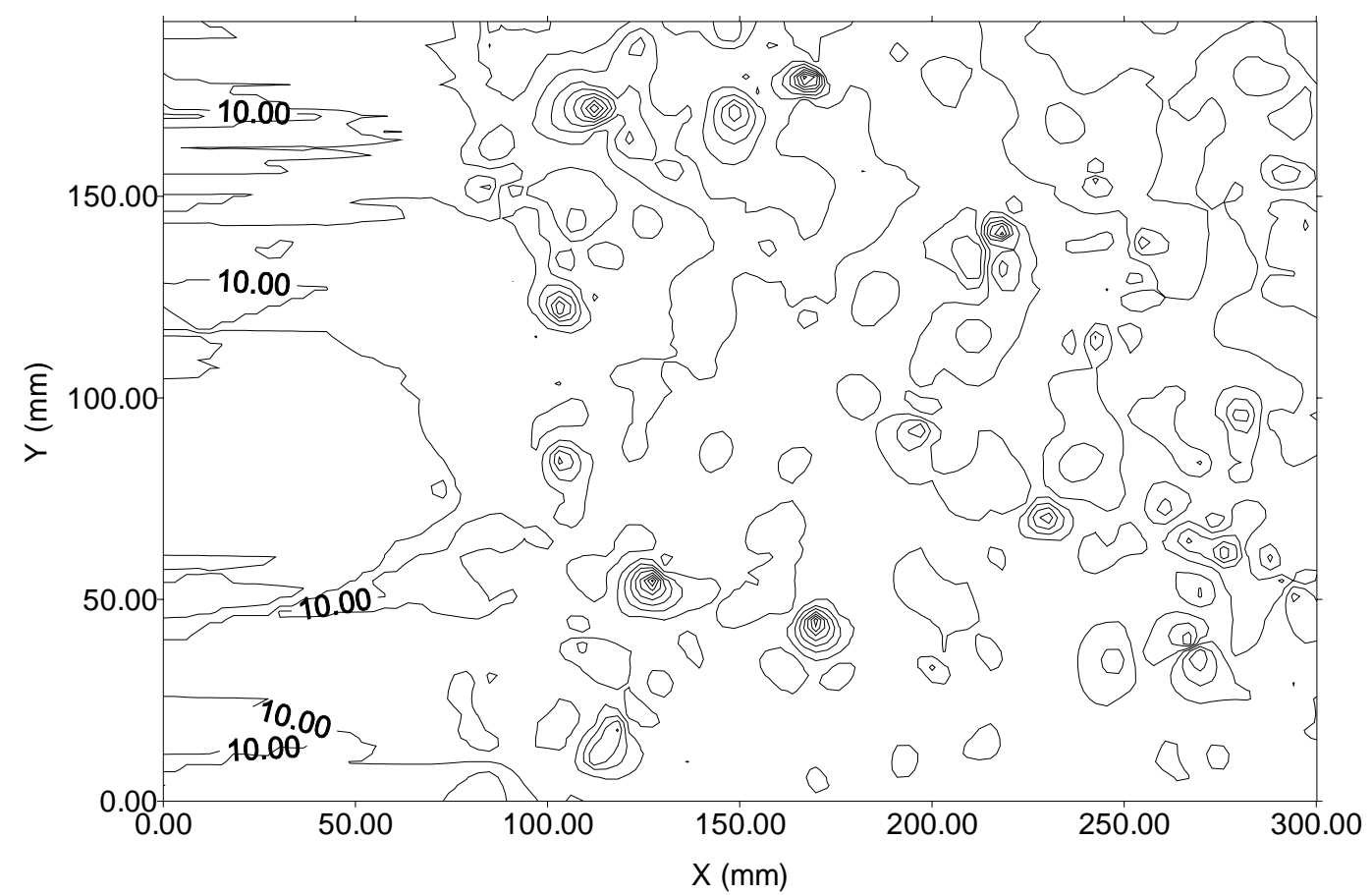

FIGURA 91. Visualização das Isolinhas do Gradiente da Velocidade Vertical (direção $Z$ ) com a grade de malha quadrada de espaçamento entre barras de 3,90 cm e rotação de $210 \mathrm{rpm}$. 


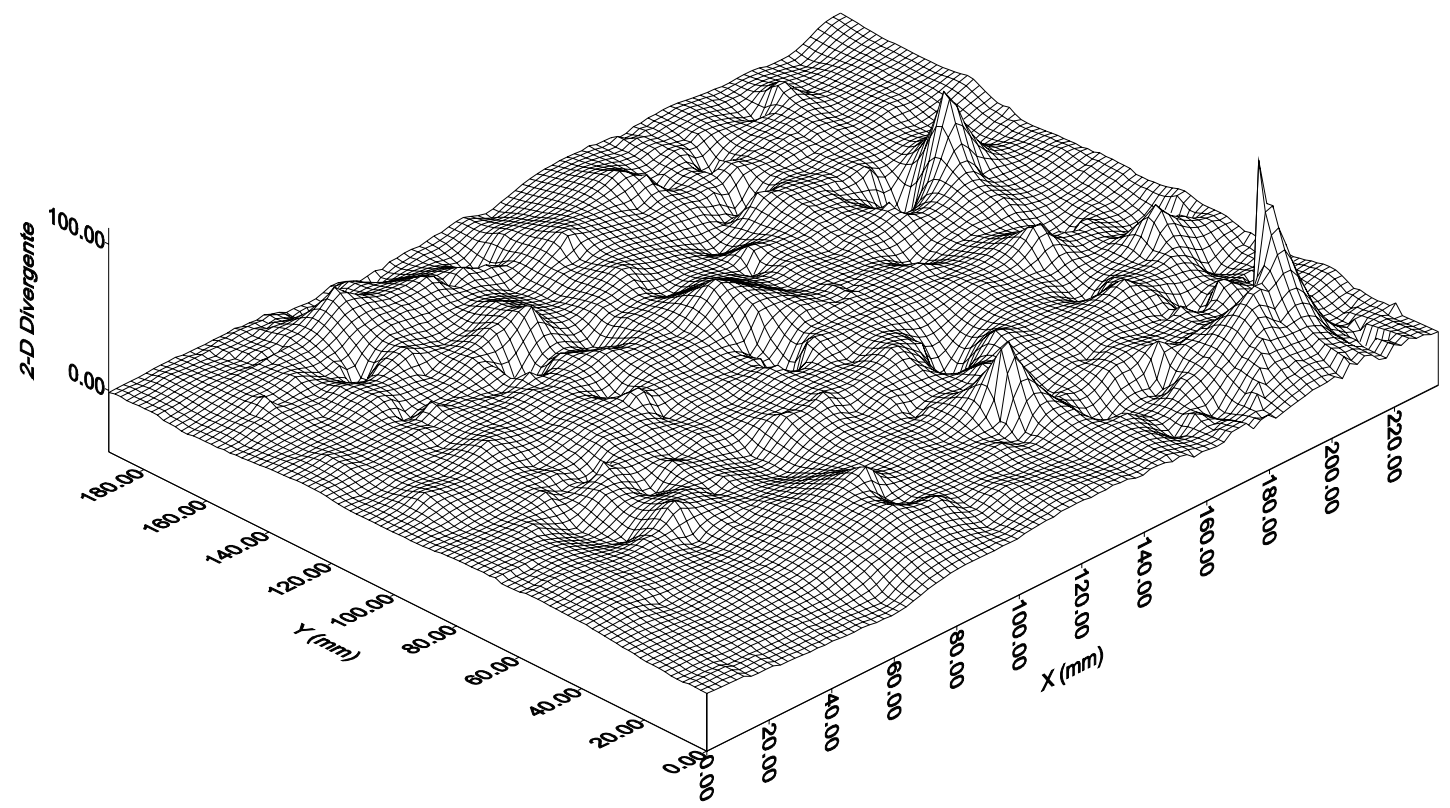

FIGURA 92. Visualização do Gradiente da Velocidade Vertical (direção Z) com a grade de malha quadrada de espaçamento entre barras de 3,90 cm e rotação de 240 rpm.

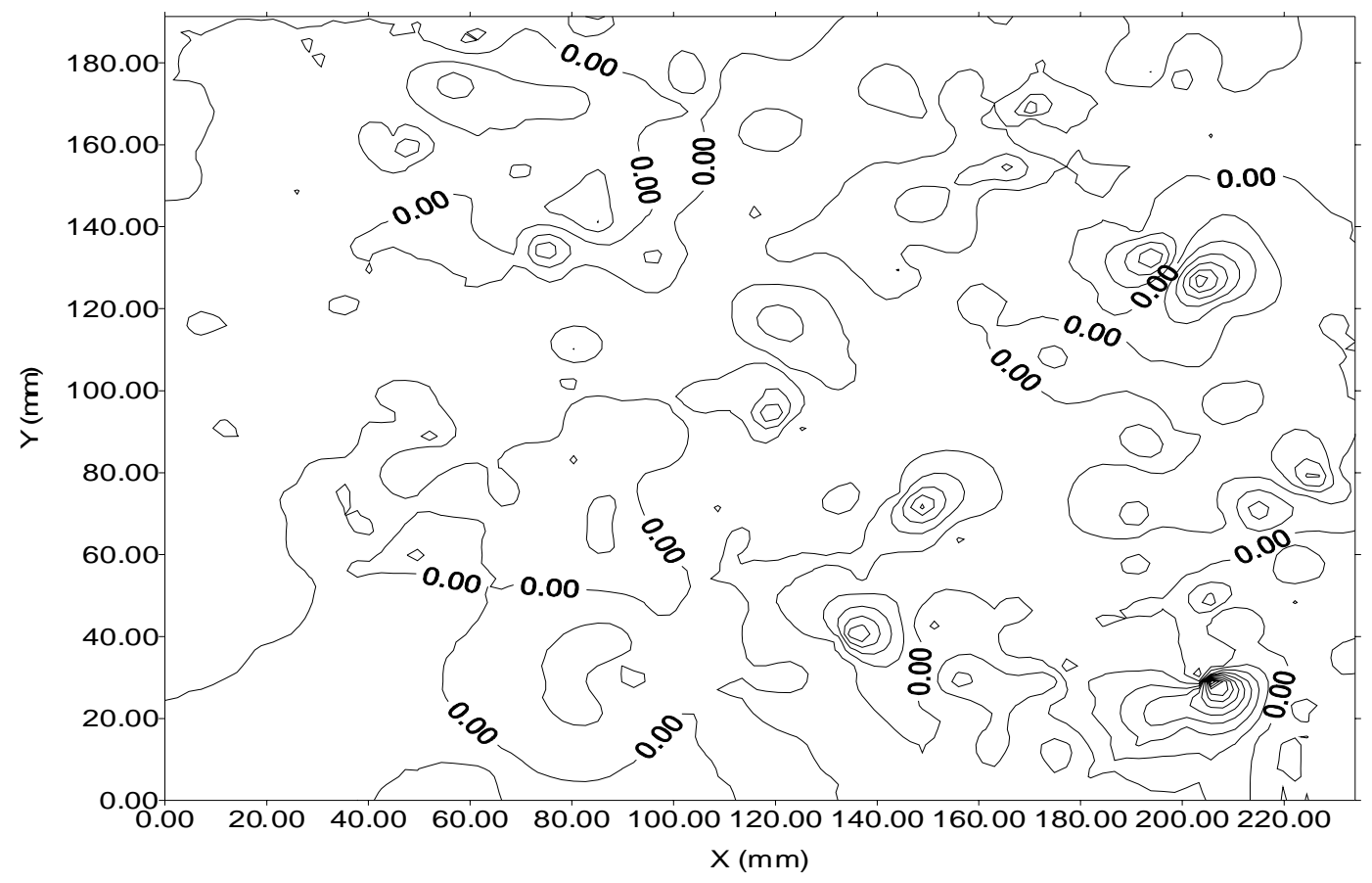

FIGURA 93. Visualização das Isolinhas do Gradiente da Velocidade Vertical (direção $Z$ ) com a grade de malha quadrada de espaçamento entre barras de 3,90 cm e rotação de $240 \mathrm{rpm}$. 


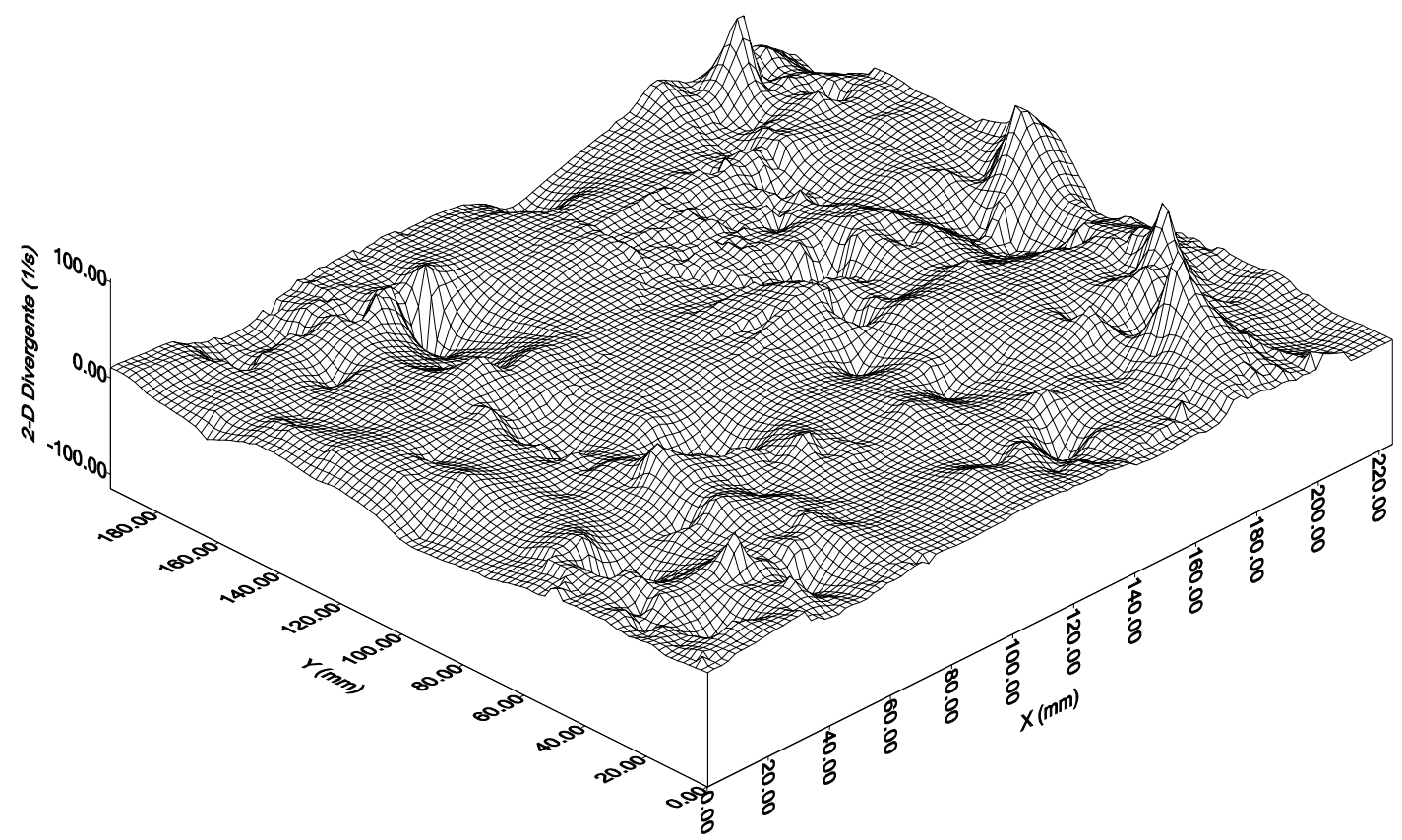

FIGURA 94. Visualização do Gradiente da Velocidade Vertical (direção Z) com a grade de malha quadrada de espaçamento entre barras de $6,45 \mathrm{~cm}$ e rotação de 180 rpm.

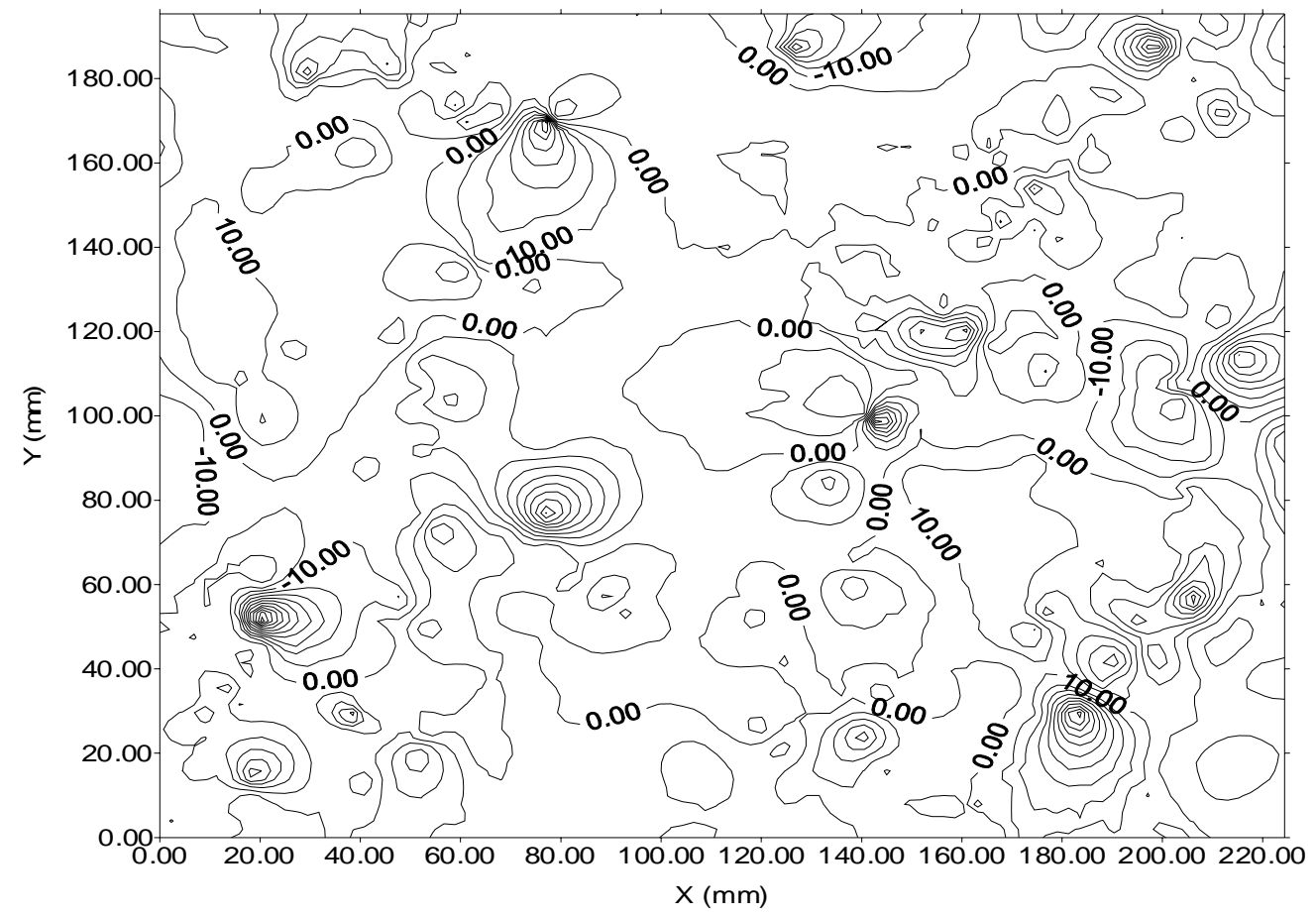

FIGURA 95. Visualização das Isolinhas do Gradiente da Velocidade Vertical (direção $Z$ ) com a grade de malha quadrada de espaçamento entre barras de 6,45 cm e rotação de $180 \mathrm{rpm}$. 


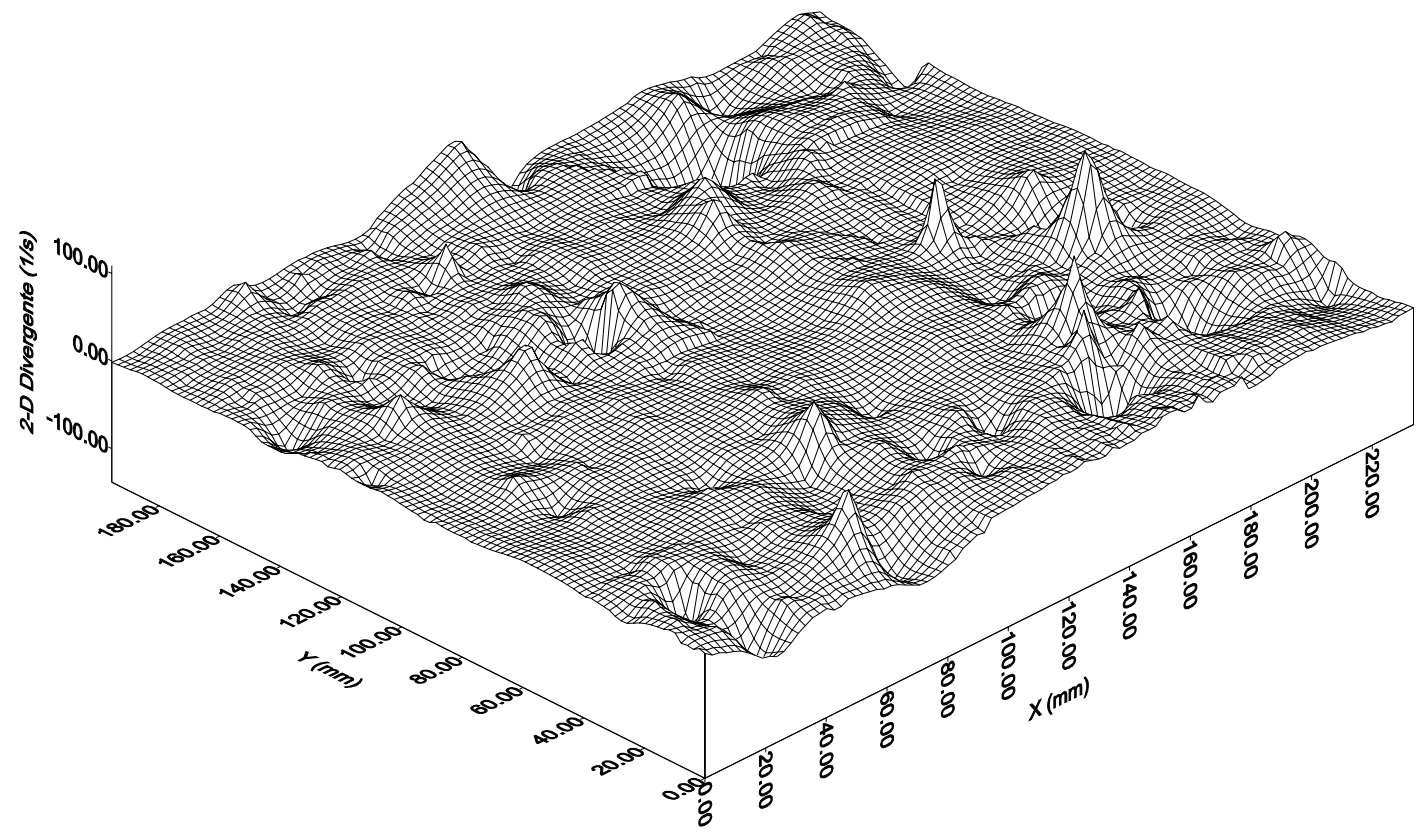

FIGURA 96. Visualização do Gradiente da Velocidade Vertical (direção Z) com a grade de malha quadrada de espaçamento entre barras de 6,45 cm e rotação de 200 rpm.

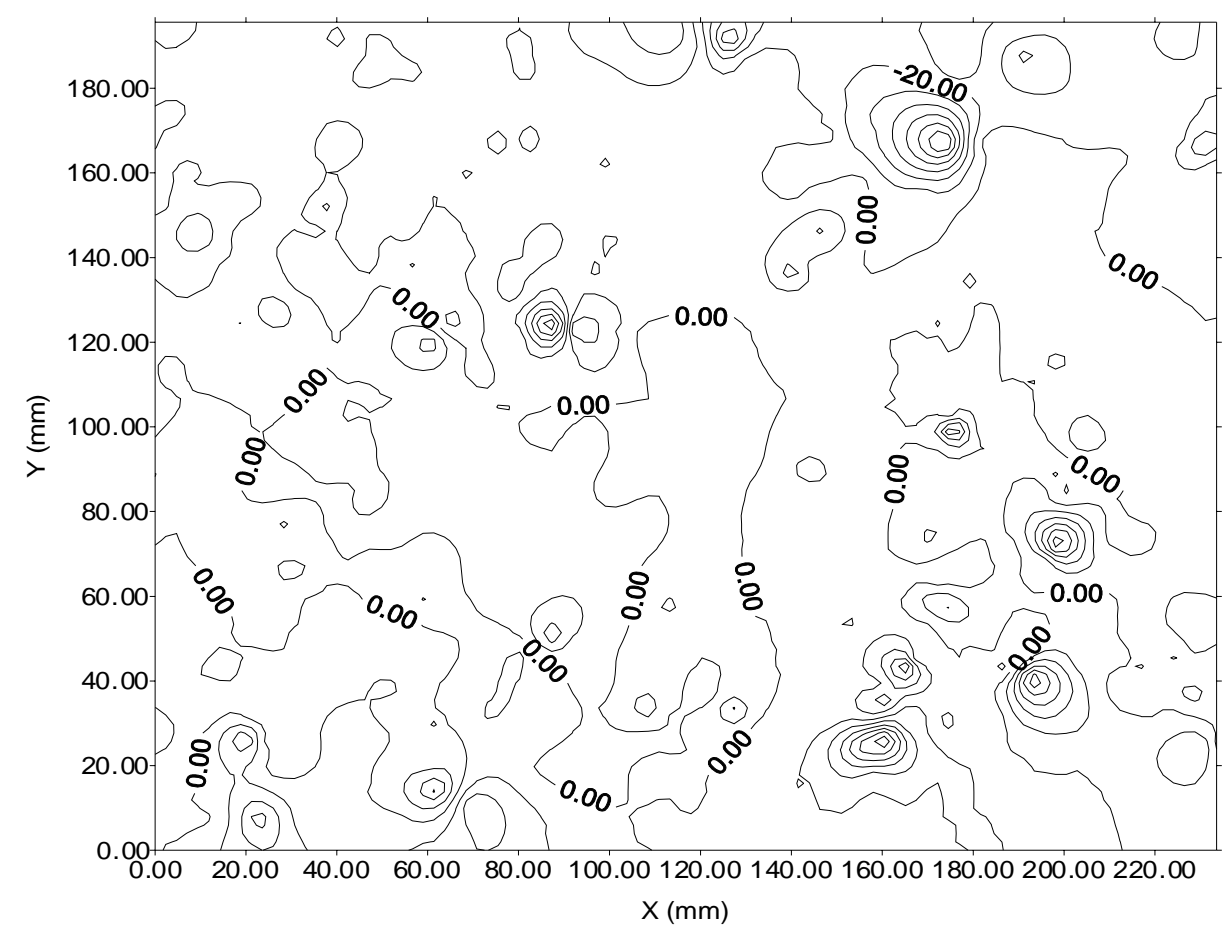

FIGURA 97. Visualização das Isolinhas do Gradiente da Velocidade Vertical (direção $Z$ ) com a grade de malha quadrada de espaçamento entre barras de 6,45 cm e rotação de $200 \mathrm{rpm}$. 


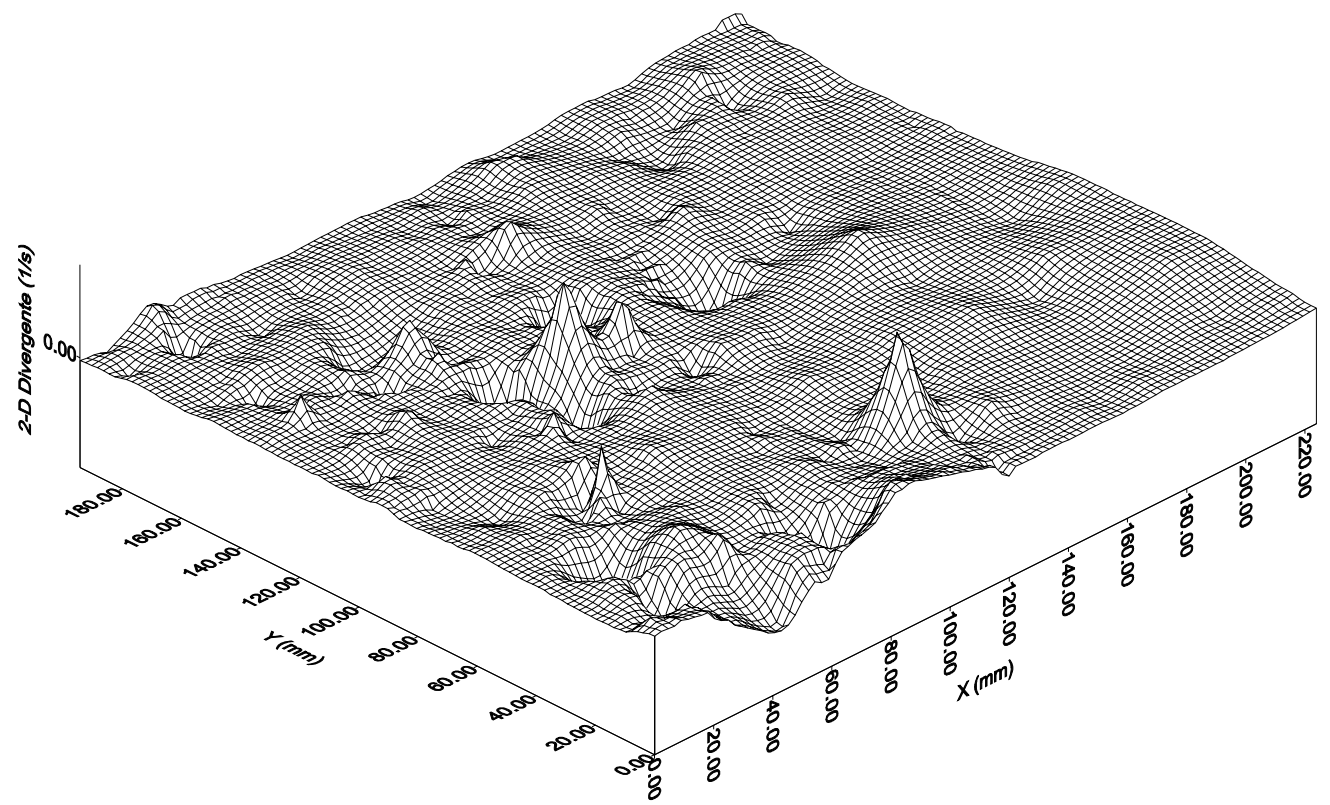

FIGURA 98. Visualização do Gradiente da Velocidade Vertical (direção Z) com a grade de malha quadrada de espaçamento entre barras de 6,45 cm e rotação de 220 rpm.

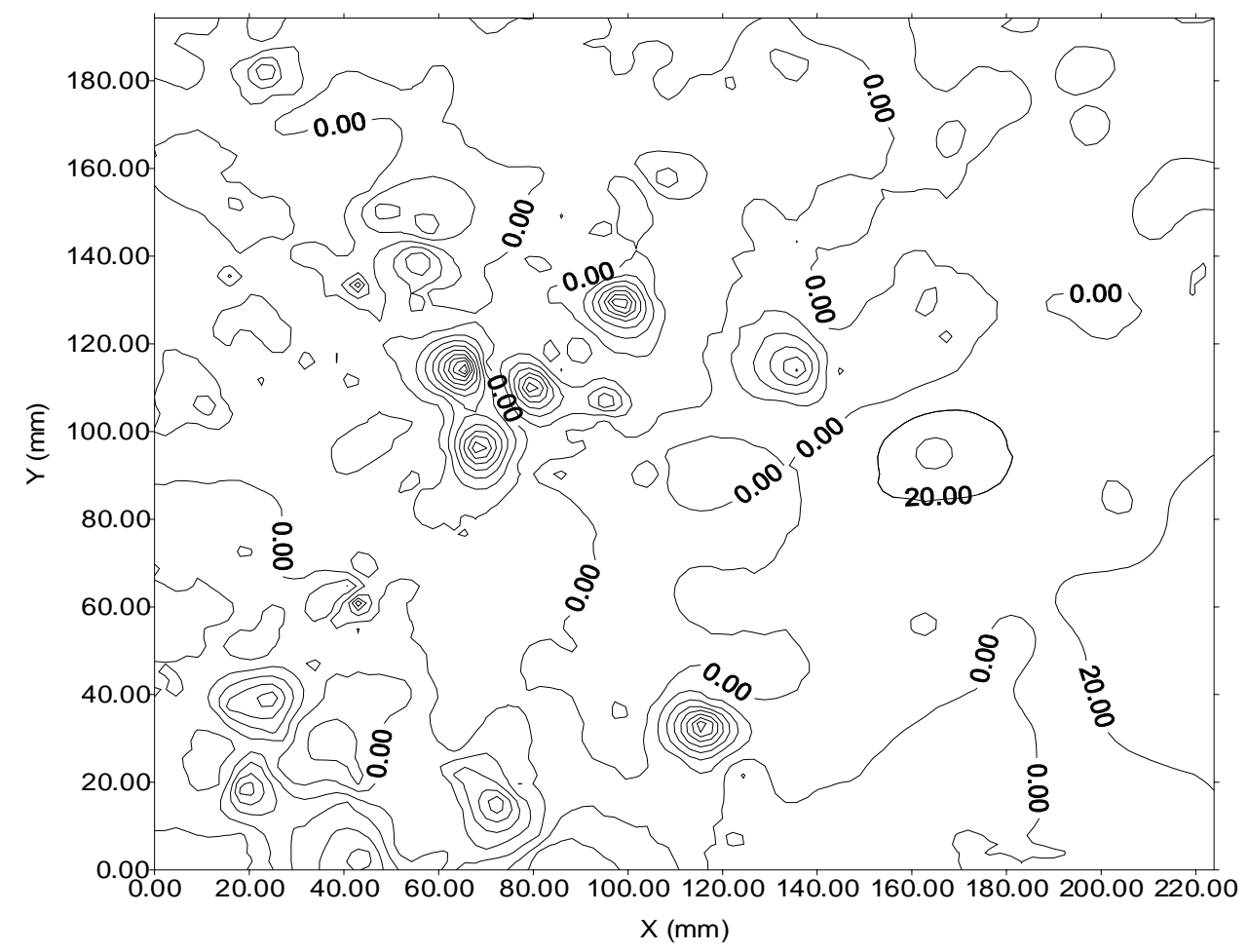

FIGURA 99. Visualização das Isolinhas do Gradiente da Velocidade Vertical (direção $Z$ ) com a grade de malha quadrada de espaçamento entre barras de 6,45 cm e rotação de 220 rpm. 


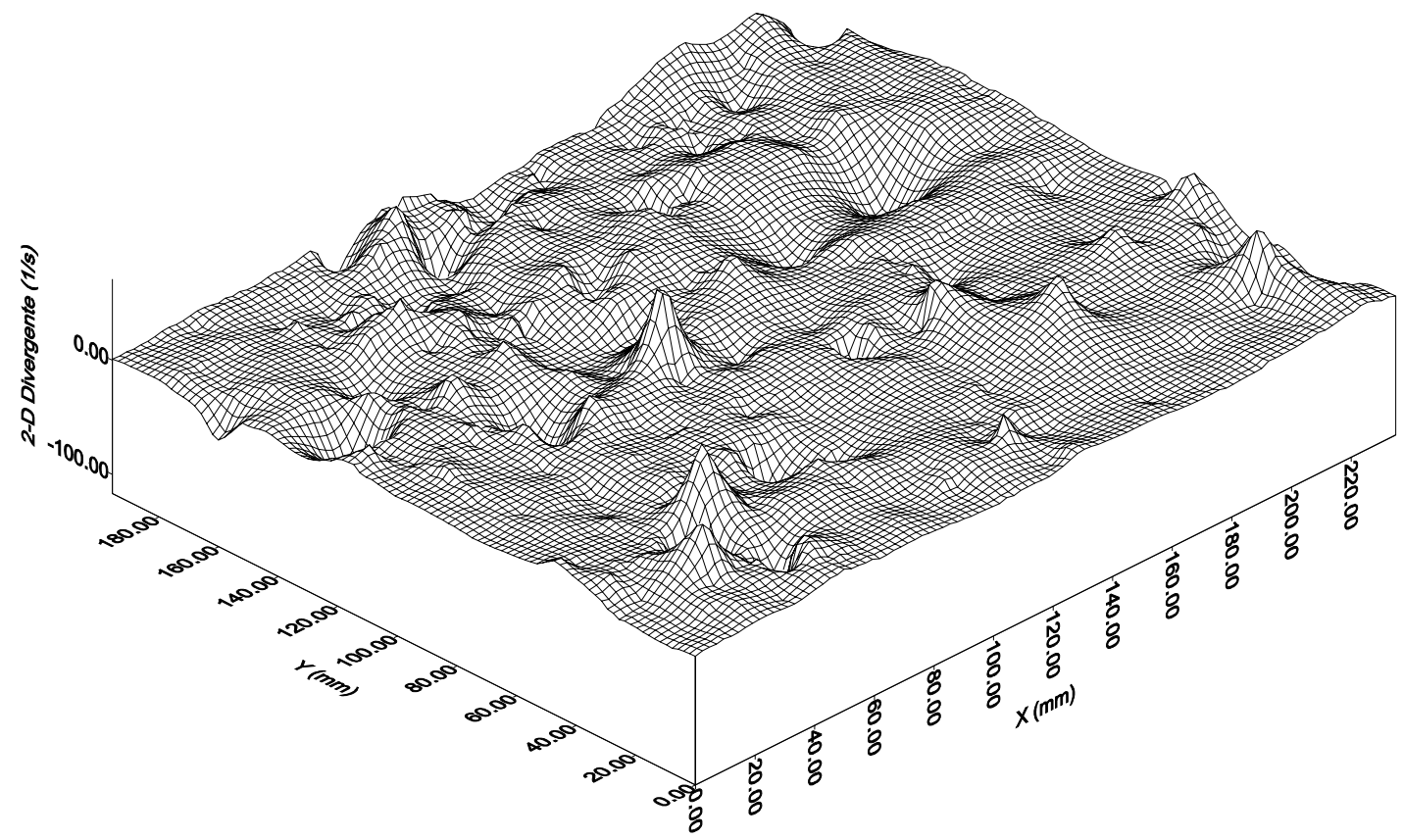

FIGURA 100. Visualização do Gradiente da Velocidade Vertical (direção Z) com a grade de malha quadrada de espaçamento entre barras de 6,45 cm e rotação de 250 rpm.

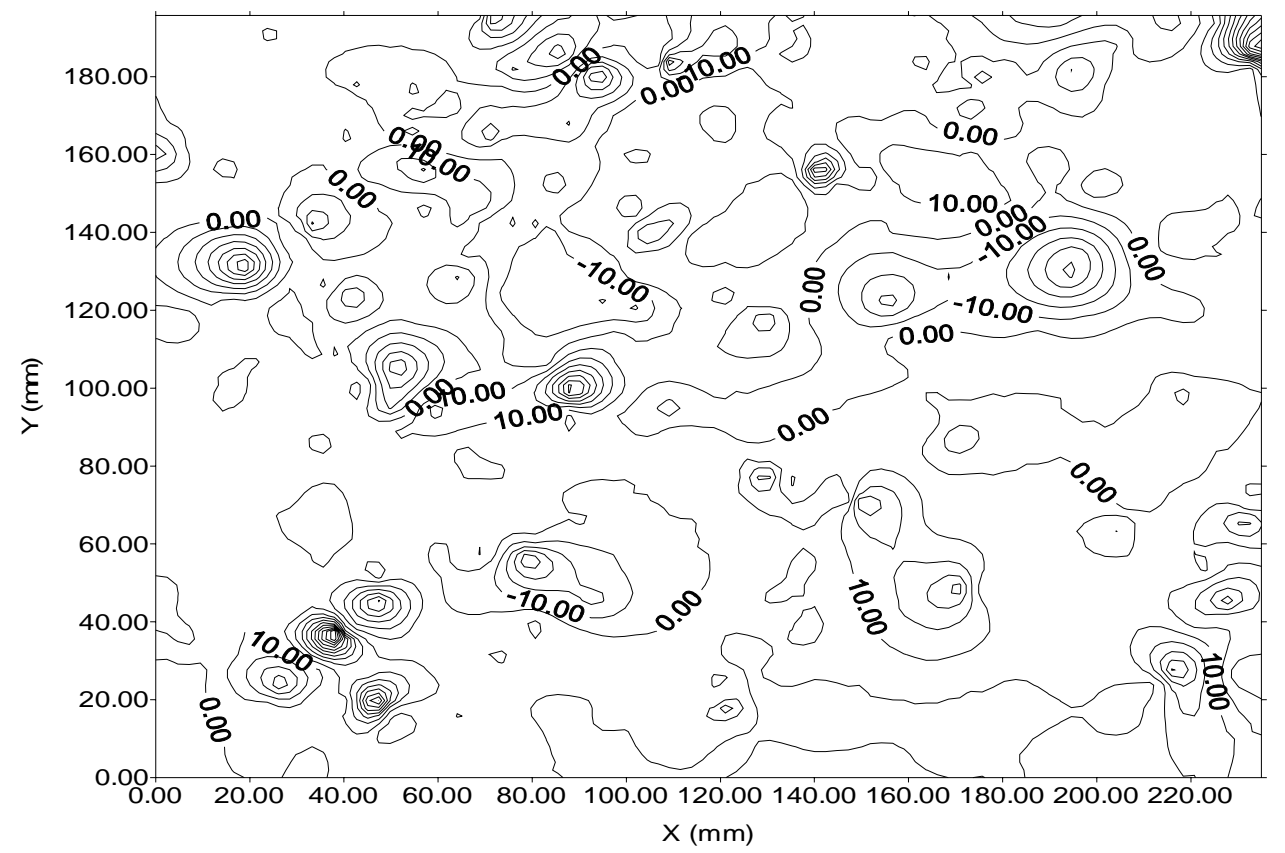

FIGURA 101. Visualização das Isolinhas do Gradiente da Velocidade Vertical (direção $Z$ ) com a grade de malha quadrada de espaçamento entre barras de 6,45 cm e rotação de 250 rpm. 


\subsubsection{Ajuste do valor RMS do gradiente da velocidade vertical em} função da rotação

O valor RMS espacial ao longo do eixo $x$ foi obtido a partir da equação (109) para dados espaciais e os resultados são apresentados aqui por meio de tabela e de gráficos. Objetivou-se, nos gráficos abaixo, um melhor ajuste através de regressão; assim, a equação obtida foi utilizada na estimativa de uma faixa de valores para rotação, que não foi ensaiada e que está dentro da faixa de $\mathrm{K}_{2}$ estimado.

TABELA 6: Valores de RMS obtidos pelo método fotográfico para o gradiente de velocidade vertical

\begin{tabular}{c|c}
\hline ENSAIO & Valor RMS \\
\hline Egf120 & 10.405 \\
\hline Egf140 & 13.298 \\
\hline Egf160 & 11.042 \\
\hline Egf180 & 13.633 \\
\hline Egf200 & 20.821 \\
\hline Egm140 & 6.873 \\
\hline Egm160 & 6.867 \\
\hline Egm180 & 5.731 \\
\hline Egm210 & 6.241 \\
\hline Egm240 & 6.796 \\
\hline Egl180 & 5.799 \\
\hline Egl200 & 7.555 \\
\hline Egl220 & 9.347 \\
\hline Egl250 & 12.048 \\
\hline
\end{tabular}


Rotação vs RMS foto

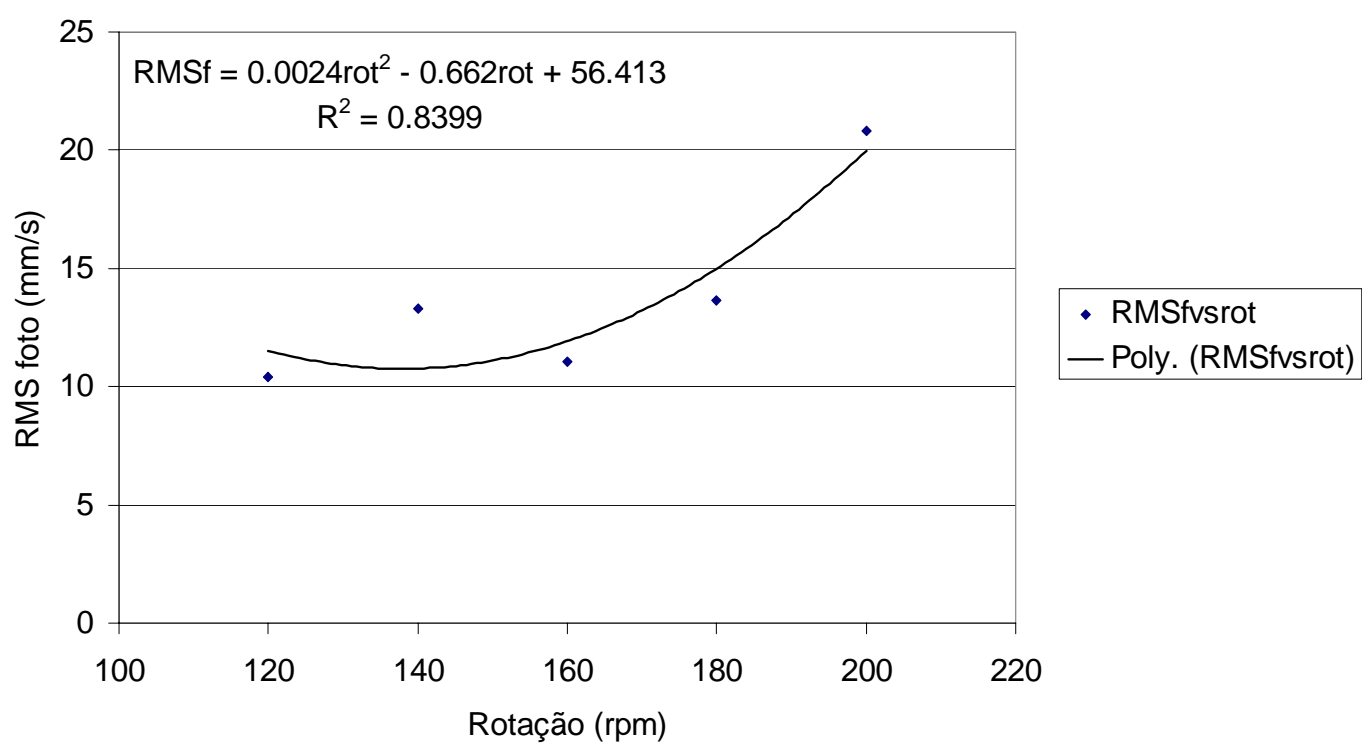

FIGURA 102: Melhor ajuste para RMS foto versus freqüência de oscilação da grade de 26,5 mm de abertura e barras com 10,0 mm de espessura

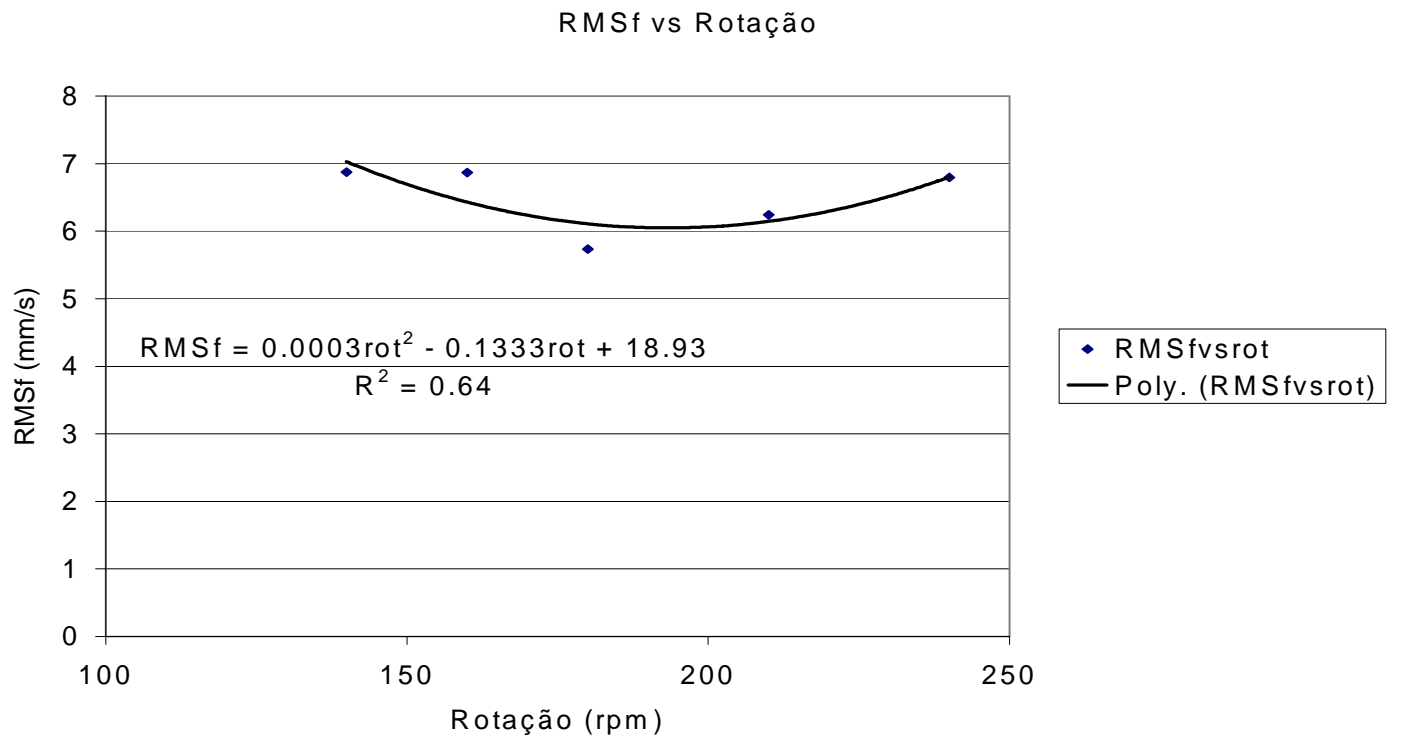

FIGURA 103: Melhor ajuste para RMS foto versus freqüência de oscilação da grade de 39,0 mm de abertura e barras com 10,0 mm de espessura 
RMSf vs Rotação

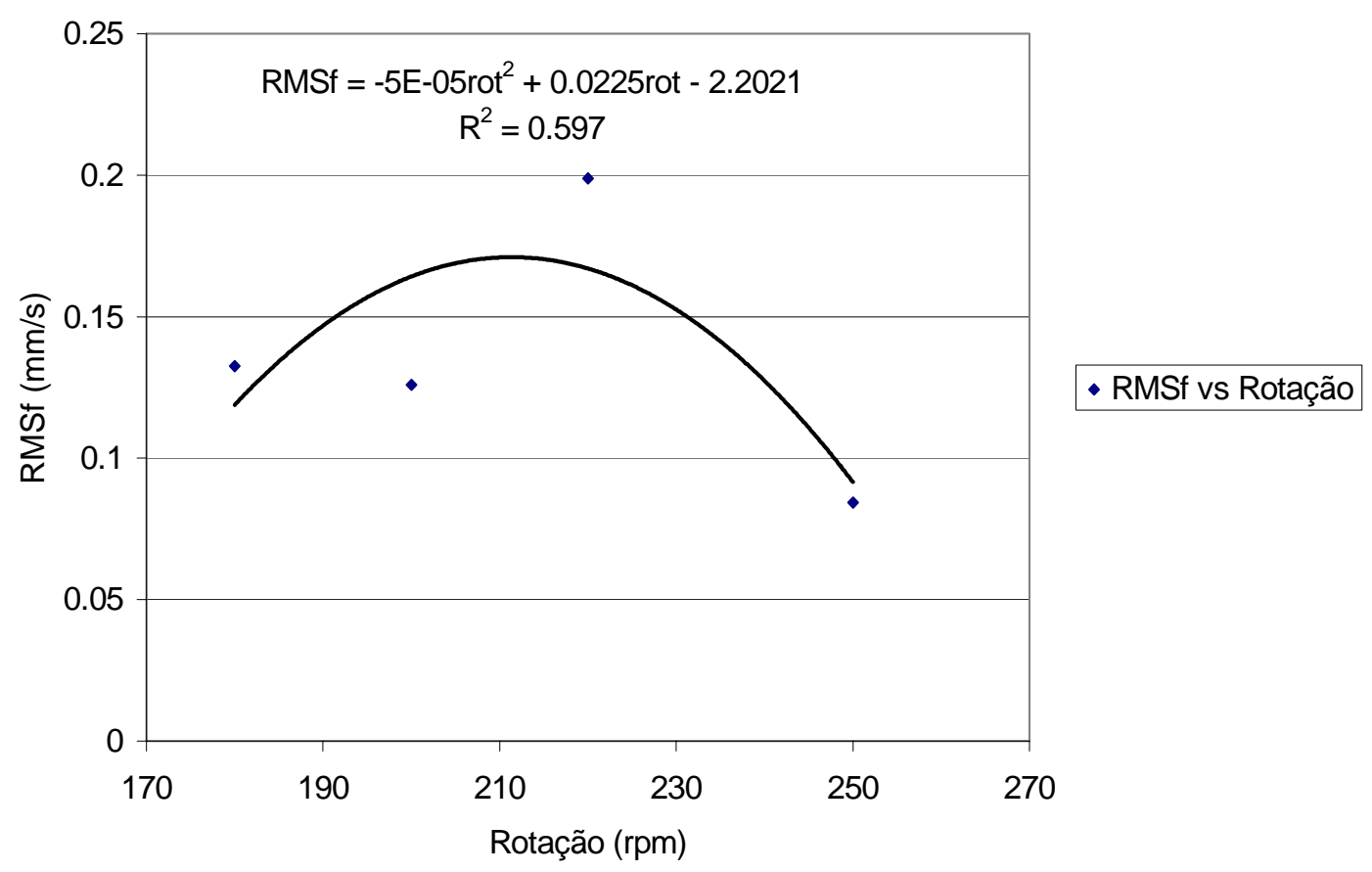

FIGURA 104: Melhor ajuste para RMS foto versus freqüência de oscilação da grade de 64,5 mm de abertura e barras com 10,0 mm de espessura

Nota-se que o valor RMS obtido pelo método fotográfico em função da rotação (freqüência de oscilação da grade), apresentou como melhor ajuste à função de segundo grau, similar ao que foi observado nos gráficos das FIGURAS 15, 16, 17, dos resultados referentes aos valores de RMS do método da sonda ótica. Vale ressaltar, que tal constatação citada acima justifica a opção pela função de segundo grau.

A função de autocorrelação espacial ao longo do eixo $x$ e o espectro foram obtidos e analisados nesta seção e ambos foram conseguidos por meio do gradiente da velocidade vertical (2 D divergente), com o objetivo de se conseguir uma idéia quantitativa dos dados da superfície livre.

Os resultados alcançados serão apresentados no item 5.4. e 5.5. e comparados aos resultados do método da sonda ótica. 
5.4. Comparação entre a Função de autocorrelação da sonda ótica e do método fotográfico

Autocorrelação Sonda egf120

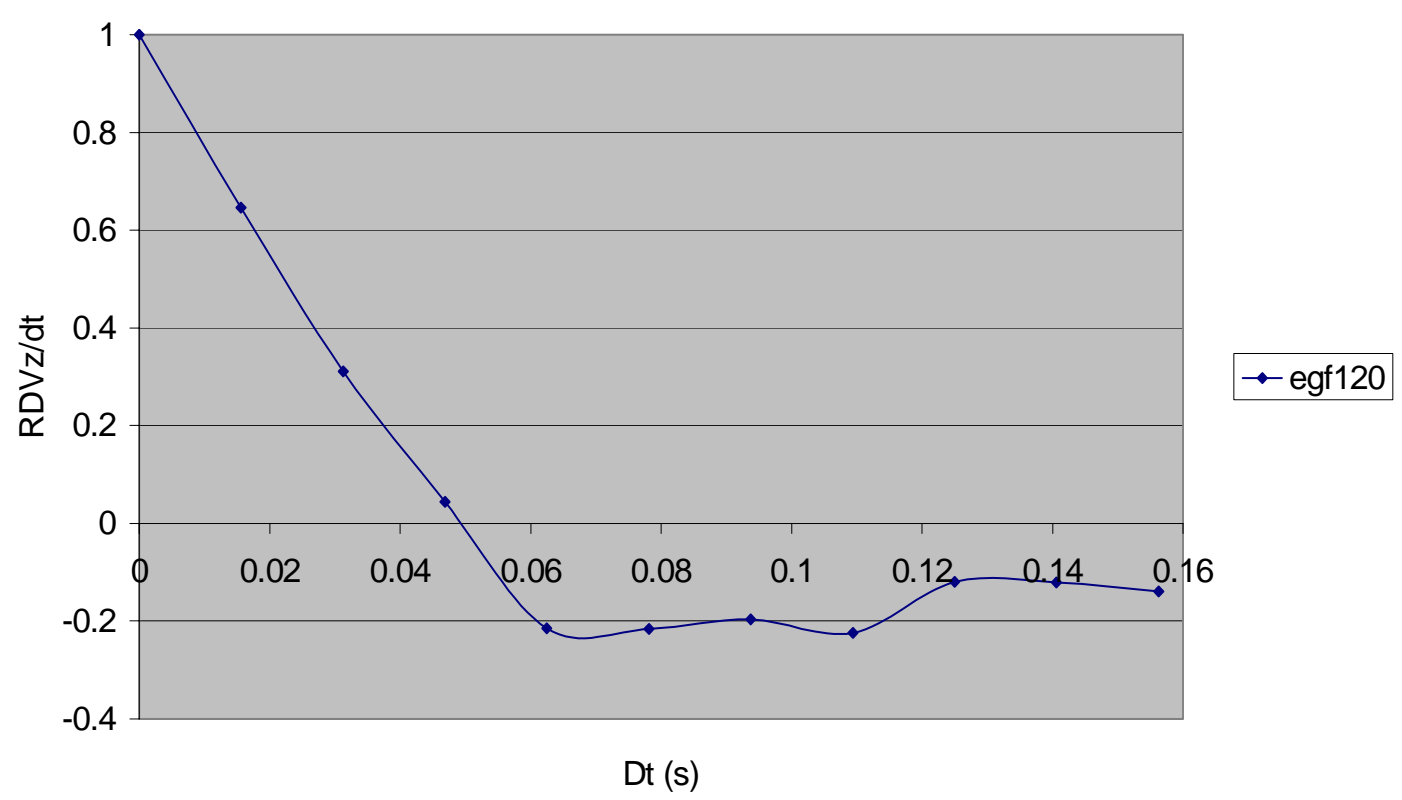

FIGURA 105: Autocorrelação da Sonda: Ensaio da Grade de 26,5mm de abertura e barras com 10,0mm de espessura (Freqüência de oscilação da grade de 120 rpm)

Autocorrelação da Foto egf120

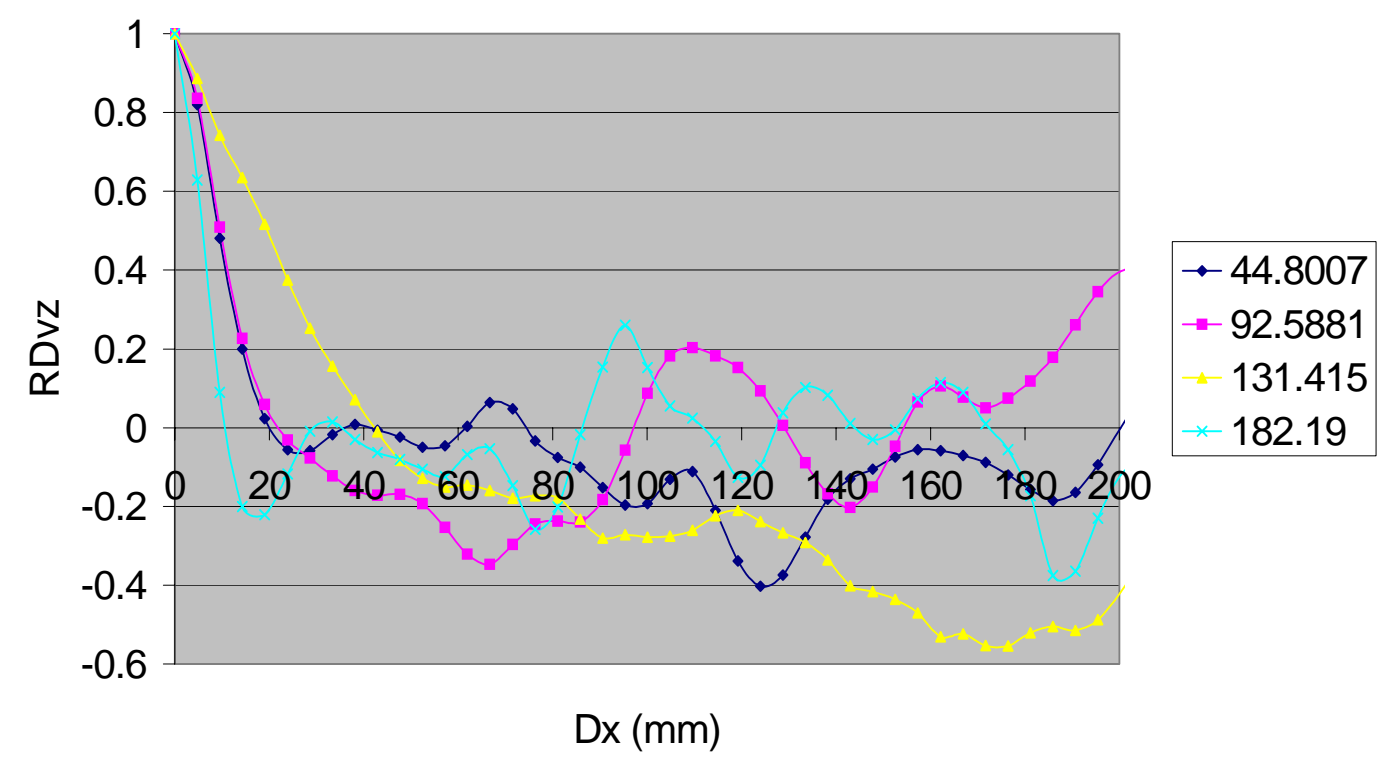

FIGURA 106: Autocorrelação da Foto: Ensaio da Grade de 26,5mm de abertura e barras com 10,0mm de espessura (Freqüência de oscilação da grade de 120 rpm) 
Autocorrelação Sonda egf140

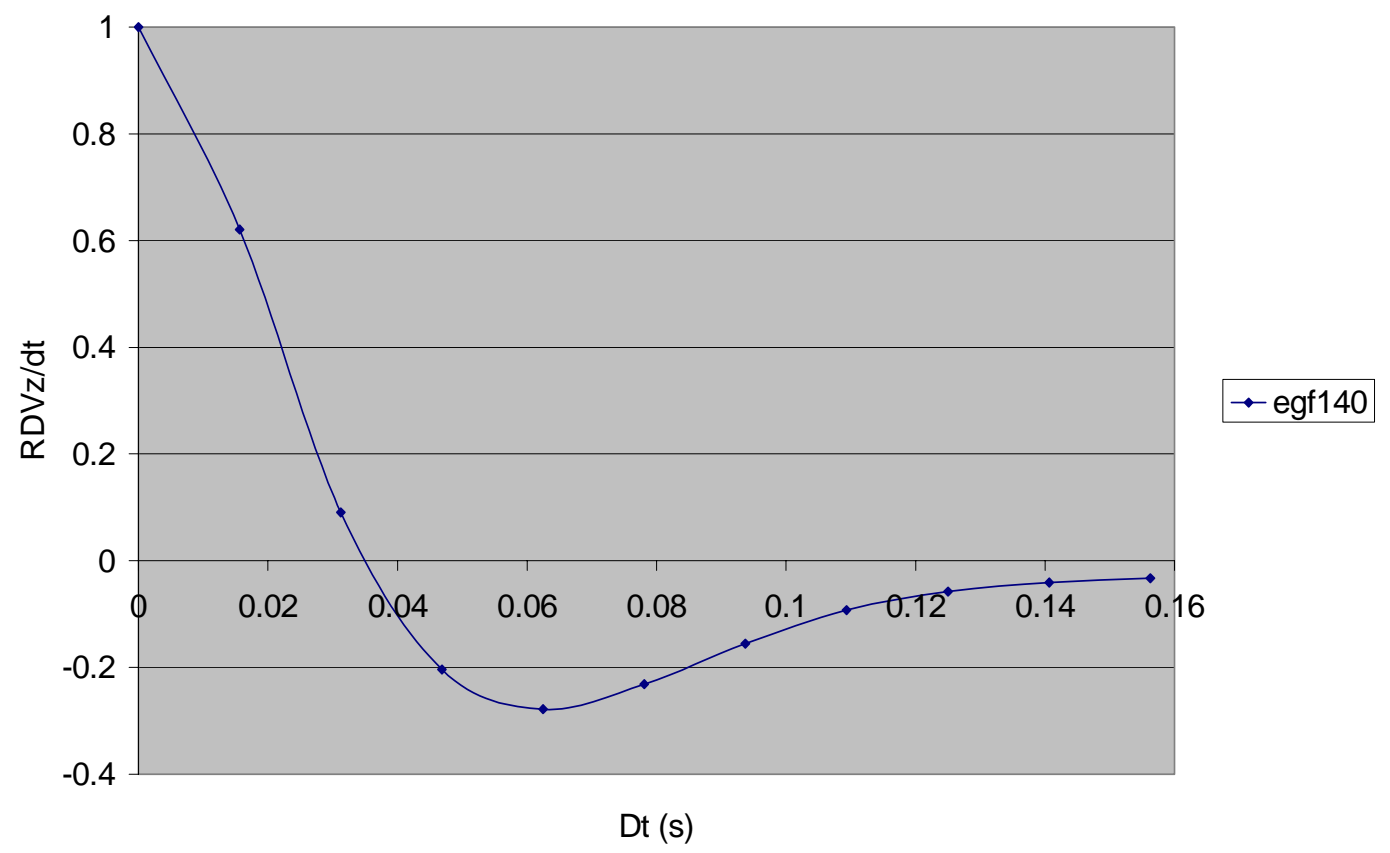

FIGURA 107: Autocorrelação da Sonda: Ensaio da Grade de 26,5mm de abertura e barras com 10,0mm de espessura (Freqüência de oscilação da grade de 140 rpm)

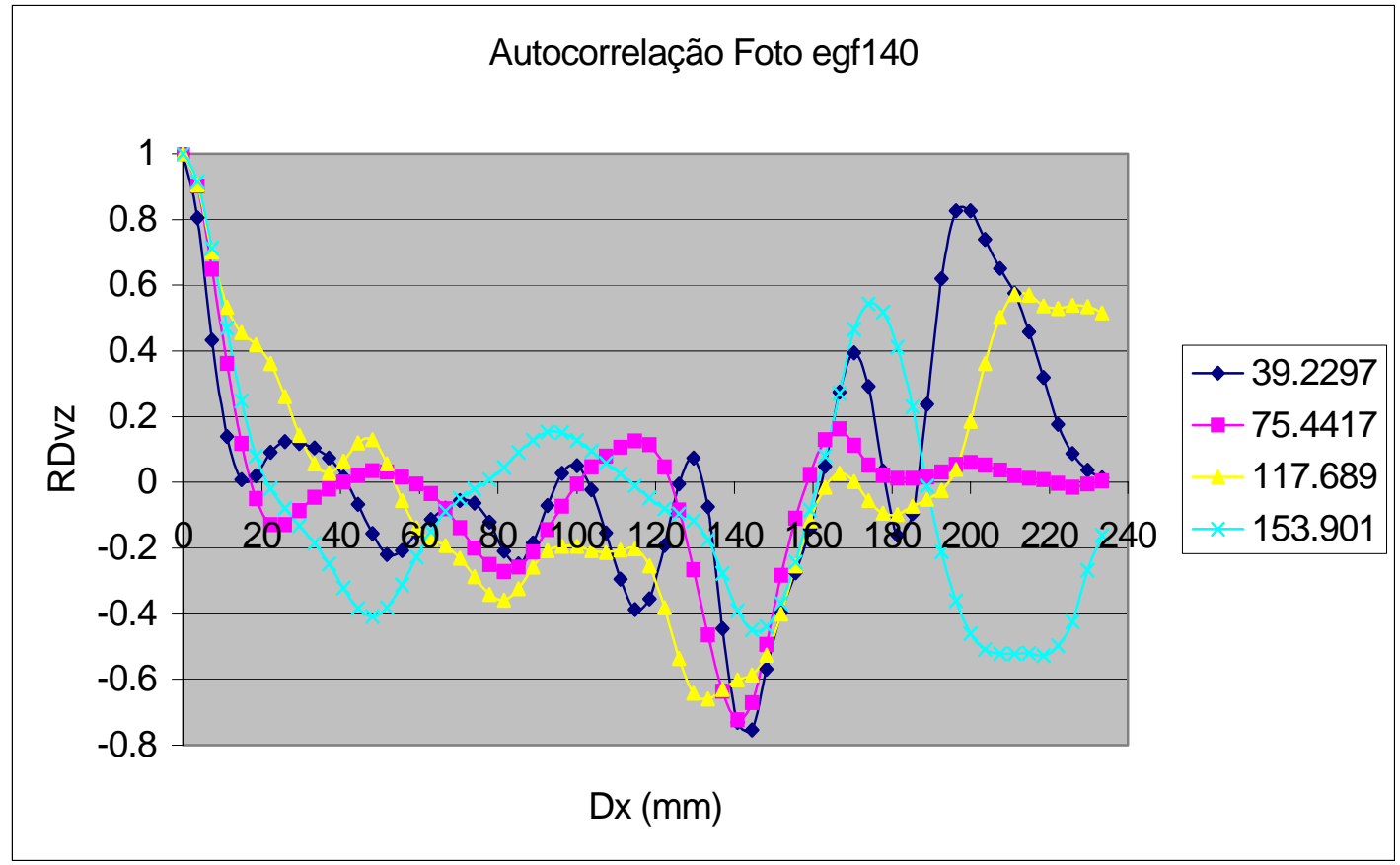

FIGURA 108: Autocorrelação da Foto: Ensaio da Grade de 26,5mm de abertura e barras com 10,0mm de espessura (Freqüência de oscilação da grade de 140 rpm) 
Autocorrelação Sonda egf160

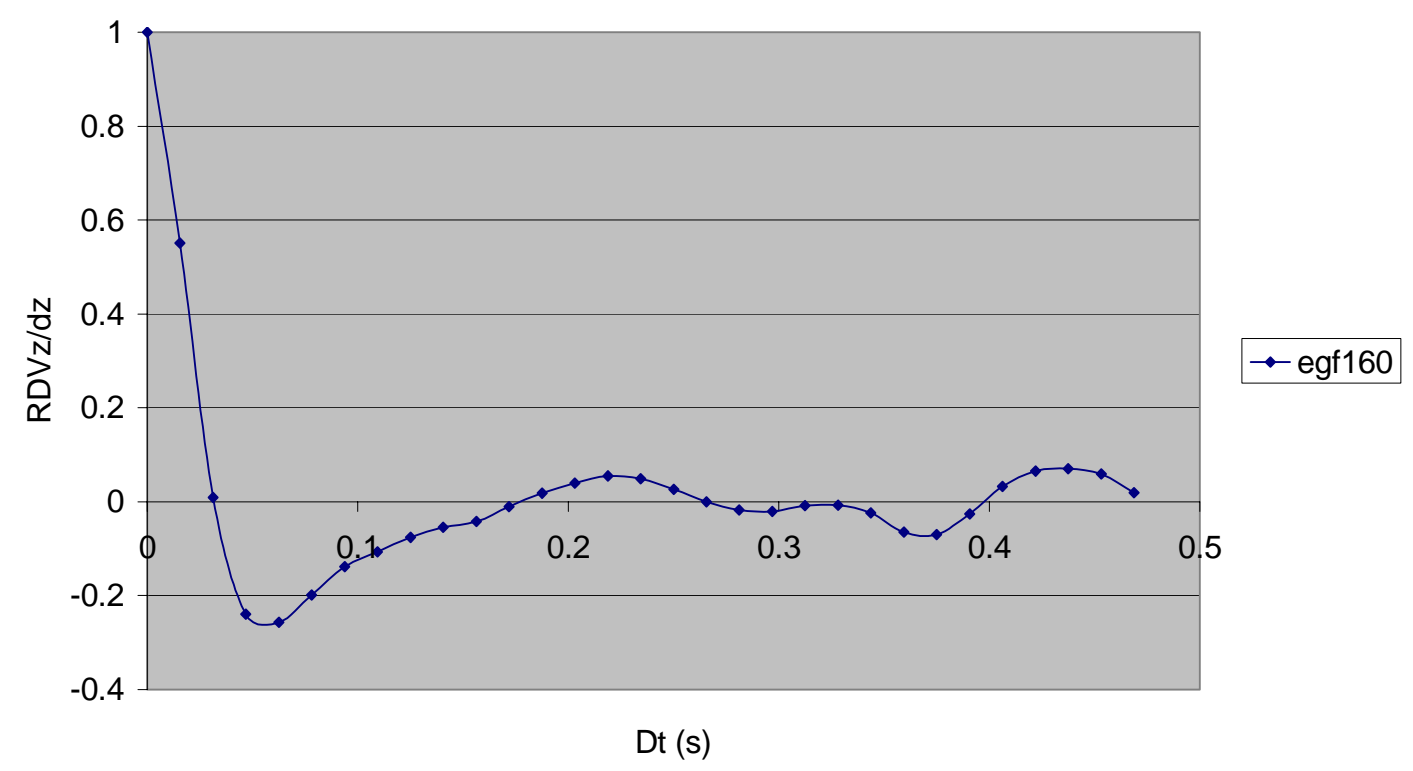

FIGURA 109: Autocorrelação da Sonda: Ensaio da Grade de 26,5mm de abertura e barras com 10,0mm de espessura (Freqüência de oscilação da grade de 160 rpm)

Autocorrelação Foto egf160

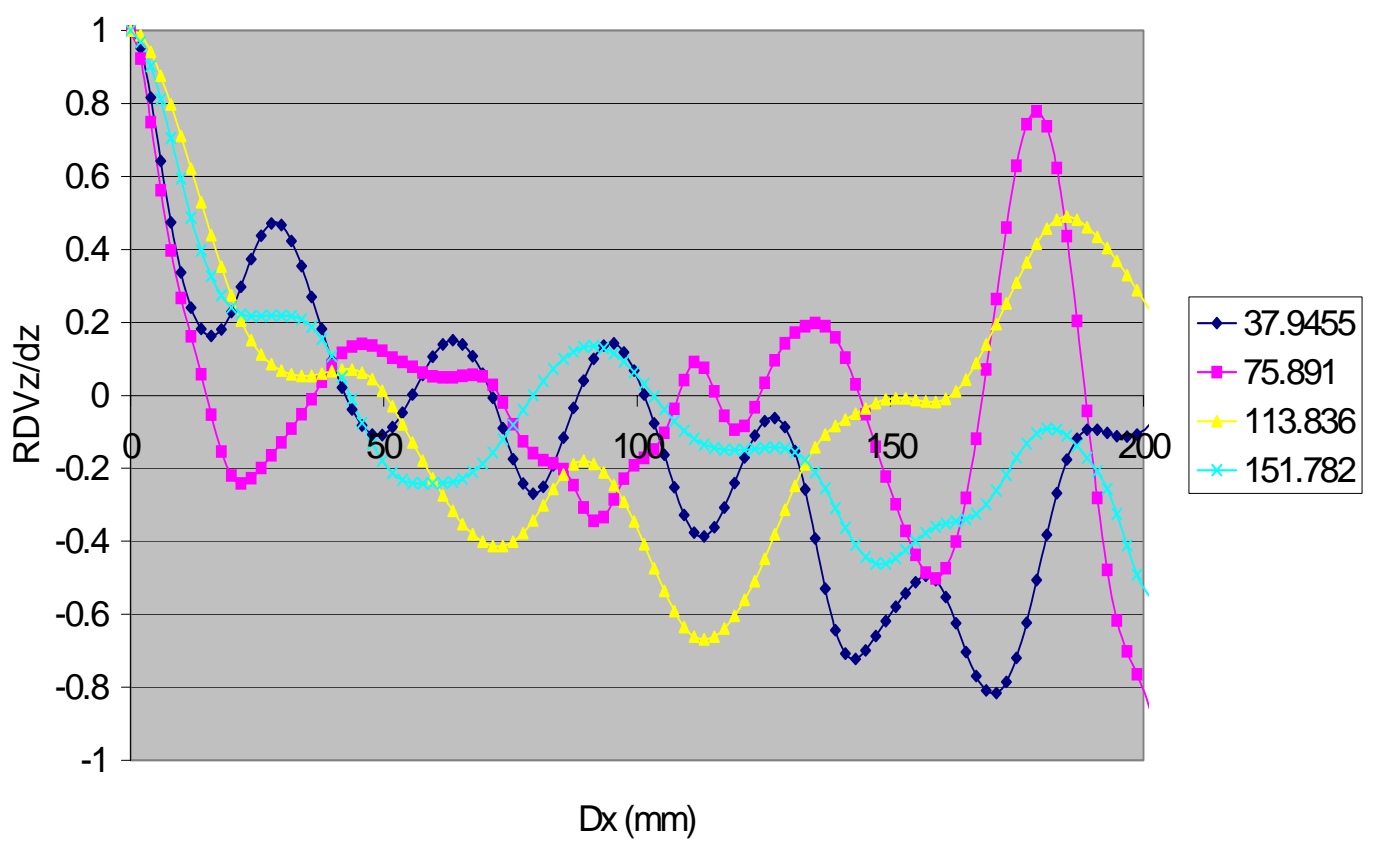

FIGURA 110: Autocorrelação da Foto: Ensaio da Grade de 26,5mm de abertura e barras com 10,0mm de espessura (Freqüência de oscilação da grade de 160 rpm) 
Autocorrelação Sonda egf180

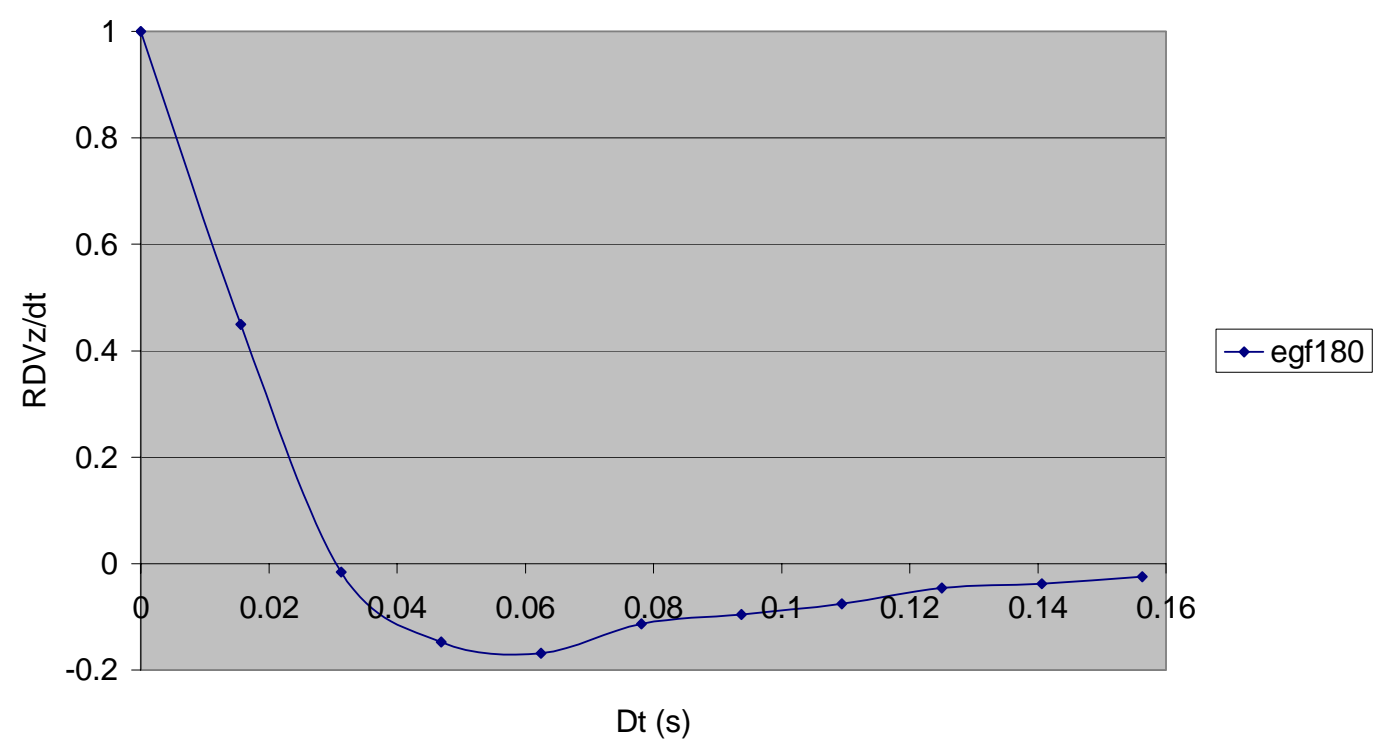

FIGURA 111: Autocorrelação da Sonda: Ensaio da Grade de 26,5mm de abertura e barras com 10,0mm de espessura (Freqüência de oscilação da grade de 180 rpm)

\section{Autocorrelação Foto egf180}

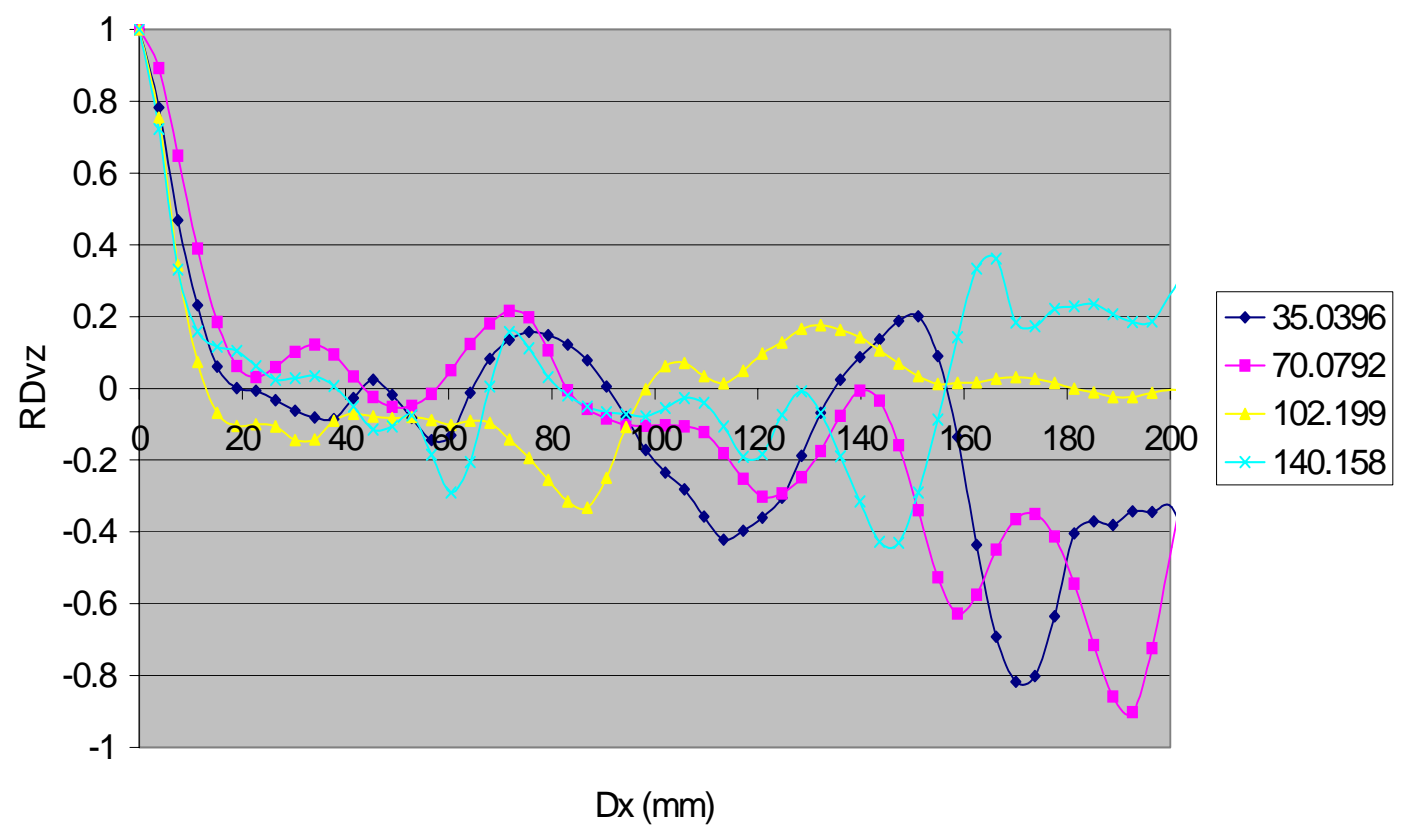

FIGURA 112: Autocorrelação da Foto: Ensaio da Grade de 26,5mm de abertura e barras com 10,0mm de espessura (Freqüência de oscilação da grade de 180 rpm) 


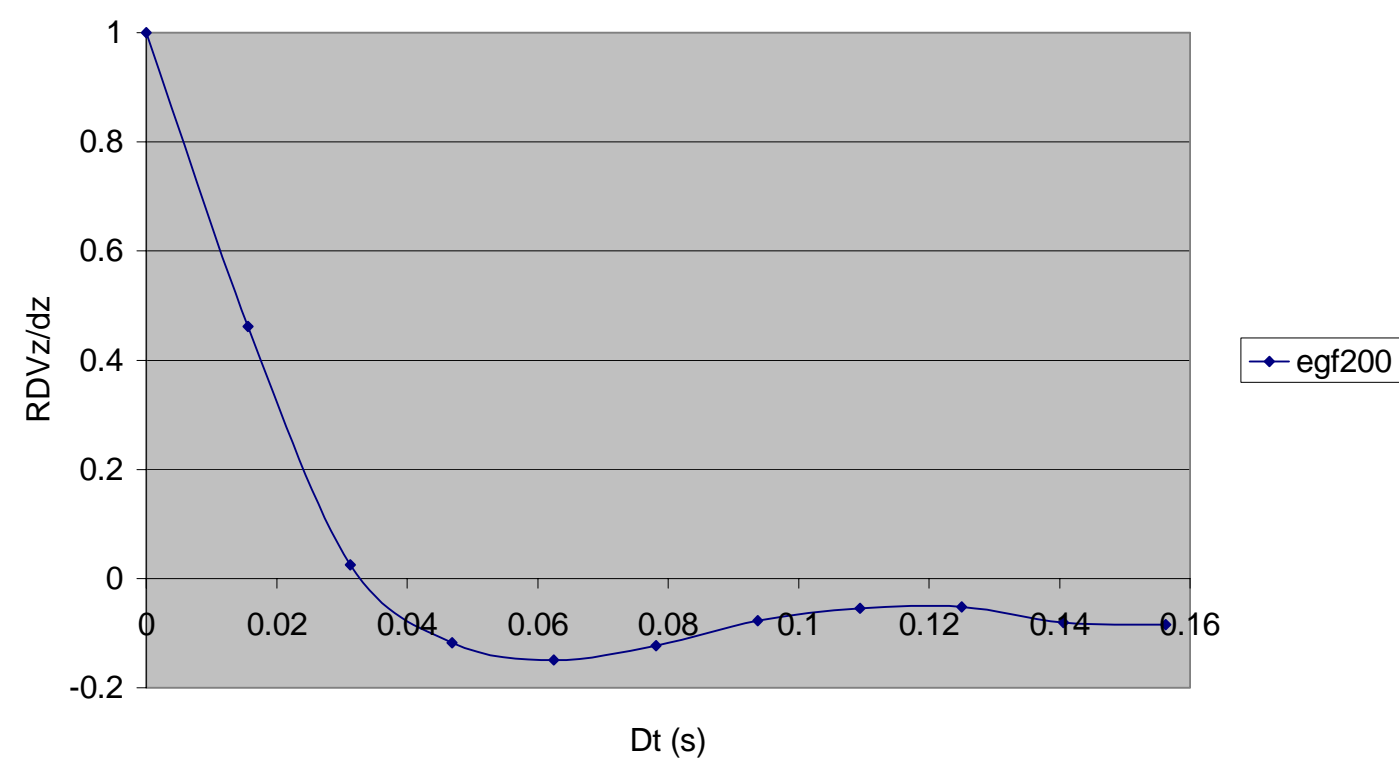

FIGURA 113: Autocorrelação da Sonda: Ensaio da Grade de 26,5mm de abertura e barras com 10,0mm de espessura (Freqüência de oscilação da grade de 200 rpm)

Autocorrelação Foto egf200

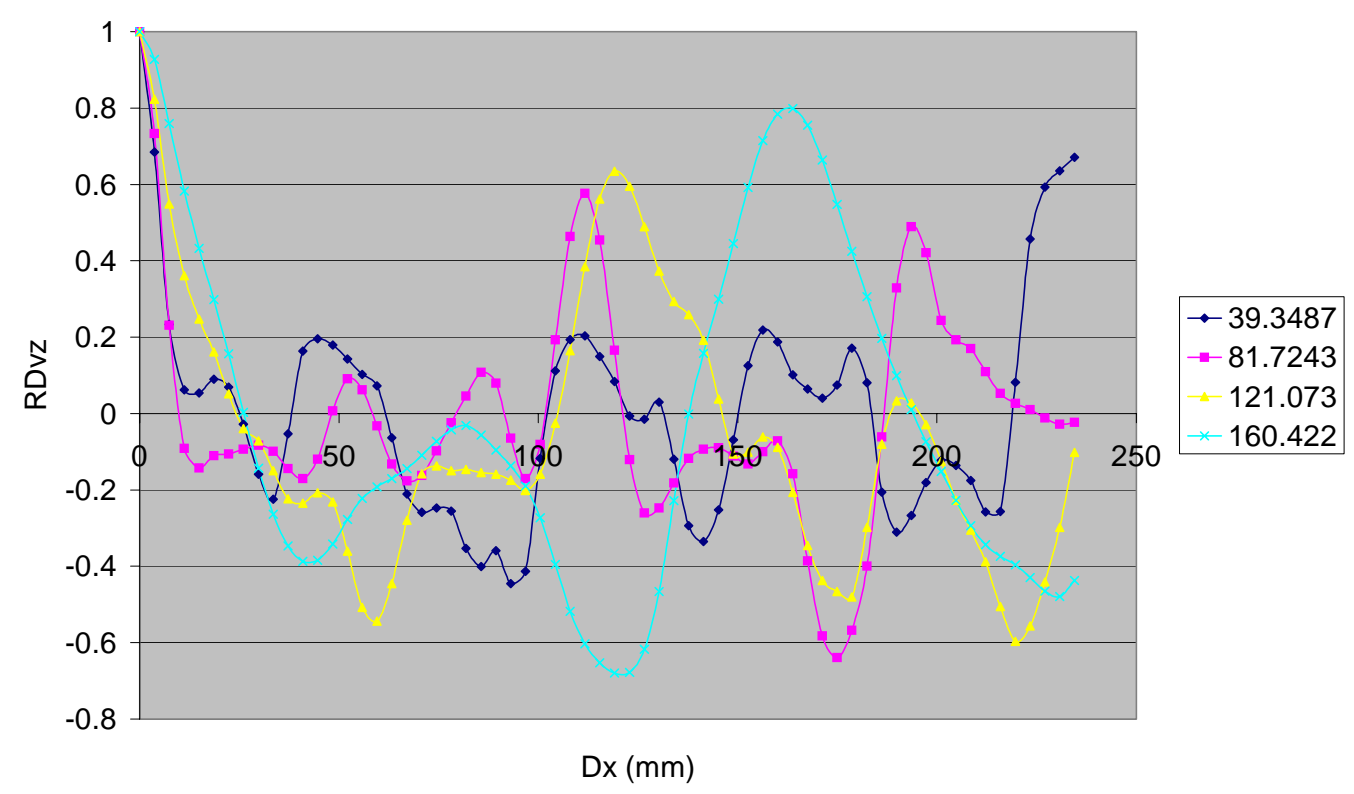

FIGURA 114: Autocorrelação da Foto: Ensaio da Grade de 26,5mm de abertura e barras com 10,0mm de espessura (Freqüência de oscilação da grade de 200 rpm) 
Autocorrelação Sonda egm140

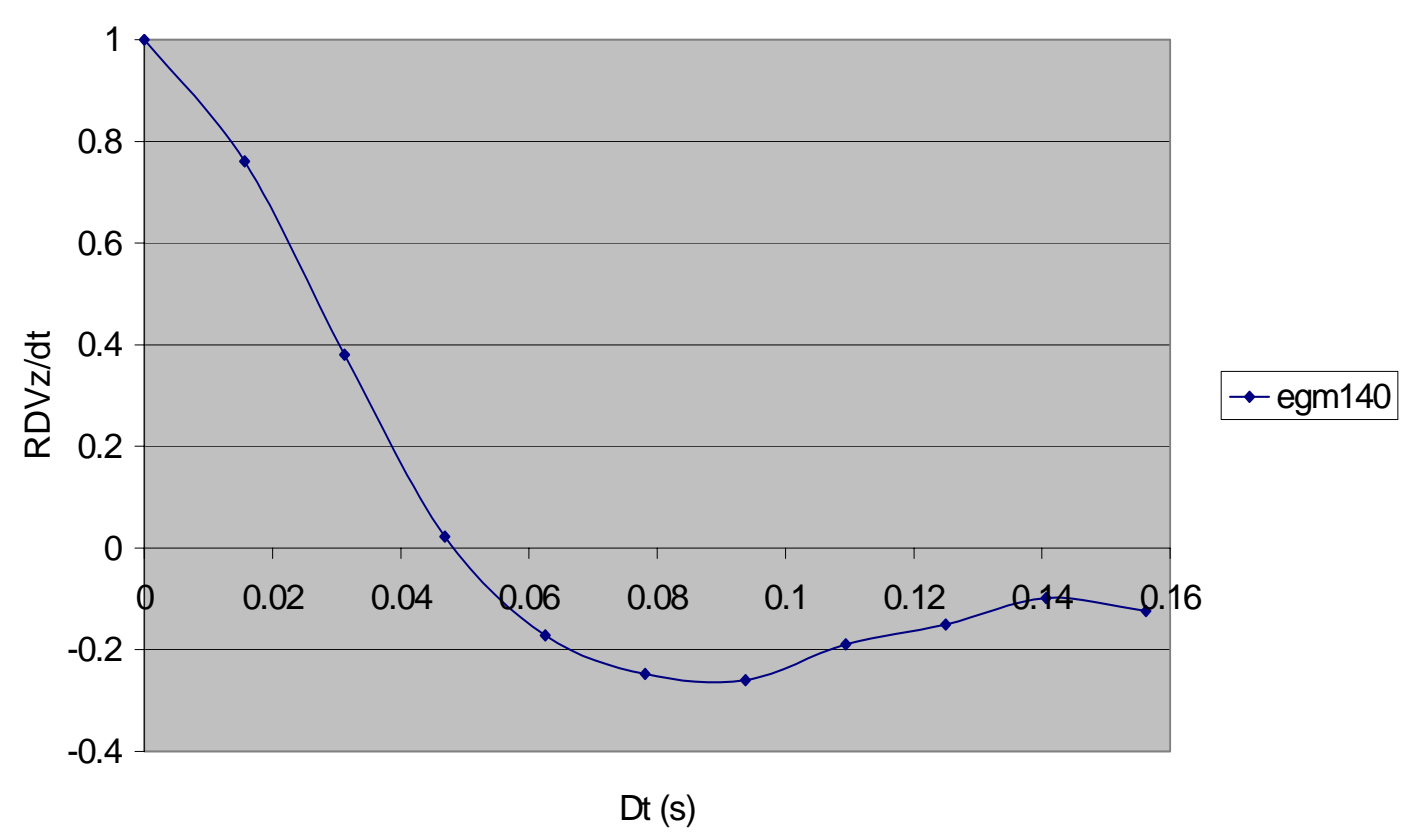

FIGURA 115: Autocorrelação da Sonda: Ensaio da Grade de 39,0mm de abertura e barras com 10,0mm de espessura (Freqüência de oscilação da grade de 140 rpm)

Autocorrelação Foto egm 140

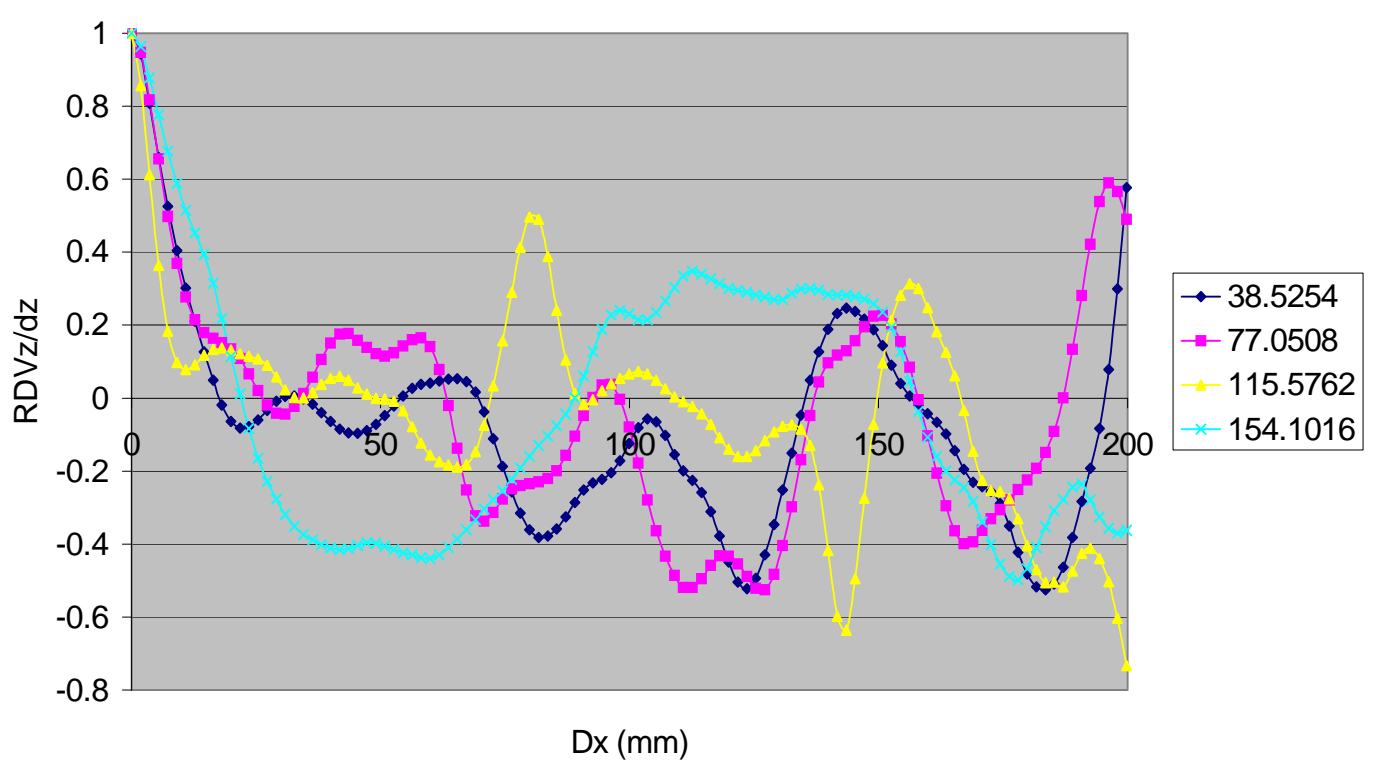

FIGURA 116: Autocorrelação da Foto: Ensaio da Grade de 39,0mm de abertura e barras com 10,0mm de espessura (Freqüência de oscilação da grade de 140 rpm) 


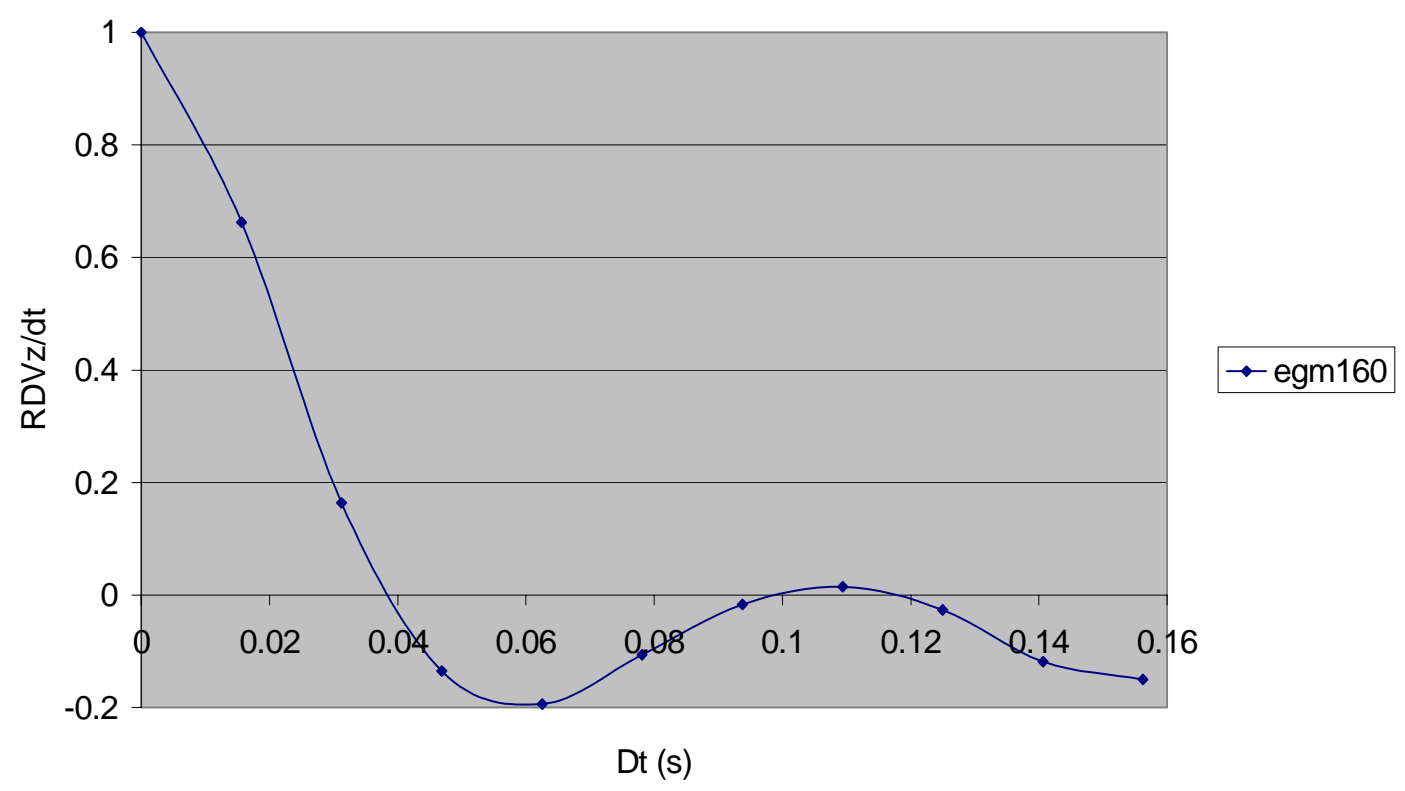

FIGURA 117: Autocorrelação da Sonda: Ensaio da Grade de 39,0mm de abertura e barras com 10,0mm de espessura (Freqüência de oscilação da grade de 160 rpm)

Autocorrelação Foto egm160

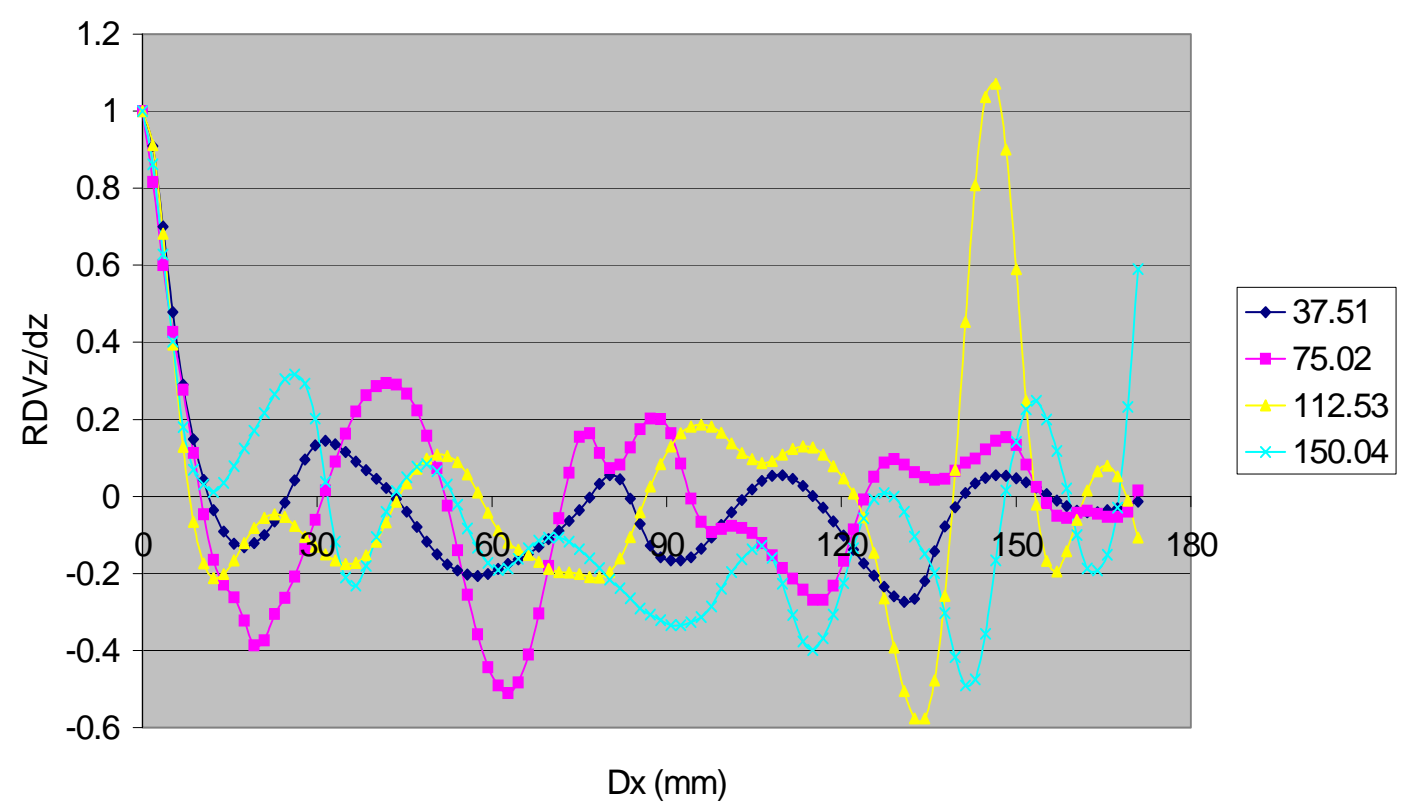

FIGURA 118: Autocorrelação da Foto: Ensaio da Grade de 39,0mm de abertura e barras com 10,0mm de espessura (Freqüência de oscilação da grade de 160 rpm) 
Autocorrelação Sonda egm180

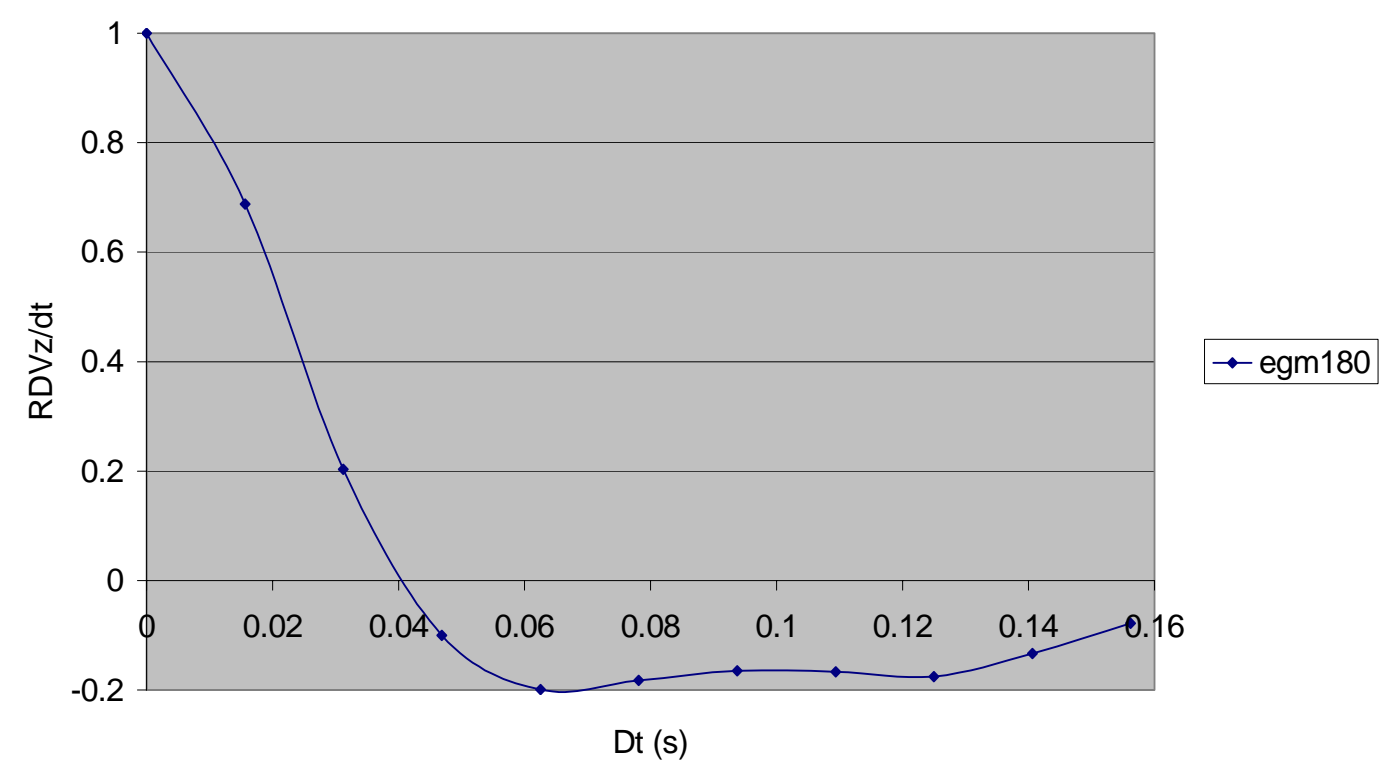

FIGURA 119: Autocorrelação da Sonda: Ensaio da Grade de 39,0mm de abertura e barras com 10,0mm de espessura (Freqüência de oscilação da grade de 180 rpm)

Autocorrelação Foto egm180

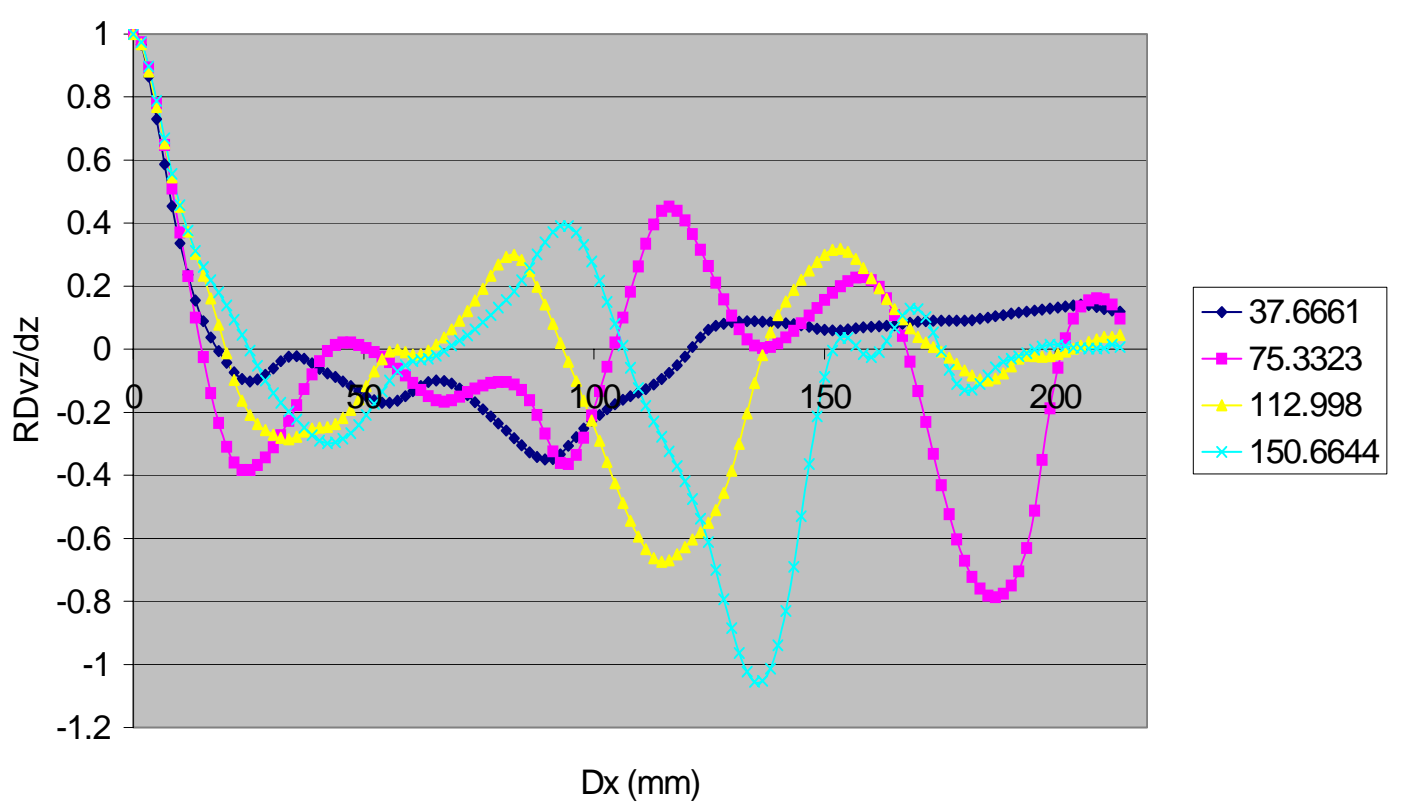

FIGURA 120: Autocorrelação da Foto: Ensaio da Grade de 39,0mm de abertura e barras com 10,0mm de espessura (Freqüência de oscilação da grade de 180 rpm) 


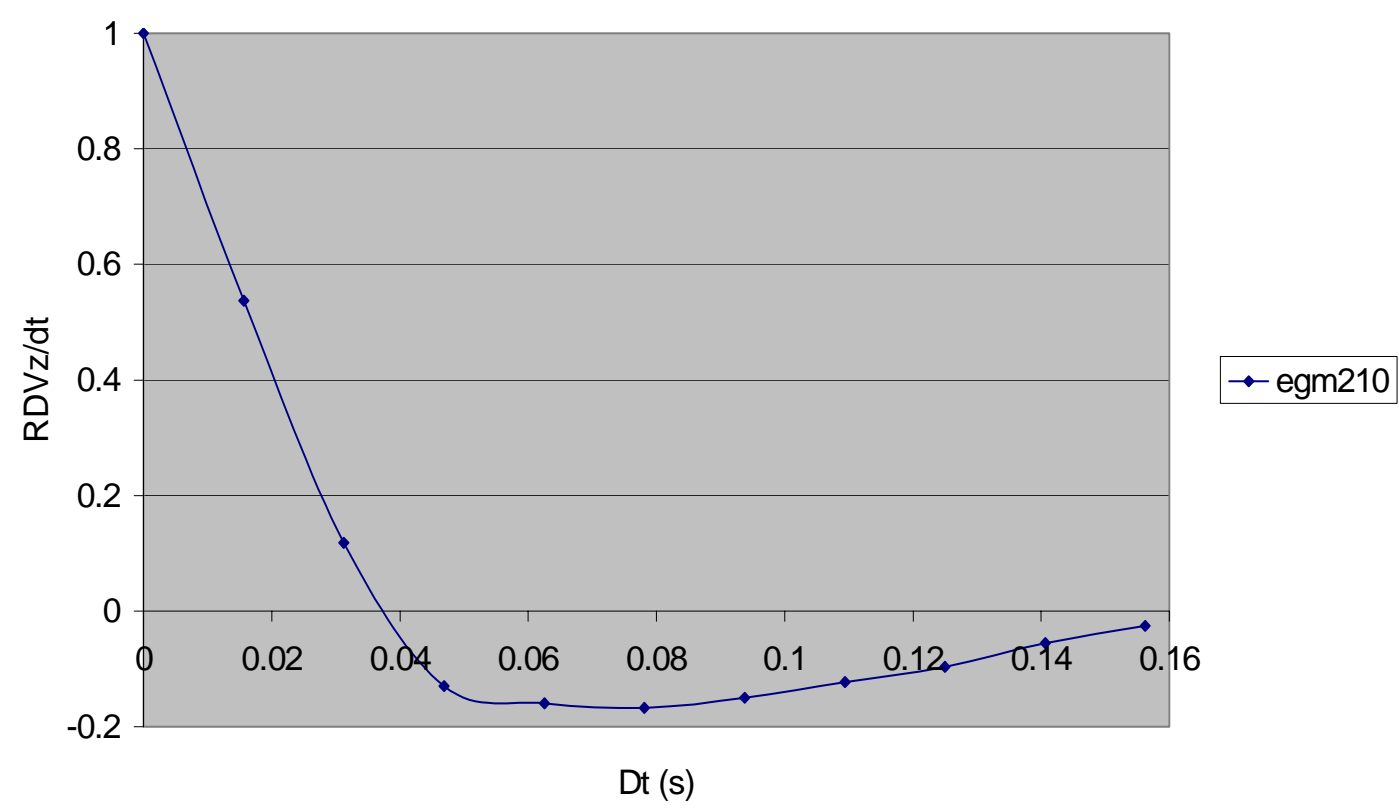

FIGURA 121: Autocorrelação da Sonda: Ensaio da Grade de 39,0mm de abertura e barras com 10,0mm de espessura (Freqüência de oscilação da grade de 210 rpm)

Autocorrelação Foto egm210

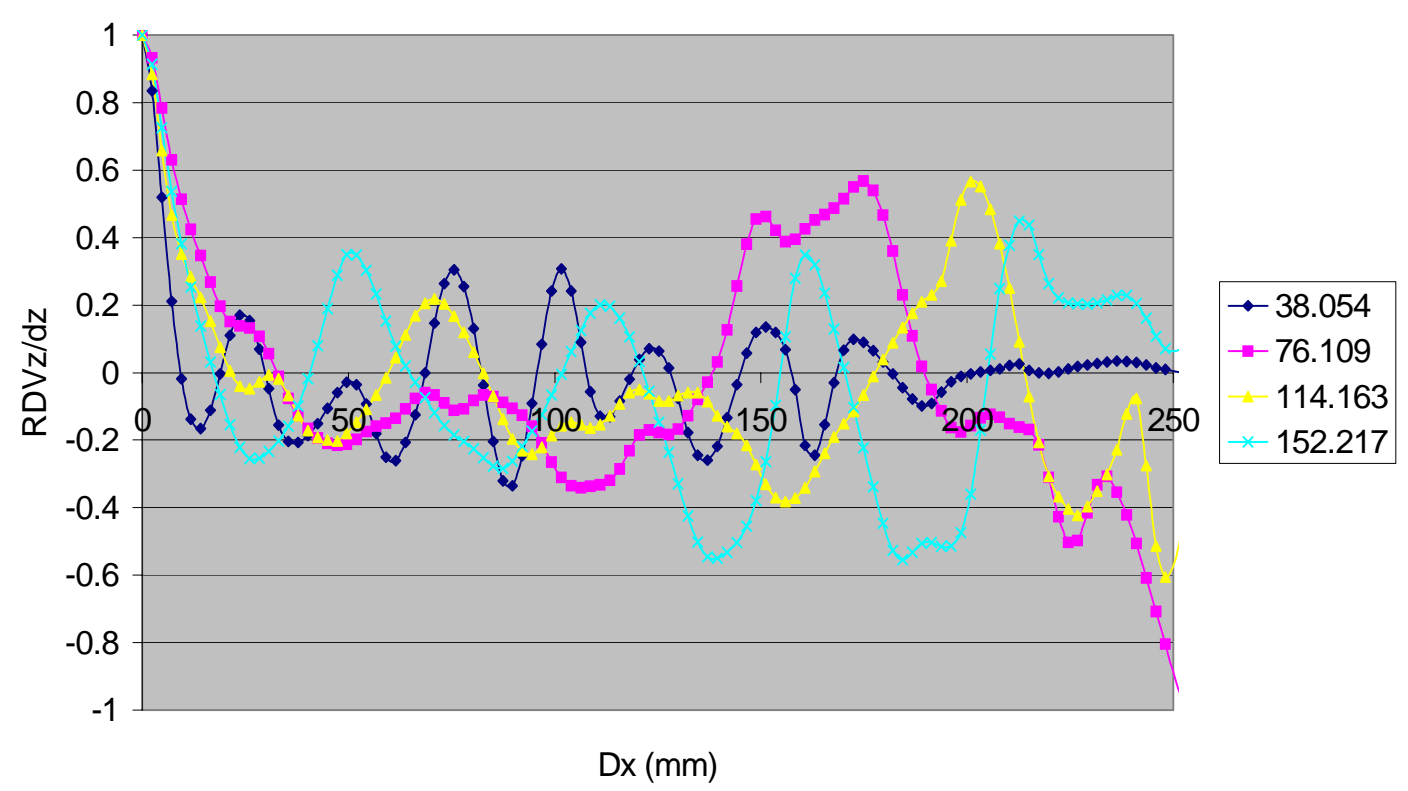

FIGURA 122: Autocorrelação da Foto: Ensaio da Grade de 39,0mm de abertura e barras com 10,0mm de espessura (Freqüência de oscilação da grade de 210 rpm) 


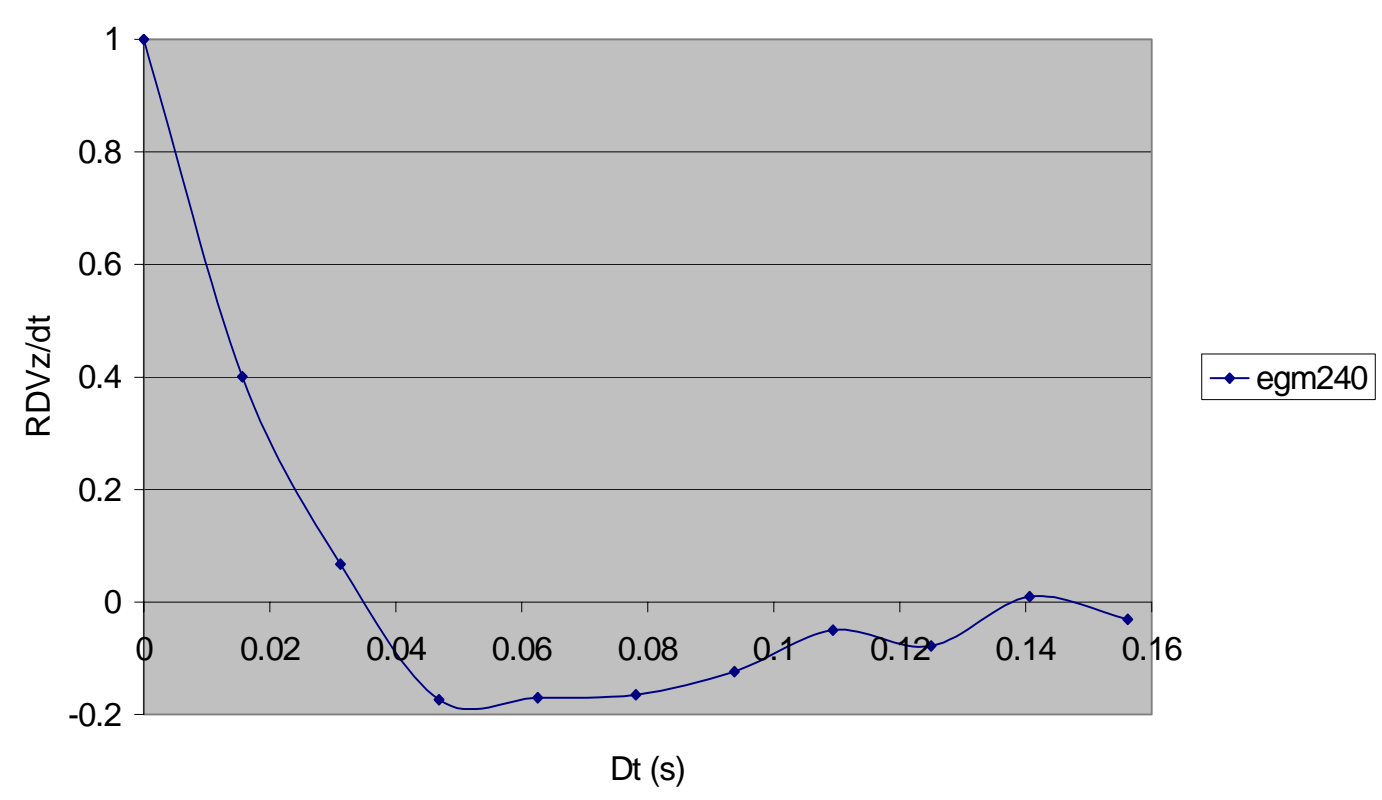

FIGURA 123: Autocorrelação da Sonda: Ensaio da Grade de 39,0mm de abertura e barras com 10,0mm de espessura (Freqüência de oscilação da grade de 240 rpm)

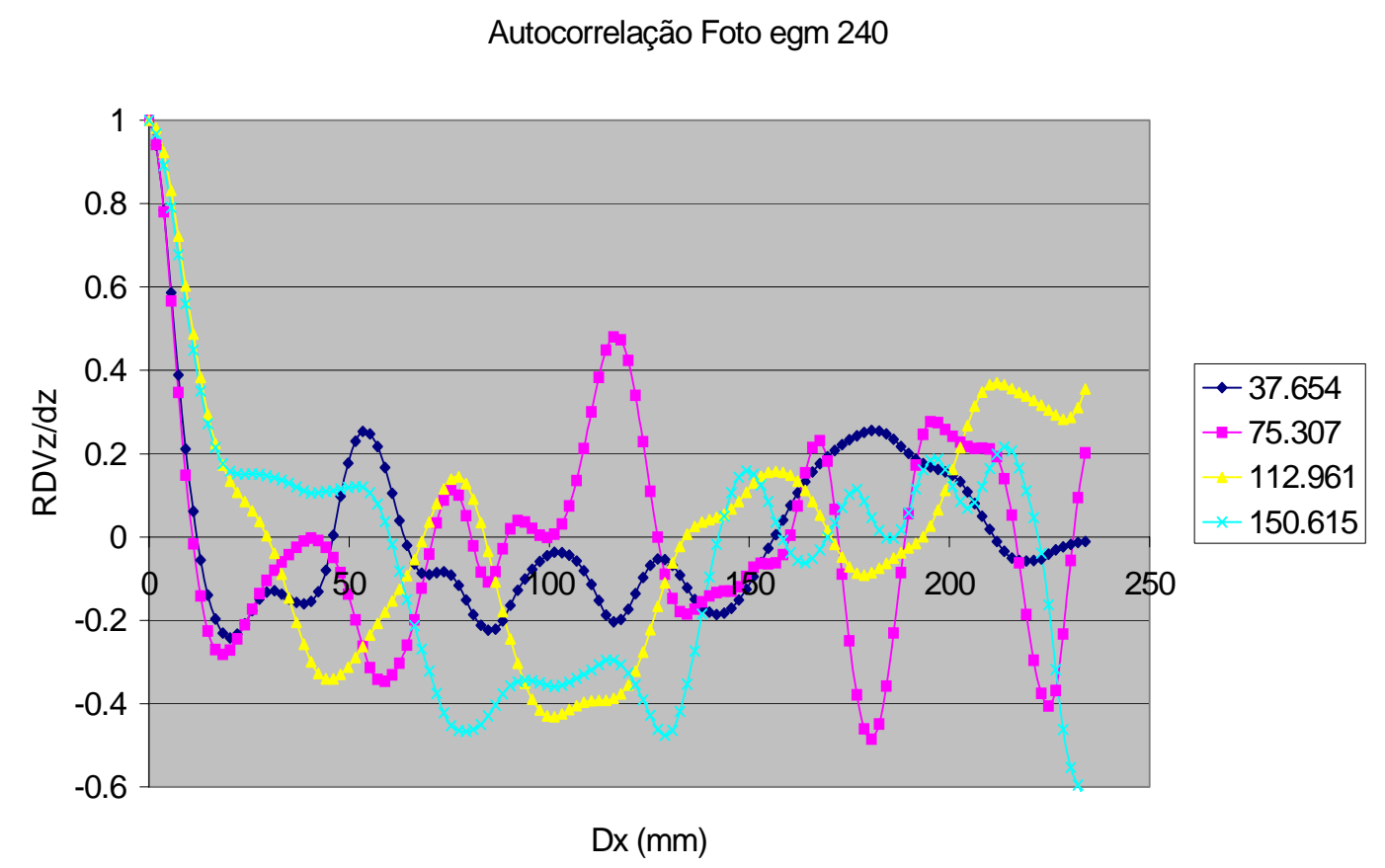

FIGURA 124: Autocorrelação da Foto: Ensaio da Grade de 39,0mm de abertura e barras com 10,0mm de espessura (Freqüência de oscilação da grade de 240 rpm) 
Autocorrelação Sonda egl180

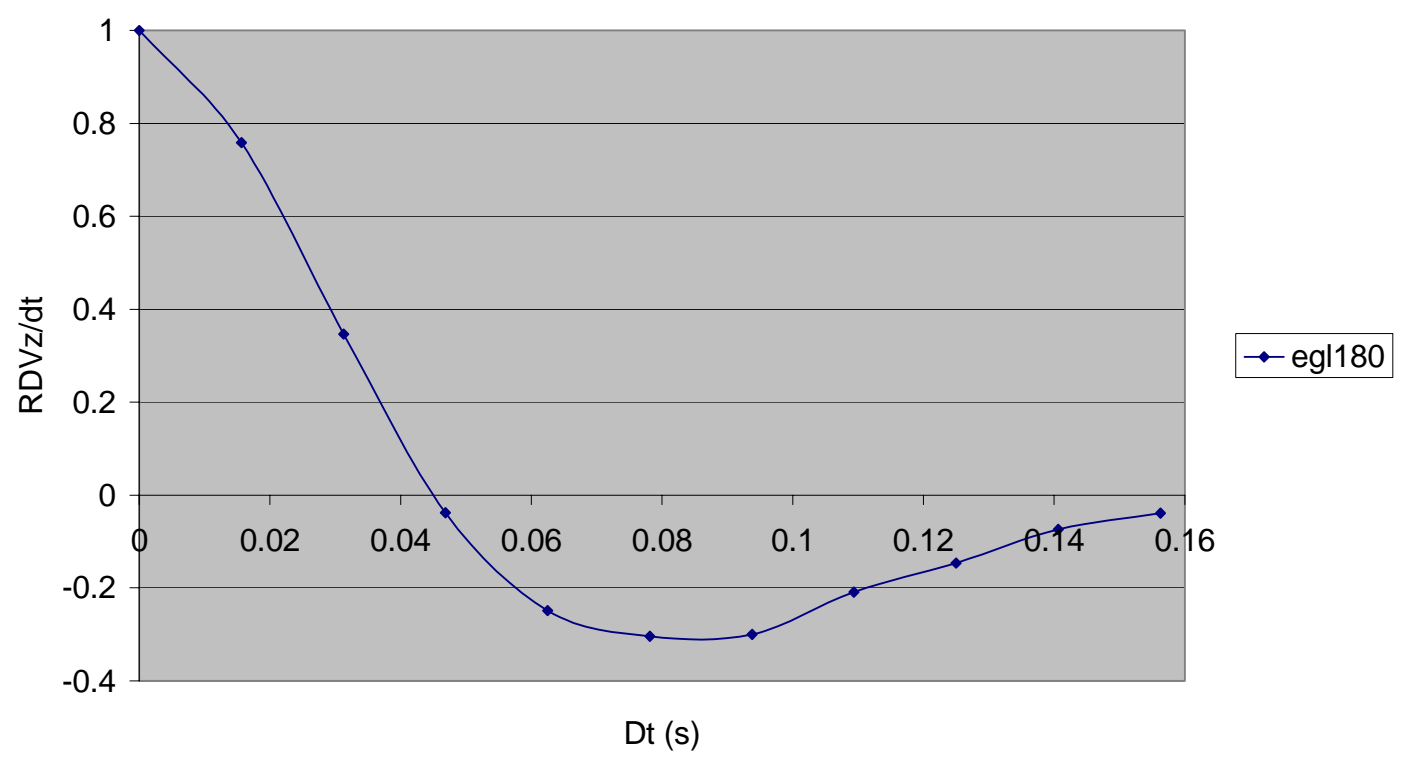

FIGURA 125: Autocorrelação da Sonda: Ensaio da Grade de 64,5mm de abertura e barras com 10,0mm de espessura (Freqüência de oscilação da grade de 180 rpm)

Autocorrelação Foto egl180

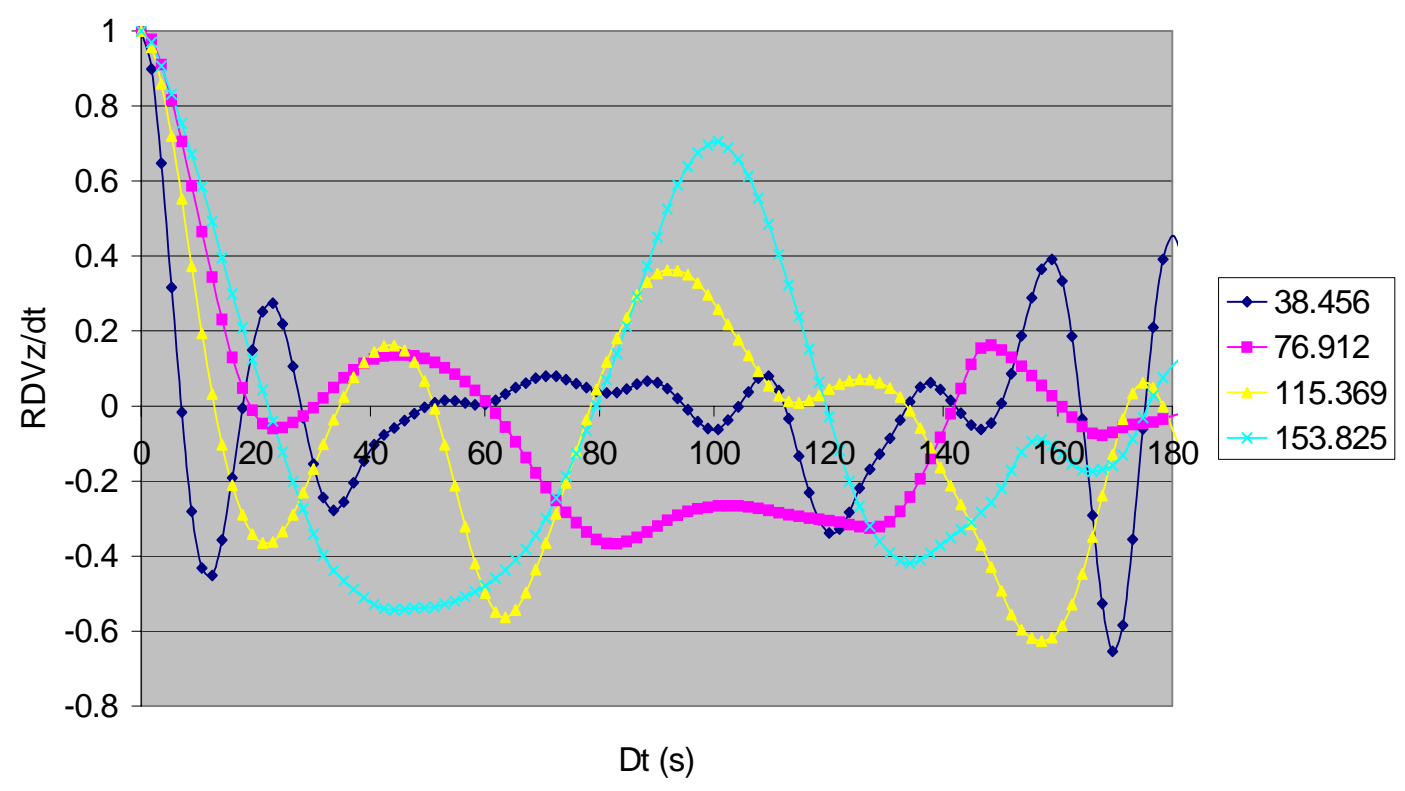

FIGURA 126: Autocorrelação da Foto: Ensaio da Grade de 64,5mm de abertura e barras com 10,0mm de espessura (Freqüência de oscilação da grade de 180 rpm) 
Autocorrelação Sonda egl200

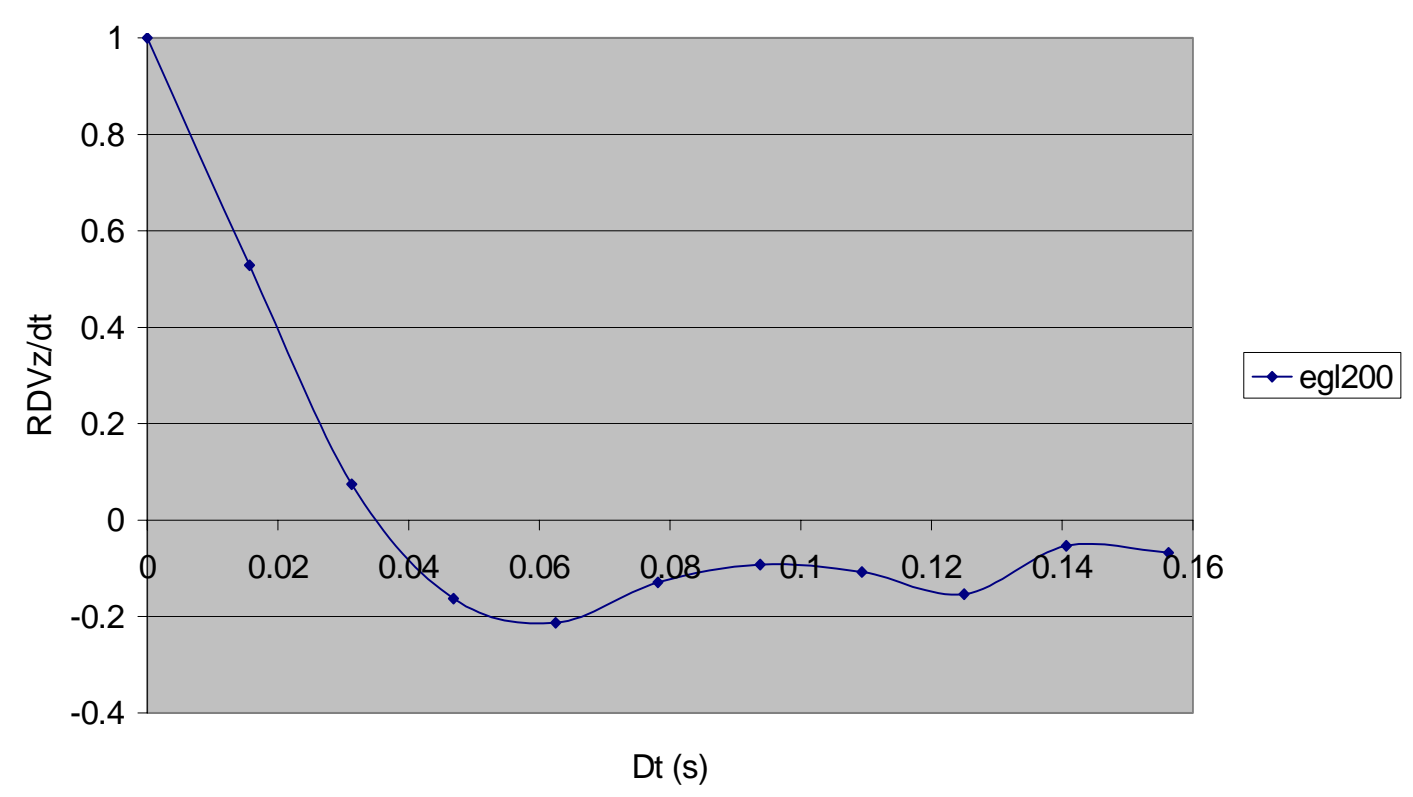

FIGURA 127: Autocorrelação da Sonda: Ensaio da Grade de 64,5mm de abertura e barras com 10,0mm de espessura (Freqüência de oscilação da grade de 200 rpm)

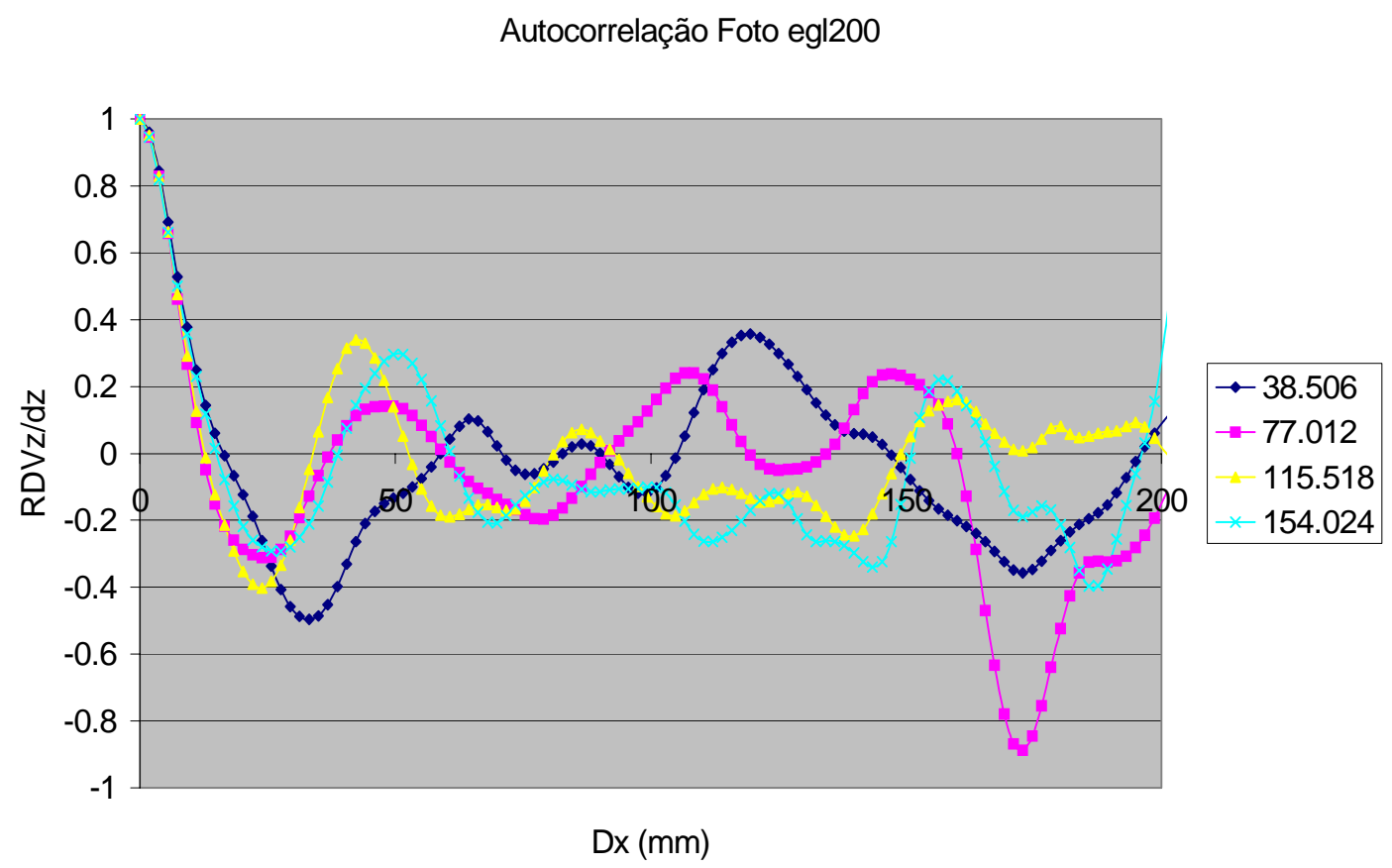

FIGURA 128: Autocorrelação da Foto: Ensaio da Grade de $64,5 \mathrm{~mm}$ de abertura e barras com 10,0mm de espessura (Freqüência de oscilação da grade de 200 rpm) 


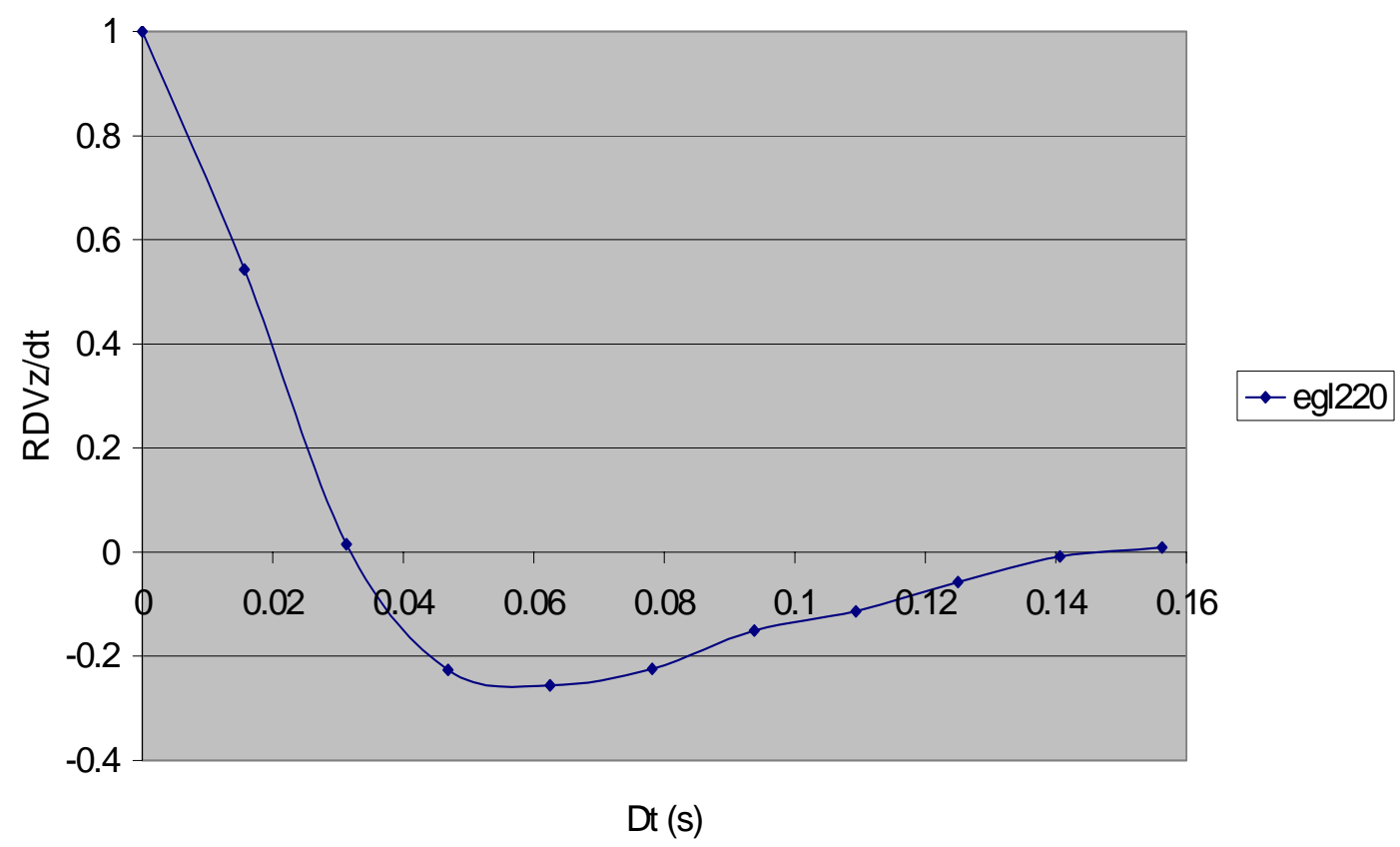

FIGURA 129: Autocorrelação da Sonda: Ensaio da Grade de $64,5 \mathrm{~mm}$ de abertura e barras com 10,0mm de espessura (Freqüência de oscilação da grade de 220 rpm)

Autocorrelação Foto egl220

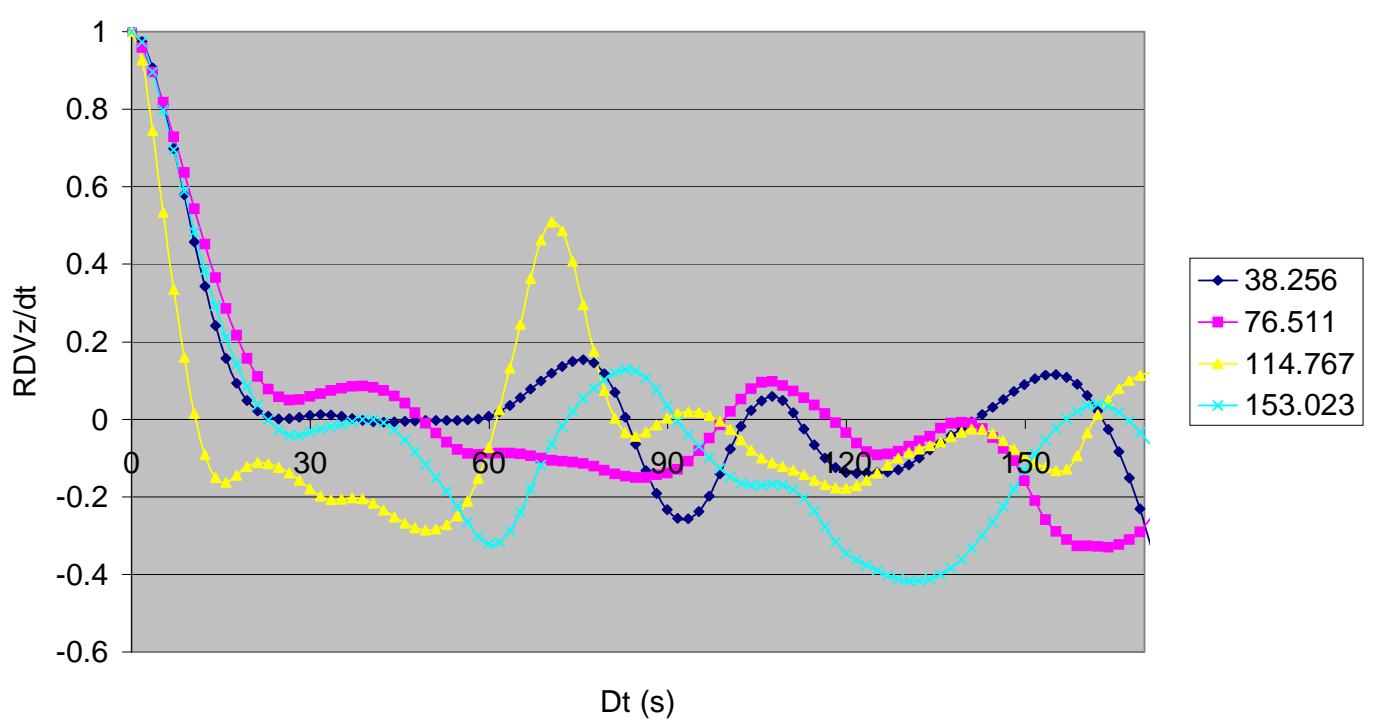

FIGURA 130: Autocorrelação da Foto: Ensaio da Grade de 64,5mm de abertura e barras com 10,0mm de espessura (Freqüência de oscilação da grade de 220 rpm) 
Autocorrelação Sonda egl250

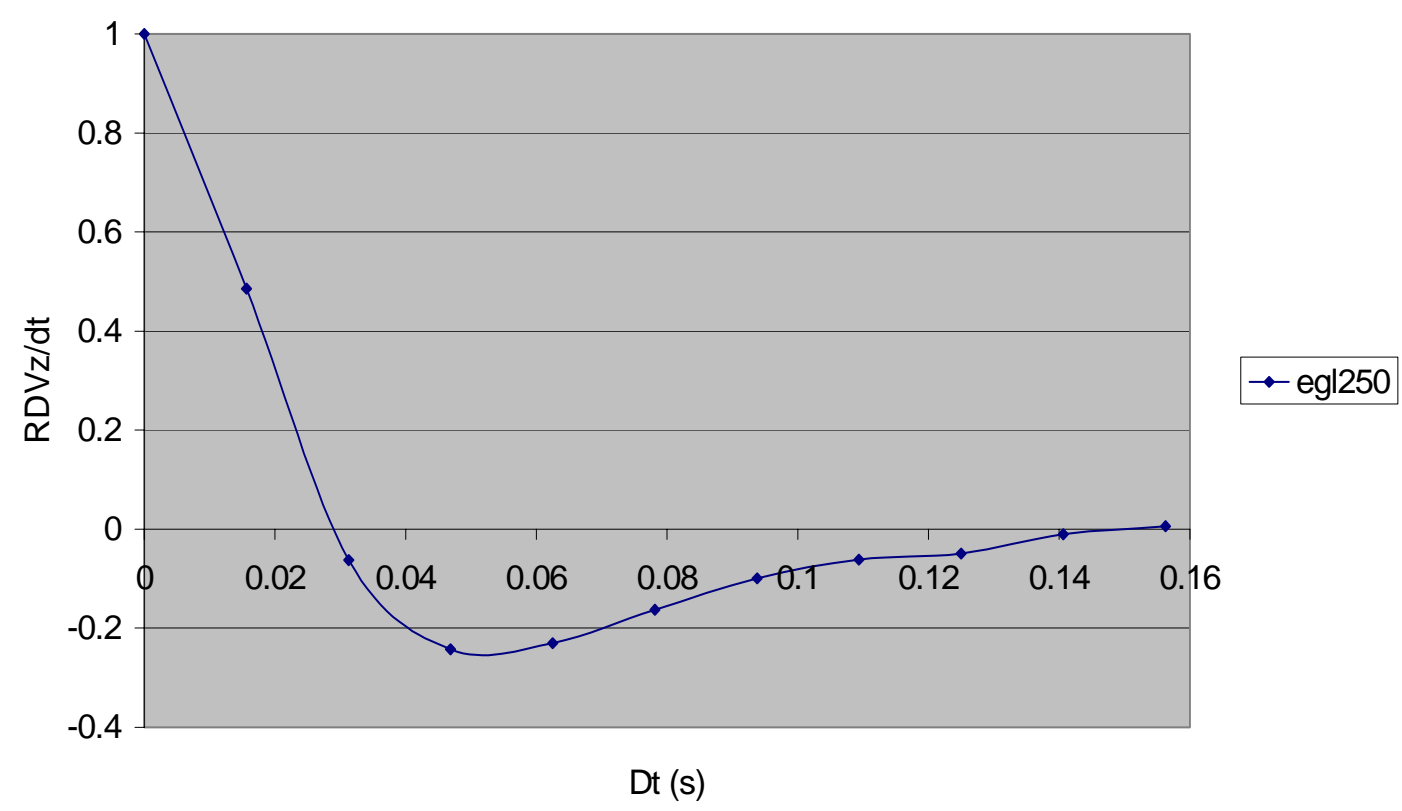

FIGURA 131: Autocorrelação da Sonda: Ensaio da Grade de 64,5mm de abertura e barras com 10,0mm de espessura (Freqüência de oscilação da grade de 250 rpm)

\section{Autocorrelação Foto egl 250}

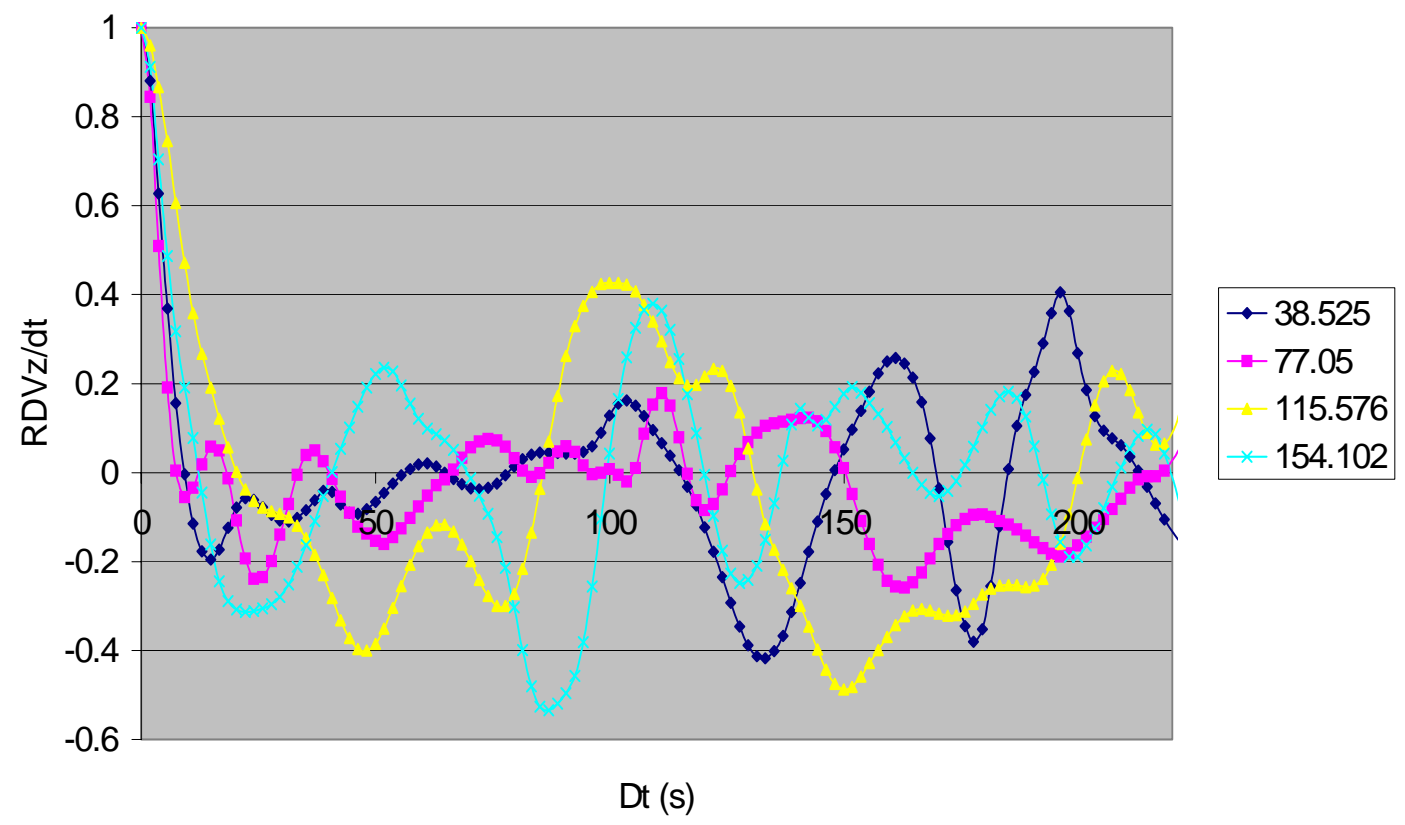

FIGURA 132: Autocorrelação da Foto: Ensaio da Grade de 64,5mm de abertura e barras com 10,0mm de espessura (Freqüência de oscilação da grade de 250 rpm) 
5.5. Comparação entre o Espectro de freqüência da sonda ótica e o Espectro do método fotográfico

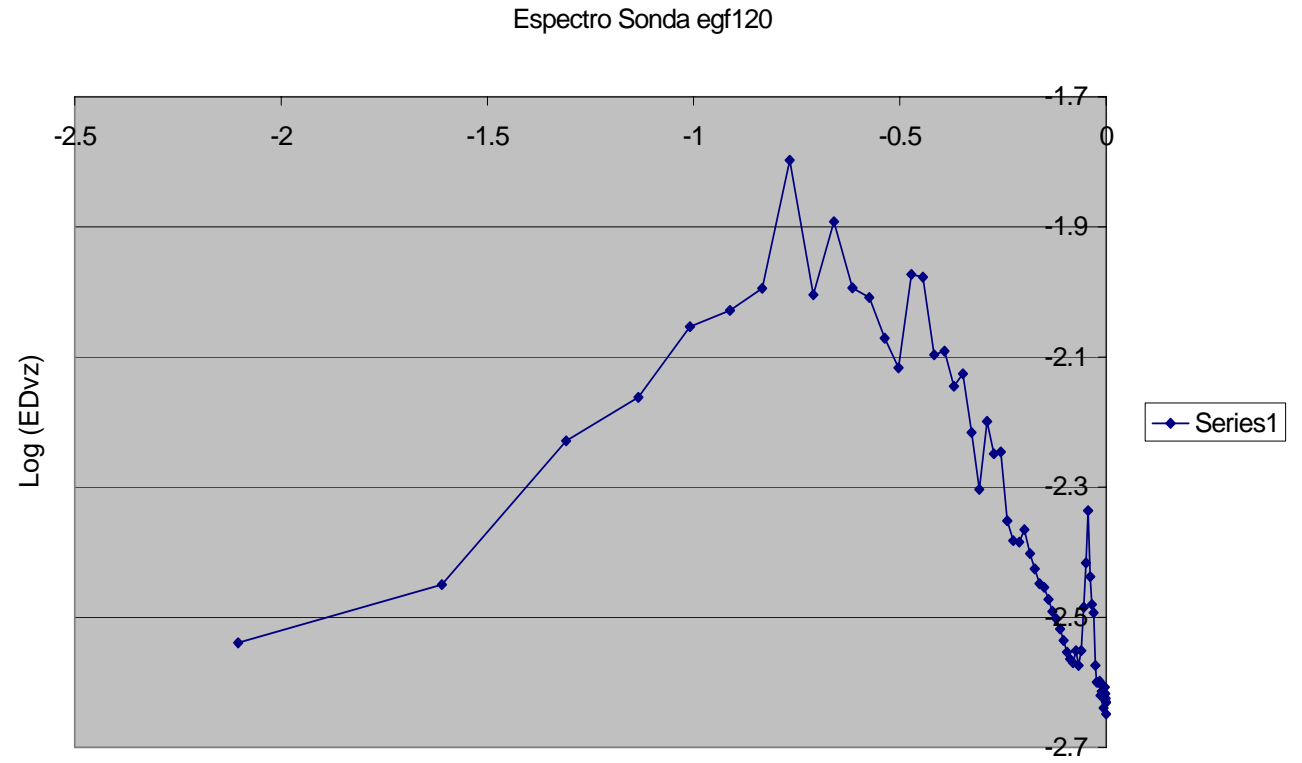

$\log (f) \mathrm{Hz}$

FIGURA 133: Espectro da Sonda: Ensaio da Grade de 26,5mm de abertura e barras com 10,0mm de espessura (Freqüência de oscilação da grade de 120 rpm)

Espectro egf120

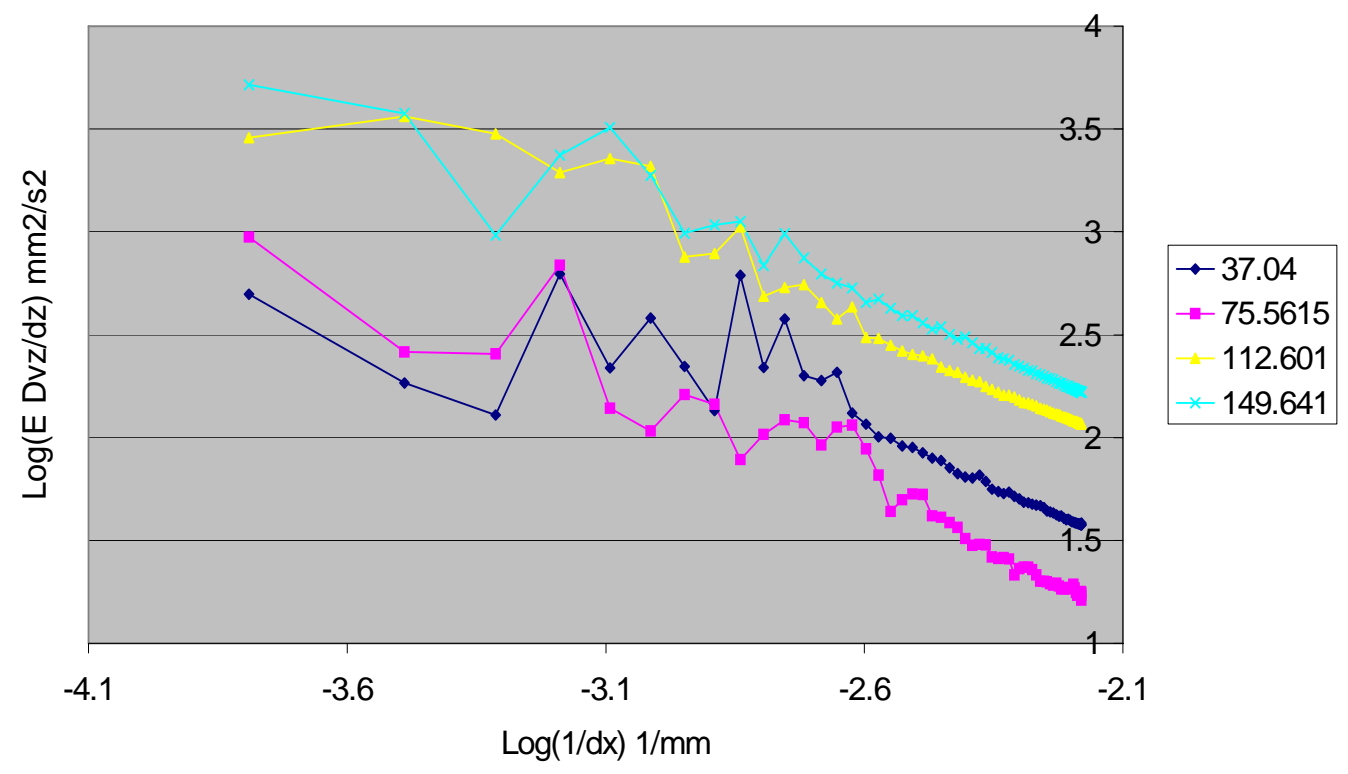

FIGURA 134: Espectro da Foto: Ensaio da Grade de 26,5mm de abertura e barras com 10,0mm de espessura (Freqüência de oscilação da grade de 120 rpm) 


\section{Espectro Sonda egf140}

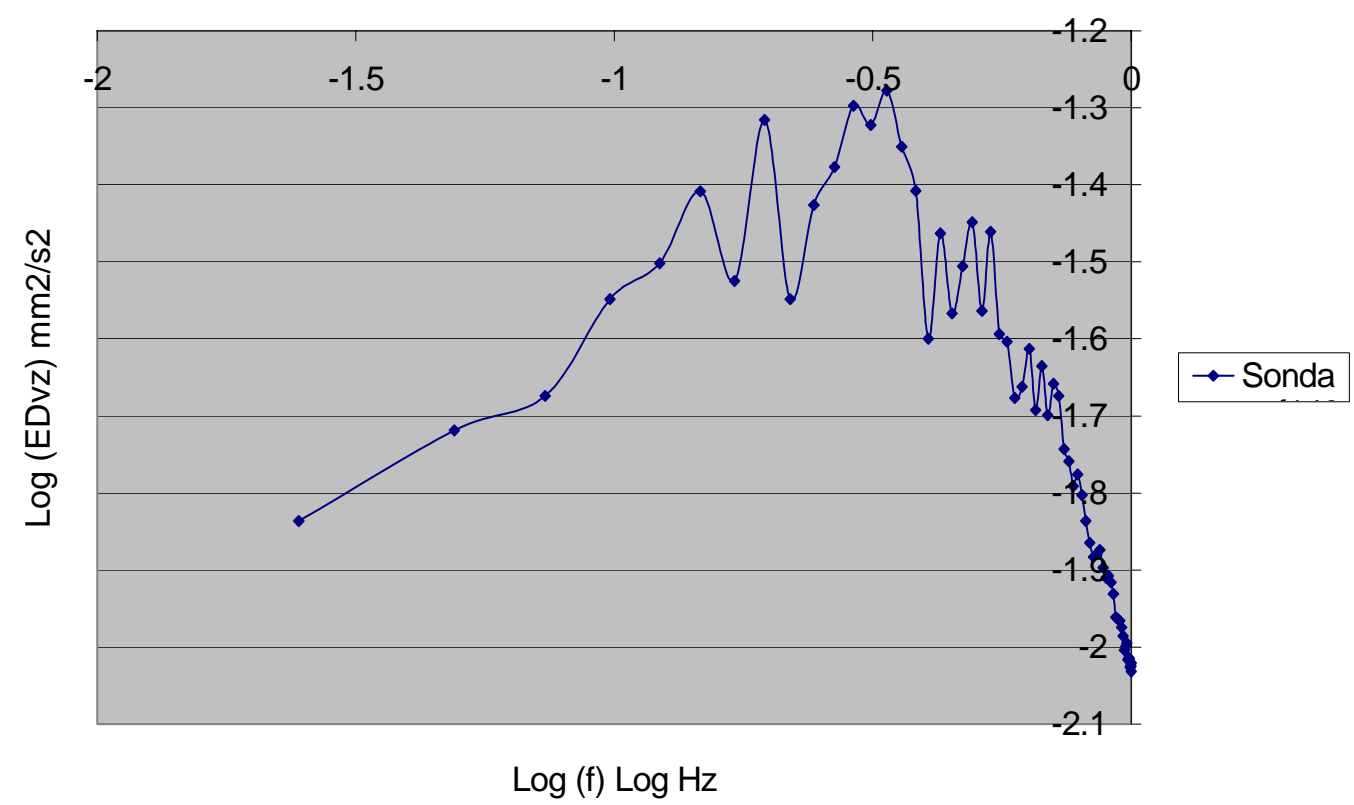

FIGURA 135: Espectro da Sonda: Ensaio da Grade de 26,5mm de abertura e barras com 10,0mm de espessura (Freqüência de oscilação da grade de 140 rpm)

\section{Espectro egf140}

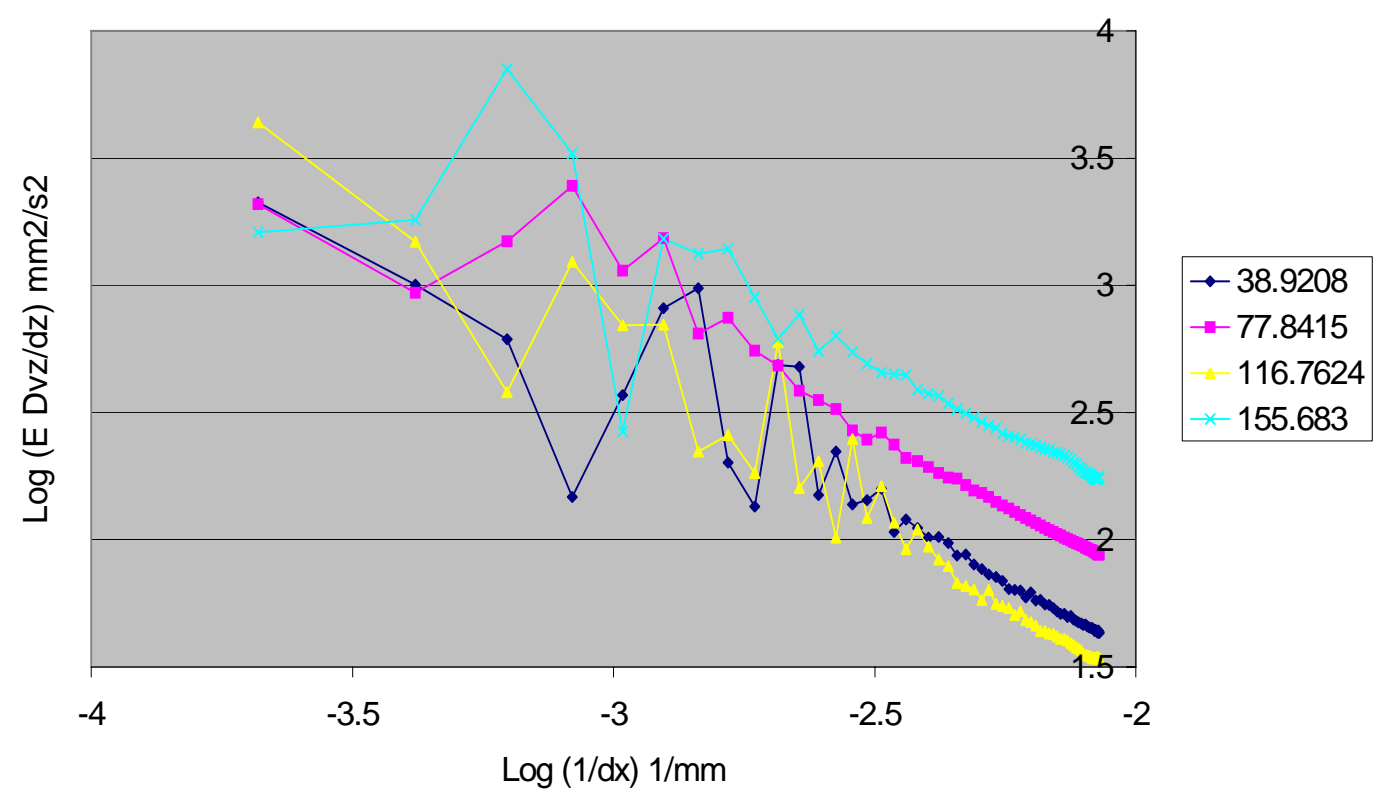

FIGURA 136: Espectro da Foto: Ensaio da Grade de 26,5mm de abertura e barras com 10,0mm de espessura (Freqüência de oscilação da grade de 140 rpm) 


\section{Espectro Sonda egf160}

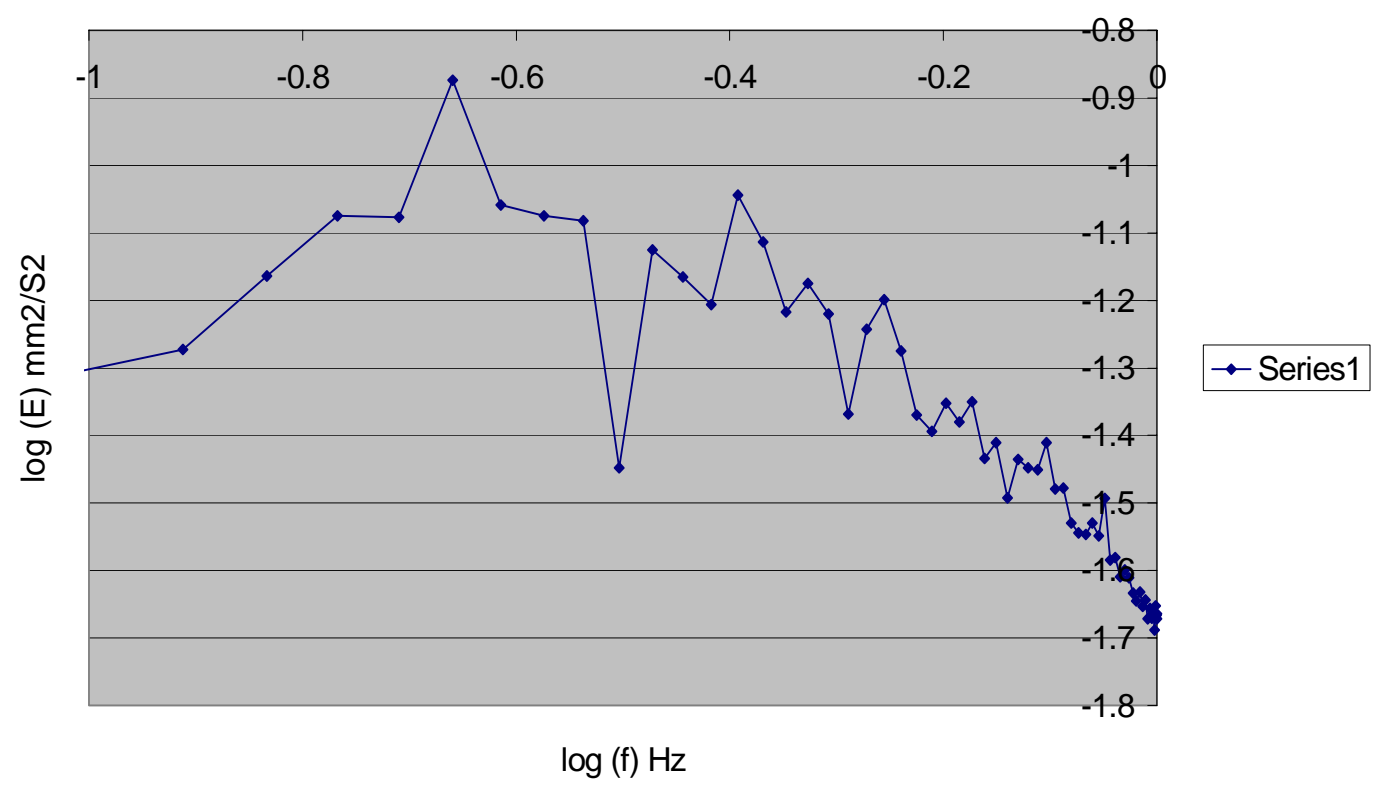

FIGURA 137: Espectro da Sonda: Ensaio da Grade de 26,5mm de abertura e barras com 10,0mm de espessura (Freqüência de oscilação da grade de 160 rpm)

\section{Espectro egf160}

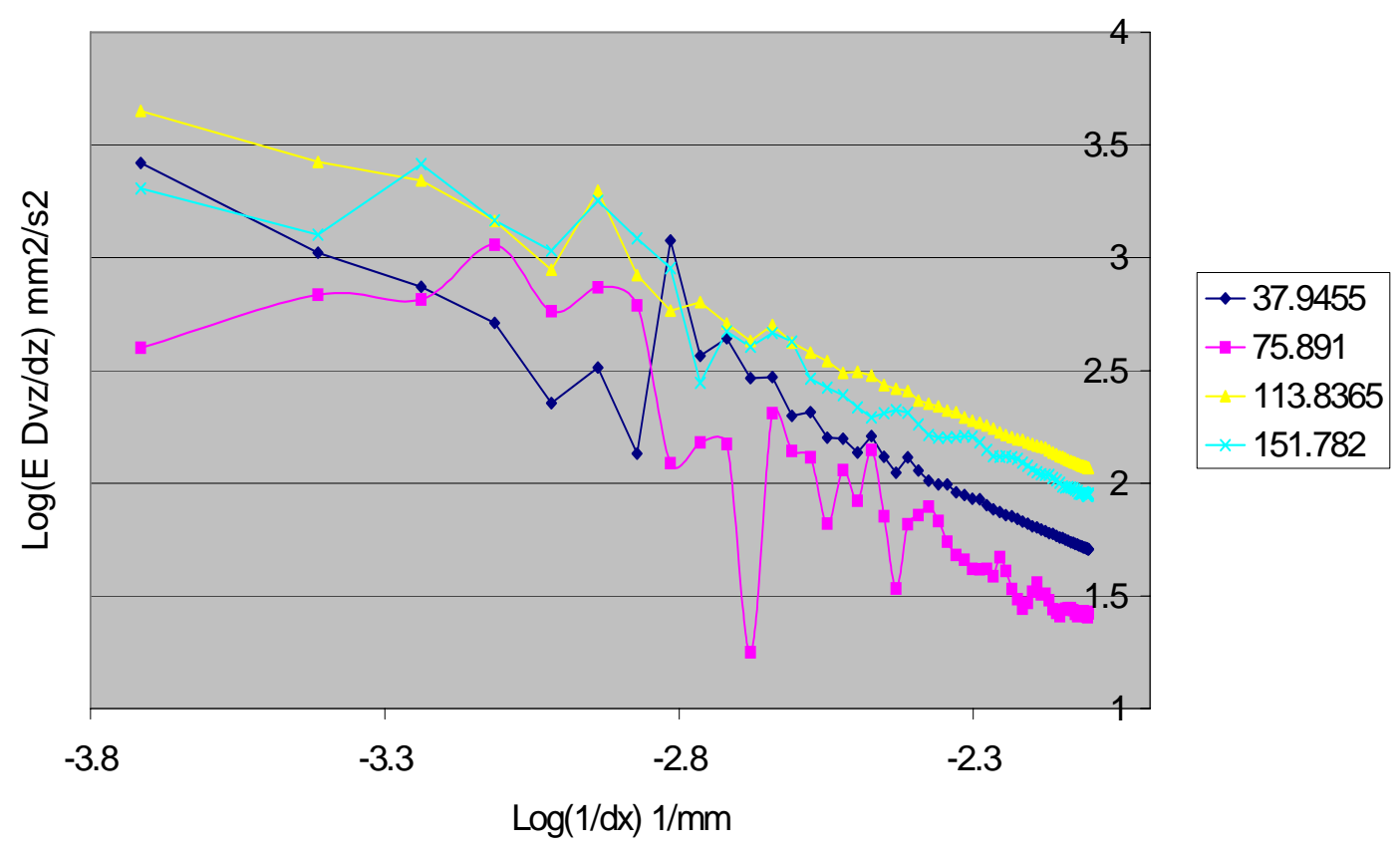

FIGURA 138: Espectro da Foto: Ensaio da Grade de 26,5mm de abertura e barras com 10,0mm de espessura (Freqüência de oscilação da grade de 160 rpm) 
Espectro sonda egf180

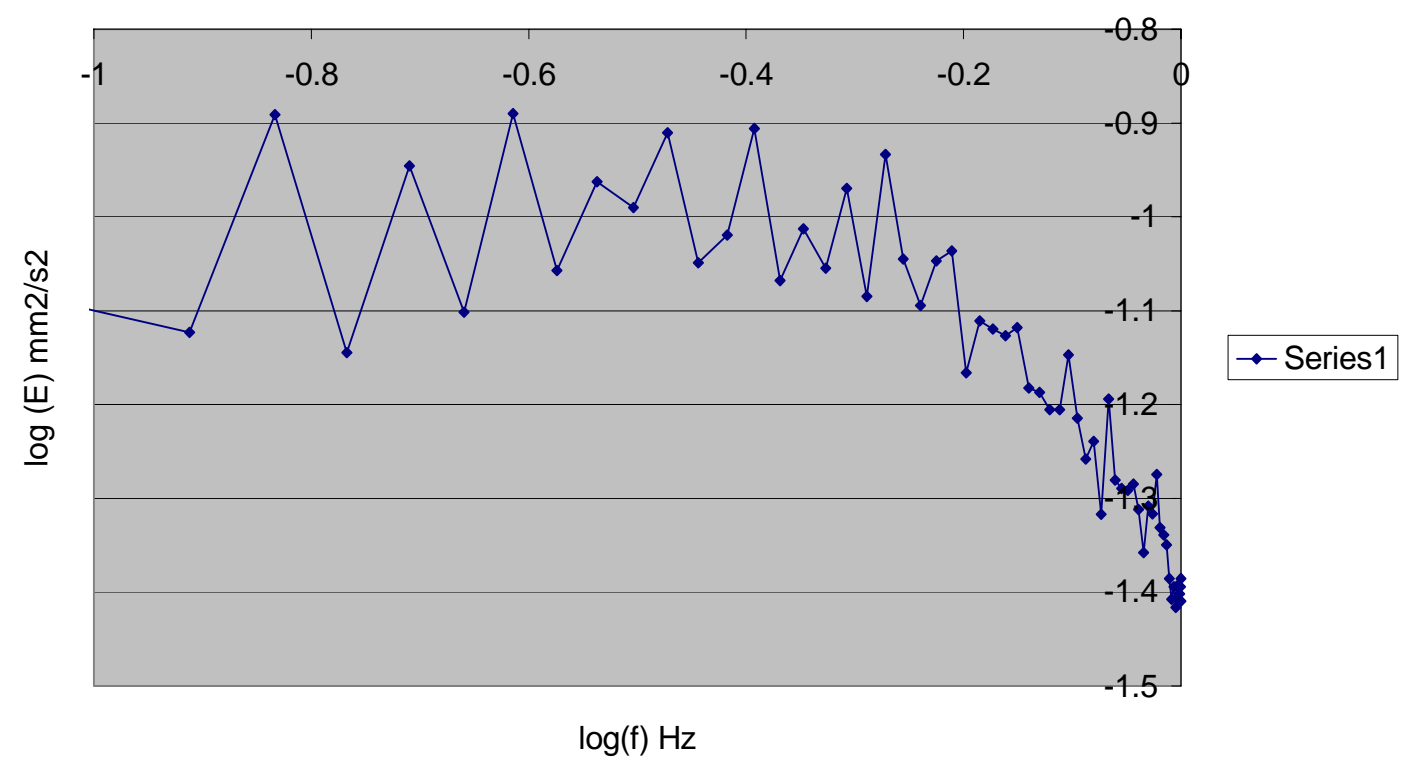

FIGURA 139: Espectro da Sonda: Ensaio da Grade de 26,5mm de abertura e barras com 10,0mm de espessura (Freqüência de oscilação da grade de 180 rpm)

Espectro egf180

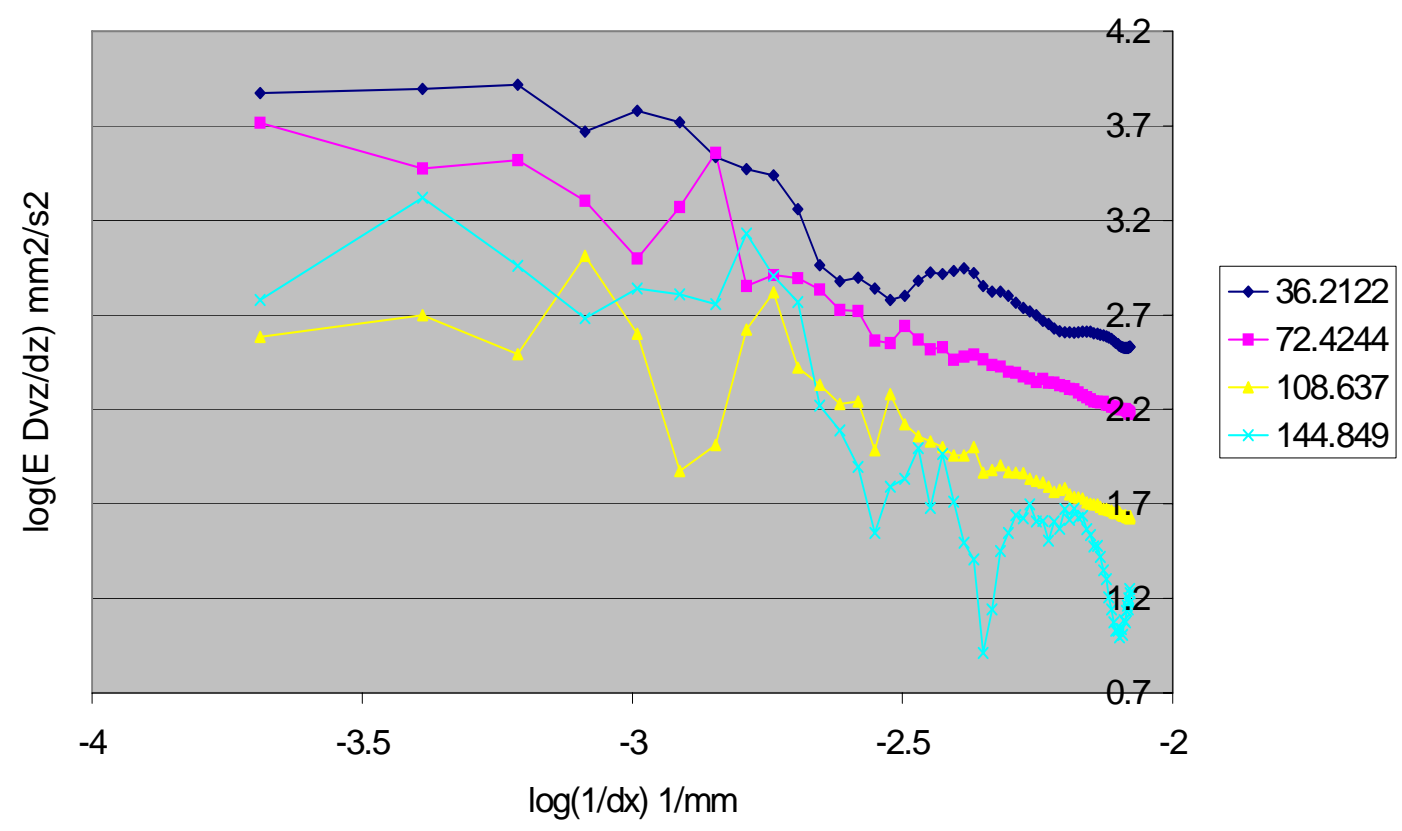

FIGURA 140: Espectro da Foto: Ensaio da Grade de 26,5mm de abertura e barras com 10,0mm de espessura (Freqüência de oscilação da grade de 180 rpm) 
Espectro Sonda egf200

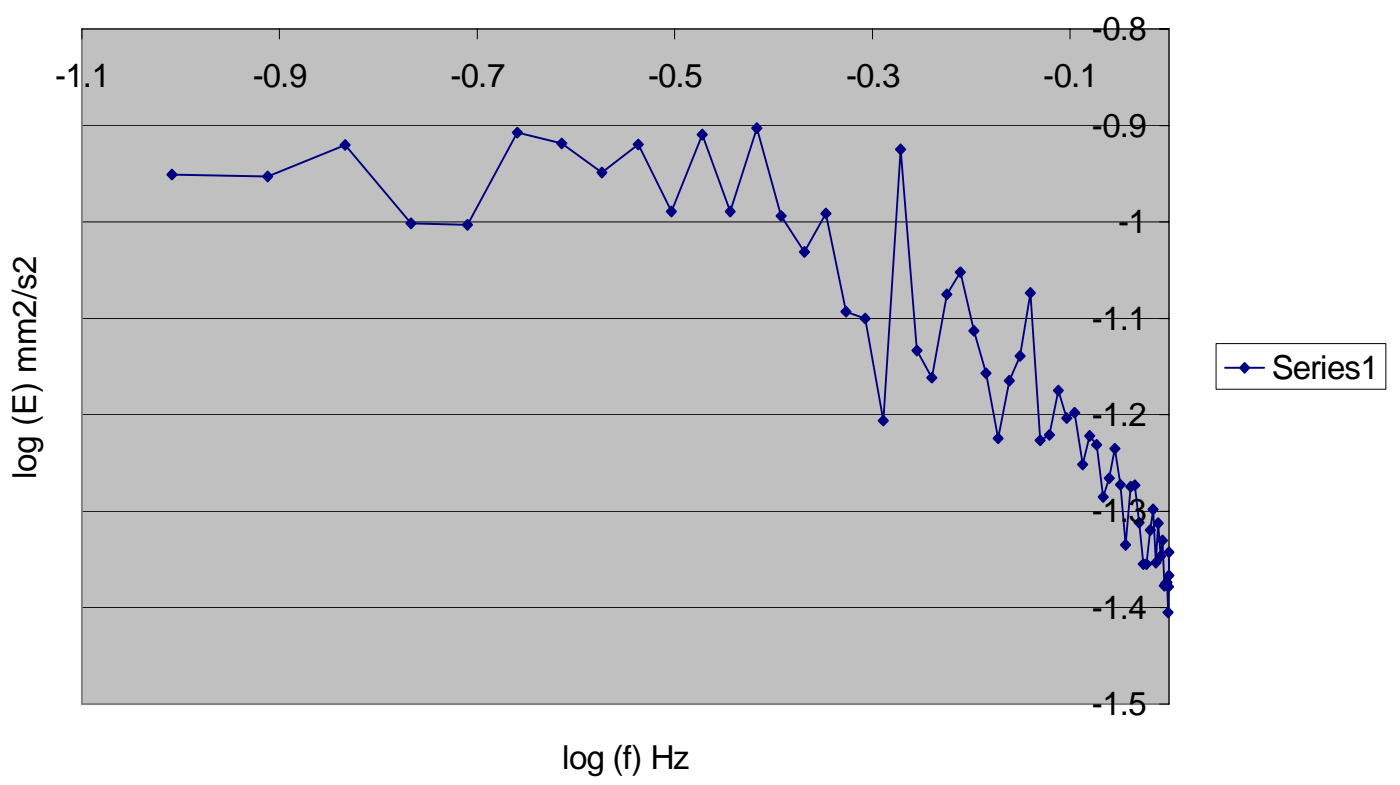

FIGURA 141: Espectro da Sonda: Ensaio da Grade de 26,5mm de abertura e barras com 10,0mm de espessura (Freqüência de oscilação da grade de 200 rpm)

Espectro

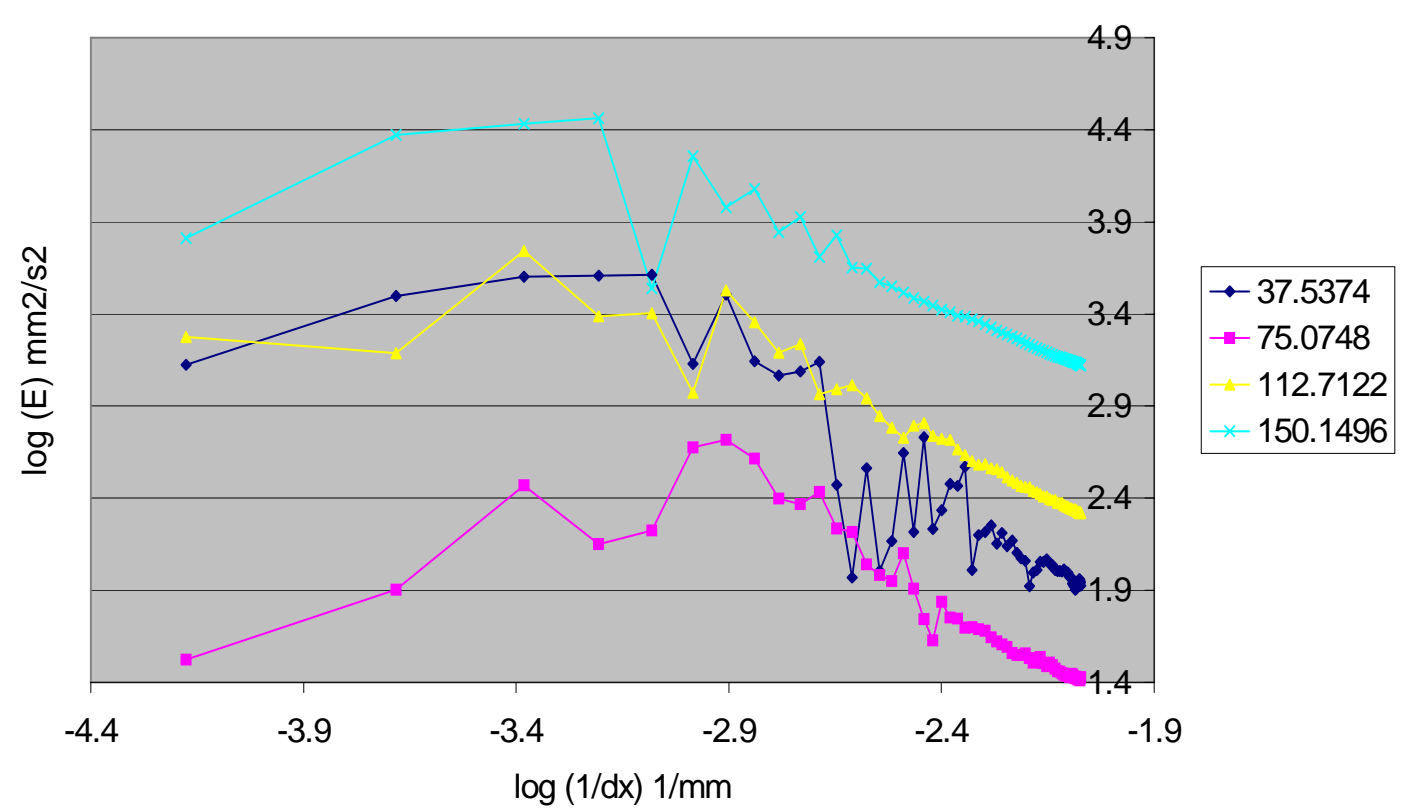

FIGURA 142: Espectro da Foto: Ensaio da Grade de 26,5mm de abertura e barras com 10,0mm de espessura (Freqüência de oscilação da grade de 200 rpm) 


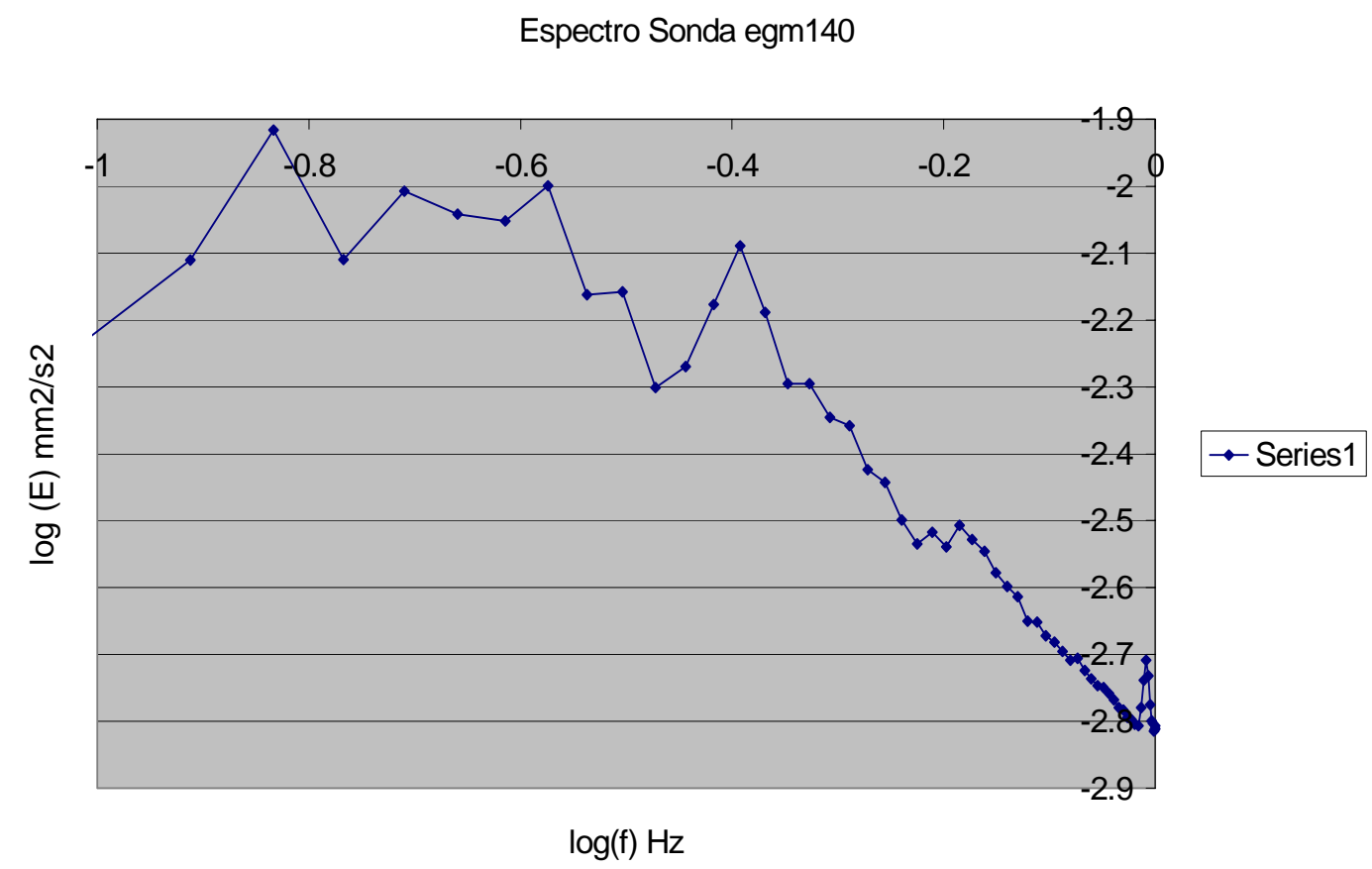

FIGURA 143: Espectro da Sonda: Ensaio da Grade de 39,0mm de abertura e barras com 10,0mm de espessura (Freqüência de oscilação da grade de 140 rpm)

\section{Espectro Foto egm140}

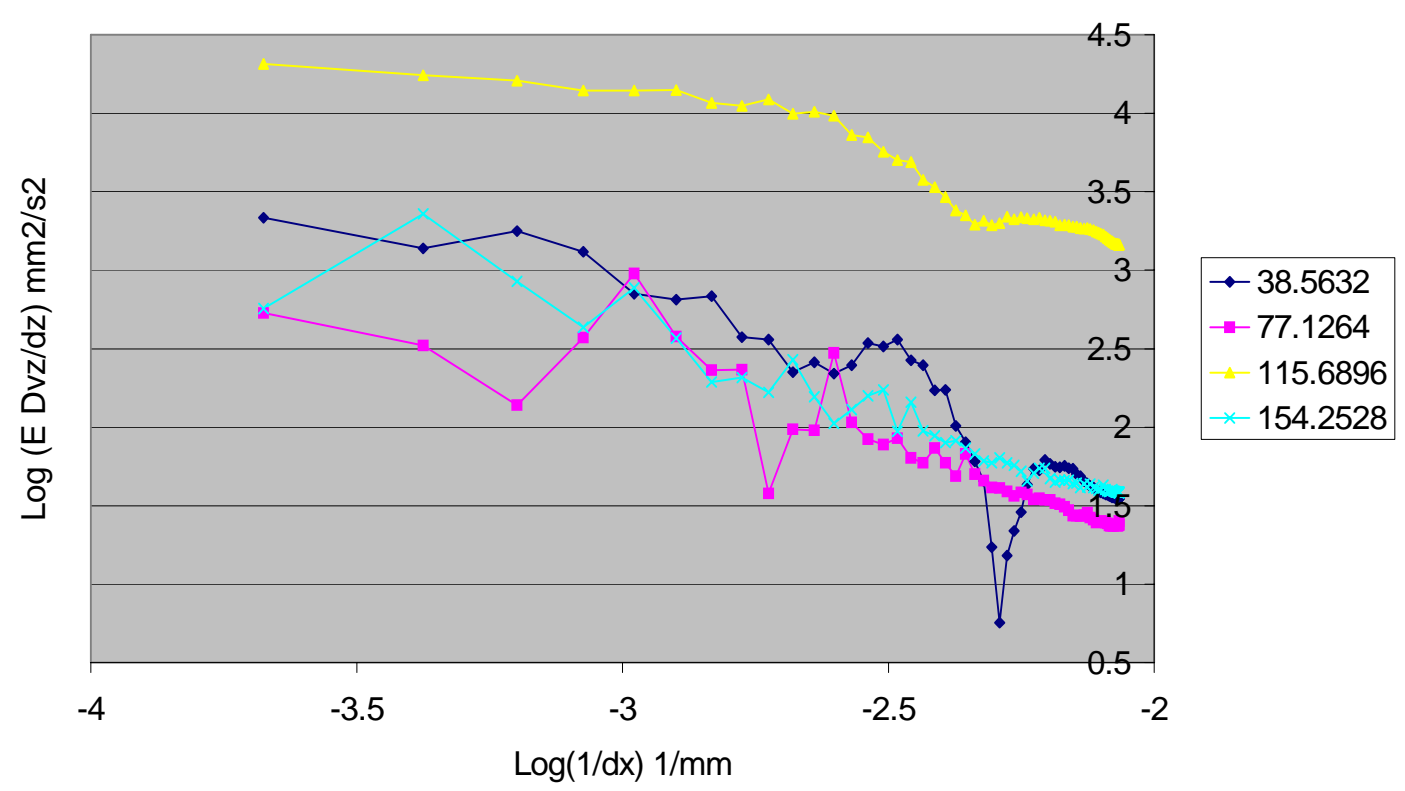

FIGURA 144: Espectro da Foto: Ensaio da Grade de 39,0mm de abertura e barras com 10,0mm de espessura (Freqüência de oscilação da grade de 140 rpm) 


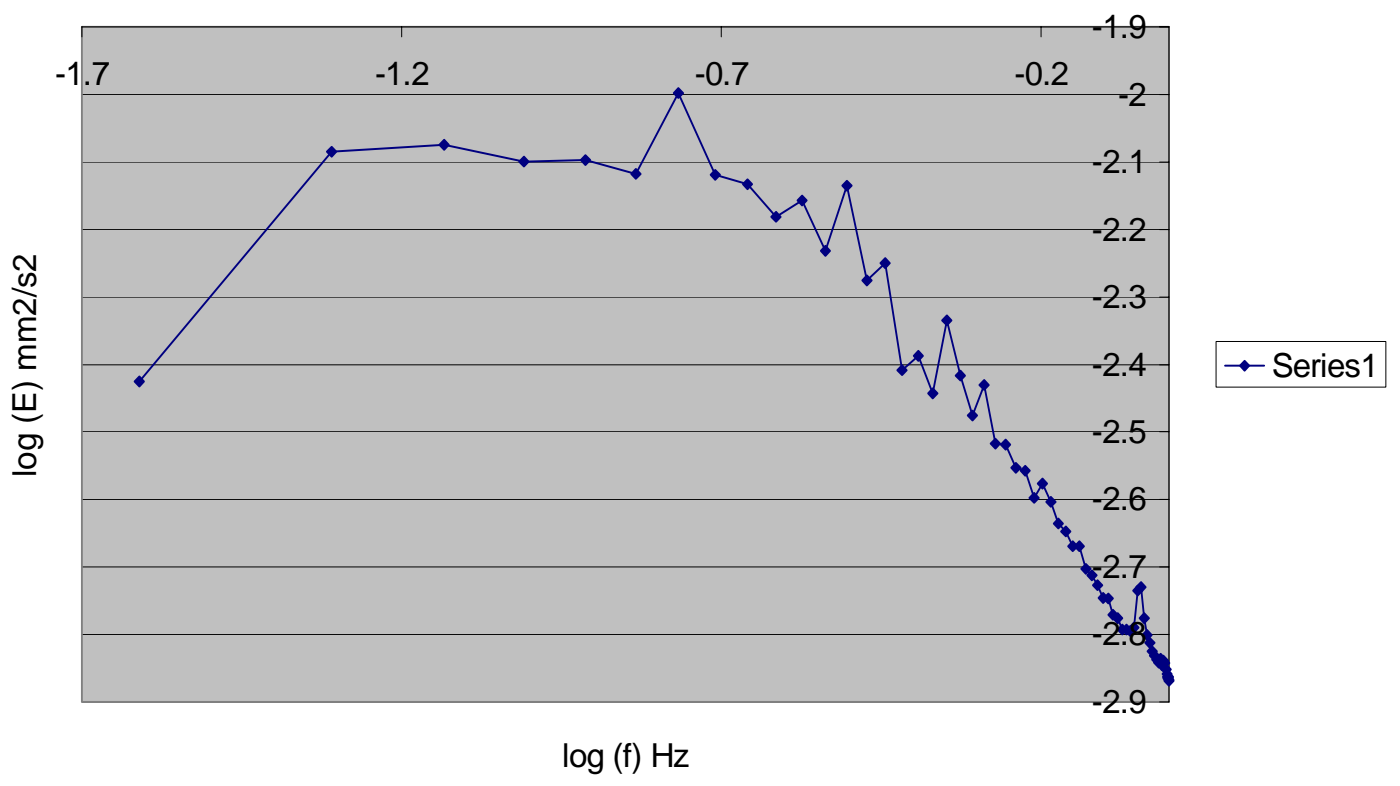

FIGURA 145: Espectro da Sonda: Ensaio da Grade de 39,0mm de abertura e barras com 10,0mm de espessura (Freqüência de oscilação da grade de 160 rpm)

\section{Espectro Foto egm160}

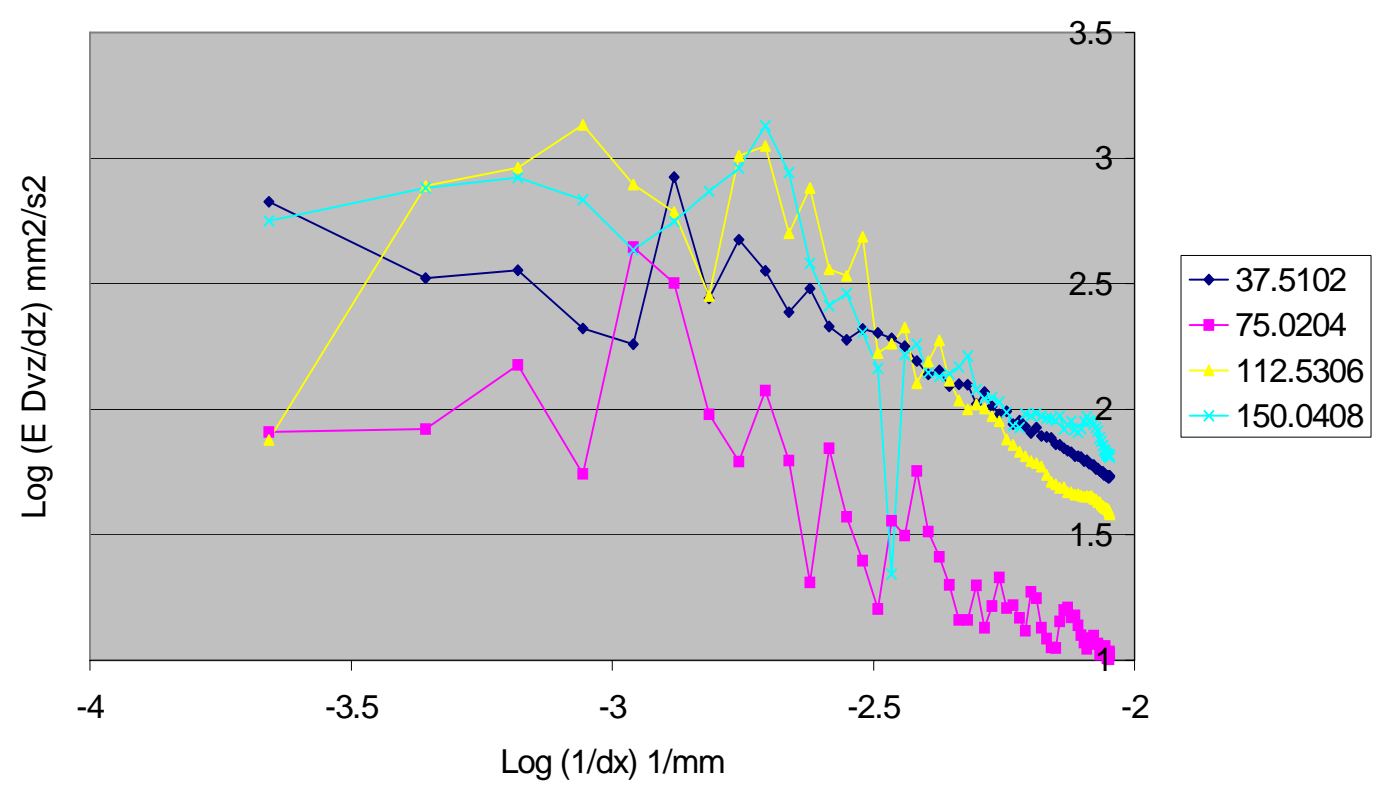

FIGURA 146: Espectro da Foto: Ensaio da Grade de 39,0mm de abertura e barras com 10,0mm de espessura (Freqüência de oscilação da grade de 160 rpm) 


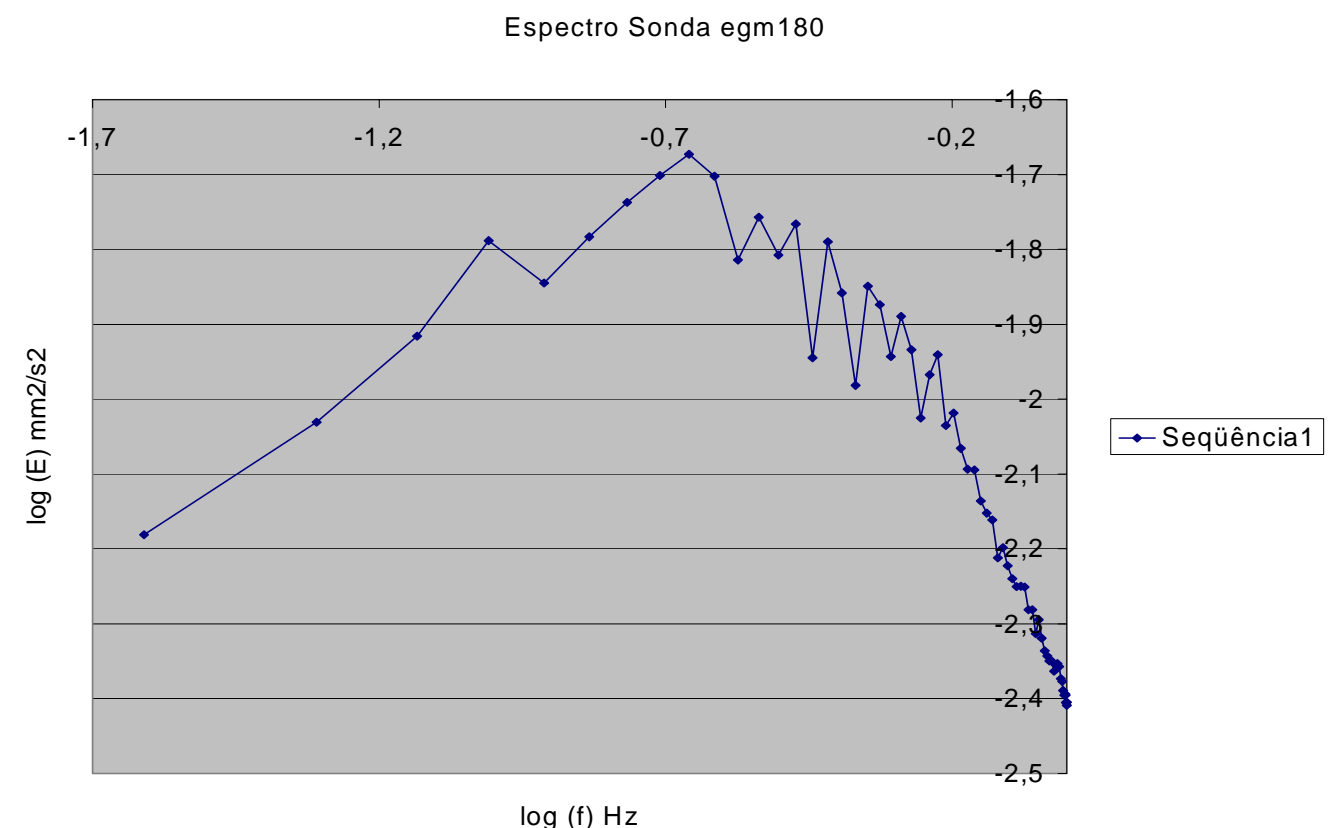

FIGURA 147: Espectro da Sonda: Ensaio da Grade de 39,0mm de abertura e barras com 10,0mm de espessura (Freqüência de oscilação da grade de 180 rpm)

Espectro Foto egm180

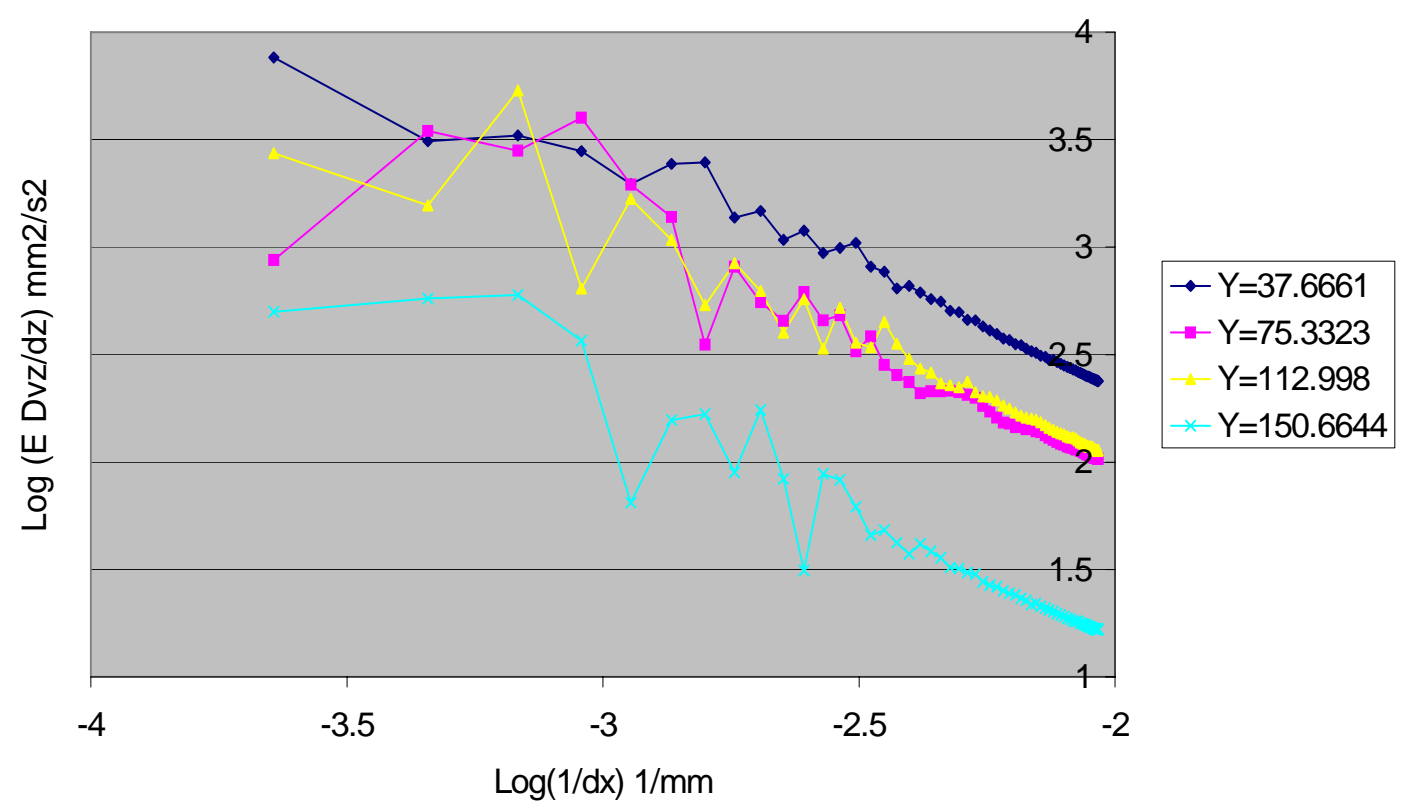

FIGURA 148: Espectro da Foto: Ensaio da Grade de 39,0mm de abertura e barras com 10,0mm de espessura (Freqüência de oscilação da grade de 180 rpm) 
Espectro Sonda egm210

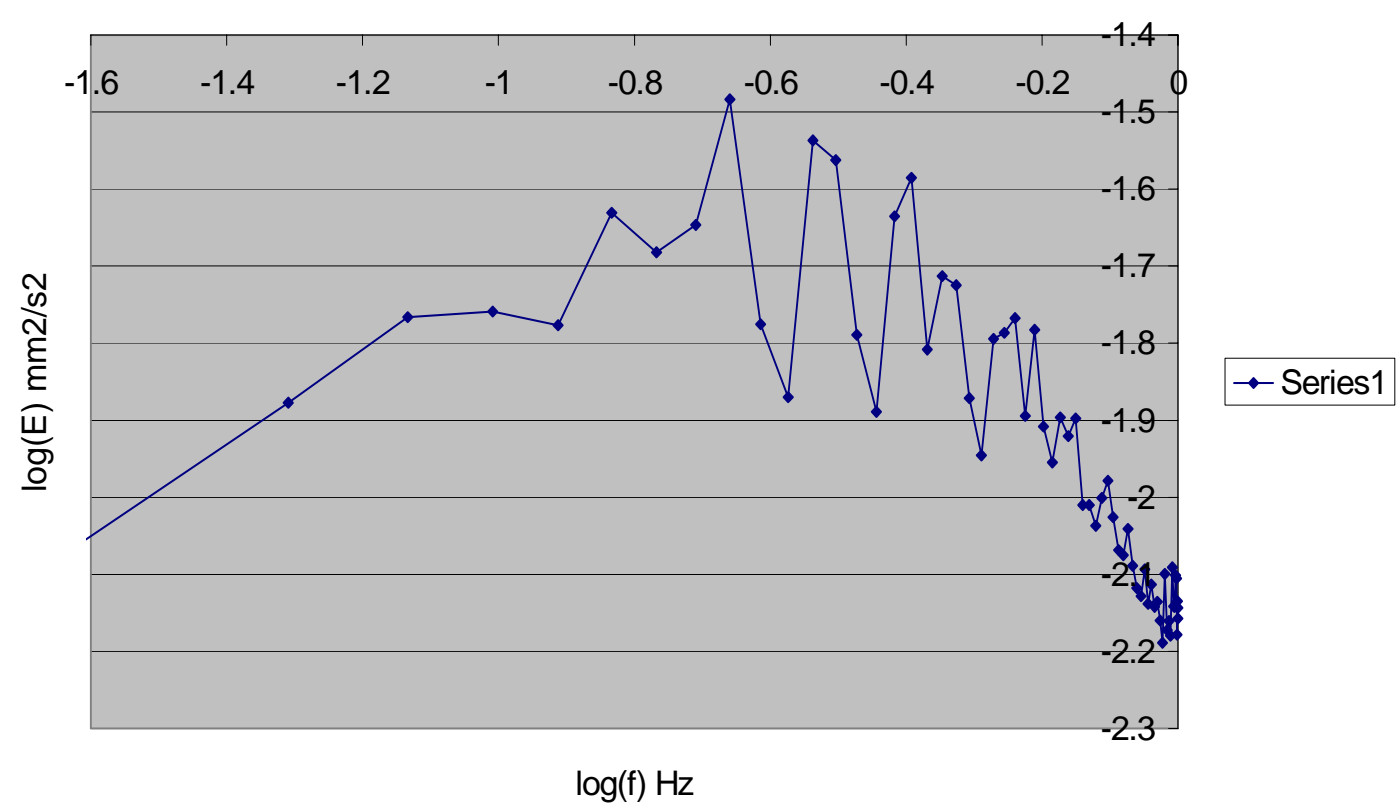

FIGURA 149: Espectro da Sonda: Ensaio da Grade de 39,0mm de abertura e barras com 10,0mm de espessura (Freqüência de oscilação da grade de 210 rpm)

\section{Espectro Foto egm 210}

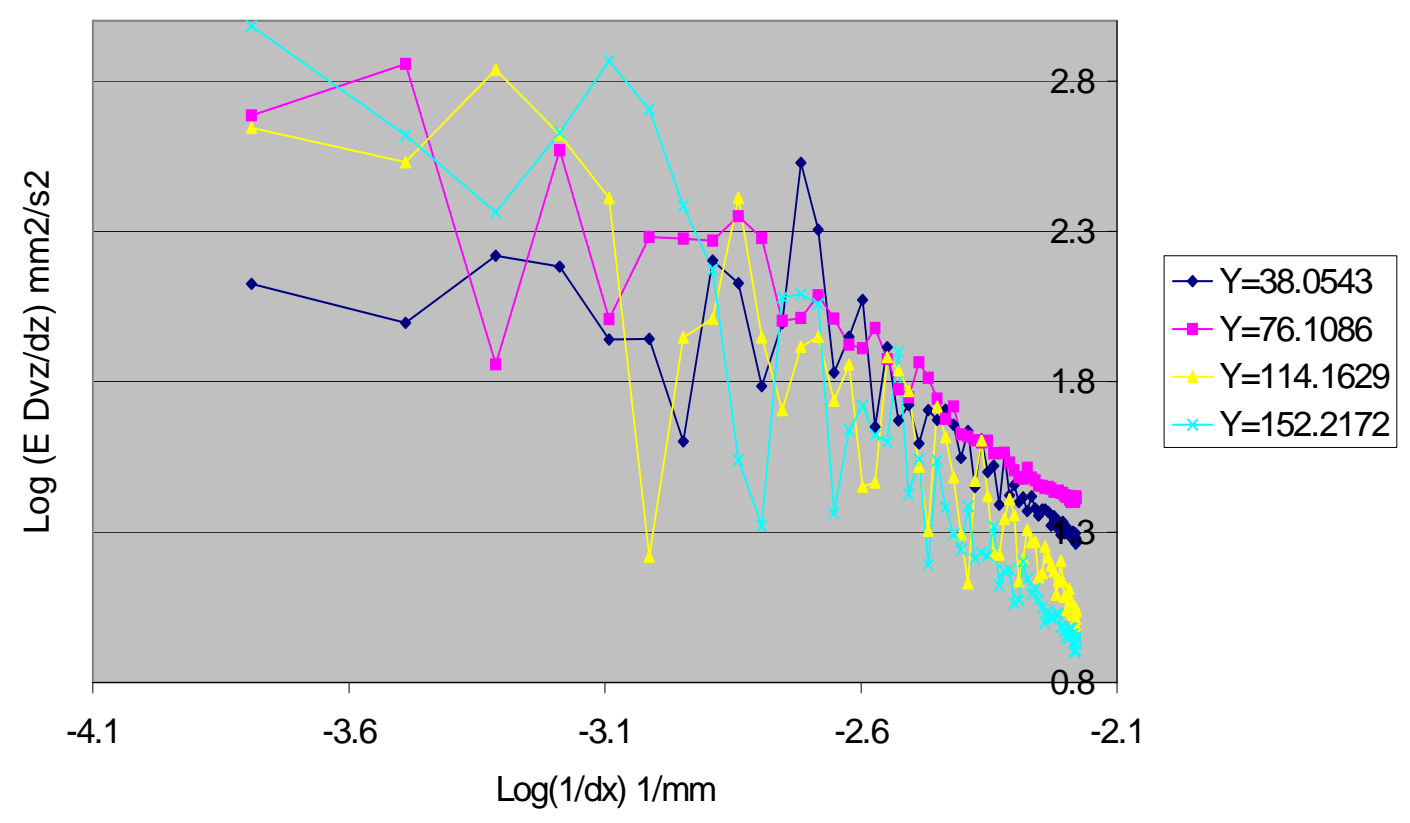

FIGURA 150: Espectro da Foto: Ensaio da Grade de 39,0mm de abertura e barras com 10,0mm de espessura (Freqüência de oscilação da grade de 210 rpm) 


\section{Espectro Sonda egm240}

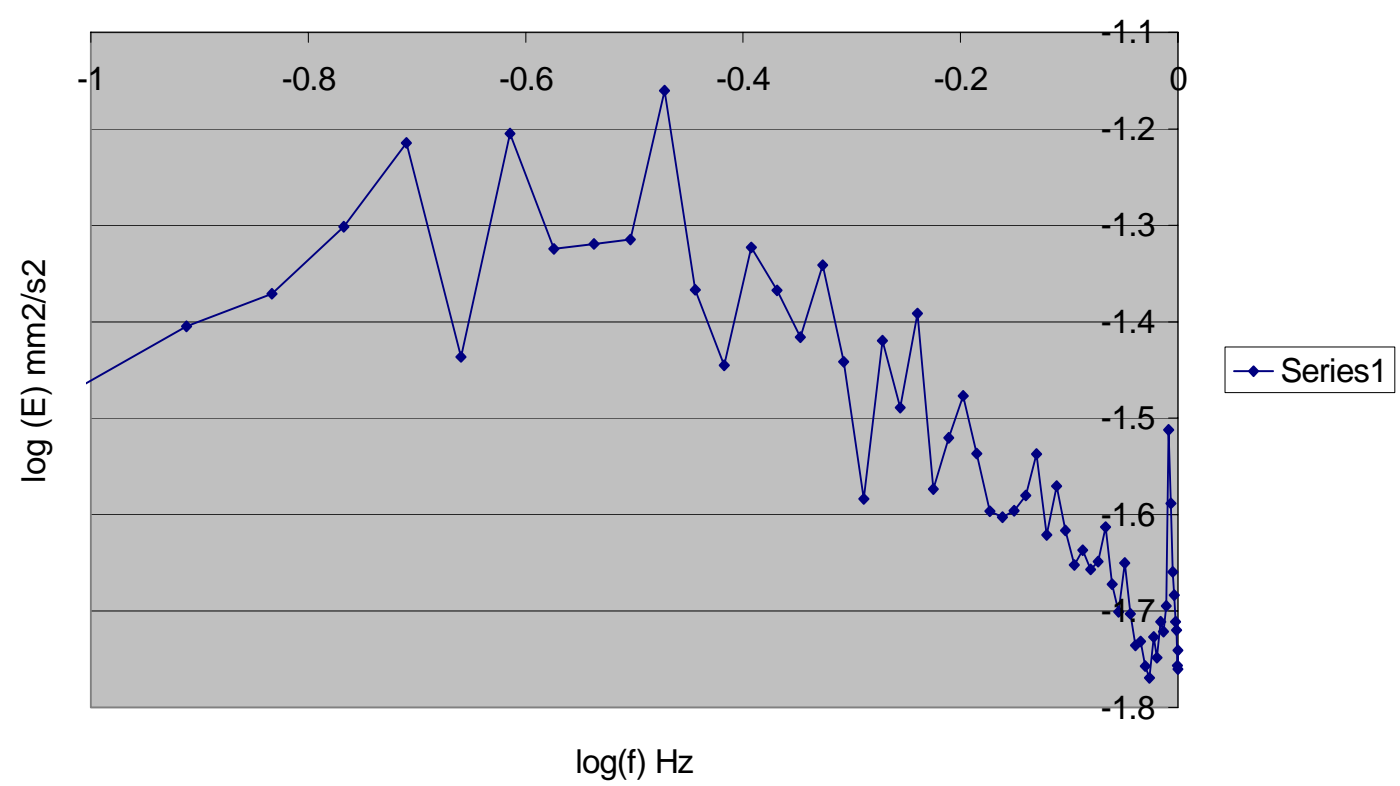

FIGURA 151: Espectro da Sonda: Ensaio da Grade de 39,0mm de abertura e barras com 10,0mm de espessura (Freqüência de oscilação da grade de 240 rpm)

\section{Espectro Foto egm240}

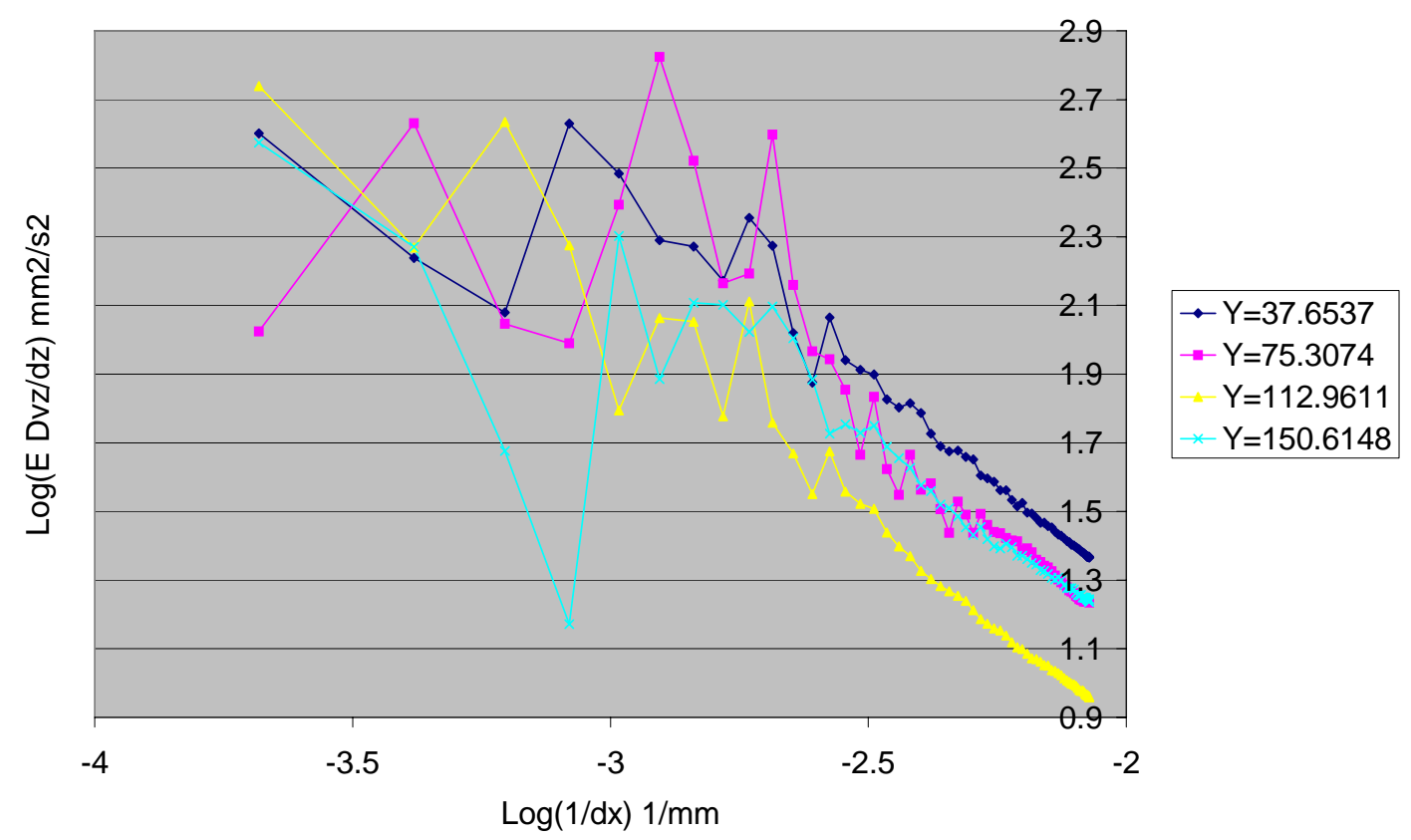

FIGURA 152: Espectro da Foto: Ensaio da Grade de 39,0mm de abertura e barras com 10,0mm de espessura (Freqüência de oscilação da grade de 240 rpm) 
Espectro da Sonda egl180

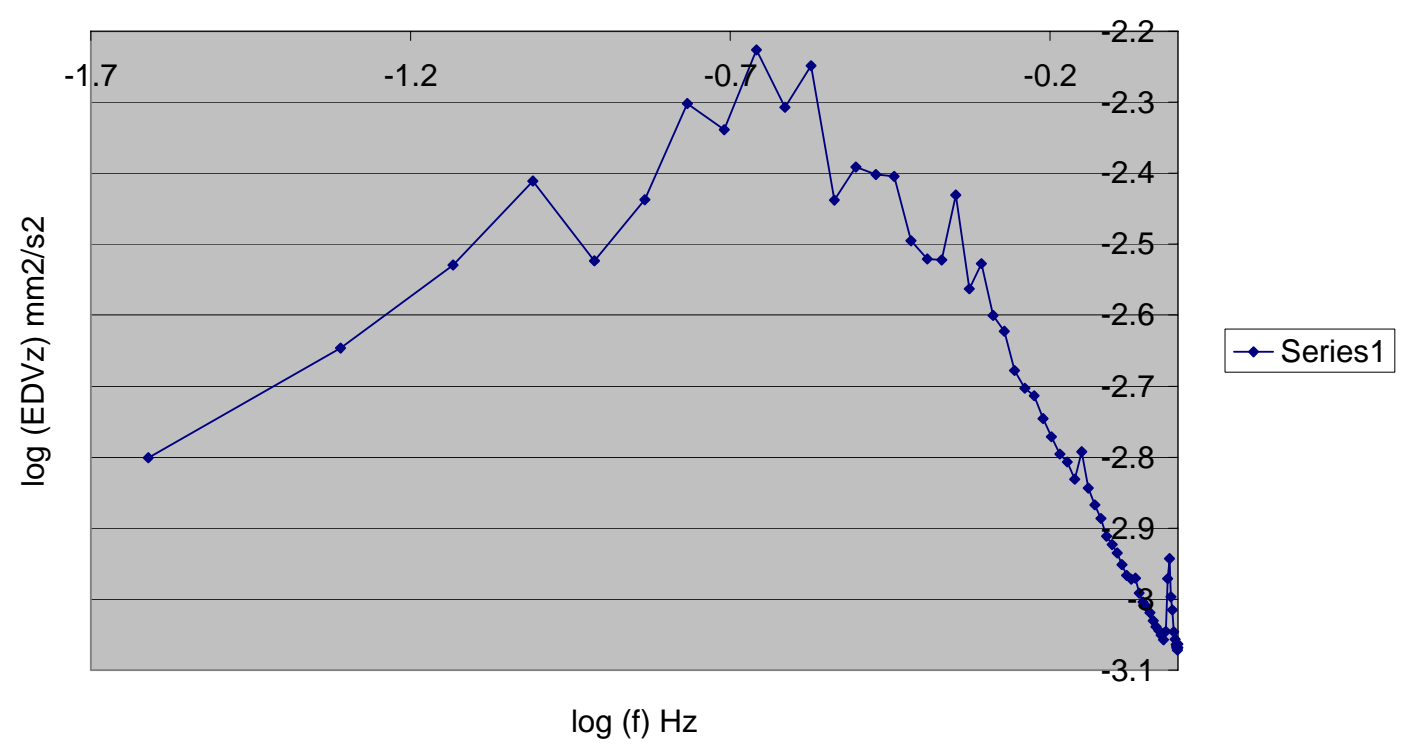

FIGURA 153: Espectro da Sonda: Ensaio da Grade de 64,5mm de abertura e barras com 10,0mm de espessura (Freqüência de oscilação da grade de 180 rpm)

\section{Espectro foto egl180}

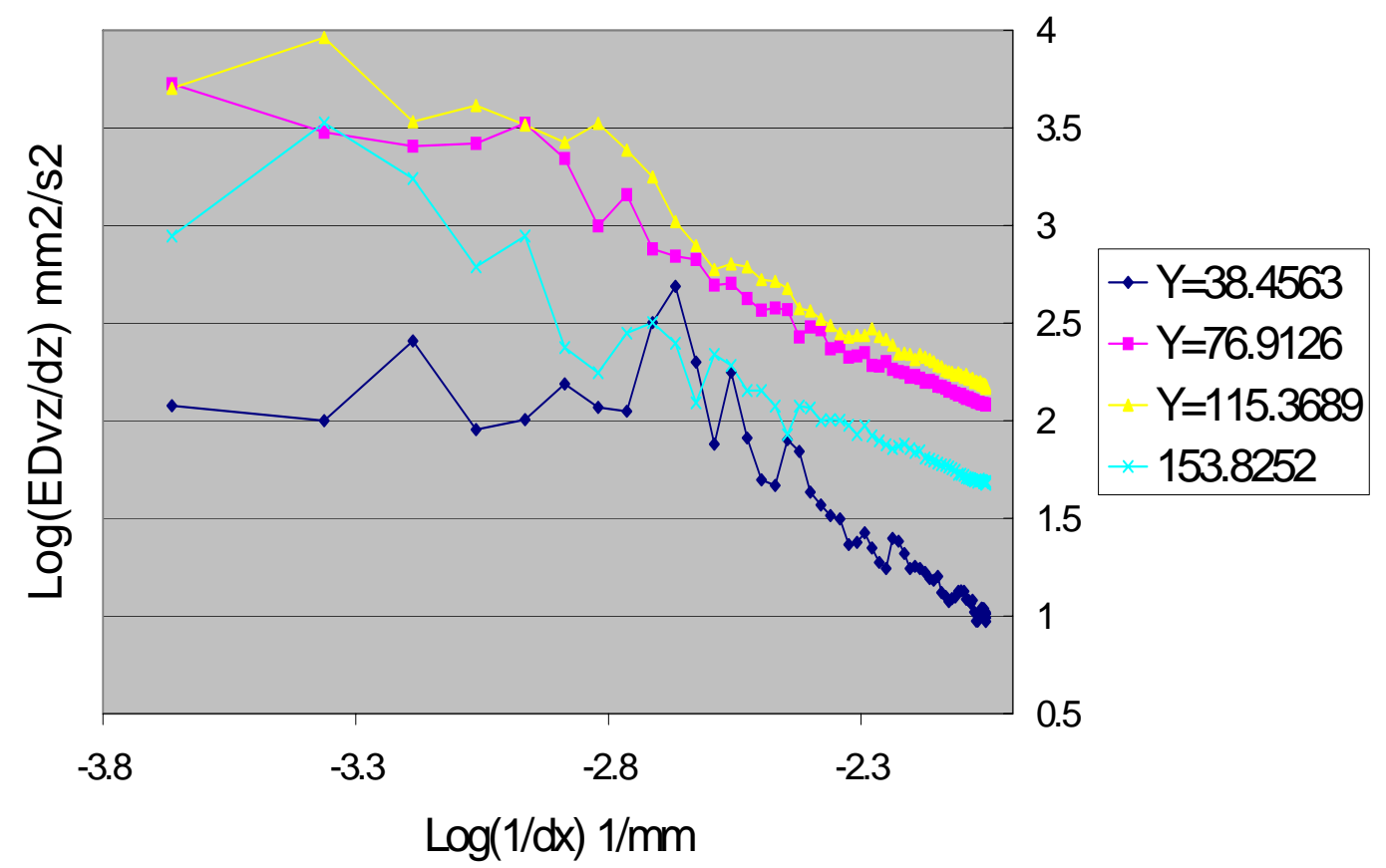

FIGURA 154: Espectro da Foto: Ensaio da Grade de 64,5mm de abertura e barras com 10,0mm de espessura (Freqüência de oscilação da grade de 180 rpm) 
Espectro da Sonda eglar200

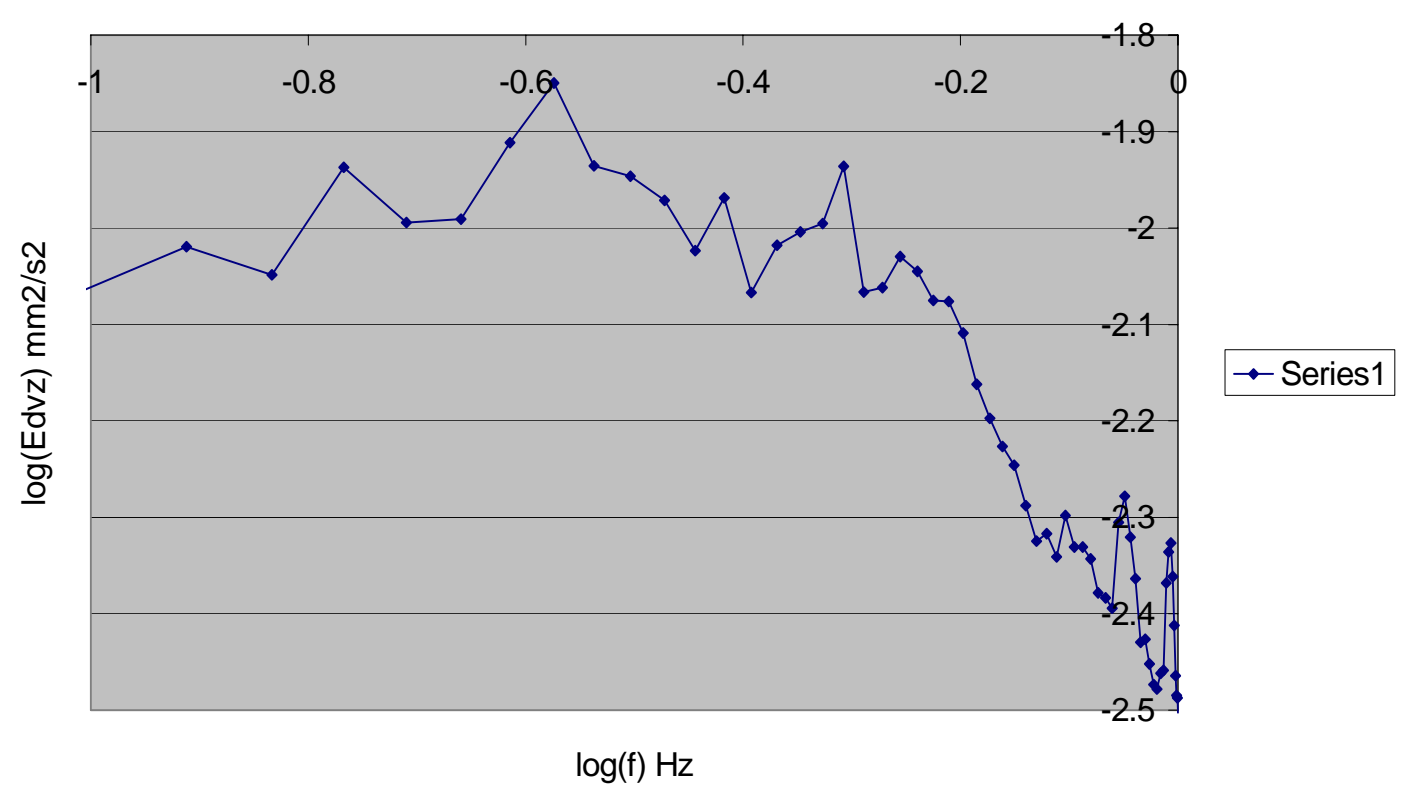

FIGURA 155: Espectro da Sonda: Ensaio da Grade de 64,5mm de abertura e barras com 10,0mm de espessura (Freqüência de oscilação da grade de 200 rpm)

Espectro foto egl200

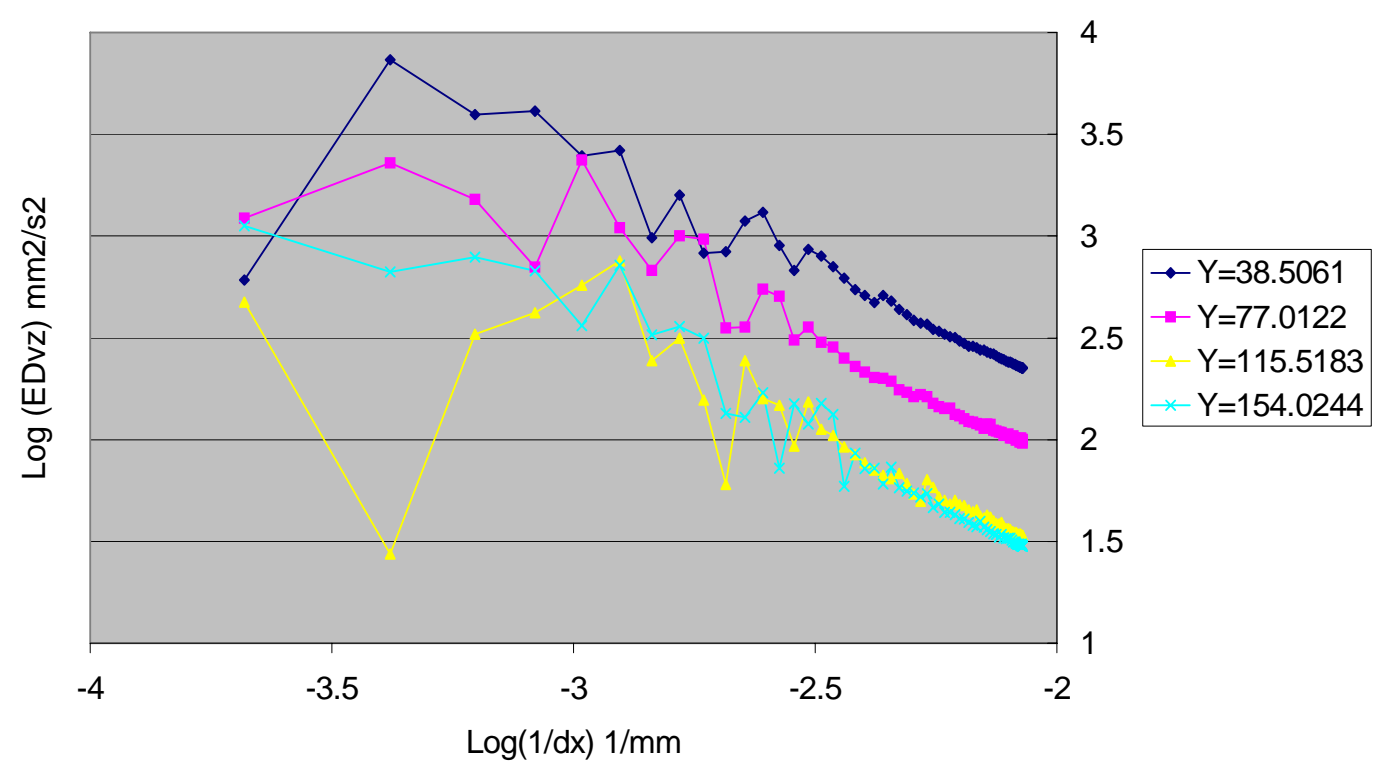

FIGURA 156: Espectro da Foto: Ensaio da Grade de 64,5mm de abertura e barras com 10,0mm de espessura (Freqüência de oscilação da grade de 200 rpm) 


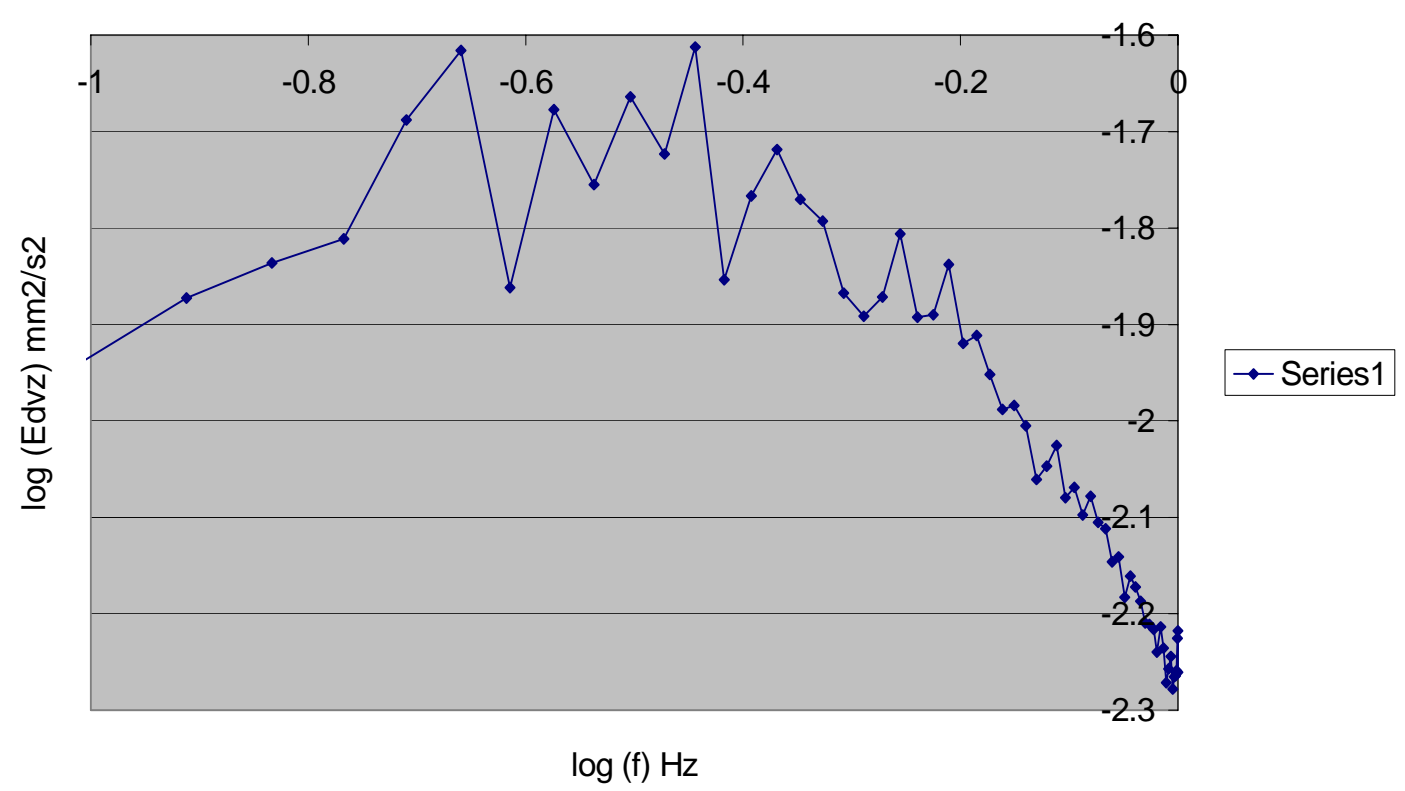

FIGURA 157: Espectro da Sonda: Ensaio da Grade de 64,5mm de abertura e barras com 10,0mm de espessura (Freqüência de oscilação da grade de 220 rpm)

\section{Espectro foto egl220}

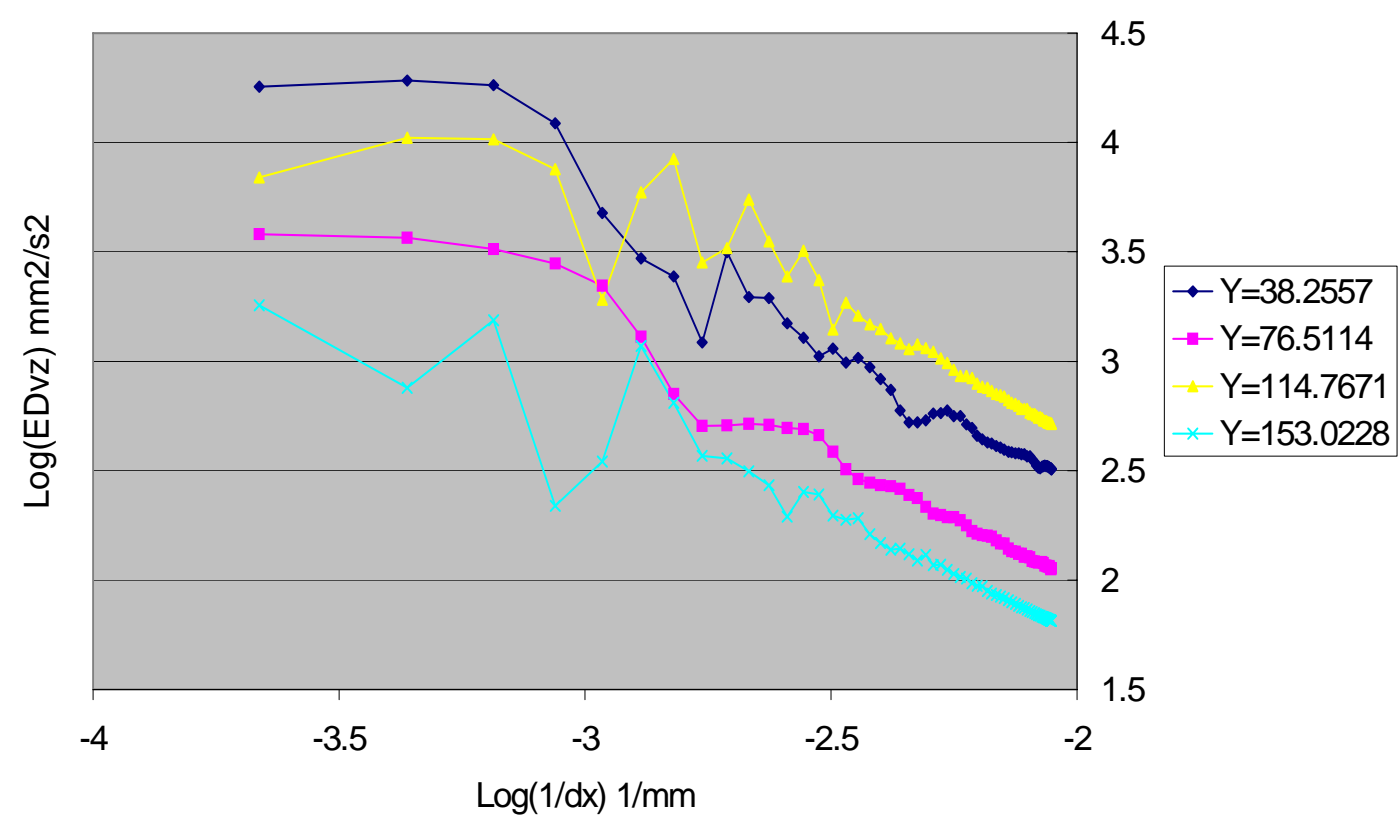

FIGURA 158: Espectro da Foto: Ensaio da Grade de 64,5mm de abertura e barras com 10,0mm de espessura (Freqüência de oscilação da grade de 220 rpm) 
Espectro da Sonda egl250

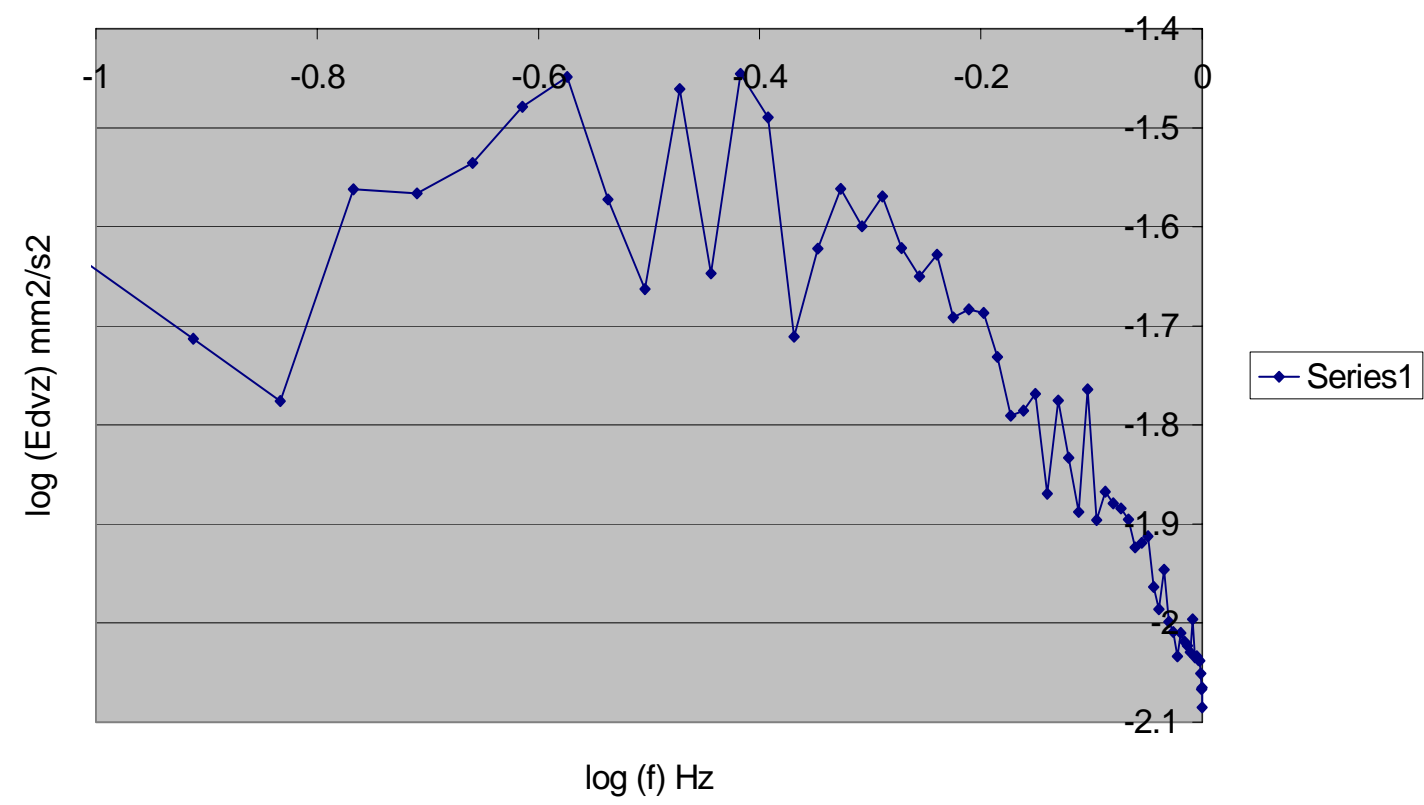

FIGURA 159: Espectro da Sonda: Ensaio da Grade de 64,5mm de abertura e barras com 10,0mm de espessura (Freqüência de oscilação da grade de 250 rpm)

\section{Espectro foto egl250}

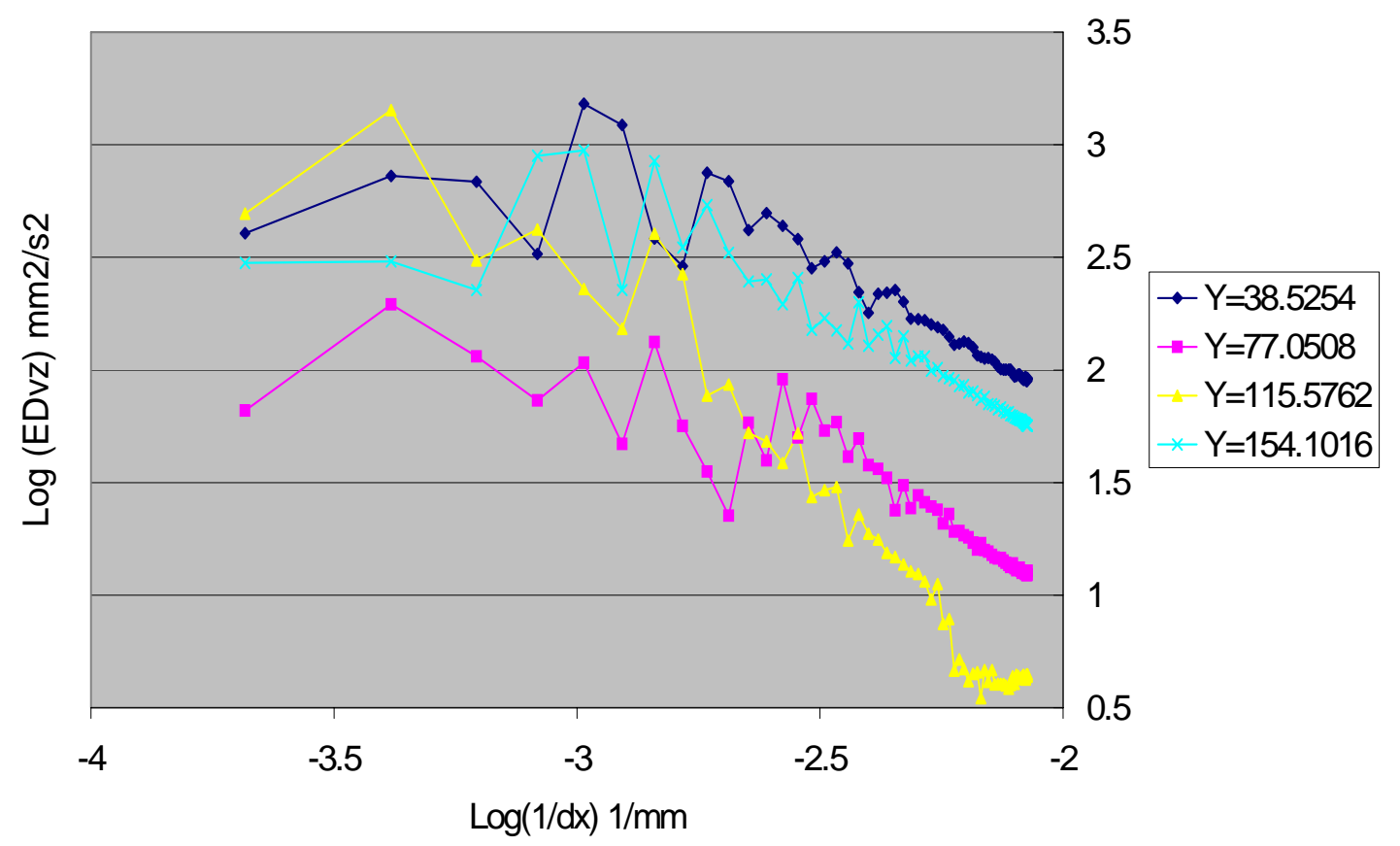

FIGURA 160: Espectro da Foto: Ensaio da Grade de 64,5mm de abertura e barras com 10,0mm de espessura (Freqüência de oscilação da grade de 250 rpm) 
Em todos os catorze ensaios, foram obtidos os espectros do gradiente da velocidade vertical na superfície livre. Os gráficos destes espectros, plotados em papel log-log, apresentam inclinações similares para a envoltória dos picos, quando comparados aos encontrados nos espectros obtidos com os dados da sonda ótica. O espectro segue uma inclinação de -1 para baixos valores de $\log (1 / \mathrm{dx})$, similares ao espectro apresentado por MC CREADY, ET AL. (1986) e TAMBURRINO (1994).

\subsection{Relação entre o coeficiente de reaeração $K_{2}$ e o valor RMS do} método ótico

Nesta seção são apresentados os resultados finais, onde plotou-se o valor RMS versus $\mathrm{K}_{2}$ estimado e RMS versus $\mathrm{K}_{2}$ obtido em laboratório.

TABELA 7: Valores de $\mathrm{K}_{2}$ e RMS da sonda medidos em laboratório e estimados para a grade de 26,5 $\mathrm{mm}$ de abertura e barras com 10,0 $\mathrm{mm}$ de espessura

\begin{tabular}{c|c|c|c|c}
\hline & LABORATÓRIO & \multicolumn{2}{l}{ ESTIMADO } & RMS sonda \\
\hline Rotação & $\mathrm{K}_{2}$ & RMS sonda & $\mathrm{K}_{2}$ & $\mathrm{~V}$ \\
\hline Rpm & $\mathrm{h}^{-1}$ & $\mathrm{~V}$ & $\mathrm{~h}^{-1}$ & \\
\hline & & & & 0.0172 \\
\hline 115 & 0.082 & & 0.081963 & 0.0352 \\
\hline 120 & 0.107 & 0.066 & 0.110087 & 0.0972 \\
\hline 140 & 0.102 & 0.132 & 0.123875 & 0.1222 \\
\hline 150 & 0.143 & & 0.123875 & 0.1222 \\
\hline 150 & 0.118 & & 0.13939 & 0.1432 \\
\hline 160 & 0.112 & 0.197 & 0.147861 & 0.1522 \\
\hline 165 & 0.116 & & 0.16638 & 0.1672 \\
\hline 175 & 0.140 & & 0.176492 & 0.1732 \\
\hline 180 & 0.278 & 0.254 & 0.176492 & 0.1732 \\
\hline 180 & 0.184 & & 0.218257 & 0.18652 \\
\hline 198 & 0.206 & & 0.223469 & 0.1872 \\
\hline 200 & 0.286 & 0.264 & 0.276351 & 0.18612 \\
\hline 218 & 0.216 & & &
\end{tabular}


K2 vs RMS sonda (Grade Fina)

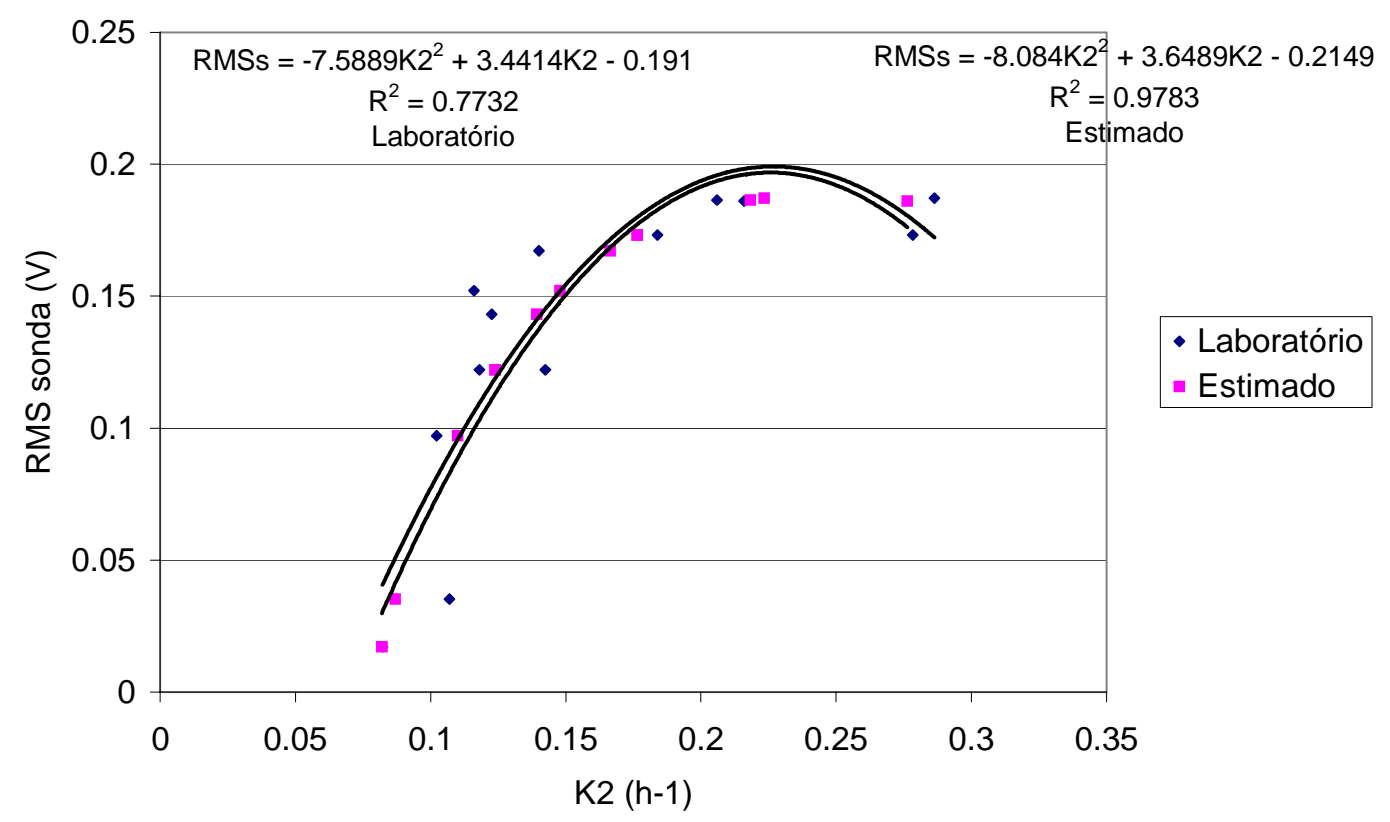

FIGURA 161: $K_{2}$ em função de RMS (Grade de 26,5 mm de abertura e barras com $10 \mathrm{~mm}$ de espessura).

TABELA 8: Valores de $\mathrm{K}_{2}$ e RMS da sonda medidos em laboratório e estimados para a grade de 39,0 mm de abertura e barras com 10,0 mm de espessura

\begin{tabular}{c|c|c|c|c}
\hline & \multicolumn{2}{|c|}{ LABORATÓRIO } & \multicolumn{2}{c}{ ESTIMADO } \\
\hline Rotação & $\mathrm{K}_{2}$ & RMS sonda & $\mathrm{K}_{2}$ & RMS sonda \\
\hline Rpm & $\mathrm{h}-1$ & $\mathrm{~V}$ & $\mathrm{~h}-1$ & $\mathrm{~V}$ \\
\hline & & & & 0.056966 \\
\hline 90 & 0.051 & & 0.066238 & 0.0685 \\
\hline 116 & 0.065 & & 0.076131 & 0.04406 \\
\hline 140 & 0.081 & 0.05465 & 0.083051 & 0.0335 \\
\hline 155 & 0.086 & & 0.085495 & 0.03275 \\
\hline 160 & 0.092 & 0.05251 & 0.089556 & 0.0335 \\
\hline 168 & 0.076 & & 0.094904 & 0.03574 \\
\hline 178 & 0.100 & & 0.096011 & 0.04034 \\
\hline 180 & 0.089 & 0.08517 & 0.098836 & 0.0415 \\
\hline 185 & 0.105 & & 0.100571 & 0.04475 \\
\hline 188 & 0.103 & & 0.104738 & 0.04694 \\
\hline 195 & 0.099 & & 0.106576 & 0.05275 \\
\hline 198 & 0.128 & & 0.114258 & 0.05554 \\
\hline 210 & 0.143 & 0.101 & 0.119685 & 0.0685 \\
\hline 218 & 0.134 & & 0.134405 & 0.10994 \\
\hline 238 & & & 0.135974 & 0.1135 \\
\hline 240 & & 0.16855 & & \\
\hline
\end{tabular}




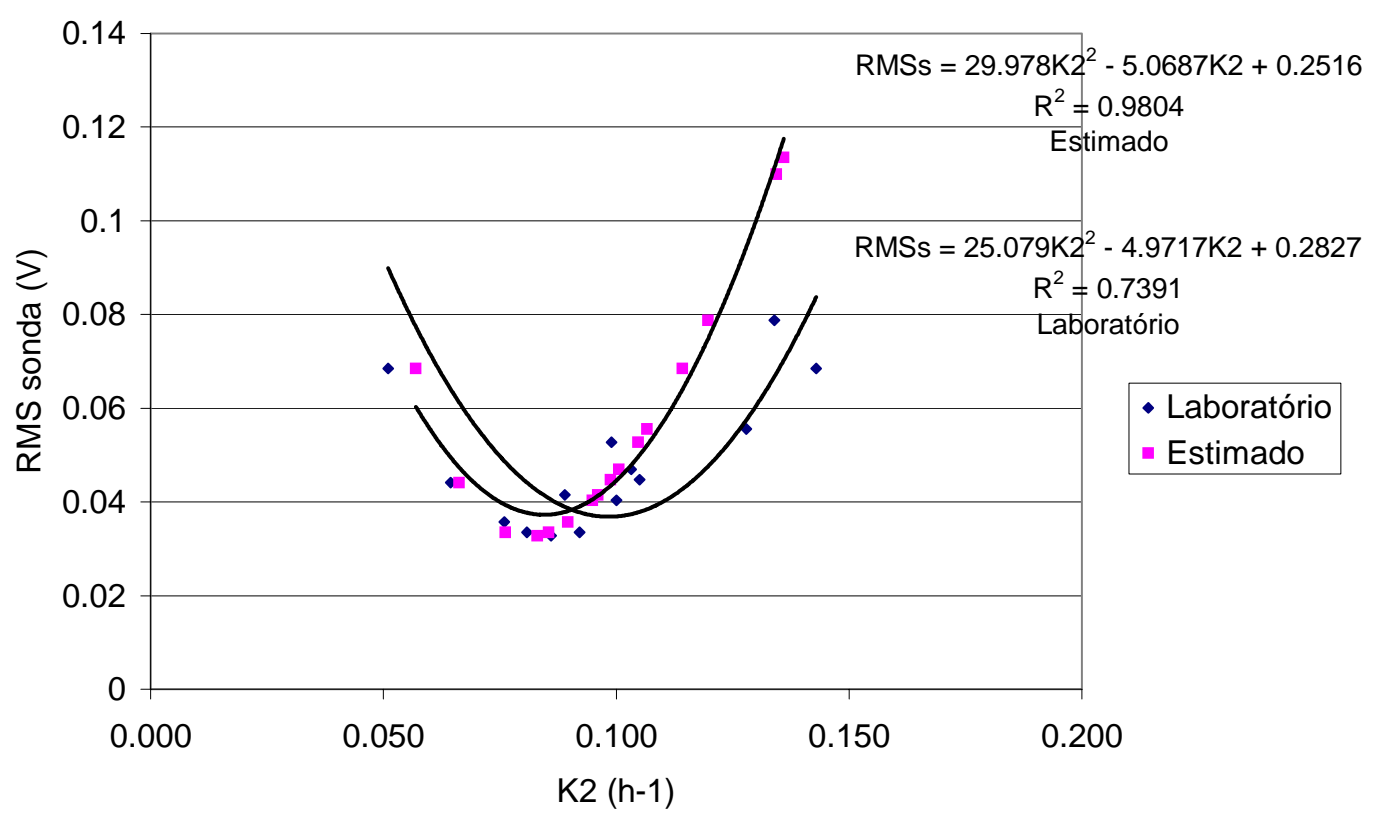

FIGURA 162: $K_{2}$ em função de RMS (Grade de 39,0 mm de abertura e barras com 10,0 mm de espessura).

TABELA 9: Valores de $K_{2}$ e RMS da sonda medidos em laboratório e estimados para a grade de $64,5 \mathrm{~mm}$ de abertura e barras com $10,0 \mathrm{~mm}$ de espessura

\begin{tabular}{c|c|c|c|c}
\hline \multicolumn{2}{c|}{ LABORATÓRIO } & \multicolumn{2}{c}{ ESTIMADO } \\
\hline Rotação & $\mathrm{K}_{2}$ & RMS sonda & $\mathrm{K}_{2}$ & RMS sonda \\
\hline Rpm & $\mathrm{h}^{-1}$ & $\mathrm{~V}$ & $\mathrm{~h}^{-1}$ & $\mathrm{~V}$ \\
\hline & & & & 0.008625 \\
\hline 165 & 0.073 & & 0.072365 & 0.019048 \\
\hline 172 & 0.0782 & & 0.074264 & 0.0306 \\
\hline 180 & 0.074 & 0.04111 & 0.076495 & 0.052552 \\
\hline 196 & & & 0.08116 & 0.055188 \\
\hline 198 & 0.0845 & & 0.081763 & 0.0578 \\
\hline 200 & 0.074 & 0.0779 & 0.08237 & 0.0578 \\
\hline 200 & 0.0831 & & 0.08237 & 0.065492 \\
\hline 206 & & & 0.084219 & 0.0826 \\
\hline 218 & 0.0898 & & 0.088043 & 0.099625 \\
\hline 220 & 0.081 & 0.09595 & 0.088697 & 0.102868 \\
\hline 235 & 0.0938 & & 0.093759 & 0.1153 \\
\hline 238 & 0.1065 & & 0.094805 & \\
\hline 250 & 0.095 & 0.13857 & 0.099109 & \\
\hline
\end{tabular}


K2 vs RMS sonda (Grade Larga)

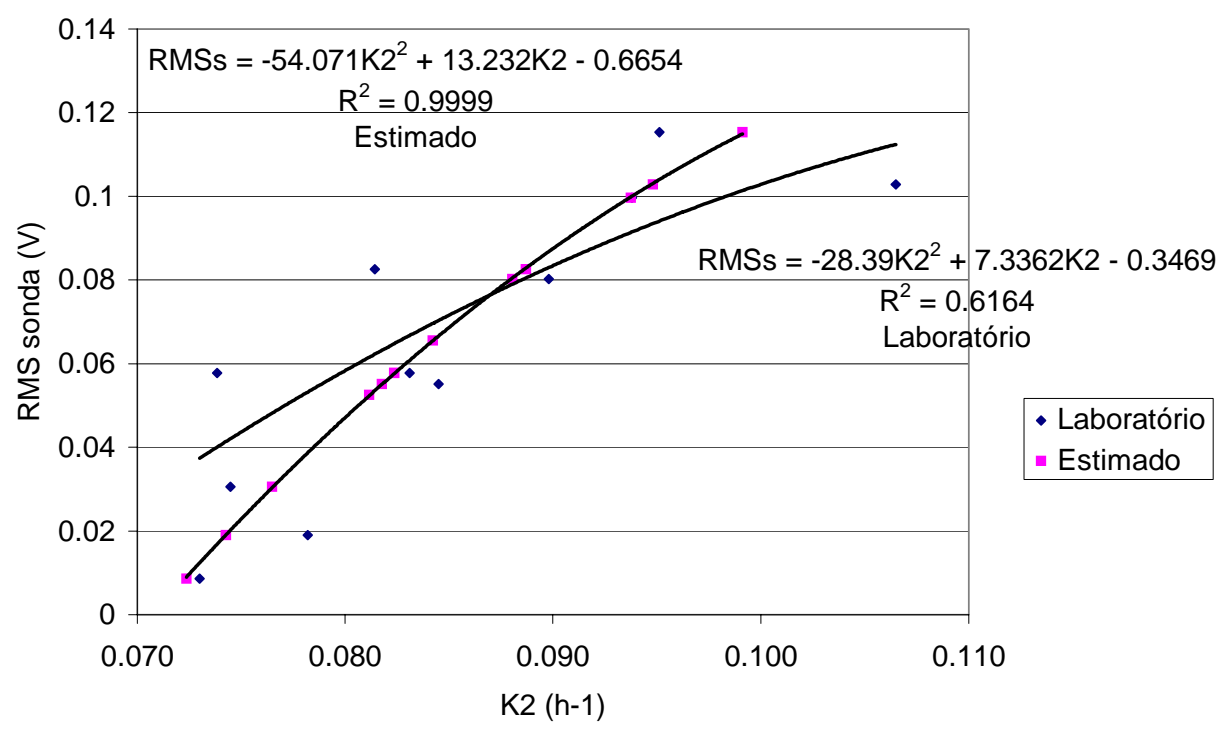

FIGURA 163: $K_{2}$ em função de RMS (Grade de 64,5 mm de abertura e barras com 10,0 mm de espessura).

5.7. Relação entre o coeficiente de reaeração $K_{2}$ e o valor $R M S$ do método fotográfico

TABELA 10: Valores de $K_{2}$ e RMS foto medidos em laboratório e estimados para a grade de 26,5 mm de abertura e barras com 10,0 mm de espessura

\begin{tabular}{c|c|c|c|c}
\hline & LABORATÓRIO & \multicolumn{2}{l}{ ESTIMADO } & RMS foto \\
\hline Rotação & $\mathrm{K}_{2}$ & RMS foto & $\mathrm{K}_{2}$ & $\mathrm{~mm} / \mathrm{s}$ \\
\hline Rpm & $\mathrm{h}^{-1}$ & $\mathrm{~mm} / \mathrm{s}$ & $\mathrm{h}^{-1}$ & \\
\hline & & & & 12.023 \\
\hline 115 & 0.082 & & 0.08196 & 11.533 \\
\hline 120 & 0.107 & 10.405 & 0.08694 & 10.773 \\
\hline 140 & 0.102 & 13.298 & 0.11009 & 11.113 \\
\hline 150 & 0.143 & & 0.12388 & 11.113 \\
\hline 150 & 0.118 & & 0.12388 & 11.933 \\
\hline 160 & 0.112 & 11.042 & 0.13939 & 12.523 \\
\hline 165 & 0.116 & & 0.14786 & 14.063 \\
\hline 175 & 0.140 & & 0.16638 & 15.013 \\
\hline 180 & 0.278 & 13.633 & 0.17649 & 19.4266 \\
\hline 180 & 0.184 & & 0.17649 & 20.013 \\
\hline 198 & 0.206 & & 0.21826 & 26.1546 \\
\hline 200 & 0.286 & 20.821 & 0.22347 & \\
\hline 218 & 0.216 & & 0.27635 & \\
\hline
\end{tabular}


K2 vs RMS foto (Grade Fina)

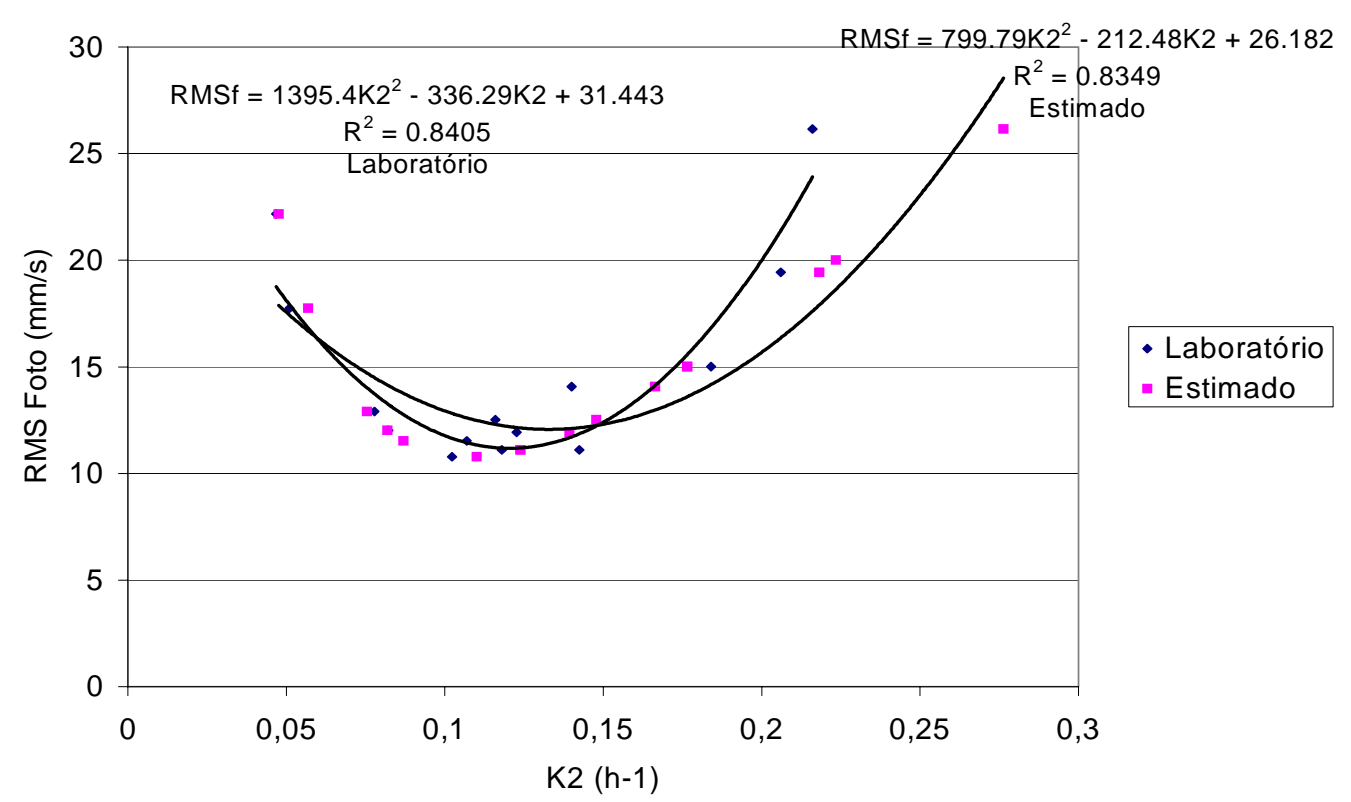

FIGURA 164: RMS Foto em função de $\mathrm{K}_{2}$ (Grade de 26,5 mm de abertura e barras com 10,0 mm de espessura).

TABELA 11: Valores de $K_{2}$ e RMS foto medidos em laboratório e estimados para a grade de $39 \mathrm{~mm}$ de abertura e barras com $10 \mathrm{~mm}$ de espessura

\begin{tabular}{c|c|c|c|c}
\hline \multicolumn{3}{|c|}{ LABORATÓRIO } & \multicolumn{2}{c}{ ESTIMADO } \\
\hline Rotação & $\mathrm{K}_{2}$ & RMS foto & $\mathrm{K}_{2}$ & RMS foto \\
\hline Rpm & $\mathrm{h}^{-1}$ & $\mathrm{~mm} / \mathrm{s}$ & $\mathrm{h}^{-1}$ & $\mathrm{~mm} / \mathrm{s}$ \\
\hline & & & & \\
\hline 90 & 0.051 & & 0.056966 & 9.363 \\
\hline 116 & 0.065 & & 0.066238 & 7.504 \\
\hline 140 & 0.081 & 6.8728 & 0.076131 & 6.148 \\
\hline 155 & 0.086 & & 0.083051 & 5.476 \\
\hline 160 & 0.092 & 6.8673 & 0.085495 & 5.282 \\
\hline 168 & 0.076 & & 0.089556 & 5.0028 \\
\hline 178 & 0.100 & & 0.094904 & 4.7078 \\
\hline 180 & 0.089 & 5.7311 & 0.096011 & 4.656 \\
\hline 185 & 0.105 & & 0.098836 & 4.537 \\
\hline 188 & 0.103 & & 0.100571 & 4.4728 \\
\hline 195 & 0.099 & & 0.104738 & 4.344 \\
\hline 198 & 0.128 & & 0.106576 & 4.2978 \\
\hline 210 & 0.143 & 6.241 & 0.114258 & 4.167 \\
\hline 218 & 0.134 & & 0.119685 & 4.1278 \\
\hline 238 & & & 0.134405 & 4.1978 \\
\hline 240 & & 6.7956 & 0.135974 & 4.218 \\
\hline
\end{tabular}


K2 vs RMS foto (Grade Média)

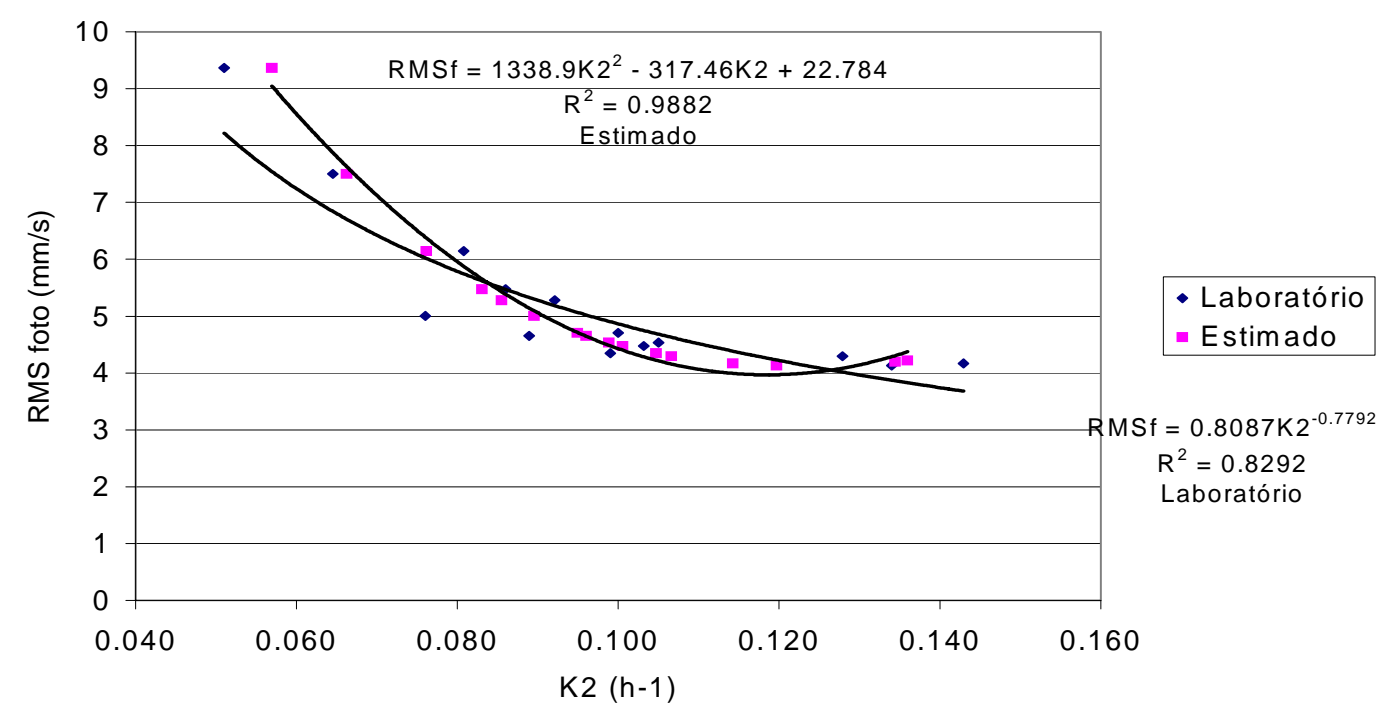

FIGURA 165: RMS Foto em função de $\mathrm{K}_{2}$ (Grade de $39 \mathrm{~mm}$ de abertura e barras com 10mm de espessura)

TABELA 12: Valores de $\mathrm{K}_{2}$ e RMS da sonda medidos em laboratório e estimados para a grade de $64,5 \mathrm{~mm}$ de abertura e barras com 10mm de espessura

\begin{tabular}{c|c|c|c|c}
\hline & \multicolumn{2}{|c|}{ LABORATÓRIO } & \multicolumn{2}{c}{ ESTIMADO } \\
\hline Rotação & $\mathrm{K}_{2}$ & RMS foto & $\mathrm{K}_{2}$ & RMS foto \\
\hline Rpm & $\mathrm{h}^{-1}$ & $\mathrm{~mm} / \mathrm{s}$ & $\mathrm{h}^{-1}$ & $\mathrm{~mm} / \mathrm{s}$ \\
\hline & & & & \\
\hline 165 & 0.073 & & 0.072365 & 4.4365 \\
\hline 172 & 0.0782 & & 0.074264 & 5.0616 \\
\hline 180 & 0.074 & 5.7986 & 0.076495 & 5.776 \\
\hline 196 & & & 0.08116 & 7.2048 \\
\hline 198 & 0.0845 & & 0.081763 & 7.3834 \\
\hline 200 & 0.074 & 7.5553 & 0.08237 & 7.562 \\
\hline 200 & 0.0831 & & 0.08237 & 7.562 \\
\hline 206 & & & 0.084219 & 8.0978 \\
\hline 218 & 0.0898 & & 0.088043 & 9.1694 \\
\hline 220 & 0.081 & 9.3466 & 0.088697 & 9.348 \\
\hline 235 & 0.0938 & & 0.093759 & 10.6875 \\
\hline 238 & 0.1065 & & 0.094805 & 10.9554 \\
\hline 250 & 0.095 & 12.0475 & 0.099109 & 12.027 \\
\hline
\end{tabular}


K2 vs RMS foto (Grade Larga)

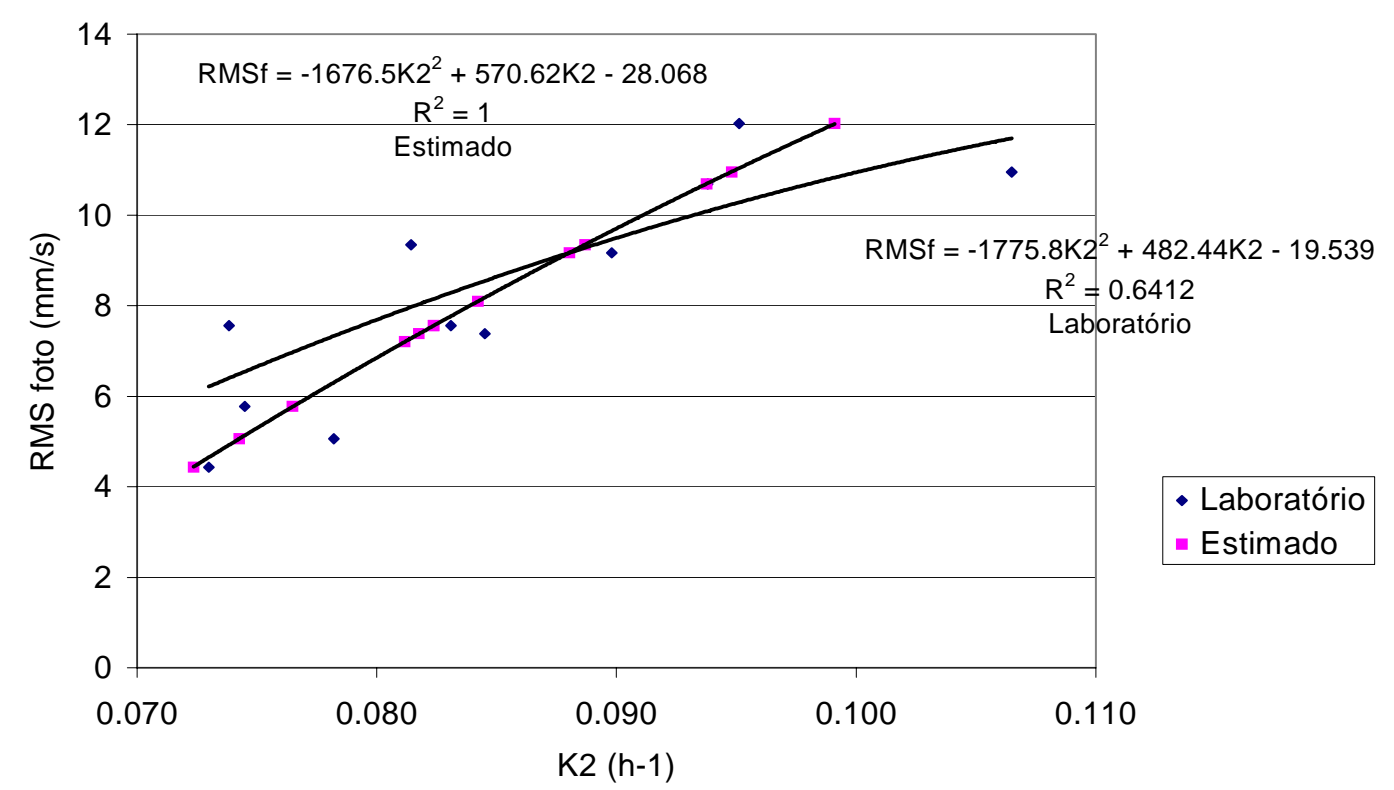

FIGURA 166: RMS Foto em função de $\mathrm{K}_{2}$ (Grade de 64,5 mm de abertura e barras com 10mm de espessura) 


\section{CONCLUSÕES}

A pesquisa aqui apresentada, pôde verificar algumas hipóteses básicas e concluir a validade da importância do campo de velocidade na transferência de massa, representada pelo coeficiente de reaeração.

Nesta pesquisa buscou-se, como objetivo, incluir um melhoramento no método fotográfico, através da introdução de um segundo disparo de flash na metade do tempo de exposição. Esta nova forma de tomada da fotografia tornou mais fácil e mais preciso o cálculo das derivadas das componentes da velocidade e acrescentou às características descritas na literatura, ou seja, o método mais poderoso de quantificar a visualização de um escoamento e um dos poucos capazes de dar instantaneamente mapas de magnitude das velocidades, a simplicidade de cálculo e aumento na precisão.

Esse método mostrou-se também ser um meio muito rápido, e de muito baixo custo, quando se deseja obter campos de velocidade na superfície livre. Isso justificase pelo pouco tempo gasto para se obter as fotos e, após digitalização e interpolação, conseguir os gráficos representativos dos campos de velocidade, com grande número de vetores velocidade.

Outro objetivo do presente trabalho era medir o campo de velocidade na superfície livre, pelo método fotográfico, e por meio dos parâmetros turbulentos obter-se uma avaliação qualitativa do método ótico.

A autocorrelação do gradiente da velocidade vertical comparado com a autocorrelação obtida a partir do sinal elétrico da sonda ótica apresenta uma boa resposta quanto a "rapidez" com que perdem a correlação, permitindo assim, justificar uma relação entre os dois métodos. 
O espectro do gradiente de velocidade é descrito pela teoria linear apresentada na literatura como de grande importância na caracterização da transferência de massa na interface ar/água, justificando sua obtenção. Porém não foi possível a comparação com o espectro do coeficiente de transferência de massa, devido a não se ter dados das flutuações de $\mathrm{K}_{\mathrm{L}}$.

Na comparação dos espectros pelos dois métodos (método ótico e método fotográfico), observou-se inclinações similares para ambos os espectros.

Por intuição imagina-se que quanto maior a rotação maior deve ser o valor de $\mathrm{K}_{2}$, para uma mesma grade oscilante. Porém, em alguns valores de $\mathrm{K}_{2}$, como ocorre para a grade larga entre os ensaios egl180 e egl200, houve um decréscimo em seu valor, tal fato se justifica pelo conceito de instabilidade superficial citado em COSTA (1992), que supõe a ocorrência de um abaixamento de temperatura devido à evaporação da camada líquida interfacial. A teoria da instabilidade superficial supõe que para baixa umidade, ou seja, ar mais seco, os valores de $\mathrm{K}_{2}$ são mais elevados.

O valor RMS em função da rotação, tanto para os valores obtidos pelo método ótico quanto pelo método fotográfico, apresentaram o melhor ajuste para a função do segundo grau, sendo este o parâmetro turbulento que apresentou melhor correlação com o coeficiente de reaeração.

Este trabalho ganha importância na área de transporte de massa em meios turbulentos pois, apesar de se encontrar boas bibliografias sobre o tema, dificilmente há publicações que relacionam o campo de velocidade na superfície livre à transferência de massa interfacial.

Sugere-se como continuidade o estudo da relação entre os espectros de turbulência tomados em função do espaço, método fotográfico, e os tomados em função do tempo, método ótico. 
ANEXOS 


\section{ANEXO I}

ensaio da grade fina 120

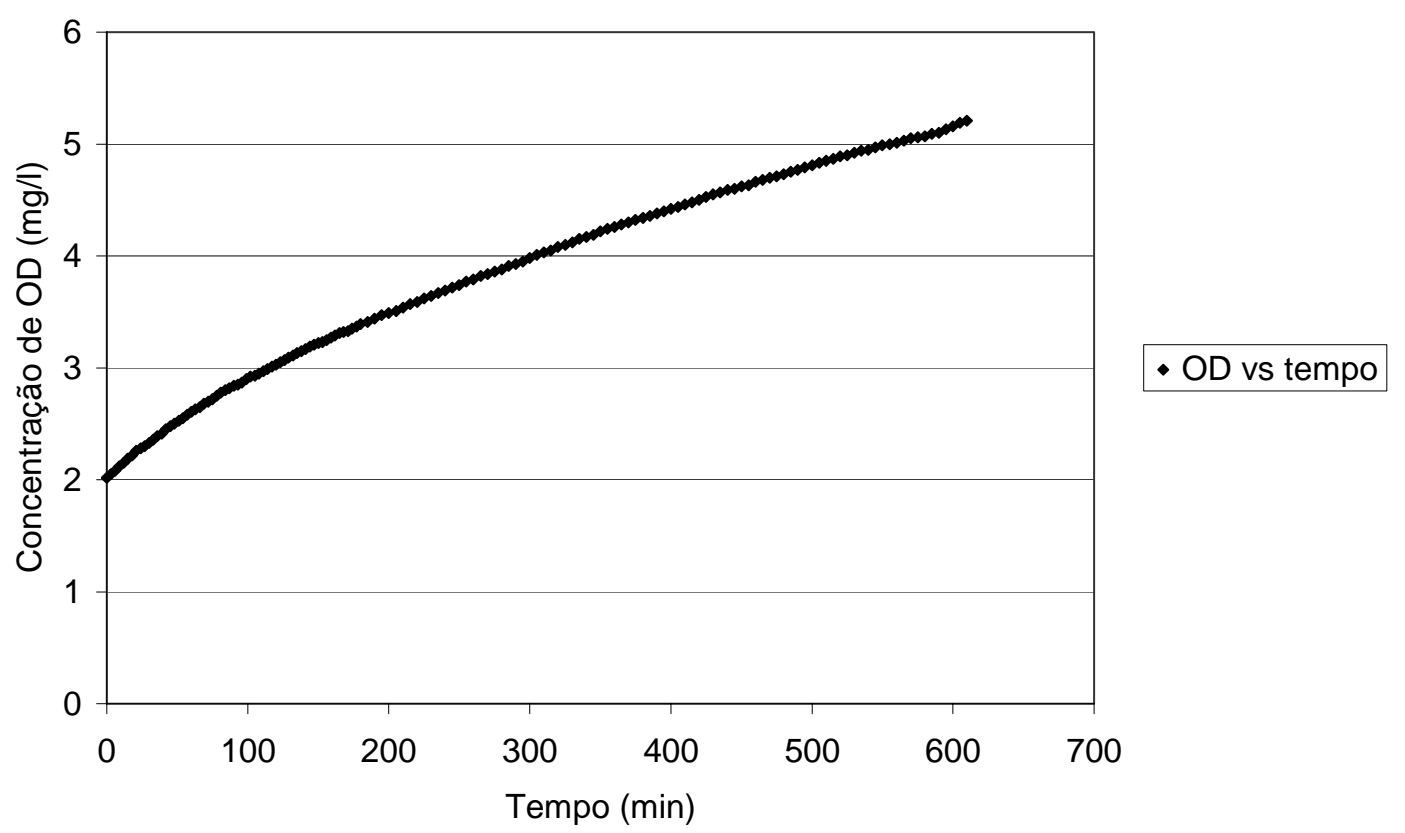

ensaio da grade fina 140

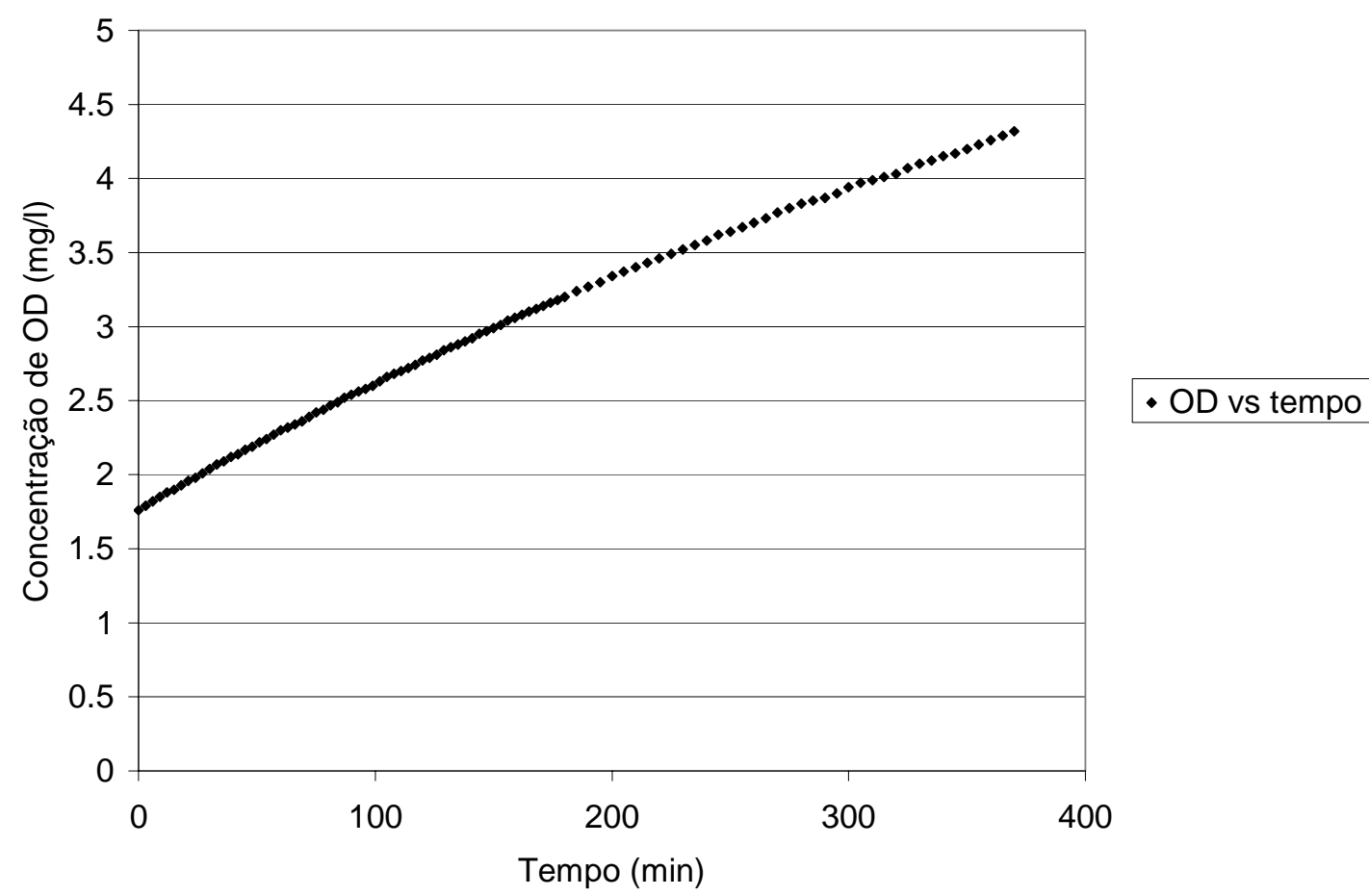


Ensaio da Grade Fina 160

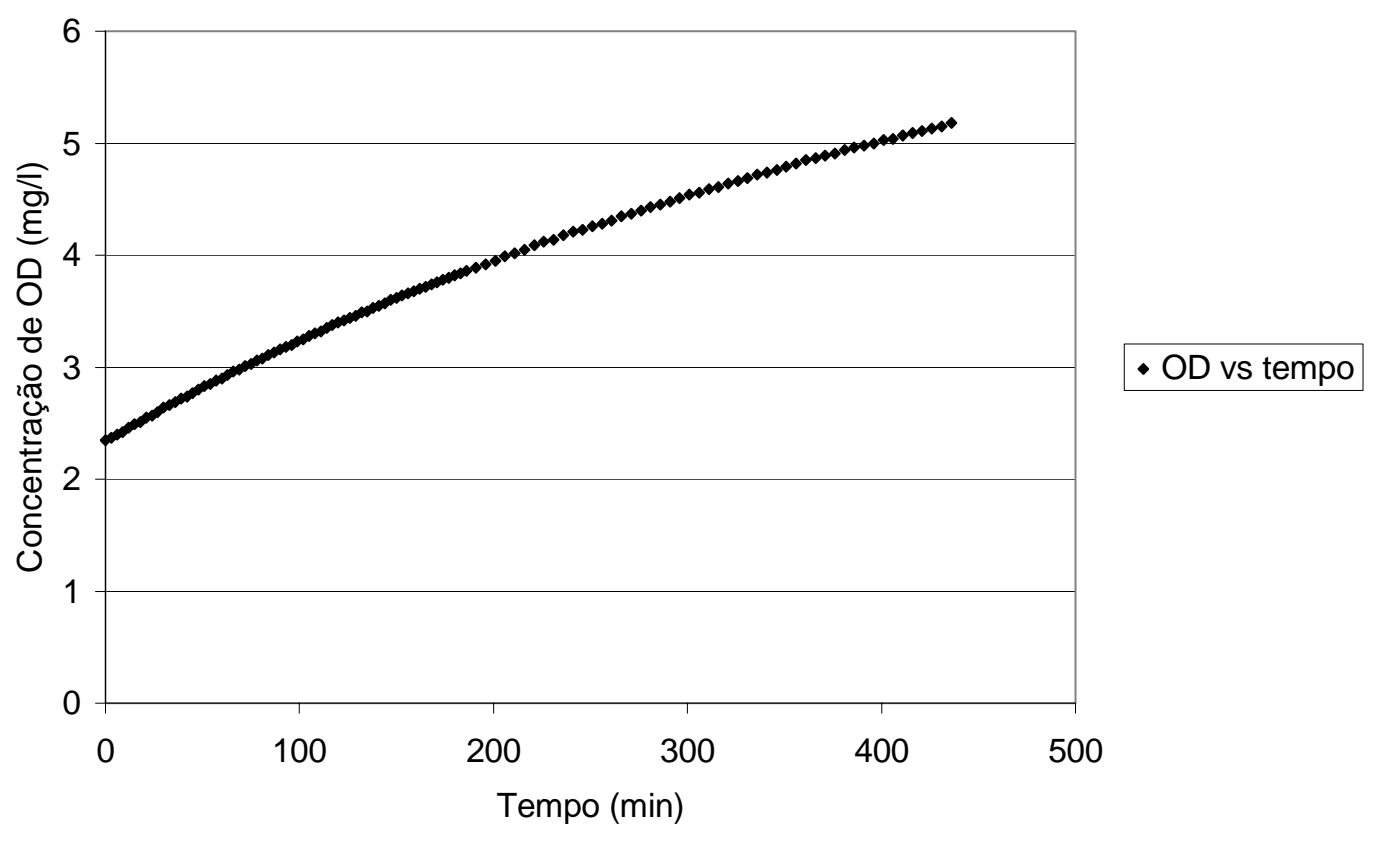

Ensaio da Grade Fina 180

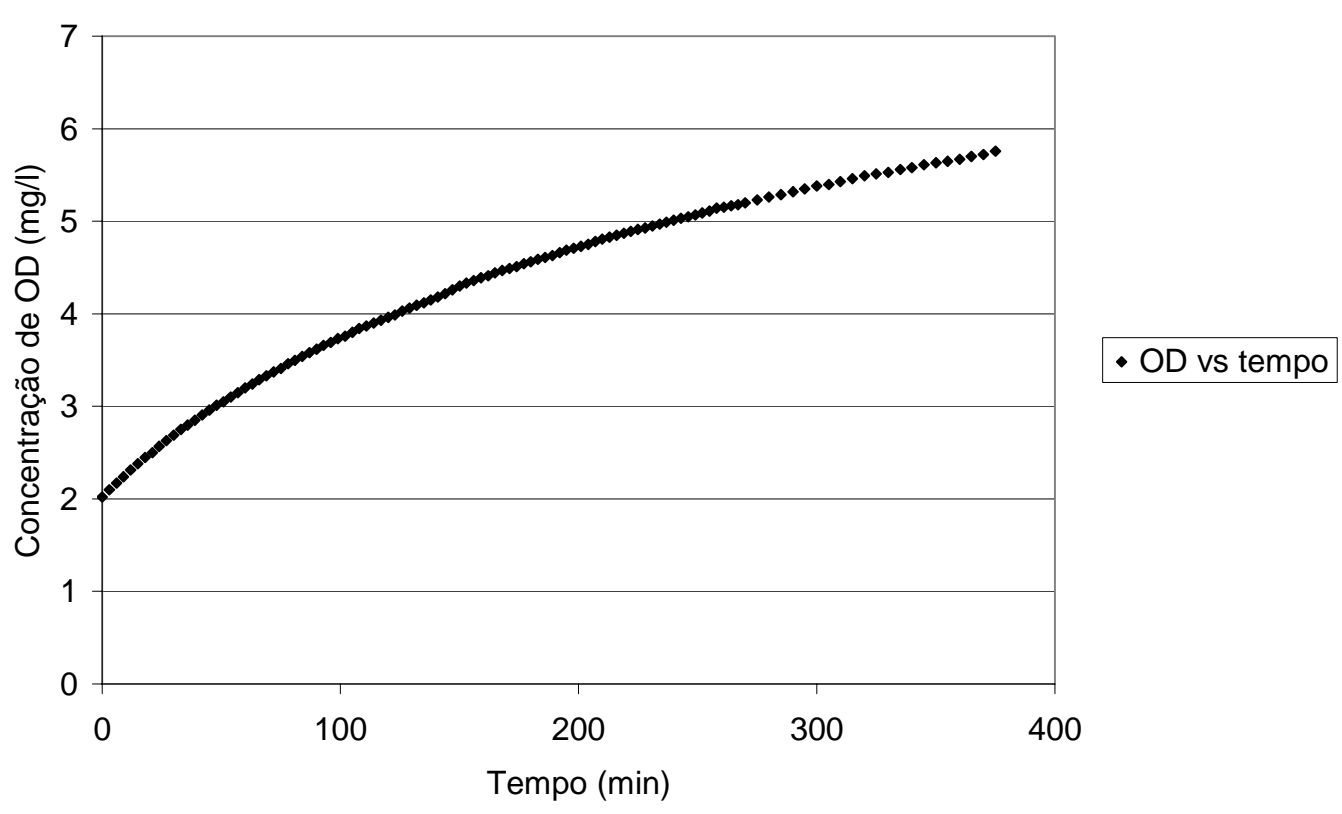


Ensaio da Grade Fina 200

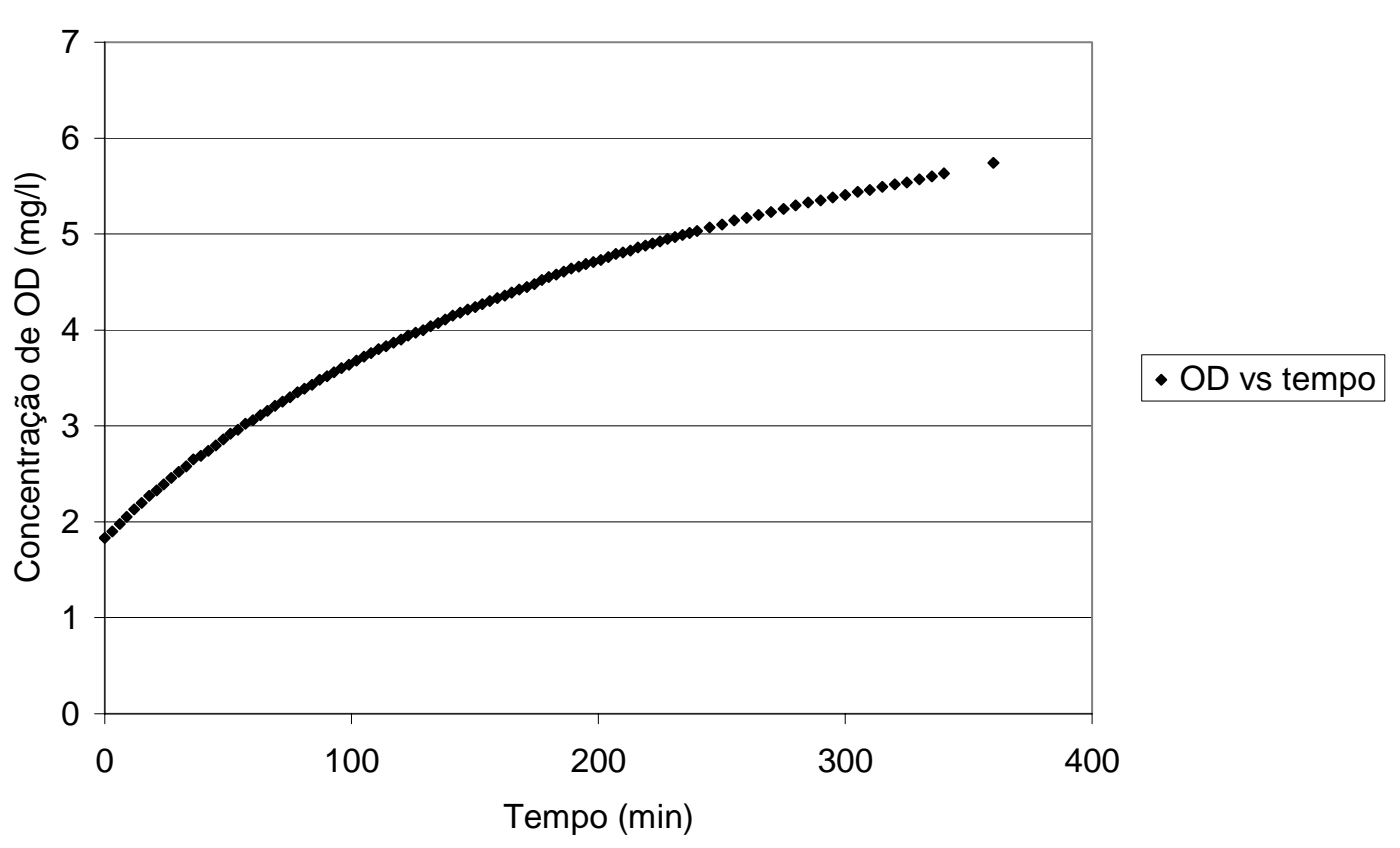

Ensaio da Grade Média 140

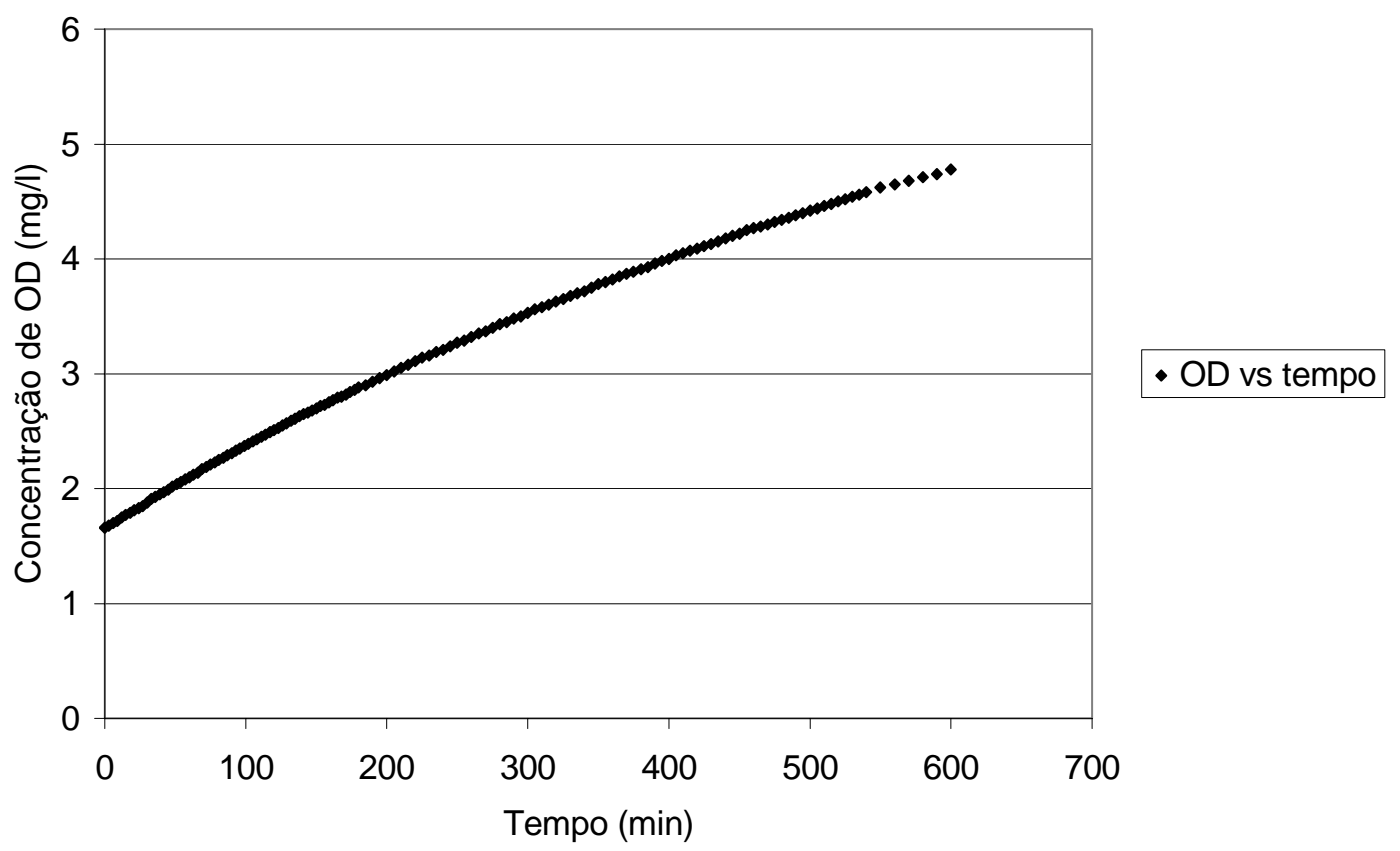


Ensaio da Grade Média 160

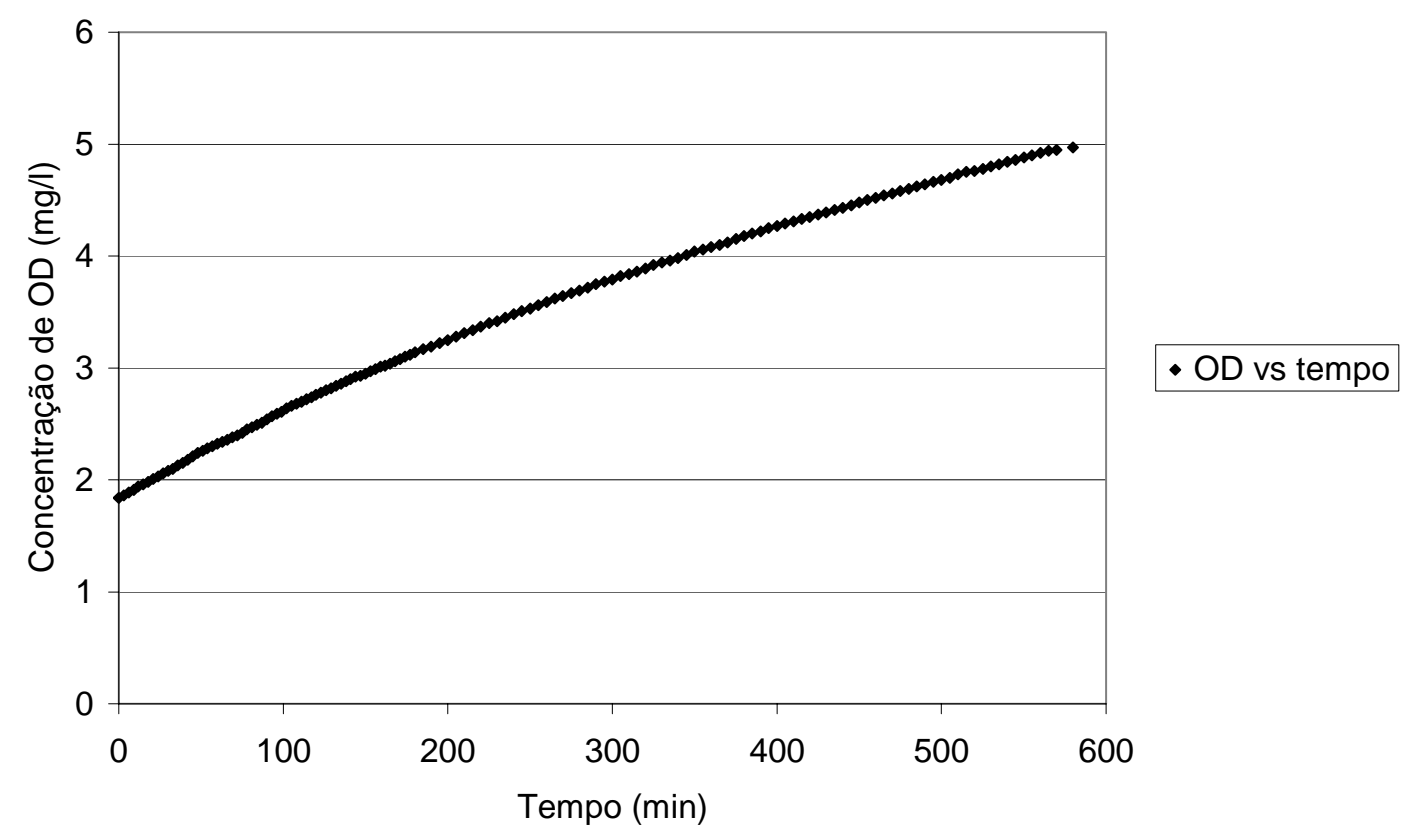

Ensaio da Grade Média 180

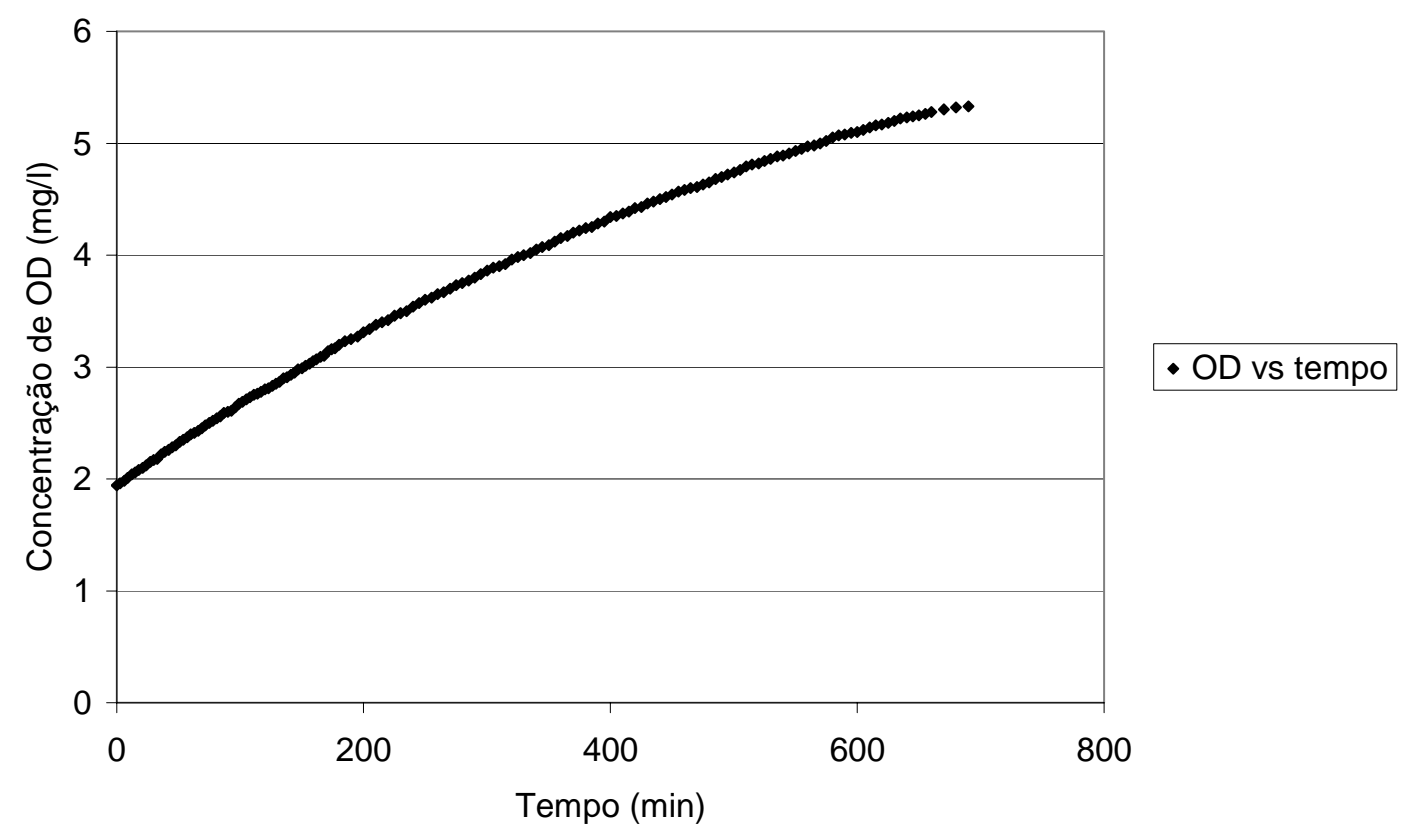


Ensaio da Grade Média 210

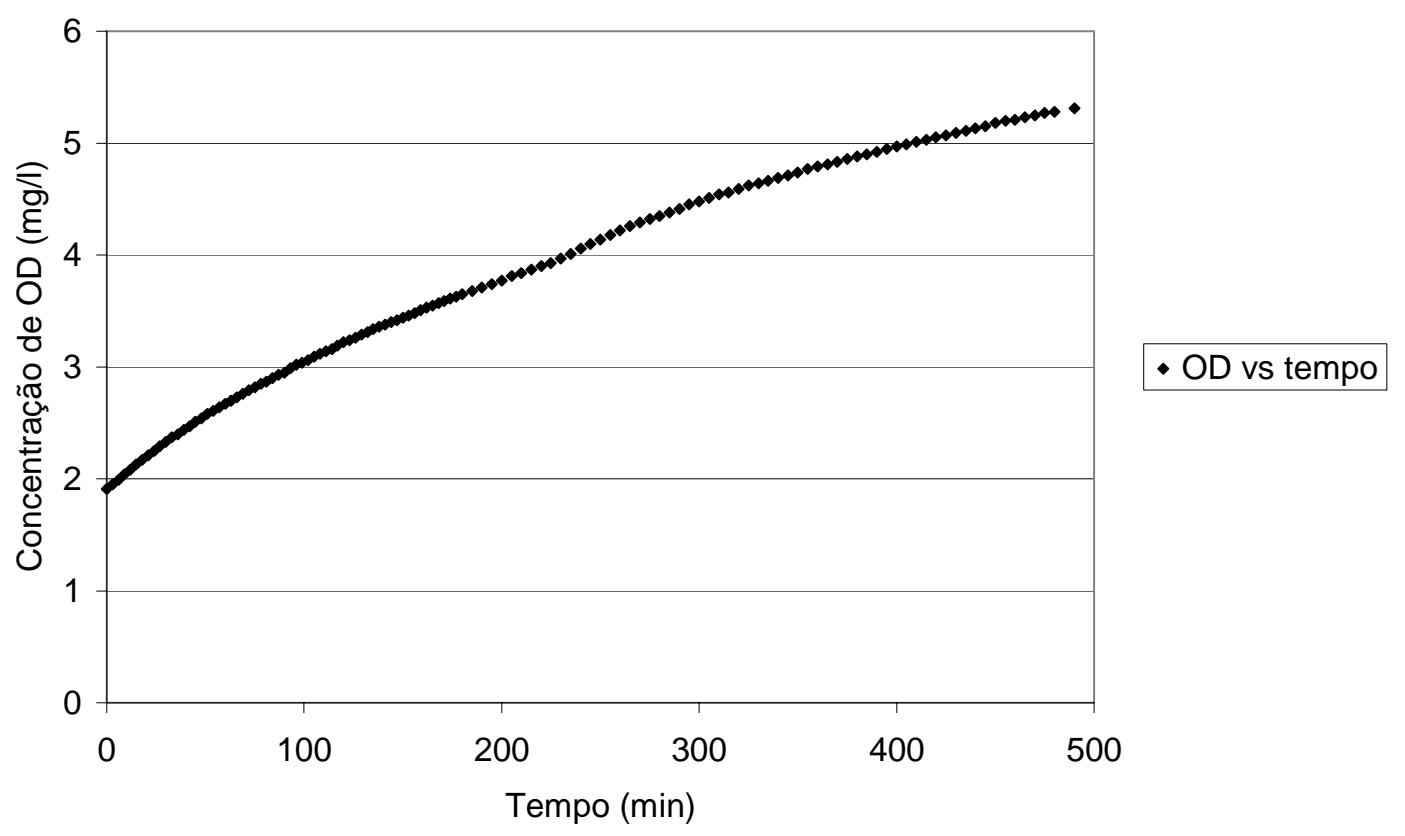

Ensaio da Grade Média 240

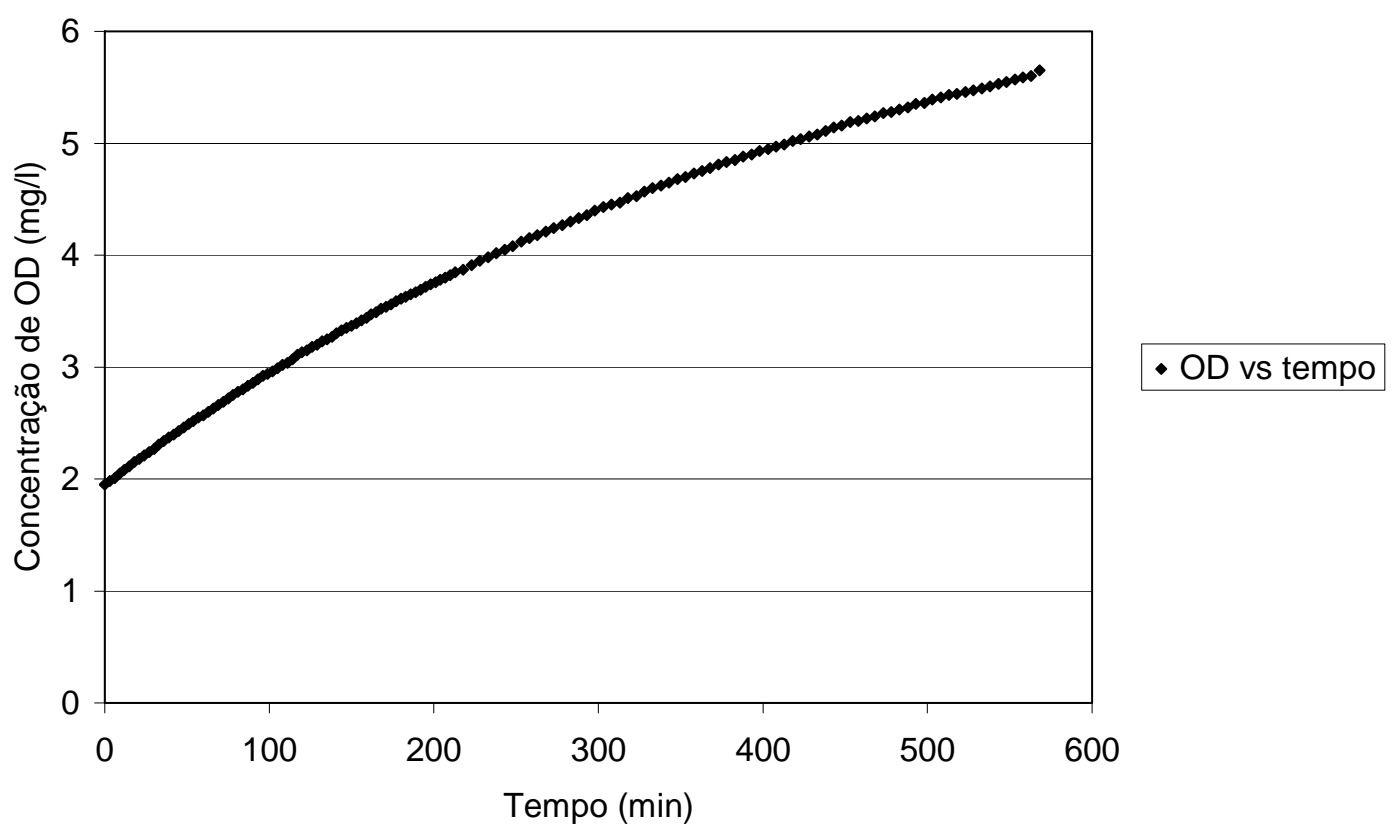


Ensaio da Grade Larga 180

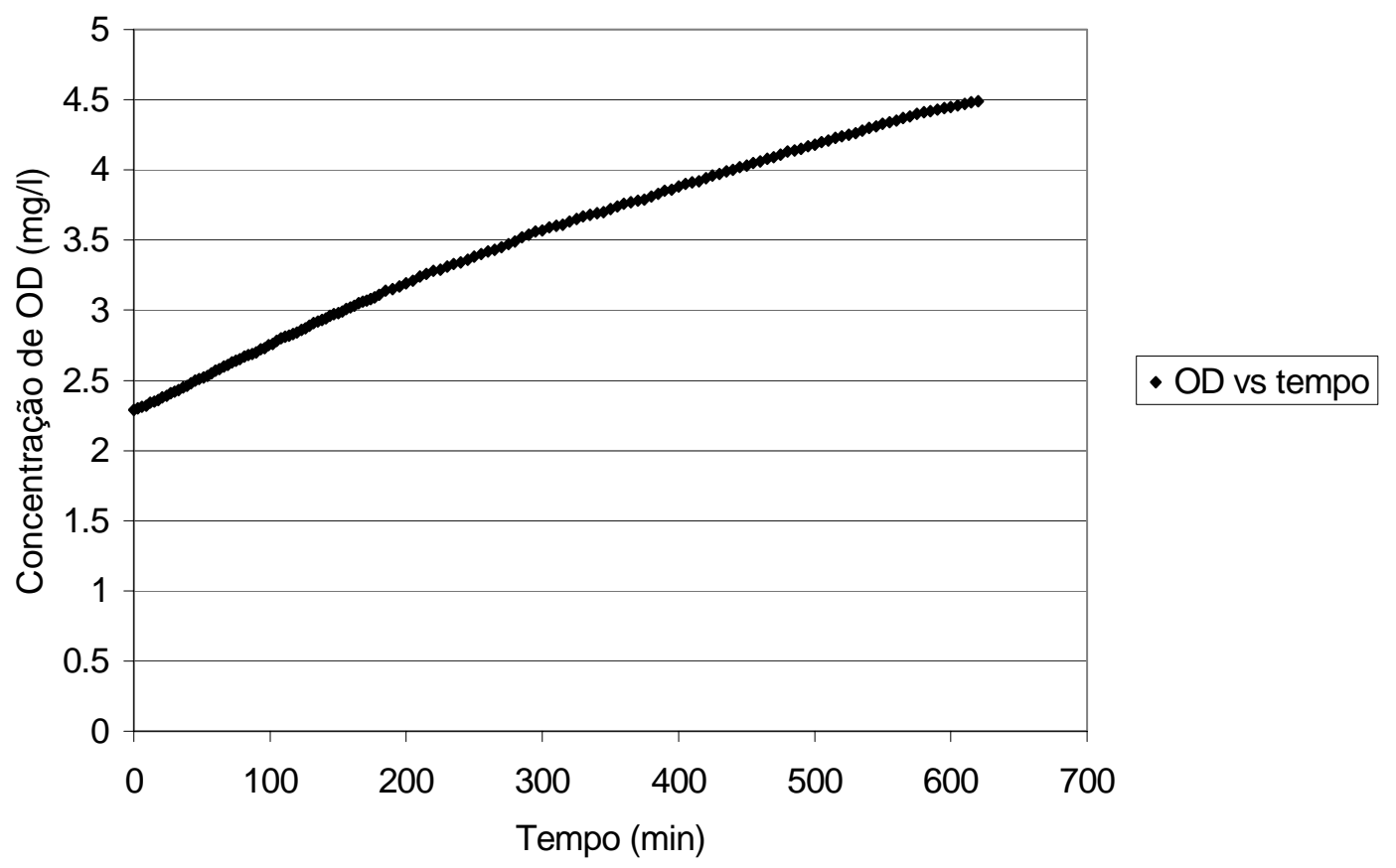

Ensaio da Grade Larga 200

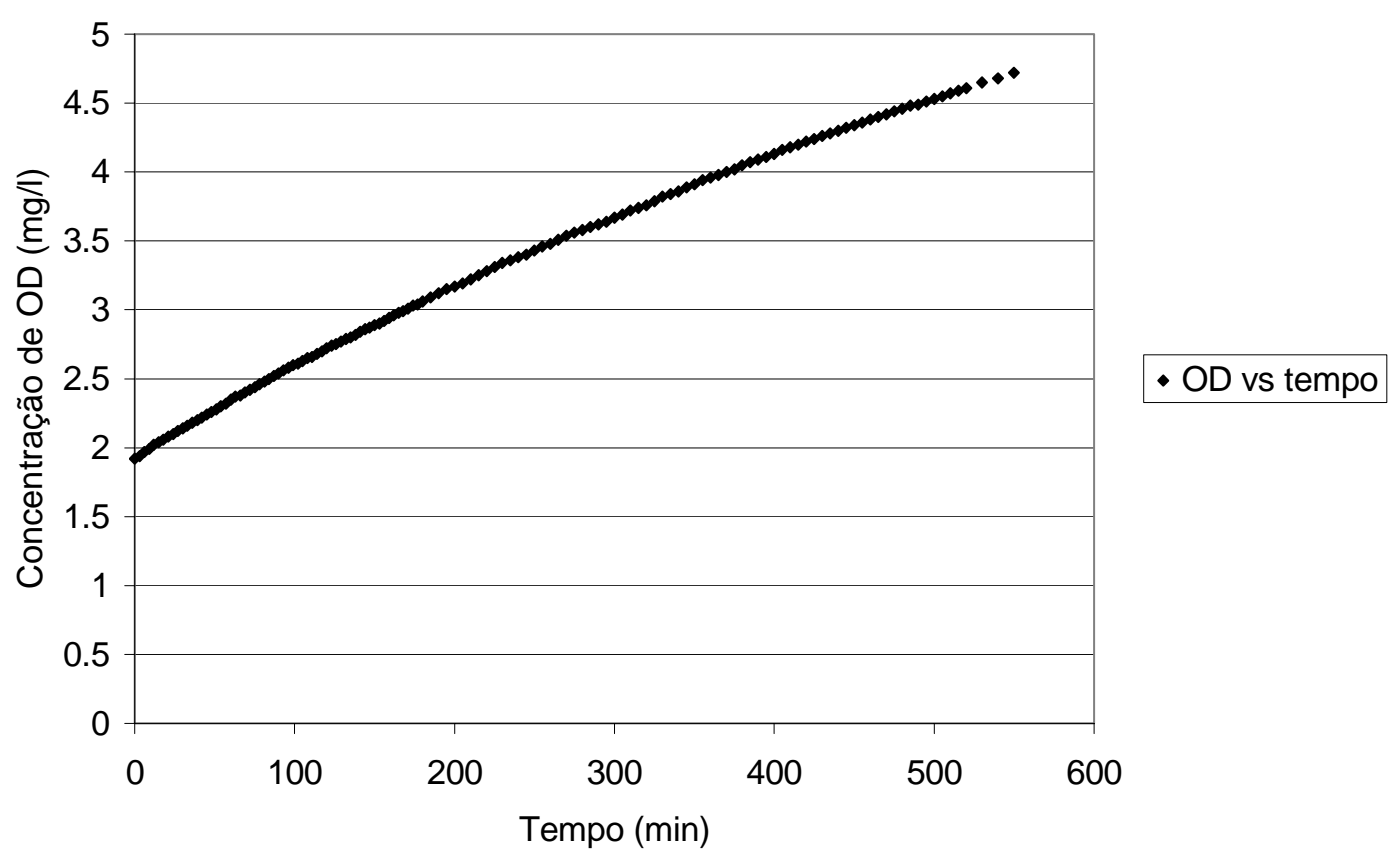


Ensaio da Grade Larga 220

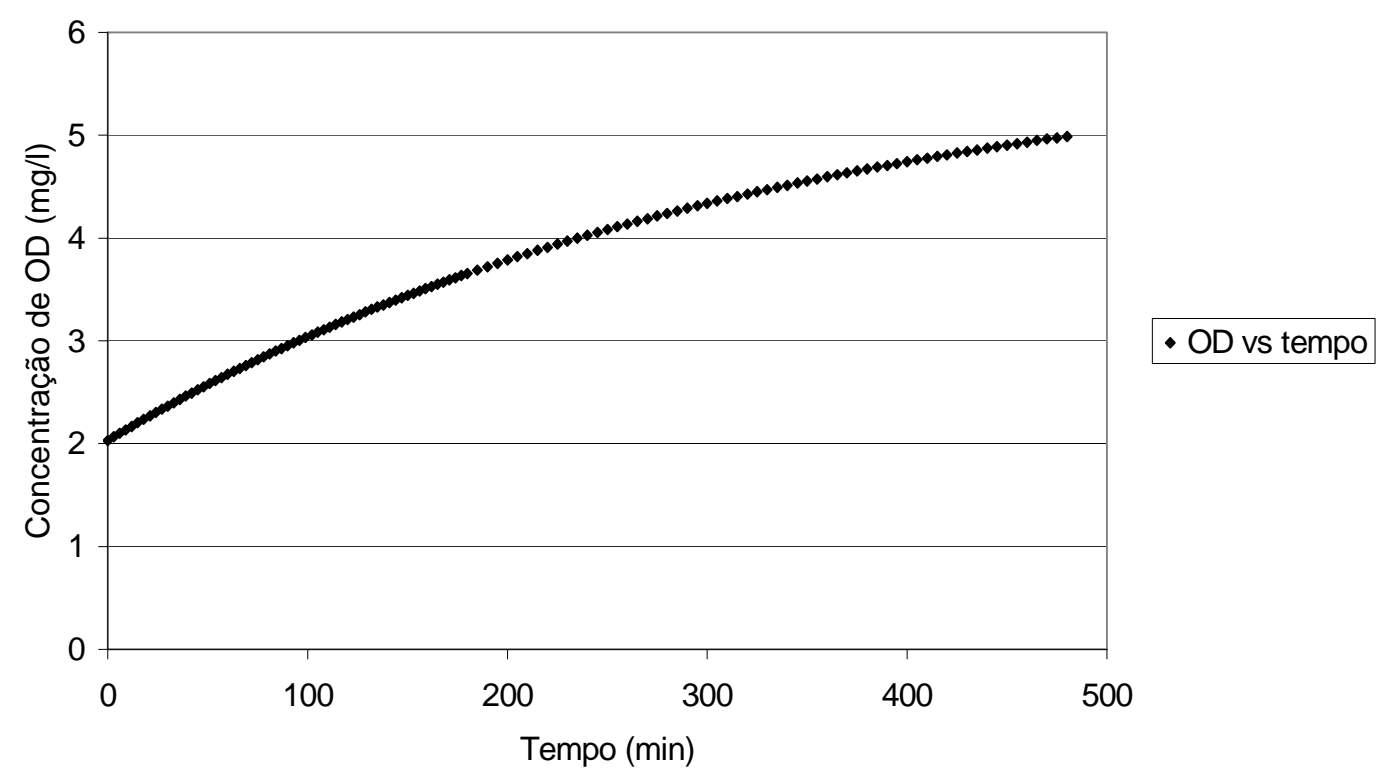

Ensaio da Grade Larga 250

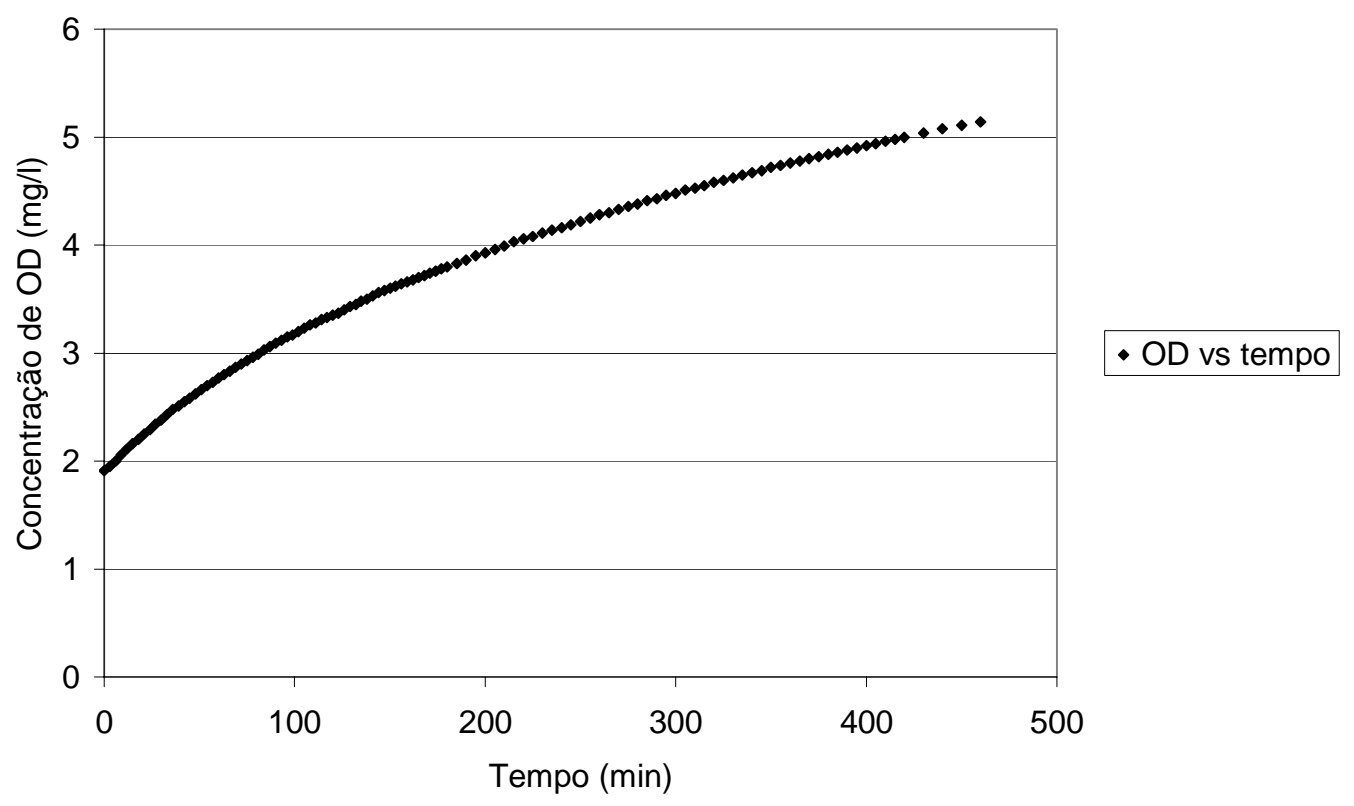


ANEXOS II 


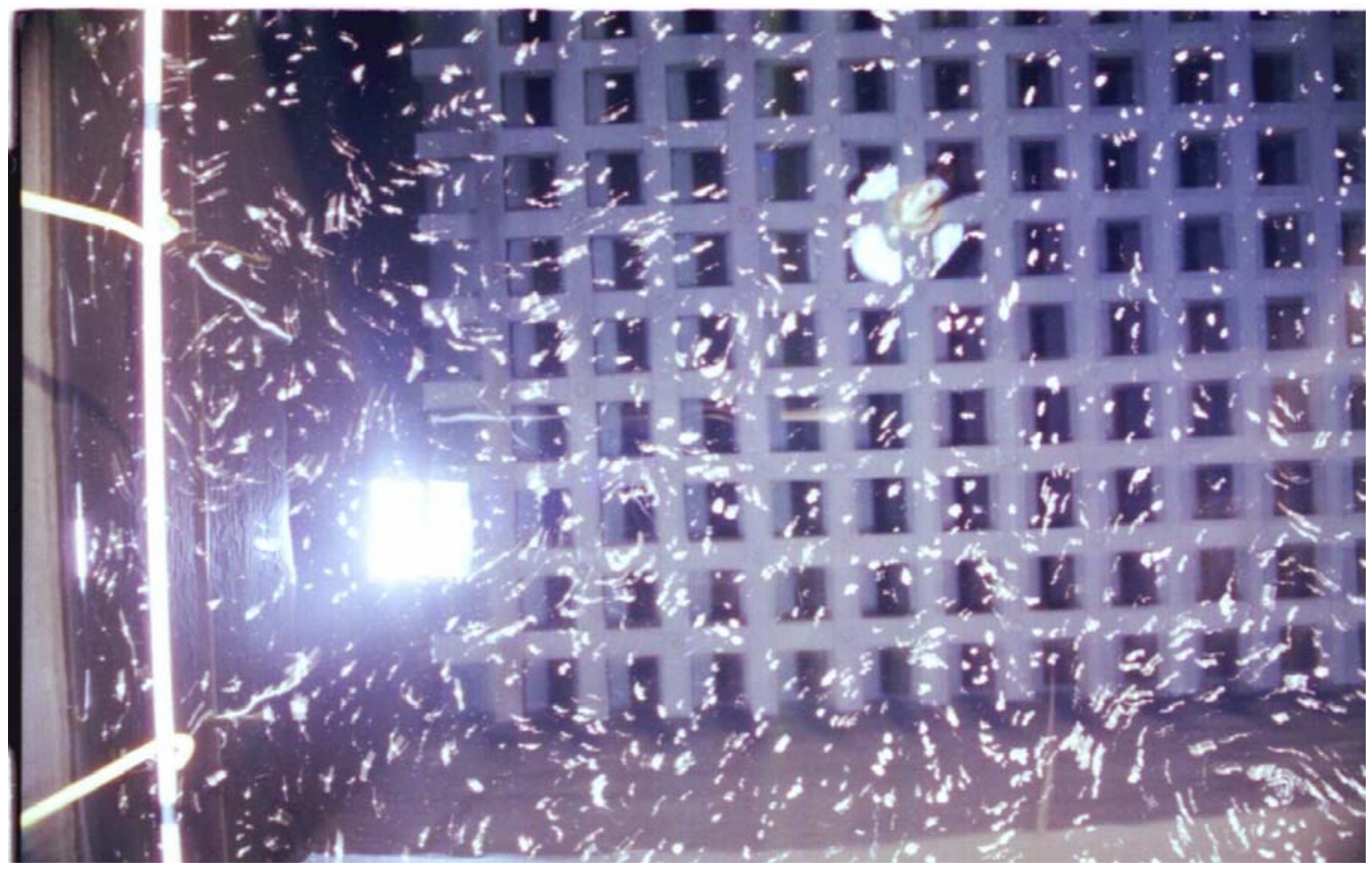

ENSAIO DA GRADE FINA 120 RPM

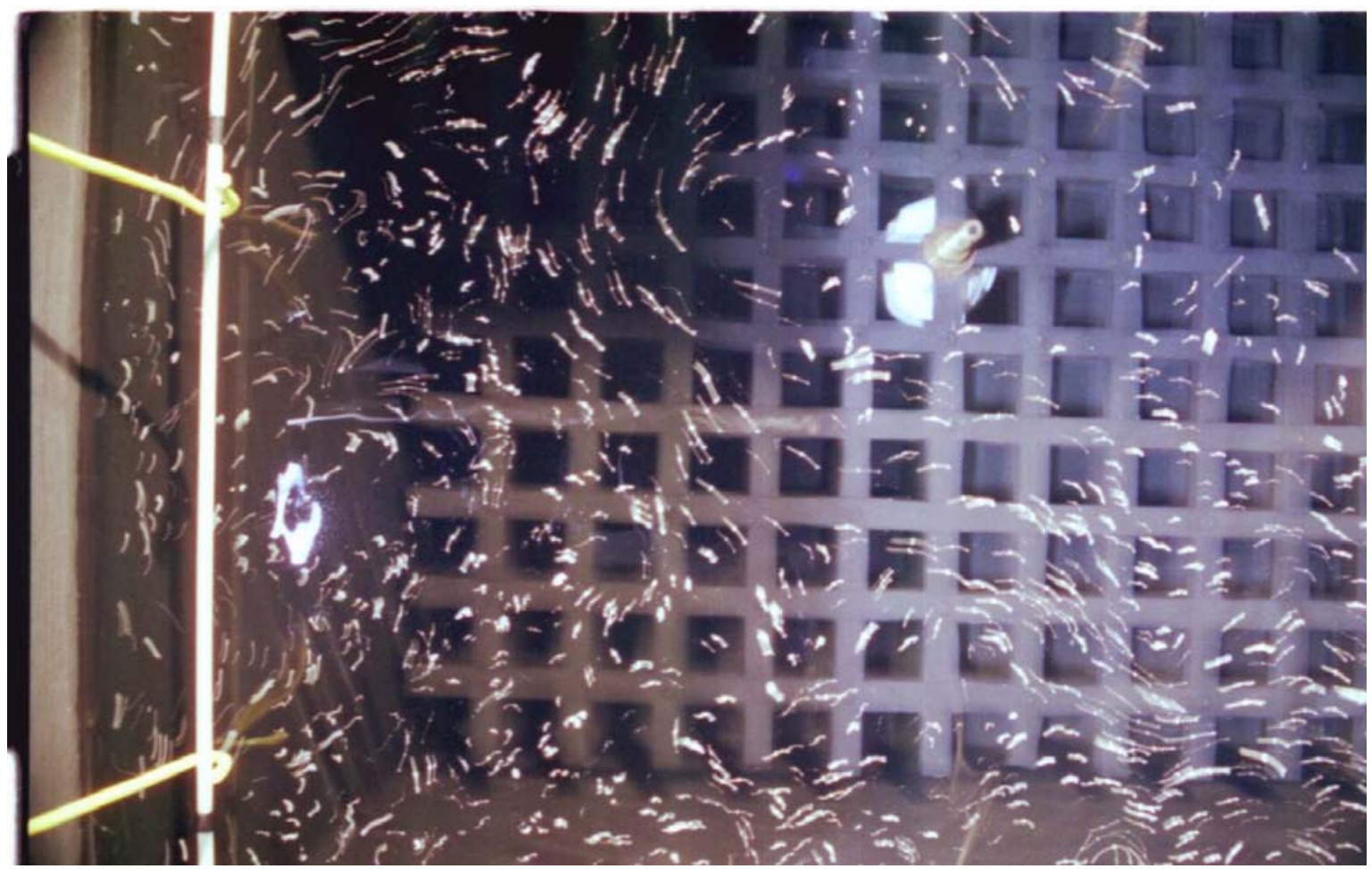

ENSAIO DA GRADE FINA 140 RPM 


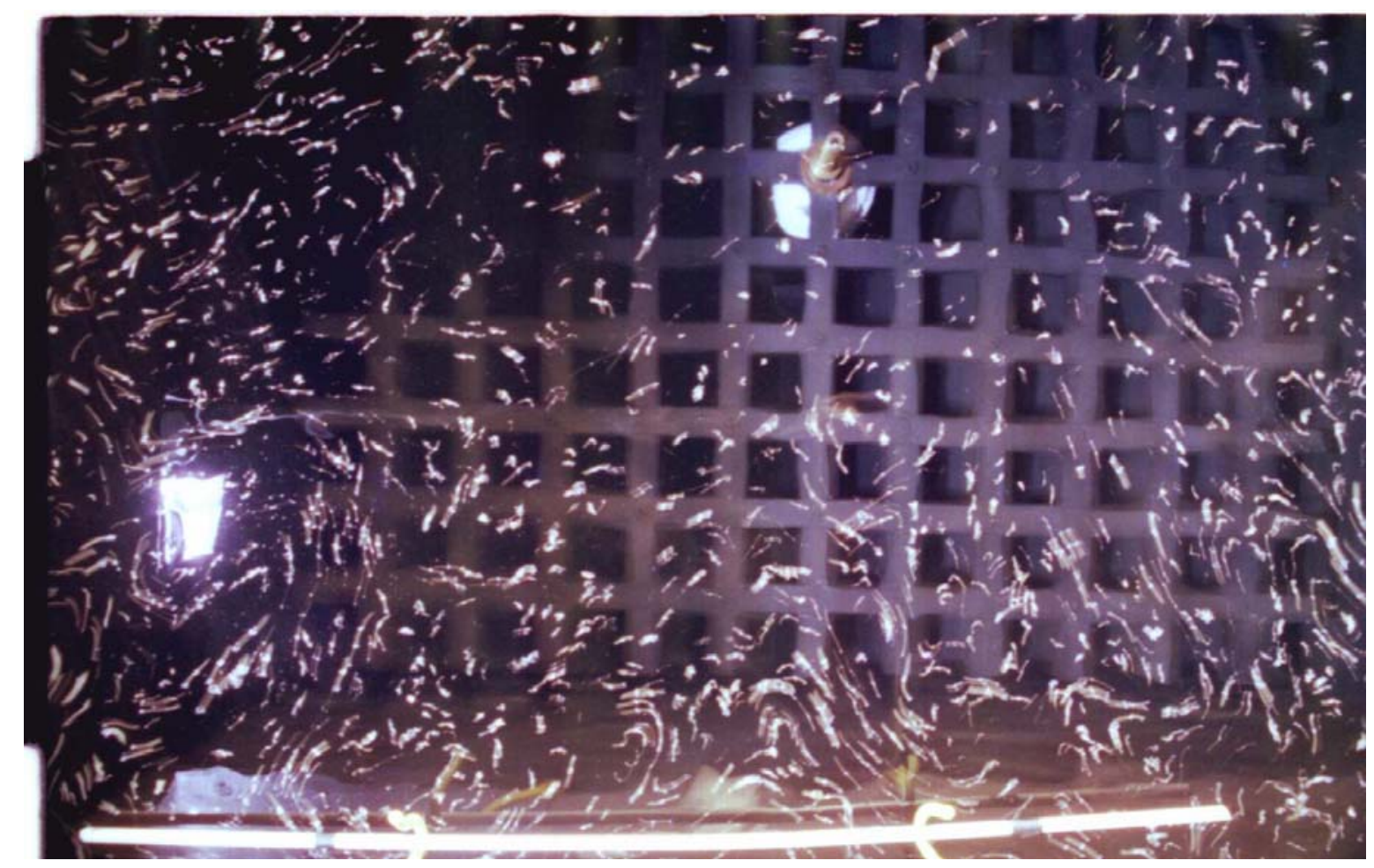

ENSAIO DA GRADE FINA 160 RPM

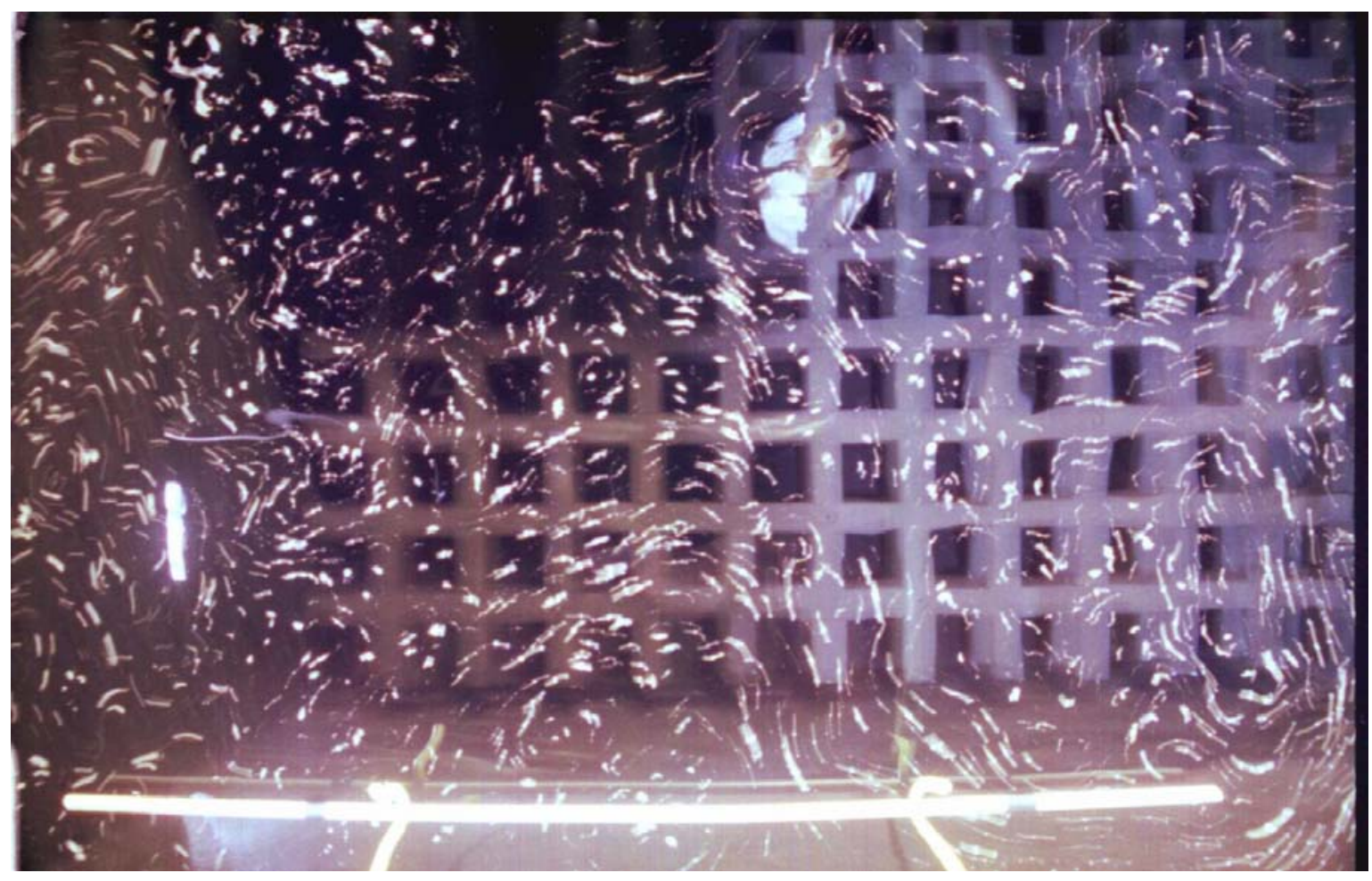

ENSAIO DA GRADE FINA 180 RPM 


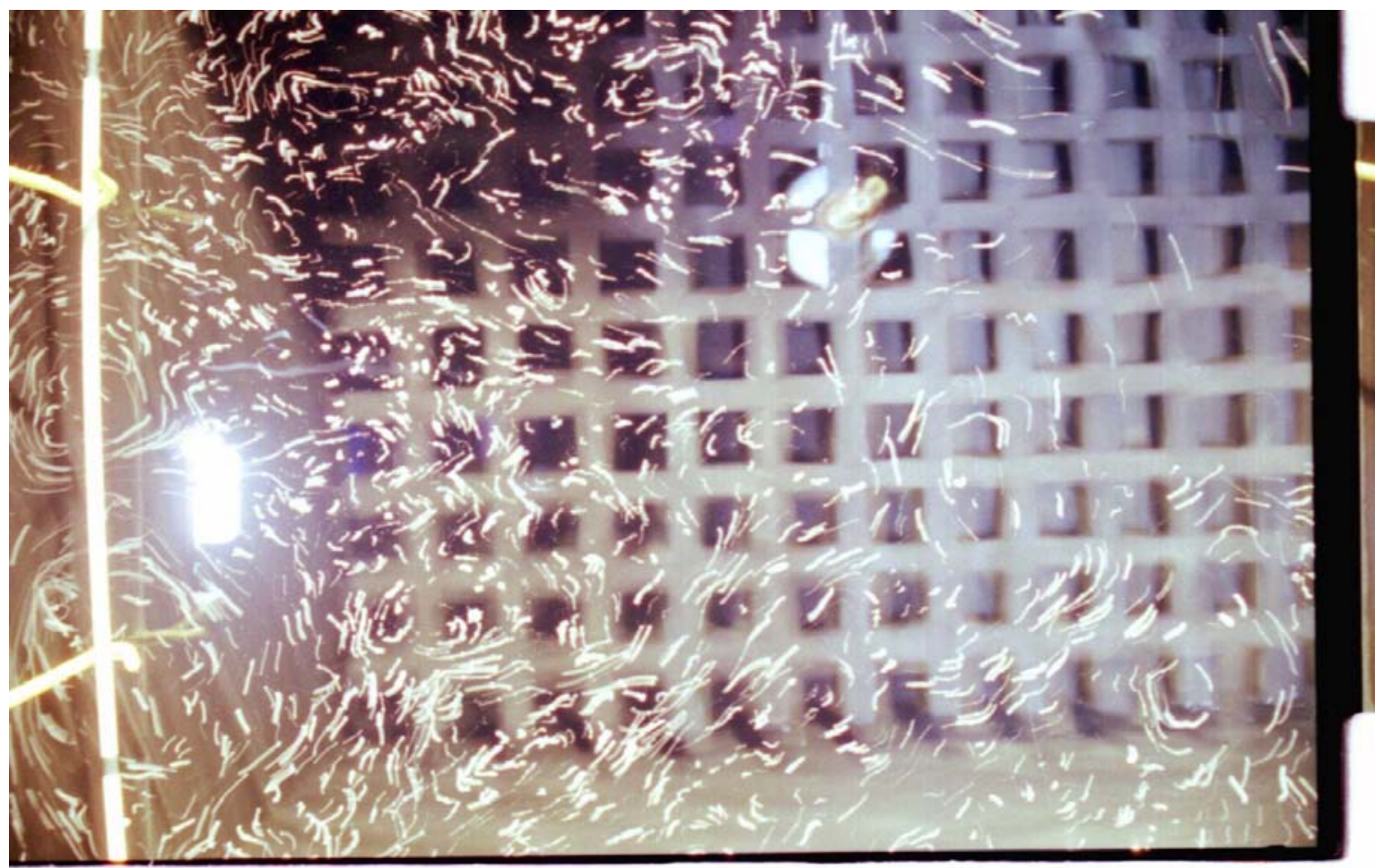

ENSAIO DA GRADE FINA 200 RPM

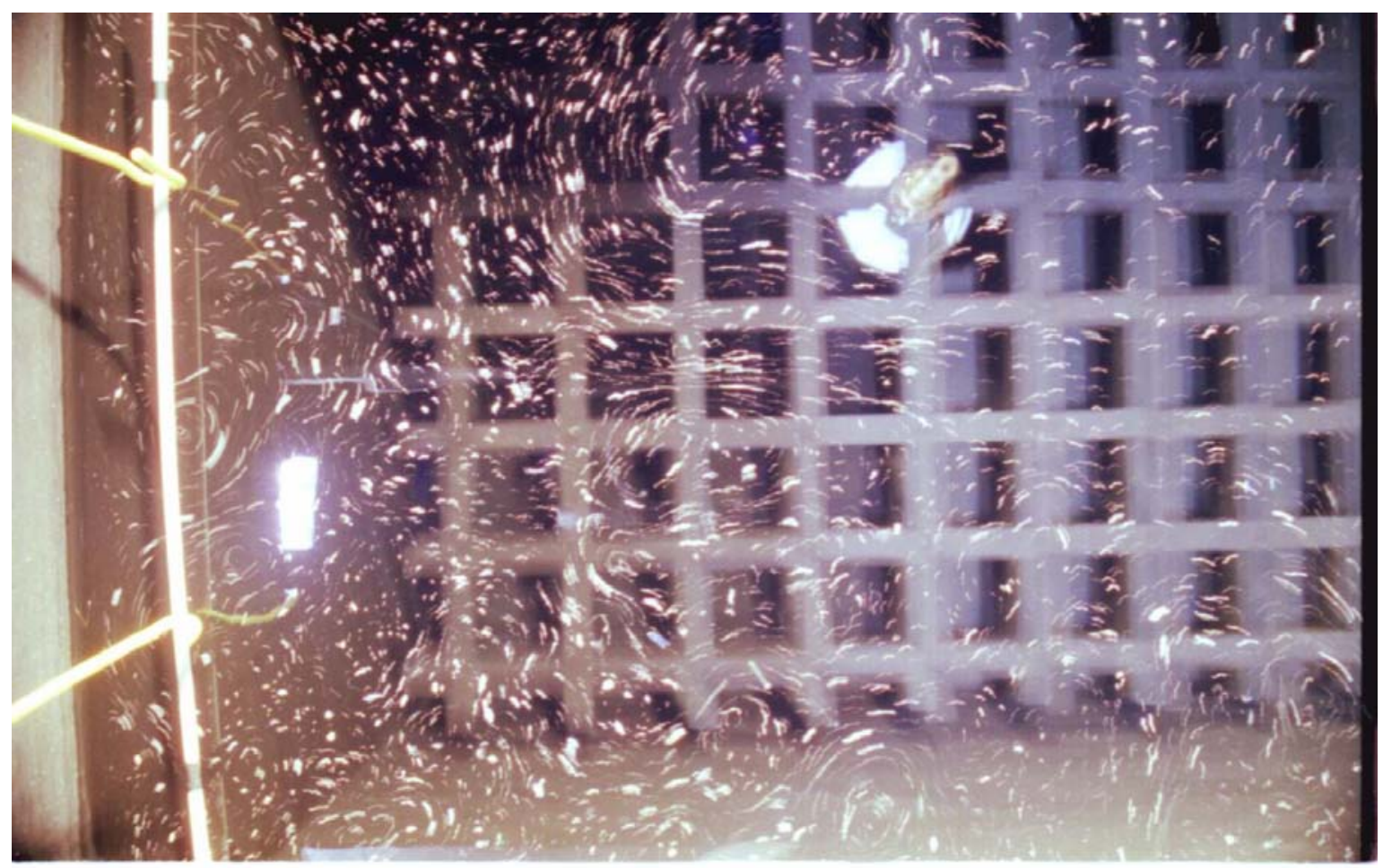

ENSAIO DA GRADE MÉDIA 140 RPM 


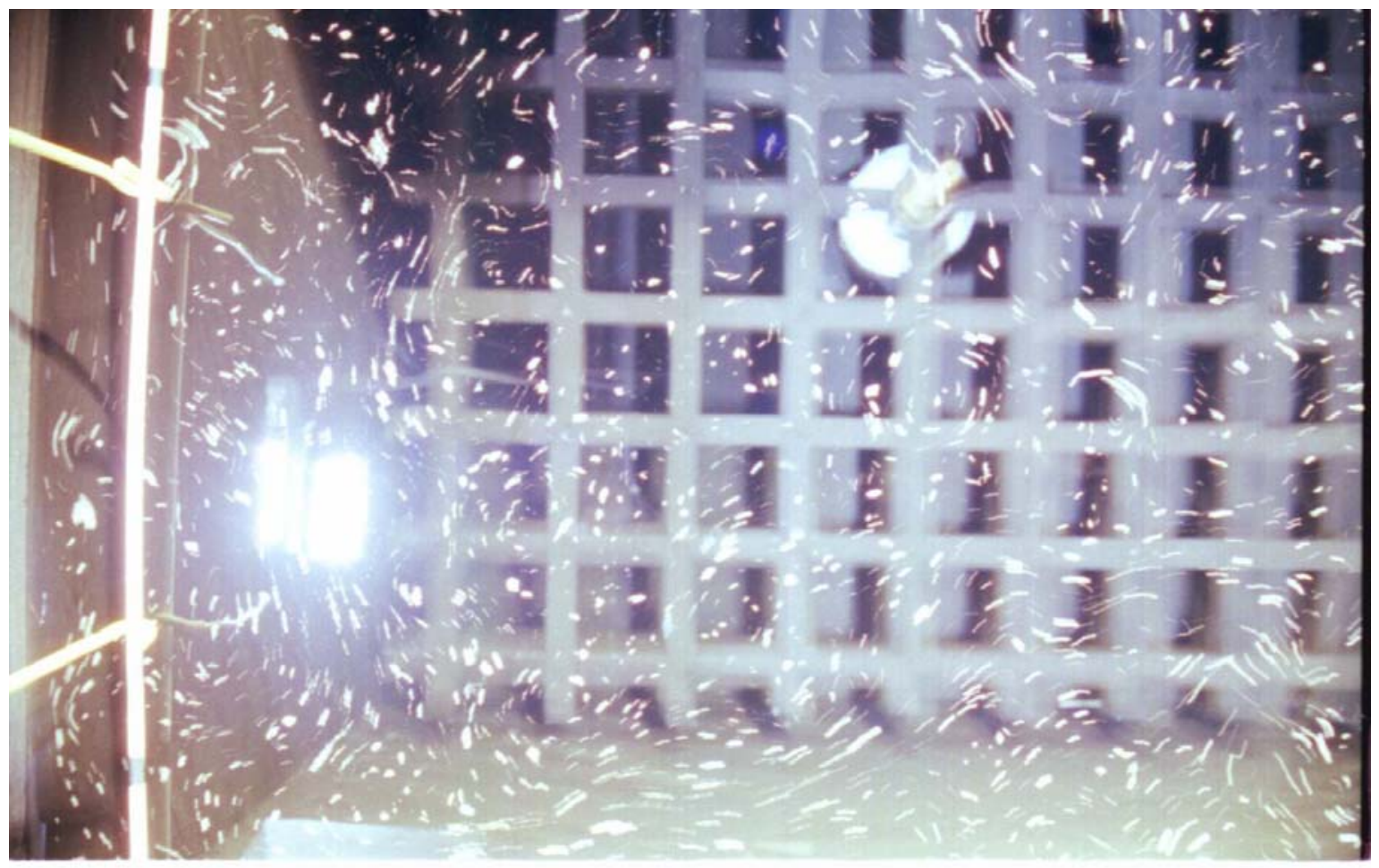

ENSAIO DA GRADE MÉDIA 160 RPM

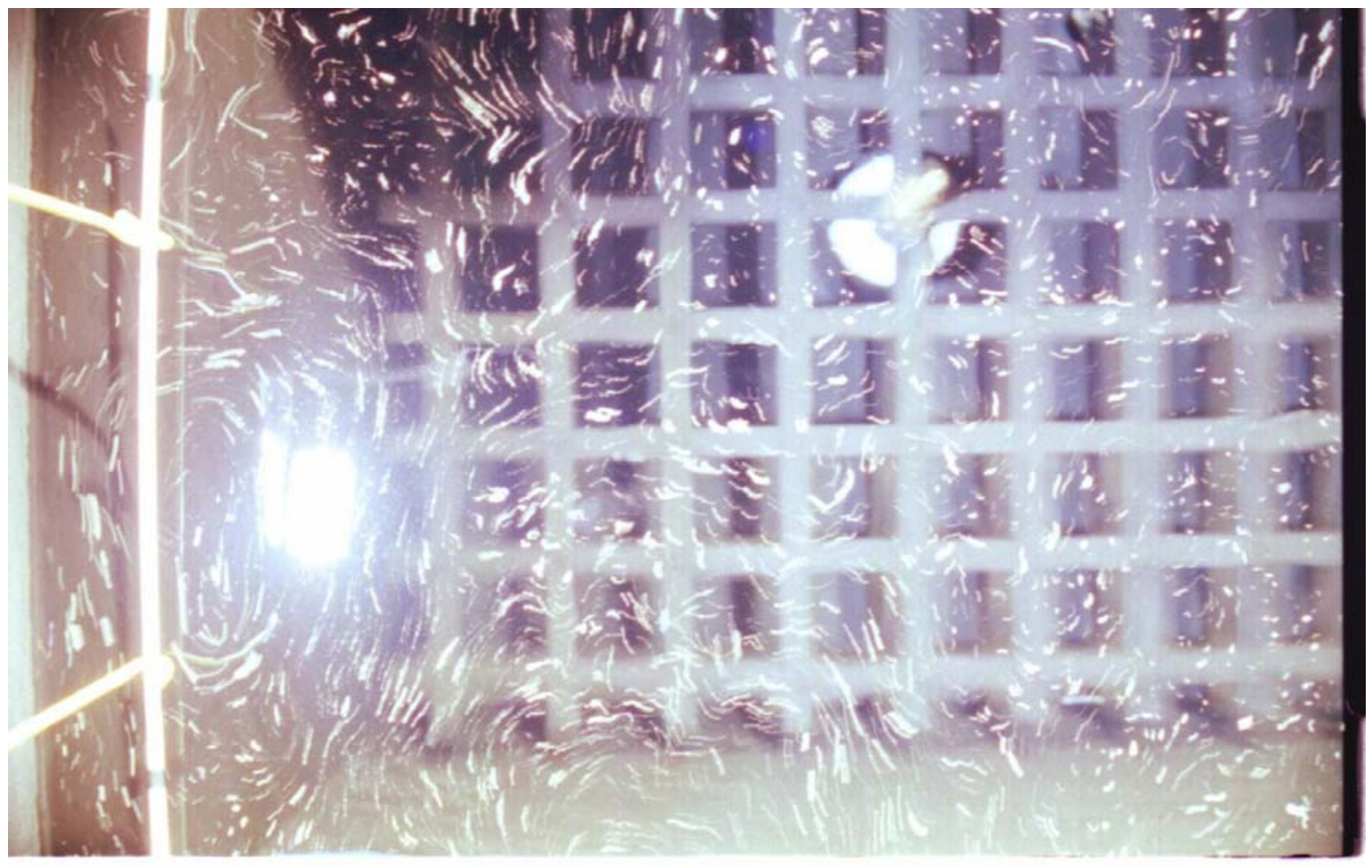

ENSAIO DA GRADE MÉDIA 180 RPM 


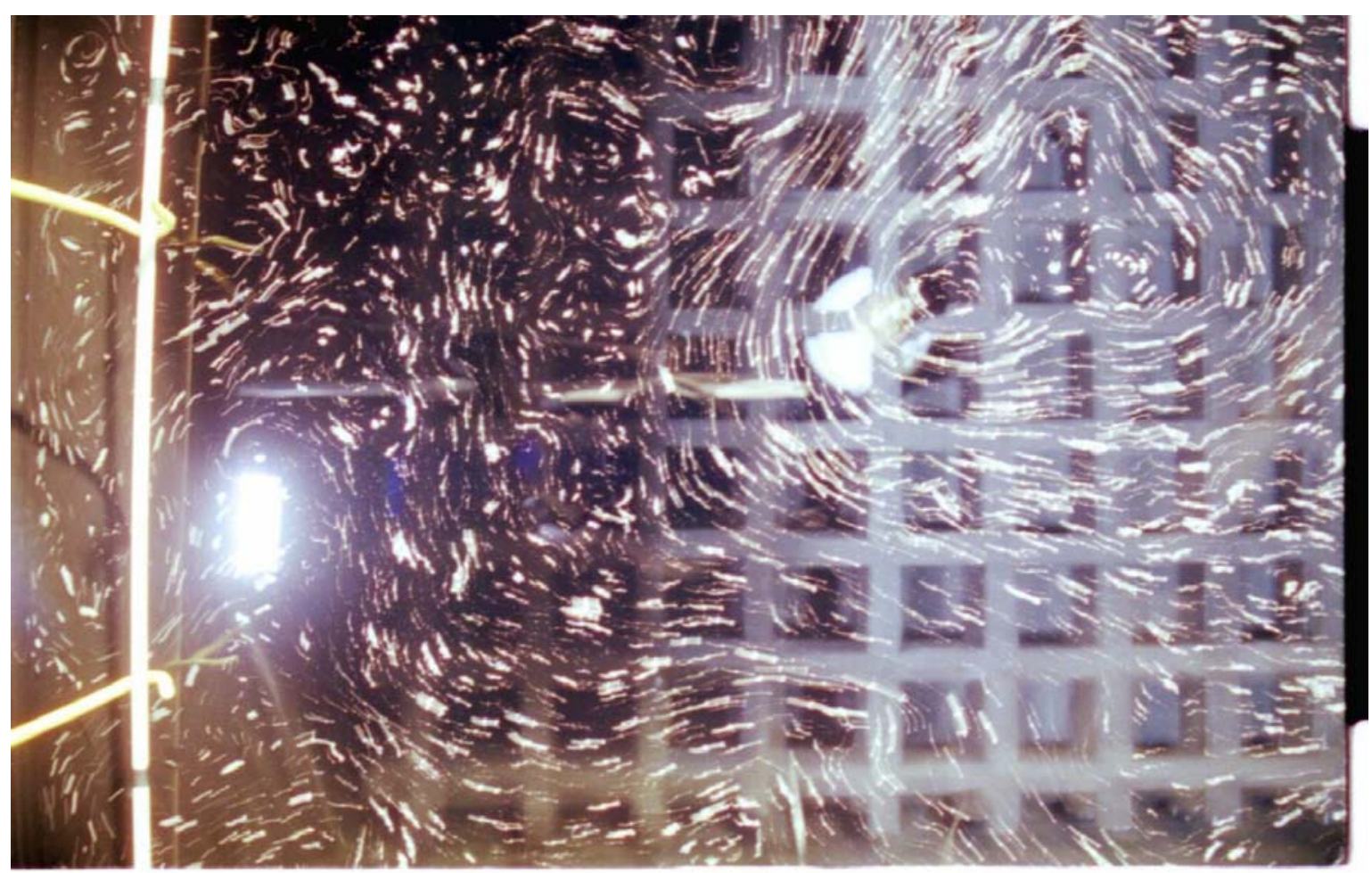

ENSAIO DA GRADE MÉDIA 210 RPM

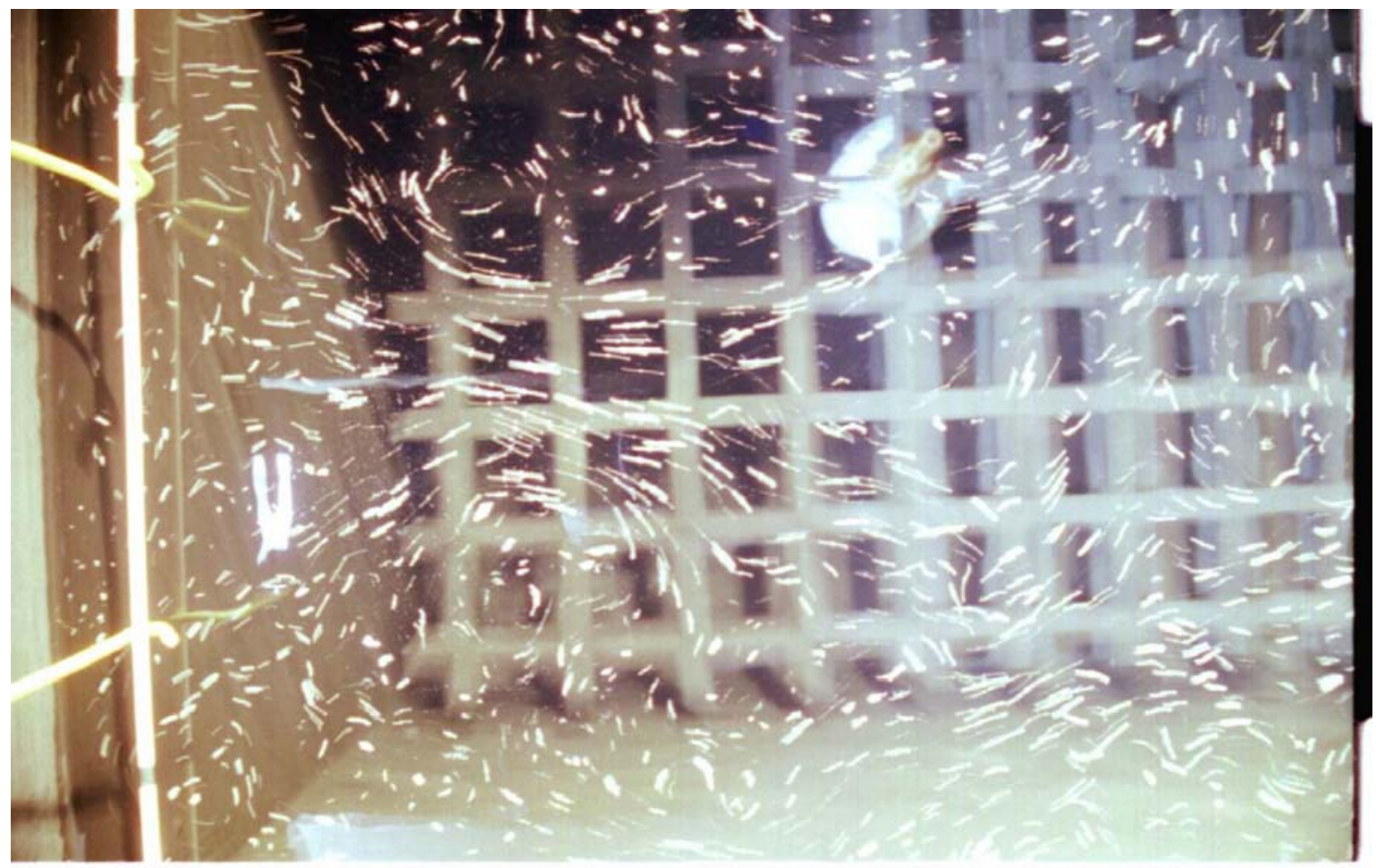

ENSAIO DA GRADE MÉDIA 240 RPM 


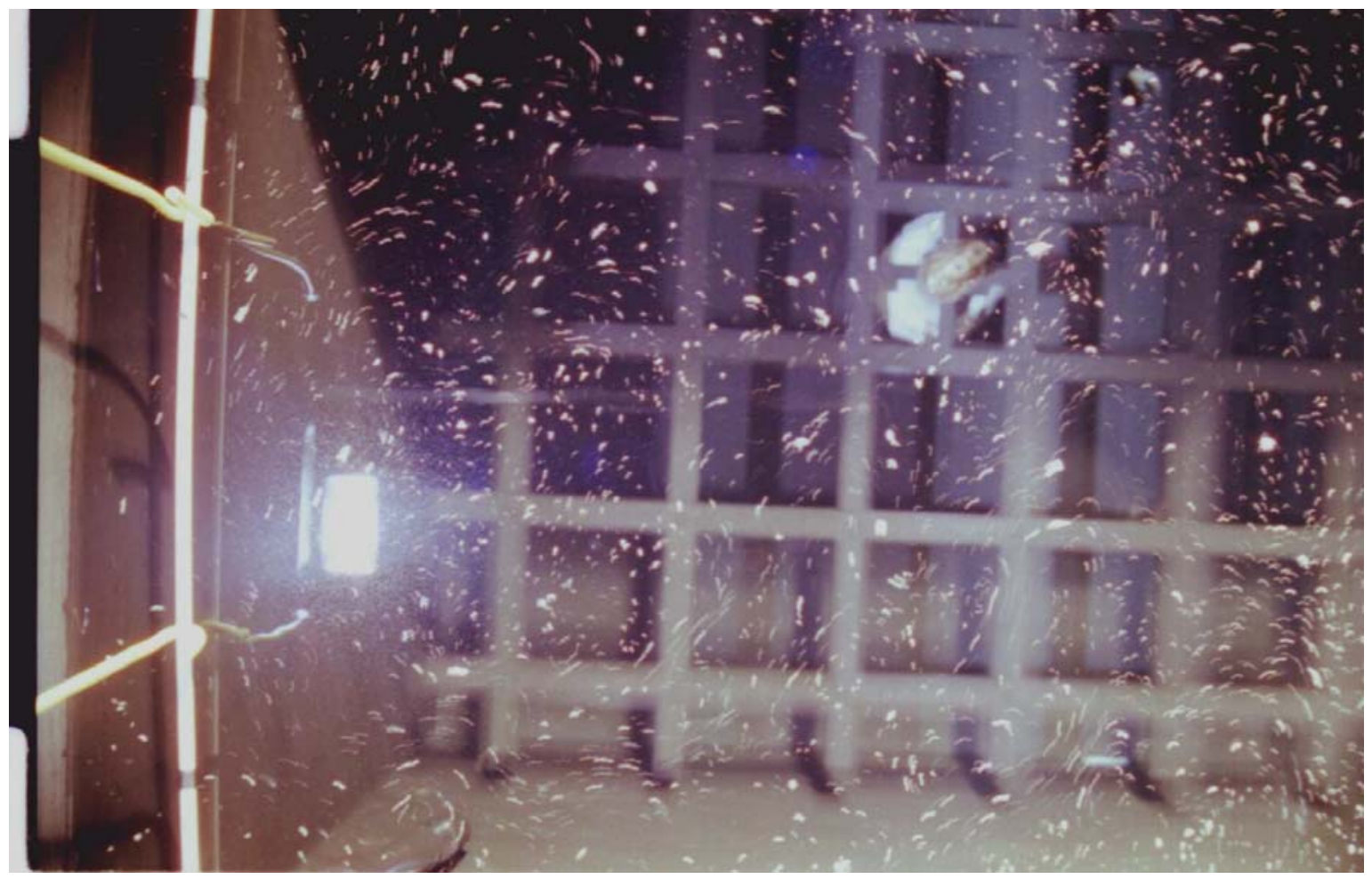

ENSAIO DA GRADE LARGA 180 RPM

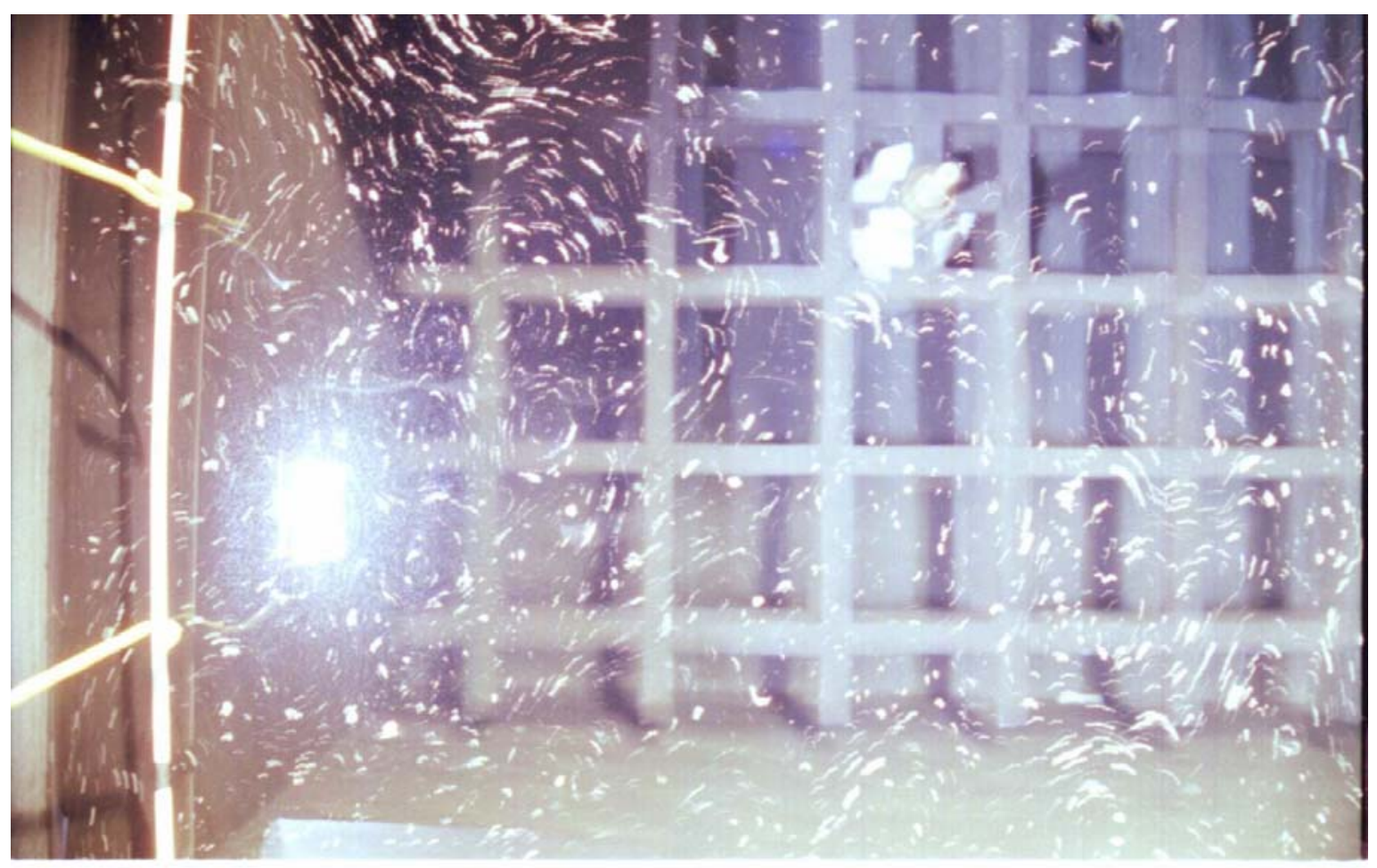

ENSAIO DA GRADE LARGA 200 RPM 


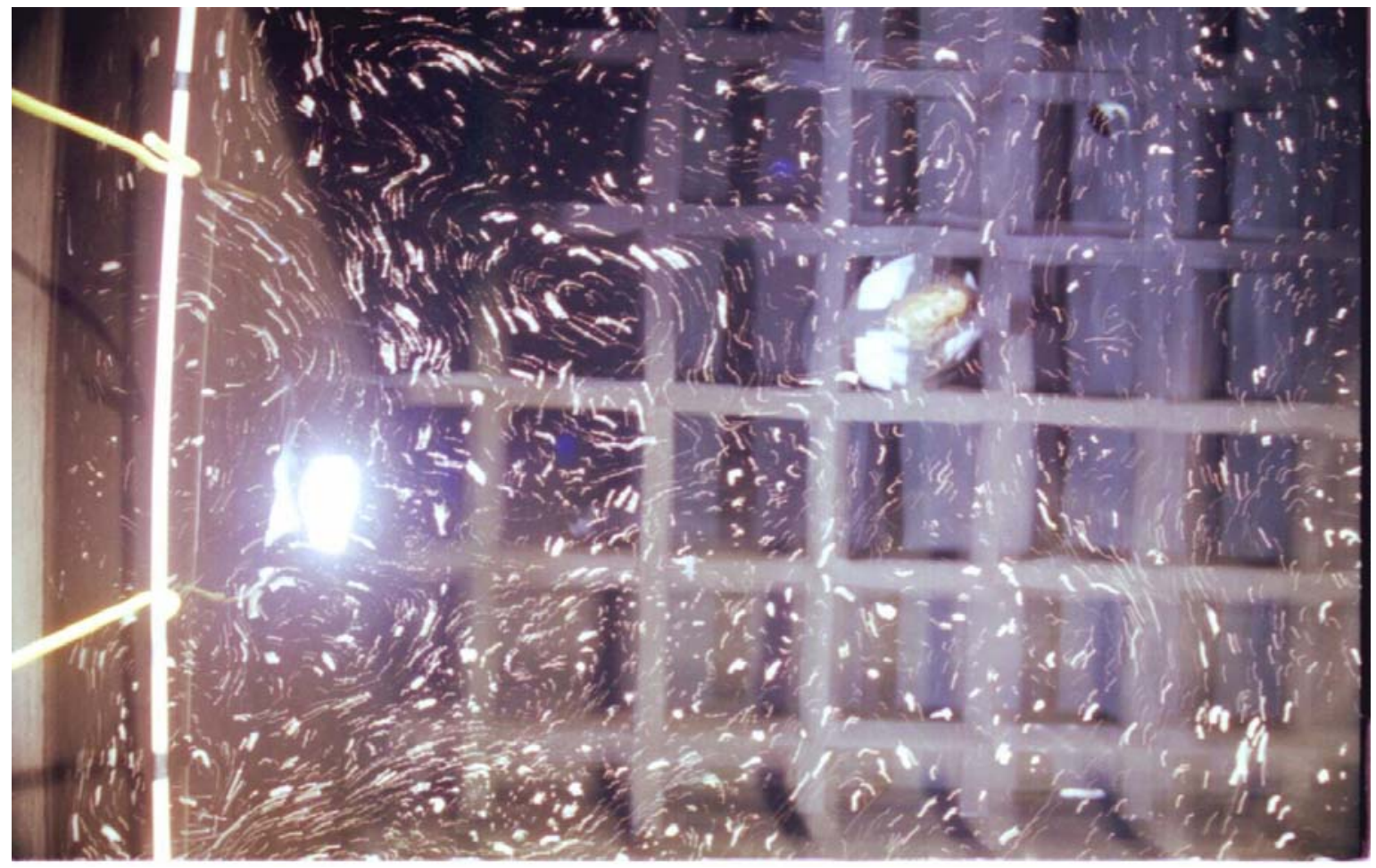

ENSAIO DA GRADE LARGA 220 RPM

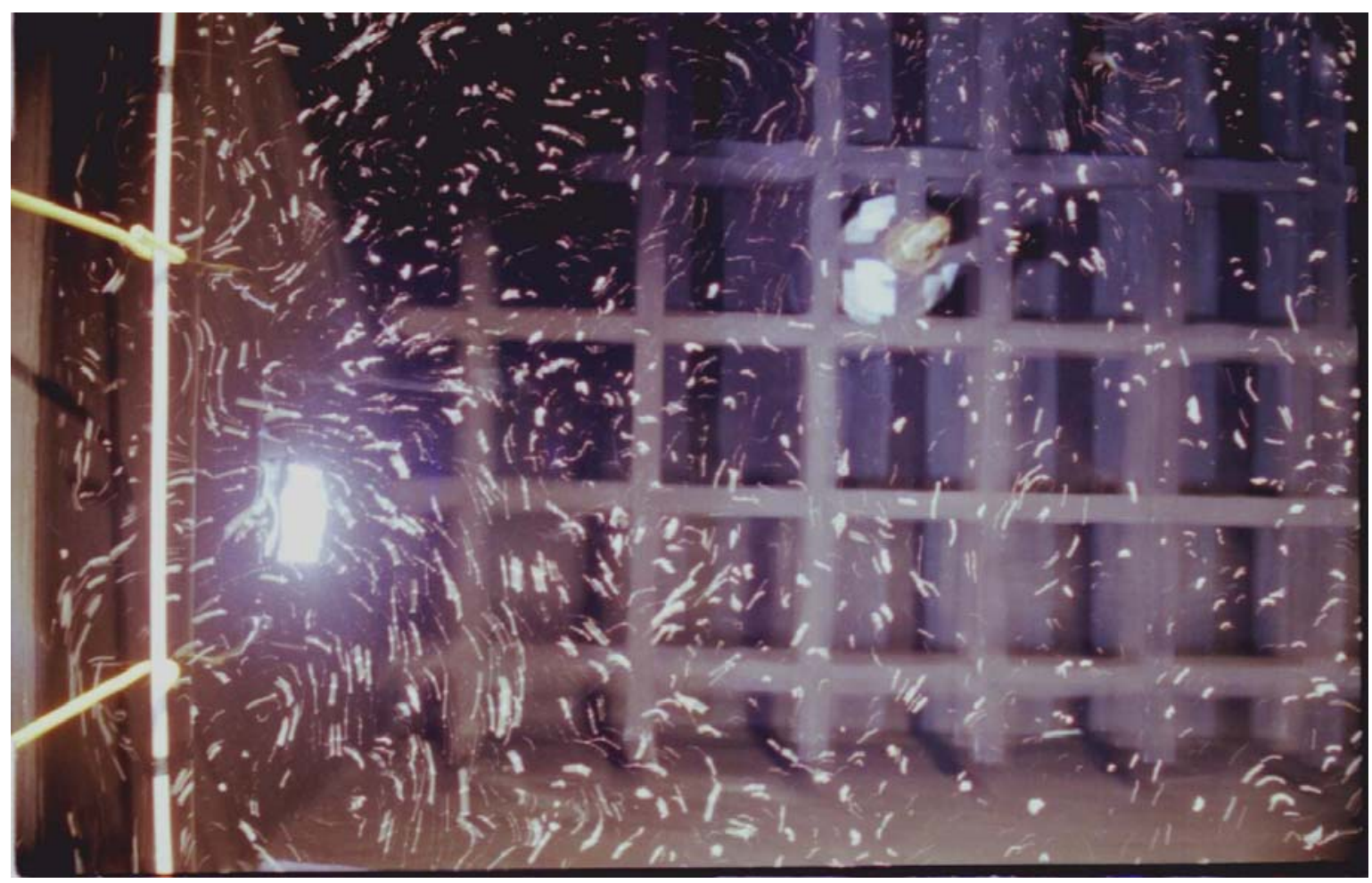

ENSAIO DA GRADE LARGA 250 RPM 
ANEXOS III 


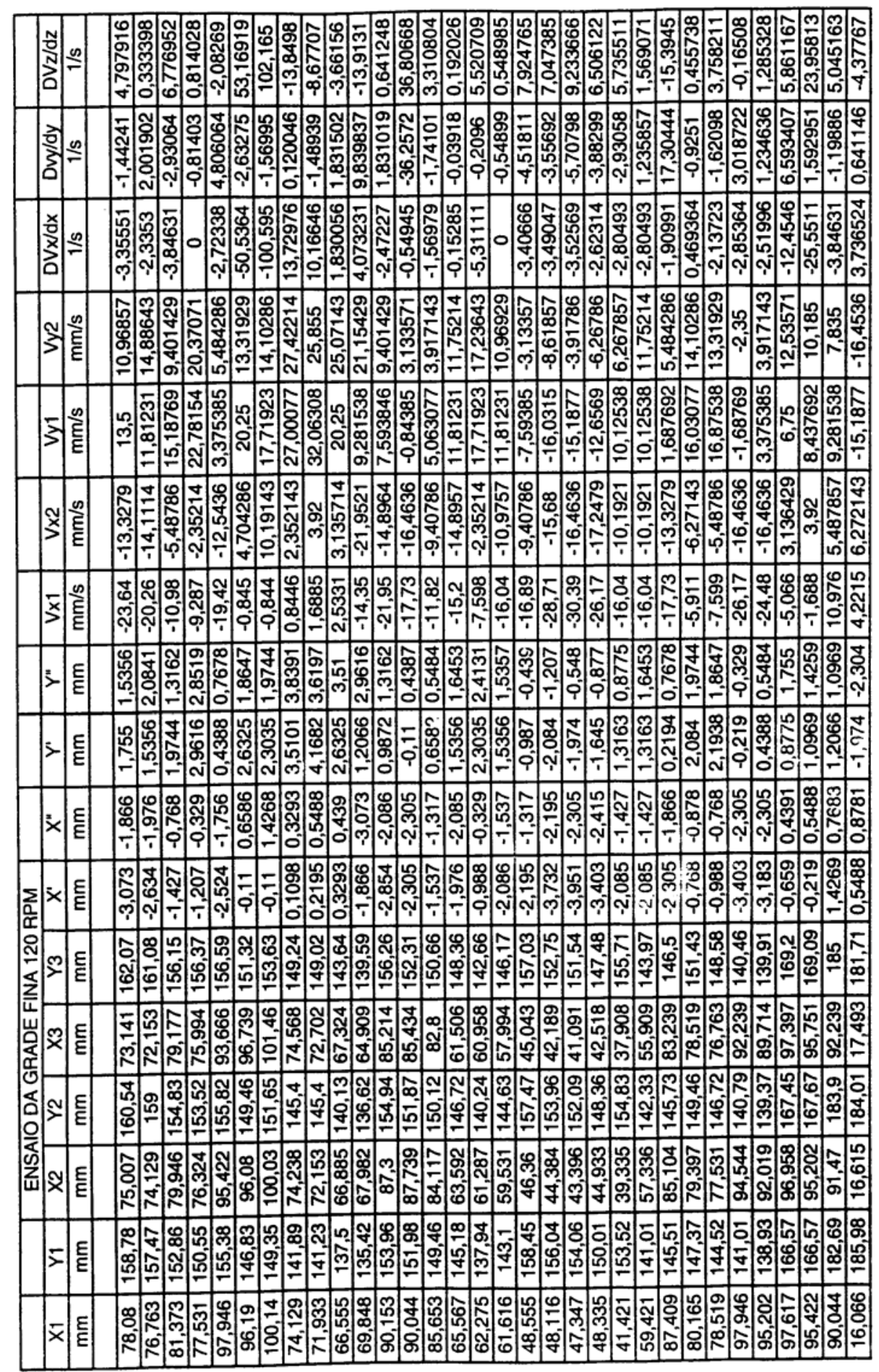




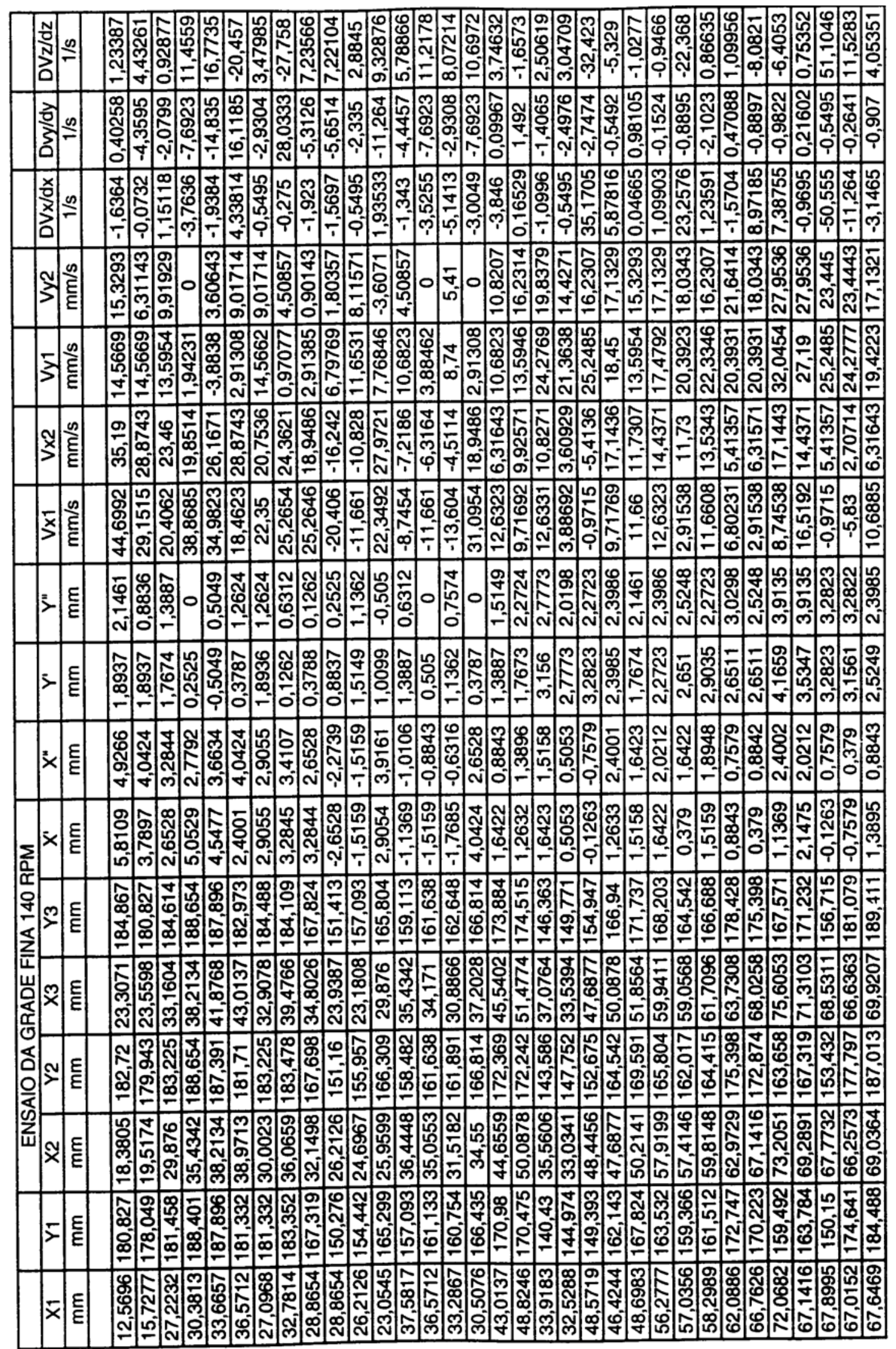




\begin{tabular}{|c|c|c|c|c|c|c|c|c|c|c|c|c|c|c|c|c|c|c|c|}
\hline & & के & क्ञ & & 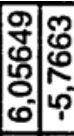 & 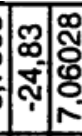 & 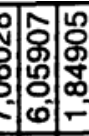 & 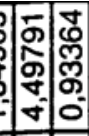 & 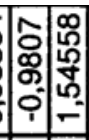 & & कृ: & & مी & 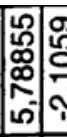 & 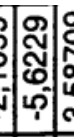 & 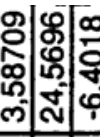 & : & & 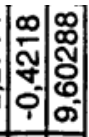 \\
\hline & & 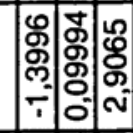 & $\begin{array}{lll}0 \\
0\end{array}$ & : & 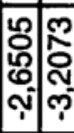 & 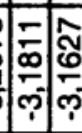 & 忒 & : & 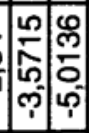 & & 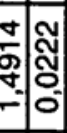 & : & דָ & ד: & 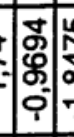 & 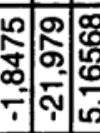 & : & : & 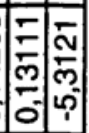 \\
\hline & & 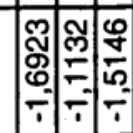 & 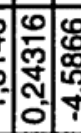 & & & & & 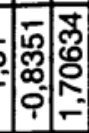 & & & & & : & 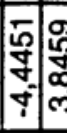 & 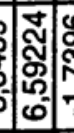 & 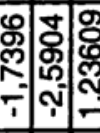 & 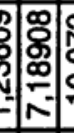 & i & 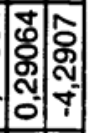 \\
\hline & & 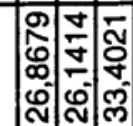 & |ิ: & 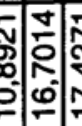 & 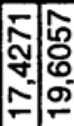 & & : & 商造 & 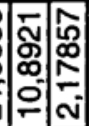 & & & : & 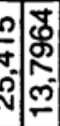 & 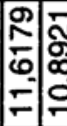 & $\left(\begin{array}{l}0 \\
0 \\
0 \\
0\end{array}\right.$ & 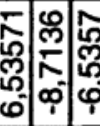 & $5 \div \div$ & অ: & 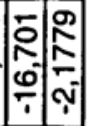 \\
\hline & & 商: & సิ & 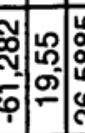 & 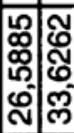 & 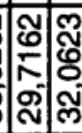 & ড় & 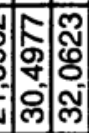 & 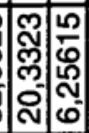 & $\begin{array}{l}0 \\
0 \\
0 \\
0\end{array}$ & 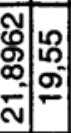 & 我 & 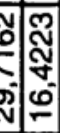 & 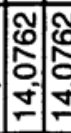 & : & \begin{tabular}{l|l}
0 \\
0 \\
0
\end{tabular} & $\mid \begin{array}{l}0 \\
0 \\
0\end{array}$ & & 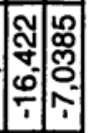 \\
\hline & & 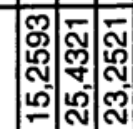 & : & & & 周商 & 氕 & : & 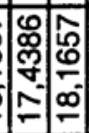 & $\left|\begin{array}{c}\bar{N} \\
\hat{N} \\
0 \\
0 \\
0\end{array}\right|$ & 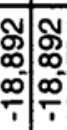 & & : & 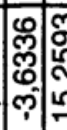 & 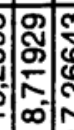 & 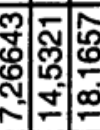 & 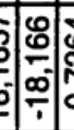 & & \\
\hline & & 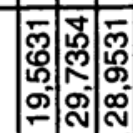 & : & & & $\infty \%$ & 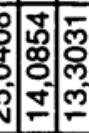 & 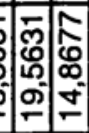 & 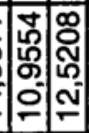 & 产: & 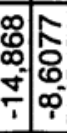 & 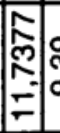 & 角 & 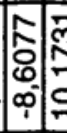 & : & 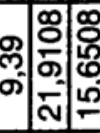 & s: & & 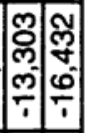 \\
\hline & हो| & 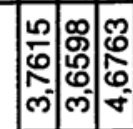 & 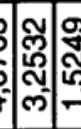 & : & 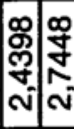 & & 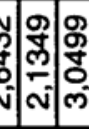 & ڤ్రి & 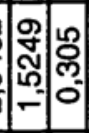 & \begin{tabular}{c:}
0 \\
0 \\
\hdashline
\end{tabular} & \begin{tabular}{l|l}
8 & 9 \\
0 \\
0
\end{tabular} & 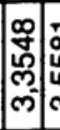 & గ్రి: & : & $=-0$ & 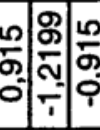 & $\because \div$ & & 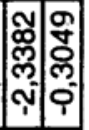 \\
\hline & 티 & 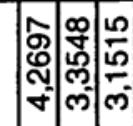 & : & 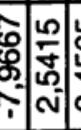 & & 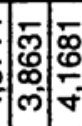 & 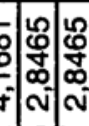 & 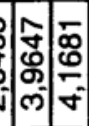 & 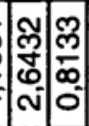 & స్ల్ల & 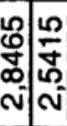 & 恿 & : & 商 & $=5$ & $=0 \%$ & $171^{\circ}$ & & \\
\hline & हᄐ & 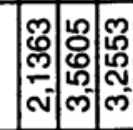 & 항ㄷ- & $=-2$ & 0 & & & & 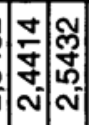 & 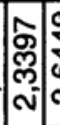 & 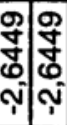 & $\left|\begin{array}{c}2 \\
\\
0\end{array}\right|$ & $\begin{array}{l}n \\
\\
\end{array}$ & 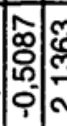 & $=0$ & 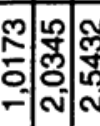 & j) & & ণั \\
\hline & 티 & 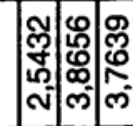 & ר్ & స్. & 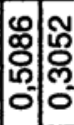 & 00 & 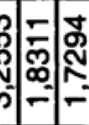 & స్యి & 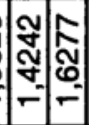 & 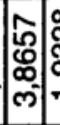 & $=$ & เิ็ & ज̦ & [' & 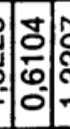 & స్心 & cons & & \\
\hline & 트 & 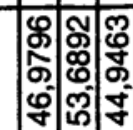 & 守 & 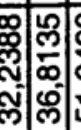 & 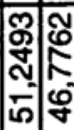 & 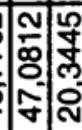 & 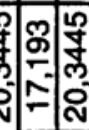 & : & 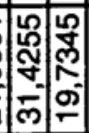 & : & 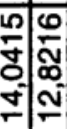 & 电足 & 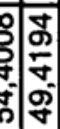 & $\mid$ & ని| & প্লীয়/ & is: & & \\
\hline & & స్ల్య & 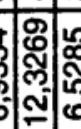 & 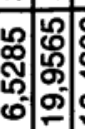 & 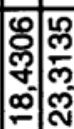 & & & 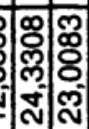 & 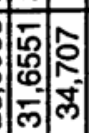 & : & & s: & : & 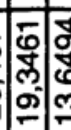 & ज़ & స్తి & int & & | \\
\hline & & |ळ|ळ̆| & Fo & হ্লেন্স্রে & পুষ & & 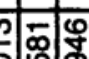 & 잉 & ஜூ্ঠ & & & ল্লিম্র & & & & & & & \\
\hline & & & & & & & & & & & & & & & & & & & \\
\hline & हE & : & 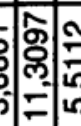 & 웛 & 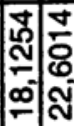 & 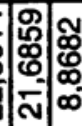 & 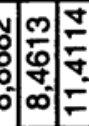 & : & 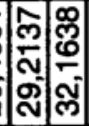 & $\mid$ & 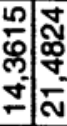 & 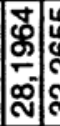 & مُ & $\mid \begin{array}{ll}0 \\
\vdots \\
0 \\
0 \\
0 \\
0\end{array}$ & 90 & 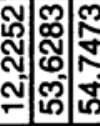 & ปิ: & & 8 \\
\hline & है & 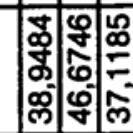 & 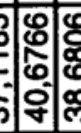 & :్రి:్లి & 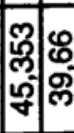 & 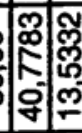 & \begin{tabular}{l|l}
0 \\
0 \\
0
\end{tabular} & 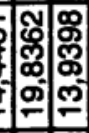 & 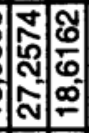 & స్తి & & 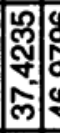 & s. & \begin{tabular}{|l|} 
\\
\\
0 \\
0 \\
\end{tabular} & 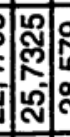 & 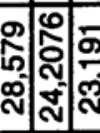 & 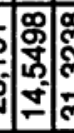 & & : \\
\hline & & 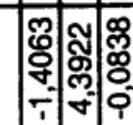 & 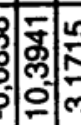 & 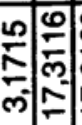 & 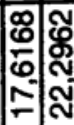 & & స్ & 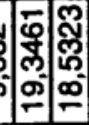 & 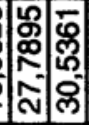 & స్ట్రి & & 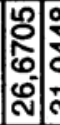 & 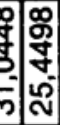 & के & : & 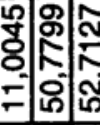 & 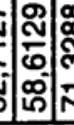 & & \\
\hline
\end{tabular}




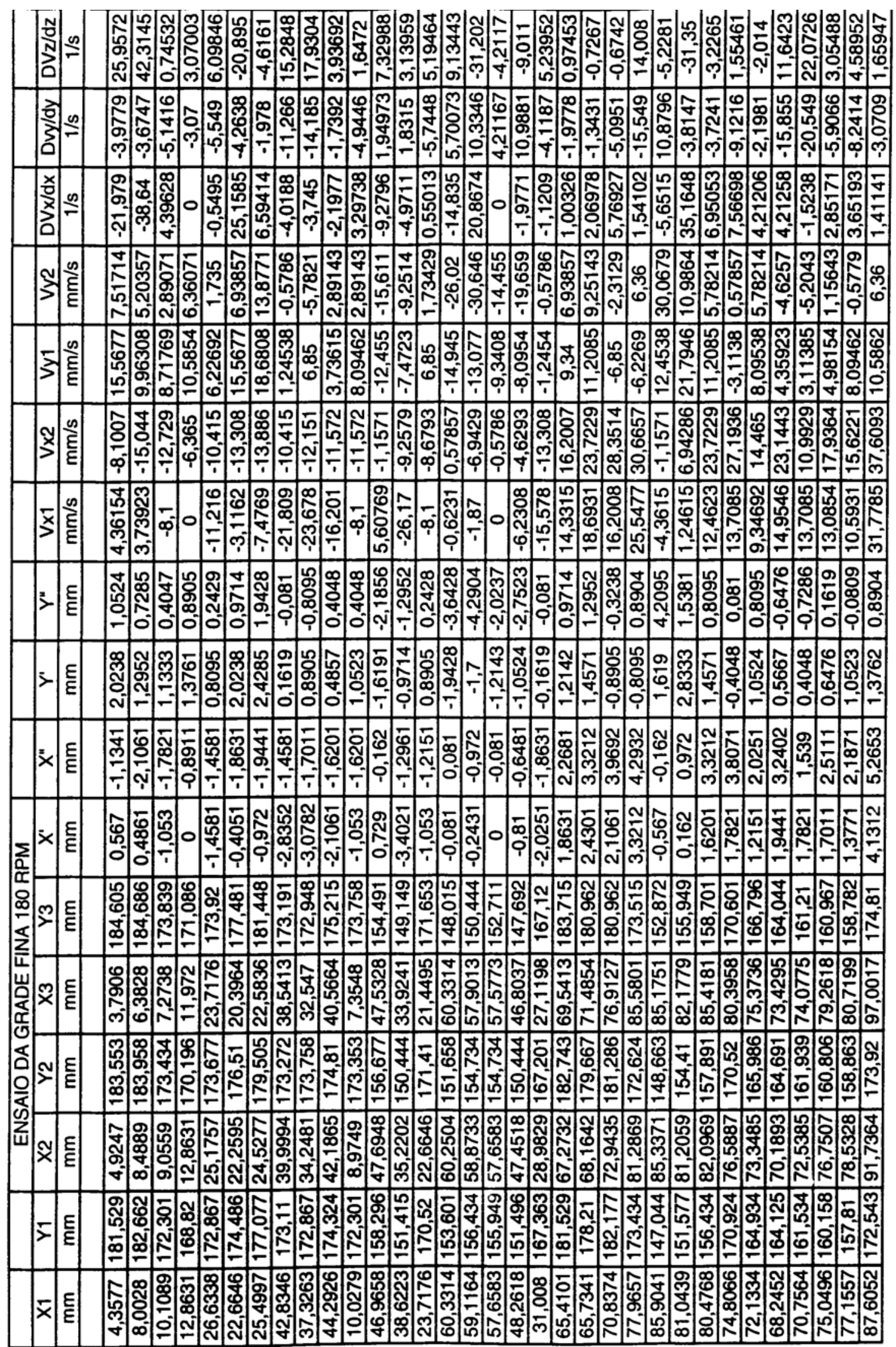




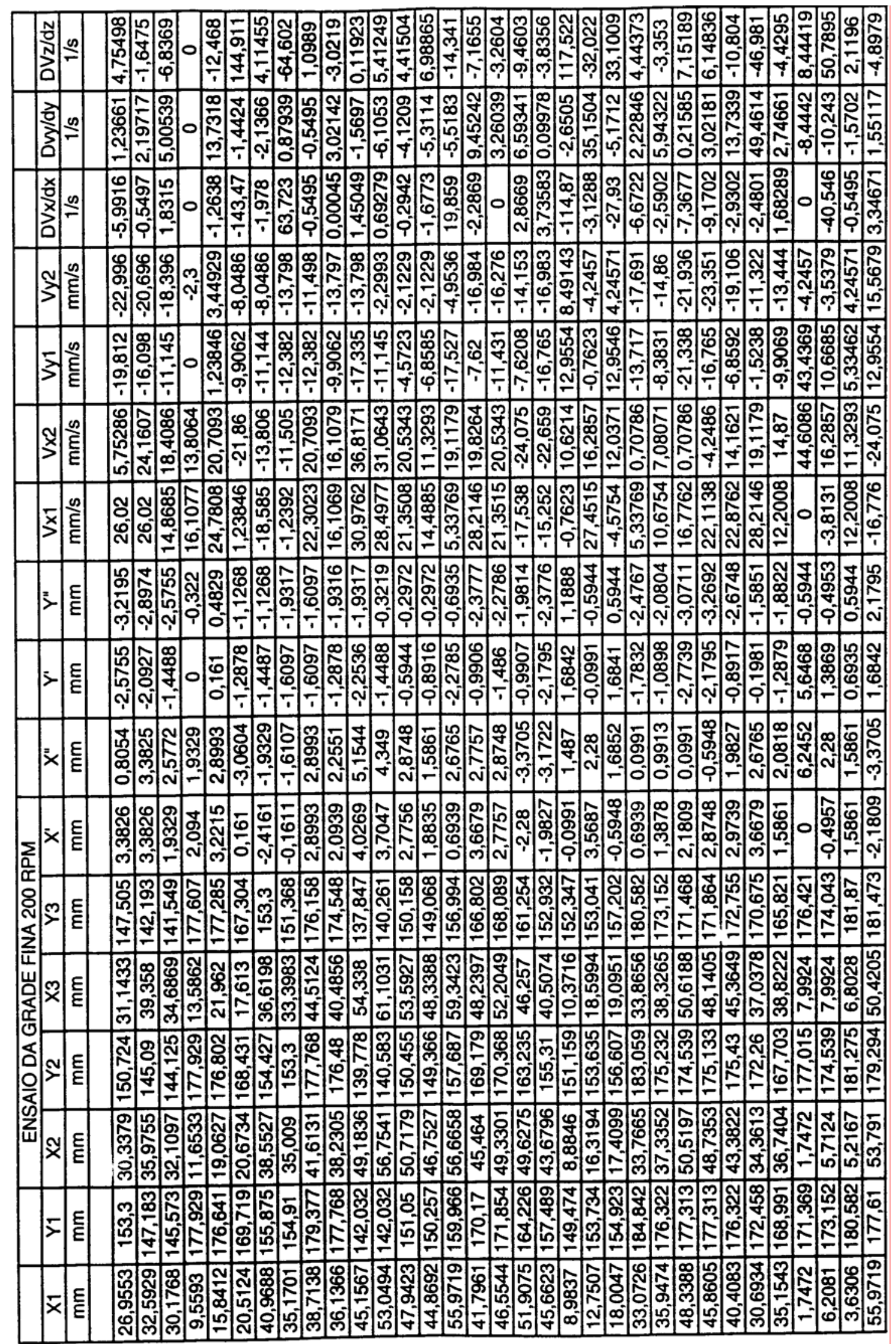




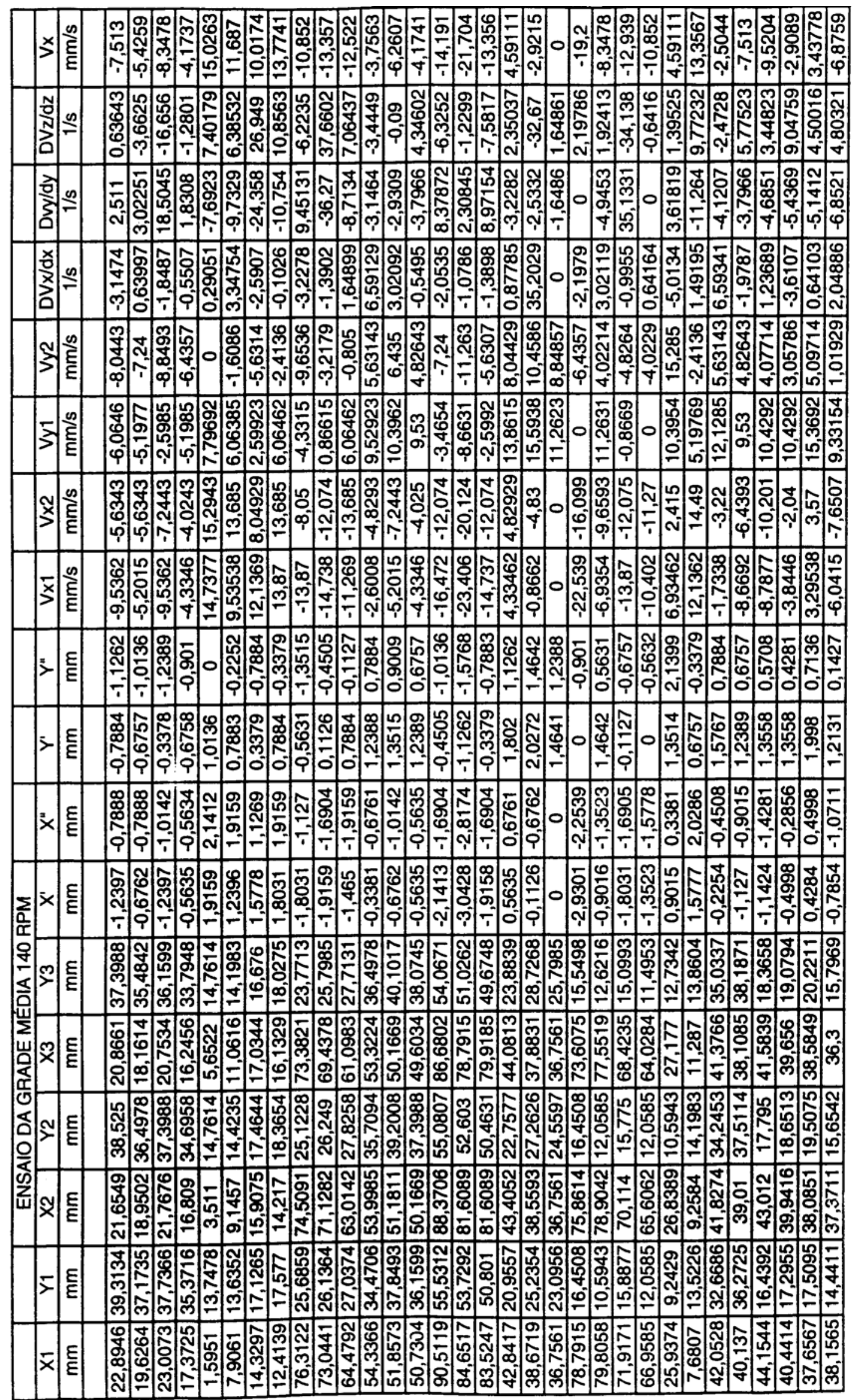




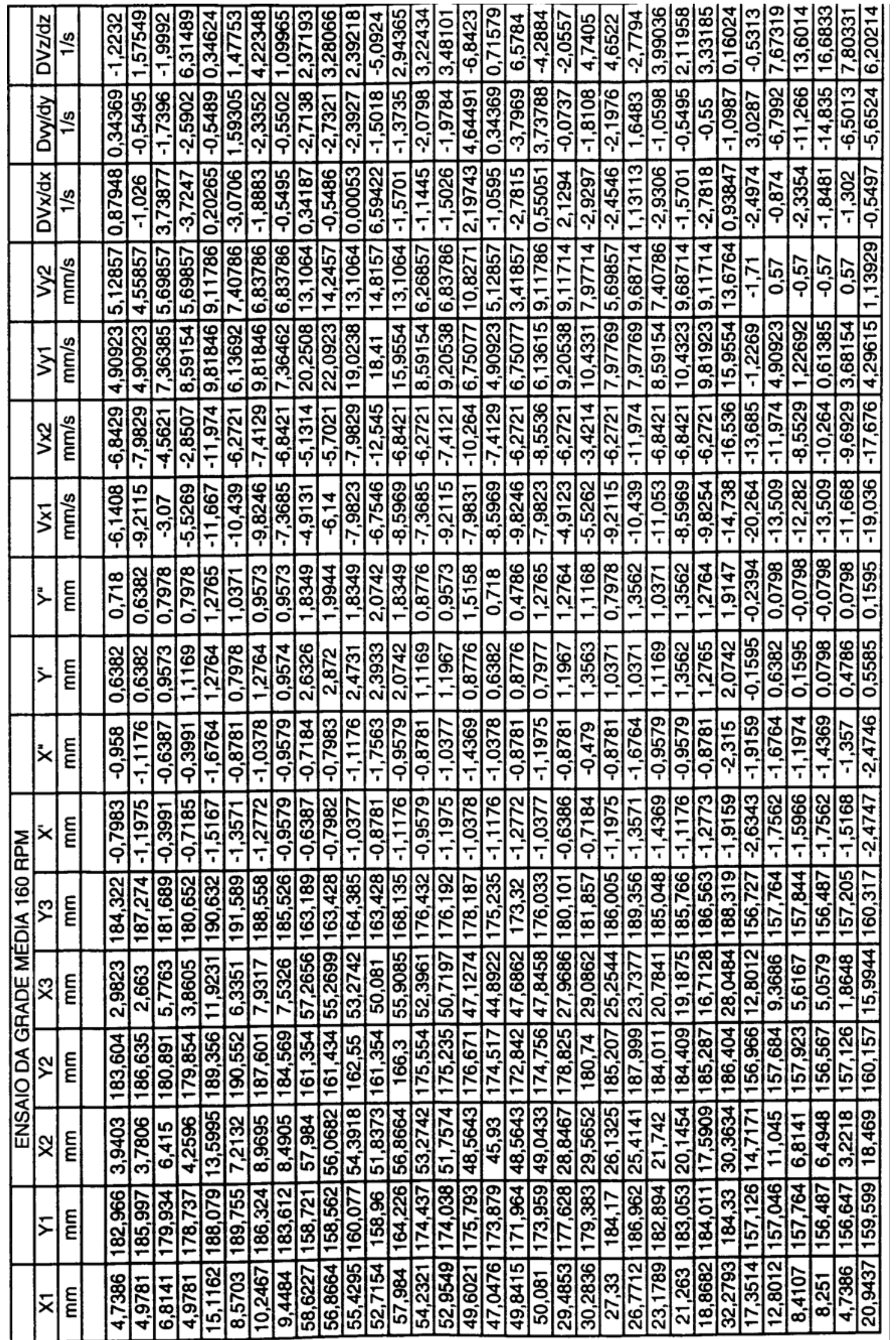




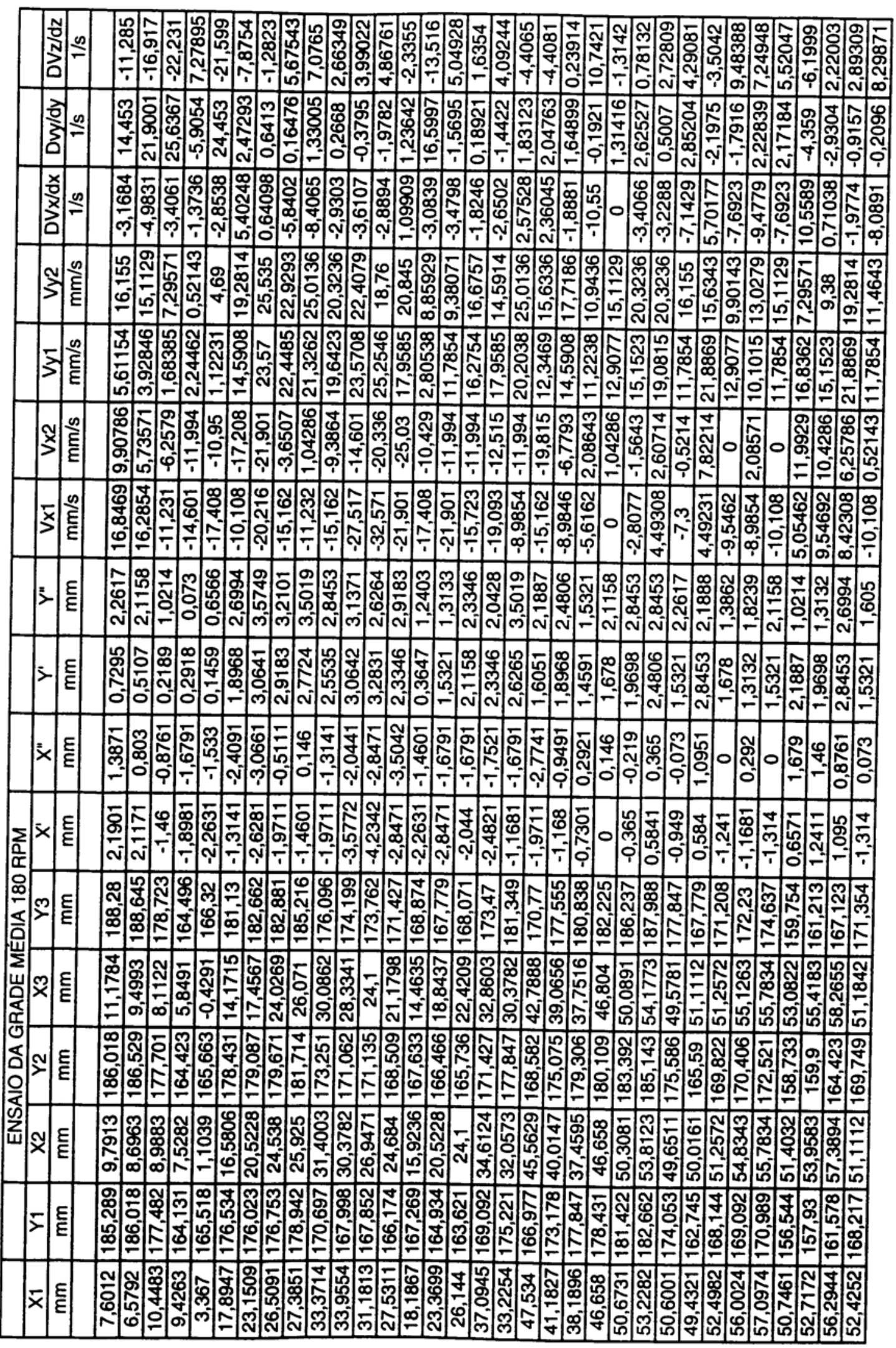




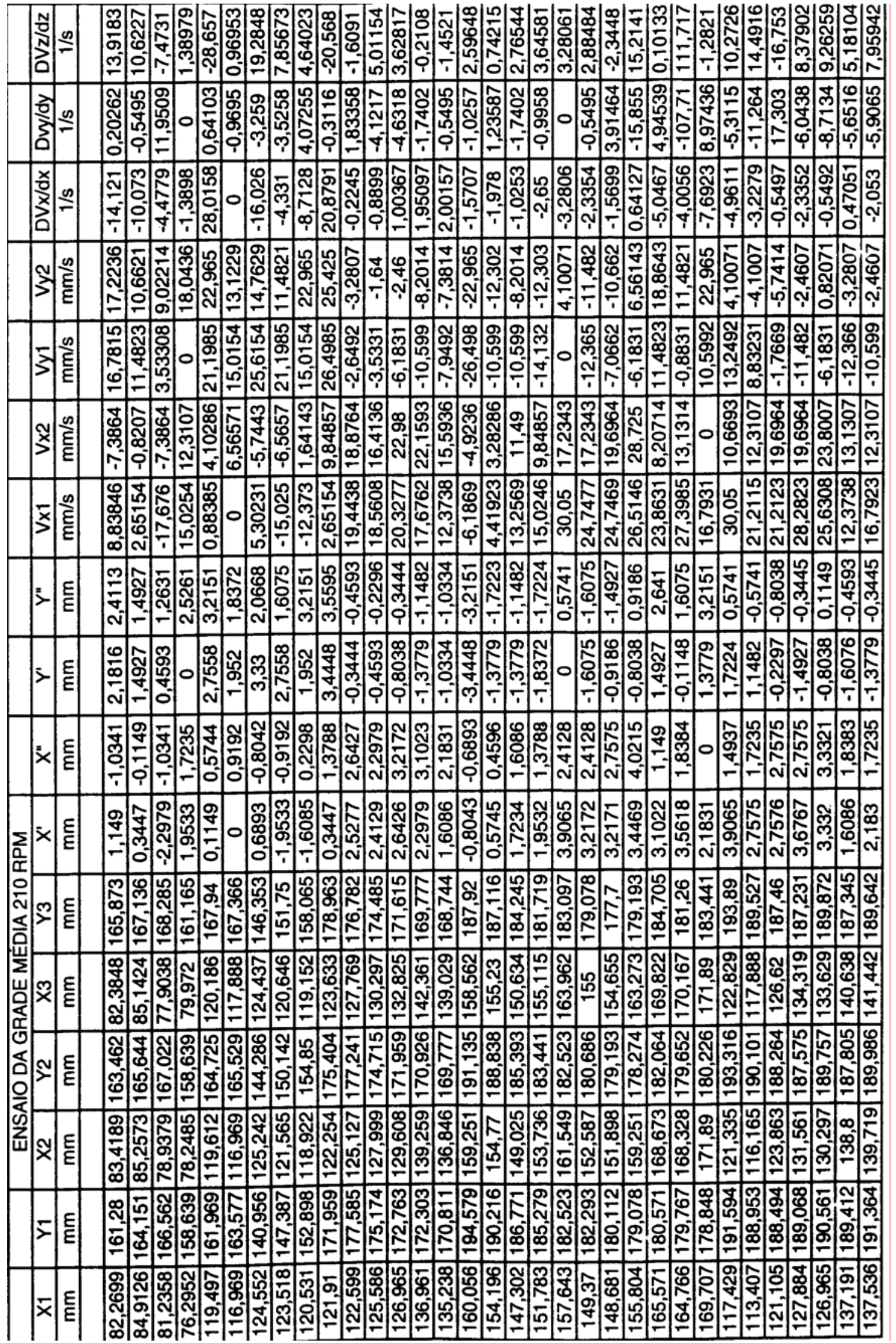




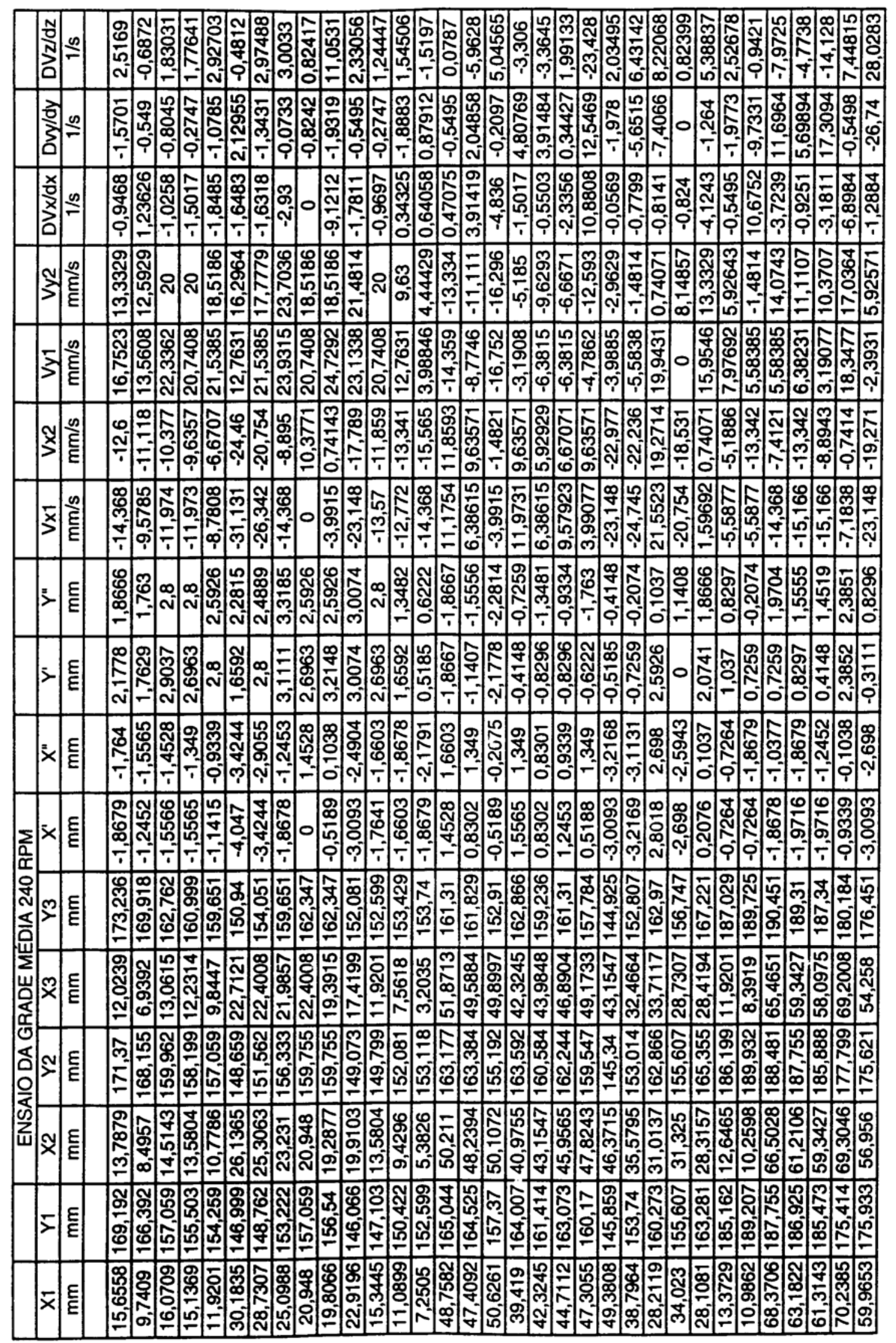




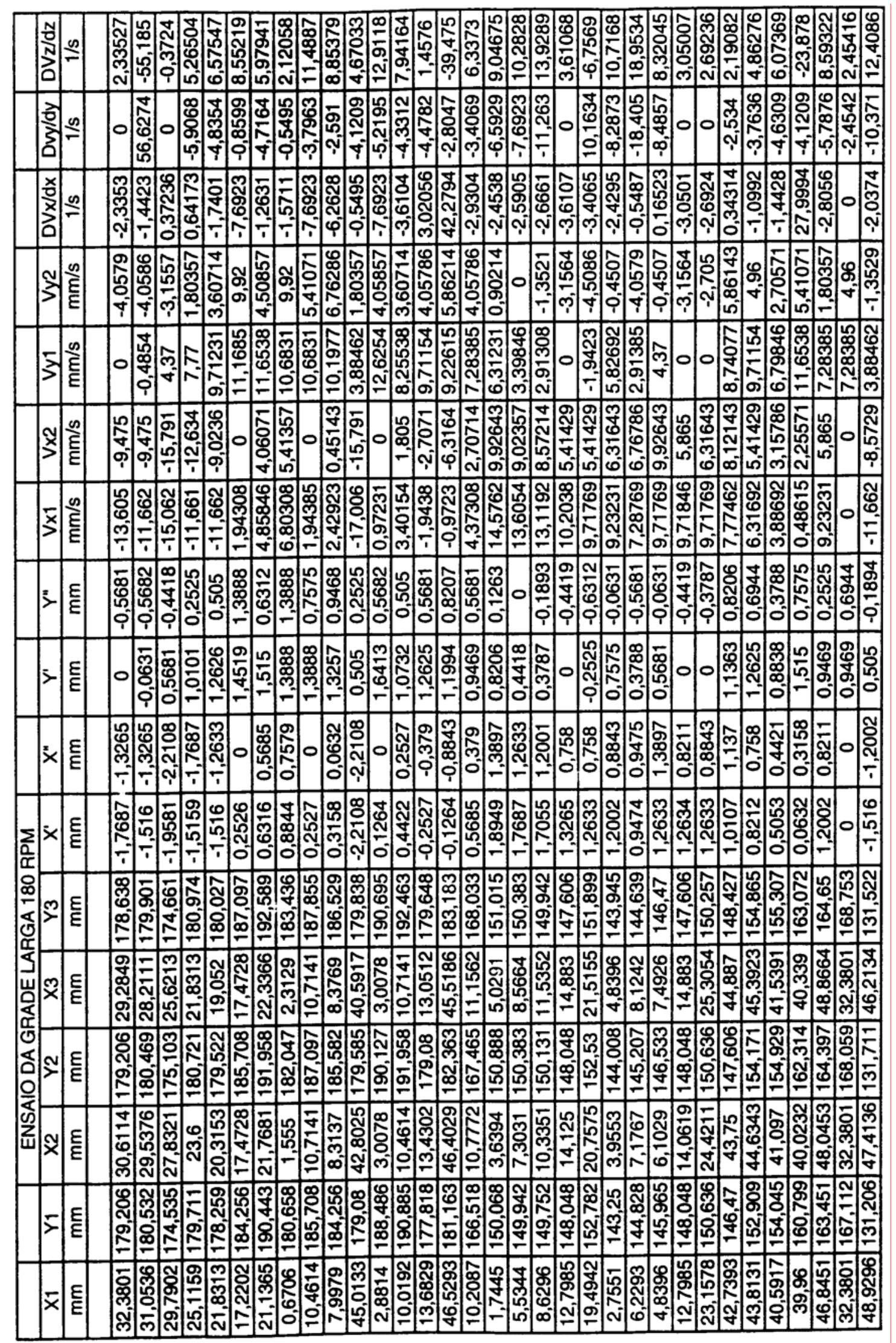




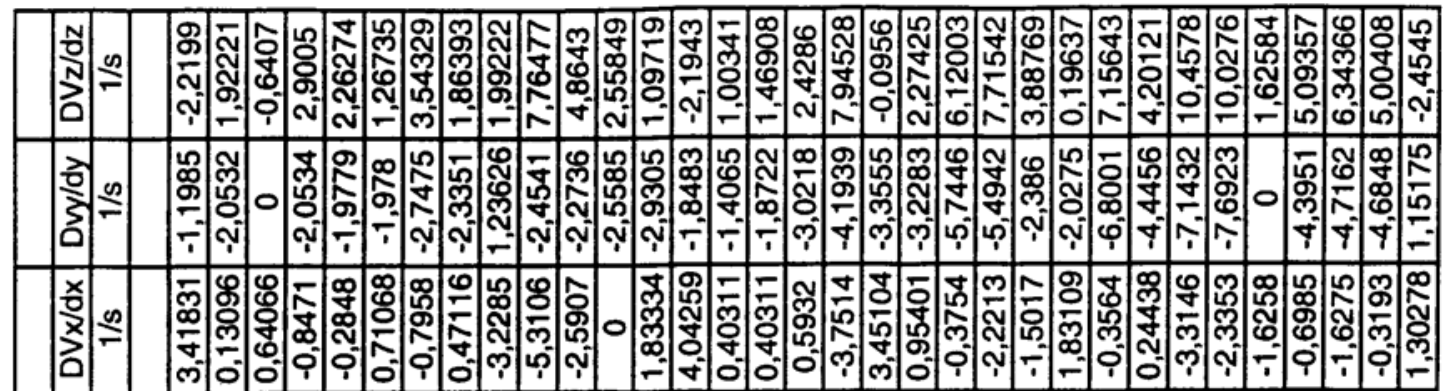

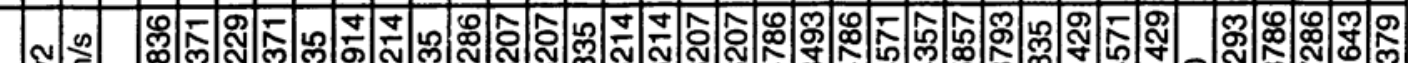

స్

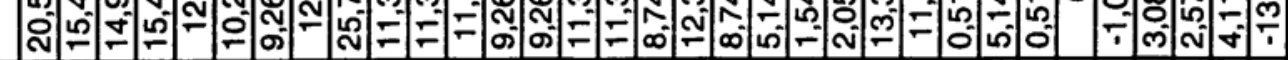

३ ఇ

₹

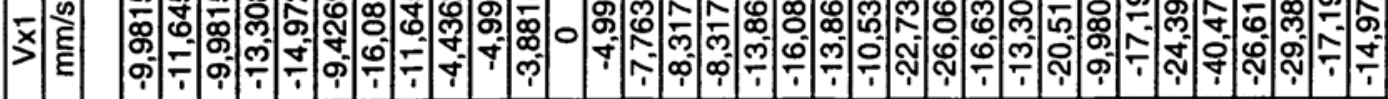

-

خ E

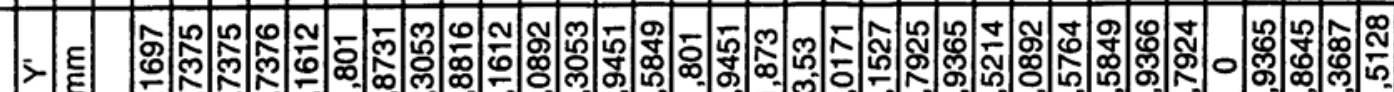

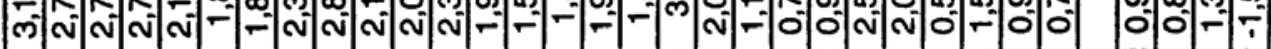

×

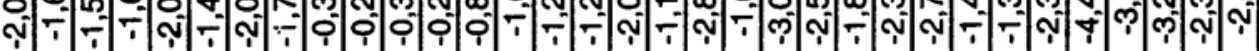

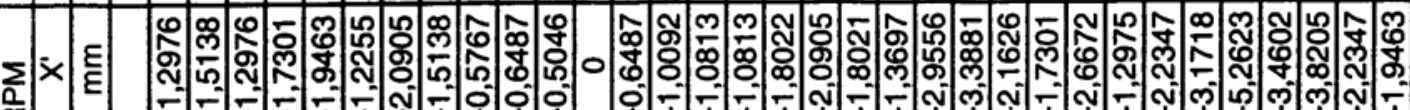

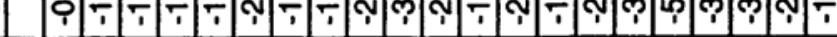

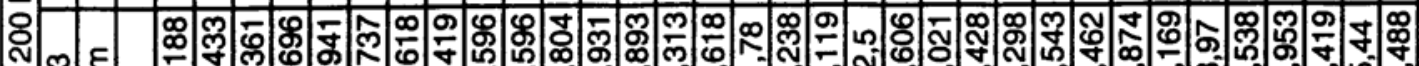
代

(2)

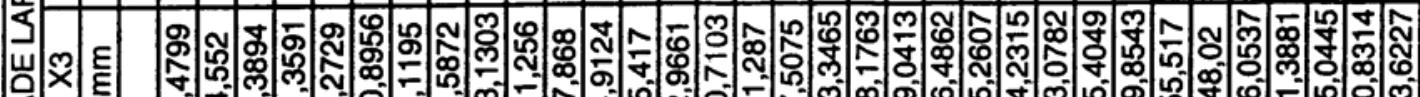
Qै ह

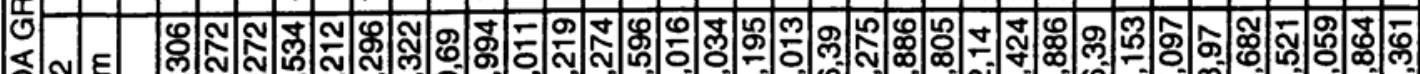
结

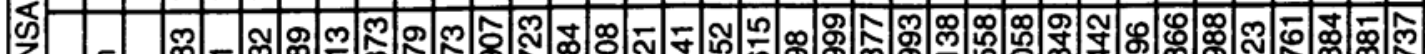
ખ)

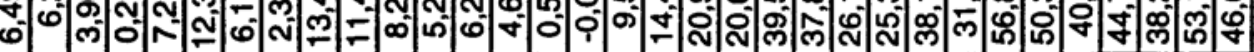

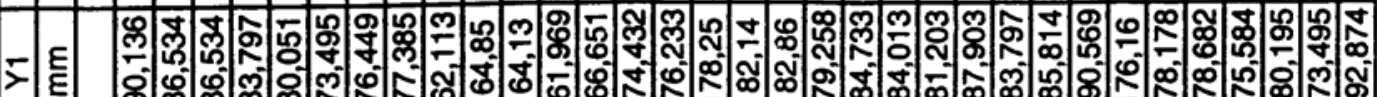

$>$ ₹

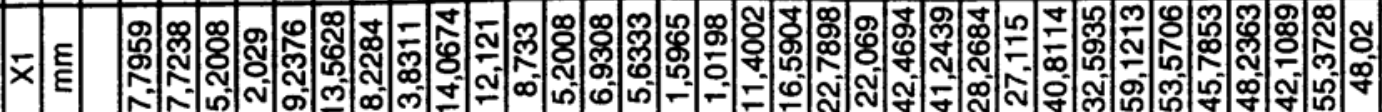




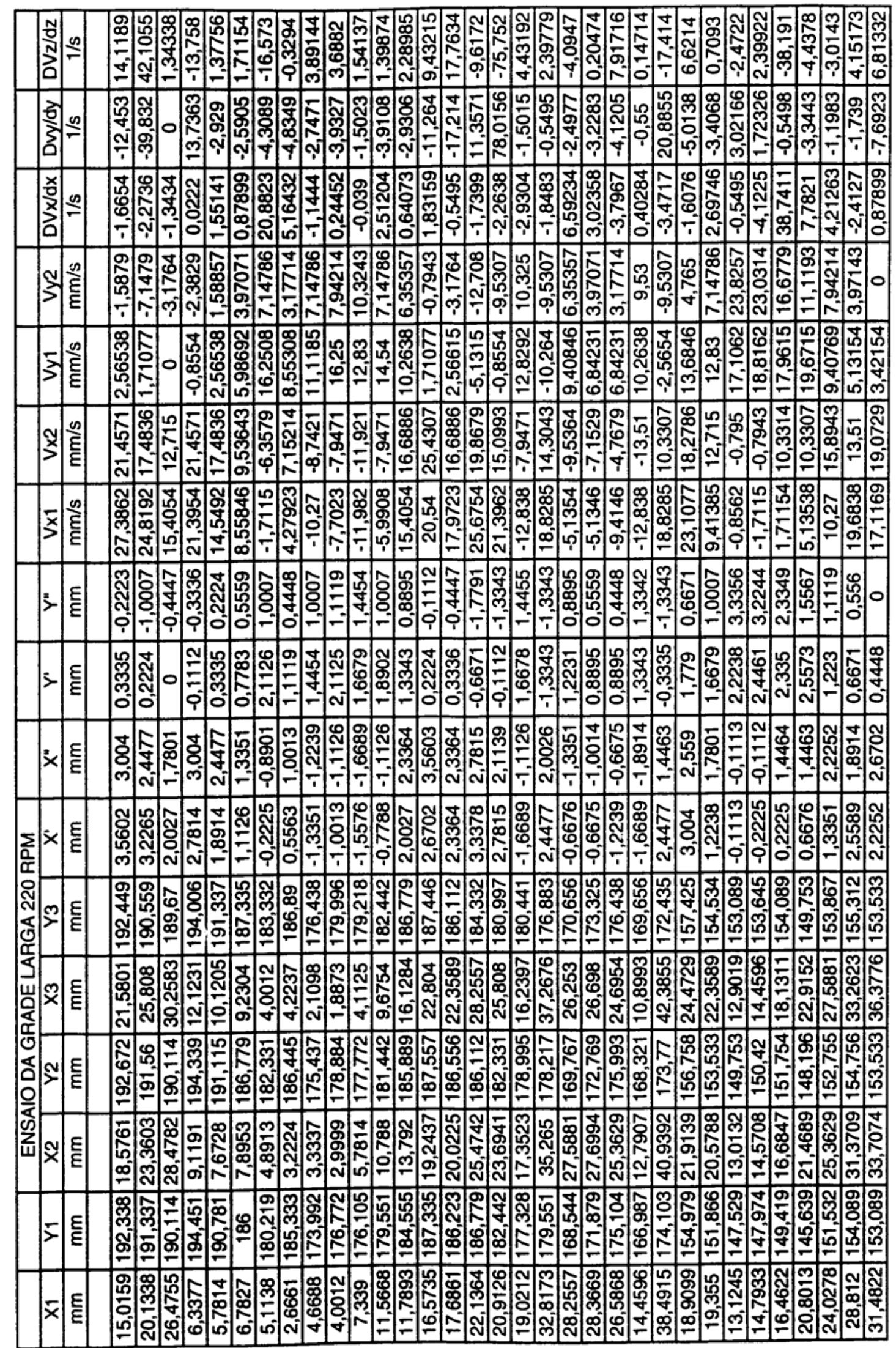




\begin{tabular}{|c|c|c|c|c|c|c|c|c|c|c|c|c|c|c|c|c|c|c|c|c|c|}
\hline & त्र| त्र| & 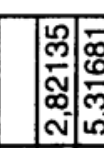 & 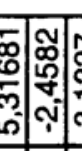 & 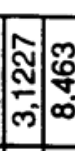 & & & & va & 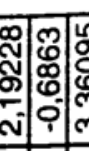 & & 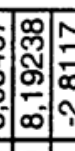 & 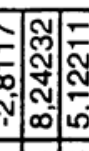 & 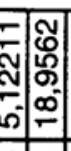 & 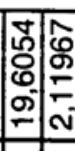 & 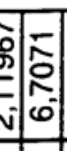 & 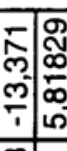 & 它 & 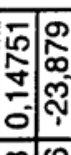 & $\infty$ & 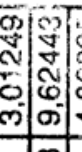 & \\
\hline & & 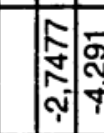 & $\begin{array}{c}5 \\
\bar{y}\end{array}$ & 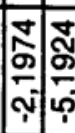 & 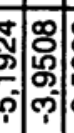 & 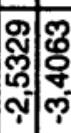 & | & 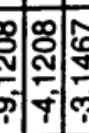 & 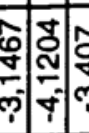 & 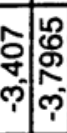 & 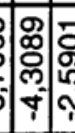 & 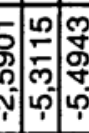 & 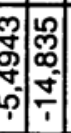 & 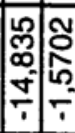 & 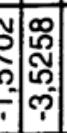 & 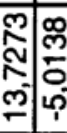 & & 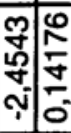 & 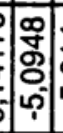 & & \\
\hline & & 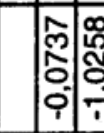 & : & 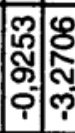 & ș: & & & 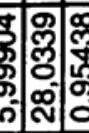 & 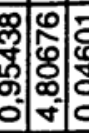 & & & \begin{tabular}{lll}
0 \\
0 \\
\hdashline
\end{tabular} & 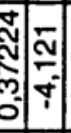 & & 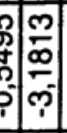 & \begin{tabular}{l|l} 
\\
0
\end{tabular} & & 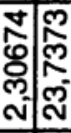 & 9 & & \\
\hline & & 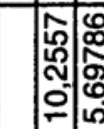 & 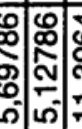 & छ़| & సळ: & ळ: & & 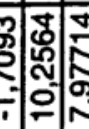 & $\begin{array}{c}\nabla \\
\end{array}$ & 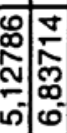 & 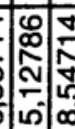 & 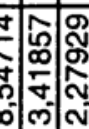 & 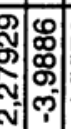 & 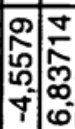 & : & 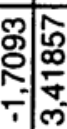 & $\mid$ & 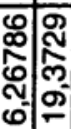 & ה & 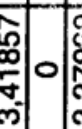 & స్র \\
\hline & & 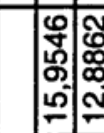 & 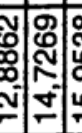 & 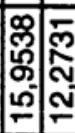 & vat: & & & & 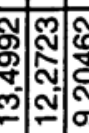 & 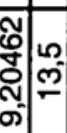 & 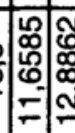 & 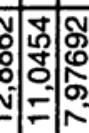 & 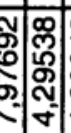 & 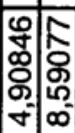 & : & & $\mathscr{ం}$ & 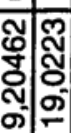 & م & অ্তু & 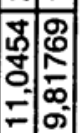 \\
\hline & & 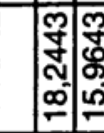 & :ొ & শ্রিত্র & $\frac{\mathrm{N}}{\mathrm{N}} \overline{\mathrm{N}}$ & & & 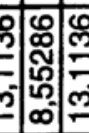 & & & 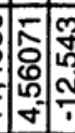 & 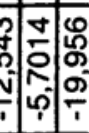 & 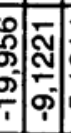 & 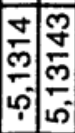 & 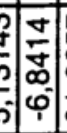 & : & 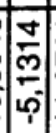 & 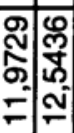 & बis & & 空象=- \\
\hline & & 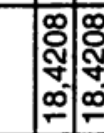 & 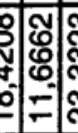 & ক্লো & f: & & & مُ & : & & 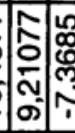 & : & 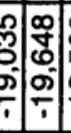 & 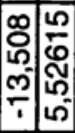 & : & 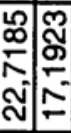 & 10 & N̂n & mి: & 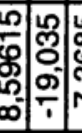 & 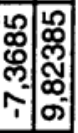 \\
\hline & $\bar{E}$ & 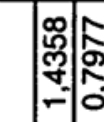 & $\begin{array}{c}0 \\
0 \\
0\end{array}$ & 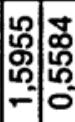 & : & & & ?: & 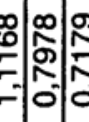 & 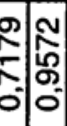 & $\mid$\begin{tabular}{l}
2 \\
\hdashline \\
0 \\
0
\end{tabular} & 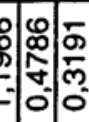 & 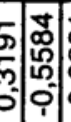 & 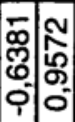 & 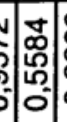 & 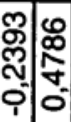 & & ojN & 10 & $\begin{array}{l}0 \\
\vdots \\
\vdots \\
0\end{array}$ & $0=1$ \\
\hline & & ง. & $=0 \Omega$ & & & & & ה్ & & & 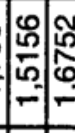 & 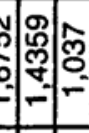 & $=$ & 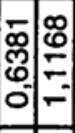 & $\mid \begin{array}{l}0 \\
0 \\
0\end{array}$ & 힝츠 & | & & $\mid \begin{array}{l}\infty \\
0\end{array}$ & 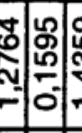 & \\
\hline & है & 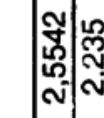 & הู: & 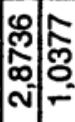 & : & & 芯 & :̊. & 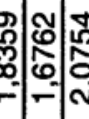 & 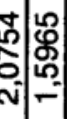 & 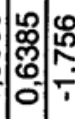 & 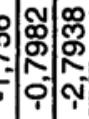 & & 冬: & $\mid \begin{array}{l}\infty \\
\vdots \\
0 \\
0 \\
\vdots \\
\vdots\end{array}$ & m/ & & శ్ర: & & : & $\div .1$ \\
\hline & है & స్ల్లి & 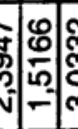 & 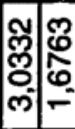 & $=0$ & ల్ల్రి & 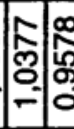 & : & $\begin{array}{lll}0 & 0 \\
0 & 0 \\
0\end{array}$ & 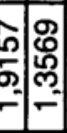 & 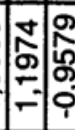 & \begin{tabular}{l|l}
$\mathbf{1}$ \\
\hdashline
\end{tabular} & 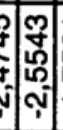 & \begin{tabular}{l|l}
2 & $\bar{T}$ \\
\hdashline & 0
\end{tabular} & $\frac{0}{50}$ & 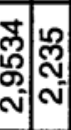 & Ю & $=a^{\infty}$ & : & 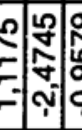 & 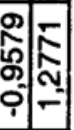 \\
\hline & 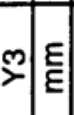 & 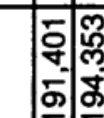 & : & 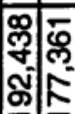 & مै: & ळ্চিত্ঠ & & & : & ר్. & 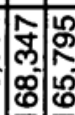 & مึ: & 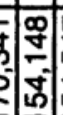 & 牙 & $\widehat{y}$ & 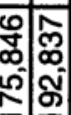 & 工 & ט্থ & R্尺 & প্রিহ্ব & \\
\hline & & & & & 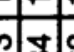 & & & & & & & & & |बा & & & & & & & \\
\hline & & & งి| & & 㥈 & & ర్ల్లী & & & 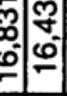 & సै| & 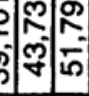 & & \begin{tabular}{l|l} 
\\
\hdashline \\
\hdashline \\
\end{tabular} & $=$ & 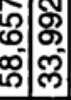 & 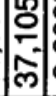 & & & & कै \\
\hline & & 象适 & :士 & প্তি & उ़्্ডি & ৫হ & g⿵人丶 & চ্তিণ্ণু & র্লিল্ড & ঢத & న্ণী: & OT: & ज़ & ఐొి & |ळ & 禺 & 10 & $\begin{array}{l}0 \\
y\end{array}$ & & 雨 & \\
\hline & & & & & & & & & & & & & & นิ์ & กิ & ๑) & & 뷔의 & 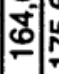 & 70 & 의의 \\
\hline & & প্তে & & $\overline{8}$ & প্রে & : & স্ট্ভ & & $\bar{v}$ & గ్రీగ & S৷ & 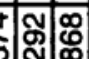 & & ণ্ল্লাঁ্ল & 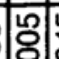 & & & 18 & đI & ঠাম্রাহ & \\
\hline & & & & & & & & & & \pm 0 & & & & & & & & & & & \\
\hline & $\bar{\Sigma}$ & 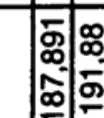 & : & 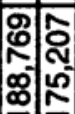 & 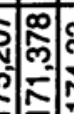 & প্লাষ্ডে & No & & ț & & 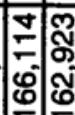 & 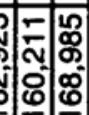 & & 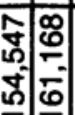 & & & & & 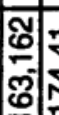 & & \\
\hline & $E$ & N্ & 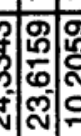 & 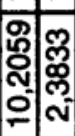 & مी: & ஜ్రి & 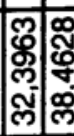 & 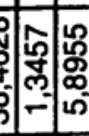 & 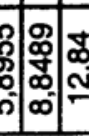 & & 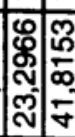 & 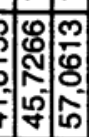 & 路 & 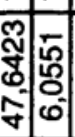 & $\mid \frac{7}{A}$ & No & & & |ิ & 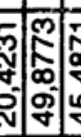 & \\
\hline
\end{tabular}




\section{REFERÊNCIAS BIBLIOGRÁFICAS}

AGÜI, J.C.; JIMENEZ, J. (1987). On the performance of particle tracking. Journal of Fluid Mechanics, v.185, p.447-468.

BARBOSA JR., A.R. (1989). Desenvolvimento de metodologia para determinação do coeficiente de reaeração dos escoamentos naturais da água com o emprego de traçador gasoso. São Carlos 187 p. Dissertação (Mestrado) - Escola de Engenharia de São Carlos, Universidade de São Paulo.

BENNETT, J.P.; RATHBUN, R.E. (1972). Reaseration in open-channel flow. Washington U.S.Government Printing Office. (Geological survey professional paper, n.737). p.75.

BIRD, R.B.et al. (1960). Tranasport phenomena. Singapore, Willey International,. P.780

BOYLE, W.C; BERTHOUEX, A.M.; ROONEY, T.C. (1974). Pitfall in paramenter estimation for oxygen transfer data. Journal of the Environmental Engeineering Division, v.100, n.2, p.391-408.

BROW, L.C; BAILLOD, CR. (1982). Modeling and interpreting oxygen transfer data. Journal of the Environemtnal Engineering Division, v.108, n.4, p.607628.

BRUMLEY, B. (1984). Turbulence mesurements near the free surface in sterred grid experiments in gas transfer at water surface. In: BRUSTSAERT,W.; JIRKA, G.H., ed. Gas transfer at water surface. Dordrechet, D.Reidel. p.83-92..

BRUMLEY, B.H.; JIRKA, G.H.(1987). Near-surface turbulence in a grid-stirred tank. Journal of Fluid Mechanics, v.183, n.1, p.235-263.

CAMPBELL, J.A.; HANRATTY, T.J. (1983). Mechanism of turbulent mass transfer at a solid boundary. A.I.C.H.E.Journal, v.29, n.2, p.221-9.

CHENG, N.S.; LAW, A.W.K. (2001). Measurement of turbulence generated by oscillating grid. Journal of Hidraulic Engineering, v.127, n.3, p.201-208, Mar.

CHU, C.R.; JIRKA, G.H. (1991). Turbulent velocity and gas concentration measurements in the near-surface layer. In: WILHELMS, E.C.; GULLIVER, J.S., ed. Air water mas transfer. New York, ASCE. p.160-172. 
COSTA, O.S. (1992). Análise do efeito da umidade sobre o coeficiente de reoxigenação. Sào Carlos. 86p. Dissertação (Mestrado) - Escola de Engenharia de São Carlos, Universidade de São Paulo.

CREMASCO, M.A. (1998). Fundamentos de transferência de massa. Campinas, Ed.da UNICAMP. p.741.

COULSON, J.M.; RICHARDSON, J.F. (1985). Chemical engineering. Fundação Calouste Gulbernkian. v.1

CUNHA, A.C. (1993). Tranferência de gases em sistemas líquidos altamente agitados induzidos por hélices do tipo turbina em tanques cilíndricos. São Carlos. 176p. Dissertação (Mestrado) - Escola de Engenharia de São Carlos, Universidade de São Paulo.

DICKEY, T.D. et al. (1984). A laboratory technique for investigating the relationship between gas transfer and fluid turbulence. In: BRUTSAERT, W.; JIRKA, G.H., ed. Gas transfer at water surface. Dordrechet, D.Reidel. p.93-100.

DE SILVA, I.P.D.; FERNADO, H.J.S. (1994). Oscillating grids as a source of nearly isotropic turbulence. Phisics Fluids, v.6, n.7, p.2455-2466, July.

FEGHALI, J.P. (1974). Mecânica Dos fluidos. Rio de Janeiro, Livros Técnicos e Científicos. v.1

FORTESCUE, G.E.; PEARSON, J.R.A. (1967). On gas absorption into a turbulent liquid. Chemical Engineering Science, v.22, p.1163-1176.

FOX, R.W.; McDONALD, A.T. (1995). Introdução á mecânica dos fluidos. 4.ed. Rio de Janeiro, Livros Técnicos e Científicos.

FREYMUTH, P. (1993). Flow visualization in fluid mechanics. Review of Scientific Instruments, v.64, n.1, p.1-17.

GULLIVER, J.S. (1991). Introduction to air-water mass transfer. In: WILHELMS, E.C.; GULLIVER, J.S., ed. Air water mass transfer. New York, ASCE. p.1-7.

GULLIVER, J.S.; TAMBURRINO, A. (1995). Turbulent surface deformation and their relationship to mass transfer in a open-channel. In: JÄHNE, B.;

MONAHAN, E.C., ed. Air water gas transfer. Heidelberg. p.589-600.

HINES, A.L.; MADDOX, R.N. (1985). Mass transfer - fundamentals and applications. New Jersey, Prentice-Hall. p.542.

HINZE, J.O. (1959). Turbulence. New York, McGraw-Hill. p.586. 
HOPFINGER, E.L.; TOLY, J.A. (1976). Spacially decaying turbulence and its relation to mixing acrossdensity interfaces. Journal of fluid mechanics, v.78, n.1, p.155-175.

HUNT, J.C.R. (1984). Turbulence structure and turbulent diffusion near gas/liquid interfaces. In: BRUTSAERT, W.; JIRKA, G.H., ed. Gas transfer at water surface. Dordrechet, D.Reidel. p.67-82.

KISHINESSKY, M.K.H.; SEREBRIANSKY, V.T. (1955). The mechanicsm of mass transfer at the gas-liquid interface with vigorrous stirring. Journal Applied Chemistry, n.29, p.29-33.

McCREADY, M.J.; HANRATTY, T. (1984). Concentration fluctuations close to a sheared gas-liquid interfaces. A.I.C.H.E. Journal, v.30, n.5, p.816-820.

McCREADY, M.J.; VASSILIADOU, E.; HANRATTY, T. (1986). Computer simulation of turbulence mass transfer at a mobile interface. A.I.C.H.E. Journal, v.32, n.7, p.1108-1115.

MELLO, E.D. (1996). Sistema ótico para avaliação do coeficiente de reaeração superficial em corpos d água. São Carlos. 150 p. Dissertação (mestrado) Escola de Engenharia de São Carlos, Universidade de São Paulo.

MIRANDA, L.M. (2000). Estudo da deformação superficial gerada pela turbulência na interface ar/água, no domínio da frequência, e sua relação com o coeficiente de aeração. São Carlos. 125 p. Dissertação (Mestrado) Escola de Engenharia de São Carlos, Universidade de São Paulo.

MOMESSO, A.M. (1996). Absorção e dessorção de gases através da interface ar-água em sistemas de agitação mecânica. São Carlos. 145 p. Dissertação (Mestrado) - Escola de Engenharia de São Carlos, Universidade de São Paulo.

RODI, W. (1980). Turbulence models and their application in hidraulics. Delft, IAHR.

ROMA, W.N.L. (1988). Medida dos parâmetros de turbulência superficial e sua interrelação com o coeficiente de reaeração. São Carlos. 74 p. Tese (Livre-docência) - Escola de Engenharia de Sào Carlos, Universidade de São Paulo.

ROMA, W.N.L.; GIORGETTI, M.F. (1995). Optical detection of turbulencerelated parameters and correlation with reaeration coefficient in gridstirred tank. /Comunicação pessoal/

SCHULZ, H.E. (1985). Investigação do mecanismo de reoxigenação da água em escoamento e sua correlação com o nível de turbulência junto à superfície. 
São Carlos. 299 p. Dissertação (Mestrado) - Escola de Engenharia de São Carlos, Universidade de São Paulo.

SOUZA FILHO, F.A. (1995). Modelação numérica da hidrodinâmica em canais com a utilização de modelos de turbulência. São Carlos. 148p. Dissertação (Mestrado) - Escola de Engenharia de São Carlos, Universidade de São Paulo.

TAMBURRINO, A. (1994). Free-surface kinematics: measurement and relation to the mass transfer coefficient in open-channel flow. Minnesota, $237 \mathrm{p}$. Tese (Doutorado) - Faculty of the Graduate School, University of Minnesota.

TAMBURRINO, A.; GULLIVER, J.S. (1991). Surface renewal due to large flow strucrtures in open-channel flow. In: WILHELMS, E.C.; GULLIVER, J.S., ed. Air water mass transfer. New York, ASCE. p.126-138.

TENNEKES, H.A.; LUMLEY, J.L. (1972). First course in turbulence. Massachusetts. The Massachusetts Institute of Technology. p.300.

THOMPSON, S.M.; TURNER, J.S. (1975). Mixing across na interface due to turbulence generated by na oscillating grid. Journal of Fluid Mechanics, v.67, n.2, p.349-368.

TOOR, H.L.; MARCHELLO, J.M. (1958). Film-penetration model for mass and heat transfer. A.I.C.H.E.Journal, v.4, n.1, p.97-101.

ORLINS, J.J.; GULLIVER, J.S. (2000). Measurements of free turbulence. In: INTERNATIONAL SYMPOSIUM ON GAS TRANSFER AT WATER SURFACES, 4., Flórida, /Comunicação pessoal/

WHITMAN, W.G. (1923). A Preliminary experimental confirmation of the two film theory of gas absorption. Chemkical and Metallurgical Engineering, v.29, n.4, p.146-148. 